UNIVERSIDADE DE SÃO PAULO

FACULDADE DE ECONOMIA, ADMINISTRAÇÃO E CONTABILIDADE DEPARTAMENTO DE ADMINISTRAÇÃO PROGRAMA DE PÓS-GRADUAÇÃO EM ADMINISTRAÇÃO

INTEGRAÇÃO DA CADEIA DE SUPRIMENTOS NO BRASIL: UM ESTUDO EM EMPRESAS DE GRANDE PORTE

Fernando Scandiuzzi

Orientador: Prof. Dr. Marcio Mattos Borges de Oliveira

SÃO PAULO 
Prof. Dr. João Grandino Rodas Reitor da Universidade de São Paulo

Prof. Dr. Reinaldo Guerreiro

Diretor da Faculdade de Economia, Administração e Contabilidade

Prof. Dr. Adalberto Américo Fischmann

Chefe do Departamento de Administração

Prof. Dr. Lindolfo Galvão de Albuquerque Coordenador do Programa de Pós-Graduação em Administração 


\title{
INTEGRAÇÃO DA CADEIA DE SUPRIMENTOS NO BRASIL: UM ESTUDO EM EMPRESAS DE GRANDE PORTE
}

\author{
Tese apresentada ao Departamento de \\ Administração da Faculdade de \\ Economia, Administração e \\ Contabilidade da Universidade de São \\ Paulo, visando à obtenção do título de \\ Doutor em Ciências
}

Orientador: Prof. Dr. Marcio Mattos Borges de Oliveira

\author{
Versão Corrigida \\ (Versão Original disponível na FEA) \\ SÃO PAULO \\ 2011
}




\section{FICHA CATALOGRÁFICA}

Elaborada pela Seção de Processamento Técnico do SBD/FEA/USP

\section{Scandiuzzi, Fernando}

Integração da cadeia de suprimentos no Brasil: Um estudo em empresas de grande porte / Fernando Scandiuzzi. -- São Paulo, 2011. $303 \mathrm{p}$.

Tese (Doutorado) - Universidade de São Paulo, 2011. Orientador: Marcio Mattos Borges de Oliveira.

1. Logística 2. Cadeia de suprimentos 3. Alianças estratégicas I. Universidade de São Paulo. Faculdade de Economia, Administração e Contabilidade II. Título.

$$
\text { CDD - } 658.78
$$


Dedico este trabalho aos meus avôs maternos e paternos, aos meus pais Antônio e Eladir, a minha irmã Fernanda, a minha namorada Liliana e ao meu cunhado Carlos. 


\section{AGRADECIMENTOS}

Agradeço a Deus pela oportunidade de vida.

Aos meus pais, Antônio e Eladir, pela dedicação e exemplo de vida.

Aos meus avôs, maternos e paternos, pelo exemplo de vida.

A minha irmã Fernanda, pela fraternidade e carinho.

A minha namorada Liliana, pelo amor, companheirismo e dedicação.

Ao meu cunhado Carlos, pela amizade fraterna.

Ao meu orientador Marcio Mattos Borges de Oliveira, pela amizade, dedicação e paciência durante estes anos.

A Sônia Valle Walter Borges de Oliveira, pela amizade e colaboração.

Aos professores Alceu Salles Camargo Júnior, Janaína de Moura Engracia Giraldi, Perla Calil Pongeluppe Wadhy Rebehy e Alberto Borges Matias pelas valiosas orientações

Aos respondentes da pesquisa, sem os quais este trabalho não seria possível.

A empresa Linkedin, por ser a facilitadora no contato com os respondentes.

Ao amigo Ernesto Pereira Lopes pelo aprendizado em minha área profissional e, principalmente, pela amizade

Aos professores colegas e coordenadores das instituições de ensino Barão de Mauá e COC, pelo aprendizado conjunto durante esses anos de docência.

Aos colegas do grupo de pesquisa PAPO.

Aos meus amigos e amigas mais íntimos pela força.

Aos professores da FEA-USP e FEARP-USP, pelo conhecimento transmitido.

Aos funcionários da FEA-USP e FEARP-USP, pela colaboração.

E a todos aqueles que de maneira direta ou indireta contribuíram para a realização deste trabalho. 


\section{RESUMO}

As empresas enfrentam hoje um ambiente complexo e altamente competitivo, com os consumidores cada vez mais exigentes e os ciclos de vida dos produtos cada vez menores. Para reagir a estas forças, são necessárias mudanças radicais nas organizações, de forma a tornarem as empresas mais competitivas. Entretanto, os recursos e competências para que isto ocorra são frequentemente difíceis de serem obtidos por uma única empresa. Neste contexto, para se manterem competitivas, as empresas buscaram juntar esforços para conseguirem uma maior coordenação e colaboração entre os parceiros na cadeia de suprimentos em uma abordagem chamada Gerenciamento da Cadeia de Suprimentos (Supply Chain Management). $\mathrm{Na}$ literatura estudada, enquanto vários autores afirmaram que uma maior integração entre as empresas participantes de uma cadeia resulta em melhores desempenhos para estas empresas, outros mostraram que os benefícios dessa integração não puderam ser confirmados. Por outro lado, alguns autores afirmaram que os benefícios deveriam ocorrer por toda a cadeia e não apenas para algumas empresas participantes. Neste contexto, torna-se claro a importância da mensuração do desempenho, tanto das empresas como das cadeias as quais elas pertencem, e também relacioná-lo com o nível de integração da cadeia. Assim, este presente trabalho estudou a relação entre a integração da cadeia de suprimentos e o desempenho, tanto das empresas isoladamente quanto da cadeia como um todo, de empresas nacionais de grande porte. O presente estudo é do tipo quantitativo e descritivo, utilizando o método de levantamento (survey) transversal auto-administrado, onde o questionário ficou disponível on line. Foram estudadas 135 empresas, de 13 setores diferentes, selecionadas por uma amostragem não-probabilística por julgamento. Os dados obtidos foram analisados de duas formas: na primeira forma foi utilizada a Análise Fatorial (para reduzir os número de variáveis) seguido pela análise por Regressão Linear (para verificar a relação entre os constructos) e na segunda forma a análise foi realizada pela técnica de Modelagem de Equações Estruturais (Structural Equation Modeling - SEM). Foram propostas três hipóteses a serem verificadas - Hipótese 1 (H1): Existe uma relação positiva entre integração da cadeia de suprimentos e desempenho organizacional individual; Hipótese 2 (H2): Existe uma relação positiva entre integração da cadeia de suprimentos e desempenho global da cadeia de suprimentos e a Hipótese 3 (H3): Existe uma relação positiva entre desempenho organizacional individual e desempenho global da cadeia de suprimentos. Como resultado final, as três hipóteses foram confirmadas, tanto pela Análise de Regressão, quanto pela Modelagem de Equações Estruturais. Também verificou-se o comportamento dos três constructos de acordo com os setores estudados. Observou-se a existência de diferença de entre os setores apenas para o constructo "integração da cadeia de suprimentos". Assim, os setores estudados são estatisticamente semelhantes nos constructos "desempenho individual" e "desempenho da cadeia de suprimentos".

Palavras-chaves: Logística, Cadeia de Suprimentos, Alianças Estratégicas 


\begin{abstract}
Today, companies face a complex and highly competitive environment, with consumers increasingly more demanding and products life cycles shrinking. To fight these forces, radical changes are needed in organizations in order to make companies more competitive. However, the resources and skills for this are often difficult to obtain by a single company. In this context, to remain competitive, companies have joined efforts to achieve greater coordination and collaboration among supply chain partners in an approach called Supply Chain Management. The literature, while several authors stated that further integration among the companies of a chain results in better performance for them, others have shown that the benefits of integration could not be confirmed. On the other hand, some authors stated that the benefits should occur throughout the chain and not just for some participating companies. In this context, it is clear the importance of performance measurement, both businesses and chains which they belong, and also relate it to the level of integration of the chain. Thus, this present work studied the relationship between supply chain integration and performance, both individually and corporate chain as a whole, of large national companies. This study is quantitative and descriptive, using the method of transverse self-administered survey, that the questionnaire was available online. We studied 135 companies from 13 different sectors, selected by a non-probability sampling for trial. Data obtained were analyzed in two ways: first a Factor Analysis was used (to reduce the number of variables) followed by linear regression analysis (to check the relationship between the constructs) and the second way the analysis was performed using the technique Structural Equation Modeling - SEM. We proposed three hypotheses to be verified - Hypothesis 1 (H1): There is a positive relationship between supply chain integration of organizational and individual performance; Hypothesis 2 (H2): There is a positive relationship between supply chain integration and overall performance of the chain supply and Hypothesis $3(\mathrm{H} 3)$ : There is a positive relationship between individual organizational performance and global performance of the supply chain. As a final result, the three hypotheses were confirmed, both by Regression Analysis, and by Structural Equation Modeling. It was observed the behavior of the three constructs according to the sectors studied. It was observed that there are differences between sectors only for the construct "integration of the supply chain." Thus, the sectors studied are statistically similar in constructs "individual performance" and "supply chain performance."
\end{abstract}

Keywords: Logistics, Supply Chain, Strategic Alliances 


\section{SUMÁRIO}

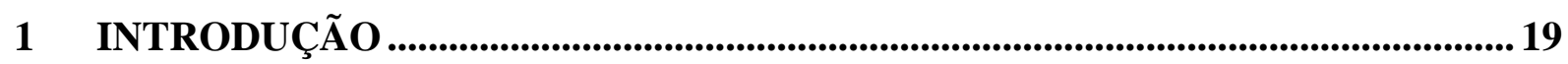

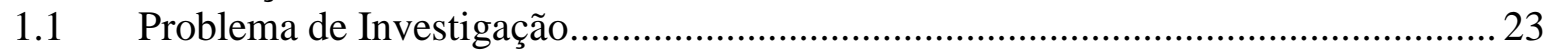

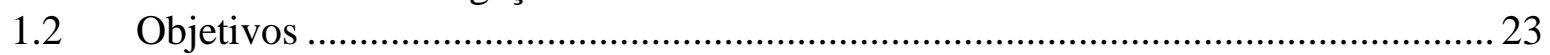

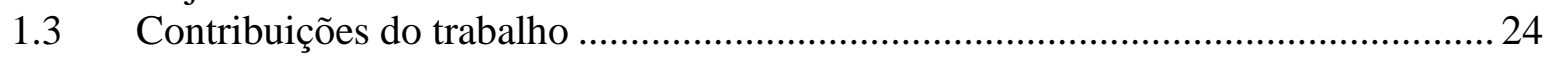

2 FUNDAMENTAÇÃO TEÓRICA ..........................................................................26

2.1 Da logística ao Gerenciamento da Cadeia de Suprimentos .................................... 28

2.2 O Gerenciamento da Cadeia de Suprimentos....................................................... 30

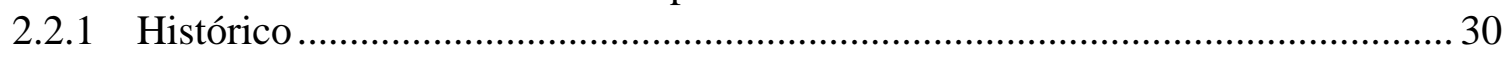

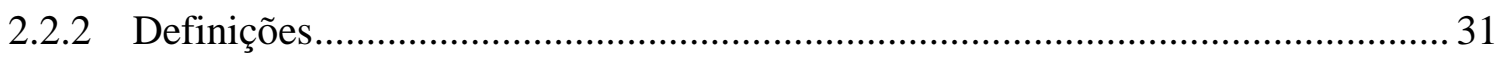

2.2.3 Objetivos do Gerenciamento da Cadeia de Suprimentos ................................... 34

2.2.4 Causas do surgimento do Gerenciamento da Cadeia de Suprimentos .................. 36

2.2.5 Processos, Elementos e Modelos do Gerenciamento da Cadeia de Suprimentos 37

2.2.6 Benefícios do Gerenciamento da Cadeia de Suprimentos .....................................53

2.2.7 Problemas e Desafios do Gerenciamento da Cadeia de Suprimentos ................... 55

2.2.8 Soluções para o Gerenciamento da Cadeia de Suprimentos ................................. 61

2.2.9 Conclusões sobre o Gerenciamento da Cadeia de Suprimentos ...........................6 68

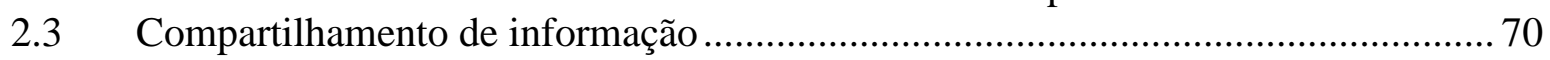

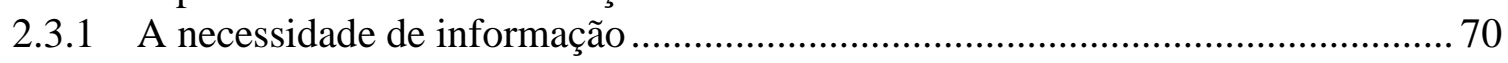

2.3.2 A falta de informação e suas conseqüências ................................................. 70

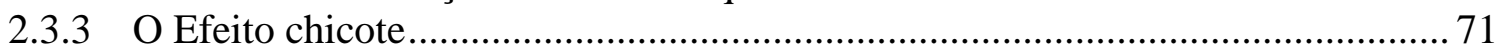

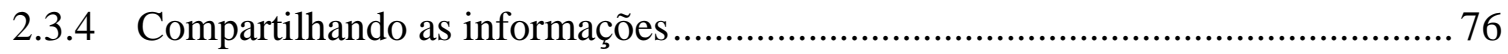

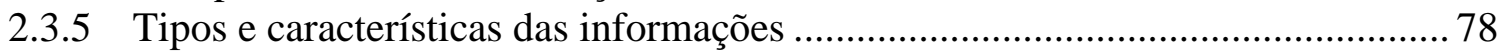

2.3.6 Benefícios do compartilhamento da informação................................................ 81

2.3.7 Problemas e dificuldades no compartilhamento da informação........................... 82

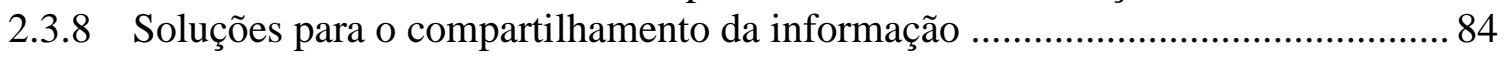

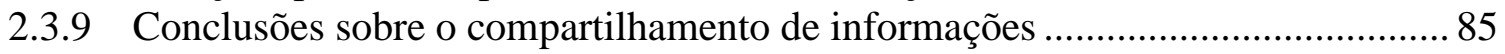

2.4 A importância dos sistemas e tecnologias de informação ....................................... 86

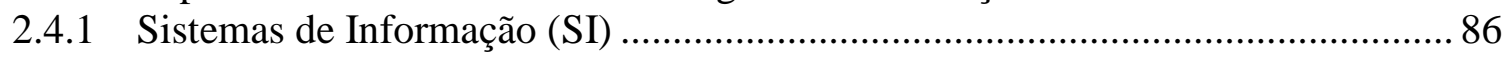

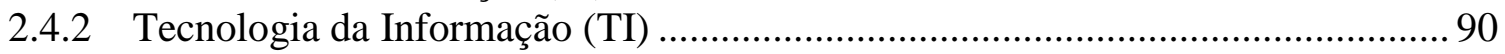

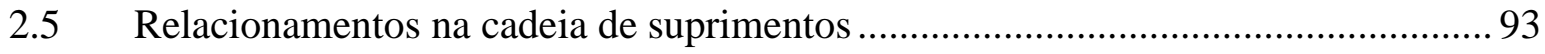

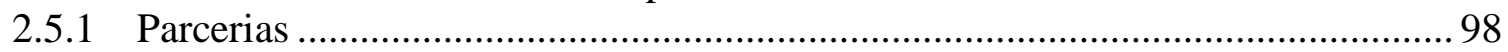

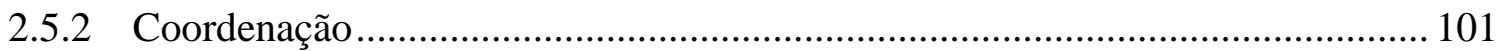

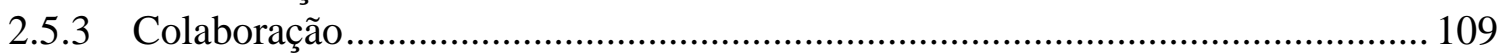

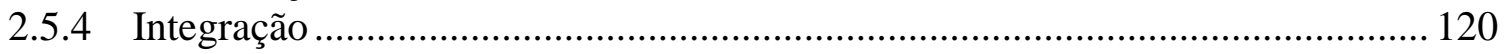

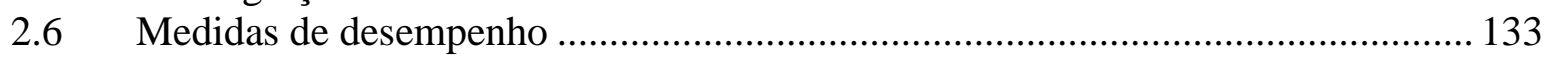

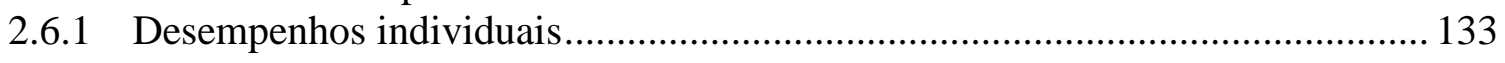

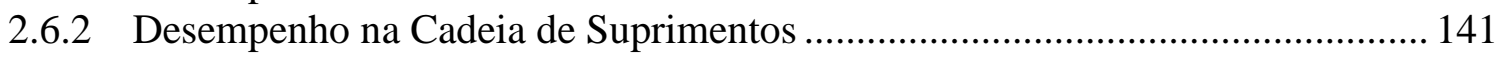

2.6.3 Dificuldades na mensuração do desempenho da cadeia de suprimentos ............ 164

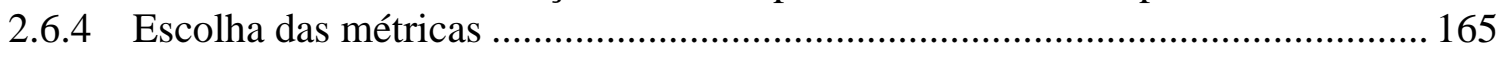

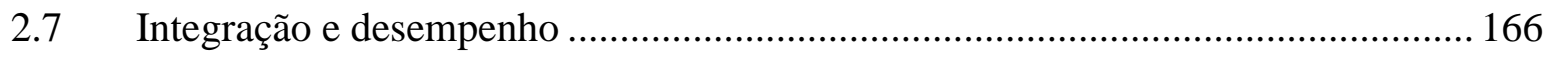

3 MÉTODO................................................................................................................ 173

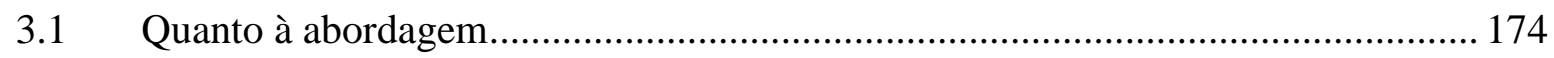

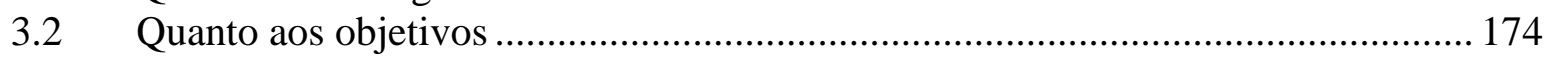

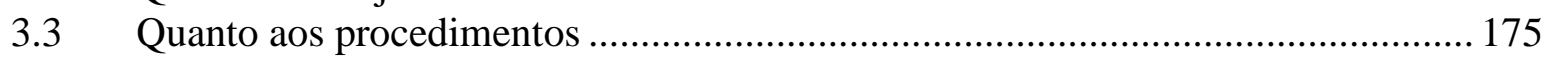

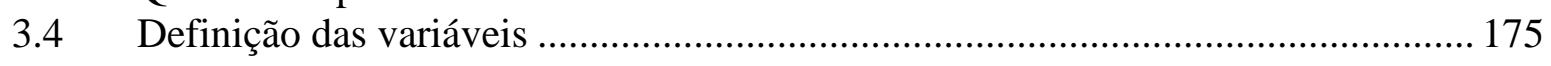




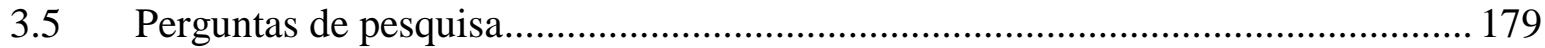

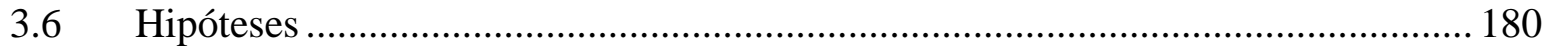

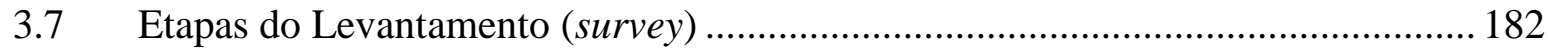

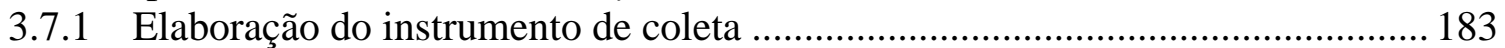

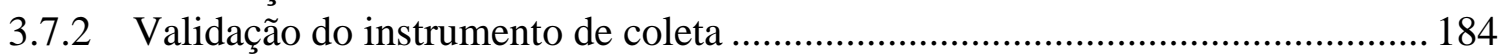

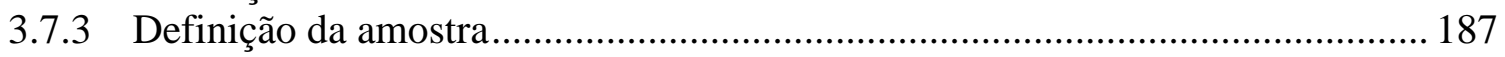

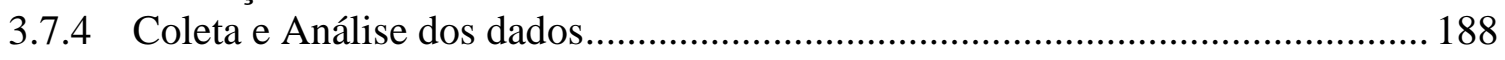

4 APRESENTAÇÃO E DISCUSSÃO DOS RESULTADOS ................................... 192

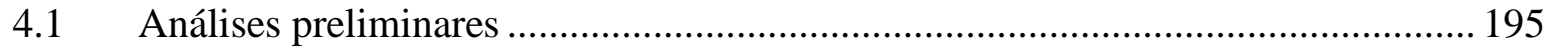

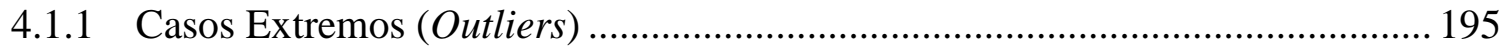

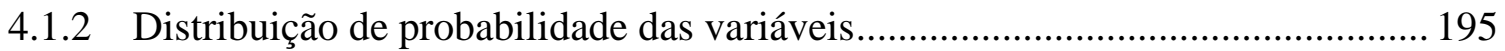

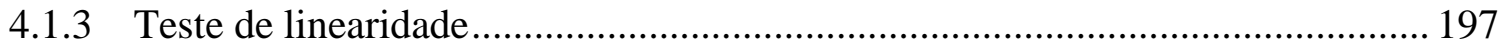

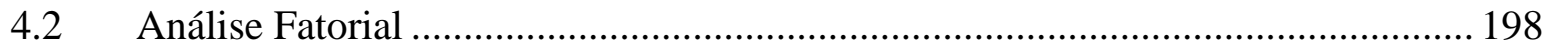

4.2.1 Constructo Integração da Cadeia de Suprimentos................................................ 199

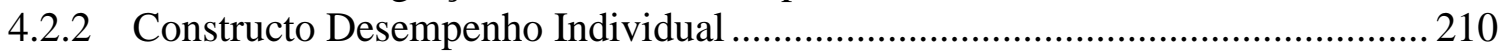

4.2.3 Constructo Desempenho da Cadeia de Suprimentos......................................... 219

4.2.4 Análise da Confiabilidade dos Fatores ............................................................... 229

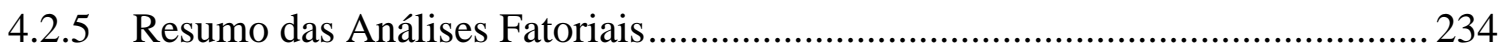

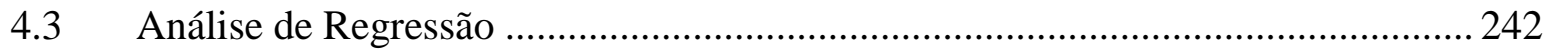

4.4 Teste de Significância - Análises dos Setores .......................................................... 251

4.5 Modelagem de Equações Estruturais ................................................................... 259

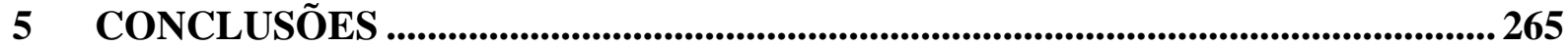

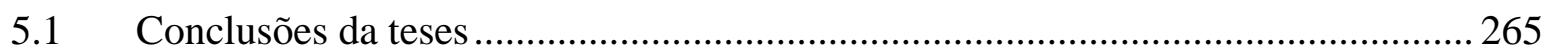

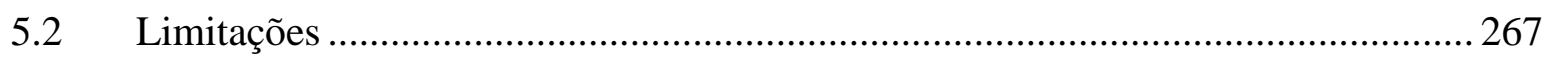

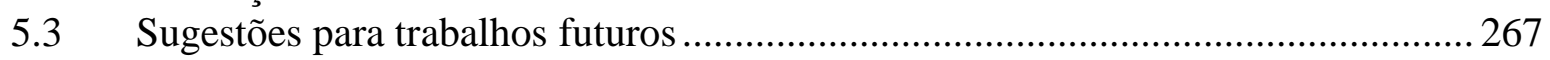

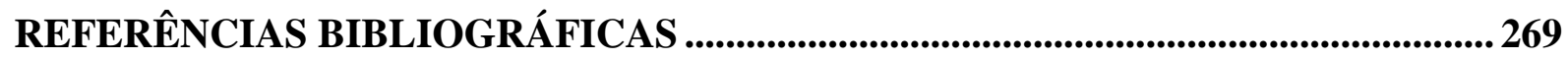

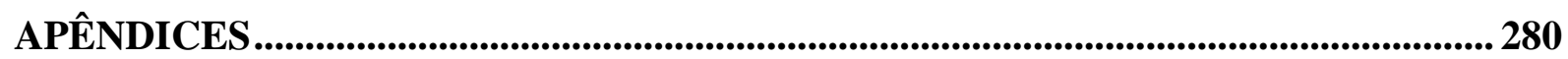

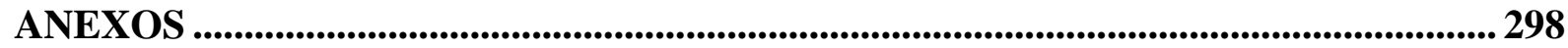




\section{LISTA DE ILUSTRAÇÕES}

Ilustração 1 - Evolução do Gerenciamento da Cadeia de Suprimentos ................................... 29

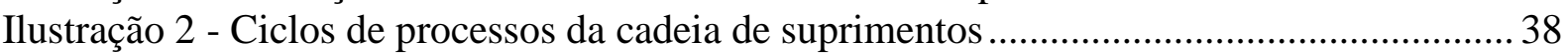

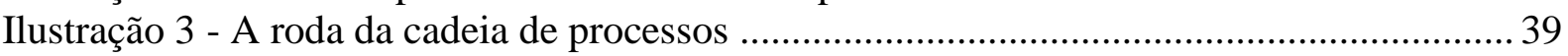

Ilustração 4 - Elementos estruturais da cadeia de suprimentos .............................................. 41

Ilustração 5 - A Casa do Gerenciamento da Cadeia de Suprimentos ........................................ 42

Ilustração 6 - Elementos e decisões chaves no gerenciamento da cadeia de suprimentos ....... 43

Ilustração 7 - Diferentes tipos de ligações entre as empresas ................................................. 45

Ilustração 8 - Sub-processos do Gerenciamento da Cadeia de Suprimentos ............................. 46

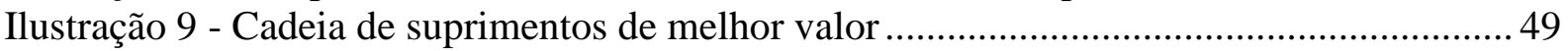

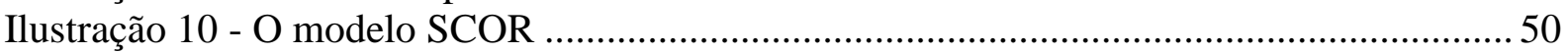

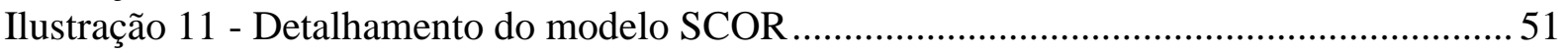

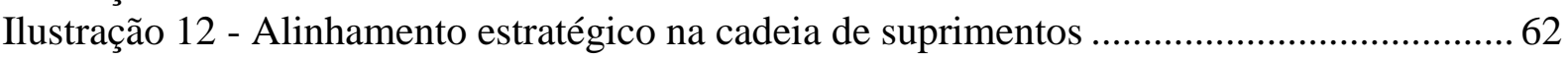

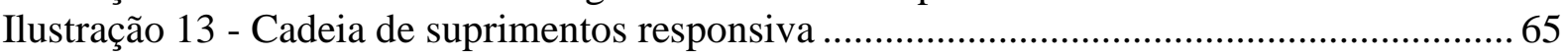

Ilustração 14 - Descontentamento na cadeia de suprimentos................................................ 67

Ilustração 15 - Modelo de Contingência para compreender a implementação da cadeia de

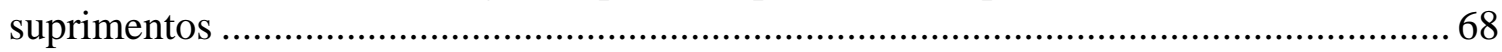

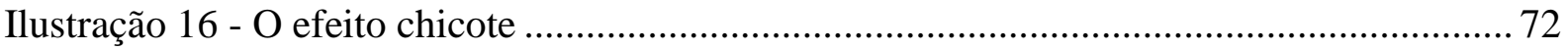

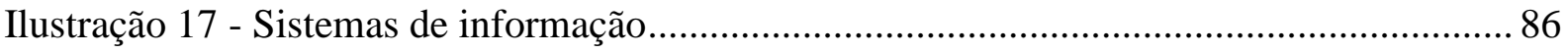

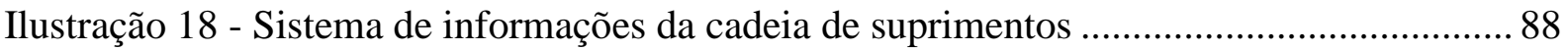

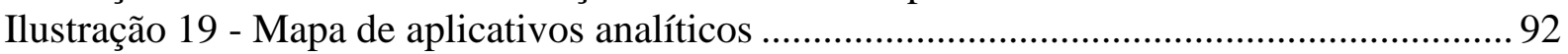

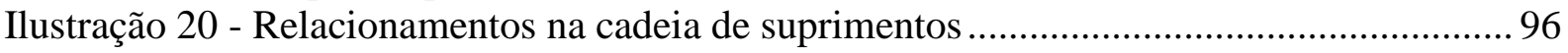

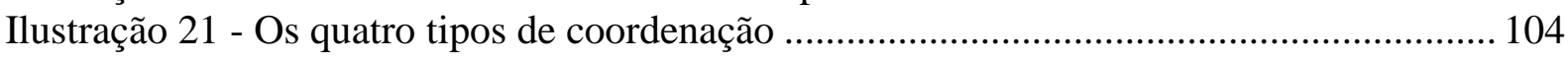

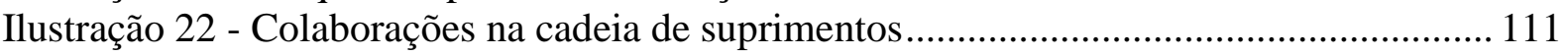

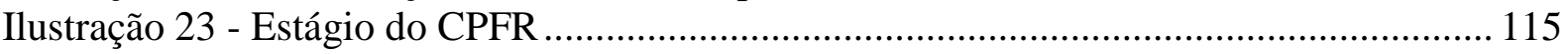

Ilustração 24 - Configuração básica da cadeia de suprimentos para a colaboração................ 118

Ilustração 25 - Os seis tipos de integração ........................................................................ 122

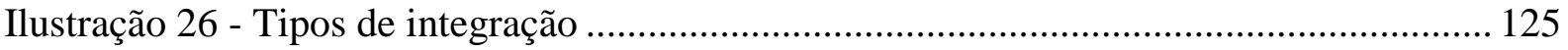

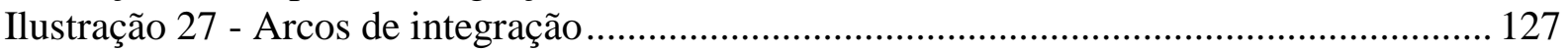

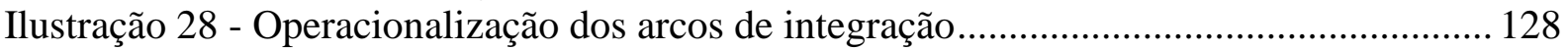

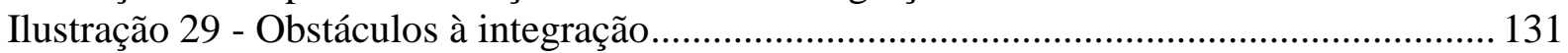

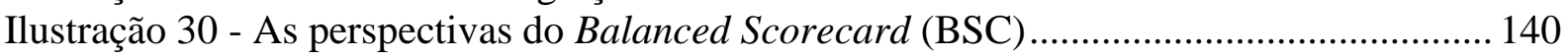

Ilustração 31 - Modelo Estratégico de Rentabilidade ......................................................... 152

Ilustração 32 - Como as atividades logísticas afetam o EVA ............................................... 153

Ilustração 33 - Medidas e métricas conforme os cinco processos básicos do modelo SCOR 157

Ilustração 34 - Ligação entre o gerenciamento da cadeia de suprimentos e o Balanced

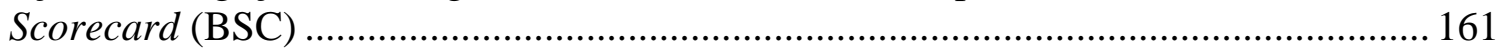

Ilustração 35 - O Balanced Supply Chain Scorecard (BSCS) .......................................... 162

Ilustração 36 - Modelo de integração de Vickery et al., (2003)............................................ 168

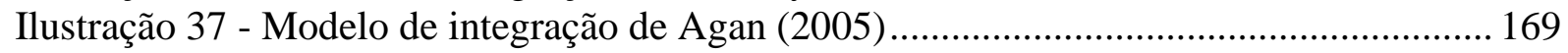

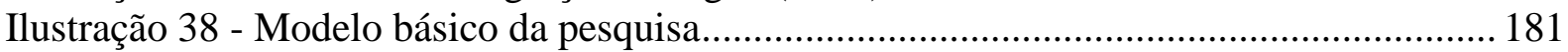

Ilustração 39 - Modelo detalhado da pesquisa .................................................................. 182

Ilustração 40 - Modelo detalhado da pesquisa e respectivas variáveis .................................. 194

Ilustração 41 - Fatores obtidos pela Análise Fatorial para a Integração da Cadeia de

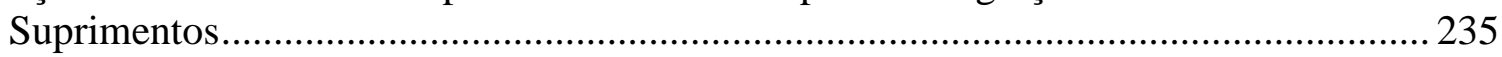

Ilustração 42 - Fatores obtidos pela Análise Fatorial para o Desempenho Individual........... 239 
Ilustração 43 - Fatores obtidos pela Análise Fatorial para o Desempenho da Cadeia de

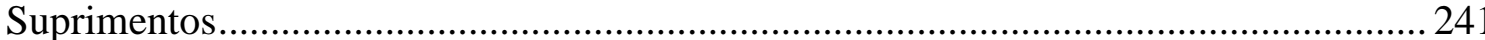

Ilustração 44 - Coeficientes de Determinação e Betas para o Modelo Inicial ........................ 260

Ilustração 45 - Estatística t para o Modelo Inicial.................................................................... 261

Ilustração 46 - Coeficientes de Determinação e Betas para o Modelo Final .......................... 262

Ilustração 47 - Estatística t para o Modelo Final.................................................................... 263 


\section{LISTA DE QUADROS}

Quadro 1 - Tópicos estudados na fundamentação teórica .27

Quadro 2 - Comparação entre cadeias tradicionais e o gerenciamento da cadeia de suprimentos

Quadro 3 - Definição de processos gerais no gerenciamento de cadeia de suprimentos ......... 47

Quadro 4 - Detalhamento do Modelos SCOR ...................................................................... 50

Quadro 5 - Diferentes estilos comportamentais de descontentamento com a cadeia de

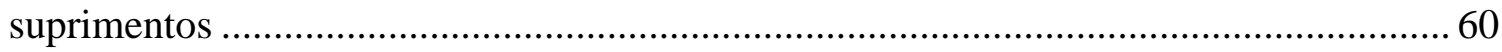

Quadro 6 - Benefícios do compartilhamento de informações ................................................. 81

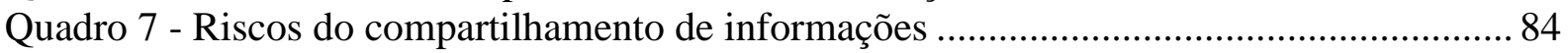

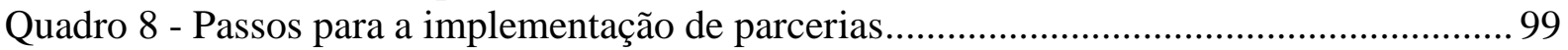

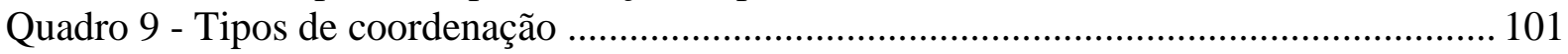

Quadro 10 - Dimensões da Integração da Cadeia de Suprimentos ....................................... 122

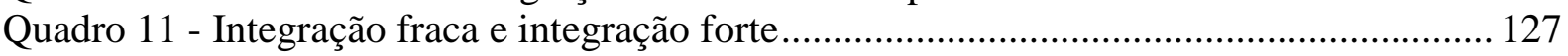

Quadro 12 - Medidas de desempenho segundo BEAMON, 1998 ....................................... 147

Quadro 13 - Medidas de desempenho segundo BEAMON, 1999 ........................................ 149

Quadro 14 - Vantagens e desvantagens de algumas medidas de desempenho ....................... 153

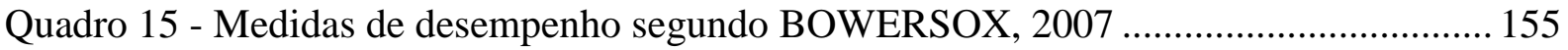

Quadro 16 - Medidas de desempenho segundo GUNASEKARAN et al., 2001 .................... 156

Quadro 17 - Medidas de desempenho segundo o Modelo SCOR .......................................... 158

Quadro 18 - Medidas de desempenho do nível 1 do Modelo SCOR .................................... 159

Quadro 19 - Objetivos e métricas do Balanced Supply Chain Scorecard (BSCS) ................ 162

Quadro 20 - Balanced Scorecard aplicado ao gerenciamento da cadeia de suprimentos...... 163

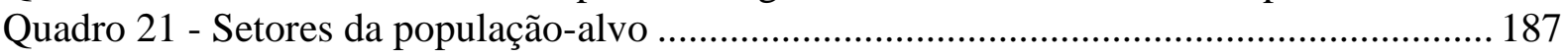

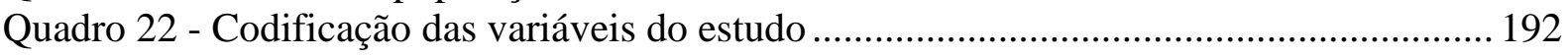

Quadro 23 - Distribuição de probabilidade das variáveis ..................................................... 196

Quadro 24 - Parâmetros da Qualidade das Análises Fatoriais .............................................. 199

Quadro 25 - Resumo das Análises Fatoriais - Integração da Cadeia de Suprimentos........... 235

Quadro 26 - Resumo das Análises Fatoriais - Desempenho Individual ................................ 239

Quadro 27 - Resumo das Análises Fatoriais - Integração da Cadeia de Suprimentos........... 241

Quadro 28 - Modelagem de Equações Estruturais - Variáveis e respectivos níveis ............. 259

Quadro 29 - Modelagem de Equações Estruturais - Medidas de adequação do modelo....... 263 


\section{LISTA DE TABELAS}

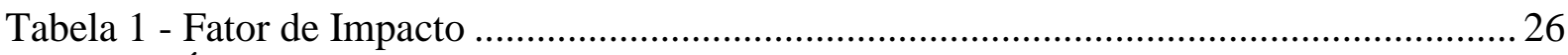

Tabela 2 - Índice H para autores ...................................................................................... 27

Tabela 3 - Como a posição na cadeia de suprimentos afeta o custo de manutenção de estoque

Tabela 4 - Setores estudados

Tabela 5 - KMO e teste de Bartlett para integração da cadeia - integração interna ............... 200

Tabela 6 - Matriz Anti-Imagem - integração da cadeia - integração interna ....................... 200

Tabela 7 - Comunalidades - integração da cadeia - integração interna................................ 200

Tabela 8 - Variância Total Explicada - integração da cadeia - integração interna................ 201

Tabela 9 - Matriz Componente - integração da cadeia - integração interna ........................ 201

Tabela 10 - KMO e teste de Bartlett para integração da cadeia - integração externa com

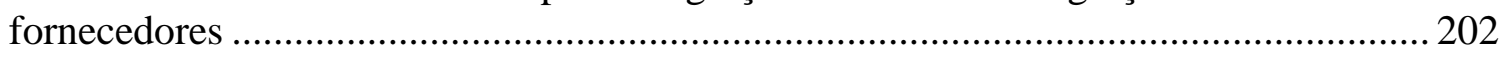

Tabela 11 - Matriz Anti-Imagem - integração da cadeia - integração externa com

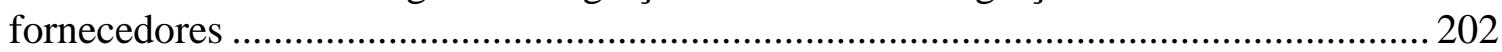

Tabela 12 - Comunalidades - integração da cadeia - integração externa com fornecedores 203

Tabela 13 - Comunalidades - integração da cadeia - integração externa com fornecedores

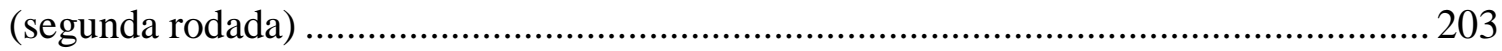

Tabela 14 - KMO e teste de Bartlett para integração da cadeia - integração externa com

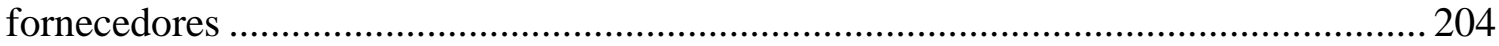

Tabela 15 - Matriz Anti-Imagem - integração da cadeia - integração externa com

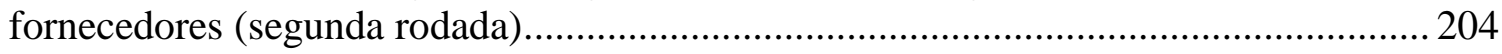

Tabela 16 - Comunalidades - integração da cadeia - integração externa com fornecedores (terceira rodada)

Tabela 17 - Variância Total Explicada - integração da cadeia - integração externa com

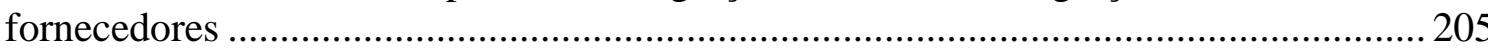

Tabela 18 - Matriz de componentes rotacionada - integração da cadeia - integração externa

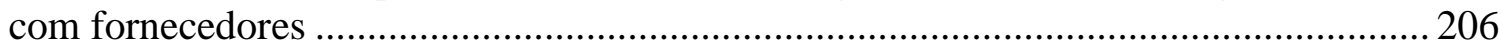

Tabela 19 - KMO e teste de Bartlett para integração da cadeia - integração externa com

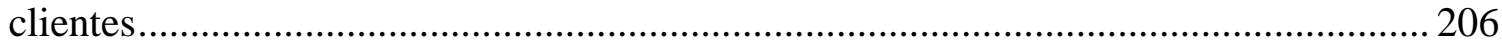

Tabela 20 - Matriz Anti-Imagem - integração da cadeia - integração externa com clientes

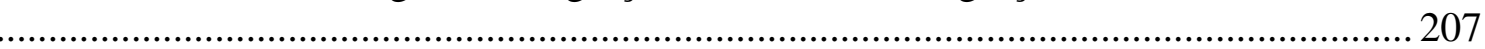

Tabela 21 - Comunalidades - integração da cadeia - integração externa com clientes ....... 207

Tabela 22 - KMO e teste de Bartlett para integração da cadeia - integração externa com

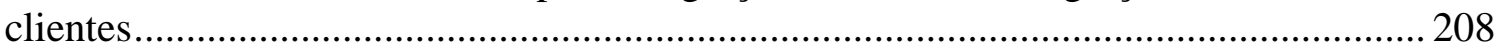

Tabela 23 - Matriz Anti-Imagem - integração da cadeia - integração externa com clientes

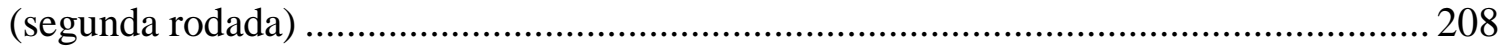

Tabela 24 - Comunalidades - integração da cadeia - integração externa com clientes

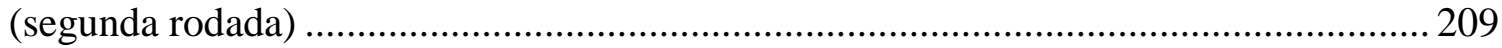

Tabela 25 - Variância Total Explicada - integração da cadeia - integração externa com

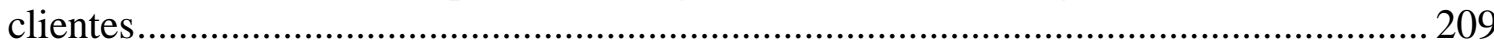

Tabela 26 - Matriz de componentes rotacionada - integração da cadeia - integração externa

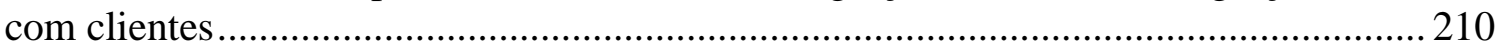

Tabela 27 - KMO e teste de Bartlett para desempenho individual - perspectiva dos processos

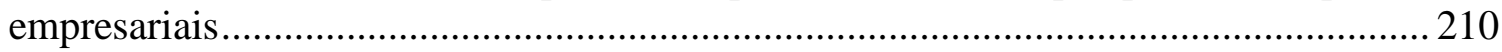

Tabela 28 - Matriz Anti-Imagem - desempenho individual - perspectiva dos processos empresariais 
Tabela 29 - Comunalidades - desempenho individual - perspectiva dos processos empresariais

Tabela 30 - Variância Total Explicada - desempenho individual - perspectiva dos processos empresariais.

Tabela 31 - Matriz de componentes rotacionada - desempenho individual - perspectiva dos processos empresariais

Tabela 32 - KMO e teste de Bartlett para desempenho individual - perspectiva dos clientes

Tabela 33 - Matriz Anti-Imagem - desempenho individual - perspectiva dos clientes........ 213

Tabela 34 - Comunalidades - desempenho individual - perspectiva dos clientes ................ 214

Tabela 35 - KMO e teste de Bartlett para desempenho individual - perspectiva dos clientes (segunda rodada)

Tabela 36 - Matriz Anti-Imagem - desempenho individual - perspectiva dos clientes (segunda rodada)

Tabela 37 - Comunalidades - desempenho individual - perspectiva dos clientes (segunda rodada)

Tabela 38 - Variância Total Explicada - desempenho individual - perspectiva dos clientes 215

Tabela 39 - Matriz de componentes rotacionada - desempenho individual - perspectiva dos clientes.....

Tabela 40 - KMO e teste de Bartlett para desempenho individual - perspectiva financeira 216

Tabela 41 - Matriz Anti-Imagem - desempenho individual - perspectiva financeira .......... 216

Tabela 42 - Comunalidades - desempenho individual - perspectiva financeira.................. 216

Tabela 43 - Variância Total Explicada - desempenho individual - perspectiva financeira.. 217

Tabela 44 - Matriz de componentes rotacionada - desempenho individual - perspectiva financeira

Tabela 45 - KMO e teste de Bartlett para desempenho individual - perspectiva da inovação e do aprendizado

Tabela 46 - Matriz Anti-Imagem - desempenho individual - perspectiva da inovação e do aprendizado

Tabela 47 - Comunalidades - desempenho individual - perspectiva da inovação e do aprendizado

Tabela 48 - Variância Total Explicada - desempenho individual - perspectiva financeira.. 218

Tabela 49 - Matriz de componentes rotacionada - desempenho individual - perspectiva da inovação e do aprendizado

Tabela 50 - KMO e teste de Bartlett para desempenho da cadeira - perspectiva dos processos empresariais

Tabela 51 - Matriz Anti-Imagem - desempenho da cadeia - perspectiva dos processos empresariais

Tabela 52 - Comunalidades - desempenho da cadeia - perspectiva dos processos empresariais

Tabela 53 - Variância Total Explicada - desempenho da cadeia - perspectiva dos processos empresariais

Tabela 54 - Matriz de componentes rotacionada - desempenho da cadeia - perspectiva dos processos empresariais

Tabela 55 - KMO e teste de Bartlett para desempenho da cadeira - perspectiva dos clientes

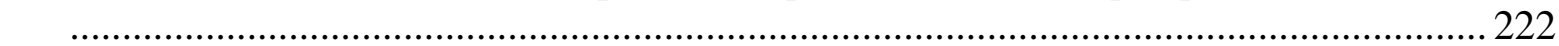

Tabela 56 - Matriz Anti-Imagem - desempenho da cadeia - perspectiva dos clientes......... 222

Tabela 57 - Comunalidades - desempenho da cadeia - perspectiva dos clientes .................. 222

Tabela 58 - KMO e teste de Bartlett para desempenho da cadeira - perspectiva dos clientes (segunda rodada) 
Tabela 59 - Matriz Anti-Imagem - desempenho da cadeia - perspectiva dos clientes (segunda rodada).

Tabela 60 - Comunalidades - desempenho da cadeia - perspectiva dos clientes (segunda rodada).

Tabela 61 - Variância Total Explicada - desempenho da cadeia - perspectiva dos clientes 223

Tabela 62 - Matriz de componentes rotacionada - desempenho da cadeia - perspectiva dos clientes....

Tabela 63 - KMO e teste de Bartlett para desempenho da cadeira - perspectiva financeira 224

Tabela 64 - Matriz Anti-Imagem - desempenho da cadeia - perspectiva financeira............ 224

Tabela 65 - Comunalidades - desempenho da cadeia - perspectiva financeira .................... 225

Tabela 66 - Comunalidades - desempenho da cadeia - perspectiva financeira (segunda

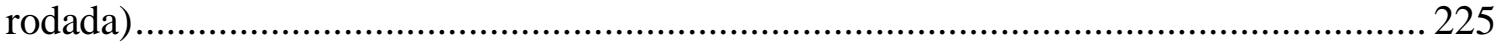

Tabela 67 - KMO e teste de Bartlett para desempenho da cadeira - perspectiva financeira 226

Tabela 68 - Matriz Anti-Imagem - desempenho da cadeia - perspectiva financeira (segunda rodada).

Tabela 69 - Comunalidades - desempenho da cadeia - perspectiva financeira (terceira rodada)

Tabela 70 - Variância Total Explicada - desempenho da cadeia - perspectiva financeira... 227

Tabela 71 - Matriz de componentes rotacionada - desempenho da cadeia - perspectiva financeira.....

Tabela 72 - KMO e teste de Bartlett para desempenho da cadeira - perspectiva da inovação e do aprendizado

Tabela 73 - Matriz Anti-Imagem - desempenho da cadeia - perspectiva da inovação e do aprendizado

Tabela 74 - Comunalidades - desempenho da cadeia - perspectiva da inovação e do aprendizado

Tabela 75 - Variância Total Explicada - desempenho da cadeia - perspectiva da inovação e do aprendizado

Tabela 76 - Matriz de componentes rotacionada - desempenho da cadeia - perspectiva da inovação e do aprendizado

Tabela 77 - Análise de Confiabilidade - integração da cadeia - integração interna

Tabela 78 - Análise de Confiabilidade - integração da cadeia - Compartilhamento de Informações

Tabela 79 - Análise de Confiabilidade - integração da cadeia - Participação do Fornecedor no Negócio

Tabela 80 - Análise de Confiabilidade - integração da cadeia - Integração Externa com Clientes.

Tabela 81 - Análise de Confiabilidade - Desempenho Individual - Entrega

Tabela 82 - Análise de Confiabilidade - Desempenho Individual - Eficiência dos Aspectos da Produção

Tabela 83 - Análise de Confiabilidade - Desempenho Individual - Flexibilidade

Tabela 84 - Análise de Confiabilidade - Desempenho Individual - Perspectiva dos Clientes

Tabela 85 - Análise de Confiabilidade - Desempenho Individual - Perspectiva Financeira Entradas

Tabela 86 - Análise de Confiabilidade - Desempenho da Cadeia - Entrega ....................... 233

Tabela 87 - Análise de Confiabilidade - Desempenho da Cadeia - Ciclo de Produção ...... 233

Tabela 88 - Análise de Confiabilidade - Desempenho da Cadeia - Perspectivas dos Clientes 
Tabela 89 - Análise de Confiabilidade - Desempenho da Cadeia - Indicadores Financeiros

Tabela 90 - Teste Kolmogorov-Smirnov (K-S) para os constructos - Análise de Regressão

Tabela 91 - Resumo do modelo de regressão - Desempenho Individual x Integração da

Cadeia.

Tabela 92 - Análise de Variância - Desempenho Individual x Integração da Cadeia

Tabela 93 - Coeficientes do modelo de regressão - Desempenho Individual x Integração da Cadeia....

Tabela 94 - Resumo do modelo de regressão - Desempenho da Cadeia x Integração da Cadeia.....

Tabela 95 - Análise de Variância - Desempenho da Cadeia x Integração da Cadeia ....

Tabela 96 - Coeficientes do modelo de regressão - Desempenho da Cadeia x Integração da Cadeia.

Tabela 97 - Resumo do modelo de regressão - Desempenho da Cadeia x Desempenho Individual

Tabela 98 - Análise de Variância - Desempenho da Cadeia x Desempenho Individual ...... 247

Tabela 99 - Coeficientes do modelo de regressão - Desempenho da Cadeia x Desempenho Individual

Tabela 100 - Normalidade dos Resíduos

Tabela 101 - Resumo das Análises de Regressão. 248

Tabela 102 - Correlações de Pearson para os constructos....

Tabela 103 - Teste Kolmogorov-Smirnov (K-S) para os constructos - Análise dos setores 251

Tabela 104 - Setores de Atividade

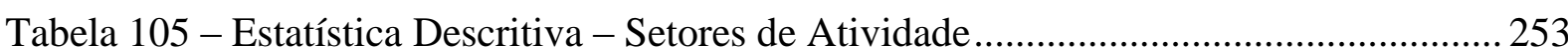

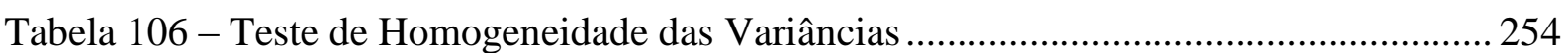

Tabela 107 - Análise de Variâncias - Setores ....................................................................... 255

Tabela 108 - Teste Post Hoc - Setores (variável dependente - Integração da Cadeia)......... 255 


\section{LISTA DE ABREVIATURAS}

APS: Advanced Planning and Scheduling (Aplicativos de compras, Planejamento Avançado e Programação)

BSC: Balanced Scorecard

BSCS: Balanced Supply Chain Scorecard

CFROI: Cash flow return on investment (Retorno sobre o investimento base caixa)

CLM: Council of Logistics Management (Conselho do Gerenciamento da Logística)

CMPC: Custo Médio Ponderado de Capital

CPFR: Collaborative Planning, Forecasting and Replenishment (Planejamento, Previsão e Reabastecimento Colaborativos)

CRM: Customer Relationship Management (Gerenciamento do Relacionamento com o Cliente)

CRP ou CR: Continuous Replenishment Programs (Programas de Reabastecimento Contínuo)

CSCMP: Council of Supply Chain Management Professionals (Conselho dos Profissionais de Gerenciamento da Cadeia de Suprimentos)

CVA: Customer value-added (Valor adicionado ao cliente)

DRE: Demonstração do Resultado do Exercício

DSS: Decision Support System (Sistemas de Apoio à Decisão - SAD)

ECR: Efficient Customer Response (Resposta Eficiente ao Consumidor)

EDI: Electronic Data Interchange (Transferência Eletrônica de Dados)

ESS: Executive Support System (Sistemas de Suporte a Executivos - SSE)

EVA: Economic value added (Valor Econômico Agregado)

IOS ou IOIS: Interorganizational Information Systems (Sistemas de Informação Interorganizacional)

JCR: Journal Citation Reports

LTI: Tucker Lewis Índex

MAF: Multiplicador de Alavancagem Financeira 
MES: Manufacturing Execution System (Sistemas integrados de controle da produção)

MIS: Management Information System (Sistemas de Informações Gerenciais - SIG)

MRP: Material Requirements Planning (Planejamento das Necessidades de Materiais)

MVA: Market value added (Valor agregado pelo mercado)

P\&D: Pesquisa e Desenvolvimento

PDV: Ponto de Venda

QRM: Quick Response Manufacturing (Manufatura em Resposta Rápida)

RBV: Resource-Based View (Visão Baseada em Recursos)

RFID: Radio-Frequency IDentification (Identificação por Radiofrequiência)

ROA: Return Over Assets (Retorno sobre o Ativo)

ROE: Return On Equity (Retorno sobre o Patrimônio Líquido)

ROIC: Return on Investiment (Retorno sobre o Ativo Investido)

SCM: Supply Chain Management (Gerenciamento da Cadeia de Suprimentos)

SCIS: Supply Chain Informations Systems (Sistema de Informações da Cadeia de Suprimentos)

SCOR: Supply Chain Operations Reference (Referência de Operações da Cadeia de Suprimentos)

SEM: Structural Equation Modeling

SFA: Sales Force Automation (Automação da força de vendas)

SI: Sistemas de informação

SPM: Strategic Profit Model (Modelo Estratégico de Rentabilidade)

SVA: Shareholder value analysis (Análise de Valor ao Acionista)

TI: Tecnologias de informação

TMS: Transport Management System (Sistema de Gerenciamento de Transportes)

TPS: Transaction Processing Systems (Sistemas de Processamento de Transações - STP)

VICS: Voluntary Interindustry Commerce Standards Association (Associação Voluntária Intersetorial de Padrões de Comércio) 
VMI: Vendor Managed Inventory (Estoque Gerenciado pelo Fornecedor)

VMR: Vendor Managed Replenishment (Reposição Gerenciada pelo Vendedor XML: eXtensible Markup Language

WACC: Weighted Average Cost of Capital (Custo Médio Ponderado de Capital - CMPC)

WMS: Warehouse Management System (Sistema de Gerenciamento de Armazéns) 


\section{INTRODUÇÃO}

Segundo Porter e Stern (2001), as empresas estão enfrentando um ambiente complexo e competitivo como nunca. Barreiras comerciais estão caindo, os consumidores tem se tornado cada vez mais exigentes e os ciclos de vida dos produtos têm se encurtado, forçando as empresas reduzirem o tempo de comercialização e também a fornecerem níveis mais elevados de serviços aos consumidores (PATTERSON et al., 2003; ELLINGER et al., 1997).

Também para Lee e Whang (2001), ao longo da última década, uma combinação de forças econômicas, tecnológicas e mercadológicas têm obrigado as empresas a analisarem e reinventarem suas estratégias de cadeia de suprimentos. Entre essas forças estão a globalização dos negócios, a proliferação da variedade de produtos, a crescente complexidade das redes de suprimentos, bem como o redução dos ciclos de vida dos produtos.

Para Gunasekaran et al. (2001), no mercado atual, forças tecnológicas e competitivas estão mudando num ritmo cada vez maior. Para reagir a estas forças, foram necessárias mudanças radicais nas organizações. Agora a viabilidade de uma empresa depende em grande parte da sua capacidade de reagir às demandas dos clientes enquanto se torna mais enxuta.

Assim, uma das primeiras questões que se observa é a preocupação com a importância de se satisfazer o consumidor, tornando-o foco do negócio. A idéia básica apresentada por Innis e La Londe (1994) é a de que um cliente satisfeito terá uma probabilidade maior de fazer novas compras, gerando um aumento nas vendas, na participação de mercado e, conseqüentemente, nos lucros da empresa. Geralmente, a área de marketing é considerada como a principal área funcional em uma empresa que trabalha com a questão da satisfação dos clientes, porém, a logística possui um papel significante na atividade de atender às necessidades dos clientes (colocando o produto certo, no local certo, na hora certa e na quantidade certa) e seu impacto não deve ser desprezado.

Nesse contexto, as necessidades dos consumidores e mudanças da tecnologia forçam os fabricantes a desenvolverem formas de se tornarem competitivas. Com isso, várias empresas estão enfatizando a flexibilidade e a agilidade para que possam responder, em tempo real, às necessidades únicas dos consumidores e dos mercados. Entretanto, as competências de 
recursos necessárias são freqüentemente difíceis de serem obtidas por uma única companhia. Torna-se, portanto imperativo para as empresas a cooperação e alavancagem de suas competências complementares e assim, as companhias separadas fisicamente estão operando de forma integrada (YUSUF et al., 2004)

Segundo Zailani e Rajagopal (2005), nessa era globalizada, a maioria das indústrias não será capaz de sobreviver simplesmente otimizando suas estruturas internas e infra-estruturas baseadas em uma estratégia de negócio. Os produtores de maior sucesso parecem ser aqueles que cuidadosamente ligaram seus processos internos a fornecedores e consumidores externos em uma única cadeia de suprimentos. Assim, a orientação das empresas produtoras em direção a satisfação do consumidor trouxe a compreensão de benefícios potenciais e da importância dos relacionamentos estratégicos e cooperativos entre comprador e fornecedor.

De acordo com Gunasekaran et al. (2001), está se tornando cada vez mais difícil e menos econômico para empresas atenderem suas necessidades por conta própria. Ao contrário, a terceirização está se tornando uma estratégia importante. Também, a tendência, sempre crescente, de globalização e de orientação para o cliente necessita que as empresas tenham uma logística sensível. O Gerenciamento de Cadeia de Suprimentos (supply chain management - SCM) é uma abordagem que evoluiu da integração destas considerações.

Também segundo Kalakota e Robinson (2002), uma empresa não pode mais ser considerada como uma simples corporação, mas sim como uma coleção de negócios entre parceiros que mantém contratos com fabricantes, operadores logísticos, fornecedores, entre outros.

Uma cadeia de suprimento geralmente consiste de múltiplos participantes, começando com fornecedores e incluindo indústrias, distribuidores, varejistas e consumidor final. A competição mais acirrada tem levado a maioria da empresas a procurar meios de aumentar seu desempenho além de seus limites e a busca na colaboração com seus parceiros têm resultado em melhores desempenhos (SIMATUPANG; SRIDHARAN, 2005).

Segundo Cagliano et al. (2006), a complexidade crescente dos produtos e, conseqüentemente, o maior nível de terceirização moveu o nível da concorrência de empresas isoladas para grupos ou cadeias de empresas, ficando reconhecida a relevância estratégica do gerenciamento da cadeia de suprimentos como uma fonte de vantagem competitiva. 
Também para Ellinger (2000) um correto gerenciamento da cadeia de suprimentos, por meio de melhores relacionamentos inter e intra empresariais, é a chave para a criação de vantagem competitiva nos dias atuais, pois gera um impacto direto nas estratégias genéricas de negócio (custo, qualidade, flexibilidade, tempo e inovação).

Para Dhahri e Chabchoub (2007), em menos de meio século, o gerenciamento da cadeia de suprimentos impôs-se como uma habilidade estratégica. Hoje, ela chega a uma nova fase, mais complexa, sendo vista como sinônimo de vantagem competitiva e servindo como um elo entre os clientes e produtos, bem como entre produtores e fornecedores.

Segundo Bayraktar et al. (2008), apesar dos curtos ciclos de vida dos produtos e dos custos reduzidos dos produtos/serviços, a idéia do "produto certo, no momento certo e no lugar certo", passou a ser possível através de avanços na comunicação e nas tecnologias de transporte. A empresa contemporânea, face a estes desafios, tem buscado lidar com as emergentes incertezas em suas cadeias de suprimento de forma mais eficaz.

De acordo com Hicks (1999), a configuração e operação de atividades e recursos da cadeia de suprimentos são fontes novas e alternativas para as empresas criarem vantagens competitivas sustentáveis. De fato, em muitas empresas, isso pode ser uma das últimas fontes de vantagem competitiva, pois a padronização de produto e "comoditização" direcionam a competição com base no preço, e fontes de diferenciação tornam-se mais difíceis de serem estabelecidas. Assim, uma cadeia de suprimento integrada pode atuar como uma fonte alternativa de diferenciação, pois ainda são poucas as empresas que conseguem tal integração.

Também segundo Lee e Whang (2001), para se manterem competitivas, as empresas devem juntar esforços para conseguirem uma maior coordenação e colaboração entre os parceiros na cadeia de suprimentos em uma abordagem chamada de "integração da cadeia de suprimentos".

De forma semelhante, Saeed (2004) afirma que a globalização, a redução dos ciclos de vida dos produtos, a concorrência baseada na rapidez e rápida mudança nas tecnologias da informação fizeram as repensar e reconfigurar suas estratégias de cadeias de suprimento. Entre várias iniciativas, elas adotaram a estreita colaboração e coordenação de suas atividades 
com seus parceiros na cadeia de suprimentos, num tipo de ação que tem sido chamada de integração da cadeia de suprimentos.

Também para Chantrasa (2005) o atual ambiente industrial é caracterizado por curtos ciclos de vida de produtos e altas expectativas dos consumidores. Para isso um correto gerenciamento da cadeia de suprimentos necessita de uma integração forte entre seus fornecedores, produtores, atacadistas e varejistas de forma a gerir eficazmente os fluxos de materiais, informações e recursos financeiros dentro e através dos membros.

Assim, muitas organizações tentam integrar e coordenar estreitamente os vários elementos de suas cadeias de suprimento, de forma a aumentar sua eficácia. Para eles, uma cadeia de suprimentos de melhor valor foca no valor total acrescentado ao cliente por meio de quatro estratégias competitivas: velocidade, custo, qualidade e flexibilidade (KETCHEN et al., 2008).

De acordo com Stadler e Kilger (2005), o objetivo de uma organização industrial é ser rentável e aumentar seus lucros, tornando-se claro a importância da mensuração do desempenho nas empresas (KUTUCUOGLU et al., 2001)

Porém, apesar de muitos estudos, como os realizados por Carr e Pearson (1999), Frohlich e Westbrook (2001), Narasimhan e Das (2001), Rosenzweig et al. (2003), Vickery et al. (2003), Agan (2005) e Sezen (2008), entre outros, mostrarem a existência de uma relação positiva entre integração da cadeia de suprimentos e desempenho organizacional individual, por outro lado, estudos como dos autores Cousins e Menguc (2006), Das et al. (2006), Badell et al. (2007) e Swink et al. (2007) mostraram que os benefícios da integração da cadeia de suprimentos não puderam ser confirmados.

Além disso, grande parte dos estudos já realizados mostrou a relação entre a integração da cadeia de suprimentos e os desempenhos individuais de cada empresa, e apenas poucos estudos (todos eles pesquisas qualitativas no formato de estudos de caso) buscaram mostrar a relação entre integração e desempenho da cadeia como um todo (FABBE-COSTES; JAHRE, 2007). 
Por outro lado, Gunasekaran et al. (2001) relatam em seus trabalhos que elos discretos em uma cadeia de suprimentos não levam a uma melhora na produtividade total da cadeia se cada um perseguir seus objetivos individualmente (o que é a prática comum). Porém, não havendo uma busca para otimizar cada elo individualmente, mas sim apenas uma melhora de desempenho, qual seria a relação entre desempenho organizacional individual e desempenho global da cadeia?

Assim, Lambert e Pohlen (2001) e Fabbe-Costes e Jahre (2007), alertam para a necessidade de se determinar a relação entre o desempenho organizacional individual e o desempenho global da cadeia de suprimentos.

\subsection{Problema de Investigação}

Diante deste contexto, é proposto o seguinte problema de investigação:

Existe relação entre a integração de empresas constituintes de uma cadeia de suprimentos com os respectivos desempenhos organizacionais individuais e global da cadeia?

\subsection{Objetivos}

O objetivo geral dessa pesquisa é verificar a existência de relação entre a integração da cadeia de suprimentos com os desempenhos organizacionais individuais e globais das cadeias em empresas brasileiras de grande porte.

Os objetivos específicos são:

a) Verificar os níveis de integração individuais atuais das empresas;

b) Verificar os desempenhos organizacionais individuais atuais das empresas;

c) Verificar desempenhos globais das cadeias as quais elas pertencem;

d) Verificar a relação entre os níveis de integração individuais com os desempenhos organizacionais individuais;

e) Verificar a relação entre os níveis de integração individuais com os desempenhos globais das cadeias as quais elas pertencem; 
f) Verificar a relação entre os desempenhos individuais das empresas com os desempenhos globais das cadeias as quais elas pertencem;

g) Verificar os níveis de integração, desempenhos organizacionais individuais e desempenhos globais da cadeia por setor de atividade.

\subsection{Contribuições do trabalho}

Ao término deste trabalho, espera-se como contribuição ao meio acadêmico os seguintes pontos:

- Elaboração e validação de um instrumento de coleta envolvendo os seguintes assuntos sobre o gerenciamento da cadeia de suprimentos: nível de integração da cadeia de suprimentos, desempenho individual das empresas e desempenho global da cadeia;

- No âmbito internacional, verificar quantitativamente a relação entre desempenho individual das empresas com o desempenho global das cadeias as quais elas pertencem. De acordo com Fabbe-Costes e Jahre (2007), os trabalhos que buscam entender esta relação são todos qualitativos (estudos de caso) e também Lambert e Pohlen (2001) afirmam a necessidade de se investigar esta relação;

- No âmbito nacional, realizar uma pesquisa quantitativa a fim de verificar a relação entre a integração das empresas na cadeia de suprimentos com seus desempenhos organizacionais individuais. Durante a etapa de revisão bibliográfica para a elaboração do capítulo da Fundamentação Teórica, todos os trabalhos nacionais encontrados que exploram este assunto são qualitativos (estudos de caso);

- Aplicação do Balanced Scorecard (BSC) no gerenciamento da cadeia de suprimentos, tanto para a avaliação dos desempenhos organizacionais como para a avaliação dos desempenhos das cadeias. Os trabalhos de Brewer e Speh (2000), Park et al. (2005) e Bhagwat e Sharma (2007) propõe uma adequação do BSC de Kaplan e Norton (1992) para o SCM, porém nenhum estudo quantitativo foi encontrado utilizando este modelo.

Assim, este trabalho estará estruturado da seguinte forma: 
Este capítulo inicial abordou, de forma introdutória, o conceito do gerenciamento da cadeia de suprimentos e a integração da cadeia de suprimentos como sendo uma das possíveis fontes de vantagem competitiva para as empresas, bem como sua importância para atingir a satisfação de seus consumidores. Também são definidos o Problema de Investigação e os Objetivos (Geral e Específicos).

O segundo capítulo, referente à fundamentação teórica, abordou os conceitos pertinentes ao trabalho, sendo eles: a evolução da logística até o gerenciamento da cadeia de suprimentos, conceitos sobre o gerenciamento da cadeia de suprimentos, a importância da informação e dos sistemas e tecnologias de informação, as formas de relacionamento e a integração da cadeia de suprimentos, a avaliação do desempenho na cadeia de suprimentos e os estudos realizados abordando integração da cadeia de suprimentos e desempenho empresarial.

O terceiro capítulo apresentou os aspectos metodológicos utilizados neste trabalho (tipo de pesquisa, perguntas de pesquisa, variáveis e hipóteses da pesquisa, instrumento de coleta, plano amostral, coleta e análise de dados e etapas da pesquisa).

O quarto capítulo abordou a descrição e análise dos dados obtidos na parte prática.

Finalmente, o quinto capítulo discorreu sobre as considerações finais, incluindo os objetivos alcançados, limitações do trabalho e possíveis sugestões e possibilidades para trabalhos futuros. 


\section{FUNDAMENTAÇÃO TEÓRICA}

Para a fase de revisão da literatura, foi realizada uma pesquisa bibliográfica, buscando reunir os principais conceitos utilizados neste trabalho. Com o objetivo de melhor caracterizar os elementos teóricos do trabalho, foram estudados em profundidade basicamente os temas de integração da cadeia de suprimentos e medidas de desempenho (tanto individual quanto da cadeia como um todo), bem como os estudos mais relevantes que abordam a relação entre eles.

A fim de garantir que a revisão da literatura abordasse o que existe de mais recente sobre o tema estudado, foram utilizados como pesquisa os melhores periódicos internacionais. Para isso foi verificado, quando possível, o fator de impacto de cada periódico utilizado, utilizando os dados do Journal Citation Reports (JCR), publicados pela Thomson Reuters por meio da plataforma ISI Web of knowledge (foram consultadas as informações do JCR Science Edition e do JCR Social Sciences Edition). A tabela 1 abaixo ilustra os principais periódicos utilizados e seus respectivos fatores de impacto.

Tabela 1 - Fator de Impacto

\begin{tabular}{lcc}
\hline & $\begin{array}{c}\text { Fator de } \\
\text { Impacto }\end{array}$ & $\begin{array}{c}\text { Fator de } \\
\text { Impacto } \\
5 \text { anos }\end{array}$ \\
\hline Decision Sciences & 2,318 & 3,131 \\
Decision Support Systems & 1,873 & 2,276 \\
European Journal of Operational Research & 1,627 & 2,084 \\
Harvard Business Review & 1,793 & 2,314 \\
International Journal of Operations \& Production Management & 1,725 & 2,022 \\
International Journal of Production Economics & 2,026 & 2,767 \\
International Journal of Technology Management & 0,526 & 0,684 \\
Journal of Operations Management & 2,42 & 3,814 \\
MIT Sloan Management Review & 1,1 & 1,764 \\
Supply Chain Management & 1,417 & 2,463 \\
\hline
\end{tabular}

Também houve a preocupação em abordar os autores considerados como referência. Durante a revisão da literatura, foram verificados quais os artigos mais relevantes em relação ao tema estudado e foi realizado um levantamento de quantas vezes os principais artigos foram citados 
por outros autores. Também, de forma semelhante aos periódicos, para cada autor foi verificado, quando possível, o Índice H. A tabela 2 abaixo mostra os Índices H dos principais autores.

Tabela 2 - Índice $\mathbf{H}$ para autores

\begin{tabular}{lc}
\hline \multicolumn{1}{c}{ Autor } & Índice H \\
\hline BALLOU, R. H. & 7 \\
BEAMON, B. M. & 7 \\
BOWERSOX, D. J. & 5 \\
CHOPRA, S. & 8 \\
COOPER, M. C. & 3 \\
ELLRAM, L. M. & 4 \\
FAWCETT, S. E. & 6 \\
FROHLICH, M. T. & 7 \\
GUNASEKARAN, A. & 9 \\
KUTUCUOGLU, K. Y. & 1 \\
LAMBERT, D. M. & 6 \\
MENTZER, J. T. & 13 \\
MONCZKA, R. M. & 8 \\
MUCKSTADT, J. A. & 9 \\
NARASIMHAN, R. & 15 \\
ROSENZWEIG, E. D. & 4 \\
SIMATUPANG, T. M. & 3 \\
SWINK, M. & 11 \\
VICKERY, S. K. & 12 \\
\hline
\end{tabular}

Assim, o quadro 1 mostra o tópicos estudados neste trabalho

\begin{tabular}{|c|c|}
\hline \multicolumn{2}{|c|}{ Quadro 1 - Tópicos estudados na fundamentação teórica } \\
\hline Tópicos & Sub-tópicos \\
\hline $\begin{array}{c}\text { Gerenciamento da } \\
\text { Cadeia de Suprimentos }\end{array}$ & $\begin{array}{l}\text { - Histórico } \\
\text { - } \text { Oefinições } \\
\text { - } \text { Caustivos do Gerenciamento da Cadeia de Suprimentos } \\
\text { - } \text { Processos, Elementiamentos e Modelos Cadeia de Suprimentos } \\
\text { - } \quad \text { Penefícios do Gerenciamento da Cadeia de Suprimentos } \\
\text { - } \quad \text { Soluçõoes para o Gerenciamento da Cadeia de Suprimentos } \\
\text { - Conclusões sobre o Gerenciamento da Cadeia de Suprimentos }\end{array}$ \\
\hline $\begin{array}{l}\text { Compartilhamento de } \\
\text { informação }\end{array}$ & $\begin{array}{l}\text { - } \quad \text { A necessidade de informação } \\
\text { - } \quad \text { A falta de informação e suas consequiências } \\
\text { - } \quad \text { Efeito chicote } \\
\text { - } \quad \text { Tipos e características das informações } \\
\text { - } \quad \text { Benefícios do compartilhamento da informação } \\
\text { - } \quad \text { Problemas e dificuldades no compartilhamento de informações } \\
\text { - } \quad \text { Conclusões sobre o compartilhamento de informações }\end{array}$ \\
\hline
\end{tabular}




\begin{tabular}{|c|c|c|}
\hline Tópicos & \multicolumn{1}{c|}{ Sub-tópicos } \\
\hline $\begin{array}{c}\text { A importância dos } \\
\text { sistemas e tecnologias de } \\
\text { informação }\end{array}$ & $\bullet$ Sistemas de Informação (SI) \\
\hline & & \\
Relacionamentos na & & $\bullet$ Pecnologia da Informação (TI) \\
cadeia de suprimentos & $\bullet$ Colaboração \\
\hline & $\bullet$ Integração \\
\hline & $\bullet$ Desempenhos individuais \\
Medidas de desempenho & $\bullet$ Dificuldades na mensuração do desempenho da cadeia de suprimentos \\
& $\bullet$ Escolha das métricas \\
\hline Integração e desempenho & & \\
\hline
\end{tabular}

\subsection{Da logística ao Gerenciamento da Cadeia de Suprimentos}

Segundo Lambert et al. (1998), até recentemente muitos consultores e acadêmicos viam o conceito de Gerenciamento da Cadeia de Suprimentos (Supply Chain Management - SCM) sem distinção da Logística, como definida pelo Conselho do Gerenciamento da Logística (Council of Logistics Management - CLM) em 1986. O Gerenciamento da Cadeia de Suprimentos era visto como sendo a logística fora da empresa, incluindo os clientes e fornecedores. A Logística, como definida pelo CLM, já incluía orientação da cadeia de suprimentos ao se afirmar "do ponto de origem até o ponto do consumo". Assim, na necessidade de se diferenciar os dois conceitos, em 1998, o CLM anunciou uma versão modificada da Logística, deixando claro que ela seria apenas uma parte do Gerenciamento da Cadeia de Suprimentos.

Também para Ballou (2007), torna-se claro as tentativas de se distinguir Logística de Gerenciamento de Cadeia de Suprimentos. Assim, o Conselho dos Profissionais de Gerenciamento da Cadeia de Suprimentos (Council of Supply Chain Management Professionals - CSCMP), a mais conceituada organização de praticantes, acadêmicos e pesquisadores de gerenciamento da cadeia de suprimentos, originada do antigo CLM, definiu que o Gerenciamento da Cadeia de Suprimentos engloba o planejamento e o gerenciamento de todas atividades envolvidas na seleção de matérias-primas, compra de produtos, produção e todas atividades de gerenciamento logístico, incluindo também a coordenação e a colaboração com parceiros do canal, que podem ser fornecedores, intermediários, provedores de serviço e consumidores. Em essência, ele integra o gerenciamento de demanda e da oferta, dentro e fora das empresas. 
Por outro lado, ainda segundo o mesmo autor, o CSCMP define Logística (Gerenciamento Logístico) como sendo parte do Gerenciamento da Cadeia de Suprimentos que planeja, implementa e controla o fluxo eficientemente, para frente e reverso, e a estocagem de bens, os serviços e as informações relacionadas entre o ponto de origem e o ponto de consumo com o objetivo de atender as necessidades dos clientes.

Assim, para Ballou (2007), a administração de processos e de atividades é basicamente o papel da Logística, isto é, gerenciar atividades como transporte, estoques, entrepostos e processamentos de pedidos que estão sob a responsabilidade da função de logística. Por outro lado, o Gerenciamento da Cadeia de Suprimentos refere-se à administração de processos e de atividades, coordenação interfuncional (refere-se a colaborar e desenvolver relacionamento com outras áreas funcionais na mesma empresa, como marketing e finanças) e coordenação interorganizacional (tem a ver com colaborar e coordenar fluxos de produtos entre os membros do canal). Em outras palavras, o Gerenciamento da Cadeia de Suprimentos é visto como gerenciador de fluxo de produtos entre várias empresas enquanto que a Logística é vista como gerenciadora de atividades do fluxo de produtos somente dentro da empresa. A ilustração 1 mostra essa distinção.

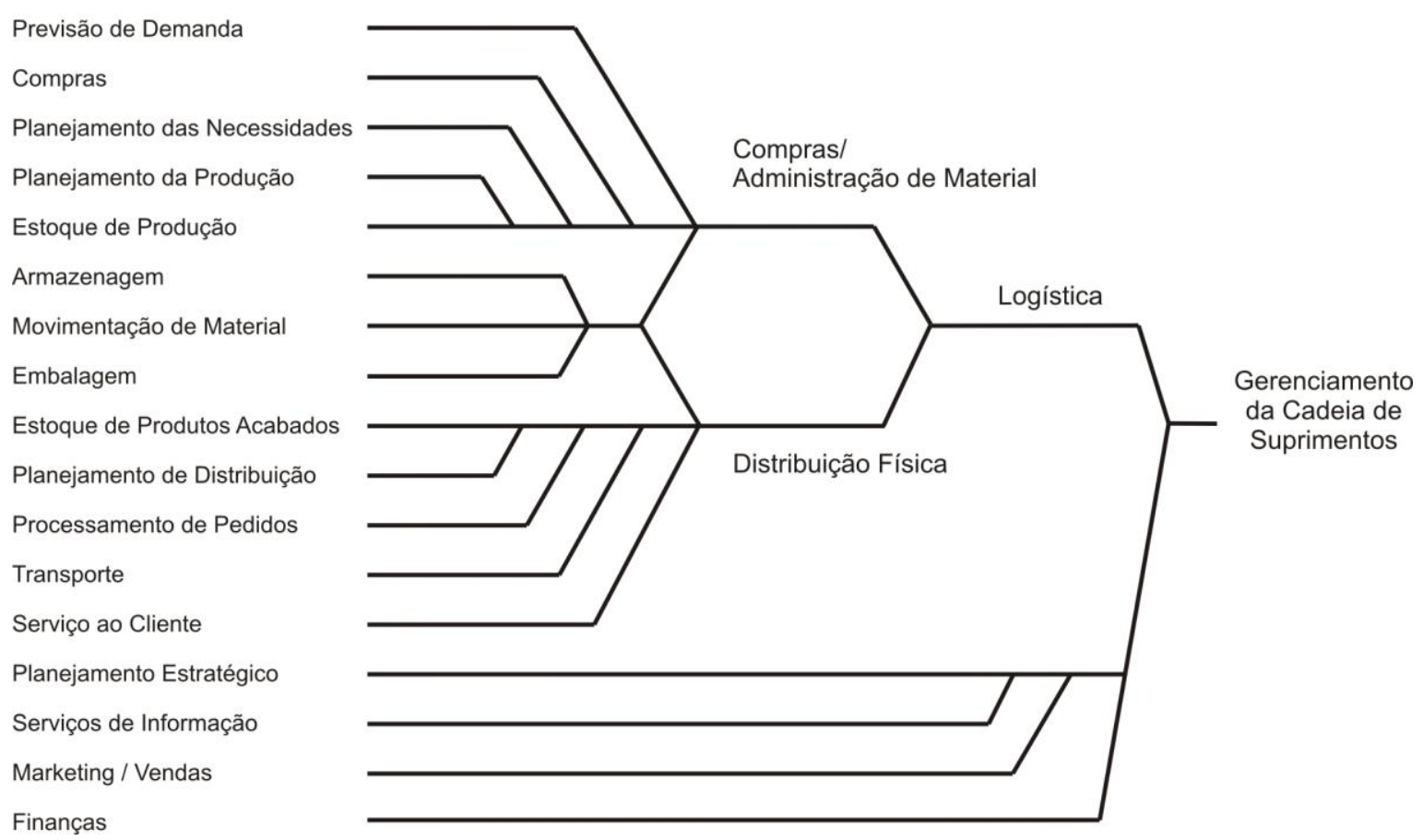

Ilustração 1 - Evolução do Gerenciamento da Cadeia de Suprimentos FONTE: BALLOU, 2007 


\subsection{O Gerenciamento da Cadeia de Suprimentos}

\subsubsection{Histórico}

Cooper et al. (1997) afirmam que o conceito de gerenciamento da cadeia de suprimentos, apareceu pela primeira vez na literatura em meados dos anos 80, porém as suposições deste conceito são significantemente antigas, incluindo o gerenciamento de operações interorganizacionais (surgido na década de 60) e as idéias mais recentes de compartilhamento de informações e troca de estoques por informação.

Também para Ballou (2007), o conceito de Gerenciamento da Cadeia de Suprimentos (Supply Chain Management - SCM) não é uma novidade e vários pioneiros no estudo da logística tiveram muitas das idéias adotadas pelos atuais entusiastas da cadeia de suprimentos. $\mathrm{O}$ autor cita que no ano 1964, os estudiosos Heskett, Ivie e Glaskowsky afirmavam que “...cada transferência de bens entre uma empresa para a próxima requer coordenação de demanda e oferta entre muitas instituições no canal, do cultivador de trigo ao consumidor de farinha.".

Lambert et al. (1998) discorrem sobre as iniciativas precedentes ao gerenciamento da cadeia. Os pesquisadores de marketing tais como Wroe Alderson e Louis P. Bucklin conceituaram os fatores chaves explicando o porquê e como os canais são criados e estruturados. Do ponto de vista da cadeia de suprimentos, esses pesquisadores estavam no caminho certo, em especial nas áreas de: (1) identificar quem deve ser um membro do canal de marketing, (2) descrever a necessidade da coordenação desses canais e (3) desenhar canais atuais de marketing. No entanto, nos últimos trinta anos os pesquisadores estudaram o poder e os conflitos com resultados questionáveis e ignoraram duas questões críticas. Primeiro, eles não consideraram as contribuições dos fornecedores aos fabricantes, negligenciando a importância da perspectiva da cadeia como um todo. E segundo, eles focaram nas atividades de marketing e nos fluxos dos canais, e omitiram a necessidade de integrar e gerenciar múltiplos processos chaves entre as empresas.

Para Mclaren et al. (2002), os negócios, no início do século XX, eram freqüentemente operações integradas verticalmente, ou seja, as empresas desempenhavam internamente as funções de produção, suprimento, armazenagem, vendas e logística. Entretanto, por volta do 
final da década de 90, a integração vertical já tinha quase desaparecido e muitas empresas incluíram parceiros externos em suas cadeias de suprimentos.

De acordo com Stadler e Kilger (2005), o termo Gerenciamento da Cadeia de Suprimentos foi criado por dois consultores, Oliver e Webber, no ano 1982. Na visão deles, o gerenciamento da cadeia eleva a missão da logística em se tornar uma preocupação dos altos escalões, já que “... apenas os altos escalões podem assegurar que objetivos funcionais conflitantes ao longo da cadeia de suprimentos sejam reconciliados e balanceados... e finalmente, que uma estratégia de sistemas integrados que reduz o nível de vulnerabilidade seja desenvolvida e implementada".

\subsubsection{Definições}

De acordo com Chopra e Meindl (2003), uma cadeia de suprimentos engloba todos os estágios envolvidos, direta ou indiretamente, no atendimento de um pedido de um cliente, incluindo não só fabricantes e fornecedores, mas também transportadoras, depósitos, varejistas e os próprios clientes. Ela representa os fluxos de produtos ou suprimentos, de informações e monetário que se deslocam ao longo da cadeia, incluindo, em cada empresa, todas as funções envolvidas no pedido do cliente, como marketing, operações, finanças, etc. Para os autores, na realidade, um fabricante pode receber material de diversos fornecedores e depois abastecer diversos distribuidores. Portanto, a maioria das cadeias de suprimentos é, na verdade, composta por redes, sendo assim mais correto utilizar um termo como "rede de suprimentos" para descrever a estrutura da maioria das cadeias de suprimentos.

Segundo Lambert et al. (1998) muitos dos múltiplos relacionamentos dentro de uma cadeia de suprimentos estão sendo chamados de gerenciamento de cadeia de suprimentos. No entanto, uma cadeia de suprimentos não é somente uma cadeia de relacionamentos restritos (entre duas empresas), mas sim uma rede de múltiplos relacionamentos e múltiplas empresas, oferecendo a oportunidade de capturar a sinergia das integrações inter e intra-empresarias e dos gerenciamentos. Neste sentido, ao gerenciamento da cadeia de suprimento lida com toda a excelência dos processos empresariais e representa uma nova forma de gerenciar as transações e os relacionamentos entre todos os membros da cadeia de suprimentos. 
Trkman et al. (2007) afirmam que o gerenciamento da cadeia de suprimento é o elo entre os recursos e processos empresarias, que começam com a busca de material-prima e se estende até a entrega do item final para o consumidor final.

Para Mclaren et al. (2002), o gerenciamento da cadeia de suprimentos é uma disciplina bem estabelecida que envolve a coordenação do planejamento interno, produção e esforços de aquisição de uma empresa com seus parceiros externos (ex: fornecedores, varejistas, etc.).

O gerenciamento de cadeia de suprimento trata de processos, recursos humanos, tecnologia e infra-estruturas que permitam a transformação de matérias-primas em produtos acabados e serviços, e assim oferecidos a clientes para satisfazer seus desejos, necessidades e demandas (COOPER et al., 1997).

Já Lambert et al. (1998) definem o gerenciamento da cadeia de suprimento como a integração dos processos de negócios desde o consumidor final até os primeiros fornecedores que fornecem os produtos, serviços e informações de forma a acrescentar valor aos clientes.

Zailani e Rajagopal (2005) definem a cadeia de suprimentos como uma rede que inclui vendedores de matéria-prima, plantas que transformam essas matérias-primas em produtos úteis e centros de distribuição para levar esses produtos aos consumidores. Conhecida também como cadeia de valor, ela é a seqüência que envolve a produção e entrega de um produto ou serviço. Assim o gerenciamento da cadeia de suprimentos pode ser considerado como sendo a integração simultânea dos requisitos dos consumidores, processos internos e desempenho dos fornecedores

Para Nabavi (2006), o gerenciamento da cadeia de suprimentos refere-se à criação de valor no projeto, nos processos, no controle e na entrega de bens e serviços para os clientes e seus respectivos fluxos entre os fornecedores em um esforço coordenado, criando valor para a cadeia e para seus consumidores.

Para Rafele (2004), o gerenciamento da cadeia de suprimentos deve ser visto como um processo integrado, no qual as matérias-primas são transformadas em produtos finais e então entregues aos clientes, onde várias entidades trabalham juntas a fim de modificar produtos semi-fabricados, desenvolvendo algumas atividades principais, como: produção 
(transformação de entradas em saídas); armazenagem (recuperação dos estoques); transporte (satisfação da solicitação do cliente) e outras. Cada uma dessas atividades pode influenciar o desempenho da cadeia.

Mentzer et al. (2001) define uma cadeia de suprimentos como sendo um conjunto de três ou mais entidades (organizações ou indivíduos) diretamente envolvidos, a montante e a jusante, nos fluxos de produtos, de serviços, de informações e financeiro deste os fornecedores de insumos até o cliente. Os autores distinguem entre uma "cadeia de suprimentos direta", uma "cadeia de suprimentos estendida" e uma "cadeia de suprimentos máxima". A "cadeia direta" engloba a empresa, seus fornecedores e seus clientes. Já a "cadeia estendida" inclui os fornecedores dos fornecedores e os clientes dos clientes. E finalmente a "cadeia máxima" inclui todas as organizações envolvidas, como: operadores logísticos, fornecedores de recursos financeiros e prestadores de serviços.

Cooper e Ellram (1993) definem o gerenciamento da cadeia de suprimentos como sendo uma filosofia integrativa para gerenciar todo o fluxo de um canal de distribuição desde o fornecedor até o consumidor final. Elas resumiram as diferenças entre uma cadeia de suprimentos tradicional e práticas de gerenciamento da cadeia de suprimentos como mostra o quadro 2.

Quadro 2 - Comparação entre cadeias tradicionais e o gerenciamento da cadeia de suprimentos

\begin{tabular}{|c|c|c|}
\hline Elementos & Tradicional & Cadeia de Suprimento \\
\hline Gerenciamento de Estoque & Esforços Independentes & $\begin{array}{l}\text { Reduções conjuntas nos canais de } \\
\text { estoques }\end{array}$ \\
\hline Custo Total & Minimizar custo da Empresa & Eficiências de custos por todo o canal \\
\hline Horizonte de tempo & Curto Prazo & Longo Prazo \\
\hline $\begin{array}{l}\text { Compartilhamento da } \\
\text { informação e } \\
\text { monitoramento }\end{array}$ & $\begin{array}{l}\text { Limite para as necessidades de } \\
\text { transações atuais. }\end{array}$ & $\begin{array}{l}\text { Requerido para processos de } \\
\text { planejamento e monitoramento }\end{array}$ \\
\hline Planejamento conjunto & Baseado em transações & Baseado em continuidade \\
\hline $\begin{array}{l}\text { Compatibilidade de } \\
\text { filosofias das empresas }\end{array}$ & Não é relevante & $\begin{array}{l}\text { Compatível no mínimo para } \\
\text { relacionamentos chaves }\end{array}$ \\
\hline Distância do fornecedor & $\begin{array}{l}\text { Grande, proporcionando } \\
\text { competição }\end{array}$ & Baixa, proporcionando coordenação \\
\hline Liderança do canal & Não necessário & Necessário para foco na coordenação \\
\hline $\begin{array}{l}\text { Divisão de riscos e de } \\
\text { retornos }\end{array}$ & Cada empresa possui o seu & Dividido em longo prazo \\
\hline $\begin{array}{l}\text { Velocidade das operações, } \\
\text { informações e fluxo de } \\
\text { estoques }\end{array}$ & $\begin{array}{l}\text { Orientação para } \\
\text { "Armazém”(armazenagem, } \\
\text { estoque de segurança) } \\
\text { interrompido por barreiras dos } \\
\text { fluxos. }\end{array}$ & $\begin{array}{l}\text { Orientação para "canal de } \\
\text { distribuição" (velocidade do estoque) } \\
\text { interconectando os fluxos: JIT, QR } \\
\text { através do canal. }\end{array}$ \\
\hline Sistemas de Informação & independente & $\begin{array}{l}\text { Compatível, sendo elemento chave } \\
\text { para boa comunicação }\end{array}$ \\
\hline
\end{tabular}

FONTE: COOPER; ELLRAM, 1993 
Sudrajat (2007) lista alguns elementos comuns nas várias definições de Gerenciamento de Cadeia de Suprimentos: o produto e seu fluxo (incluindo seus componentes, peças e materiais); fornecedores e os fornecedores dos fornecedores; empresas; clientes e clientes dos clientes; informação e seu fluxo; criação de valor; integração; colaboração; agilidade/flexibilidade.

Também Agan (2005) define as capacidades de operações que são relevantes ao gerenciamento da cadeia de suprimentos como sendo: conhecimento e habilidades dos funcionários e capabilidades das empresas tais como a seleção de fornecedor, a colaboração e o aprendizado com parceiros.

Assim, segundo Cooper et al. (1997), apesar das várias definições existentes na literatura sobre o gerenciamento da cadeia de suprimentos, alguns elementos parece se repetir entre elas:

- Desenvolve-se por meio de vários estágios de crescimento da integração e da coordenação intra e inter-organizacional, atingindo toda a cadeia, desde a fonte inicial (os fornecedores dos fornecedores) até o cliente final;

- Envolve muitas organizações independentes, sendo, portanto de extrema importância o gerenciamento conjunto;

- Inclui o fluxo bidirecional de produtos (materiais e serviços) e informações, bem como as atividades gerenciais e operacionais associadas.

- Procura entregar alta qualidade aos clientes com o uso apropriado de recursos e construir vantagens competitivas para toda a cadeia.

\subsubsection{Objetivos do Gerenciamento da Cadeia de Suprimentos}

Para Chopra e Meindl (2003), a lucratividade é um fator importante para a cadeia de suprimentos e eles sugerem, inicialmente, duas medidas gerenciais óbvias para aumentar a lucratividade:

- Vender todo o estoque excedente - a produção em excesso, gerando estoques, pode aumentar a disponibilidade do produto em seu mercado original, porém o excedente deve ser vendido (como por exemplo, em outra região) para tornar isso possível e

- Reduzir a margem perdida com uma falta de estoque - a estratégia para reduzir a margem perdida com a falta de estoque inclui a criação de uma fonte de reserva (como 
por exemplo, compra do produto em um concorrente) para que os clientes não sejam perdidos

Power (2005), com base nas definições de outros autores, define o objetivo do gerenciamento da cadeia de suprimentos como sendo o de facilitar as ligações entre cada componente da cadeia, removendo barreiras de comunicação e redundâncias e facilitando a interação e a tomada de decisão, por meio de coordenação, monitoramento e controle de processos.

Também para Lambert et al. (1998), objetivo do gerenciamento da cadeia de suprimentos é maximizar a competitividade e a rentabilidade para todos os membros da cadeia, incluindo o consumidor final. Conseqüentemente, processos de integração e iniciativas de reestruturação da cadeia de suprimentos devem objetivar a eficiência e a efetividade total do processo entre os membros envolvidos.

Segundo Cooper et al. (1997), com base com vários autores, os objetivos do gerenciamento da cadeia de suprimentos são: diminuir o montante de recursos necessários para providenciar o nível adequado de atendimento ao cliente, sincronizar as necessidades dos clientes com o fluxo de materiais a partir do fornecedores, reduzir o volume de estoques, aumentar o nível de serviço ao cliente e construir uma vantagem competitiva para toda cadeia.

De forma semelhante, Simatupang e Sridharan (2005) afirma que uma cadeia de suprimento é projetada para atingir uma meta global em toda cadeia, onde o objetivo é otimizar os lucros totais através de diferenciação funcional e interdependência de processos empresariais, de modo a oferecer produtos e serviços aos clientes. A preocupação principal no gerenciamento de cadeias de suprimento é criar processos ágeis e coesos, capacitando os membros da cadeia a atender as necessidades do consumidor a custos mais baixos.

De acordo com Sahin e Robinson (2002), o objetivo da cadeia de suprimento é fornecer valor para o consumidor final em termos de produtos e serviços, e gerar lucro para cada participante do canal.

Também para Zailani e Rajagopal (2005), o objetivo da gestão da cadeia de suprimentos é melhorar o processo inteiro em vez de focar na otimização local de unidades de negócio particulares. 
Para Chopra e Meindl (2003), o objetivo de toda cadeia é maximizar o valor global gerado, sendo esse valor a diferença entre o valor do produto final para o cliente e o esforço realizado pela cadeia para atender ao seu pedido. Para a maioria das cadeias de suprimentos comerciais, o valor está ligado à lucratividade da cadeia (diferença entre a receita gerada pelo cliente e o custo total no decorrer da cadeia). Assim, a lucratividade da cadeia de suprimentos é o lucro total a ser dividido por todos seus membros e, portanto, quanto maior sua lucratividade, mais bem sucedida será a cadeia, sendo esse sucesso medido em termos de lucratividade da cadeia inteira e não com base nos lucros de um estágio isolado.

Já Bowersox et al. (2007) definem seis objetivos operacionais para a cadeia de suprimentos: (1) capacidade de resposta, (2) variância mínima, (3) redução de estoque, (4) consolidação de cargas, (5) qualidade e (6) apoio ao ciclo de vida dos produtos.

\subsubsection{Causas do surgimento do Gerenciamento da Cadeia de Suprimentos}

Para Morgan (2004), no final dos anos 90, quando os sistemas de produção já tinham sido otimizados, a atenção se voltou para as cadeias de suprimentos. Isto ocorreu em resposta às mudanças que estavam exigindo novas configurações de cadeia de suprimentos, tais como a globalização, o comércio eletrônico e o aumento da necessidade de lidar com altas demandas. Esta combinação de fatores levou ao conceito de "agilidade" e "reconfiguração", assim como a realização da chamada concorrência de "cadeia de suprimentos versus cadeia de suprimentos".

Power (2005) relata que a atual importância dada ao gerenciamento da cadeia de suprimentos ocorre devido às seguintes causas: diminuição no ciclo de vida dos produtos; diminuição do nível de padronização dos produtos e demanda para alterações (aumento da customização); consumidores demandando períodos mais curtos para entrega; elevado nível de competição devido à globalização e diminuição das barreiras tarifárias; e aumento dos níveis de dinamismo, complexidade (número de mudanças) e incertezas nos mercados globais.

De acordo com Nabavi (2006), o gerenciamento da cadeia de suprimentos vem ganhando atenção por parte dos pesquisadores nos últimos anos devido às mudanças ocorridas na economia e na tecnologia. A cooperação internacional, a terceirização, o downsizing, a desintegração vertical, as novas tecnologias facilitadoras da cooperação entre parceiro e a 
tecnologia da informação dando suporte à integração de informações são alguns dos fatores que têm transformado os mercados de concorrência entre as empresas para concorrência entre cadeias de suprimento.

\subsubsection{Processos, Elementos e Modelos do Gerenciamento da Cadeia de Suprimentos}

Após expostas as definições, os objetivos e as causas do surgimento do gerenciamento da cadeia de suprimentos, serão abordados os processos e os elementos que compõem a cadeia de suprimentos, bem como alguns modelos propostos por vários autores.

De acordo com Trkman et al. (2007), para lidar com os desafios, as empresas devem aceitar alguns princípios da administração baseada em processos, especialmente aqueles destinados a administrar de forma bem sucedida suas cadeias de suprimentos. O paradigma do processo implica em uma nova maneira de olhar a empresa, não mais divididas em unidades funcionais, divisões e departamentos, mas sim em processos. Em seu trabalho, o autor cita que um processo como sendo um conjunto de um ou mais procedimentos ou atividades interligados realizam um objetivo, transformando uma série de recursos (entradas) em uma série de resultados (saídas), como bens e/ou serviços através de uma combinação de pessoas, métodos, e ferramentas.

Para Chopra e Meindl (2003), a cadeia de suprimentos é uma seqüência de processos e fluxos que acontecem dentro e entre diferentes estágios da cadeia, que se combinam para atender às necessidades dos clientes por um produto. Há duas maneiras de visualizar os processos realizados na cadeia de suprimento:

- Visão cíclica - os processos são divididos em uma série de ciclo, cada um realizado na ligação entre dois estágios sucessivos de uma cadeia de suprimentos (elos). A ilustração 2 mostra estes ciclos. 


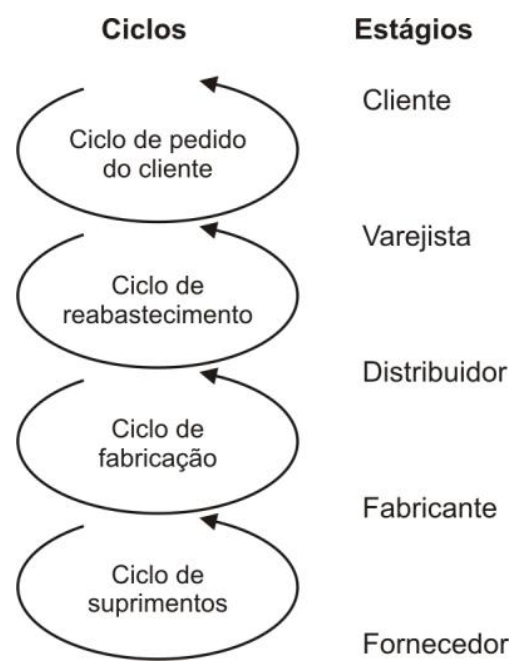

Ilustração 2 - Ciclos de processos da cadeia de suprimentos FONTE: CHOPRA; MEINDL, 2003

- Visão empurrar/puxar - os processos são divididos em duas categorias: acionados em resposta aos pedidos dos clientes (puxado) ou em antecipação aos pedidos (empurrados)

Segundo Croxton et al. (2002), o "Forum Global de Cadeia de Suprimentos" (The Global Supply Chain Forum) identificou oito processos-chave que devem ser implementados nas empresas e entre as empresas em uma cadeia de suprimentos. Cada processo percorre as empresas da cadeia de suprimentos e as funções corporativas em cada empresa, e estão listados a seguir:

- Gerenciamento do Relacionamento com o Cliente (Customer Relationship Management - CRM) - define como os relacionamentos com consumidores devem ser desenvolvidos e mantidos, incluindo o estabelecimento de acordos de produtos/serviços entre empresas e consumidores;

- Gerenciamento de Serviços aos Consumidores - define o contato da empresa com consumidor, incluindo gerenciamento dos acordos de produtos/serviços e fornece uma fonte única de informações sobre os clientes;

- Gerenciamento de Demanda - fornece a estrutura para equilibrar as necessidades dos clientes com as capacidades da cadeia de suprimentos;

- Execução de pedido - inclui todas as atividades para definir as necessidades dos consumidores e para elaborar a rede logística e cumprir os pedidos dos clientes; 
- Gerenciamento do Fluxo Produtivo - inclui todas as atividades necessárias para mover os produtos entre as fábricas e para obter, implementar e gerenciar a flexibilidade da produção na cadeia de suprimentos;

- Gerenciamento de Relacionamento com Fornecedores - define como são desenvolvidos e mantidos os relacionamentos com os fornecedores, incluindo o estabelecimento dos acordos de produtos/serviços entre a empresa e seus fornecedores;

- Desenvolvimento de Produtos e Comercialização - fornece a estrutura para desenvolver e trazer ao mercado novos produtos, em conjunto com os consumidores e fornecedores e

- Gerenciamento de Devoluções - Inclui todas as atividades relacionadas às devoluções, logística reversa, comunicação pós-vendas e cancelamento de pedidos

Segundo Kim (2006), como a cadeia de suprimentos é composta por vários processos interligados, seu sucesso depende da excelência da cadeia de processos. Para isso, o autor coloca a necessidade de se conhecer a "roda da cadeia de processos", descrita na ilustração 3.

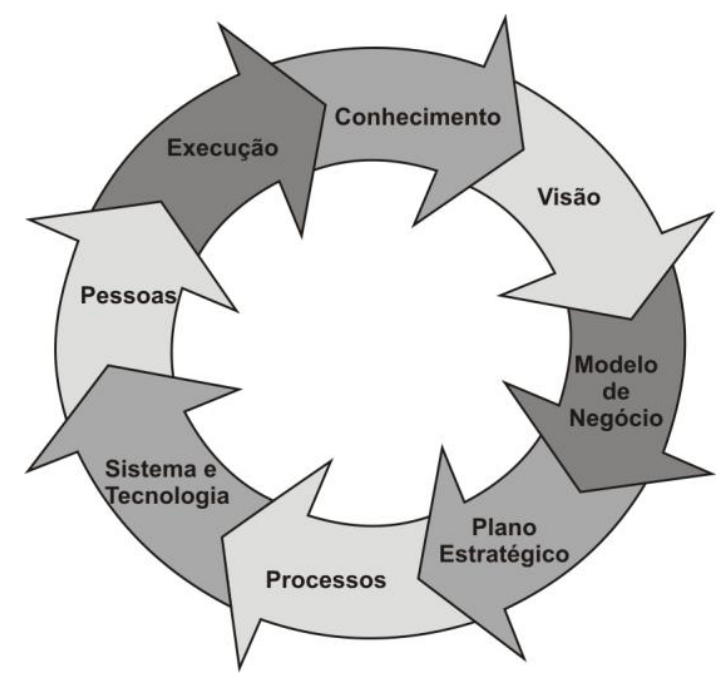

Ilustração 3 - A roda da cadeia de processos FONTE: KIM, 2006

A roda descreve a ordem de um contínuo planejamento estratégico e processo de execução, desde o entendimento até a execução: (1) Entender o ambiente, a concorrência e as necessidades do cliente; (2) Estabelecer a visão; (3) Construir um modelo de negócio baseado na proposição de valor e na cultura colaborativa; (4) Desenvolver estratégias competitivas e prioridades, dado um objetivo comum para toda a cadeia de suprimentos; (5) Sincronizar 
processos-chave da cadeia de suprimentos baseados na lógica do negócio; (6) Investir em sistemas e tecnologias (como por exemplo, ferramentas e facilitadores para dar apoio aos processos); (7) Fazer com que as pessoas aceitem os processos de mudanças e capacite-as; (8) Executar eficazmente e eficientemente de uma maneira voltada para o resultado.

Dando continuidade ao seu modelo, Kim (2006) sugere que após compreender a roda dos processos é necessário projetar a cadeia dos processos, de tal maneira que ela reflita planos estratégicos detalhados e o modelo do negócio, o qual deveria ser desenvolvido baseado na visão condizente com as necessidades dos clientes em um setor. Assim, a construção e implementação de uma cadeia do processo requer a adesão aos dez princípios da colaboração e sincronização da cadeia do processo, listados abaixo: (1) Assegurar um comprometimento de alta gerência dos membros da cadeia do processo; (2) Desenvolver uma cultura colaborativa baseada em uma comunicação aberta e responsabilidade compartilhada; (3) Compartilhar recursos, capacidades e riscos baseados em relacionamentos ganha-ganha de confiança; (4) Ligar a cadeia de suprimentos como um completo processo sincronizado e abrangente; (5) Projetar processos tendo em mente as necessidades dos clientes; (6) Executar o trabalho através das pessoas que ocupam a melhor posição; (7) Realizar apenas atividades que agregam valor; (8) Alinhar as métricas de desempenho com as metas e incentivos em torno de todos os processos; (9) Conquistar resultados para os objetivos comuns dos principais stakeholders; e (10) Solucionar problemas e conflitos conjuntamente.

Para Fawcett e Magnan (2002), o gerenciamento da cadeia de suprimentos está geralmente associado com avançadas tecnologias de informação, com rápidos e responsivos serviços de logística e, cada vez mais, com gerenciamento do relacionamento com os clientes.

Power (2005) relata em seus estudos que os três principais elementos de um modelo de cadeia de suprimento integrada são: sistemas de informação (gerenciamento de fluxos financeiro e de informação), gerenciamento de estoques (gerenciamento de fluxo de produto e material) e relacionamentos de cadeia de suprimento (gerenciamento de relações entre parceiros comerciais).

Swaminathan et al. (1998) classificaram os diferentes elementos da cadeia de suprimentos em duas amplas categorias: 
- Elementos Estruturais - os elementos estruturais (caracterizados como agentes estruturais) estão envolvidos na produção e transporte dos produtos e são classificados em dois conjuntos básicos: produção e transporte e

- Elementos de Controle - os elementos de controle (caracterizados como políticas de controle) ajudam na coordenação do fluxo de produtos de uma maneira eficiente e são classificados em: controle de estoques, controle da demanda, controle de suprimento, controle de fluxo e controle de informações. A ilustração 4 aborda esses elementos.

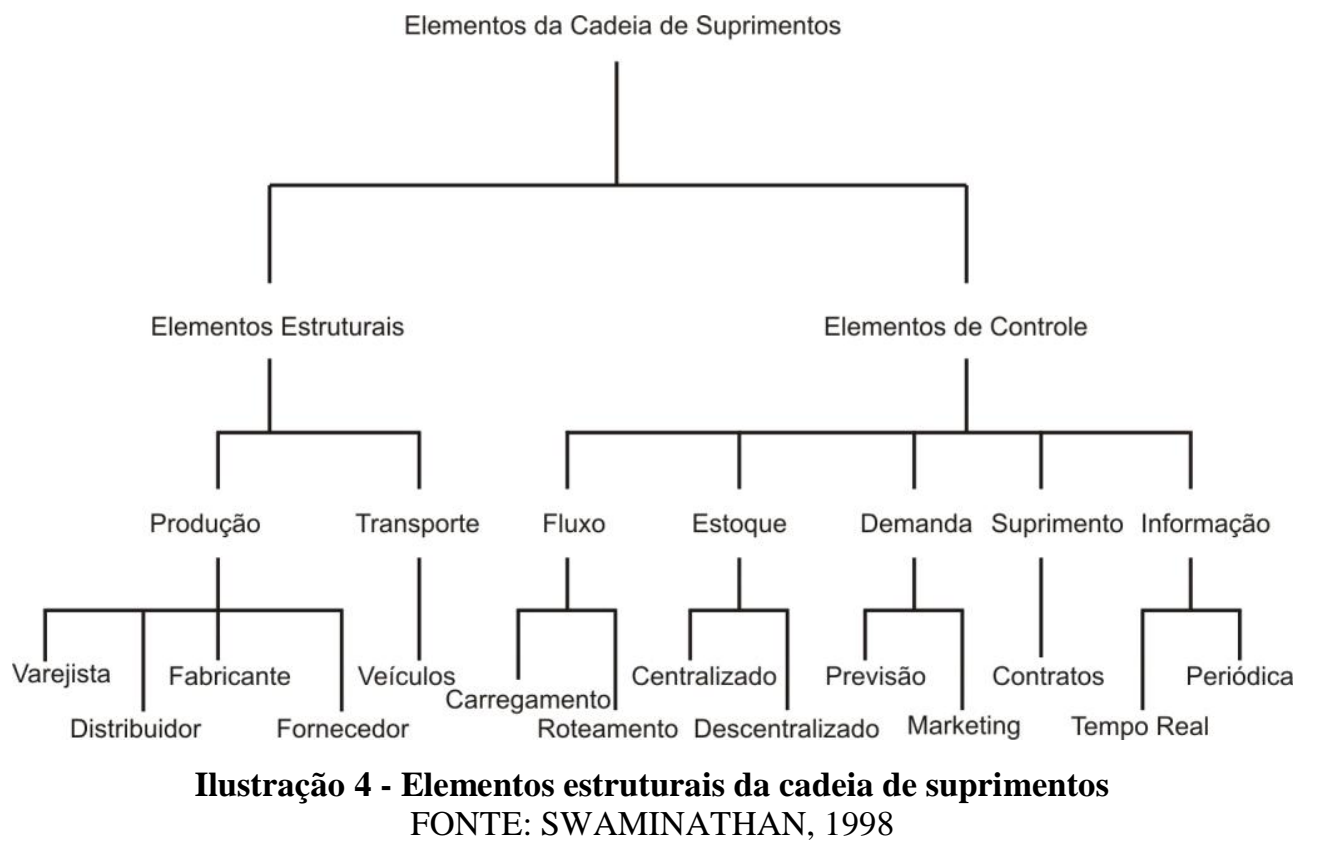

Para Gunasekaran et al. (2008), os cinco elementos funcionais básicos em uma cadeia de valor são: (1) compras (máximo desconto ao comprar), (2) logística de entrada (baixos custos de transporte), (3) operações (baixos custos de produção), (4) marketing e vendas (grande variedade de produtos/alta disponibilidade) e (5) logística de saída (baixos custos de transportes).

Stadler e Kilger (2005) na tentativa de reunir os elementos fundamentais para um correto gerenciamento da cadeia de suprimentos propõem um modelo denominado "A Casa do Gerenciamento da Cadeia de Suprimentos (House of SCM) mostrados na ilustração 5. 


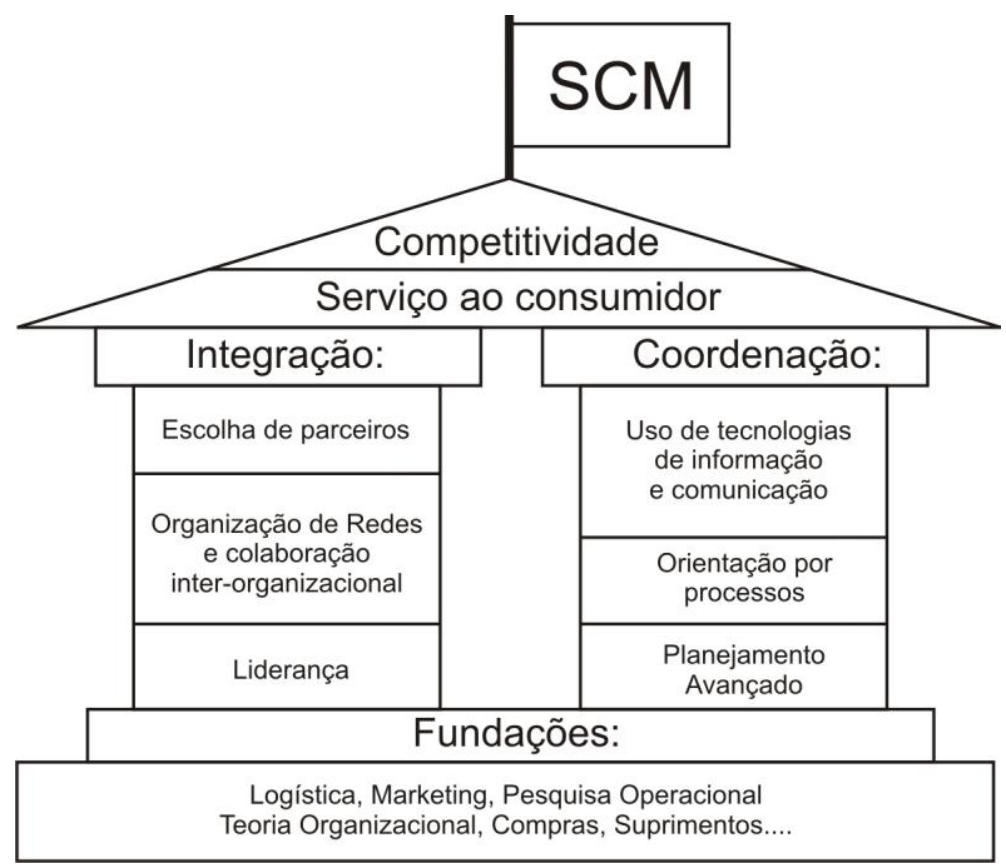

Ilustração 5 - A Casa do Gerenciamento da Cadeia de Suprimentos FONTE: STADLER; KILGER, 2005

O teto representa o principal objetivo do gerenciamento da cadeia que é a competitividade, que é suportada pelo serviço ao consumidor. A competitividade pode ser melhorada de várias maneiras, como por exemplo, reduzindo custos, aumentando a flexibilidade com respeito a mudanças nas demandas dos consumidores ou fornecendo uma qualidade superior de produtos e serviços. O teto está sobre dois pilares, considerados os dois principais componentes do gerenciamento da cadeia de suprimentos, que são a integração de uma rede de empresas e a coordenação de informações, materiais e fluxos financeiros.

A integração deve ser suportada pelos seguintes elementos: Em primeiro lugar, a consolidação do gerenciamento da cadeia requer a escolha de parceiros adequados. Em segundo lugar, ela deve ser apoiada por uma rede eficaz e bem sucedida de empresas, consistindo de empresas separadas legalmente, mas com a necessidade da colaboração inter-organizacional. Em terceiro lugar, para que a colaboração inter-organizacional ocorra, novos conceitos de liderança de forma a alinhar as estratégias entre os parceiros são importantes.

Por outro lado, a coordenação dos fluxos ao longo da cadeia pode ser executada eficientemente com a utilização de novas tecnologias de informação e comunicação. Estes permitem que processos outrora executados manualmente sejam automatizados. Para a ocorrência da coordenação, as atividades entre os membros da cadeia devem ser 
inspecionadas em busca de atividades. Assim, a orientação por processo freqüentemente incorpora um replanejamento seguido de uma padronização do novo processo. Para se atender aos pedidos dos consumidores, a disponibilidade de materiais, de pessoas, de maquinário e de ferramentas precisa ser planejada. Neste contexto, o planejamento de produção e distribuição, bem como o planejamento de compras, devem ser coordenados considerando agora a relações entre as várias empresas da cadeia, sendo isso um desafio para os novos Sistemas de Planejamentos Avançados.

Finalmente, como fundações do modelo estão as atividades de logística e transporte, marketing, pesquisa operacional, comportamento organizacional, organização industrial e economia de custos de transação.

Cooper et al. (1997) criaram um modelo de gerenciamento de cadeia de suprimentos que foi melhorado por eles mesmos no ano seguinte, porém com alteração na ordem dos autores na citação, passando a serem referenciados como Lambert et al. (1998). Para eles, o gerenciamento da cadeia de suprimentos abrange a combinação de três elementos interligados: a estrutura da cadeia de suprimentos (rede de participantes e respectivas conexões entre eles), os processos da cadeia (que produzem um resultado específico de valor ao cliente) e os componentes de gerenciamento da cadeia (variáveis gerenciais pelas quais os processos são integrados e gerenciados pela da cadeia). A ilustração 6 mostra esses elementos.

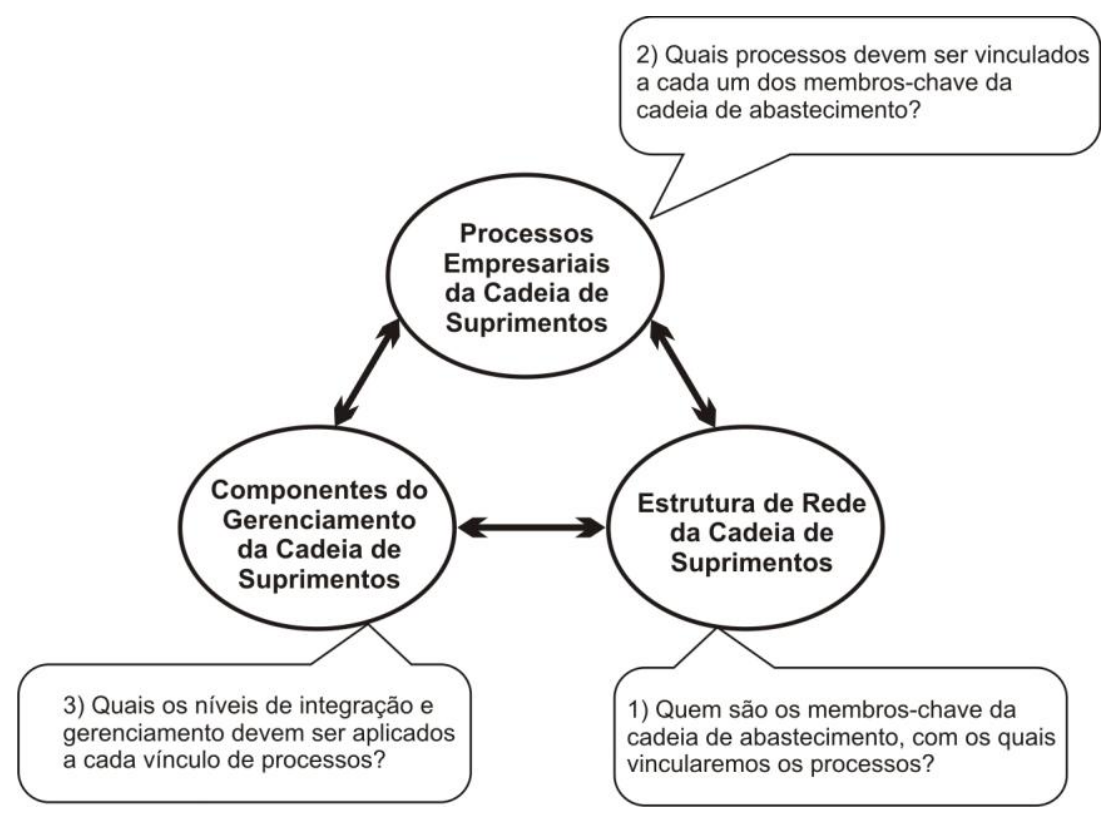

Ilustração 6 - Elementos e decisões chaves no gerenciamento da cadeia de suprimentos FONTE: LAMBERT et al., 1998 
Detalhando cada elemento, tem-se:

- Estrutura - um elemento importante é conhecer e compreender a estrutura da cadeia estruturada. Os autores definem três aspectos estruturais primários:

○ Membros da cadeia - são todas as empresas com que a empresa principal interage direta ou indiretamente, divididos em membros primários (todas as empresas que possuem atividades gerenciais e ou operacionais no processo das transações designadas a produzir um resultado especifico para um cliente ou mercado em particular) e membros de suporte (empresas que simplesmente providenciam recursos, conhecimentos, utilidades para as empresas primárias da cadeia). Com isso pode-se definir o ponto de origem (quando não existem fornecedores primários) e o ponto de final ou de consumo da cadeia;

○ Dimensões da rede - são as estruturas horizontais (se refere ao número de camadas dentro de uma cadeia), verticais (se refere ao número de fornecedores e clientes representados em cada camada) e a posição horizontal da empresa principal nos pontos finais da cadeia (perto da fonte inicial de suprimento ou perto do cliente final);

○ Diferentes tipos de ligação de processos entre a cadeia - são os diferentes tipos de ligações entre as empresas, podendo ser (1) ligação de processos gerenciados (a empresa integra seus processos com um ou mais clientes e/ou fornecedores), (2) ligação de processos monitorados (apesar de não serem processos críticos, é importante para a empresa que os processos estejam integrados e gerenciados corretamente entre os membros), (3) ligação de processos não gerenciados (a empresa não está ativamente envolvida ou os processos não são críticos o suficiente para ela utilizar seus recursos de monitoramento) e (4) ligação de processos entre não membros (a empresa integra seus processos com empresas que não fazem parte da cadeia, mas de alguma forma afetará o desempenho da cadeia).

A ilustração 7 aborda os elementos de estrutura 


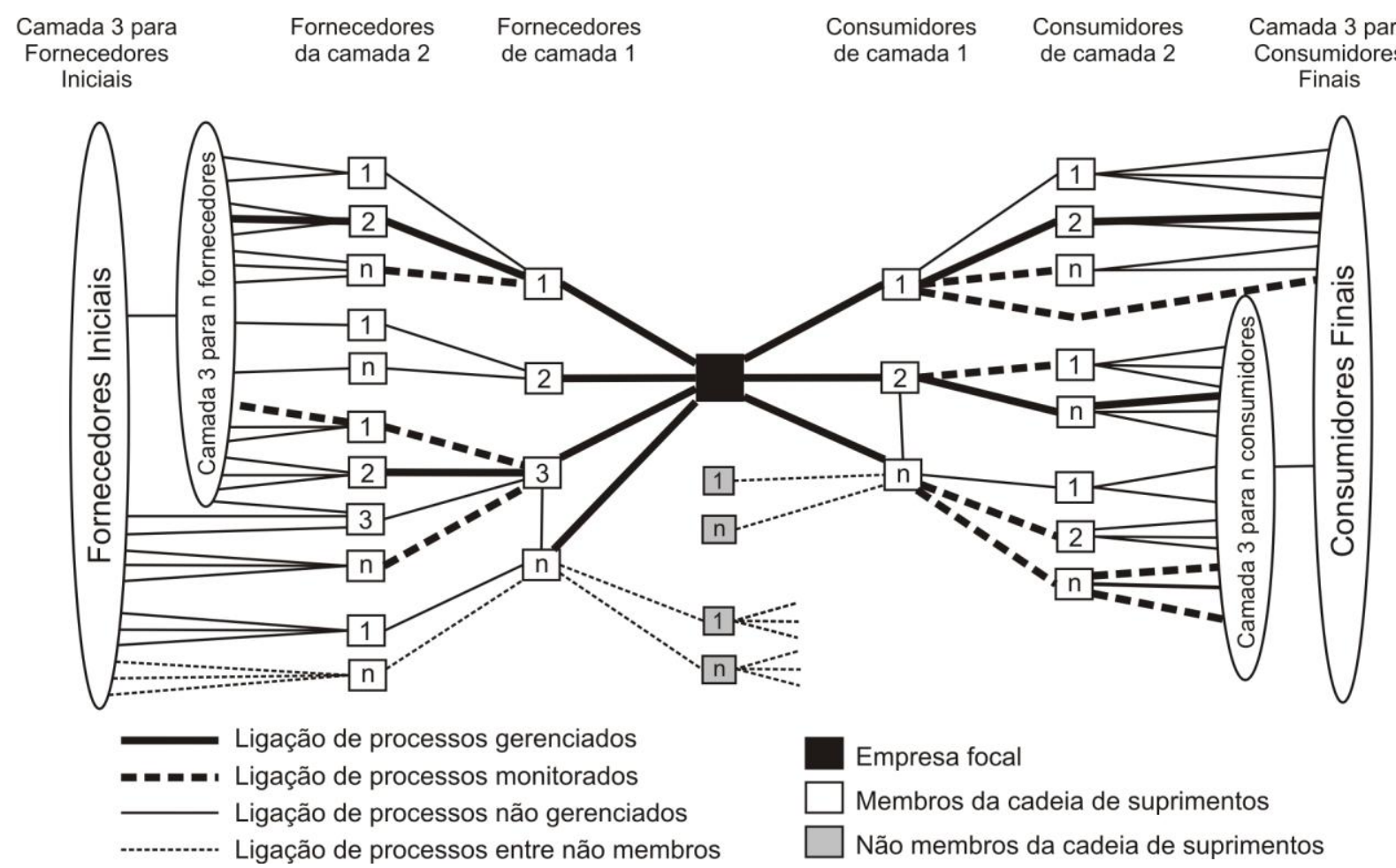

Ilustração 7 - Diferentes tipos de ligações entre as empresas FONTE: LAMBERT et al., 1998

- Processos - quando um relacionamento é construído entre duas empresas, com certeza suas atividades internas estarão ligadas e gerenciadas entre elas, porém empresas na mesma cadeia têm estruturas de atividades diferentes. Algumas empresas enfatizam uma estrutura funcional, algumas uma estrutura de processos e outras uma estrutura combinada de processos e funções. Um processo pode ser visto como uma estrutura de atividades designada para agir com foco no consumidor final e no gerenciamento dinâmico dos fluxos envolvendo produtos, informação, dinheiro, conhecimento ou idéias. Entre as empresas que utilizam estrutura de processos, geralmente cada uma possui um número diferente de processos (consistindo em diferentes atividades) e seus processos podem possuir diferentes denominações, mesmo que sejam similares. Isso pode causar significantes ineficiências nas cadeias de suprimentos. Para os autores, gerenciamento da cadeia de suprimentos pode ser representado de maneira simplificada por fluxos de informações e produtos e uma série de processos empresariais penetrando por vários "silos" funcionais internos a empresa, bem como por vários "silos" externos por toda a cadeia de suprimentos. Assim, os processos transacionais se tornam os processos da cadeia de suprimentos ligando as empresas interna e externamente. Os autores definiram oito sub-processos chave para o Gerenciamento da Cadeia de Suprimentos, abordados na ilustração 8: 
(1) gerenciamento de relacionamento com cliente;

(2) gerenciamento de serviços ao consumidor;

(3) gerenciamento de demanda;

(4) execução do pedido;

(5) gerenciamento de fluxo de produção;

(6) gerenciamento de relacionamento com fornecedor;

(7) desenvolvimento e comercialização de produto e

(8) gerenciamento de devoluções.

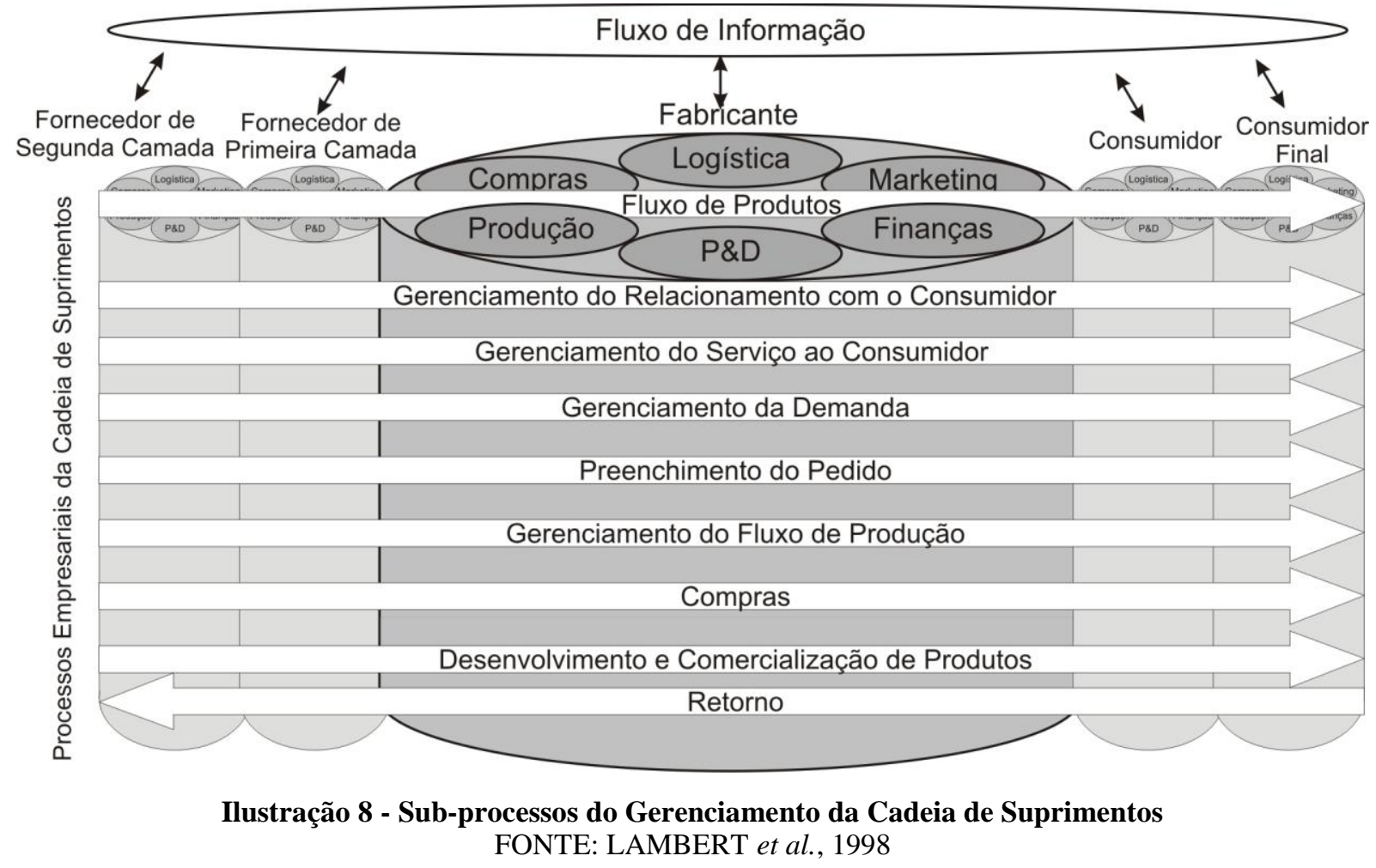

- Componentes - o gerenciamento dos componentes pode ser dividido em dois grupos: (1) Físico e Técnico, composto por componentes mais visíveis, tangíveis e mensuráveis, sendo eles os métodos de planejamento e controle, a estrutura de atividades e fluxo do trabalho, a estrutura organizacional, a estrutura facilitadora da comunicação e do fluxo de informações e a estrutura facilitadora do fluxo de produtos e (2) Comportamental e Gerencial, composto por componentes menos tangíveis e visíveis, sendo eles os métodos gerenciais, a estrutura de poder e liderança, a estrutura de risco e remuneração e a cultura e atitude. Uma premissa importante que merece ser destacada no gerenciamento da cadeia de suprimentos é que existem certos 
componentes de gerenciamento que são comuns dentro de todos os processos empresariais de uma cadeia, sendo eles críticos e fundamentais para o sucesso da cadeia, uma vez que eles representam e determinam como cada ligação dos processos é integrada e é gerenciada.

De maneira muito semelhante, Fuente et al. (2008) reuniram, com base em estudos de vários autores, vários processos que compõem a cadeia de suprimentos, descritos a seguir no quadro 3.

Quadro 3 - Definição de processos gerais no gerenciamento de cadeia de suprimentos

\begin{tabular}{|c|c|}
\hline Processo Geral & Descrição \\
\hline Gerenciamento de Demanda & $\begin{array}{ll}\text { - } & \text { Previsão de vendas. } \\
\text { - } & \text { Elaboração de planejamento agregado: } \\
\text { - } & \text { Manufatura, compras, recursos. } \\
\text { - } & \text { Revisão periódica do planejamento agregado } \\
\end{array}$ \\
\hline Gerenciamento de Pedidos & $\begin{array}{l}\text { - } \quad \text { Recebimento de pedidos: produto final ao cliente. } \\
\text { - } \quad \text { Recebimento de devoluções e classificação: } \\
\text { - } \quad \text { Produtos e materiais oriundos dos clientes. }\end{array}$ \\
\hline $\begin{array}{l}\text { Gerenciamento de } \\
\text { Manufatura }\end{array}$ & $\begin{array}{l}\text { - } \quad \text { Manufatura do produto: Do planejamento agregado a validação do pedido. } \\
\text { - } \quad \text { Estabelecimento de capacidade: Recursos humanos e materiais. } \\
\text { - } \quad \text { Reprocessamento de produtos e materiais devolvidos }\end{array}$ \\
\hline $\begin{array}{l}\text { Gerenciamento de } \\
\text { Aquisições }\end{array}$ & $\begin{array}{l}\text { - } \quad \text { Matérias-primas e aquisição de serviços para a manufatura e pedidos. } \\
\text { - } \quad \text { Gerenciamento de estoques e depósitos. } \\
\text { - Gerenciamento de materiais para envio a operações de recuperação }\end{array}$ \\
\hline $\begin{array}{l}\text { Gerenciamento de } \\
\text { Distribuição }\end{array}$ & $\begin{array}{l}\text { - } \quad \text { Entrega de produtos acabados e matérias-primas ao cliente certo. } \\
\text { - Operador de logística e seleção de meios de transporte: relacionado às } \\
\text { condições dos materiais }\end{array}$ \\
\hline $\begin{array}{l}\text { Gerenciamento de Serviços } \\
\text { ao Cliente }\end{array}$ & $\begin{array}{l}\text { - } \quad \text { Ponto de contato com o consumidor. } \\
\text { - Obtenção de informações sobre o consumidor: pedidos, serviços, } \\
\text { problemas, reclamações. }\end{array}$ \\
\hline Gerenciamento de Clientes & $\begin{array}{ll} & \text { Seleção de clientes, aceitação e classificação. } \\
\text { - } & \text { Relação contratual com o cliente. } \\
\text { - } & \text { Métricas de serviço. } \\
\text { - } & \text { Serviço ao Consumidor: Análise de informações. }\end{array}$ \\
\hline $\begin{array}{l}\text { Gerenciamento de } \\
\text { Fornecedores }\end{array}$ & $\begin{array}{l}\text { - } \quad \text { Identificação do fornecedor, validação e classificação. } \\
\text { - } \quad \text { Relacionamento de serviço entre fornecedor e indústria. } \\
\text { - } \quad \text { Monitoramento do serviço dos fornecedores. } \\
\text { - } \quad \text { Análise de informações dos fornecedores. }\end{array}$ \\
\hline
\end{tabular}

Fonte: FUENTE et al., 2008

Também na busca de um modelo, Ketchen et al. (2008), propõem o conceito da cadeia de suprimento de melhor valor, baseada em um conjunto de suposições e práticas, sendo seu foco o gerenciamento estratégico de toda cadeia como um meio de criar vantagens competitivas e melhorar o desempenho. Estas cadeias devem centrar-se em quatro prioridades competitivas: velocidade (muitas vezes chamada de tempo de ciclo e que corresponde ao tempo de duração 
do início à conclusão do processo de suprimento), qualidade (refere-se à confiança das atividades da cadeia), custo (envolve a busca da redução de despesas de forma a gerar benefícios para a cadeia e para os clientes) e flexibilidade (refere-se a uma cadeia responsiva, de forma a atender as necessidades dos clientes). O equilíbrio destas quatro estratégias faz uma cadeia proporcionar um alto nível de valor adicionado ao cliente final.

Para conseguir este equilíbrio, os autores propõem um modelo de cadeias de suprimento de melhor valor. Tais cadeias devem estar baseadas em três elementos ligados ao gerenciamento estratégico que eles chamam de 3 A's: Agilidade (capacidade em agir rapidamente em resposta às mudanças de oferta e procura), Adaptabilidade (vontade e capacidade em reformular a cadeia, quando necessário) e Alinhamento (criação de consistência nos interesses de todos os participantes da cadeia de suprimentos). Além desses três elementos, os autores definem quatro áreas chaves: fornecimento estratégico (muitas vezes chamado de logística de entrada, fornecendo matéria prima e sendo cada vez mais um elemento de grande importância nos produtos e serviços), gestão da logística (deve ser gerenciada como um esforço integrado em busca das vantagens competitivas), sistemas de informação da cadeia de suprimentos (sistemas de informações eficazes proporcionam importantes benefícios como redução de custos e maior produtividade) e gerenciamento de relacionamentos (refere-se à gestão dos relacionamentos entre os participantes da cadeia de suprimentos). A ilustração 9 expõe o modelo proposto. 


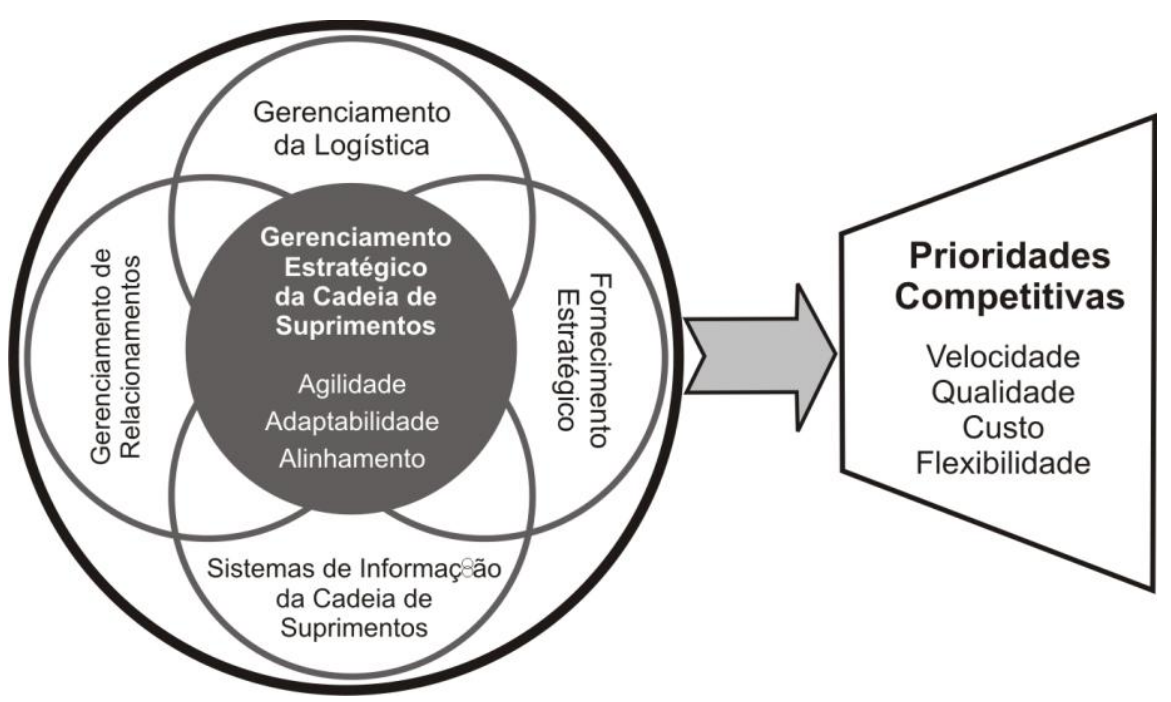

Ilustração 9 - Cadeia de suprimentos de melhor valor FONTE: KETCHEN et al., 2008

Segundo Allnoch (1997), Power (2005) e Shepherd e Gunter (2006), talvez a mais bem sucedida iniciativa para criar um modelo de gerenciamento de cadeia de suprimentos foi, até então, o Modelo SCOR.

O Modelo "Referência de Operações da Cadeia de Suprimentos" (Supply Chain Operations Reference - SCOR) foi criado em 1997 por um consórcio formado por mais de setenta empresas industriais nos Estados Unidos chamado Conselho de Cadeia de Suprimento (Supply Chain Council). O SCOR define processos comuns de gerenciamento da cadeia de suprimento e os combina com análises das melhores práticas, benchmarking (padrões) de medidas de desempenho e uso de software (SUPPLY CHAIN COUNCIL, 2006).

Para Power (2005), a intenção do modelo SCOR é criar um modelo de negócio para gerenciar cadeia de suprimento que pode ser usado mundialmente independente da indústria e localização geográfica. Porém o uso do modelo não significa uma solução para empresas, mas fornece a elas uma linguagem comum para discutir problemas da cadeia de suprimento, desenvolver padrões de medidas e direcionar o desenvolvimento de softwares de gerenciamento da cadeia de suprimento.

O modelo é baseado em cinco processos gerais da cadeia de suprimento: planejamento, compras, produção, distribuição e retorno. A ilustração 10 mostra e o quadro 4 detalha esses processos. 


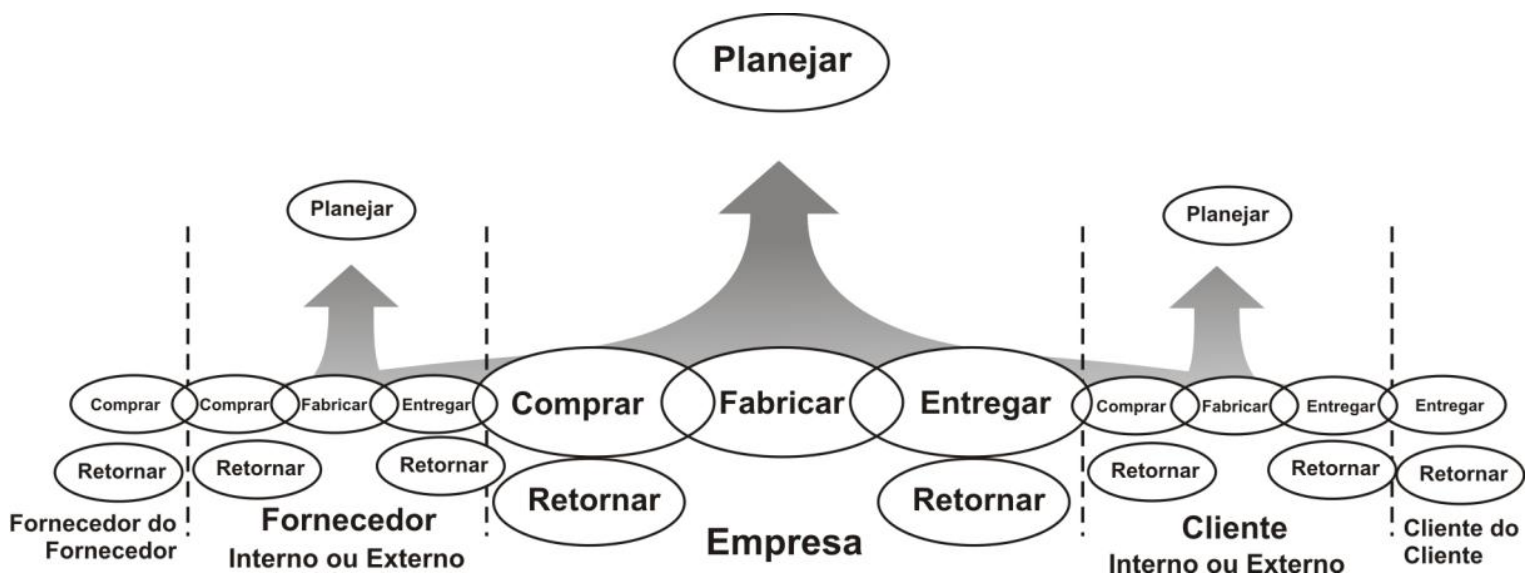

Ilustração 10 - O modelo SCOR

FONTE: SUPPLY CHAIN COUNCIL, 2006

Quadro 4 - Detalhamento do Modelos SCOR

\begin{tabular}{|c|c|}
\hline Processo & Detalhamento \\
\hline Planejamento & $\begin{array}{l}\text { - Equilibrar recursos com necessidades e comunicar os planos para toda a cadeia de } \\
\text { suprimentos, incluindo os processos de retorno, compras, produção e distribuição; } \\
\text { - Gerenciamento das normas empresariais, desempenho da cadeia, coleta de dados, } \\
\text { estoques, capital, transporte, planejamento da configuração e regulamentos; } \\
\text { - Alinhar os planos da cadeia de suprimentos com os planos financeiros; }\end{array}$ \\
\hline Compras & $\begin{array}{l}\text { - Agendar entregas; receber, verificar, transferir produtos e autorizar o pagamento dos } \\
\text { fornecedores; } \\
\text { - Identificar e selecionar fontes de suprimentos (quando não determinada), bem como } \\
\text { produtos sob encomenda; } \\
\text { - Gerenciar as normas empresariais, avaliar o desempenho do fornecedor e manutenção } \\
\text { dos dados.; } \\
\text { - Gerenciar estoque, capital, matéria prima, rede de fornecedores, requisitos de } \\
\text { importação / exportação, acordos com fornecedores; }\end{array}$ \\
\hline Produção & $\begin{array}{l}\text { - Agendar atividades de produção, determinar lotes de produtos, produção e testes, } \\
\text { embalagem, ciclo do produto e liberação para entrega; } \\
\text { - Determinar a engenharia para produtos sob encomenda; } \\
\text { - Gerenciar normas, desempenho, dados, produtos em processo, equipamentos e } \\
\text { instalações; transporte, cadeia produtiva, bem como o cumprimento de regras para a } \\
\text { produção; }\end{array}$ \\
\hline Distribuição & $\begin{array}{l}\text { - Todas as etapas do gerenciamento do pedido desde o processamento das requisições e } \\
\text { cotações dos clientes, até roteamento das entregas e seleção dos operadores; } \\
\text { - Gerenciamento dos armazéns para o recebimento e a separação dos produtos para } \\
\text { carregamento e envio; } \\
\text { - Faturamento } \\
\text { - Gerenciar as regras de entrega, desempenho, informações, estoques de produtos } \\
\text { acabados, capital, transporte, ciclo de vida dos produtos e requisitos de importação / } \\
\text { exportação; }\end{array}$ \\
\hline Retorno & $\begin{array}{l}\text { - Todos os passos do retorno dos produtos defeituosos aos fornecedores; } \\
\text { - Todos os passos do retorno de manutenção, reparo e revisão geral dos produtos aos } \\
\text { fornecedores; } \\
\text { - Todos os passos de retorno de produtos em excesso aos fornecedores; } \\
\text { - Gerenciar as normas de retorno, desempenho, coleta de dados, retorno de estoques, } \\
\text { capital, transporte e configuração da rede, bem como exigências regulatórias e } \\
\text { regulamentos. }\end{array}$ \\
\hline
\end{tabular}

FONTE: SUPPLY CHAIN COUNCIL, 2006 
O modelo foi ainda decomposto em três níveis de detalhamento. No Nível 1 a empresa define as metas de desempenho e reúne as informações necessárias para desenvolver seu próprio modelo SCOR, definindo os cinco processos básicos. No nível 2 ela cria sua própria "configuração de cadeia de suprimento", considerando seus bens, gama (mix) e volume de produtos e necessidades tecnológicas. Os cinco tipos de processo do nível 1 são decompostos em vinte e seis categorias de processo. Com essa informação a empresa pode determinar seu desempenho esperado para que no nível 3 ela possa trabalhar no detalhamento de seu desempenho. A ilustração 11 mostra esse detalhamento (POWER, 2005; STADLER; KILGER, 2005; SUPPLY CHAIN COUNCIL, 2006).

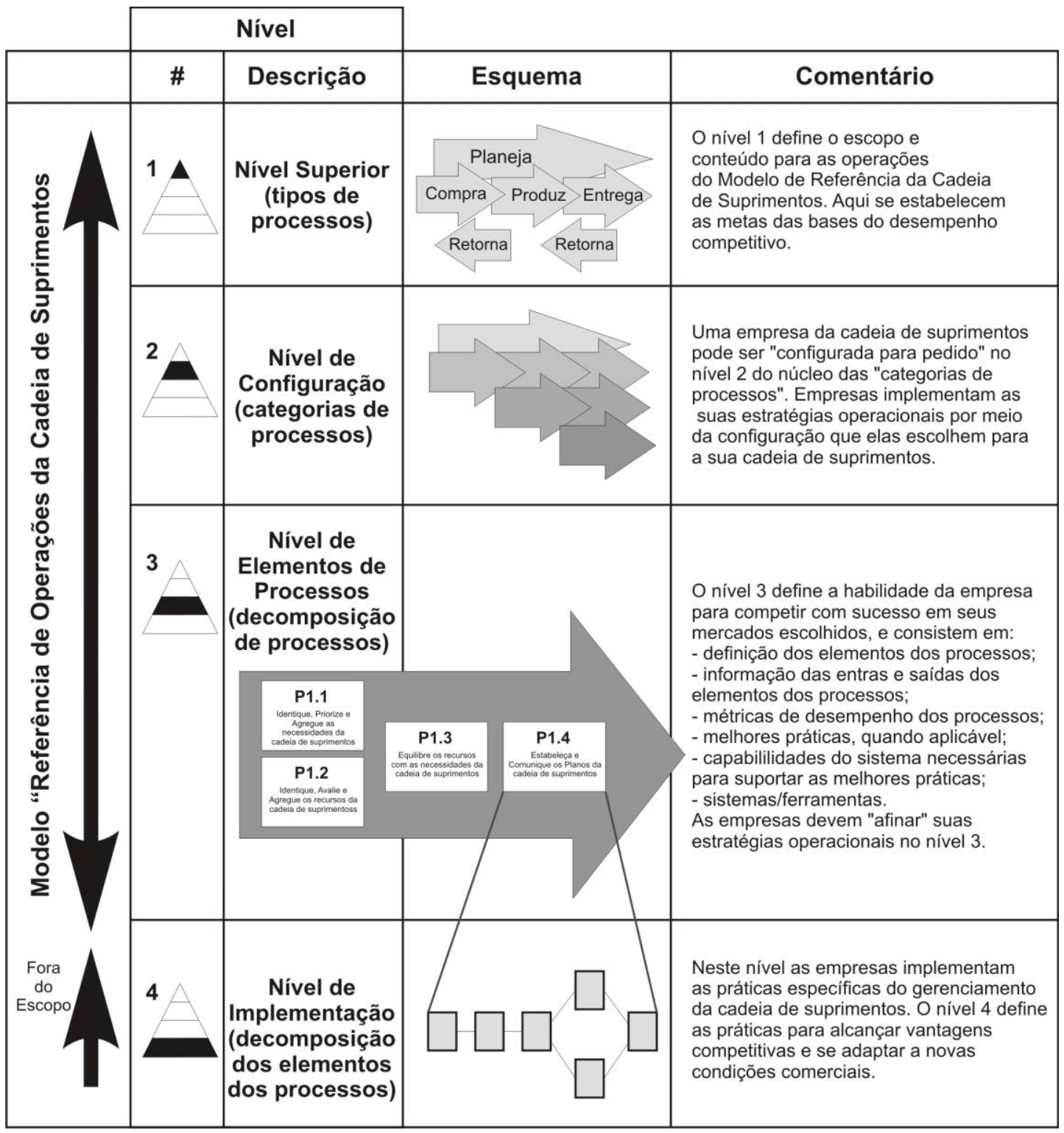

Ilustração 11 - Detalhamento do modelo SCOR FONTE: POWER, 2005; STADLER; KILGER, 2005; SUPPLY CHAIN COUNCIL, 2006 
O Modelo SCOR atua também como uma referência na determinação de métricas de medida de desempenho na cadeia de suprimentos. Após o detalhamento dos processos, indicadores de desempenho são sugeridos para cada nível, e será abordado em detalhes no tópico 2.6 deste trabalho.

Ainda Power (2005), com base em vários autores, discorre sobre alguns benefícios e algumas falhas do Modelo SCOR. Entre os benefícios, pode-se citar: potencial para melhorias a nível estratégico no gerenciamento da cadeia de suprimento por meio de benchmarking; fornecimento de uma plataforma comum de comunicação entre parceiros comerciais; identificação de pontos a serem melhorados na cadeia de suprimentos permitindo a distribuição mais eficaz de recursos; estabelecimento de padrões, processos e medidas de desempenhos claros para o gerenciamento da cadeia de suprimentos; e desenvolvimento mais rápido de softwares de gerenciamento da cadeia de suprimentos. Por outro lado, ainda segundo o autor, algumas falhas seriam: falhas ao modelar as interfaces entre parceiros comerciais e os motivos que levam eles a ignorarem os processos de desenvolvimento de produtos, além de ser deficitário em relação a determinação dos níveis de serviço aos clientes.

Para Stedman (2000), apesar de algumas grande empresas estarem utilizando o modelo SCOR, o número de empresas que implementaram totalmente as diretrizes e tem tido resultados positivos é relativamente pequeno. Para eles, este baixo nível de implementação pode ser devido às falhas apresentadas pelo modelo.

Lockamy e Mccormack (2004) desenvolveram o "Modelo de Maturidade do Gerenciamento da Cadeia de Suprimentos". Com o propósito de avaliar em qual estágio a empresa e/ou a cadeia estão com relação ao Gerenciamento da Cadeia de Suprimentos. Os autores tomaram como base o Modelo de Referência em Operações da Cadeia de Suprimentos (Supply Chain Operations Reference Model - SCOR). Assim, o modelo de Lockamy e Mccormack (2004) apresenta cinco níveis:

- Nível 1 - Ad hoc - neste nível a cadeia está desestruturada, e má definida. Processos, atividades e estruturas organizacionais não estão baseados em processos horizontais, enquanto o desempenho do processo é imprevisível. Os custos do gerenciamento da cadeia são altos, e o nível de satisfação dos clientes e a cooperação funcional são baixos; 
- Nível 2 - Definidos - os processos básicos do gerenciamento da cadeia estão definidos e documentados, porém as atividades e a organização basicamente permanecem tradicionais. Os custos do gerenciamento são altos, nível de satisfação dos clientes melhorou, mas é ainda baixa;

- Nível 3 - Ligados - este nível representa um ponto de ruptura. A cooperação entre os departamentos da empresa, clientes e fornecedores está estabelecida. Os custos do gerenciamento da cadeia começam a diminuir, e o nível de satisfação dos clientes começa a mostrar uma melhora significativa;

- Nível 4 - Integrados - neste nível, a empresa, seus clientes e fornecedores atuam em forma de cooperação. As estruturas organizacionais estão baseadas nos procedimentos do gerenciamento da cadeia e existem medidas de desempenhos para a cadeia. Práticas avançadas do gerenciamento da cadeia se formam como, por exemplo, a previsão colaborativa entre os membros da cadeia. Como consequiência, os custos da cadeia são drasticamente reduzidos e

- Nível 5 - Estendidos - neste nível a competição é baseada nas cadeias de suprimentos. A colaboração entre as empresas é grande e surgem equipes multi-empresariais com processos e metas comuns.

Após expostos alguns modelos, torna-se interessante ressaltar alguns benefícios, bem como alguns problemas e desafios do gerenciamento da cadeia de suprimentos.

\subsubsection{Benefícios do Gerenciamento da Cadeia de Suprimentos}

Segundo Simatupang et al. (2002), empresas trabalhando em conjunto podem se tornar mais efetivas e eficientes ao encorajar a integração na cadeia de suprimentos. Uma cadeia de suprimentos integrada resulta em compartilhamento de informações de uma maneira precisa e oportuna, o que gera a otimização do fluxo de materiais ao longo da cadeia e elimina todos os processos que falham em otimizar o valor do produto.

Croom et al. (2000) relatam outros benefícios que podem surgir com o gerenciamento da cadeia de suprimentos, entre eles níveis menores de estoque (implicando em riscos e custos mais baixos), aumento na produtividade e melhoria nos procedimentos gerenciais da empresa (aquisições, manufatura, distribuição, etc.). Para eles, o gerenciamento da cadeia é também 
uma maneira de implementar processos padronizados, com modelos de linguagens comuns, e arquiteturas que compartilhem informações para alcançar o máximo desempenho da cadeia.

Diversos pesquisadores sugerem que um melhor desempenho pode ser alcançado por meio da consolidação das bases de consumidores e fornecedores, eliminação de passos desnecessários na cadeia, aceleração dos fluxos de informações e materiais e criação de parcerias de longo prazo entre os principais consumidores e fornecedores de modo a alavancar as capacidades de várias empresas na cadeia (ZAILANI; RAJAGOPAL, 2005)

Para Dhahri e Chabchoub (2007), boa parte do atual interesse no gerenciamento da cadeia de suprimentos é motivada pelas oportunidades que surgem com o grande volume de dados e benefícios que podem ser alcançados por meio de análises sofisticadas dos mesmos. As implicações desta abundância de informações disponíveis são enormes. Informações mudam a maneira como as cadeias de suprimentos podem e deveriam ser efetivamente gerenciada e essas mudanças podem levar, entre outras coisas, a estoques mais baixos. Em outras palavras, o aproveitamento eficaz das informações disponíveis pode tornar as cadeias mais eficientes do que nunca.

Segundo Zailani e Rajagopal (2005), muitas empresas buscam adotar o conceito de gerenciamento da cadeia de suprimentos, pois esperam com isso reduzir custos por meio do corte de estoques e da melhora da eficiência ao longo da cadeia, no menor custo total entregue aos clientes finais.

Barratt (2004) ressalta que cadeias de suprimento que utilizam a colaboração para integrar suprimento e demanda, apresentam desempenhos significativamente melhores, e se beneficiam das relações mais próximas entre as empresas, surgindo oportunidades para grandes melhorias.

Segundo Fawcett et al. (2008) as vantagens do gerenciamento da cadeia de suprimentos são: produtos e serviços únicos, ciclos mais rápidos de Pesquisa e Desenvolvimento (P\&D), melhor qualidade dos produtos, competitividade em custo, ciclos menores de pedidos, flexibilidade às necessidades dos clientes, melhora no desempenho de entrega, melhor gerenciamento do Ativo, melhoria na velocidade do ciclo financeiro e relações melhores entre as empresas da cadeia. 
Para Morgan (2004), baseado na sua definição de cadeias ágeis, as principais características de uma cadeia de suprimentos ágil são: resposta rápida ao cliente, melhores sistemas de fabricação, flexibilidade, programação sincronizada com a demanda final, processos de fornecimentos controlados, capacitação de todos os parceiros, utilização do comércio eletrônico, desenvolvimento de produtos competitivos e melhoria de custos. Neste contexto, segundo o autor, as grandes contribuições que o conceito de cadeia de suprimentos trouxe foram: motivar os gerentes a pensarem fora da organização, reconhecer as interdependências que existem entre e nas organizações; e também reconhecer os impactos financeiros e de logística nas transações entre as empresas e entre nações.

Nessa mesma idéia, Yusuf et al. (2004) definem a agilidade de uma cadeia de suprimentos como sendo a medida de quão bem se dão os relacionamentos envolvidos nos processos de criação, produção e entrega de produtos e serviços, fazendo com que eles se desenvolvam da melhor maneira para atingir quatro objetivos essenciais: atender melhor os clientes em relação aos concorrentes, atingir uma personalização de massa a um custo de produção em massa, dominar as mudanças e incerteza através de estruturas adaptáveis, e alavancar o impacto das pessoas nas empresas através da tecnologia da informação.

Assim, entre os vários possíveis benefícios citados pelos autores, pode-se resumir em: redução dos estoques, redução dos custos; aumento da eficiência, aumento dos lucros, redução do tempo de ciclo, melhor desempenho nos relacionamentos com clientes e fornecedores e aumento da vantagem competitiva

\subsubsection{Problemas e Desafios do Gerenciamento da Cadeia de Suprimentos}

De acordo com Stadler e Kilger (2005), a coordenação dos fluxos de materiais, de informações e financeiros dentro de uma grande empresa multinacional é uma tarefa desafiadora e recompensadora. Obviamente, formar uma cadeia de suprimentos a partir de um grupo de empresas individuais, para que ele atue como uma entidade única é mais difícil ainda.

Para Lambert et al. (1998), a maior fraqueza do gerenciamento da cadeia de suprimento é que as empresas participantes dizem conhecer com certeza quem são os membros de sua cadeia, o que nem sempre é uma verdade. Tem havido poucos esforços em identificar os membros da 
cadeia, os processos chaves que necessitam de integração ou o que os gerentes devem fazer para gerenciar com sucesso uma cadeia de suprimentos.

Também para Barratt (2004), em seu estudo, com base em vários autores, tem sido mostrado que a implementação da colaboração na cadeia de suprimento tem se mostrado difícil. Além do excesso de confiança na tecnologia na tentativa de implementá-la, as empresas estão falhando na definição de quais parceiros são os ideais para colaborar e, principalmente, está havendo uma falta de confiança entre os parceiros.

Fawcett e Magnan (2002) afirmam que vários estudos têm mostrado que poucas empresas estão realmente empenhadas na integração intensiva da cadeia de suprimentos e que menos empresas ainda procuram mapear em suas cadeias de suprimentos quem são os fornecedores dos fornecedores ou os clientes dos clientes.

Segundo Simchi-Levi et al. (2003), os efeitos prejudiciais da perspectiva local no desempenho da cadeia de suprimentos podem ser vistos examinando-se como os membros da cadeia comprometem-se com as medidas de desempenho ao longo da cadeia. Como eles possuem individualmente políticas de previsão de demanda, sistemas de pedidos, sistemas de estoques, instalações, transporte e preços, eles tornam-se envolvidos em uma série de implicações que contribuem para a ineficácia de custo, um serviço ao consumidor ruim e menor lucratividade da totalidade da cadeia.

Para Simatupang e Sridharan (2002), não existe dúvida que existe considerável antagonismo entre os membros de uma cadeia de suprimentos, devido a uma mútua desconfiança e a dificuldades no relacionamento antes e durante a cooperação. A manifestação da desconfiança e das dificuldades cooperativas é freqüentemente na forma de conflito, o qual impede que os esforços dos membros melhorem o desempenho total da cadeia. Segundo os autores, a literatura aponta em geral três tipos de causas de conflito: diferenças entre as metas e objetivos dos membros (conflito de metas), desentendimentos sobre o domínio das decisões e ações (conflito de domínio) e diferenças de percepções da realidade usadas na tomada de decisões conjunta (conflito de percepção).

Já para Dhahri e Chabchoub (2007), os problemas no gerenciamento da cadeia de suprimento surgem a partir da incompreensão e falta de gerenciamento de diferentes processos que 
constituem a cadeia de suprimentos, assim como as inapropriadas técnicas utilizadas para resolver estes problemas. Perante esta realidade, os gestores estão em busca de novas técnicas e ferramentas para gerir, de forma eficaz e eficiente, toda a cadeia.

Para Nabavi (2006) a falta de coordenação e de informação são as duas principais fontes de problemas no gerenciamento da cadeia de suprimentos. Direta ou indiretamente elas podem ocasionar acúmulo de estoque, custos de vendas perdidas e excesso de capacidade de produção. A falta de informação dos pontos de vendas e o uso de dados locais para o cálculo da demanda podem gerar previsões enganosas ocasionando estoques excessivos ou falta de estoques e influenciando de maneira errônea a determinação das capacidades produtivas dos fornecedores.

De acordo com Jammernegg e Reiner (2007), constantemente as empresas se deparam com situações de "trade-offs", onde os benefícios gerados pela escolha de uma alternativa em uma tomada de decisão contrapõem os prejuízos acarretados por essa mesma escolha. Nas operações logísticas, esse processo pode ser representado pela relação entre estoques, nível de serviço oferecido aos clientes, vendas e custos (quanto maior os estoques, maiores serão o nível de serviço aos clientes, as vendas e os custos, e vice-versa). Assim, um dos grandes desafios do gerenciamento da cadeia de suprimentos é reduzir os custos sem comprometer o nível de serviço aos clientes.

Hicks (1999) explica que a meta do planejamento da cadeia de suprimento é atingir o mais eficiente e rentável sistema de cadeia de suprimento que satisfaça as necessidades dos consumidores, e que decisões desta natureza incorrem tipicamente em altos gastos e riscos significantes.

Nos estudos realizados por Fuente et al. (2008), foram identificados os seguintes problemas: grande parte das cadeias são fragmentadas (cada membro somente foca nos seus processos), dificuldades na integração de processos e nas decisões entre fornecedores e clientes, e falta de sistemas de informação conectando os diferentes membros da cadeia.

Também Fawcett et al. (2008) apontam várias "barreiras" para um correto gerenciamento da cadeia. Entre eles pode-se citar: falta de comprometimento da alta gerência, falta de alinhamento das estratégias e filosofias entre as empresas, falta de habilidade ou vontade no 
compartilhamento de informações, falta de confiança entre as empresas, falta de vontade em compartilhar riscos e ganhos, falta de flexibilidade nos processos ou sistemas organizacionais, conflitos inter-funcionais, medidas de desempenhos inconsistentes ou inadequadas, resistência à mudanças e falta de treinamento para as novas habilidades necessárias.

Para Bayraktar et al. (2008), a cadeia de suprimentos é repleta de incertezas. Para eles, as fontes dessas incertezas têm como base o processo de adaptar a oferta com a procura. Entre elas, as incertezas de oferta, compostas pelos leads times de entrega, tempos de transporte, tempos das máquinas e desempenhos dos funcionários, causam um impacto significante no desempenho da cadeia. Por outro lado, as dificuldades na previsão das necessidades dos clientes constituem a principal fonte de incerteza da demanda.

Segundo Trkman et al. (2007), enquanto que a separação das atividades da cadeia entre as diferentes empresas possibilita a especialização e a economia em escala, muitas questões importantes e problemas precisam ser resolvidos para o sucesso das operações nas cadeias. A maioria dos problemas relacionados com o gerenciamento da cadeia de suprimentos é proveniente de incertezas ou da inabilidade em coordenar várias atividades e parceiros. Outro problema é que as empresas freqüentemente tendem a otimizar seus próprios desempenhos, desconsiderando os benefícios da cadeia como um todo (otimização local ao invés de global).

Da mesma forma, Gunasekaran et al. (2004) afirmam que a máxima eficiência de cada elo da cadeia, não necessariamente leva a otimização global da cadeia, pois a tentativa de obter um lucro máximo em um elo pode prejudicar a lucratividade do elo anterior ou posterior.

Simatupang e Sridharan (2005) também relatam em seus estudos alguns problemas encontrados no gerenciamento da cadeia de suprimentos, que eles chamam de "descontentamentos com a cadeia de suprimentos". Para eles, o descontentamento com a cadeia ocorre quando dois ou três participantes que trabalham juntos ao longo da mesma cadeia de suprimento percebem diferenças no ambiente organizacional que afetam sua capacidade de ter melhor desempenho. Nessa situação, ações tomadas por uma das partes são geralmente benéficas para ela, mas tem efeitos danosos aos outros participantes. Entre as questões envolvidas pode-se citar controle de preços, de estoques, de operações, de informação e até controle sobre a estrutura do canal. Esse descontentamento leva a perdas tais 
como altos custos logísticos e gastos desnecessários de incerteza da demanda incluindo excedente de estoque, queda de preço e desabastecimentos.

Em seus estudos, os autores detectaram seis fontes de descontentamento, que são:

- Objetivos estratégicos incongruentes - é a situação onde membros da cadeia possuem ênfases diferentes em suas estratégias para gerar vantagens competitivas;

- Medidas de desempenho desintegradas - significa que as medidas de desempenho são baseadas em métricas individuais isoladas e não na cadeia como um todo. Entre as razões para esta desintegração pode-se citar a falta de conhecimento de medidas de desempenho para a cadeia de suprimento ou uma inclinação proposital em direção as medidas individuais;

- Má representação da autoridade de decisão - refere-se às diferenças em procedimento de tomadas de decisão que leva a decisões contraproducentes, isto se deve ao fato que os membros da cadeia possuem diferentes autoridades de decisão e diferentes perspectivas de responsabilidades;

- Incentivos desalinhados - refere-se a determinar recompensas e punições incompatíveis com a otimização do desempenho da cadeia de suprimento como um todo. Um exemplo seria um comprador querer reduzir seu custo de compra, exigindo do varejista um desconto ao adquirir um volume e, por outro lado, o atacadista querer reduzir seus custos de recebimento e descarregamento e enviar volumes menores ao varejista. Incentivos desalinhados induzem os participantes individuais a tomar decisões intencionalmente, não satisfazendo os objetivos da cadeia como um todo;

- Distorção de informação - a assimetria de informação ocorre quando um participante tem melhor acesso a certas fontes de informação, quando comparado aos outros participantes, podendo levar vantagem. Este problema pode ocorrer se o fabricante ou o varejista forem relutantes em compartilhar suas informações.

- Processos empresariais fragmentados - ocorre quando os processos logísticos de cada empresa operam de forma isolada, não havendo sinergia entre as empresas. Esses processos fragmentados contribuem com vários desperdícios ao longo da cadeia de suprimento que levam a custos operacionais altos.

Todas essas fontes contribuem separadamente ou coletivamente para reduzir os lucros totais na cadeia. Ainda segundo os autores, o comportamento de descontentamento pode ser 
explicado pelo modelo criado pelos pesquisadores Blake e Mouton, onde as necessidades próprias e as do outro interagem como ilustrado no quadro 5. O eixo vertical mede a preocupação de um membro com seus próprios interesses em uma escala que varia de baixa a alta. O eixo horizontal mede sua preocupação com os interesses de outros membros. Cada participante pode ser visto tanto como comprador ou vendedor (um comprador em relação aos seus fornecedores e um vendedor em relação aos seus compradores). A combinação destes dois eixos conduz a quatro estilos gerais de comportamento de descontentamento com a cadeia: fuga, omissão, concorrência e acordo. Cada estilo leva a insatisfação no relacionamento, pois impede cada participante de melhorar o desempenho da cadeia como um todo.

Quadro 5 - Diferentes estilos comportamentais de descontentamento com a cadeia de suprimentos

\begin{tabular}{|c|c|c|c|}
\hline & & \multicolumn{2}{|c|}{ Preocupação com os interesses dos outros } \\
\hline & & Baixa & Alta \\
\hline \multirow{2}{*}{$\begin{array}{l}\text { Preocupação com os } \\
\text { interesses próprios }\end{array}$} & Baixa & $\begin{array}{c}\text { Fuga } \\
\text { (Nós dois perdemos) }\end{array}$ & $\begin{array}{c}\text { Omissão } \\
(\text { Eu perco, você ganha) }\end{array}$ \\
\hline & Alta & $\begin{array}{c}\text { Concorrência } \\
(\text { Eu ganho, você perde) }\end{array}$ & $\begin{array}{c}\text { Acordo } \\
\text { (Nós dois ganhamos um pouco e } \\
\text { perdemos um pouco) }\end{array}$ \\
\hline
\end{tabular}

FONTE: SIMATUPANG; SRIDHARAN, 2005

Assim, Ballou (2007) sugere uma série de desafios mais prováveis que o Gerenciamento da Cadeia de Suprimentos irá se deparar em um futuro próximo:

- Uma estratégia de geração de receitas para a cadeia de suprimentos será tão importante quanto uma de redução de custos;

- Os benefícios cada vez maiores do gerenciamento da cadeia podem ser fáceis de identificar, mas são difíceis de serem alcançados;

- Coordenação e colaboração, com confiança mútua são os elementos mais importantes para gerar oportunidades cada vez maiores;

- Compartilhamento de informações entre os membros da cadeia em conjunto com o avanço tecnológico poderão ser chamados de coordenação, compromisso e cooperação;

- Métricas cada vez mais avançadas serão necessárias para identificar os benefícios da cadeia de suprimentos e para controlar suas posições no canal de distribuição;

- Métodos para compartilhar benefícios precisarão ser mais bem definidos e aperfeiçoados; 
- Relacionamento da cadeia de suprimentos pode não ser eterno para todos os elos, então bons exemplos de coordenação na cadeia de entre algumas empresas serão poucos e por pouco tempo;

- A mudança de pessoal de logística para pessoal de gerenciamento de cadeia de suprimentos deve ser expandida para incluir o relacionamento e o desenvolvimento de confiança entre os elos;

- Operações, compras e logísticas vão se fundir nas organizações, provavelmente sob o nome de cadeia de suprimentos.

Entre os problemas encontrados no gerenciamento da cadeia de suprimentos, um dos mais importantes, segundo a bibliografia pesquisada é o Efeito Chicote (ou Bullwhip Effect), que será abordado em detalhes mais adiante.

\subsubsection{Soluções para o Gerenciamento da Cadeia de Suprimentos}

Segundo Chopra e Meindl (2003), para uma cadeia ser bem sucedida, as estratégias competitivas de cada empresa, bem como as estratégias competitivas das áreas funcionais (marketing, finanças, P\&D, etc.), devem estar alinhadas com a estratégia da cadeia de suprimentos. Para eles, a estratégia competitiva de uma empresa define o conjunto de necessidades do consumidor que ela pretende satisfazer por meio de seus produtos e serviços. Assim, para atingir o alinhamento estratégico, cada empresa da cadeia deve seguir três etapas básicas:

1) Entender o cliente - a empresa precisa entender as necessidades reais dos clientes, como: quantidade e a variedade de produtos necessária, tempo de resposta que o cliente está disposto a tolerar, o nível de serviços exigido, o preço do produto, a taxa de inovação esperada, entre outros;

2) Entender a cadeia de suprimentos - a empresa deve entender como é a cadeia a qual participa e qual sua tarefa nessa cadeia. Entre as várias configurações de cadeias, podem-se citar dois exemplos bem distintos. De um lado estão as cadeias responsivas (cadeias hábeis em: atender com lead times curtos, responder com amplos escopos de quantidades exigidas, atender a um nível de serviço muito elevado, entre outros) com características típicas de demandas com alto nível de incerteza e de outro lado estão as cadeias eficientes (cadeias hábeis em trabalhar com custos reduzidos de fabricação e entrega) mais propícias a demandas mais estáveis. 
3) Realizar o alinhamento estratégico - a empresa deve alinhar suas estratégias da cadeia com as necessidades dos clientes. Para alcançar um alinhamento completo, uma empresa deve garantir que todas as funções da cadeia de valor possuam estratégias coerentes e que sustentem a estratégia competitiva. A ilustração 12 aborda esse alinhamento.

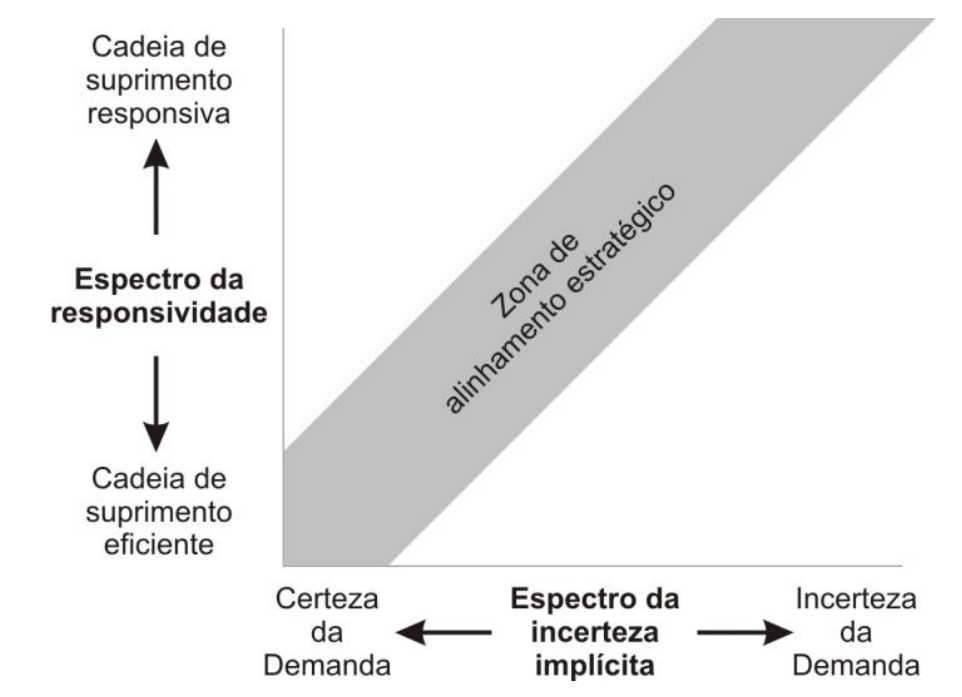

Ilustração 12 - Alinhamento estratégico na cadeia de suprimentos FONTE: CHOPRA; MEINDL, 2003

Ainda segundo os autores, outra questão importante a ser considerada no gerenciamento da cadeia de suprimentos é a redução da incerteza da demanda, que pode ser conseguida melhorando a coordenação entre suprimento e demanda. Entre as formas de reduzir a incerteza da demanda pode-se citar:

- Melhores previsões - a melhoria na precisão das previsões pode aumentar significativamente os lucros e uma empresa, e ao mesmo tempo, reduzir o excesso de estoque e as vendas perdidas pela falta de estoques. As empresas tentam compreender melhor seus clientes e coordenar suas ações na cadeia de suprimentos para melhorar a precisão das previsões. $\mathrm{O}$ uso de sistemas de informação para planejamento da demanda também é um fator importante para obter uma melhor previsão;

- Resposta rápida - é o conjunto de ações realizadas por uma cadeia de suprimentos que levam a redução do lead time de ressuprimento. Ao reduzir o lead time, os gerentes conseguem aumentar a precisão de suas previsões, permitindo uma melhor coordenação entre oferta e demanda e conseqüentemente o aumento da lucratividade; 
- Adiamento (postponement) - refere-se ao atraso da diferenciação do produto para o momento mais próximo de sua venda. Com o adiamento, todas as atividades anteriores à diferenciação do produto requerem previsões agregadas que são mais exatas que as previsões para um produto individual. As previsões individuais são necessárias próximas ao momento da venda quando a demanda é conhecida com exatidão. Logo, $\mathrm{o}$ adiamento permite a cadeia coordenar melhor o suprimento e a demanda. $\mathrm{O}$ adiamento pode ser uma ação forte para aumentar o lucro. Se a cadeia consegue adiar a diferenciação do produto para depois da chegada do pedido do cliente, haverá expressivo aumento nos lucros e poderá haver redução nos estoques;

- Fonte de suprimento sob medida - consiste em manter um fornecedor caro e com lead time curto (maior flexibilidade) como medida de segurança para um fornecedor barato, mas com lead time longo (menor flexibilidade). Neste caso, o fornecedor barato deve se concentrar na eficiência e deve ser acionado apenas para suprir a parcela previsível da demanda, enquanto que o fornecedor caro deve priorizar a responsividade e ser acionado para suprir a parcela incerta da demanda.

Também, de acordo com Bayraktar et al. (2008), o verdadeiro sucesso reside na capacidade de gerenciar as incertezas da demanda com as capabilidades existentes na cadeia e, nesse contexto, o entendimento e a prática do gerenciamento da cadeia de suprimento tornaram-se pré-requisitos essenciais para gerenciar essas incertezas e permitir uma crescente rentabilidade nos mercados globais cada vez mais competitivos. Neste contexto, o gerenciamento da cadeia de suprimentos foca em um conjunto de abordagens e práticas para reduzir a incerteza ao longo da cadeia por meio de uma melhor integração entre fornecedores, fabricantes, distribuidores e clientes.

Para os autores, a necessidade de uma previsão da demanda mais acurada é uma questão a ser buscada. O compartilhamento das informações do ponto-de-venda entre os parceiros da cadeia e a análise desde dados por meio de técnicas de mineração de dados (data mining) podem ajudar a melhorar previsão. Ainda para os autores, a previsão de demanda é uma ferramenta essencial para o planejamento da produção e do estoque, o gerenciamento da capacidade e a definição do nível de serviço ao cliente. 
Para Sahin e Robinson (2002), o compartilhamento de informações é geralmente considerado por vários autores como uma cura genérica para os problemas da cadeia de suprimentos e, portanto, seu estudo merece atenção.

Segundo Nabavi (2006) a tecnologia da informação e o compartilhamento de informação são dois fatores essenciais para o gerenciamento da cadeia de suprimentos. A utilização das tecnologias de informação aumenta a eficiência e permite a integração das informações, tornando a cadeia mais ágil e responsiva.

Para Lee e Whang (2001) a Internet pode ser um elemento facilitador do gerenciamento da cadeia de suprimentos. Em seus estudos, os autores demonstram os benefícios gerados com a utilização dos negócios eletrônicos (e-business) para os processos da cadeia. Entre eles podese citar: aumento da eficiência, melhor aproveitamento dos ativos, maior rapidez nas negociações, redução do tempo total de atendimento do pedido, melhora no serviço ao cliente e na responsividade, penetração em novos mercados, maior retorno sobre os ativos e maior valor para os acionistas.

Hicks (1999) sugere duas diferentes abordagens para melhorar a cadeia de suprimentos: focar na tecnologia de informação ou na logística. A primeira tem a informação como chave para a melhoria da cadeia de suprimentos, com o foco principal sobre o planejamento colaborativo, o compartilhamento de informação e a sincronia das empresas com fornecedores e consumidores. A segunda tem foco mais interno e está interessada na análise quantitativa de problemas logísticos complexos.

Também para Chantrasa (2005), o compartilhamento de informações, que é uma forma de integração de informações, é um elemento chave para se conseguir uma firme integração entre os membros da cadeia.

Para Sezen (2008) enquanto que a integração e o compartilhamento de informações são as mais conhecidas maneiras de aumentar o desempenho na cadeia de suprimentos o projeto (design) de uma cadeia de suprimentos também tem um papel crítico para alcançar os níveis de desempenhos desejados. Cadeias de suprimento bem projetadas podem suprir as mudanças das necessidades dos clientes por meio de capacidade adequada, fornecedores e distribuidores localizados em pontos estratégicos e bons relacionamentos entre os membros do canal. 
De acordo com Gunasekaran et al. (2008), uma característica essencial para o sucesso do gerenciamento da cadeia de suprimentos é a agilidade. Mason-Jones e Towill (1999) afirmam que "agilidade" deve ser interpretada como sendo a utilização do conhecimento das características do mercado para explorar oportunidades rentáveis em um mercado em constante mudança. Assim, Gunasekaran et al. (2008) definem um modelo de Cadeia de Suprimentos Responsiva como sendo uma rede de empresas que é capaz de criar riqueza para seus stakeholders num ambiente competitivo reagindo rapidamente e com baixos custos às mudanças de necessidade do mercado. Para que isso ocorra, deve existir (1) rede de parcerias entre as empresas, (2) sistemas e tecnologias de informação e (3) gerenciamento do conhecimento. Como conseqüência, esta cadeia mais responsiva fornece uma maior rapidez e flexibilidade. A ilustração 13 aborda a Cadeia de Suprimentos Responsiva.

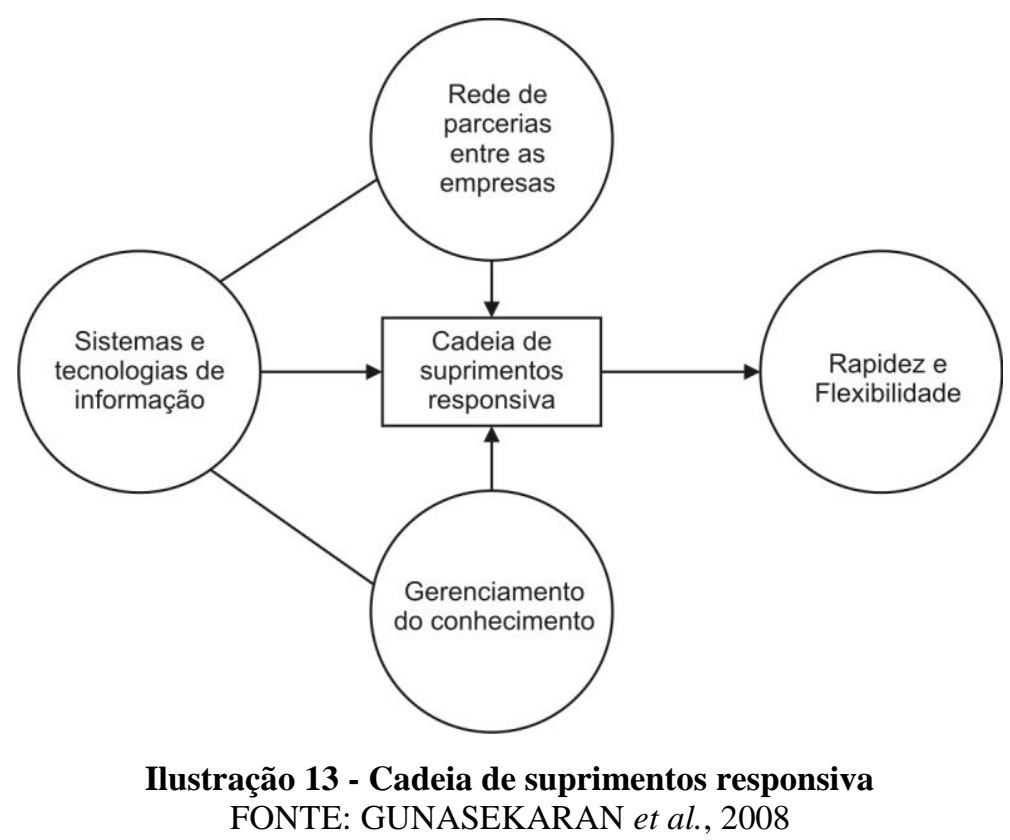

De acordo com Chopra e Meindl (2003) o sucesso da cadeia consiste em buscar um equilíbrio entre responsividade e eficiência. Para isso as empresas devem examinar quatro fatores-chave de desempenho da cadeia:

1) Estoque - o estoque existe na cadeia de suprimentos devido a uma inadequação entre suprimento e demanda. Essa inadequação pode ser intencional, ou por redução de custos na fabricação de grandes lotes ou por estratégia de antecipar a demanda futura. As mudanças nas políticas de estoque podem alterar drasticamente a eficiência e a responsividade da cadeia. Um alto nível de estoque pode tornar uma cadeia mais 
responsiva, mas isso a torna menor eficiente e vice-versa. Ao analisar a cadeia como um todo, deve-se considerar todo o estoque espalhado por essa cadeia, indo desde matérias-primas, passando por produtos em processamento e finalizando em produtos acabados mantidos por fornecedores, fabricantes, distribuidores e varejistas;

2) Transporte - o transporte mobiliza os produtos entre diferentes estágios na cadeia de suprimentos. As várias opções entre modais de transporte ou rotas também causa um impacto na eficiência e responsividade. O uso, por exemplo, do modal aéreo, pode tornar a cadeia mais responsiva, porém menos eficiente;

3) Instalação - as instalações são os locais "para" ou "de" onde o estoque é transportado. A quantidade, a localização e a capacidade das instalações (fábricas ou armazéns) são fatores que também impactam na eficiência e responsividade. Um número maior de armazéns pode trazer uma boa responsividade, porém pode acarretar em um custo maior;

4) Informação - a informação consiste em dados ou análises a respeito do estoque, do transporte, das instalações e dos clientes que fazem parte da cadeia de suprimento, sendo ela potencialmente o principal fator de desempenho da cadeia, pois afeta diretamente cada um dos três fatores-chave anteriores. A informação pode tornar as cadeias mais responsivas e eficientes. Com informações sobre os padrões de demanda dos clientes, uma empresa pode produzir e armazenas em antecipação à demanda, o que caracteriza uma cadeia responsiva. Por outro lado, a informação também pode tornar a cadeia mais eficiente, pois a empresa poderá prever melhor a demanda e produzir somente as quantidades e variedades necessárias.

Para Lambert e Pohlen (2001), para implementar uma estratégia de cadeia de suprimentos, além do compartilhamento de informação, são necessárias métricas corretas de forma a alinhar os desempenhos com os objetivos dos membros da cadeia. Essas métricas estão alinhadas podem direcionar a atenção e os esforços dos gerentes para as áreas que necessitam de melhoras e com isso aumentar o desempenho da cadeia. Para isso, eles devem pensar não em otimizar suas próprias operações, mas sim a cadeia como um todo, sendo necessários conhecer toda a cadeia e estabelecer métricas para ela.

Segundo Chen e Paulraj (2004), várias são ações tomadas pelas empresas em busca do correto gerenciamento das cadeias de suprimentos em que elas participam. Entre elas, pode-se citar: foco nas necessidades dos clientes, uso das tecnologias de informação, redução do número de 
fornecedores primários, predominância de contratos de longo prazo entre empresa e fornecedores, comunicação inter-organizacional de "via dupla", envolvimento dos fornecedores no desenvolvimento de novos produtos, uso de equipes multifuncionais e integração das atividades logísticas entre as empresas.

Power (2005) relata que os elementos críticos na implementação do gerenciamento da cadeia de suprimentos são a escolha correta de tecnologia de informação e a habilidade das empresas em gerenciarem as negociações.

Simatupang e Sridharan (2005) sugerem que para resolver o descontentamento com a cadeia de suprimento, a primeira etapa é identificar as fontes que influenciam esses comportamentos (fuga, omissão, concorrência e acordo), que são: objetivos estratégicos incongruentes, medidas de desempenho desintegradas, má representação da autoridade de decisão, incentivos desalinhados, distorção da informação e processos empresarias fragmentados. Assim, conhecidas as causas do descontentamento, os autores propõem os "antídotos" para elas, conforme a ilustração 14. Os antídotos atuam em dois níveis distintos: um empenho conjunto e condutores de colaboração empresarial. Ao nível do empenho conjunto, os membros da cadeia precisam desenvolver e comunicar objetivos estratégicos mútuos, bem como criar medidas de desempenho para o sucesso global. Já no nível de condutores de colaboração empresarial, os membros precisam criar colaborativamente condutores empresariais apropriados como compartilhamento de informação, sincronismo na tomada de decisão, incentivos alinhados e processos inter-empresariais aperfeiçoados (compras, armazenagem, transporte, etc.).

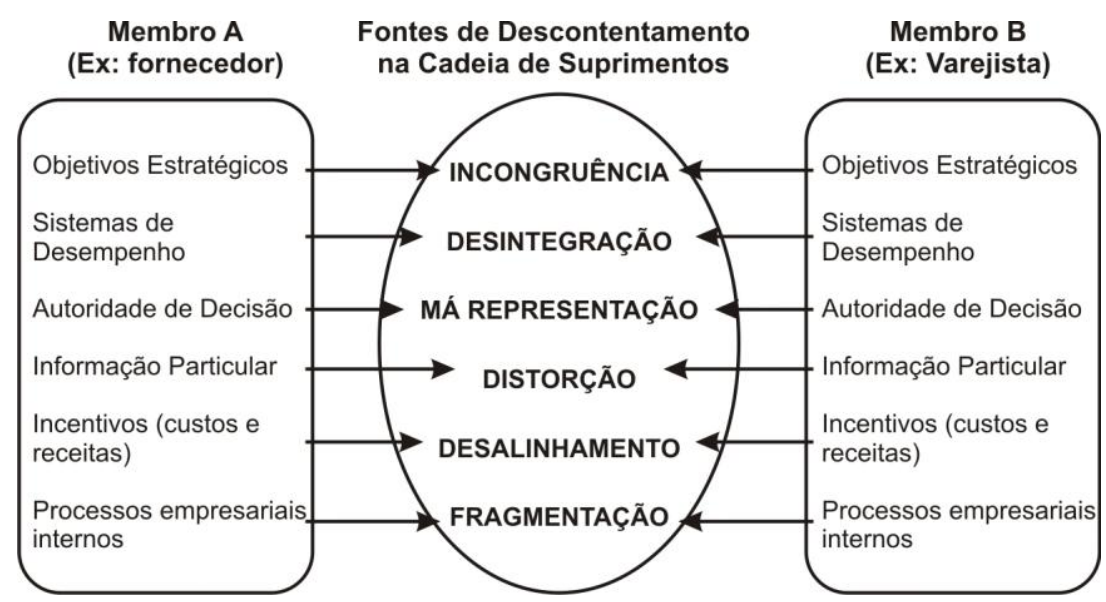

Ilustração 14 - Descontentamento na cadeia de suprimentos FONTE: SIMATUPANG; SRIDHARAN, 2005 
Em busca de uma melhor compreensão do processo de implementação do gerenciamento da cadeia de suprimentos, Fawcett et al. (2008) propõem um modelo denominado "Modelo de Contingência para compreender a implementação da cadeia de suprimentos". Neste modelo, conforme a ilustração 15, estão representados os motivos que levam as empresas a adotarem a colaboração, as barreiras da implementação da cadeia de suprimentos, os benefícios trazidos com a implementação da cadeia de suprimentos e os elementos facilitadores de uma correta implementação.

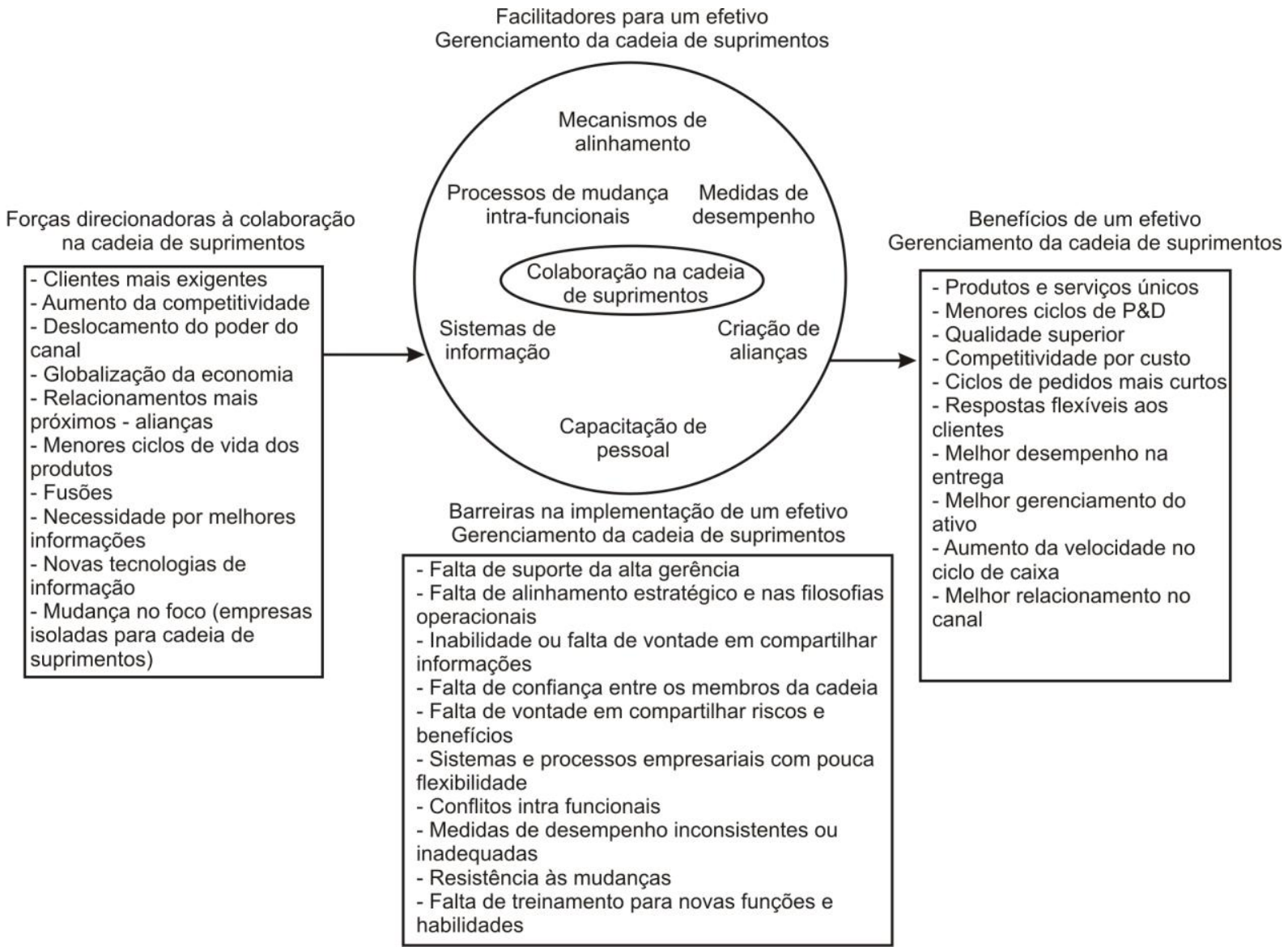

Ilustração 15 - Modelo de Contingência para compreender a implementação da cadeia de suprimentos FONTE: FAWCETT et al., 2008

\subsubsection{Conclusões sobre o Gerenciamento da Cadeia de Suprimentos}

Assim, finalizando este tópico, algumas conclusões podem ser descritas sobre o gerenciamento da cadeia de suprimentos. 
Para Ballou (2007), Algumas conclusões podem ser feitas a partir da observação do gerenciamento de fluxo de produto nos dias atuais:

1) Pode-se dizer que o Gerenciamento da Cadeia de Suprimentos se preocupa em aproveitar as oportunidades de gerenciamento integrado de fluxo de produtos pelas funções e entre os membros do canal;

2) A Logística é agora considerada como um sub sistema do Gerenciamento da Cadeia de Suprimentos;

3) Compras e Produção agora estão incluídas no escopo do Gerenciamento da Cadeia de Suprimentos (como resultado, o Gerenciamento da Cadeia de Suprimentos é responsável por 70 a 80 por cento do custo de vendas em muitas empresas);

4) Apesar do Gerenciamento da Cadeia de Suprimentos promover coordenação, integração, desenvolvimento de relacionamento e colaboração por todo canal de distribuição, atualmente é pouco usado (atualmente o Gerenciamento da Cadeia de Suprimentos é praticado como Logística e não com o amplo escopo teórico existente).

Assim, ainda segundo o autor, talvez os gerentes comecem a usar o Gerenciamento da Cadeia de Suprimentos quando seus benefícios estiverem mais bem documentados e as técnicas e ferramentas necessárias para se alcançar os benefícios estiverem mais refinadas.

Muito tem sido escrito sobre Gerenciamento da Cadeia de Suprimentos nos últimos anos e, apesar de várias divergências, um princípio parece ser comum: o sucesso depende da habilidade em identificar as mudanças no ambiente competitivo e então estruturar os recursos da cadeia para ajudar a empresa a competir de maneira eficiente. Em outras palavras, este sucesso depende da adaptabilidade da empresa, e toda a cadeia, a um mercado intenso e competitivo (FAWCETT et al., 2007).

Nesse contexto, cada empresa deve fornecer a cadeia de suprimentos capabilidades e recursos com o objetivo de trazer mais rapidamente ao mercado novos produtos e serviços, ao menor custo possível, com as características certas e com o melhor valor agregado. $\mathrm{O}$ futuro espera uma cadeia de suprimentos internacional e enxuta (GUNASEKARAN et al., 2001).

Entre as várias soluções expostas pelos diversos autores para o correto gerenciamento da cadeia de suprimentos, uma das mais importantes é o compartilhamento de informações entre os membros da cadeia, que será abordada no tópico seguinte. 


\subsection{Compartilhamento de informação}

\subsubsection{A necessidade de informação}

Segundo Fawcett et al. (2007), a informação apresenta-se como um grande diferencial competitivo. Ela substitui estoques, acelera desenvolvimento de novos produtos, encurta ciclos de preenchimento de pedidos, direciona processos de reengenharia e coordena atividades da cadeia de suprimentos. Ainda segundo os autores, dentre todos os recursos que uma empresa administra, a informação tem talvez recebido a maior atenção, sendo considerada primordial para a implementação de suas estratégias na cadeia.

Para Chopra e Meindl (2003), a informação é crucial para o desempenho de uma cadeia de suprimentos, pois é o alicerce sobre o qual os gerentes de cadeia de suprimentos estruturam suas decisões. Sem informação, não sabe o que os clientes querem, quanto estoque está armazenado e qual o momento de produzir ou embarcar mais produtos. Assim, as informações fazem com que a cadeia de suprimentos seja visível aos seus gerentes, podendo tomar decisões mais acertadas, melhorando o desempenho de suas empresas e da cadeia de suprimentos como um todo.

Ainda, segundo os autores, para determinar os níveis de estoque são necessárias informações dos clientes sobre a demanda, informações de fornecedores sobre disponibilidade e informações sobre os níveis atuais de estoque, custos e margens. A determinação das políticas de transporte requer informações sobre clientes, fornecedores, rotas, custos, tempos e quantidades a serem transportadas. As decisões sobre instalações exigem informações sobre fornecedores e demanda, assim como dados sobre capacidades, receitas e custos da empresa. Nesse sentido, pode-se dizer que a informação é o aspecto mais importante da cadeia de suprimentos sem a qual nenhum dos outros aspectos conseguiria proporcionar um alto nível de desempenho.

\subsubsection{A falta de informação e suas conseqüências}

De acordo com Bayraktar et al. (2008), muitas técnicas de previsão de demanda se baseiam em dados históricos e assumem a validade de padrões das demandas passadas para o futuro próximo. Devido ao alto grau de sensibilidade das previsões para os valores dos períodos mais recentes, esta abordagem, em geral, produz distorções entre a demanda real e as previsões. Na prática, as previsões de demanda raramente são exatas e tornam-se ainda pior em níveis mais elevados da cadeia de suprimento, isto é, nos elos iniciais da cadeia. $\mathrm{Na}$ 
maioria das cadeias de suprimento, cada elo individual tentar racionalizar suas quantidades pedidas de acordo com lotes econômicos de compras, criando uma distorção sobre a verdadeira demanda dos clientes e fazendo com que a informação chegue alterada nos elos iniciais da cadeia de suprimento. Promoções e alterações de preços também contribuem para a distorção da demanda. Como cada elo realiza sua previsão da demanda, os erros são amplificados, ocorrendo o chamado "efeito chicote" ao longo de toda a cadeia.

\subsubsection{O Efeito chicote}

Segundo Lee et al. (1997), o efeito chicote também conhecido como efeito Forrester, whiplash ou whipsaw, acontece na manufatura quando informações sobre a demanda dos clientes para qualquer produto tornam-se cada vez mais distorcidas, movendo-se contra o fluxo de produtos na cadeia de suprimento. Em outras palavras, os pedidos de uma empresa aos seus fornecedores tendem a ter uma maior variação do que os pedidos dos clientes para a empresa, tornando a demanda dos clientes distorcidas. Esta distorção aumenta a medida que os pedidos são passados para os elos anteriores da cadeia.

Para Dhahri e Chabchoub (2007), o "efeito chicote" (Bullwhip Effect), é uma distorção na demanda do mercado (cliente final), quando esta demanda se propaga deste o varejo até o início da cadeia (fornecedor de matérias-primas), onde este último elo recebe informações incertas da real demanda do mercado.

De forma semelhante, Chopra e Meindl (2003), discorrem que com o efeito chicote, a variabilidade dos pedidos é amplificada em cada elo da cadeia, partindo do varejista em direção aos fornecedores dos fabricantes e, de acordo com Stadler e Kilger (2005), surpreendentemente, esse fenômeno também ocorre mesmo que a demanda de itens finais esteja razoavelmente estável. A ilustração 16 demonstra o efeito chicote. 


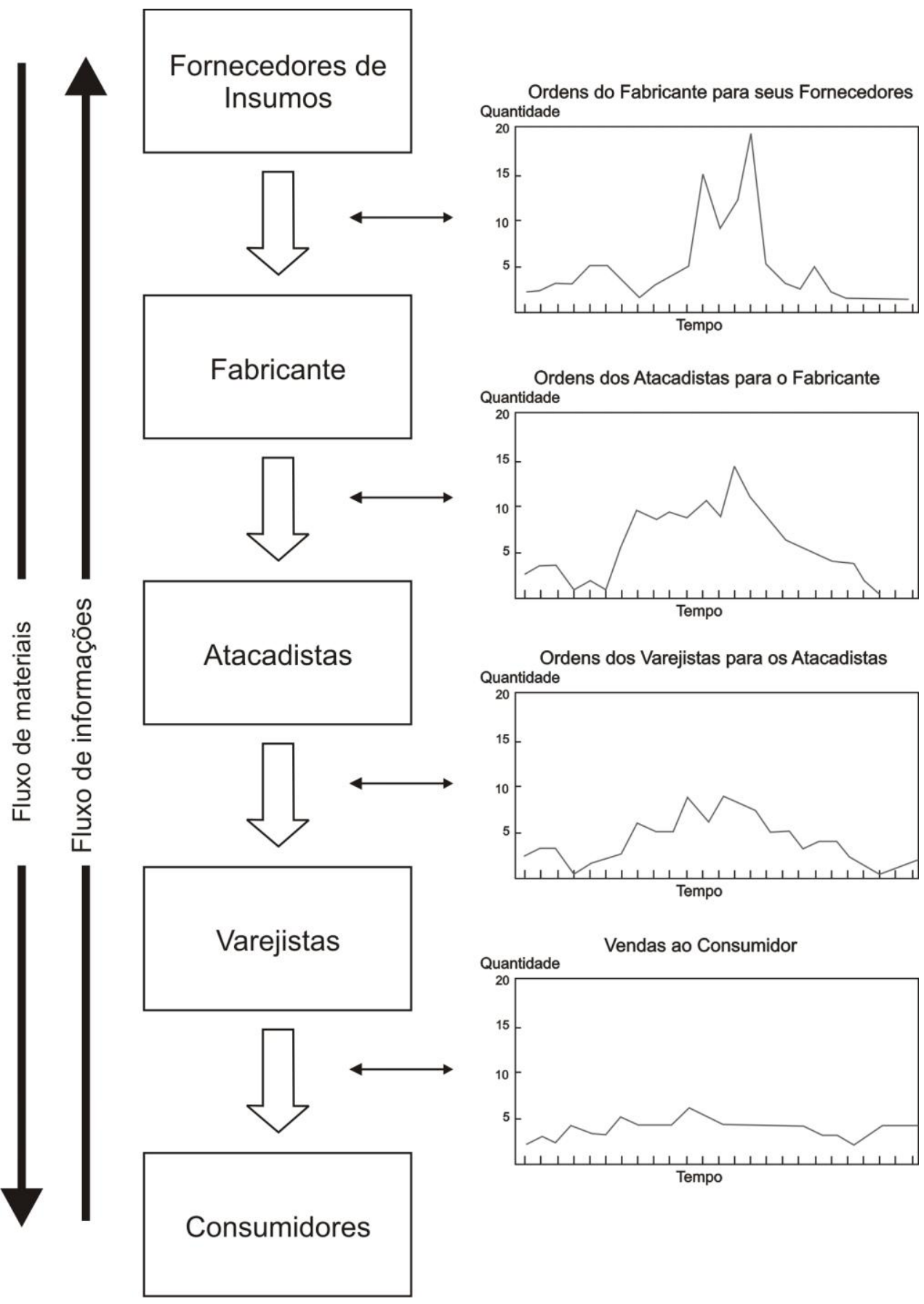

Ilustração 16 - $O$ efeito chicote

FONTE: CHOPRA; MEINDL, 2003

\subsubsection{Causas do efeito chicote}

Bayraktar et al. (2008) citam que o efeito chicote foi primeiro notificado e estudado por Jack Forrester em uma série de análises por simulação. Ele nomeou este problema como "amplificação de demanda" (ou demanda amplificada) e concluiu ainda que o problema do efeito chicote surgia devido as características do próprio sistema, com suas políticas, estrutura 
organizacional e atrasos entre os fluxos de material e de informação, não dependendo de forças externas.

Ainda Bayraktar et al. (2008) citam a utilização do "jogo da distribuição de cerveja" ("beer distribution game") para o estudo do efeito chicote, onde observou-se que a má percepção das informações de retorno e reação irracional dos decisores (decision makers) em um complexo sistema, acabavam por criar informações distorcidas. As dificuldades que as pessoas têm para perceber o impacto de suas decisões de pedidos devido à complexidade do sistema e o tempo elevado entre encomendar e receber acabam gerando o efeito chicote.

Lee et al. (1997), no entanto, indicam que efeito chicote está presente, mesmo se todos os membros da cadeia de suprimentos comportassem de maneira ótima, a menos que a cadeia seja redesenhada com interações estratégicas diferentes. Seus estudos salientam que o efeito chicote deriva principalmente de quatro fatores: previsão de demanda, lote de pedidos, alterações nos preços, e racionamento e escassez de recursos.

Para Cooper et al. (1997), várias são as causas para o aparecimento do efeito chicote: lead time longo, utilização de várias técnicas de previsão, flutuação dos preços e descontos por volume comprado e transportado.

Geary et al. (2006) enfatizam algumas variáveis: falta de sistemas de controle, tempos elevados de atividade na cadeia, baixo grau de transparência de informação, vários número de elos e falta de sincronização.

Também Sahin e Robinson (2002) afirmam que as causas da amplificação da demanda (efeito chicote) são: variações sazonais do varejo, flutuações aleatórias de vendas, políticas de promoção e desconto, limitações de capacidade da fábrica ocasionando excesso de pedidos em tempos de escassez, lead-time do ciclo de pedido atrasando a transmissão das informações de demanda em tempo hábil e compras tradicionais e políticas de estoque reagindo em excesso perante as mudanças ocorridas nos padrões da demanda.

De acordo com Stadler e Kilger (2005), a causa principal do efeito chicote se deve ao fato de que cada entidade faz uso de informações disponíveis localmente enquanto toma suas decisões de compra para enfrentar as demandas. Outra característica importante é o tempo de 
demora entre a tomada de decisão (ex: encomendar) e sua realização (ex: recebimento da remessa correspondente).

\subsubsection{Conseqüências do efeito chicote}

Lee et al. (1997) afirmam que a distorção de informações gerada pelo efeito chicote gera estoques excessivos, previsões menos acuradas, capacidades ociosas ou insuficientes, e geralmente custos mais elevados ao longo de todo o sistema.

Para Chopra e Meindl (2003), o efeito chicote distorce as informações na cadeia de suprimentos levando estágios diferentes a fazer análises muito distintas sobre a demanda, gerando como resultado a falta de coordenação entre a cadeia. Eles ainda complementam as consequiências citadas pelos autores anteriores adicionando a diminuição do nível de serviço aos clientes (devido à falta de produtos) e, conseqüentemente, a redução de lucratividade (devido às vendas perdidas).

Conforme Dhahri e Chabchoub (2007), o efeito chicote conduz a várias mudanças invisíveis nos processos e no comportamento pessoal. Em seus estudos, os autores afirmam que ineficiência e ineficácia podem aparecer em diferentes formas, tais:

- Investimento excessivo em estoques por toda a cadeia de suprimento como revendedores, distribuidores, operadores de logística e produtores, que necessitam salvaguardar-se contra as variações;

- Níveis baixos de serviços aos clientes causados pela falta de produtos em alguma parte da cadeia, devido à variabilidade e meios insuficientes para enfrentar as variações;

- Vendas perdidas decorrentes da escassez causada pelas variações;

- A produtividade do capital investido em instalações operacionais fica abaixo do esperado, com as vendas perdidas;

- Os tomadores de decisão (decisions-makers) reagem às flutuações da demanda e fazem novos investimentos ou mudam os planos de capacidade em função do pico de demanda. Estas decisões são provavelmente erradas, pois os picos de demanda são irreais e podem ser eliminados por meio das reorganizações da cadeia;

- Variações de demanda provocam variações na cadeia logística, causando mais uma vez flutuações na utilização da capacidade planejada de transporte, gerando novamente uma gestão não otimizada de transporte, aumentando assim seus custos. 
Ainda segundo Chopra e Meindl (2003), várias são as conseqüências do efeito chicote, podendo-se citar:

- Custo de fabricação - o efeito chicote aumenta os custos de fabricação, pois os fabricantes e seus fornecedores tentam satisfazer a remessa dos pedidos que é mais variável do que a demanda real dos clientes finais;

- Custo de estoque - o feito chicote aumenta os custos de estoque, pois para lidar com a crescente variabilidade da demanda é necessário manter um nível mais alto de estoque do que seria necessário se não houvesse esse efeito;

- Lead time de ressuprimento - o efeito chicote prolonga os leads times de ressuprimento da cadeia. A crescente variabilidade resultante do efeito chicote torna os cronogramas da empresa e de seus fornecedores muito mais difíceis de serem seguidos em comparação com uma situação de demanda mais estável. Há períodos em que a capacidade e os estoques disponíveis não são capazes de atender aos pedidos, gerando assim lead times mais longos na cadeia, tanto da empresa quanto de seus fornecedores;

- Custo de transporte - o efeito chicote aumenta o custo de transporte da cadeia de suprimentos. Como conseqüência do efeito chicote, as exigências de transporte oscilam significativamente, acarretando um aumento no custo do transporte, pois a capacidade excedente de transporte precisa ser mantida para dar conta de períodos de alta demanda;

- Custo de mão-de-obra para embarque e recebimento - o efeito chicote eleva os custos de mão-de-obra associados a embarque e recebimento na cadeia. As necessidades de mão-de-obra para embarque e/ou recebimento, tanto na empresa quanto em seus fornecedores e clientes (atacadistas e varejistas), oscilam de acordo com os pedidos. Assim, os diversos estágios têm a opção de manter o excesso ou variar a capacidade de mão-de-obra de acordo com as oscilações e, portanto, impactando em um aumento no custo total;

- Nível de disponibilidade do produto - o efeito chicote prejudica o nível de disponibilidade do produto, pois a grande oscilação dos pedidos torna mais improvável que a empresa seja capaz de satisfazer aos pedidos de todos os clientes (distribuidores e varejistas), aumentando as chances desses distribuidores e varejistas 
sofrerem escassez de estoque e, conseqüentemente, levando à perda de vendas na cadeia de suprimentos e

- Relacionamento na cadeia de suprimentos - o efeito chicote influencia negativamente o desempenho de cada elo da cadeia, prejudicando assim os relacionamentos entre eles. Há uma tendência de culpar os outros elos, pois as pessoas envolvidas em cada elo acreditam que estão fazendo o melhor possível, o que leva a uma perda de confiança entre os elos e dificulta a coordenação.

\subsubsection{Eliminando o efeito chicote}

Assim, como o efeito chicote é um problema comum entre muitas empresas líderes, a capacidade para identificar e quantificar as suas causas leva a uma série de sugestões para reduzir ou eliminar o seu impacto.

Para Lau et al. (2008), a escolha das políticas de estoques, o aumento do compartilhamento de informações e o comprometimento dos parceiros com pedidos iniciais são freqüentemente citados como recursos eficazes para se alcançar uma melhor coordenação da cadeia e suavizar o efeito chicote.

Também para Sahin e Robinson (2002), as possíveis estratégias para gerenciar o efeito chicote são: encurtar o lead-time do ciclo do pedido, compartilhar os dados dos pontos de venda dos varejistas com todos os membros da cadeia e alterar os procedimentos de controle de estoque para fornecer uma correção mais gradual perante as mudanças de demanda.

\subsubsection{Compartilhando as informações}

Tradicionalmente, os varejistas tomam suas próprias decisões de reposição de estoques baseados em suas previsões de demanda e estrutura de custos (ex: custos de manutenção de estoques e custos de pedidos). Muitos dos problemas associados ao gerenciamento da cadeia de suprimentos, como o efeito chicote, podem ser atribuídos à deficiência no compartilhamento de informações entre os vários membros (elos) da cadeia (LAU et al., 2008).

Para Fawcett et al. (2007), compartilhamento da informação é o elemento fundamental das colaborações empresarias e do gerenciamento da cadeia de suprimentos. Também Trkman et al. (2007) afirmam que as informações devem estar prontamente disponíveis para todas as 
empresas na cadeia, e os processos empresariais devem ser estruturados de forma a permitir o pleno uso dessas informações.

Segundo Chopra e Meindl (2003), a estratégia de uma cadeia de suprimentos é bem sucedida quando a cadeia é vista como um todo e não como estágios individuais fragmentados. Para que isso aconteça, as empresas pertencentes a essa cadeia precisam de informações precisas e periódicas sobre todas as funções e organizações da empresa na cadeia sendo, portanto necessário o compartilhamento de informações entre elas.

Para Mentzer,Min et al. (2000), o compartilhamento de informações na cadeia de suprimentos refere-se à amplitude que informações críticas e particulares são comunicadas para uma empresa parceira na cadeia.

De acordo com Zhou e Benton (2007), três aspectos são relevantes para um correto compartilhamento de informações:

- Qualidade das informações - mensura o grau em que as informações trocadas entre empresas satisfazem as suas necessidades. Em seus estudos eles detectaram várias características importantes sobre a qualidade das informações sendo elas: precisão (exatidão), credibilidade, relevância, facilidade de acesso, integridade, aceitação, freqüência de obtenção e informações sempre atualizadas;

- Conteúdo das informações - o conteúdo das informações pode ser classificado como informações do fornecedor, informações do produtor, informações do consumidor, informações do distribuidor e informações do varejista. Basicamente pode-se destacar dois fluxos de informações: as informações que os produtores compartilham com seus consumidores (informações do produtor) e as informações que os consumidores compartilham com seus produtores (informações do consumidor) e

- Tecnologias de apoio ao compartilhamento de informações - as aplicações emergentes de Tecnologia de Informação (TI) para o gerenciamento da cadeia de suprimentos podem ser classificadas dentro de três categorias. A primeira categoria é a execução da cadeia de suprimentos, que foca em atividades diárias de curto prazo, tais como gestão de armazenagem, gestão de transporte e produção colaborativa. A segunda categoria é o planejamento da cadeia de suprimentos, que foca-se em atividades de médio e longo prazo. E finalmente a terceira categoria é a gestão da execução da cadeia de suprimentos, que liga as duas primeiras. 
Para Thonemann (2002), o compartilhamento da informação é um ponto significante para o aperfeiçoamento do gerenciamento da cadeia de suprimentos. Para ele, as práticas típicas de compartilhamento de informações incluem: programações de produção, previsões de demanda e dados dos pontos de venda. Ainda segundo o autor, a integração de tais fluxos de informação pode exigir tarefas com um alto nível de complexidade.

Segundo Sahin e Robinson (2002), o compartilhamento de informações pode ocorrer em vários níveis. Em um nível do tipo "não compartilhamento de informações" a única demanda de dados que o fornecedor recebe são pedidos dos seus clientes imediatos. Já no nível de "total compartilhamento de informações", as informações estão disponíveis completamente para apoiar o ambiente de tomada de decisões. Entre esse dois extremos pode-se ter um nível intermediário denominado "compartilhamento parcial de informação".

Já para Bowersox et al. (2007), para atingir um alto grau de cooperação na cadeia, é necessário que os participantes compartilhem não apenas dados de transações, mas sim informações estratégicas, como por exemplo informações sobre planos futuros de cada uma.

\subsubsection{Tipos e características das informações}

Devaraj et al. (2007) denominam o compartilhamento das informações de "integração de informações". Para eles, o compartilhamento das informações pode ser dividido em:

- Informações orientadas para a demanda - são compostas por: compartilhamento em tempo real dos dados dos pontos de vendas, previsão de vendas, perfil dos consumidores e gerenciamento do relacionamento com os clientes e

- Informações orientadas para o fornecimento - são compostas por: políticas de ressuprimento, nível de estoque e plano mestre de produção.

Ainda para os autores, o compartilhamento das informações varia de empresa para empresa, dependendo do nível de integração, por meio da Internet, entre a empresa e seus clientes e fornecedores, variando de pouca ou nenhuma integração até integração total entre as partes.

Para Chantrasa (2005), existem muitos tipos de informações compartilhadas em uma cadeia de suprimentos, incluindo dados de vendas, níveis de estoque, especificações de produtos, previsão de vendas e capacidade, programação e custos de produção. Essas informações 
compartilhadas podem variar de acordo com os tipos de organizações e suas formas de relacionamento.

O autor ainda comenta algumas "filosofias" associadas à essas informações. Com relação as informações de estoques, o Programas de Reabastecimento Contínuo (Continuous Replenishment Programs - CRP) ou o Estoque Gerenciado pelo Fornecedor (Vendor Managed Inventory - VMI) podem ser utilizados.

Segundo Simatupang e Sridharan (2002), os dados, que são compartilhados mais freqüentemente, incluem a disponibilidade de recursos (ex: capacidade, estoques e competências), o tipo de desempenho (ex: tempo, qualidade, custos e flexibilidade), os tipos dos processos (ex: previsão, pedidos, entregas, reabastecimento e serviços) e o tipo do contrato. Para os autores, o avanço da tecnologia da informação, como a Internet, permite que esses dados possam ser coletados e transferidos em tempo real ou sob demanda. Assim, uma maior visibilidade da cadeia de suprimentos é a chave para melhorar o desempenho de todo sistema.

Segundo Sahin e Robinson (2002), entre os tipos de informações, pode-se citar: status e custos de produção, disponibilidade de transporte e descontos por quantidade, dados da demanda de todos os membros do canal, custos e níveis de estoque, capacidade disponível e estratégias promocionais planejadas.

Para Chopra e Meindl (2003), o tipo de informação a ser compartilhada depende da estratégia adotada pela empresa, entre produção "puxada" ou "produção" empurrada. Os sistemas empurrados normalmente exigem uma informação em forma de sistemas elaborados de Planejamento das Necessidades de Materiais (MRP) para acompanhar ao máximo a programação da produção e reduzir seu custo e também criando para os fornecedores as programações de tipos de peças, quantidades e prazos. Por outro lado, os sistemas puxados exigem uma informação sobre a demanda real a ser transmitida com extrema agilidade por toda a cadeia de suprimentos para que a produção e a distribuição dos produtos possam refletir a demanda real com precisão.

Os autores ainda dividem as informações necessárias em uma cadeia de suprimentos nos seguintes itens básicos, que correspondem a diferentes estágios da cadeia de suprimentos: 
- Informações do fornecedor - informações sobre que produtos podem ser comprados, a que preço, com qual lead time e onde podem ser entregues. Incluem também informações sobre a situação do pedido, as modificações e os modos de pagamentos.

- Informações de fabricação - informações sobre quais produtos podem ser fabricados, em quantidade, em quais instalações, com qual lead time, a que custo e em lotes de qual tamanho.

- Informações de distribuição e varejo - informações sobre o que deve ser transportado, de qual lugar, em que quantidade, por qual meio, a que preço, quando e onde deve ser armazenado e com qual lead time.

- Informações sobre a demanda - informações de quem está comprando, o que está comprando, a qual preço, onde e qual quantidade. Incluem também as informações sobre previsão e distribuição da demanda.

Para que possam ser úteis nas tomadas de decisões a respeito da cadeia de suprimentos, Chopra e Meindl (2003) afirmam que as informações devem ter as seguintes características:

- As informações devem ser precisas - informações pouco precisas podem tornar inviável a tomada de decisões corretas. Assim, as informações devem criar uma imagem da realidade que esteja, no mínimo, inclinada à precisão;

- As informações devem estar acessíveis no tempo certo - para tomar boas decisões, o gerente precisa de informações atualizadas e de fácil acessibilidade. Muitas vezes existem informações precisas, mas no momento em que se tornam acessíveis já estão defasadas ou, quando são atualizadas, não se encontram accessíveis e

- As informações devem ser úteis - muitas vezes as empresas possuem grande quantidade de dados que não colaboram para a tomada de decisão. Assim, as empresas devem analisar quais informações devem ser registradas para que fontes valiosas não sejam desperdiçadas com dados insignificantes e para que os dados realmente importantes não passem despercebidos.

Convém discorrer a seguir sobre alguns possíveis benefícios do compartilhamento das informações, bem como os problemas e dificuldades e as possíveis soluções para um correto compartilhamento. 


\subsubsection{Benefícios do compartilhamento da informação}

Para Lau et al. (2008), o compartilhamento de informações sobre demanda e estoques tem mostrado melhorar as decisões de quantidades pedidas para os fornecedores em modelos de cadeia de suprimento com uma demanda conhecida e fixa.

Devaraj et al. (2007) comentam alguns benefícios do compartilhamento das informações. As informações da previsão de demanda dos clientes geram uma maior visibilidade aos fornecedores, facilitando assim suas compras de matéria prima e o planejamento de suas capacidades. As informações advindas do compartilhamento da programação da produção entre fabricantes e seus fornecedores reduzem a incerteza de previsão e possibilitam uma produção mais detalhada e no prazo correto. As informações dos estoques dos clientes tornam a programações da produção dos fabricantes mais precisas, como também melhores embarques de produtos.

Ainda, segundo os autores, existem fortes evidências sugerindo que altos níveis de integração de informações dentro de uma cadeia de suprimento estão associados a um grande benefício potencial para as empresas.

Em seu trabalho, Chantrasa (2005) levantou vários benefícios obtidos pelo compartilhamento de informações em uma cadeia de suprimentos, como: redução de custos de estoques e de falta de estoques, redução do "efeito chicote", aperfeiçoamento da função de compras, melhor alocação de estoques e aperfeiçoamento do relacionamento e da confiança de parceiros. $\mathrm{O}$ autor fez um levantamento sobre os vários possíveis benefícios trazidos pelo compartilhamento de informações, classificando em "casos gerais de compartilhamento de informações", "parcerias e alianças estratégias" e "tecnologia da informação e implementação de sistemas". O quadro 6 resume tais benefícios.

Quadro 6 - Benefícios do compartilhamento de informações

\begin{tabular}{|c|l|}
\hline Categoria & \multicolumn{1}{|c|}{ Benefícios do Compartilhamento de Informações } \\
\hline & - Melhora a lucratividade total da cadeia; \\
& - Aumenta o valor ao consumidor; \\
& - Reduz os custos da cadeia (ex: custos de manutenção de estoques e custos de \\
atrasos na entrega); \\
Casos gerais de & - Facilita a coordenação da cadeia; \\
compartilhamento & - Reduz o comportamento oportunista dos parceiros; \\
de informações & - Promove confiança e comprometimento entre os parceiros; \\
& $\begin{array}{l}\text { - Melhora o nível do serviço; } \\
\text { - Reduz quantidades excessivas de pedidos aos produtores; }\end{array}$ \\
& - Possibilita melhores decisões sobre alocação da capacidade; \\
& - Promove eficiência na alocação de produtos aos produtores; \\
& - Melhora as decisões de compras; \\
\hline
\end{tabular}




\begin{tabular}{|c|c|}
\hline Categoria & Benefícios do Compartilhamento de Informações \\
\hline & $\begin{array}{l}\text { - Diminui a ansiedade sobre o número de produtos recebidos do fornecedor; } \\
\text { - Melhora o planejamento e programação da produção contra possíveis faltas }\end{array}$ \\
\hline $\begin{array}{l}\text { Parcerias e alianças } \\
\quad \text { estratégicas }\end{array}$ & $\begin{array}{l}\text { - Aumenta a estabilidade de demanda do mercado; } \\
\text { - Melhora os níveis de lucratividade; } \\
\text { - Aumenta a estabilidade de suprimento; } \\
\text { - Reduz tempo de setup; } \\
\text { - Melhora o layout por processos; } \\
\text { - Melhora o design de produtos; } \\
\text { - Aumenta a captura de dados; } \\
\text { - Reduz os custos de seleção de fornecedores e de negociação; } \\
\text { - Melhora a qualidade de encomendas e da entrega de produtos; } \\
\text { - Aumenta a comunicação; } \\
\text { - Aumenta a resolução de conflitos; } \\
\text { - Diminui a probabilidade de comportamentos oportunistas dos parceiros; } \\
\text { - Aumenta o acesso a novos mercados; } \\
\text { - Promove relacionamentos mais próximos com parceiros estratégicos }\end{array}$ \\
\hline $\begin{array}{l}\text { Tecnologia da } \\
\text { Informação e } \\
\text { implementação de } \\
\text { sistemas }\end{array}$ & $\begin{array}{l}\text { - Reduz o lead time de entrega; } \\
\text { - Reduz custos de transação; } \\
\text { - Facilita a programação da produção e entrega mais eficiente; } \\
\text { - Reduz níveis de estoques devido a falta de ciclos de pedidos; } \\
\text { - Diminui os erros de transação; } \\
\text { - Melhora o relacionamento com parceiros comerciais; } \\
\text { - Aumenta as vendas e a participação de mercado }\end{array}$ \\
\hline
\end{tabular}

FONTE: CHANTRASA, 2005

\subsubsection{Problemas e dificuldades no compartilhamento da informação}

Para Fawcett et al. (2007), o velho ditado, “informação é poder” permanece no mundo dos negócios nos dias atuais. Como resultado, muitos indivíduos não estão abertos a dividir informações que eles julgam que poderia colocar suas empresas em desvantagens competitivas. Assim, um grande volume de preciosas informações, que poderiam aumentar a capacidade de tomada de decisões, permanece guardado e indisponível, impossibilitando um melhor fluxo das operações.

Nesse contexto, os autores identificaram quatro barreiras que impedem um melhor compartilhamento das informações, A primeira barreira é a complexidade e o custo dos sistemas avançados (tecnologias) para compartilhar informações. Uma segunda barreira é a incompatibilidade dos sistemas. A terceira barreira são os diferentes níveis de conectividade existentes dentro de uma cadeia. A última barreira é a falta de compreensão dos gerentes na importância e benefícios do compartilhamento das informações.

Harland et al. (2007), em suas pesquisas com base em vários autores, relatam as possíveis barreiras à integração de informações na cadeia de suprimentos. Entre elas estão: falta de alinhamento estratégico (estratégias divergentes) entre as empresas, tamanho diferente entre as empresas, falta de consciência dos benefícios potenciais, falta de motivação e atuar em um setor (ou contexto regional) pouco desenvolvido. 
De acordo com Simatupang e Sridharan (2002) um dos problemas relativo às informações é a assimetria de informação. Informações assimétricas referem-se a diferentes partes possuindo diferentes estados de informações privadas sobre condições da demanda, produtos e operações da cadeia. O problema das informações assimétricas surge porque as empresas participantes geralmente "seguram" o conhecimento necessário sobre suas intenções e planos mútuos para harmonizar adequadamente seus serviços e atividades. Os membros da cadeia freqüentemente não querem compartilhar suas informações privadas completamente e fielmente com todos os outros membros, devido ao valor econômico (atual ou percebido) dessas informações. Como resultado, a cadeia de suprimentos sofre de decisões não-ótimas e de comportamento oportunista.

De maneira complementar, Simchi-Levi et al. (2003) afirmam que decisões não-ótimas ocorrem quando os membros não possuem visibilidade suficiente para resolver várias implicações na tomada de decisão porque a falta de informações faz com que as decisões sejam tomadas em um âmbito estreito, que não garante que os produtos fluam propriamente para os consumidores finais.

Simatupang e Sridharan (2002) ainda acrescentam que, com o compartilhamento de informações limitado, os membros não possuem percepções consistentes das necessidades do mercado e visibilidade sobre o desempenho nos outros níveis da cadeia. Conseqüentemente, as decisões são tomadas baseando-se na melhor estimativa dos dados disponíveis.

Segundo Chantrasa (2005) o compartilhamento de informações pode ser arriscado. Os riscos do compartilhamento de informações incluem a perda de poder para com os parceiros, a possibilidade de um parceiro revelar informações importantes para a concorrência, os altos custos de participar de um sistema de informações inter-organizacional e deixar-se influenciar por informações não confiáveis e imprecisas. Além disso, o sucesso do compartilhamento de informações é incerto devido a questões delicadas, como o comportamento de parceiros e consumidores e a gestão da tecnologia usada no compartilhamento de informações.

Ainda, para o autor, devido à importância associada com os benefícios e riscos do compartilhamento de informações, as organizações de uma cadeia podem ter dificuldades 
para decidir se elas deveriam compartilhar informações com seus parceiros ou quais tipos de informações deveriam ser compartilhados.

De maneira semelhante aos benefícios, o autor fez um levantamento sobre os vários possíveis riscos trazidos pelo compartilhamento de informações. O quadro 7 resume tais riscos.

\section{Quadro 7 - Riscos do compartilhamento de informações}

\begin{tabular}{|c|c|}
\hline Categoria & Riscos do Compartilhamento de Informações \\
\hline $\begin{array}{l}\text { Casos gerais de } \\
\text { compartilhamento } \\
\text { de informações }\end{array}$ & $\begin{array}{l}\text { - Aumenta os custos de aquisição de informações; } \\
\text { - Traz a possibilidade de informações não-confiáveis e imprecisas; } \\
\text { - Parceiros podem voluntariamente revelar informações para a concorrência; } \\
\text { - Requer alto nível de confiança entre parceiros; } \\
\text { - Perda de privacidade; } \\
\text { - Perda da integridade de dados }\end{array}$ \\
\hline $\begin{array}{c}\text { Parcerias e alianças } \\
\text { estratégicas }\end{array}$ & $\begin{array}{l}\text { - Impede todas as outras oportunidades possíveis; } \\
\text { - Produtores podem ser sensíveis a qualquer sinal de inadequação nos produtos; } \\
\text { - Parceiros podem não satisfazer as especificações (incompetência dos } \\
\text { parceiros); } \\
\text { - Aumenta a negligência dos parceiros; } \\
\text { - Perda do controle da parceria; } \\
\text { - Perda de conhecimentos competitivos; } \\
\text { - Reduz o controle, a flexibilidade e a eficiência da administração; } \\
\text { - Incompatibilidade de culturas, objetivos e habilidades técnicas; } \\
\text { - Competição no lugar da cooperação; } \\
\text { - Altos custos de desenvolvimento de relacionamentos }\end{array}$ \\
\hline $\begin{array}{l}\text { Tecnologia da } \\
\text { Informação e } \\
\text { implementação de } \\
\text { sistemas }\end{array}$ & $\begin{array}{l}\text { - Altos custos de adoção de tecnologia da informação; } \\
\text { - Custos de manutenção do sistema; } \\
\text { - Maior dependência dos parceiros; } \\
\text { - Aplicações EDI mudam rapidamente; } \\
\text { - Requer adaptações à múltiplas especificações padrões das indústrias }\end{array}$ \\
\hline
\end{tabular}

FONTE: CHANTRASA, 2005

\subsubsection{Soluções para o compartilhamento da informação}

Para Fawcett et al. (2007), a maior parte das empresas ainda precisam descobrir como equilibrar o compartilhamento das informações com suas estratégias. Eles identificaram algumas ações que poderiam ser utilizadas: balancear o uso da tecnologia com o conhecimento humano na toma de decisão; diagnosticar corretamente a necessidade da empresa e a tecnologia a ser adotada; combinar tecnologia com as capabilidades da empresa; entender os três elementos da tecnologia (processos, pessoas e medidas de desempenho) e investir proativamente em uma cultura de compartilhamento de informações. 
Também para Welker et al. (2008), o compartilhamento de informação é um catalisador para uma melhor coordenação e planejamento da cadeia de suprimentos. Este compartilhamento pode ser facilitado por avanços nas tecnologias de informação e comunicação (por exemplo, maior poder de processamento de informação permite compartilhamento de informação em tempo real), que em alguns casos pode ser visto como uma condição necessária para se atingir uma integração de cadeia de suprimentos.

\subsubsection{Conclusões sobre o compartilhamento de informações}

Zhou e Benton (2007) trazem como conclusão de seus estudos alguns princípios básicos sobre o papel do compartilhamento das informações no gerenciamento da cadeia de suprimentos: o compartilhamento eficaz de informações, bem como a prática eficaz da cadeia de suprimentos são condições necessárias para se conseguir uma melhora no desempenho da cadeia. Quanto mais alto é o nível de compartilhamento de informações, maior é a chance da cadeia de suprimentos alcançar um desempenho superior.

Para Fawcett et al. (2007) o compartilhamento das informações é condição necessária para o aumento de desempenho da cadeia de suprimentos, e esse compartilhamento é diretamente influenciado pelas culturais organizacionais e pela disposição e vontade dos gerentes em compartilhar suas informações. Porém, nota-se que a disposição e vontade são negligenciadas e mal interpretadas, recebendo pouca atenção gerencial e pouco investimento. Por outro lado, alguns líderes no gerenciamento da cadeia estão começando a quebrar esta barreira, demonstrando que quando o compartilhamento e a disposição em dividir informações caminham juntas, as empresas podem atingir grandes benefícios.

Assim, fica claro que o compartilhamento das informações é um dos fatores importantes a ser considerado para o correto gerenciamento da cadeia de suprimentos. Fica claro também que o uso da tecnologia de informação, que será abordada no tópico seguinte, é um dos principais facilitadores do compartilhamento das informações. 


\subsection{A importância dos sistemas e tecnologias de informação}

\subsubsection{Sistemas de Informação (SI)}

Laudon e Laudon (2006) definem um Sistema de Informação (SI) como sendo um conjunto de componentes inter-relacionados, que trabalham juntos para coletar, recuperar, processar, armazenar e distribuir informação com a finalidade de facilitar o planejamento, o controle, a coordenação, análise e o processo decisório em empresas e outras organizações.

Para O'brien (2004) um Sistema de Informação depende dos recursos humanos (incluem os usuários finais e os especialistas em SI), de hardware (consistem em máquinas e mídia), software (programas e procedimentos), dados (banco de dados e bases de conhecimento) e redes (mídia e redes de comunicação) para executar atividades de entrada, processamento, produção, armazenamento e controle, que convertem recursos de dados em produtos de informação.

Segundo Laudon e Laudon (2006), dependendo do tipo de problema organizacional, assim como os níveis de informação e decisão na empresas obedecem à hierarquia empresarial, os Sistemas de Informação servem a diferentes funções e diferentes níveis organizacionais. Neste contexto, os autores sugerem quatro níveis: Estratégico, Tático e Operacional, conforme pode ser observado na ilustração 17.

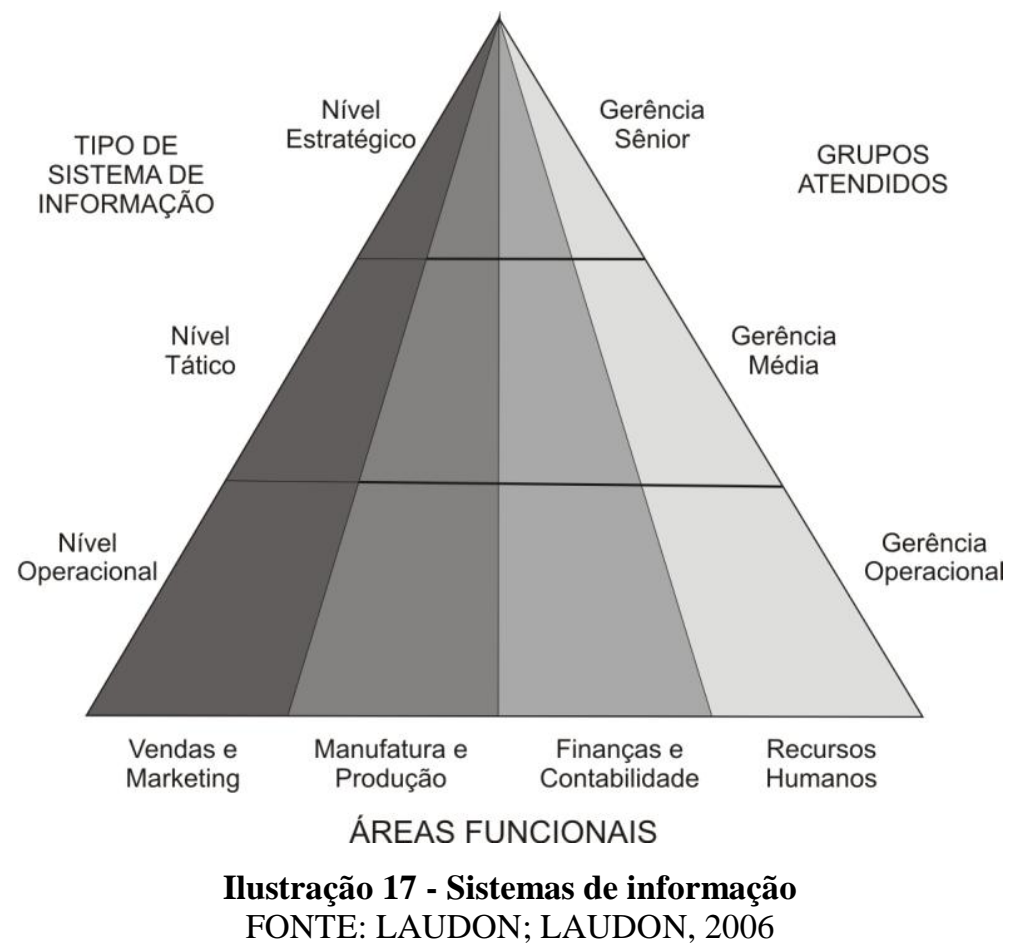


As características de cada um desses níveis são:

- Nível estratégico - auxiliam a alta gerência na determinação de estratégias, definições de objetivos empresariais e no planejamento de longo prazo. Geralmente são conhecidos como Sistemas de Suporte a Executivos (SSE ou ESS - Executive Support System);

- Nível tático ou gerencial - usados para o monitoramento, controle e avaliação dos recursos para atingir os objetivos e metas empresariais e para tomada de decisão. Geralmente são conhecidos como Sistemas de Informações Gerenciais (SIG ou MIS Management Information System) e Sistemas de Apoio à Decisão (SAD ou DSS Decision Support System) e

- Nível operacional - monitoram as atividades e transações elementares da empresa, envolvendo o registro e monitoramento das atividades rotineiras necessárias para conduzir o negócio. Geralmente são conhecidos como Sistemas de Processamento de Transações (STP ou TPS - Transaction Processing Systems).

De forma semelhante ao modelo de Sistema de Informação proposto por Laudon e Laudon (2006), onde existem níveis hierárquicos, Bowersox et al. (2007) propõem o Sistema de Informações da Cadeia de Suprimentos (Supply Chain Informations Systems - SCIS). Para eles, os SCIS são fios que ligam as atividades logísticas a um processo integrado sendo que essa integração se dá em quatros níveis:

- Sistemas de transação - caracterizado por regras formais, comunicações e procedimentos padronizados;

- Controle gerencial - focaliza a avaliação do desempenho e seu relatório;

- Análise de decisões - focaliza as ferramentas de software para dar assistência aos gerentes na identificação, avaliação e comparação das alternativas estratégicas e táticas da cadeia de suprimentos e de logística para a melhoria da efetividade, e

- Planejamento estratégico - organiza e sintetiza os dados de transações de uma ampla gama de modelos de planejamento dos negócios e de tomada de decisões.

A ilustração 18 mostra o Sistema de Informações da Cadeia de Suprimentos. 


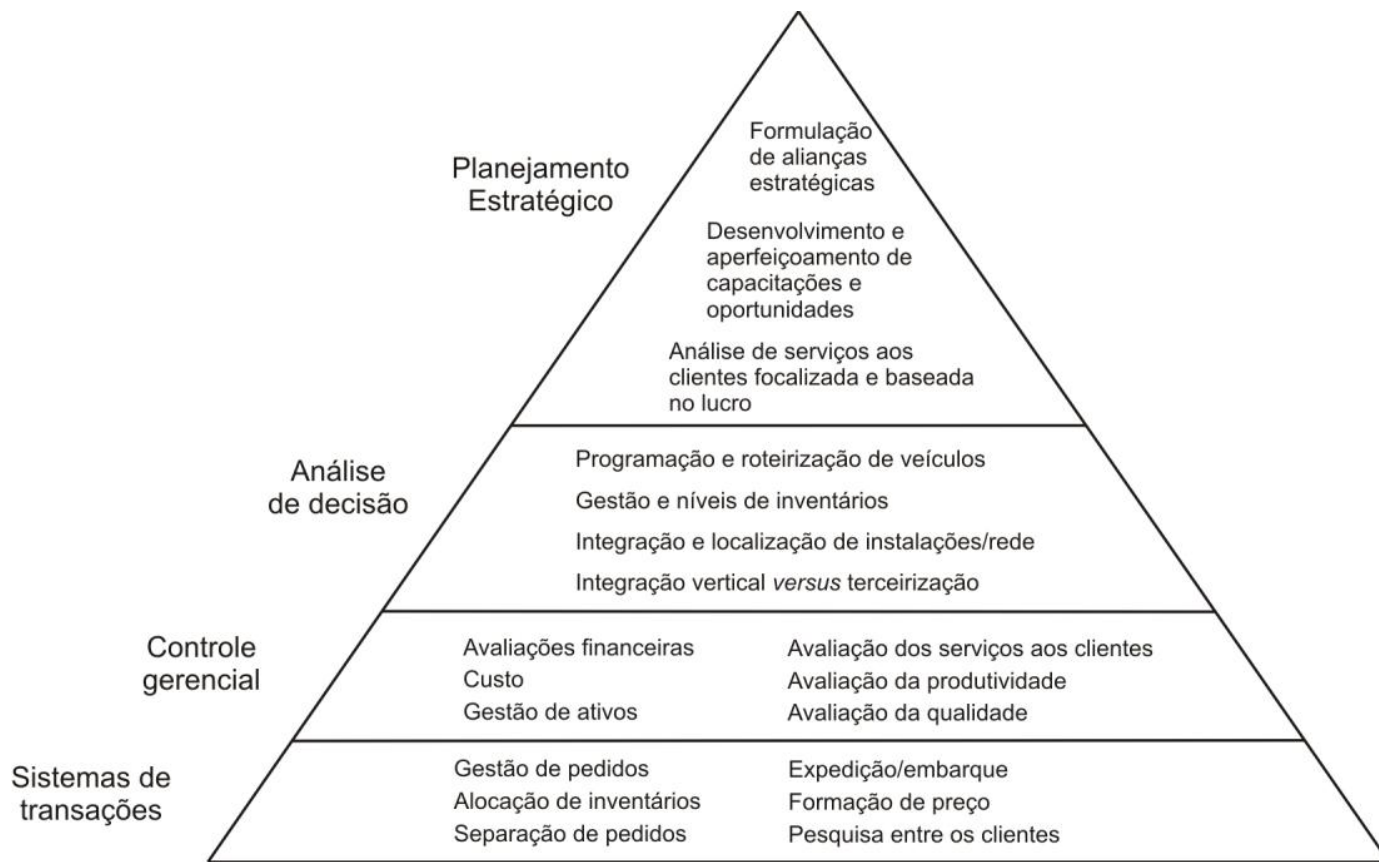

Ilustração 18 - Sistema de informações da cadeia de suprimentos FONTE: BOWERSOX, 2007

Com base no SCIS, o autor define seus quatro componentes: (1) Planejamento de Recursos Empresariais (ERP), (2) Sistemas de Comunicação, como por exemplo, a Internet, a Transferência Eletrônica de Dados (Electronic Data Interchange - EDI), o Código de Barras e a Identificação por Radiofrequiência (Radio-Frequency IDentification - RFID), (3) Sistemas de Execução, como por exemplo o Sistema de Gerenciamento de Transportes (Transport Management System - TMS) e o Sistema de Gerenciamento de Armazéns (Warehouse Management System - WMS) e (4) Sistemas de Planejamento.

Para Chopra e Meindl (2003), os sistemas de tecnologia da informação são muito importantes em todo estágio da cadeia de suprimentos, pois permitem que as empresas reúnam e analisem as informações. Assim, eles atuam como os "olhos e ouvidos" dos gerentes da cadeia, recebendo e enviando as informações necessárias para uma boa decisão, sendo que seu uso pode exercer um impacto muito significativo no desempenho das cadeias.

De acordo com Mclaren et al. (2002), para reduzir as ineficiências em uma cadeia de suprimentos, as empresas estão cada vez mais usando sistemas de informação para integrar os sistemas e processos ao longo de toda cadeia. 
Nesse contexto, surgem os sistemas de informação no intuito de compartilharem as informações entre as empresas, os chamados Sistemas de Informação Inter-organizacional (Interorganizational Information Systems - IOIS ou IOS). De acordo com Hadaya e Cassivi (2007), os IOS foram propostos pela primeira vez no início da década de 1980, quando os pesquisadores Barrett e Konsynski os usaram para referirem-se a um sistema automatizado de informações compartilhado entre duas ou mais empresas. Os IOISs são redes de computadores que dão apoio às trocas de informações além dos limites da empresa e permitem a integração eletrônica de transações e processos de negócios efetuados por duas ou mais empresas. A troca eletrônica de dados (EDI - Electronic Data Interchange) é provavelmente a tecnologia usada mais comum, permitindo a troca de informações entre parceiros de negócios.

Agan (2005), com base em diversos autores, define os sistemas de informação interorganizacionais (IOS) com sendo os sistemas automatizados que ligam uma empresa com seus fornecedores, clientes ou distribuidores e possibilitando a troca de informações além dos limites da empresa, facilitando a troca de produtos e serviços e aumentando a vantagem competitiva das empresas.

Também para Saeed (2004), os IOS são sistemas de informação compartilhados por duas ou mais empresas. Exemplos de tais sistemas incluem sistemas de troca eletrônica de dados (Electronic Data Interchange - EDI), "extranets", sistemas de gerenciamento da cadeia de suprimentos, sistemas de compras e sistemas de comércio eletrônico. Estes módulos são implementados em conjunto para formar um sistema abrangente de forma a dar suporte a diferentes atividades das empresas e das atividades das empresas com seus fornecedores.

Para Seidmann e Sundararajan (1997), geralmente as empresas associam os sistemas de informação inter-organizacionais (IOS) e o compartilhamento de informação como sendo orientados para o aumento da eficiência operacional por meio da redução dos custos de pedido e de estoques e da redução do lead time de suprimento.

Para Mclaren et al. (2002), o desejo de compartilhar informações e promover uma gestão colaborativa da cadeia de suprimentos faz com que as empresas, cada vez mais, adotem Sistemas de Informação Inter-organizacional (Interorganizational Information Systems - IOS) 
para a colaboração da cadeia. Os autores classificaram os sistemas que dão apoio a esses vários graus de coordenação e colaboração da cadeia em de três tipos principais:

(1) sistemas baseados em mensagens que transmitem informações para as aplicações dos parceiros usando tecnologias como fax, e-mail, EDI ou mensagens XML (eXtensible Markup Language);

(2) centros de compras eletrônicas ou portais que facilitam a compra de bens ou serviços por meio de catálogos eletrônicos, propostas ou leilões;

(3) sistemas compartilhados de gerenciamento colaborativo da cadeia de suprimentos que incluem o planejamento colaborativo, a previsão e as capacidades de reabastecimento, além da funcionalidade das compras eletrônicas.

\subsubsection{Tecnologia da Informação (TI)}

Para Russ e Camp (1997), a tecnologia de informação, que fez o mundo se tornar uma aldeia global através de transferências "na velocidade da luz" de dados e arquivos, é uma das principais forças motrizes na integração da cadeia de suprimentos. Através da Internet, um simples arquivo de dados pode ser acessado simultaneamente por entidades separadas fisicamente. Embora as primeiras aplicações de TI fossem usadas para dar suporte seguro à transferência de relatórios comerciais, os aplicativos foram estendidos eventualmente para a gerência de logística

Para Zhou e Benton (2007), durante os últimos dez anos, a gestão da cadeia de suprimentos e a gestão da tecnologia da informação têm atraído muita atenção de profissionais liberais e pesquisadores. Conforme a tecnologia da informação evolui, as empresas tendem a tornar-se mais integradas.

Segundo Chopra e Meindl (2003), a Tecnologia da Informação (TI) consiste em ferramentas (hardwares e softwares) utilizadas para obter e ter acesso às informações e para analisá-las, de maneira a poder tomar as melhores decisões.

Chantrasa (2005) afirma que a Tecnologia da Informação (TI) é uma importante viabilizadora para uma gestão eficaz da cadeia de suprimentos. Para o autor, devido aos ciclos de vida dos produtos cada vez menores, a TI torna-se necessária para dar apoio aos processos logísticos. Também o autor ressalta que muito do interesse atual na gestão da cadeia de suprimento é 
motivado pelas possibilidades que são introduzidas pela abundância de dados e pelas economias inerentes às análises sofisticadas desses dados.

Também para Fawcett et al. (2007), avanços ocorridos na tecnologia de informação têm mudado a prática dos negócios modernos, tornando possível a colaboração no gerenciamento das cadeias de suprimentos. Para eles, para as empresas responderem eficientemente às novas mudanças elas devem estar sempre atentas às informações de seus ambientes e tomarem decisões rápidas. Por esta razão, as empresas estão investindo altos montantes em tecnologia de informação para aumentar suas habilidades em administrar informação e todo o conhecimento dentro de uma cadeia de suprimentos.

Em seu estudo, Agan (2005), com base em outros autores, levantou pontos importantes sobre as tecnologias de informação aplicadas a cadeia de suprimentos. Para o autor, a tecnologia de informação tem reduzido os custos de coordenação e os riscos associados com as relações interorganizacionais. Além disso, ele considera que toda a cadeia de suprimentos está baseada na tecnologia de informação. Por meio da TI, clientes e fornecedores podem se comunicar de maneira rápida e as informações ajudam tornam as tomadas de decisões mais eficientes. Assim, a TI interliga as empresas de uma cadeia, tornado a rede mais coordenada e unificada, propiciando um aumento na qualidade, uma redução nos prazos de entrega e custos e, principalmente, uma maior vantagem competitiva da empresa.

As tecnologias de informação têm uma função central no gerenciamento da cadeia de suprimentos, possibilitando coletar, analisar e disseminar as informações entre os membros da cadeia a fim de melhorar as tomadas de decisões. Ao conectar os administradores dentre os limites funcional e organizacional, e prove-los com informações relevantes, precisas e atualizadas a tecnologia reduz as distancias tanto temporal quanto espacial tornando-os capazes de tomar decisões melhores, com maior embasamento e colaboração (FAWCETT et al., 2007)..

Power (2005), também conclui que a tecnologia de informação é elemento essencial para o gerenciamento da cadeia de suprimentos. Para o autor, a aplicação eficaz de tecnologia de informação para integrar as atividades de cadeia de suprimento tem o efeito de diminuir níveis de complexidade entre as empresas 
Para Chopra e Meindl (2003), as TIs podem ser segmentadas na cadeia de suprimentos de acordo com os estágios da cadeia em que se concentram e com a fase de decisões da cadeia que são utilizadas. Essa classificação é dada por uma matriz onde o eixo vertical corresponde ao nível de funcionalidade que as TIs desempenham e o eixo horizontal corresponde aos estágios da cadeia de suprimentos. A ilustração 19 mostra esta matriz, já com as seguintes TIs consideradas pelo autor: Aplicativos de compras, Planejamento Avançado e Programação (Advanced Planning and Scheduling - APS), Planejamento de transportes e estoque, Execução de transporte e Sistemas de Gerenciamento de Armazéns (Warehouse Management System - WMS), Sistemas de gerenciamento de cadeia de suprimentos (Supply Chain Management - SCM), Aplicativos de Gestão de relacionamento com cliente (Customer Relationship Management - CRM) e Automação da força de vendas (Sales Force Automation - SFA), Planejamento da demanda e Sistemas integrados de controle da produção (Manufacturing Execution System - MES).

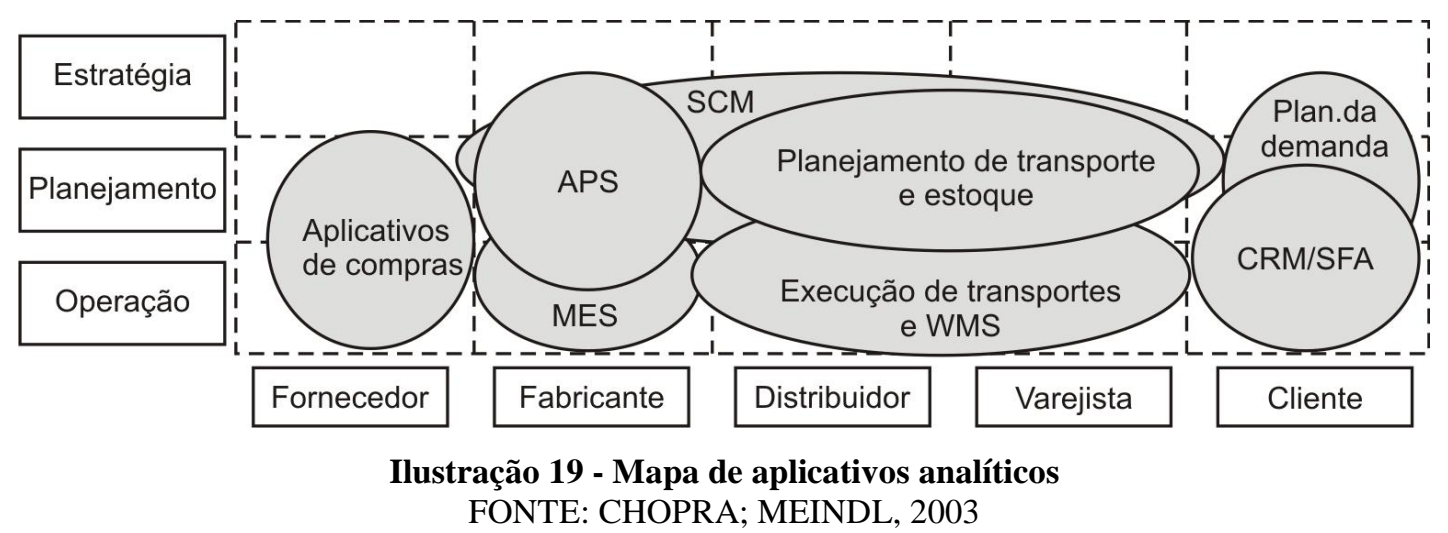

Por meio das tecnologias de informação, as empresas podem compartilhar informações com mais facilidade. Porém, para o correto gerenciamento da cadeia de suprimentos, as empresas devem se relacionar de maneira mais próxima. Torna-se necessário então desenvolver novos relacionamentos (que podem variar desde uma simples colaboração até uma integração total de estratégias e atividades), na busca de alcançar uma posição estratégica melhor e obter lucros mais elevados em comparação com outras cadeias de suprimento (FUENTE et al., 2008). Esses relacionamentos serão discutidos no tópico a seguir. 


\subsection{Relacionamentos na cadeia de suprimentos}

Para Searcy (2002), apesar de existirem várias teorias que estão em busca de explicar a natureza das relações entre as empresas, a abordagem de "Redes de Contatos" (Network) e a "Visão Baseada em Recursos" (Resource-Based View - RBV) parecerem melhor explicar a relação entre as empresas que estão implementando o Gerenciamento da Cadeia de Suprimento. A Visão Baseada em Recursos considera a cooperação vertical como fonte de recursos e capacitação. Cada empresa deveria focar nas suas competências e desenvolver alianças com as outras partes da Cadeia. Nesta teoria, as firmas devem focar no desenvolvimento interno de competências e confiar em seus parceiros da cadeia, construindo recursos e competências que ela não possui, porém necessita. Em outras palavras, as empresas deveriam tentar uma integração externa com outras empresas da cadeia, sendo isso vital para seu sucesso e também da cadeia de suprimento como um todo.

Segundo Agan (2005), a RBV pressupõe racionalidade e vê os gerentes como seres racionais, avaliando alternativas e tomando decisões que maximizem seus interesses próprios. Os recursos devem ser valiosos, difíceis de imitar, ou seja, insubstituíveis a ponto de gerarem vantagem competitiva. Os recursos podem ser elementos tangíveis (por exemplo, instalações e equipamentos) ou intangíveis (por exemplo, propriedade intelectual, imagem da marca, redes de contatos das empresas) e/ou recursos humanos, (cultura, know-how técnico, treinamento de funcionário, lealdade). No entanto, os limites entre tipos diferentes de recursos podem facilmente ser confundido. Enquanto componentes tangíveis são relativamente fáceis de serem imitados pelos concorrentes, componentes intangíveis e de recursos humanos são mais resistentes por causa de sua natureza ambígua.

Já para Skjoett-Larsen (1999), se a Visão Baseada em Recursos nos diz por que as relações na cadeia de suprimentos são formadas, a abordagem de Redes de Contatos nos diz como os relacionamentos da cadeia são estabelecidos e fortalecidos. Esta teoria inclui três componentes: atividades, atores e recursos, e seus relacionamentos mútuos. Os atores são empresas individuais que controlam seus próprios recursos. Esta abordagem foca nos processos de troca e adaptação entre as empresas em uma cadeia de suprimento. Os Processos de troca incluem todas as trocas entre as empresas, incluindo trocas sociais, administrativas e operacionais. Os processos de adaptação são as modificações mutuas necessárias para que as trocas ocorram, sendo as atividades de integração externa entre as empresas são exemplos 
desses processos. São por meio de processos de adaptação que os relacionamentos entre as empresas são fortalecidos e se tornam mais estáveis.

Para Fuente et al. (2008), a economia global tem mudado as regras de mercado entre empresas envolvidas em uma determinada cadeia de suprimentos. Torna-se necessário desenvolver novos relacionamentos colaborativos e cooperativos pela cadeia de suprimento, para aumentar o grau de integração, e com isso alcançar uma posição estratégica melhor e obter lucros mais elevados em comparação com outras cadeias de suprimento.

Segundo Chan e Qi (2003), atualmente, os fabricantes enfrentam uma crescente pressão das exigentes demandas dos consumidores referentes à customização, melhorias na qualidade e tempo de resposta. Por outro lado, eles precisam reduzir o custo de produção, diminuir o lead time e diminuir os níveis de estoque para assegurar a lucratividade. Para sobreviver sob estas pressões, mais e mais empresas estão se esforçando para desenvolver parcerias estratégias de longo prazo com alguns fornecedores competentes e colaborar com eles no desenvolvimento de produtos, controle de estoques e terceirização de processos.

De acordo com Yusuf et al. (2004), numa tentativa de conviver com a instabilidade dos mercados, as empresas devem olhar além dos custos e vantagens de qualidade. Velocidade, qualidade e flexibilidade estão sendo utilizadas como meio de resposta às necessidades únicas dos consumidores e dos mercados. Entretanto as competências e recursos necessários para atingir a ampla gama de objetivos são freqüentemente difíceis de serem alcançadas por uma empresa individualmente. Nestas circunstâncias, as empresas estão buscando cooperar e alavancar os recursos e competências básicas entre elas. Assim, as forças motrizes da integração da cadeia de suprimentos incluem avanços na tecnologia da informação, necessidades complexas do consumidor, intensa competição global e o desejo de serem os primeiros a comercializar produtos inovadores.

Para Chantrasa (2005), tradicionalmente, a maioria das organizações tem visto a si mesmas como entidades que existem independentemente de outras organizações e que precisam realmente competir com elas a fim de sobreviver. Entretanto, essa circunstância não pode continuar nos negócios dos dias atuais por causa da alta concorrência, de um ambiente global de negócios e da extraordinária explosão tecnológica. 
Assim, Lambert e Cooper (2000) afirmam que nesse emergente ambiente competitivo, o sucesso de um negócio dependerá da habilidade de gestão para integrar a complexa rede de relações de negócio de uma empresa, a qual leva à motivação da evolução contínua do gerenciamento da cadeia.

Segundo Agan (2005), uma premissa básica do gerenciamento de uma cadeia de suprimentos é que o relacionamento estreito entre os membros da cadeia pode dar a empresa, e a sua rede de fornecedores, vantagens competitivas em relação a outras cadeias por entregar um valor superior ao cliente através da redução de custos, aumento da qualidade e desempenho superior na entrega. Assim, o gerenciamento da cadeia envolve o desenvolvimento de estruturas interfuncionais e processos integrados de gerenciamento para as áreas de compras, produção e operações logísticas. O gerenciamento da cadeia de suprimentos tem conseguido levar os relacionamentos em direção a um patamar de colaboração e confiança dentro de uma cadeia de suprimentos.

Hadaya e Cassivi (2007) alegam que a forte concorrência entre as empresas e consumidores difíceis de satisfazer, recentemente tem forçado as empresas industriais a transformarem a forma pela qual elas se relacionam e fazem negócios com seus parceiros. A fim de melhorar seus desempenhos, os produtores têm sido induzidos a desenvolverem relacionamentos mais próximos com seus fornecedores e consumidores e a reduzirem sua base de fornecedores, de um amplo conjunto de diferentes fornecedores, para um número menor, que são tratados como parceiros.

Conforme os autores, sem uma forte colaboração entre os parceiros, seria impossível implementar as melhorias de processos (por exemplo: informação não distorcida sobre a demanda, introdução integrada de produtos e interrupção de produtos) que caracterizam uma cadeia de suprimentos.

Para Simatupang et al. (2002), a maior preocupação do gerenciamento da cadeia de suprimentos é como coordenar instituições independentes para que trabalhem juntos como um todo em busca de um objetivo comum de lucratividade em um mercado em constante mudança. 
Segundo Trkman et al. (2007), nos dias atuais, a colaboração entre diferentes empresas na cadeia de suprimentos é vital para o sucesso. Embora a importância das relações dentro de uma cadeia seja amplamente reconhecida, uma perfeita coordenação é raramente atingida na prática. Para que isso ocorra, a compreensão prévia dos processos empresarias e de seus objetivos futuros são cruciais.

Muckstadt et al. (2001) definiram quatro tipos de relacionamentos na cadeia de suprimentos. Esses relacionamentos são classificados de acordo com três dimensões: nível de integração dos sistemas de informação, nível de integração dos processos de negócio e nível de integração dos sistemas de decisão. A ilustração 20 mostra esses relacionamentos.

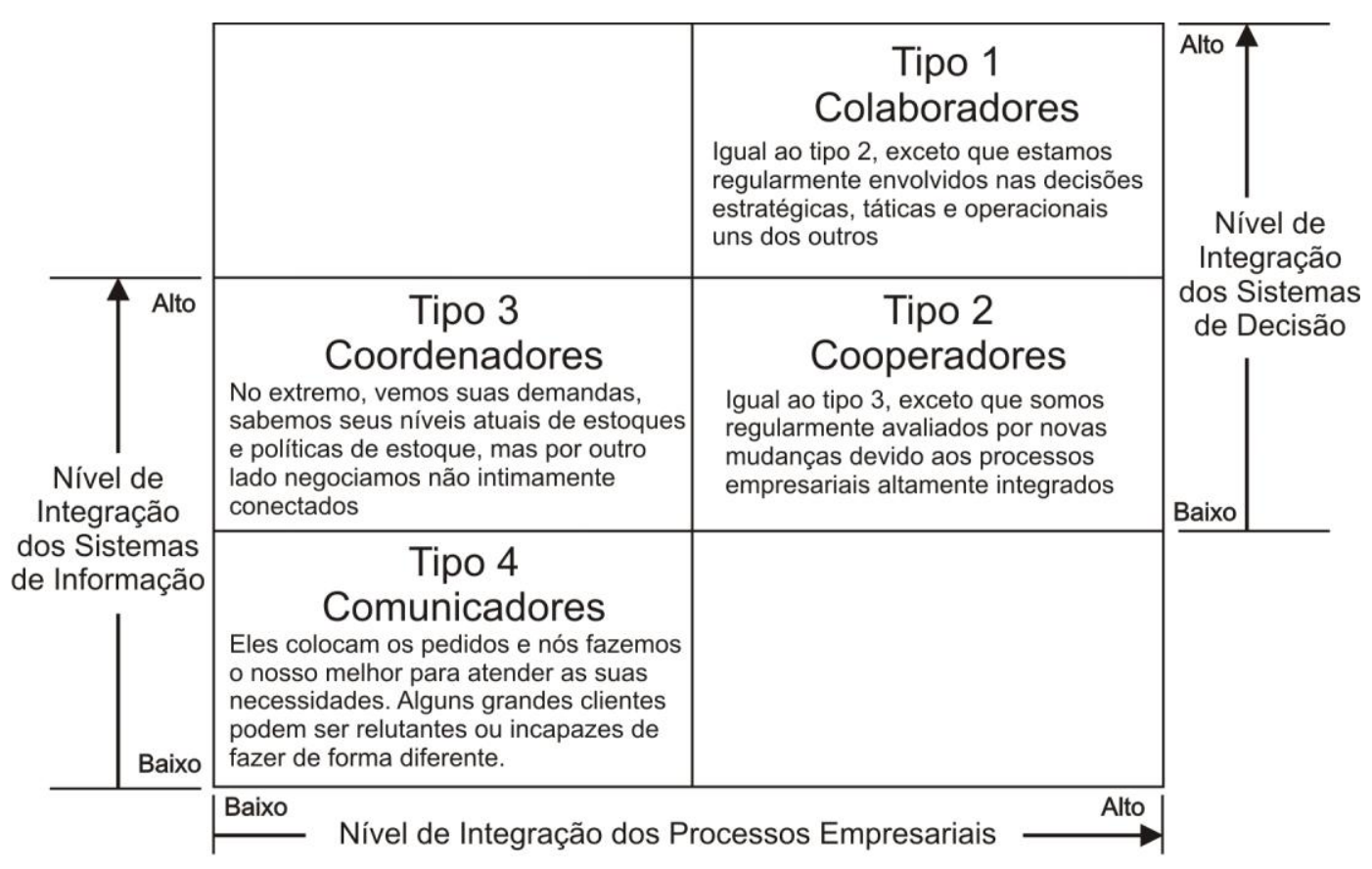

Ilustração 20 - Relacionamentos na cadeia de suprimentos FONTE: MUCKSTADT et al., 2001

- Tipo 4 (Comunicadores) - é o nível mais baixo de integração. Esse é um tipo básico de relacionamento, no qual os consumidores transmitem um pedido à empresa e esperam que ela responda a esse pedido dentro do lead-time solicitado;

- Tipo 3 (Coordenadores) - acontece quando os consumidores e uma empresa compartilham e capturam dados operacionais mais detalhados como nível de estoque, políticas de estoque e demanda dos consumidores finais; 
- Tipo 2 (Cooperadores) - ocorre quando a intensidade da integração dos processos de negócio aumenta. Nesse tipo de relacionamento, o consumidor deve comunicar planos que não são habituais, como por exemplo, o encerramento de fábricas ou unidades, diminuindo a capacidade por um período de tempo. Realizar esse nível de interação requer, de ambas as partes, uma infra-estrutura de informações e processos de apoios adequados e

- Tipo 1 (Colaboradores) - representa o nível mais alto de relacionamento. Nesse tipo de relacionamento, as empresas estão rotineiramente envolvidas nas decisões estratégicas, táticas e operacionais entre si. O plano de decisão será desenvolvido e executado colaboradoramente para se alcançar a máxima eficácia do sistema entre as empresas.

Para Ketchen et al. (2008), efetivamente integrar os participantes em uma cadeia de suprimentos é crucial para seu sucesso. Para eles, existem duas formas básicas de organizar as relações entre os participantes da cadeia de abastecimento:

- Cooperação - refere-se às relações contratuais, como a terceirização ou a subcontratação. Estas relações são altamente estruturadas, muitas vezes complexas e podem exigir intensa negociação. Os termos são definidos previamente e com detalhes. Uma cooperação eficaz, em forma de contratos bem concebidos pode garantir o correto alinhamento;

- Colaboração - refere-se a relacionamentos baseados na confiança e centrados em objetivos comuns. Nestas relações, cada parceiro vê o outro como uma extensão de si próprio, sendo um processo muito sofisticado, necessitando muito tempo e energia, porém de intensa aprendizagem.

Para Saeed (2004), os termos cooperação, colaboração, coordenação, parcerias e integração têm sido usados na literatura para capturar a noção de duas organizações trabalhando conjuntamente, desenvolvendo atividades para atingir objetivos que sejam comuns a ambas as organizações. Por outro lado, a integração da cadeia de suprimentos envolve empresas implementando processos de coordenação e rotinas de trabalho conjunto de forma a obter vantagens competitivas que não possa ser facilmente copiadas por outras cadeias concorrentes. 
Assim, apesar das divergências encontradas na literatura sobre os conceitos de parceria, coordenação, colaboração e integração, os tópicos seguintes abordam tais relacionamentos. Primeiro é apresentado o conceito de parceira que, segundo os autores, foca mais em uma relação diática (duas empresas) e, na seqüência, são apresentados os demais conceitos, focando a filosofia dão Gerenciamento da Cadeia de Suprimentos.

\subsubsection{Parcerias}

Para Porter (1985), a fim de otimizar toda a cadeia de suprimentos e não apenas criar uma otimização local em um ou dois parceiros, as empresas devem conjuntamente tomar decisões sobre fornecimento e demanda que criem um valor sustentável para todos os envolvidos. Conseqüentemente, muitas empresas estão cada vez mais desenvolvendo parcerias estratégicas com seus fornecedores e consumidores em um esforço para reduzir perdas em seus processos de aquisição e realização de pedidos.

Diante da realidade do gerenciamento da cadeia de suprimentos, parcerias ou alianças estratégicas têm recebido relevante atenção na literatura acadêmica. Ellram (1995) define parcerias como sendo um contínuo relacionamento entre duas empresas, o qual envolve um comprometimento em um longo período de tempo e um compartilhamento mútuo dos riscos e recompensas.

Para Gunasekaran et al. (2004), parcerias com fornecedores e alianças estratégicas referem-se aos relacionamentos cooperativos e mais exclusivos entre as empresas e seus fornecedores (a montante) e clientes (a jusante). Hoje em dia, muitas empresas têm tomado medidas ousadas para quebrar barreiras tanto inter e como intra-empresariais de forma a criar alianças, com o objetivo de reduzir a incerteza e de reforçar o controle dos canais de suprimento e distribuição.

Essas alianças são normalmente criadas para aumentar o desempenho financeiro e operacional de cada membro do canal através da redução de custos totais e também da redução de estoque, além de um aumento no compartilhamento de informações (MALONI; BENTON, 1997)

Segundo Zailani e Rajagopal (2005), o conceito da parceria na cadeia de suprimentos estende a perspectiva de operações de uma unidade de negócio isolada para toda a cadeia, no qual os 
relacionamentos são formados entre dois membros independentes, por meio de maiores níveis de compartilhamento de informações para alcançar os objetivos e benefícios em termos de redução nos custos totais e estoques. É um conjunto de práticas que visam à gestão e coordenação da cadeia de suprimentos desde os fornecedores de matérias-prima até o consumidor final gerando benefícios para todos os envolvidos.

\subsubsection{Passos para implementação de parcerias}

Para Zailani e Rajagopal (2005), segundo a literatura, espera-se que as parcerias de sucesso sejam caracterizadas por altos níveis de interdependência e para isso é necessário que exista confiança entre elas. Assim, Kumar et al. (2001) define que a confiança abrange dois elementos principais: (1) a confiança na confiabilidade do parceiro, que é a convicção que o parceiro cumpre sua palavra, cumpre as obrigações de seu papel prometido e é sincero e (2) a confiança na benevolência do parceiro, que é a convicção que o parceiro é interessado na prosperidade da empresa e não tomará ações imprevistas que afetarão negativamente a empresa.

Maloni e Benton (1997) sugerem alguns passos para a implementação de parcerias. O primeiro passo inclui a verificação estratégica da necessidade de uma parceria com fornecedores. A empresa deve avaliar os riscos e benefícios potenciais de uma parceria em comparação com processos tradicionais. Em seguida, critérios para parcerias potenciais são desenvolvidos e candidatos potenciais são avaliados. Uma vez que um parceiro é selecionado, o estabelecimento da atual parceria fornece o próximo passo crítico no qual os parceiros devem criar um senso de consciência sobre as necessidades e participações de todas as partes envolvidas. O último passo no processo de parceria inclui a manutenção do relacionamento, para melhorar seu desenvolvimento ou efetuar sua dissolvência. Ainda em seus estudos, os autores levantaram alguns elementos críticos para o sucesso da parceria, classificados de acordo com os passos anteriormente listados. O quadro 8 ilustra esses fatores críticos.

Quadro 8 - Passos para a implementação de parcerias

\begin{tabular}{|c|l|}
\hline Passo & \multicolumn{1}{c|}{ Fatores críticos } \\
\hline $\begin{array}{c}\text { Análise Estratégica } \\
\text { inicial }\end{array}$ & $\bullet$ Barreiras sociais e de atitudes \\
\hline $\begin{array}{c}\text { Avaliação e seleção de } \\
\text { fornecedores }\end{array}$ & • Barreiras estruturais e de procedimentos \\
\hline & - Compánios totais de custos e lucros \\
& - Estabilidade financeira \\
\hline
\end{tabular}




\begin{tabular}{|c|c|}
\hline Passo & Fatores críticos \\
\hline & $\begin{array}{l}\text { - Capacidades do parceiro } \\
\text { - Compatibilidade de gestão } \\
\text { - Localização }\end{array}$ \\
\hline $\begin{array}{l}\text { Estabelecimento da } \\
\text { parceria }\end{array}$ & $\begin{array}{l}\text { - Análise de percepção e necessidades } \\
\text { - Interação intensa } \\
\text { - Documentação }\end{array}$ \\
\hline Manutenção da parceria & $\begin{array}{l}\text { - Confiança } \\
\text { - Boa vontade } \\
\text { - Flexibilidade } \\
\text { - Habilidades de gestão de conflitos } \\
\text { - Troca social } \\
\text { - Limite de pessoal } \\
\text { - Mensuração do desempenho }\end{array}$ \\
\hline Em todas as fases & $\begin{array}{l}\text { - Apoio dos escalões mais altos } \\
\text { - Comunicação } \\
\text { - Coordenação central }\end{array}$ \\
\hline
\end{tabular}

FONTE: MALONI; BENTON, 1997

Monczka et al. (1998) detectaram em seus estudos alguns atributos relacionados com o sucesso de uma parceria. São eles: atributos das alianças (empenho; confiança e coordenação; interdependência), maneiras de comunicação (qualidade e participação; compartilhamento da informação), técnicas de resolução de conflitos (resolução conjunta de conflitos; persuasão; abrandamento; dominação; palavras severas; arbitrariedade) e processos de seleção de parceiros (avaliação de parceiros; seleção de itens comprados).

\subsubsection{Benefícios e riscos da parceria}

No trabalho realizado por Maloni e Benton (1997), foi levantada uma série de benefícios surgidos com as parcerias entre empresas e seus fornecedores. Entre eles pode-se citar: redução dos custos de transação, redução de esforços administrativos e de transferências, integração e coordenação de processos, descontos por quantidade, estabilidade da demanda (pelo comprador) e da oferta (pelo fornecedor), melhora no design de produtos, melhora na transferência de dados e melhor comunicação.

Por outro lado, Maloni e Benton (1997) também levantaram uma série de riscos: de diminuição da competitividade caso a parceria termine, frustração com relação ao parceiro caso ele não satisfação às expectativas, possível superestimação dos benefícios e possível influência do elo mais fraco pelo elo mais forte. 


\subsubsection{Coordenação}

De acordo com Bowersox et al. (2007), na perspectiva da cadeia de suprimentos, as relações entre as empresas passam de uma ligação frágil entre empresas independentes para um esforço coordenado entre empresas em busca de melhor eficiência e competitividade, guiadas por duas convicções: (1) o comportamento cooperativo reduzirá os riscos e aumentará a eficiência do processo logístico total e (2) serão eliminados o desperdício (entre eles a redução do estoque em toda cadeia) e os esforços repetidos.

Para Chopra e Meindl (2003), a coordenação ocorre quando todos os membros da cadeia de suprimentos trabalham com o objetivo de maximizar a lucratividade total em vez de cada membro se dedicar a sua própria lucratividade. A coordenação entre as empresas da cadeia exige que elas compartilhem informações relevantes entre si, sendo esse compartilhamento um fator crucial para o sucesso da cadeia. Por outro lado, a falta de coordenação pode resultar em uma perda significativa para toda cadeia.

Segundo Simatupang et al. (2002), a coordenação entre empresas independentes, como fornecedores de matéria-prima, distribuidores, provedores logísticos e revendedores, é a chave para atingir a flexibilidade necessária ao avanço dos processos de logística em resposta as rápidas mudanças de condições do mercado. Neste contexto, a coordenação da taxa de execução de pedidos para igualar ao consumo é sucesso ao ponto de vista dos clientes, atendendo a data de entrega aos clientes e custos logísticos. Por outro lado, uma coordenação ruim entre os elos da cadeia pode causar disfunções de desempenho operacional.

Os autores propõem uma classificação dos tipos de coordenação conforme ilustrado no quadro 9.

Quadro 9 - Tipos de coordenação

\begin{tabular}{|c|c|c|c|}
\cline { 3 - 3 } \multicolumn{2}{c|}{} & \multicolumn{2}{c|}{ Mutualismo de Coordenação } \\
\cline { 3 - 4 } \multicolumn{2}{c|}{} & \multicolumn{1}{c|}{ Complementaridade } & \multicolumn{1}{c|}{ Coerência } \\
\hline \multirow{2}{*}{$\begin{array}{c}\text { Foco da } \\
\text { coordenação }\end{array}$} & $\begin{array}{c}\text { Ligações } \\
\text { operacionais }\end{array}$ & $\begin{array}{l}\text { Sincronização logística } \\
\text { (Objeto: produtos/serviços e } \\
\text { logística de processos) }\end{array}$ & $\begin{array}{l}\text { Compartilhamento de } \\
\text { informações } \\
\text { (Objeto: informação) }\end{array}$ \\
\cline { 2 - 4 } & $\begin{array}{c}\text { Ligações } \\
\text { organizacionais }\end{array}$ & $\begin{array}{l}\text { Alinhamento de incentivos } \\
\text { (Objetos: benefícios e riscos) }\end{array}$ & $\begin{array}{l}\text { Aprendizado coletivo } \\
\text { (Objeto: conhecimento e } \\
\text { capacidade) }\end{array}$ \\
\hline
\end{tabular}

FONTE: SIMATUPANG et al., 2002

A classificação proposta considera duas dimensões: o mutualismo da coordenação e o foco da coordenação: 
- Mutualismo - o mutualismo de uma coordenação pode ser definido como sendo os valores subjacentes de responsabilidade entre os parceiros com uma forte ênfase em manter relacionamentos para que se tenha uma boa realização de objetivos efetivos. $\mathrm{O}$ mutualismo de coordenação é necessário para permitir aos membros da cadeia compartilhar entendimentos explícitos sobre a situação dos processos da cadeia de suprimentos (desde o começo ao fim) e o foco na melhora. $\mathrm{O}$ mutualismo pode ser dividido em complementaridade (como os membros da cadeia gerenciam coletivamente as interdependências entre as atividades logísticas para agregar valor aos clientes) e coerência (grau de consistência dos objetivos, visões, propostas e ações para atingirem metas comuns por meio de compartilhamento de informação aprendizado coletivo);

- Foco de coordenação - ligações existem quando as atividades feitas por um membro da cadeia de suprimentos afeta as atividades de outro. Portanto, ligações são as interfaces entre as empresas onde os membros da cadeia precisam coordenar suas decisões conjuntas. O foco de coordenação pode ser dividido em ligações operacionais (focam na integração de processos independentes e fluxos de informação que fornecem maneira dos parceiros fazerem os planejamentos logísticos e transações do dia a dia) e ligações organizacionais (consistem de atores interconectados que percebem e discutem sobre seus próprios interesses na realização de ações conjuntas).

Assim, como ilustrado no quadro anterior, quatro tipos de coordenação podem ser identificados baseados nas duas dimensões de coordenação: (1) sincronização logística; (2) compartilhamento de informação; (3) alinhamento de incentivos; e (4) aprendizado coletivo. Esses tipos são detalhados abaixo:

- Sincronização logística - significa reconhecer e implementar iniciativas de melhorias que significativamente contribuam para a criação de valor na compra, consumo e disposição de produtos e serviços no mercado. Este tipo de coordenação foca em igualar a variedade de produtos lançados no mercado com as necessidades dos consumidores. Entender a demanda dos consumidores e conciliar o gerenciamento de estoque e o transporte entre parceiros ajuda a fornecer uma resposta mais rápida às necessidades dos clientes, menores custos de estoque, melhor disponibilidade de produtos, obsolescência mínima e variância mínima de eventos não esperados como erros previstos e atrasos. A sincronização logística também permite aos membros participantes resolver conflitos de papéis, e então cada membro pode desempenhar 
tarefas especificas e assumir certas responsabilidades para assegurar a realização dos lucros da cadeia. Os reais desafios incluem focar em atividades principais que forneçam o real valor ao consumidor, e subordinar outras atividades de suporte para assegurar a geração de valor no processo;

- Compartilhamento de informação - este tipo de coordenação tenta manter informações relevantes, precisas e oportunas disponíveis aos tomadores de decisão. Membros da cadeia geralmente têm diferentes informações que comumente não são compartilhadas com outros (por exemplo, o varejista tem melhores informações de projeção de demanda dos consumidores do que o fabricante). Comunicação entre fabricante e varejista é feita por colocação periódica de pedidos em grandes lotes. Este comportamento de colocação de pedidos distorce informações originais de demanda, porque a variância das demandas se torna maior conforme a data do pedido percorre aos membros mais acima na cadeia. A visibilidade da data da demanda e estoque no ponto de vendas permite os membros mais acima na cadeia a atualizar as previsões e assegurar uma contínua reposição de produtos. Tecnologia de informação (TI) como a internet, intranet, softwares e sistemas de suporte a decisão podem ser aplicados para facilitar o compartilhamento de informações com consumidores e parceiros, e otimizar o desempenho da cadeia de suprimentos. A coordenação da coleta, processamento e disseminação da informação entre os membros da cadeia deve ser acompanhada por uma predisposição dos membros a usar informação compartilhada na execução de tarefas logísticas que contribuem para o desempenho financeiro e operacional;

- Alinhamento de incentivos - os incentivos definem como os tomadores de decisão devem ser recompensados ou penalizados pelas decisões que tomam. Incentivos existentes influenciam o comportamento individual do membro e suas interações com outros parceiros. Conflitos de interesse são prováveis de ocorrer quanto os incentivos existentes levam a ações que maximizam os ganhos pessoais, mas que freqüentemente reduzem a lucratividade total. Uma maneira de resolver tais conflitos de interesse é oferecer um esquema de incentivos ligados ao desempenho global, que reflete tanto a geração de valor para os consumidores e lucratividade. Este tipo de coordenação é chamado alinhamento de incentivos;

- Aprendizado coletivo - este tipo de coordenação lida com como resolver os problemas de coerência e difusão do conhecimento entre as empresas. Uma grande ênfase é feita no aprendizado prático de um com o outro para entender e criar capacidade tácita em implementar iniciativas de melhora logística. A coordenação de aprendizado coletivo 
não consiste somente de análise e síntese de melhoras, mas também incluem como assegurar a participação de colaboradores chaves na fase de implementação. Entre os vários meios de compartilhamento de conhecimento, pode-se citar a comunicação pessoal (reuniões, telefone, email, etc.), comunicações codificadas (relatórios, esquemas, etc.), treinamento e aprendizagem conjuntos.

Com base nessa classificação, os autores finalizam o modelo mostrando como os quatro tipos de coordenação levam a integração da cadeia de suprimentos por meio de quatro tipos de "laços". A ilustração 21 aborda essas relações.

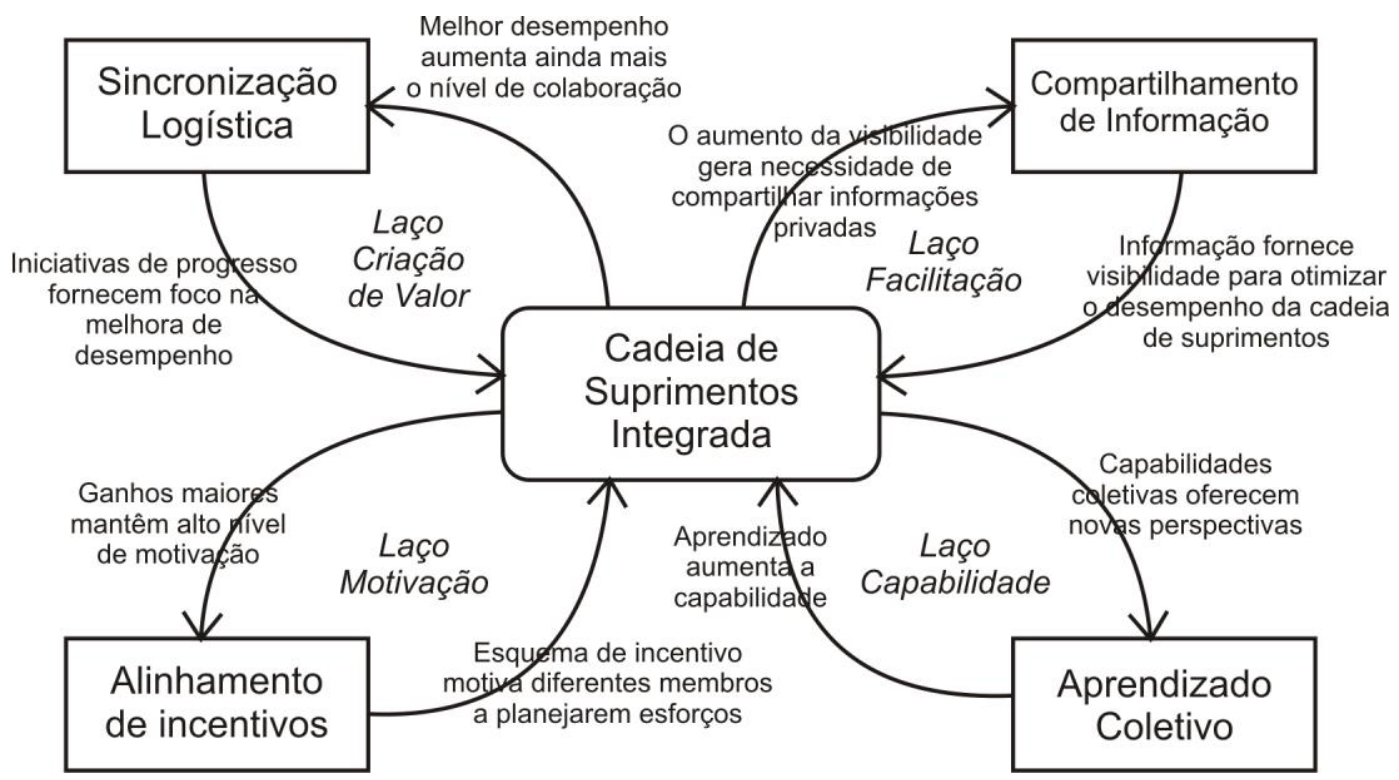

Ilustração 21 - Os quatro tipos de coordenação FONTE: SIMATUPANG et al., 2002

- Laço Criação de Valor - Empresas participantes coordenam os processos e as atividades logísticas para igualar a demanda e oferta. Espera-se que uma cadeia de suprimentos integrada resulte em uma melhora nos nível de serviço ao consumidor, menores custos e aumento de vendas. Melhores desempenhos resultantes de ações coordenadas aumentam os níveis de colaboração para melhorar a sincronização da logística;

- Laço Facilitação - Informação compartilhada possibilita a visibilidade permitindo tomar melhores decisões que otimizem a performance da cadeia de suprimentos. Deste modo, a visibilidade auxilia os membros da cadeia a integrar processos logísticos que podem ser otimizados para aumentar a velocidade de resposta para as mudanças ocorridas no mercado. Enquanto a visibilidade se intensifica entre os membros da 
cadeia, ela gera a necessidade de revelar mais informações privadas precisas e oportunas como dados de vendas, dados relacionados a custos e dados referentes a processos.

- Laço Capabilidade - o aprendizado coletivo pode aperfeiçoar a capacidade de implementar iniciativas de melhora. Entretanto, no aprendizado coletivo uma empresa ganha, mas também é preciso ceder. Além de preencher suas próprias lacunas, um parceiro deve contribuir com capacidades únicas para manter a influencia na cadeia de suprimentos. Uma cadeia de suprimentos coordenada permite aos membros participantes desenvolverem capacidades coletivas. Esta capacidade coletiva oferece nova compreensão sobre as oportunidades do mercado. Como resultado de um aprendizado coletivo, a confiança entre as partes começa a crescer e isto leva a uma melhora de desempenho;

- Laço Motivação - um esquema de incentivos é elaborado para motivar os membros da cadeia a alinhar decisões e ações em busca da lucratividade da cadeia de suprimentos. Assim, um certo nível de desempenho da cadeia que leve a benefícios mútuos é esperado. Alguns, ou todos os benefícios mútuos que resultam de melhores coordenações podem ser distribuídos em mais incentivos. Maiores ganhos de incentivos podem influenciar o comportamento dos tomadores de decisão para melhorar o desempenho da cadeia.

Para Sahin e Robinson (2002), uma cadeia de suprimentos é totalmente coordenada quando todas as decisões estão alinhadas para a realização dos objetivos globais da cadeia e, por outro lado, a falta de coordenação ocorre quando os tomadores de decisão têm informações incompletas ou incentivos que não são compatíveis com os objetivos globais da cadeia. Mesmo sobre condições de total disponibilidade de informações, o desempenho da cadeia pode ser menor que o ótimo quando cada empresa tenta otimizar seus próprios objetivos. Mecanismos de coordenação incluem estratégias de preço e sistemas de mensuração de desempenho.

Segundo Chopra e Meindl (2003), a coordenação da cadeia de suprimentos melhora se todos os estágios realizarem ações que, em conjunto, aumentem os lucros totais da cadeia. Assim, a coordenação da cadeia exige que cada estágio leve em consideração o impacto que suas ações exercem sobre os outros estágios. 
Ainda, segundo os autores, a falta de coordenação pode ocorrer tanto porque estágios diferentes da cadeia de suprimentos possuem objetivos conflitantes como também ao fato das informações que circulam entre os estágios são distorcidas. Com relação aos objetivos conflitantes, a falta de coordenação ocorre quando cada estágio da cadeia otimiza apenas seu próprio objetivo (como por exemplo seus lucros), sem considerar seu impacto na cadeia inteira. Isso pode levar a empresa a adotar medidas que acabam prejudicando a cadeia como um todo, podendo causar uma diminuição dos lucros totais dessa cadeia. Já pelo lado das informações distorcidas, é bastante comum que ocorra uma distorção das informações a medida que elas circulem pela cadeia, pelo fato de muitas vezes serem incompletas ou não são compartilhadas entre os diversos estágios. Essa distorção pode ser exacerbada quando uma cadeia produz uma ampla gama de produtos, tornando a coordenação da troca de informações um processo bastante difícil.

Também Lau et al. (2008) argumentam que a coordenação é indispensável para se reduzir estoques e neutralizar a incerteza da demanda em toda a cadeia de suprimentos.

\subsubsection{Barreiras e facilitadores da coordenação}

Para Chopra e Meindl (2003), qualquer fator que resulte na otimização de cada elo em separado ou que provoque um aumento na distorção e variabilidade de informações na cadeia pode ser considerado um obstáculo à coordenação. Entre esses obstáculos, pode-se citar:

- Obstáculos de incentivo - refere-se a situações em que os incentivos oferecidos a cada estágio (elo) levam a medidas que reduzem os lucros totais. Entre essas situações, pode-se citar um exemplo de força de vendas inadequadamente estruturada, onde as metas de vendas de um fabricante são estipuladas erroneamente em relação às vendas realizadas para seu cliente (geralmente atacadistas e varejistas) e não em relação ao cliente final;

- Obstáculos de processamento de informações - refere-se a situações em que as informações de demanda são distorcidas à medida que circulam entre os elos da cadeia. Pode-se citar a falta de compartilhamento de informações ou as previsões baseadas em pedidos de cada elo do canal e não na demanda real do cliente final (efeito chicote);

- Obstáculos operacionais - refere-se às ações realizadas no período entre a emissão e atendimento de pedidos. Pode-se citar a ocorrência de pedidos em grandes lotes (muito 
maior do que o normal, acarretando em períodos sem pedidos) e longos lead times de ressuprimento (nesse caso o efeito chicote torna-se ampliado);

- Obstáculos de preço - refere-se a situações em que políticas de preço de um produto levam ao aumento na variabilidade da emissão de pedidos. Pode-se citar os descontos por quantidade e promoções ou descontos de curto prazo;

- Obstáculos comportamentais - refere-se a problemas da atitude de cada elo, onde se pode citar: falta de confiança no parceiro, não aprendizagem da empresa com seus próprios erros e tendência em culpar a outra empresa pelas oscilações.

Por outro lado, os autores definem algumas iniciativas que facilitam a coordenação na cadeia. Algumas medidas podem ser tomadas para atingir a coordenação entre os elos da cadeia. Para eles, as medidas a seguir podem aumentar os lucros totais da cadeia e abrandar o efeito chicote:

- Alinhamento de objetivos e incentivos - os gerentes podem melhorar a coordenação na cadeia alinhando objetivos e incentivos de modo que cada elo trabalhe para maximizar os lucros totais;

- Melhoria na precisão das informações - a coordenação também pode ser melhorada por meio da melhoria na precisão das informações disponíveis nos diversos elos da cadeia, onde o compartilhamento dos dados sobre o ponto-de-venda e a implementação de previsões e planejamentos colaborativos são ações de grande importância;

- Melhoria no desempenho operacional - a melhoria do desempenho operacional pode ser uma boa medida gerencial para melhorar a coordenação. Neste ponto, ações como a redução do lead time de ressuprimento, o uso do intercambio eletrônicos de dados (EDI), o compartilhamento das informações e a redução nos tamanhos dos lotes são fatores a serem considerados;

- Planejamento de estratégias de preço para estabilizar os pedidos - os gerentes também podem reduzir o efeito chicote ao planejarem estratégias de preços que incentivem os varejistas a pedirem lotes menores e reduzirem a compra antecipada. Uma ação que poderia ser tomada neste caso é a mudança de descontos por quantidade no tamanho do lote (quantidade pedida em um único pedido) para descontos baseados em volume (quantidade pedido em um período, como por exemplo, um ano), ou também uma 
política de estabilização de preços, ambas as ações com a finalidade de tornarem os pedidos mais constantes (menor variabilidade) e

- Criação de parcerias estratégicas e confiança mútua - a criação de parcerias estratégicas e confiança na cadeia pode tornar as demais ações citadas anteriormente para a coordenação da cadeia mais fáceis de serem implementadas.

De forma semelhante, Kelle e Akbulut (2005), baseado na literatura, detectaram as dez maiores barreiras e os dez maiores facilitadores para a implementação da coordenação entre as empresas. Segundo os autores, as dez maiores barreiras são:

- Sistemas de informação inadequados;

- Mensurações conflitantes ou ruins;

- Objetivos operacionais inconsistentes;

- Cultura e estrutura organizacional;

- Resistência a mudança/falta de confiança;

- Práticas ruins de gerenciamento de alianças;

- Falta de visão de cadeia de suprimentos;

- Falta de comprometimento da diretoria;

- Recursos escassos;

- Falta de comprometimento dos funcionários.

Por outro lado, os dez maiores facilitadores são:

- Apoio da gerencia executiva e funcional;

- Compartilhamento honesto e aberto de informações;

- Mensurações corretas e precisas;

- Confiança, alianças sinérgicas;

- Alinhamento e racionalização da cadeia de suprimentos;

- Gerentes com experiência na cadeia;

- Processos de documentação e de posse;

- Educação e treinamento em conceitos de cadeia de suprimentos;

- Uso de conselheiros em cadeia de suprimentos;

- Uso efetivo de projetos piloto. 


\subsubsection{Colaboração}

Simatupang e Sridharan (2002) definem colaboração como sendo duas ou mais empresas independentes que trabalham juntas para planejar e executar operações da cadeia de suprimentos com maior sucesso do que tinham quando agiam isoladamente.

Também Forme et al. (2007) definem colaboração como um meio através do qual todas as empresas de uma cadeia de suprimentos estão ativamente trabalhando juntas em direção a objetivos comuns, e é caracterizada pelo compartilhamento de informações, de conhecimentos, de riscos e de benefícios. Para eles, as relações de colaboração devem ser analisadas por dois aspectos: (1) a intensidade de relação entre os parceiros (indo desde um simples compartilhamento de informações até uma verdadeira parceria, incluindo compartilhamento de experiências, riscos e lucros) e (2) a extensão da colaboração ao longo da cadeia (indo desde uma integração interna das funções, como compras, produção e distribuição, até a integração de todos os membros da cadeia).

De acordo com Kumar (2001), a gestão colaborativa da cadeia de suprimentos vai além da mera troca e integração de informações entre fornecedores e seus consumidores. Ela envolve uma tomada de decisões táticas conjuntas entre os parceiros nas áreas de planejamento colaborativo, previsão, distribuição e design de produtos.

Para Simatupang e Sridharan (2002) uma cadeia de suprimentos colaborativa simplesmente significa que duas ou mais empresas independentes trabalham conjuntamente para planejar e executar operações da cadeia com maior sucesso que se atuassem isoladamente. Em outras palavras, é a cooperação entre empresas independentes, porém relacionadas, para compartilhar recursos e capacidades para satisfazer as necessidades de seus consumidores.

Segundo Sarana e Mason (2006), o conceito de colaboração refere-se às atividades colaborativas que as empresas realizam para melhorar suas operações individuais e também as operações da cadeia como um todo. Esta colaboração pode não ocorrer naturalmente para algumas empresas, portanto elas precisam compreender os reais benefícios. Tais benefícios devem ser detectados com medidas de desempenho que demonstrem os resultados desta iniciativa. 
Para Soosay et al. (2008), "colaboração" pode ser mais bem definida como um tipo de relacionamento inter-organizacional no qual os membros participantes concordam em investir recursos, alcançar metas comuns, compartilhar informações, recursos, recompensas e responsabilidades, assim como tomar decisões e resolver problemas conjuntamente. A colaboração baseia-se na confiança mútua, sinceridade, compartilhamento de riscos e compartilhamento de recompensas que permitem uma vantagem competitiva, resultando em um desempenho melhor quando comparado a situações onde não há colaboração.

De acordo com Stank et al. (2001), as colaborações externas entre empresas devem incluir: (1) desejo de trabalhar em equipe, (2) a compreensão do ponto de vista do próximo, (3) o compartilhamento de informações e recursos e (4) atingir metas coletivas.

Lee (2000) afirma que os sistemas de gestão colaborativa da cadeia de suprimentos são projetados para dar apoio ao compartilhamento de informações e ao planejamento colaborativo entre os parceiros, em um esforço para reduzir as assimetrias das informações na cadeia.

Para Barratt (2004), antes de buscar a colaboração externa, é necessário praticá-la internamente. Colaboração não é apenas desenvolver relações mais próximas ou integrar processos entre funções relacionadas à cadeia de suprimento (aquisição, produção e logística), mas também de incluir marketing (para promoções e introduções de novos produtos e serviços) e atividades de Pesquisa e Desenvolvimento (P\&D). Além disso, colaboração não é apenas compartilhar informações em um nível operacional, mas também precisa ser implantada em níveis táticos e estratégicos entre todas as empresas da cadeia de suprimento. Caso isso não ocorra, os benefícios da integração serão limitados. Ainda segundo o autor, um dos elementos de maior sustentação da colaboração é a cultura colaborativa, que é constituída de vários elementos: confiança interna e externa, mutualidade, troca de informação, abertura, honestidade, comunicação e compreensão.

$\mathrm{O}$ autor ainda sugere que para o sucesso da colaboração na cadeia de suprimentos ocorrer, também os seguintes elementos chaves devem ser considerados: atividades funcionais cruzadas, alinhamento de processo, tomada de decisão conjunta e verdadeiras métricas de desempenho da cadeia de suprimentos. 


\subsubsection{Tipos de colaboração}

Para Barratt (2004), existem várias maneiras de colaboração na cadeia de suprimento que podem ser divididas em duas categorias principais: colaboração vertical, ocorrendo colaboração internamente (funções cruzadas) e externamente com consumidores e com fornecedores; e colaboração horizontal, ocorrendo, além da colaboração interna, a colaboração externa com concorrentes ou outras empresas, onde, por exemplo, elas poderiam compartilhar a capacidade produtiva. A ilustração 22 aborda essas colaborações.

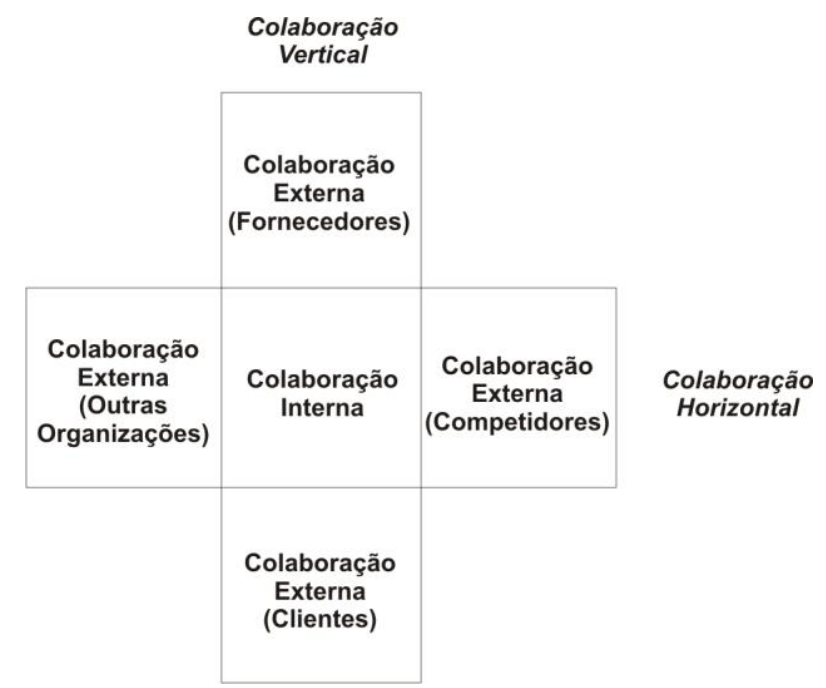

Ilustração 22 - Colaborações na cadeia de suprimentos FONTE: BARRATT, 2004

Soosay et al. (2008), em suas pesquisas sobre os tipos de colaboração, detectaram as principais formas:

- Alianças estratégicas - são amplamente vistas como um modo particular de relacionamento entre empresas, geralmente de longo prazo, no qual dois ou mais parceiros compartilham recursos, conhecimentos e capacidades, com o objetivo de aumentar a posição competitiva de cada parceiro;

- Joint ventures - as Joint ventures tradicionalmente são usadas para se desenvolver novas oportunidades de mercado nas quais a empresa, buscando por novos mercados, freqüentemente fornece bens ou serviços, estratégias de marketing e capacidade financeira enquanto a outra parte contribui com conhecimento de mercado, mão-deobra e acesso a redes do setor público e privado;

- Esquemas cooperativos - a base lógica por trás desses esforços cooperativos é focada na colaboração e compartilhamento de recursos, tanto tangíveis como intangíveis, bem como na busca das metas do negócio (ex: vantagem competitiva, sobrevivência e 
eficiência) por meio do redesenho de processos e produtos. O objetivo dos esforços cooperativos é a substituição de um esquema meramente contratual para relações de maior confiança.

- Colaboração virtual - a integração virtual refere-se a um esforço de colaboração temporário e bem forte entre entidades independentes (fornecedores, consumidores, concorrentes) que estão vinculadas por meio da tecnologia de telecomunicação. Essa tecnologia facilita o compartilhamento de custos, habilidades e acesso a mercados globais.

Também Angerhofer e Angelides (2006) afirmam que a colaboração se apresenta de várias formas, incluindo alianças estratégicas, "joint ventures", logística terceirizada, contratos de curto e longo prazo, parcerias de suprimento, e parcerias entre revendedores e fornecedores. As colaborações também ocorrem nos diversos níveis. A colaboração, no nível estratégico, preocupa-se com as decisões que podem influenciar a direção futura da cadeia de suprimentos, por exemplo, investimento de capital e reestruturação da rede, através da aceitação ou exclusão de participantes. Em nível gerencial, a principal preocupação é a otimização do fluxo de bens e envolve a previsão, o planejamento e o controle de recursos. Já no nível operacional, ela abrange tarefas repetitivas e rotineiras tais como agendamento de produção e transporte bem como controle de estoques.

\subsubsection{Iniciativas de colaboração}

Andraski (1994), Cooke (1998), Barratt e Oliveira (2001), Simatupang e Sridharan (2002), Chopra e Meindl (2003), Cassivi (2006) e Yao et al. (2007) descrevem, com base na literatura, algumas iniciativas de colaboração entre as empresas, como: Resposta Eficiente ao Consumidor (Efficient Customer Response - ECR), Estoque Gerenciado pelo Fornecedor (Vendor Managed Inventory - VMI), Programa de Reabastecimento Contínuo (Continuous Replenishment Program - CRP ou CR) e Planejamento, Previsão e Reabastecimento Colaborativos (Collaborative, Planning, Forecasting, and Replenishment-CPFR).

\subsection{Resposta Eficiente ao Consumidor (Efficient Customer Response - ECR)}

A primeira iniciativa robusta criada para permitir a integração na cadeia de suprimentos data de 1992, quando quatorze patrocinadores de associações comerciais, criaram um grupo chamado "Movimento da Resposta Eficiente ao Consumidor", com o propósito de liderar uma transformação sem precedentes nas práticas de negócios. Por meio do ECR, empresas 
industriais e comerciais, juntamente com os demais integrantes da cadeia de suprimentos (operadores logísticos, bancos, fabricantes de equipamentos, etc.) trabalham em conjunto na busca de padrões comuns e processos eficientes que permitam minimizar os custos e aperfeiçoar a produtividade em suas relações. Os benefícios na cadeia poderiam ser conquistados pela superioridade em quatro estratégias centrais: promoções eficientes, reabastecimento eficiente, sortimento de loja eficiente e introduções eficientes de produtos. Assim, foi proposto, pela primeira vez, a importância da necessidade de desenvolver um relacionamento baseado na confiança entre produtores e varejistas (incluindo fornecedores e consumidores em geral), com o compartilhamento de informações estratégicas a fim de otimizar os resultados globais da cadeia de suprimentos (BARRAT, OLIVEIRA; 2001)

\subsection{Estoque Gerenciado pelo Fornecedor (Vendor Managed Inventory - VMI)}

O VMI é uma técnica desenvolvida em meados de 1980, pelo qual o produtor (fornecedor) tem a total responsabilidade de gerir a política de estoques de seu cliente, incluindo o processo de reabastecimento, sendo ele, provavelmente, a primeira ligação baseada na confiança entre fornecedores e clientes (segundo a literatura, o sucesso do VMI depende do relacionamento de confiança entre fornecedor e cliente, com um extenso compartilhamento de informações).

Para Yao et al. (2007), os benefícios potenciais do VMI são muito convincentes e podem ser resumidos como redução do custo de estoque para o fornecedor e o comprador e melhoria nos níveis de serviço ao consumidor, tais como redução no ciclo de tempo do pedido e um melhor índice de atendimento. A implementação de VMI requer tanto o compartilhamento de informações quanto a coordenação e integração dos processos entre compradores e fornecedores. Em geral, compradores compartilham as informações sobre o status de demanda e estoque com seus fornecedores (compartilhamento de informações) para que os fornecedores possam controlar o estoque e a função de compra dos compradores (integração de processos).

Por outro lado, poucas empresas ainda utilizam o tradicional relacionamento baseado no VMI com seus parceiros comerciais e muitas outras abandonaram essa prática e migraram para outras técnicas de gestão da cadeia. A maior fraqueza do VMI está na visibilidade insuficiente da totalidade da cadeia, onde os dados do ponto de venda (PDV), bem como os dados dos níveis de estoques, são negligenciados, enquanto o processo de reabastecimento (e a política 
de estoques) é baseado na variação dos níveis de estoque no armazém principal do cliente ou centro de distribuição (COOKE, 1998; BARRAT; OLIVEIRA, 2001).

Segundo Chopra e Meindl (2003), para que o VMI exista, é necessário que o varejista compartilhe informações sobre a demanda com seus fornecedores. Essas informações acabam beneficiando os fornecedores, trazendo uma melhoria nas suas previsões e, conseqüentemente, uma melhor sincronia entre produção e demanda. Por outro lado, a desvantagem do VMI é que os varejistas quase sempre vendem produtos de fabricantes concorrentes, que pela perspectiva dos clientes finais são substituíveis. Porém, se um varejista tiver acordo de VMI com dois ou mais fornecedores de produtos substituíveis entre si, esses fornecedores irão ignorar o impacto da substituição e tomar suas decisões de estoque, fazendo com que o estoque no varejista se torne elevado.

\subsection{Programa de Reabastecimento Contínuo (Continuous Replenishment Program - CRP ou CR)}

O CR surgiu como uma prática de negócios em meados de 1990, em uma tentativa de melhorar e lidar com as quatro estratégias centrais do ECR (ANDRASKI, 1994). Em termos da gestão da cadeia de suprimentos, o CR dá um passo à frente do VMI e revela os níveis de estoques nas lojas varejistas. Pela primeira vez, os dados do PDV são usados para gerar uma previsão de vendas. A política de estoques é então baseada na previsão de vendas, construída a partir de dados do histórico da demanda e não apenas mais puramente baseada nas variações dos níveis de estoques no armazém principal do cliente. Alguns clientes disponibilizaram seus dados do PDV para seus fornecedores, os quais geralmente consolidam essas informações como um padrão mensal em comparação com o ano anterior e, baseando-se nisso, tentam prever as vendas futuras (BARRAT; OLIVEIRA, 2001).

\subsection{Planejamento, Previsão e Reabastecimento Colaborativos (Collaborative Planning, Forecasting and Replenishment - CPFR)}

O CPFR, que é uma iniciativa da Associação Voluntária Intersetorial de Padrões de Comércio (Voluntary Interindustry Commerce Standards Association - VICS), define as atividades operacionais que permitem aos parceiros traçar iniciativas de colaboração na cadeia de suprimentos. CPFR tem suas origens em uma série de programas implementados nas décadas de 1980 e 1990, para otimizar as atividades de estoques e reabastecimento. Esses programas, particularmente o Estoque Gerenciado pelo Fornecedor (Vendor Managed Inventory - VMI) e 
o Programa de Reabastecimento Contínuo (Continuous Replenishment Program - CRP), foram desenhados para aproximar os parceiros da cadeia, apesar de nenhum deles realmente focar-se no compartilhamento de informações entre parceiros. Nesse contexto o CPFR busca pegar as vantagens operacionais de todos esses programas e adicionar mecanismos colaborativos para facilitar a troca de informações em uma cadeia de suprimentos com vários níveis (CASSIVI, 2006).

Para Cassivi (2006), o CPFR é segmentado em estágios, como mostra a ilustração 23. O primeiro estágio, Planejamento, envolve dois passos críticos: acordo inicial e planejamento empresarial conjunto. O próximo estágio, Previsão, inclui dois passos baseados na previsão: colaboração na previsão de vendas e colaboração na previsão de pedidos. O estágio final, Reabastecimento, compreende apenas um passo principal: geração de pedidos.

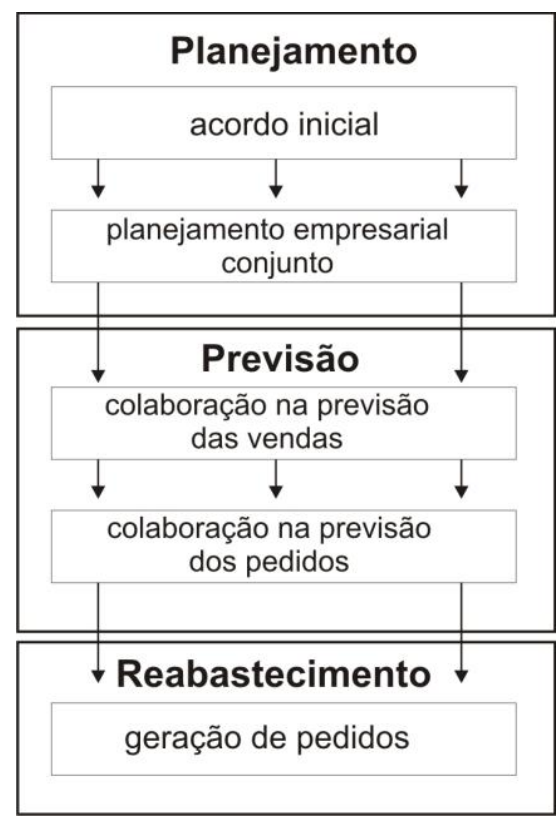

Ilustração 23 - Estágio do CPFR FONTE: CASSIVI, 2006

Ainda segundo o autor, as vantagens do CPFR são significantes. Dentre as vantagens identificadas, os parceiros do CPFR têm notado um aumento das vendas, redução de estoques e melhor serviço ao consumidor. Eles também fortificaram seus relacionamentos por meio da melhora e do incentivo da confiança em suas trocas.

Para Barratt e Oliveira (2001), com o CPFR, muitos problemas são lidados completamente pela primeira vez, como a: 
- Influência das promoções na criação da previsão de vendas (e sua influência na política de gestão de estoques);

- Influência da mudança do modelo da demanda na criação da previsão de vendas (e sua influência na política de gestão de estoques);

- Prática comum de manter altos níveis de estoques para garantir a disponibilidade de produtos nas prateleiras;

- Falta de coordenação entre a loja, o processo de compras e o planejamento logístico para varejistas;

- Falta de sincronização geral (ou coordenação) nos departamentos funcionais do produtor (planejamento de vendas/comercial, distribuição e produção) e

- Múltiplas previsões desenvolvidas dentro da mesma empresa (marketing, financeira, compras e logística).

Andraski (1994) relata que o CPFR compromete o produtor e o varejista na troca de informações de mercado, a fim de aproximarem-se de um plano específico do cliente que pode reduzir substancialmente os estoques. Neste contexto, as previsões forçam o compartilhamento de programações de promoção, dados dos pontos de venda (PDV) e dados de estoques e isso viabiliza menores lead-times e integração entre os processos de previsão e reabastecimento.

Barratt e Oliveira (2001) sugerem alguns benefícios do CPFR: ciclos de pedidos mais previsíveis, redução de custos, recebimento facilitado de cargas, redução de produtos danificados, despachos/remessas menores, trocas diárias de informações, entregas mais freqüentes, exatidão de informações, séries de produção menores, produção final postergada, informações formatadas para facilitar seu uso, melhor serviço ao consumidor, disponibilidade de informações, redução de falta de estoques, maior confiabilidade nas entregas, giros de estoques mais rápidos, informações em tempo real e redução do excesso de estoques.

Os autores, com base na literatura e também com base em suas pesquisas, listaram as barreiras à implementação do CPFR (fatores que limitam a visibilidade de parceiros comerciais da cadeia): 
- Ausência de metas compartilhadas, estabelecidas estatisticamente e baseadas no nível dos itens em estoque, na variabilidade no centro de distribuição, nos níveis de serviço ótimos entre as lojas e na capacidade e custos totais da cadeia;

- Dificuldade de gerir os processos de revisão/exceção da previsão (previsão de vendas e pedidos);

- Promoções e eventos de novos itens não são planejados conjuntamente;

- As previsões não são comunicadas de forma clara ao longo da cadeia;

- Inexistência de um sistema integrado de apoio à decisão para fornecer dados sobre consumidores, clientes e o mercado;

- As empresas corporativas não estão alinhadas com seus parceiros comerciais-chave para maximizar os objetivos regionais/locais mútuos alinhados às estratégias corporativas;

- Os parceiros comerciais não trabalham juntos para assegurar um desempenho de entrega consistente;

- Não há avaliação das diferentes alternativas de fluxo de produto. As previsões conjuntas semanais de vendas e pedidos não são comunicadas internamente e não alimentam os processos de produção e reabastecimento;

- Falta de disciplina para executar as fases preliminares (e preparatórias) do processo CPFR (particularmente nos estágios do acordo inicial e do plano conjunto de negócios).

Seguindo o conceito de colaboração, Holweg et al. (2005) identificaram quatro tipos diferentes de configurações de colaboração na cadeia de suprimentos, diferenciadas pela colaboração do estoque e pelo planejamento da colaboração entre as empresas. A ilustração 24 mostra estas configurações. 


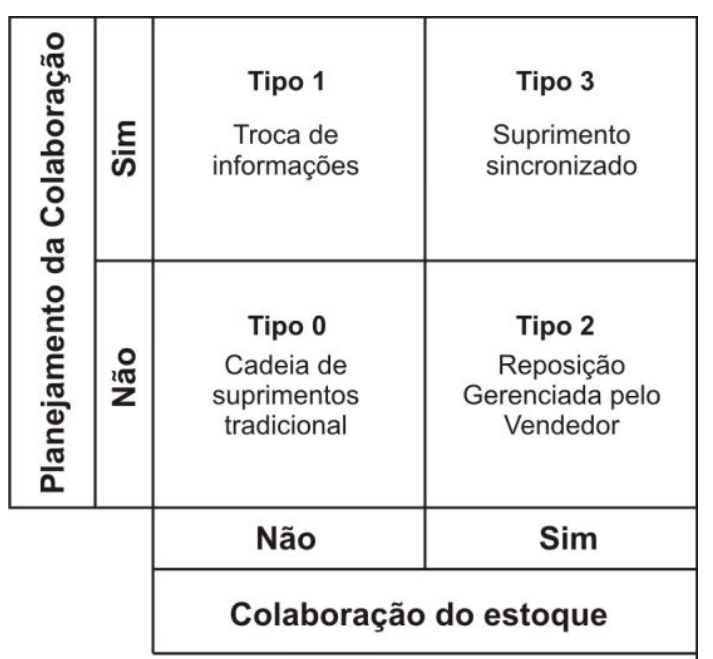

Ilustração 24 - Configuração básica da cadeia de suprimentos para a colaboração FONTE: HOLWEG et al., 2005

- Tipo 0 - A Cadeia de Suprimentos Tradicional - "Tradicional" significa que cada nível na cadeia de suprimento emite ordens de produção e reposição de estoque sem considerar a situação nos demais elos - acima ou abaixo - da cadeia de suprimentos. Esta é maneira como a maioria das cadeias de suprimentos ainda funciona, sem colaboração formal entre cliente e fornecedor;

- Tipo 1 - Troca de Informações - A troca de Informações (ou Compartilhamento de Informações) significa que o consumidor e o fornecedor operam independentemente, mesmo assim trocam informações e planos de ação para alinhar suas previsões de capacidade e planejamento a longo prazo. O compartilhamento de informações ajuda a criar no sistema uma demanda mais visível e previsível. Esta etapa é constantemente divulgada como um objetivo chave na implementação de VMI, mas não é utilizado com freqüência. A razão é que o consumidor freqüentemente não tem um processo de previsão e planejamento que possa gerar para o fornecedor a informação com o nível de detalhe requerido, no momento e no tempo certo. Ligar os processos de planejamento do consumidor e do fornecedor em nível de detalhamento suficiente também é a base fundamental em direção à implementação da estratégia do Planejamento, Previsão e Reabastecimento Colaborativos (Collaborative Planning, Forecasting and Replenishment - CPFR);

- Tipo 2 - Reposição Gerenciada pelo Vendedor (Vendor Managed Replenishment VMR), também conhecido por VMI - O tipo 2 significa que a tarefa de geração da ordem de reposição é dada ao fornecedor, que então assume a responsabilidade pela manutenção do estoque do vendedor, e subseqüentemente, dos níveis de serviço do 
vendedor. Reposição Gerenciada pelo Vendedor, também chamada de Estoque Gerenciado pelo Vendedor (Vendor Managed Inventory - VMI). É uma das pedras fundamentais da iniciativa de Resposta Eficiente ao Consumidor (Efficient Consumer Response - ECR) no setor de alimentação, e existem projetos similares no setor têxtil, chamado de Manufatura em Resposta Rápida (Quick Response Manufacturing QRM) e

- Tipo 3 - Suprimento Sincronizado - O suprimento sincronizado elimina um ponto de decisão e funde a decisão de reposição com o planejamento de produção e materiais do fornecedor. Aqui o fornecedor toma conta da reposição de estoque do consumidor em nível operacional, e usa esta visibilidade no planejamento das suas próprias operações de suprimento.

\subsubsection{Benefícios da colaboração}

Lambert e Pohlen (2001) citam alguns benefícios resultantes da colaboração entre as empresas. Tomando como exemplo o uso do VMI entre um elo da cadeia, nota-se que essa relação pode reduzir custos e provocar uma queda nos preços ao consumidor final. Por outro lado, as receitas podem aumentar devido o aumento de vendas totais da cadeia de suprimentos, devido a uma melhor disponibilidade de produtos aos consumidores finais ou também devido à melhor qualidade por trabalhar com um grupo seleto de fornecedores. Pelo lado do fornecedor, logo após a implementação do VMI, ele sofre uma diminuição imediata em vendas e suas despesas podem aumentar por assumir a posse e responsabilidade do estoque do cliente, mas por outro lado os custos devem diminuir devido a redução dos custos de processamento de pedido e de previsão incorreta da demanda. Neste último caso, os custos de estoque parado diminuem quando se usa a data de reposição do ponto de venda e não previsões e também diminuem os custos de manutenção de estoque de segurança. Já pelo lado da empresa cliente, os custos de estoques são reduzidos por passarem suas posses aos fornecedores. Como conclusão, os autores afirmam que empurrar a posse de estoque para trás (para o fornecedor), reduz o custo de estoque parado, para o consumidor e para toda a cadeia de suprimentos, devido à posse dos produtos serem do fornecedor a um valor menor.

Segundo Mentzer,Foggin et al. (2000), os benefícios da colaboração incluem a redução dos custos dos processos, dos níveis de estoques e dos custos de produção devido a coordenação da demanda dos consumidores atuais com os planos de produção dos fornecedores. Além disso, o autor ressalta que a colaboração também resulta em menores tempos de ciclo para 
lançamento de novos produtos, melhores níveis de serviço (baseado em falta de estoques, lead times e qualidade) e uma melhor compreensão das necessidades do consumidor final ao longo de toda a cadeia.

Para Mclaren et al. (2002), o resultado da gestão colaborativa da cadeia de suprimentos não é apenas a redução de perdas em toda cadeia, mas melhor sensibilidade, satisfação do consumidor e competitividade entre todos os membros da parceria. Deste modo, os sistemas de gestão colaborativa da cadeia de suprimentos permitem que as empresas progridam além da mera troca e otimização de informações de nível operacional e possam transformar um negócio e seus parceiros em empresas mais competitivas.

De acordo com Mclaren et al. (2002), é importante notar que a verdadeira colaboração requer mais do que simples foco na otimização transacional ou nas funções operacionais. Assim, Walter et al. (2001) afirma que os relacionamentos colaborativos de alto desempenham requerem não apenas um foco nas funções de criação direta de valor ou de cliente-fornecedor, mas também um foco na construção de relacionamentos indiretos e nas funções de suporte.

\subsubsection{Integração}

Para Frohlich e Westbrook (2001), na última década tem ocorrido um consenso crescente da importância estratégica da integração entre fornecedores, fabricantes e consumidores. Nesse contexto, vários autores notaram que a eficiente integração dos fornecedores na cadeia de suprimentos será um fator chave para que alguns fabricantes atinjam a melhoria necessária para continuarem competitivos.

De acordo com Zailani e Rajagopal (2005), as empresas, nos últimos anos, têm percebido o crescimento da importância de se integrar fornecedores, produtores e consumidores em uma cadeia de suprimentos, sendo que uma integração eficaz serve como um fator-chave para algumas empresas ganharem vantagem competitiva. Assim, os autores definem a integração da cadeia de suprimentos como a formação de uma rede de suprimentos, conectando fornecedores, cliente e a própria empresa.

Segundo Cooper et al. (1997), para implementar o gerenciamento da cadeia de suprimentos é necessário algum nível de coordenação entre as empresas. Isto inclui a integração dos processos e funções dentro das empresas e entre toda a cadeia de suprimento. Este 
gerenciamento da cadeia é movido pelo reconhecimento da sub-otimização que ocorre quando as empresas tentam otimizar seus próprios resultados ao invés de integrarem suas metas e atividades para otimizar o resultado da cadeia total.

Também para Power (2005), a base da integração pode ser caracterizada pela cooperação, colaboração, compartilhamento de informação e de tecnologia, confiança, parcerias e uma mudança fundamental no gerenciamento de processos, passando de processos funcionais individuais para processos integrados na cadeia.

Recentes avanços tecnológicos têm aumentado dramaticamente a habilidade das empresas em se integrarem. Esta integração por meio da tecnologia os autores denominaram conectividade. Para eles, o aumento da conectividade promete mudar as capacidades competitivas, sendo a maior das mudanças a habilidade da informação em substituir estoques na cadeia. $\mathrm{O}$ aumento da conectividade está também reduzindo o tempo de desenvolvimento novos produtos e o tempo de colocação de pedidos. A conectividade em tempo real também fornece benefícios menos tangíveis tais como a possibilitar dos gerentes detectem com antecedência tendências ambientais e pontos de inflexão, tornando as empresas mais competitivas (FAWCETT et al., 2007)

Para Bowersox et al. (2007), a integração das empresas na cadeia de suprimentos muda os arranjos tradicionais entre elas, passando de relações frágeis de compra e venda para uma relação mais forte e coordenada, aumentando a eficiência e a competitividade geral.

De acordo com Cagliano et al. (2006), várias são as práticas utilizadas em busca da integração da cadeia de suprimentos, como por exemplo o VMI e CPFR. Dentro dessas práticas é importante reconhecer dois elementos distintos. Algumas práticas estão destinadas a integrar os fluxos físicos dos produtores em direção aos clientes, enquanto que outras práticas são mais orientadas para a coordenação e integração das informações e dos fluxos de dados dos clientes em direção aos fornecedores. Para os autores, essas duas maneiras de integração dos processos da cadeia de suprimentos são diferentes em sua natureza. O primeiro tipo de integração requer uma união mais estreita dos sistemas de produção entre o cliente e o fornecedor e até uma co-localização de plantas. Como resultado, freqüentemente a integração de fluxos físicos é estreitamente relacionada às práticas de compra. O segundo tipo de 
mecanismo de integração visa trazer as informações, de modo a aperfeiçoar as atividades internas e a gestão de operações.

\subsubsection{Tipos de integração}

Segundo Venkatachalam (2006), a integração da cadeia de suprimentos consiste em seis tipos de integração: sistemas (equipamentos e hardwares), aplicação (para manipular os dados de vários sistemas), informação, conhecimento, domínio funcional (alguns softwares como ERP, SCM e CRM) e capital humano. A ilustração 25 mostra esse modelo.

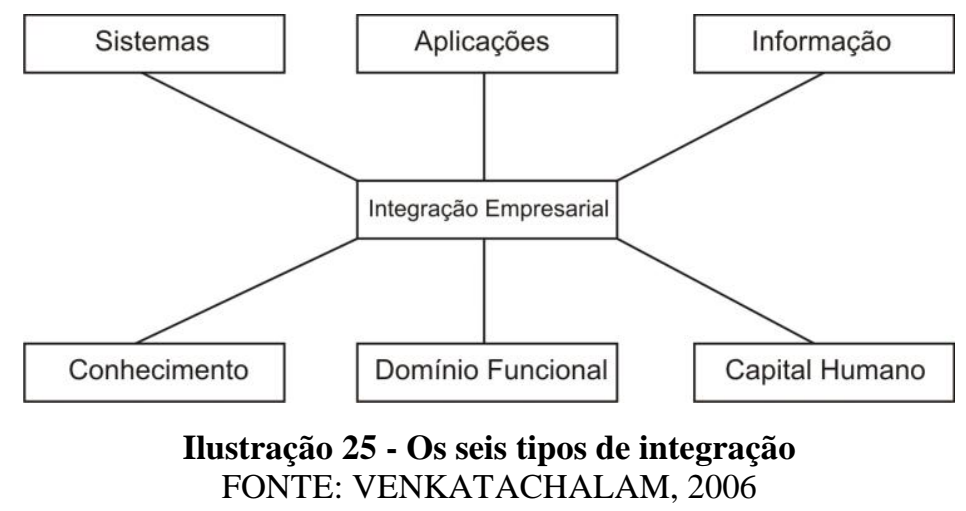

Para Lee (2000), para gerenciar de maneira eficaz as crescentes necessidades dos clientes e as ofertas de produtos nas complexas cadeias globais de suprimentos é necessária a integração entre os parceiros. Para o autor, a integração da cadeia de suprimentos se dá por três dimensões essenciais: (1) integração de informação, (2) coordenação e compartilhamento de recursos e (3) ligação dos relacionamentos organizacionais. O quadro 10 ilustra esses elementos.

Quadro 10 - Dimensões da Integração da Cadeia de Suprimentos

\begin{tabular}{|c|c|c|}
\hline Dimensão & Elementos & Como \\
\hline Integração da informação & $\begin{array}{c}\text { Informação; } \\
\text { Conhecimento }\end{array}$ & $\begin{array}{c}\text { Planejamento, Previsão e } \\
\text { Reabastecimento Colaborativos }\end{array}$ \\
\hline $\begin{array}{c}\text { Coordenação e } \\
\text { Compartilhamento de recursos }\end{array}$ & Decisões; Trabalho & $\begin{array}{c}\text { Delegação da decisão, realinhamento do } \\
\text { trabalho, terceirização. }\end{array}$ \\
\hline $\begin{array}{c}\text { Ligação dos Relacionamentos } \\
\text { Organizacionais }\end{array}$ & $\begin{array}{c}\text { Responsabilidade; Riscos } \\
\text { / Custos / Benefícios }\end{array}$ & $\begin{array}{c}\text { Comunicação estendida e medidas de } \\
\text { desempenho, incentivos de realinhamento }\end{array}$ \\
\hline
\end{tabular}

FONTE: LEE, 2000

Segundo Vickery et al. (2003), o conceito de integração na cadeia de suprimentos representa a integração tanto intra-empresarial (integração interna das áreas e processos da empresa, também chamada de integração horizontal) como inter-empresarial (integração externa entre as várias empresas da cadeia, também chamada de integração vertical). 
Zailani e Rajagopal (2005) estudaram as variáveis que envolvem a integração da cadeia de suprimentos. Eles dividiram as variáveis em independentes e dependentes. As variáveis independentes que afetam o desempenho da integração da cadeia de suprimentos foram classificadas em quatro categorias principais:

- Compartilhamento de informações - o compartilhamento de informações refere-se à troca de informações entre empresa, consumidores e fornecedores. Devem ser considerados o volume e o tipo de informação que são compartilhadas e também a existência de sistemas informais de comunicação;

- Integração interna - aborda a integração geral de todas as funções internas e departamentos da empresa;

- Integração externa com fornecedores - pela integração com os fornecedores, é verificado o quão próximo as empresas estão trabalhando. Devem ser abordados o nível de envolvimento e influência dos fornecedores nas decisões da empresa e também o nível de parceria estratégica adotada (grau de parceria, formal ou informal, que a empresa faz com seus fornecedores);

- Integração externa com consumidores - de forma parecida com o item anterior, pela integração com os fornecedores, é verificado o quão próximo as empresas estão trabalhando. Devem ser abordados o nível de envolvimento e influência dos clientes nas decisões da empresa e também as respostas (feedback) dos clientes aos produtos lançados pela empresa e as ações das empresa com relação as necessidades e reclamações dos clientes.

Já as variáveis dependentes, isto é, aquelas que medem o desempenho das empresas na cadeia, forma classificadas em três categorias:

- Qualidade - representa entregar aos clientes aquilo que eles necessitam. Os autores comentam que os fornecedores assumem um papel importante na qualidade dos produtos acabados da empresa, e para isso sugerem três fatores determinantes na escolha de fornecedores a fim de melhorar a qualidade da empresa: habilidade para atender os padrões de qualidade, habilidade de entregar produtos no prazo e histórico de desempenho;

- Entrega - a entrega dos produtos também é de extrema importância. Devem ser abordadas as seguintes dimensões: rapidez e confiabilidade da entrega e lead-time da produção e 
- Flexibilidade - a flexibilidade deve ser analisada como: flexibilidade do serviço ao consumidor (habilidade de suprir as solicitações especiais dos consumidores), flexibilidade de pedido (habilidade de modificar o tamanho, volume ou composição de pedidos durante a operação logística), flexibilidade de local (habilidade de atender clientes a partir de localizações alternativas de armazéns) e flexibilidade de tempo de entrega (habilidade de atender tempos diferentes de entrega para consumidores específicos).

Já para Paulraj et al. (2006), a integração da cadeia de suprimentos ocorre por meio de quatro tipos de integração:

- Integração Relacional - no passado, as empresas em geral contratavam um grande número de fornecedores. Recentemente uma mudança significativa ocorreu nas relações tradicionais antagônicas comprador-vendedor através do uso de um número limitado de fornecedores qualificados. Além disso, contratos com fornecedores passaram a ser de prazos mais longos, e cada vez mais os fornecedores fornecem informações aos consumidores no que tange seus processos, desempenho de qualidade, e até mesmo estrutura de custos;

- Integração de Processos - o aumento da relação entre as empresas requer uma coordenação próxima dos parceiros na cadeia de suprimentos. A tendência atual é usar parcerias estratégicas e acordos de cooperação entre empresas para forçar a integração de processos até se estender além das fronteiras de uma empresa individual;

- Integração de Informação - a comunicação inter-organizacional eficiente estimula a integração de informação entre empresas compradoras e fornecedoras. Para que conjuntamente encontrem soluções para problemas materiais ou questões de projeto, compradores e fornecedores precisam se comprometer a fornecer uma grande quantidade de informação e precisam estar dispostas a compartilhar informações sensíveis e

- Equipes Trans-Organizacionais - integração de pessoal usando equipes transorganizacionais está se tornando uma prática comum nas cadeias de suprimentos.

A ilustração 26 mostra esses elementos. 


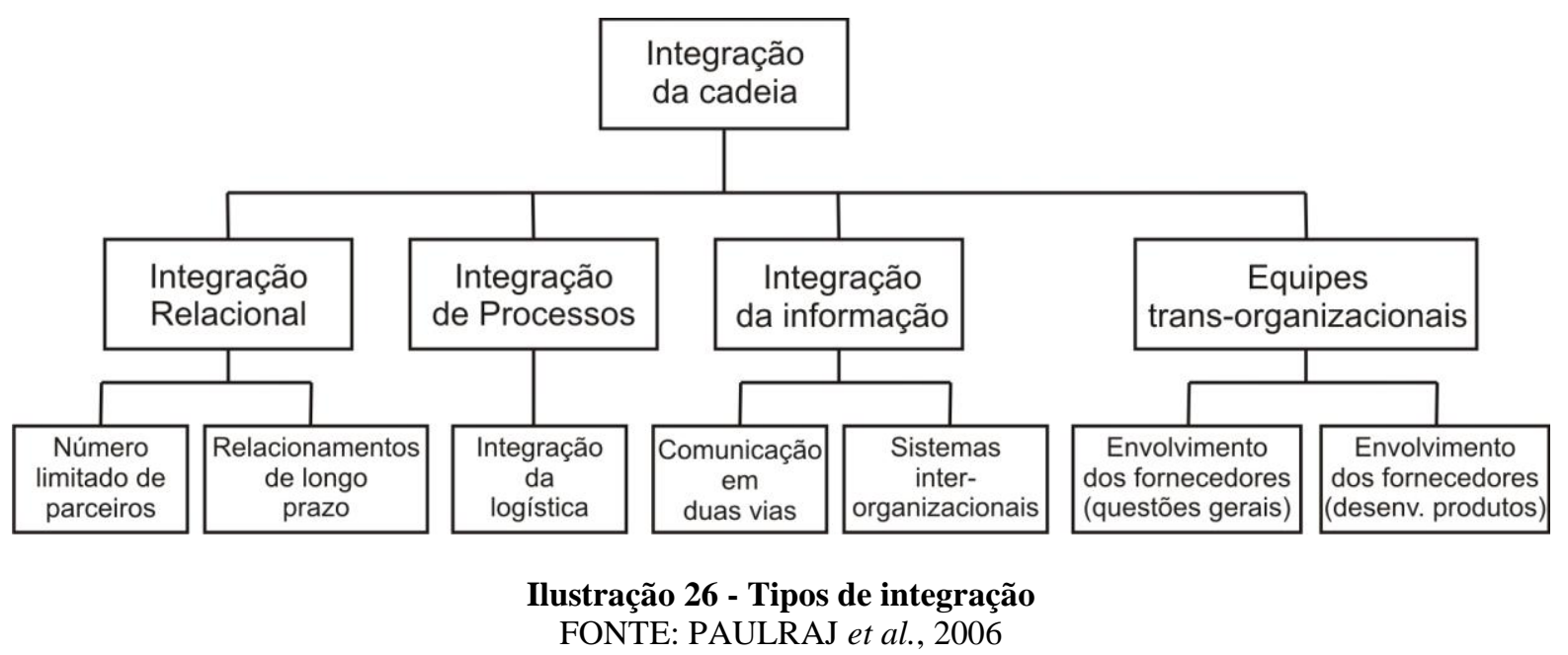

Fawcett e Magnan (2002) afirmam que o conceito de integração da cadeia de suprimentos varia muito na literatura, indo desde "integração de processos inter-funcionais dentro da empresa" até "integração completa, a montante e a jusante, de toda a cadeia de suprimentos". Os autores definem quatro tipos primários de integração:

(1) Interna - integração de processos inter-funcionais foram identificados como sendo o ponto mais importante para as iniciativas da cadeia de suprimentos;

(2) Integração com fornecedores de primeira camada - é a forma mais comum de integração da cadeia de suprimentos, sendo uma extensão natural desta forma a integração com fornecedores de segunda camada (fornecedores dos fornecedores);

(3) Integração com clientes de primeira camada - também pode ser considerada uma forma comum de integração, sendo também a extensão natural a integração com clientes de segunda camada (clientes dos clientes) e

(4) Integração completa (desde os fornecedores dos fornecedores aos clientes dos clientes) - é a forma mais rara de integração, sendo mais um ideal teórico do que uma realidade.

Para Frohlich e Westbrook (2001), a integração da cadeia de suprimentos é motivada pelo reconhecimento da interdependência entre as empresas. Anteriormente, quando havia predominâncias da empresas verticalizadas, a preocupação era ter várias áreas de uma empresa trabalhando juntas para atingir metas corporativas. Com o aumento da divisão do valor adicionado ao produto entre várias organizações (cada qual agregando valor com suas atividades essenciais), as empresas devem integrar atividades entre parceiros na cadeia de suprimentos para entregar produtos ao mercado de forma mais eficiente. Os autores definem 
as variáveis que determinam a integração da cadeia de suprimentos como sendo: acesso aos sistemas de planejamento entre as empresas; compartilhamento dos planos de produção; conhecimento dos níveis e do mix de estoque; customização de embalagens; frequiências de entregas, uso comum de equipamentos logísticos e uso comum de serviços prestados por operadores logísticos.

Das et al. (2006) também estudam a integração na cadeia de suprimentos, porém dando ênfase em uma relação diática empresa-fornecedor. Para eles, a integração com fornecedores é definida como um estado de sinergia alcançado através de uma variedade de práticas de integração entre o fornecedor, e as áreas de compras e produção de uma empresa, abrangendo a integração de informação, de atividades logísticas e das relações entre cliente e fornecedor.

Para Lee e Whang (2001) a integração não pode ser completa sem um estreito vínculo de relacionamentos entre empresas. Estas relações devem ocorrer segundo:

- Canais de comunicação - devem ser bem definidos e mantidos, com funções e responsabilidades claramente estabelecidas;

- Medidas de desempenho para os membros da cadeia - também precisam ser especificadas e controladas. Tais medidas de desempenho devem ser criadas de forma a incentivar uma maior colaboração e coordenação e

- Incentivos - devem ser alinhados entre todos os membros tendo em vista a integração da cadeia de suprimentos. Este alinhamento dos incentivos uma cuidadosa definição de mecanismos pelos quais os riscos e benefícios associados aos esforços de integração são equitativamente compartilhados.

\subsubsection{Níveis de Integração}

Para Themistocleous et al. (2004), a integração entre as empresas pode ser classificada entre Integração Fraca e Integração Forte. Baseados nesses dois tipos de integração, os parceiros da cadeia de suprimentos podem formar: (a) parcerias de treinamento de união fraca, através das quais se compartilha informações ou (b) cadeias firmemente integradas, onde há um maior grau de dependência de processos (neste caso, a integração é um fator significante, com diversas empresas compartilhando dados e processos comuns). As diferenças entre os tipos de integração estão resumidas no quadro 11. 
Quadro 11 - Integração fraca e integração forte

\begin{tabular}{|l|}
\hline Integração Fraca \\
\hline Foco na troca e compartilhamento de dados entre parceiros \\
Baixo nível de dependência de processos \\
Baixo nível de integração \\
O desenvolvimento de uma infra-estrutura integrada e homogênea entre as empresas não é importante \\
Comunicação assíncrona \\
\hline Integração Forte \\
\hline Foco na integração de processos e sistemas entre as empresas \\
Alt nível de dependência de processos \\
Alto nível de integração \\
O desenvolvimento de uma infra-estrutura integrada e homogênea entre as empresas é importante \\
Comunicação síncrona \\
\hline
\end{tabular}

FONTE: THEMISTOCLEOUS et al., 2004

Em busca de uma melhor análise da integração da cadeia de suprimentos, Frohlich e Westbrook (2001) criaram um modelo denominado "Arcos de Integração". Neste modelo, os dois conceitos básicos são a) em que direção (a montante, com fornecedores ou a jusante, com clientes) está ocorrendo a integração e b) qual a intensidade (grau de integração). Tomando este par de decisões como dimensão chave para a representação de uma posição estratégica pode-se ilustrá-las graficamente como um arco (ver ilustração 27), onde a direção do segmento mostra se a empresa está pendendo para o fornecedor ou para o consumidor, e os graus do arco indicam a extensão desta integração.

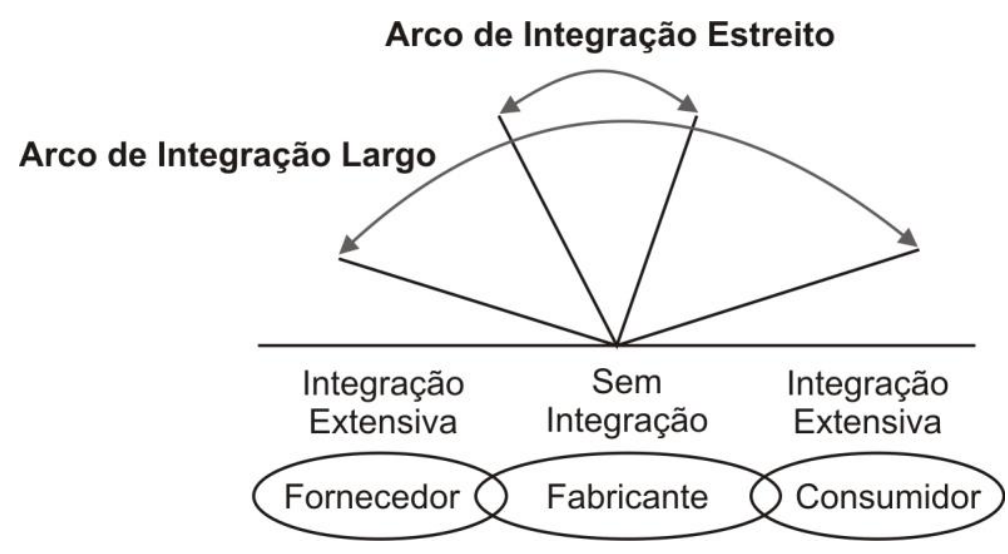

Ilustração 27 - Arcos de integração FONTE: FROHLICH; WESTBROOK, 2001

Ainda, pelo modelo, cinco situações podem ocorrer com os arcos de integração: (1) voltado para dentro, (2) voltado para periferia, (3) voltado para o fornecedor, (4) voltado para o consumidor e (5) voltado para fora. A ilustração 28 apresenta essas situações. 
Arco de Integração Voltado para Dentro

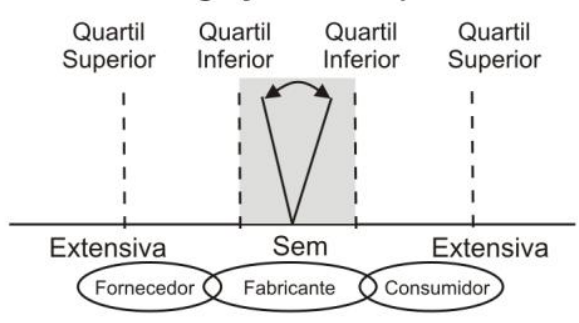

Arco de Integração Voltado para a Periferia

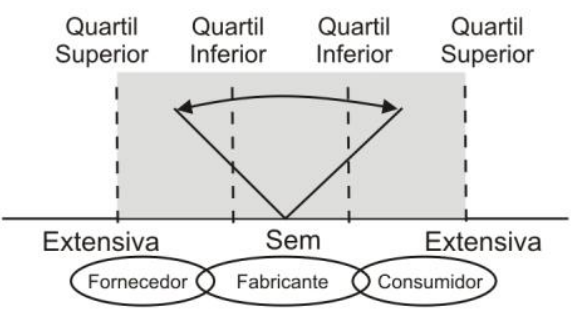

Arco de Integração Voltado para o Fornecedor

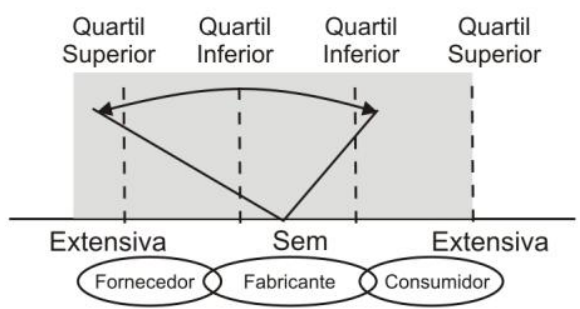

Arco de Integração Voltado para o Consumidor

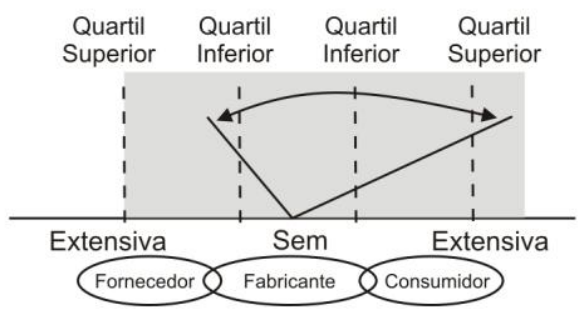

Arco de Integração Voltado para Fora

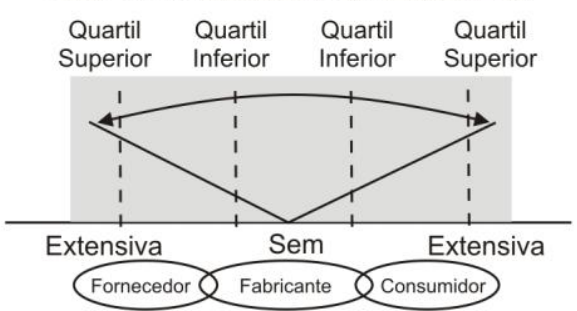

Ilustração 28 - Operacionalização dos arcos de integração FONTE: FROHLICH; WESTBROOK, 2001 


\subsubsection{Benefícios da integração}

Para Mclaren et al. (2002), uma integração e sincronização efetiva da cadeia de suprimentos pode eliminar excessos de estoques, reduzir lead times, aumentar as vendas e melhorar o serviço ao consumidor.

Kalakota e Robinson (2002), afirmam que melhorias significantes podem ser alcançadas no gerenciamento da cadeia de suprimentos por meio da integração de processos empresariais e dos fluxos de informações entre os parceiros. Para eles, alguns dos benefícios associados a integração da cadeia são:o aumento da vantagem competitiva, a redução de custos operacionais e o alcance de melhor colaboração e coordenação entre os parceiros.

Em seus estudos, Das et al. (2006) definem vários benefícios da integração. A integração promove um aumento da coordenação, das trocas valiosas de informações, do estabelecimento de metas compartilhadas, além de criar familiaridade e confiança entre as empresas. Com o desenvolvimento da confiança, os gestores trabalham com um nível menor de incertezas sobre as ações da cadeia, diminuindo o oportunismo. A integração também pode reduzir custos de produção, por meio de economias de escala, pois pode conduzir a uma redução no número de fornecedores, trabalhando com consolidação de volume.

Além disso, os autores relatam que muitos estudos de vários autores têm discutido o amplo impacto da completa integração entre as empresas, entre elas: diminuição dos custos de transação e das incertezas, aumento das economias de escala, do acesso às informações sobre processos dos fornecedores, da garantia de suprimento e de barreiras de entrada pela criação de competências difíceis de imitar.

No levantamento feito por Sezen (2008), com base em outros autores, são comentados os vários possíveis benefícios da integração da cadeia de suprimentos. Para ele, cadeias de suprimento bem integradas geram valor ao acionista ao reduzir custos e aumentar participação de mercado. Assim, empresas que alcançaram uma integração bem sucedida nas suas cadeias de suprimento tiveram como benefícios: menos estoque, fluxos de caixa com ciclos menores, menor tempo de ciclo dos pedidos, redução de custos de materiais e de logística, aumento da eficiência da mão-de-obra, melhor resposta aos consumidores e respostas mais rápidas em mercados dinâmicos. 
Levary (2000) relata que os benefícios da integração da cadeia de suprimentos são: (1) minimizar o efeito chicote, (2) maximizar a eficiência em conduzir atividades ao longo da cadeia, (3) minimizar estoques ao longo da cadeia, (4) minimizar o tempo de ciclo ao longo da cadeia e (5) atingir um nível aceitável de qualidade ao longo da cadeia de suprimentos.

\subsubsection{Problemas e dificuldades da integração}

Segundo Sahin e Robinson (2002), o gerenciamento efetivo e eficiente dos fluxos físicos, de informação e financeiros requer um sistema de abordagem para identificar, analisar e coordenar as interações entre as entidades com sucesso. Entretanto, atingir integração de cadeia de suprimentos não é uma tarefa fácil. Os objetivos geralmente conflitantes dos canais e a estrutura dinâmica em constante evolução da cadeia de suprimentos geram muitos desafios para a efetiva integração.

Para Rosenzweig et al. (2003), apesar da integração ao longo da cadeia de suprimentos ser um dos tópicos dominantes na literatura, nem sempre as empresas têm sucesso no alcance de uma maior integração. Uma das causas para a falha de programas de integração externa tem sido a falta de integração interna dentro das empresas.

Por outro lado, Das et al. (2006) relatam que existe uma oposição ativa à integração. Pesquisadores têm argumentado que, por favorecer interdependências, a integração gera inflexibilidade e impede adaptação a incertezas, podendo retardar uma resposta de mudança da organização. A integração pode trazer alguns custos não previstos, como os custos de coordenação, de compromisso e de inflexibilidade, podendo estes custos ser superiores às economias geradas pela integração. Outra questão a ser considerada é a necessidade de aquisição de melhorias em termos de habilidades e capacidade dos funcionários, à medida que eles se tornam altamente envolvidos nas responsabilidades de produção e de relacionamentos.

Assim, na conclusão de seus estudos, os autores afirmam que a integração pode trazer benefícios, mas também pode trazer desempenhos adversos. A ambigüidade na relação entre a integração de fornecedores e o desempenho é intrigante. De um lado, a integração pode levar a um aumento de desempenho através de economias na transação, escala e escopo. Por outro lado, a interdependência pode criar rigidez, inflexibilidade e problemas de coordenação que podem afetar negativamente o desempenho. A função dos gestores é determinar um ponto de equilíbrio entre os benefícios e as adversidades. 
Segundo Venkatachalam (2006), a integração entre empresas envolve três tipos genéricos de obstáculos: a) relacionados a pessoas, b) relacionados a processos e c) relacionados à tecnologia. No passado a maior parte dos sistemas empresarias se focavam em abranger os obstáculos tecnológicos da integração. Entretanto, obstáculos humanos e obstáculos de processos foram negligenciados e levaram à falha de muitos sistemas empresariais, pois não haviam sido abordados de maneira apropriada. Os obstáculos relacionados às pessoas incluem mudança da gerência, treinamento adequado, alocação de recursos e habilidade da equipe de ir ao encontro do que é necessário. Já os obstáculos relacionados a processos incluem a migração, a reengenharia e a gerenciamento de sistemas. Finalmente os obstáculos relacionados à tecnologia incluem a funcionalidade do hardware e do software, o gerenciamento de sistemas e aplicativos e a integridade e utilidade dos dados. A ilustração 29 aborda esses obstáculos.

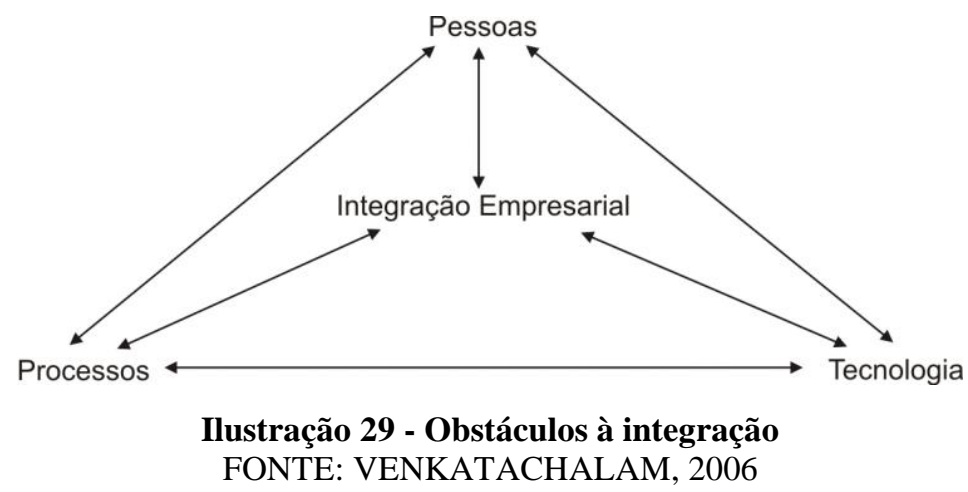

Para Chopra e Meindl (2003), o sucesso da integração da cadeia de suprimentos depende do alinhamento estratégico entre os membros da cadeia. Assim, os autores definem as seguintes variáveis como obstáculos para alcançar esse alinhamento:

- Aumento da variedade de produtos - o aumento na variedade de produtos complica a cadeia de suprimentos, pois faz com que as previsões sobre a demanda e o atendimento dessa demanda se tornem mais difíceis;

- Redução dos ciclos de vida dos produtos - a redução nos ciclos de vida do produto dificulta o alinhamento estratégico, pois a cadeia é obrigada a estar em constante adaptação com a produção e entrega de novos produtos, além de enfrentar a incerteza de demanda desses produtos;

- Clientes cada vez mais exigentes - os clientes de hoje estão exigindo um atendimento mais rápido, melhor qualidade e produtos com melhor desempenho, pelo mesmo preço 
que pagavam a anos atrás, ou seja, a cadeia deve oferecer mais para simplesmente manter seu negócio e

- Globalização - apesar das cadeias de suprimentos globais criarem muitos benefícios (como por exemplo, possuir fornecedores no mundo inteiro, podendo oferecer produtos melhores e mais baratos), ela também pode trazer problemas como a dificuldade em coordenar instalações muito distantes ou também aumento da concorrência.

\subsubsection{Conclusões sobre a integração da cadeia de suprimentos}

Segundo Kim (2006), se a empresa, através de uma integração sistemática da cadeia de suprimentos, conseguir compartilhar recursos e conhecimento tecnológico com seus parceiros, ela pode obter uma melhora significativa no desempenho através da obtenção de capacidade competitiva. Por outro lado, mesmo que uma empresa desfrute de excelentes capacidades operacionais, um alinhamento estratégico com seus parceiros na cadeia de suprimentos é indispensável para a melhora do desempenho. Entretanto, estabelecer uma parceria estratégica e colaborativa com parceiros da cadeia não é fácil, além de não existir garantias de que o estabelecimento das parcerias estratégicas colaborativas leve necessariamente à melhora do desempenho e do aumento da competitividade.

Para Power (2005), a integração de processos na cadeia de suprimento pode fornecer meios eficazes de redução de custos e melhorias de níveis de serviços ao consumidor. Contudo, a fórmula para a integração não é simples. Organizações que almejam tornar-se parte de uma rede de suprimento ampliada e integrada devem possuir uma infra-estrutura adequada para dar suporte a melhores fluxos de informação e atividades logísticas. Um componente chave desta nova estrutura é baseado em acordos colaborativos fortes e duráveis com parceiros comerciais. As cadeias mais eficazes serão aquelas capazes de integrar o conjunto formado por informações necessárias, atividades logísticas e colaboração, fornecendo benefícios compartilhados entre as organizações parceiras.

Por outro lado, de acordo com Gunasekaran et al. (2004), muitas empresas não estão conseguindo maximizar os resultados de sua cadeia de suprimentos porque muitas vezes não conseguiram desenvolver medidas de desempenho e métricas necessárias para integrar plenamente a cadeia para maximizar a eficácia e eficiência. 
Também para Rafele (2004), o desenvolvimento de um sistema de mensuração eficaz é uma questão muito difícil na integração da cadeia de suprimentos, pois devido à complexidade da interdependência entre todas as atividades da cadeia, seleção do que mensurar torna-se uma tarefa complicada.

Assim, torna-se claro a importância de se medir os resultados (desempenho) por toda a cadeia, no intuito de verificar seus reais benefícios. O tópico seguinte aborda este conceito, discutindo as métricas e os sistemas utilizados.

\subsection{Medidas de desempenho}

\subsubsection{Desempenhos individuais}

Antes de abordar o desempenho na cadeia de suprimentos, convém discorrer sobre os desempenhos individuais das empresas, ou seja, as métricas adotadas pelas empresas sem considerar sua interação na cadeia de suprimentos

\subsubsection{Histórico}

Kennerley e Neely (2003) e Morgan (2004), fazem um breve histórico sobre medidas de desempenho. Através da história, a medição de desempenho tem sido usada para avaliar o sucesso das organizações. O sistema moderno de contabilidade teve seu início na Idade Média, e desde esta época a avaliação de desempenho tem se baseado predominantemente em critérios financeiros (KENNERLEY; NEELY, 2003). De acordo com Morgan (2004), as raízes da medida de desempenho organizacional moderna estão em Veneza no século quinze, quando as bases da prática de contabilidade se iniciaram com a invenção do livro contábil de dupla entrada. A identificação do lucro e do controle do fluxo de caixa dominaram a medida de desempenho até 1900, quando William Durant, fundador da General Motors, se deu conta que o lucro não era simplesmente o resultado de um exercício contábil, mais sim o resultado de uma série de custos que se propagava dentro de uma cadeia de suprimentos. Enraizados no gerenciamento contábil, os conceitos tradicionais da medida de desempenho têm sido desafiados por profissionais de contabilidade assim como pelos acadêmicos.

Para Kennerley e Neely (2003), no início da década de 1980 havia uma crescente conscientização de que as medidas tradicionais de desempenho não eram mais suficientes para gerenciar organizações competindo nos mercados modernos. Com consumidores mais exigentes e mercados mais competitivos veio a necessidade de uma maior abrangência e foco 
externo para atividades. Muitos autores reconhecem que enquanto os sistemas tradicionais de contabilidade financeira indicam o desempenho resultante das atividades de uma organização, ela não fornece quase nenhuma indicação de como este desempenho foi atingido ou como pode ser melhorado. As deficiências nas medidas tradicionais de desempenho financeiro, e suas inadequações dadas às mudanças nos desafios competitivos encarados pelas empresas, foram largamente documentadas. Assim, vários autores sugerem que as medidas tradicionais de desempenho financeiro são históricas por natureza; fornecem pouca indicação do desempenho futuro, encorajando as ações de curto prazo; são focadas nos aspectos internos e não nos externos, com pouca consideração pelos concorrentes ou consumidores; pecam pela falta de foco estratégico; e com freqüência inibem as inovações. É amplamente aceito que as informações fornecidas pro tais sistemas baseados apenas em custos são insuficientes para o gerenciamento efetivo dos negócios nos mercados em constante mutação e altamente competitivos.

Assim, para Morgan (2004), vários argumentos contemporâneos surgiram para demonstrar que este tipo de medida de desempenho estava perdendo seu lugar. Eles argumentavam que as medidas de desempenho tradicionais estavam ainda baseadas na revolução industrial e se tornaram impróprias para os mercados radicalmente diferentes dos dias atuais.

Ainda segundo Morgan (2004) o medida do desempenho nas empresas é uma das tarefas chaves do gerenciamento integrado com atividades de planejamento, organização de atividades, motivação dos funcionários e controladoria. Dentro deste contexto, a medida de desempenho está relacionada com a estratégia e com o conjunto de métricas usadas pelos gerentes para monitorar e conduzir uma organização com base em parâmetros aceitáveis e desejáveis. No entanto, "desempenho" implica em parâmetros predeterminados e "medida" implica uma habilidade de monitorar eventos e atividades de uma forma significativa.

Neely et al. (1995) definem medida de desempenho como o processo de quantificar a eficácia e a eficiência de uma ação. Enquanto que a eficácia mede quais as necessidades dos clientes estão sendo atendidas, a eficiência mede economicamente como os recursos de uma empresa estão sendo usados para prover o nível pré-estabelecido de satisfação dos clientes. Em outras palavras, sistemas de medida de desempenho são descritos como o conjunto total de métricas usado para quantificar tanto a eficiência quanto a eficácia de uma ação. Em seus estudos, os autores definem o termo "métricas" como sendo um composto de medida, coleta de dados e 
responsabilidade para o cálculo. O termo métrico como foi definido, contem medidas reais e essencialmente as regras e procedimentos para a mensuração.

Complementando tais definições, segundo Waggoner et al. (1999), a medida de desempenho nas empresas serve para o acompanhamento do desempenho, identificando as áreas que necessitam atenção, aumentando a comunicação e o melhorando o gerenciamento.

De forma semelhante, Stainer (1997) define que um sistema de mensuração de desempenho é utilizado para determinar a eficiência de um sistema existente ou para comparar com sistemas alternativos concorrentes.

Nos estudos de Kutucuoglu et al. (2001) sobre medidas de desempenho, torna-se claro a importância da mensuração do desempenho nas empresas. Eles discutem alguns pontos, entre os quais:

- a mensuração do desempenho é a linguagem do progresso para a empresa. (indica onde a empresa está e para onde está se dirigindo), funcionando como um guia para saber se a empresa está no caminho correto para alcançar seus objetivos;

- a mensuração é uma atividade-chave de gestão que fornece aos tomadores de decisão as informações necessárias para a tomada de decisão, monitoramento do desempenho e alocação eficaz de recursos;

- a necessidade de se envolver os funcionários no desenvolvimento da mensuração de desempenho, pois eles são os indivíduos que operam os processos e que conhecem melhor as tarefas e

- a ocorrência do chamado "O fenômeno silo" em algumas praticas de mensuração do desempenho. Neste fenômeno, os gerentes só vêem suas empresas verticalmente e funcionalmente, tornando os departamentos em silos (estruturas altas, grossas e sem janelas), onde cada função esforça-se para alcançar suas metas. Essa otimização funcional freqüentemente contribui para a subotimização da empresa como um todo.

Ainda segundo os autores, um sistema de mensuração de desempenho eficaz deveria incluir as seguintes características: apresentar uma visão balanceada do sistema que está sendo mensurado; reconhecer múltiplas dimensões das medidas de desempenho; relacionar as 
medidas com os objetivos relevantes e com a estratégia empresarial; envolver funcionários para assegurar que eles dêem seu apoio e incluir tanto medidas subjetivas como objetivas.

De forma mais ampla, Amaratunga e Baldry (2002) definem o conceito de "Gerenciamento de Desempenho". Para eles, o "Gerenciamento de Desempenho" é a utilização das informações das medidas do desempenho afetando positivamente mudanças na cultura organizacional, nos sistemas e nos processos, ajudando a definir metas, alocando e priorizando recursos e compartilhando resultados em busca dessas metas. Para dar suporte a este gerenciamento, a empresa deve incluir estes elementos chaves:

- Uma metodologia estruturada para a concepção do sistema de medida de desempenho;

- Um estruturado processo de gerenciamento no uso das informações da medida de desempenho para ajudar na tomada de decisões, na definição de metas e na alocação de recursos;

- Um conjunto de especificações necessárias para as ferramentas eletrônicas que irão coletar processar e analisar os dados;

- Orientações teóricas sobre como gerenciar através de medidas e

- Um processo de revisão para garantir que as medidas sejam constantemente atualizadas de forma a refletir as mudanças na estratégia e/ou as condições de mercado.

Entre os indicadores utilizados, sem dúvida os indicadores financeiros são um dos mais utilizados pelas empresas, onde, apesar de receber várias críticas, possuem fiéis seguidores.

\subsubsection{Indicadores financeiros}

De acordo com Stadler e Kilger (2005), o objetivo de uma organização industrial é ser rentável e aumentar seus lucros (definidos como receita bruta menos custos dos produtos vendidos, despesas operacionais e impostos). Matias (2007) acrescenta também a necessidade de ser pensar na redução dos riscos.

Para Assaf Neto (2008), uma empresa possui duas grandes decisões financeiras:

- Decisão de investimento - envolve todo o processo de identificação, avaliação e seleção de alternativas de aplicações de recursos na expectativa de obtenção de benefícios econômicos futuros. Tais decisões criam valor e são economicamente 
atraentes quando o retorno esperado exceder a taxa de retorno exigida pelos proprietários de capital (credores e acionistas). Por outro lado, tais investimentos envolvem riscos, devendo ser avaliados em termos da relação risco-retorno e

- Decisão de financiamento - preocupa-se com a escolha das melhores ofertas de recursos e a melhor proporção a ser mantida (capital próprio ou de terceiros), com o objetivo central de determinar a melhor estrutura de financiamento da empresa, de forma a preservar sua capacidade de pagamento e de obter fundos com custos reduzidos em relação ao retorno que se espera da aplicação desses recursos. Nesta decisão também podem ser incluídas as decisões de dividendos (distribuição de parte dos lucros aos acionistas), pois a retenção desses dividendos pode ser uma alternativa de financiamento.

Sobre os indicadores financeiros tradicionais, Gitman (1997) descreve duas abordagens tradicionais para uma análise completa dos índices financeiros:

- Sistema DuPont - este sistema funde a Demonstração do Resultado do Exercício (DRE) e o Balanço Patrimonial em duas medidas de lucratividade: a taxa de retorno sobre o ativo total (ROA) e a taxa de retorno sobre o patrimônio líquido (ROE). O ROA é calculado pela multiplicação da margem líquida pelo giro do ativo total e o ROE se dá pela multiplicação o ROA pelo multiplicador de alavancagem financeira (MAF). O Sistema DuPont encontra-se na íntegra no Anexo A;

- Análise Geral dos Índices - neste modelo, os indicadores são classificadores em quatro categorias: (1) liquidez (mede a capacidade da empresa satisfazer suas obrigações de curto prazo), (2) atividade (mede a rapidez com que as contas circulantes - estoques, duplicatas a receber e a pagar - são convertidas em caixa), (3) endividamento (mede o montante de recursos de terceiros que está sendo usado na tentativa de gerar lucros) e (4) lucratividade (mede a lucratividade da empresa em relação a suas vendas, ativos, patrimônio líquido e ao valor da ação). Todos os indicadores estão no Anexo B.

Para Walters (1999), o acionista é o proprietário da empresa e, conseqüentemente, a "pessoa corporativa" a quem ela deve prestar contas. Assim, o desempenho da empresa deve ser gerido com a finalidade de maximizar o retorno para os investimentos dos acionistas no negócio. 
Neste contexto, Matias (2007), Assaf Neto (2008) e Rebehy (2007) identificam algumas ferramentas para medir o valor gerado ao acionista:

- Valor Econômico Agregado (Economic value added - EVA) - foi utilizado pioneiramente em Nova York por Stern Stewart, podendo ser calculado da seguinte maneira:

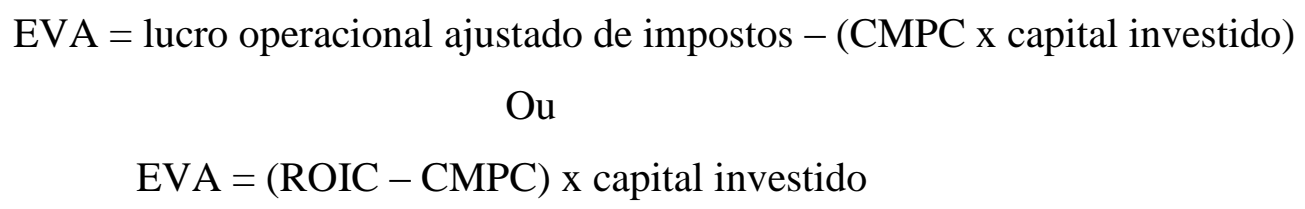

Onde: lucro operacional ajustado de impostos (também conhecido como NOPAT)

CMPC é o custo médio ponderado de capital (ou WACC)

ROIC é o retorno sobre o capital investido

Assim, um EVA positivo implica que o valor dos acionistas foi criado, enquanto um EVA negativo sugere que é necessário tomar uma ação imediata. O EVA também sugere que quaisquer aquisições prospectivas de ativos que darão um retorno menor que o CMPC não deveriam ser realizadas.

- Valor a mercado - o valor de mercado de uma empresa se dá pela multiplicação do preço da ação no mercado pela quantidade total de ações da empresa. Este método tem como uma grande vantagem a facilidade de aplicação, mas por outro lado só pode ser aplicado a empresas que possuem papeis negociados em bolsas de valores.

- Valor agregado pelo mercado (Market value added - MVA) - reflete a riqueza gerada aos proprietários de capital determinada pela capacidade da empresa em produzir resultados maiores ao seu custo de oportunidade (também pode ser encarado como quanto a empresa vale adicionalmente ao que se gastaria para repor todos o seus ativos a preços de mercado). O MVA é calculado pela diferença entre o valor total de mercado da empresa (calculado pelo produto do preço de mercado de suas ações e a quantidade de ações no mercado mais o valor de mercado de seus passivos) e o montante investido pelos acionistas e credores. Outra forma de se calcular o MVA é pela divisão do EVA pelo CMPC (ASSAF NETO, 2008). 
- Retorno sobre o investimento base caixa (Cash flow return on investment - CFROI) representa o valor presente dos fluxos de caixa livres futuros dos ativos existentes, onde o fluxo de caixa livre é o valor que está disponível aos investidores, após os impostos, provenientes das operações empresariais e investimentos em ativos. Esses fluxos futuros são trazidos a valor presente por uma taxa, que é calculada pelo custo de capital total da empresa, baseado em uma taxa mínima de atratividade (REBEHY, 2007).

Assaf Neto (2008) ainda discorre sobre as formas que uma empresa pode ser avaliada. A maximização do lucro atualmente é uma medida muito questionada, pois (1) o lucro não define a efetiva capacidade financeira de pagamento da empresa (seu critério de apuração é baseado em regime de competência e não no regime de caixa), (2) o lucro contábil não considera o risco inerente à atividade da empresa, (3) o lucro não representa o efetivo desempenho da empresa (a empresa deve ser avaliada como um todo - potencial de lucro, tecnologia, qualidade dos produtos, etc. e não somente por um único componente) e (4) o lucro ignora o valor da moeda no tempo (investidores dão maior importância aos fluxos de caixa que proporcionem, em termos equivalentes, maior riqueza inicial). Outras medidas também propostas pela literatura como o crescimento das vendas, a rentabilidade, o endividamento e liquidez, entre outras, também não podem ser isoladamente utilizadas como um eficiente processo de tomada de decisões financeiras, pois também não consideram aspectos importantes como: realização de resultados em termos de caixa, valor da moeda no tempo e diferentes níveis de riscos associados às decisões financeiras.

Ainda segundo o autor, o valor de mercado da empresa (mais precisamente a riqueza dos acionistas) é considerado o critério mais indicado para a tomada de decisões financeiras. Pelo valor de mercado, os benefícios operacionais produzidos pela empresa são expressos com base em fluxos de caixa e descontados a valor presente mediante uma taxa de atratividade (embutida a remuneração mínima exigida pelos proprietários diante do risco assumido). Em outras palavras, o valor de uma empresa depende de seu desempenho futuro esperado (do que ela é capaz de produzir) e não do capital aplicado em seus ativos, e é função dos benefícios econômicos esperados de caixa, do risco associado a esses resultados e da taxa de retorno requerida pelos investidores. 
Para Walters (1999), os críticos sugerem que o MVA tem uma vantagem sobre o EVA, pois enquanto o EVA mensura o sucesso de uma empresa durante o ano anterior, o MVA "olha para frente", refletindo a avaliação pelo mercado das perspectivas de uma empresa.

Além dos indicadores puramente financeiros, a literatura aponta a necessidade de se buscar métricas para mensurar outras perspectivas, que será discutido a seguir como "indicadores balanceados".

\subsubsection{Indicadores balanceados}

$\mathrm{Na}$ busca de um sistema de avaliação de desempenho mais equilibrado, Kaplan e Norton (1992) propuseram o modelo do Balanced Scorecard (BSC) como um meio de avaliar o desempenho da empresa em quatro diferentes perspectivas, conforme mostra a ilustração 30: a financeira, a de processos internos, a de consumidores e a de aprendizado e crescimento. Para os autores, a utilização apenas dos indicadores financeiros já não eram suficientes para avaliar o desempenho das empresas. Por outro lado, enquanto algumas empresas concentram-se em medidas financeiras de desempenho, outras têm se concentrado em medidas operacionais. Tal desigualdade não conduz às métricas que podem apresentar uma imagem clara do desempenho organizacional.

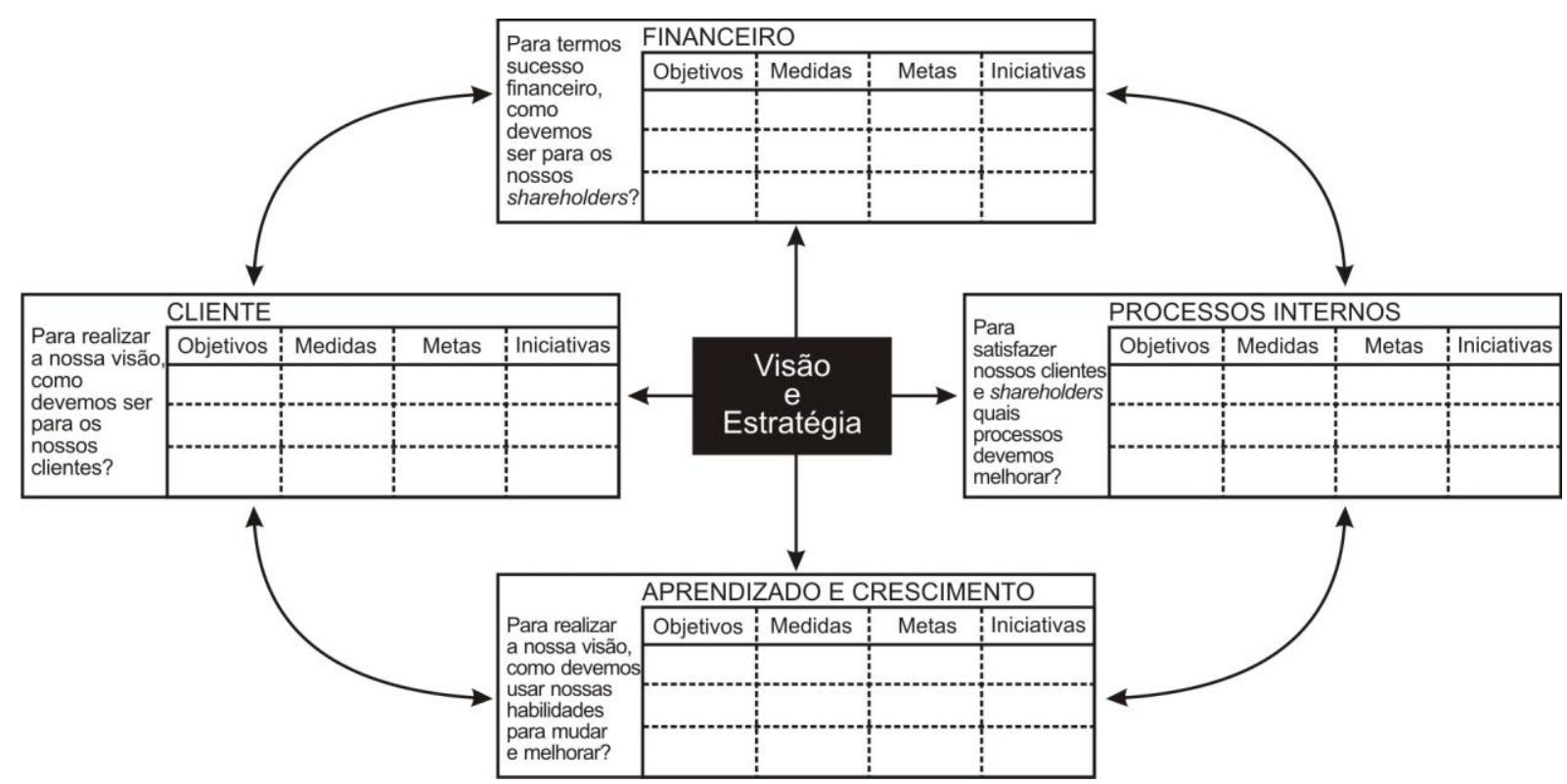

Ilustração 30 - As perspectivas do Balanced Scorecard (BSC)

FONTE: KAPLAN; NORTON, 1992 
Assim, segundo os autores, as empresas, ao criarem seus sistemas de mensuração de desempenho, devem procurar um conjunto equilibrado de indicadores, contendo indicadores financeiros, dos clientes, dos processos internos e de aprendizagem e crescimento.

Para Bhagwat e Sharma (2007), o modelo do Balanced Scorecard busca manter o equilíbrio entre objetivos de curto e longo prazo, entre avaliações financeiras e não financeiras, entre perspectivas de desempenho interna e externa.

Assim, após discorrer sobre os indicadores individuais, o próximo tópico aborda a medida de desempenho na cadeia de suprimentos.

\subsubsection{Desempenho na Cadeia de Suprimentos}

Para Gunasekaran et al. (2004), o gerenciamento da cadeia de suprimentos é necessário para administrar e controlar os fluxos nos sistemas operacionais, como controle de estoque e das atividades de planejamento de todos os recursos e restrições de tempo. Complementando esses fluxos, as empresas devem encontrar objetivos estratégicos de qualidade, rapidez, flexibilidade e custos. Para cumprir esses objetivos, as saídas dos processos da cadeia de suprimentos devem ser medidas e comparadas com uma série de indicadores padrões. Assim, para os processos serem controlados, os valores devem ser mantidos dentro de um limite definido e permanecerem, relativamente constantes.

De acordo com Gunasekaran et al. (2004), as métricas e medidas de desempenho têm um papel importante a desempenhar na determinação de objetivos, avaliação de desempenho e determinação das ações futuras nas empresas, porém para o gerenciamento da cadeia de suprimentos elas não estão recebendo suficiente atenção de pesquisadores ou profissionais.

Segundo Shepherd e Gunter (2006), para o gerenciamento da cadeia de suprimentos, apesar da necessidade de novos sistemas de medidas de desempenho, pois os sistemas tradicionais apresentam deficiências, a atenção dada esses novos sistemas ainda é escassa na literatura. Entre fatores que devem ser investigados sobre esse tema, pode-se destacar: fatores que influenciam a implementação bem sucedida de sistemas de desempenho, forças que moldam a evolução dos sistemas de desempenho e como manter esses sistemas atualizados para atender ambientes dinâmicos e mudanças de estratégias. 
De acordo com Holmberg (2000), os possíveis problemas na utilização das métricas atuais para a avaliação da cadeia de suprimentos são: falta de conexão entre a estratégia empresarial e as medidas de desempenho, tendência de utilizar apenas indicadores financeiros, uso de indicadores isolados (falta de integração entre as empresas) e falta de consideração das características da cadeia (complexidade, diferentes culturas, etc.).

Também, de acordo com Simatupang e Sridharan (2002), as medidas tradicionais e individuais de desempenho são consideradas inapropriadas para medir a maximização da lucratividade na cadeia de suprimentos e, em muitos casos, os membros não possuem métricas que refletem essa lucratividade da cadeia. Além disso, o desempenho da cadeia é medido de maneira muito simplificada e algumas vezes contra-produtivas como, por exemplo, baseado na redução de custos (o problema de medidas centradas no custo é utilizá-los para tenta minimizar os custos individuais e não maximizar o valor entregue aos consumidores finais). Assim, os autores acreditam que as métricas de desempenho da cadeia deveriam mensurar toda a cadeia e não apenas os membros individualmente e que o foco do sistema de mensuração de desempenho deveria ser na melhoria contínua para os consumidores finais, pois consumidores satisfeitos é que geram todas as vendas da cadeia.

De acordo com Lambert e Pohlen (2001), muitos fatores contribuem para a necessidade de se criar novos métodos de avaliação para gerenciar a cadeia de suprimentos incluindo:

- A falta de métricas que avalie o desempenho por toda a cadeia de suprimentos;

- A necessidade de ir além das métricas internas e adotar a perspectiva de cadeia de suprimentos;

- A necessidade de determinar a relação entre o desempenho da empresa e da cadeia de suprimentos;

- A complexidade do gerenciamento da cadeia de suprimentos;

- A necessidade de alinhar atividades e compartilhar informações de medidas de desempenho para implementar estratégias que atinjam os objetivos da cadeia de suprimentos;

- O desejo de expandir a visibilidade por toda cadeia de suprimentos;

- A necessidade de repartir benefícios e encargos resultantes das mudanças funcionais por toda a cadeia de suprimentos e 
- A necessidade de diferenciar a cadeia de suprimentos para conseguir uma vantagem competitiva.

Ainda segundo os autores, muitas medidas de desempenho utilizadas para avaliar a cadeia de suprimentos são na verdade medidas de operações logísticas internas individuais. A maioria são mensurações focadas apenas na logística de uma empresa como lead time, níveis de estoques, desempenho de tempo, índices de atraso, refugos e velocidade de resposta de produção e não são mensurações conjuntas das empresas que formam a cadeia de suprimentos.

Como exemplo do uso incorreto das medidas individuais para a análise do desempenho da cadeia de suprimentos, Lambert e Pohlen (2001) comentam o uso do giro de estoque. Para eles, o giro de estoque falha em não identificar diferenças de custo e risco ao longo da cadeia. Ao chegar mais próximo do ponto de consumo, um produto tem seu valor (preço) aumentado. Conseqüentemente, se o custo de oportunidade do dinheiro e o giro de estoque forem similares, o custo unitário de manutenção do estoque é muito maior no nível do varejo, e uma melhora no giro do estoque pelo varejista tem muito mais efeito no desempenho geral da cadeia de suprimentos do que uma melhora no giro de um fornecedor, ou fabricante. Este exemplo ilustra que a prática comum de empurrar estoque para frente na cadeia de suprimentos pode reduzir o desempenho da cadeia. A tabela 3 mostra esse efeito.

Tabela 3 - Como a posição na cadeia de suprimentos afeta o custo de manutenção de estoque

\begin{tabular}{lccccc}
\hline & Fornecedor & Fabricante & $\begin{array}{c}\text { Distribuidor/ } \\
\text { Atacadista }\end{array}$ & Varejista \\
\hline Custo unitário do produto em estoque & $\$ 5$ & $\$ 25$ & $\$ 62$ & $\$ 72$ \\
Custo anual de manutenção do estoque $(\%)$ & $36 \%$ & $36 \%$ & $36 \%$ & $36 \%$ \\
Custo unitário de manutenção com: & 1 giros & $\$ 1,80$ & $\$ 9,00$ & $\$ 22,32$ & $\$ 25,92$ \\
& 2 giros & $\$ 0,90$ & $\$ 4,50$ & $\$ 11,16$ & $\$ 12,96$ \\
& 3 giros & $\$ 0,60$ & $\$ 3,00$ & $\$ 7,44$ & $\$ 8,64$ \\
& 4 giros & $\$ 0,45$ & $\$ 2,25$ & $\$ 5,58$ & $\$ 6,48$ \\
& 5 giros & $\$ 0,36$ & $\$ 1,80$ & $\$ 4,46$ & $\$ 5,18$ \\
& 6 giros & $\$ 0,30$ & $\$ 1,50$ & $\$ 3,72$ & $\$ 4,32$ \\
& 7 giros & $\$ 0,26$ & $\$ 1,29$ & $\$ 3,19$ & $\$ 3,70$ \\
& 8 giros & $\$ 0,23$ & $\$ 1,13$ & $\$ 2,79$ & $\$ 3,24$ \\
& 9 giros & $\$ 0,20$ & $\$ 1,00$ & $\$ 2,48$ & $\$ 2,88$ \\
10 giros & $\$ 0,18$ & $\$ 0,90$ & $\$ 2,23$ & $\$ 2,59$ \\
11 giros & $\$ 0,16$ & $\$ 0,82$ & $\$ 2,03$ & $\$ 2,36$ \\
12 giros & $\$ 0,15$ & $\$ 0,75$ & $\$ 1,86$ & $\$ 2,16$ \\
\hline
\end{tabular}

FONTE: LAMBERT; POHLEN, 2001

O giro de estoque também não considera o fator risco. Quanto mais próximo do ponto de venda estiver o estoque, maior o risco do produto não atingir exatamente os requisitos dos 
consumidores. Assim, empurrar o estoque para trás e adiar sua forma final permite a cadeia de suprimentos evitar maiores custos de obsolescência. Ainda segundo os autores, o uso do custo total de manutenção do estoque por toda cadeia seria uma melhor maneira de medir o desempenho da mesma, sendo ele melhorado ao empurrar o estoque para o início da cadeia de suprimentos (rumo ao ponto de origem).

Segundo Rafele (2004), a literatura aponta algumas métricas usadas na medida de desempenho da cadeia, sendo elas: qualidade, tempo, flexibilidade, custo, satisfação do cliente, utilização dos recursos e indicadores financeiros. $\mathrm{O}$ autor ainda argumenta que para determinar as medidas de desempenho, a cadeia de suprimento deve ser dividida em suas ligações elementares (cada uma delas inclui atividades para transformar entradas em saídas), onde três pontos principais devem ser analisados: lado das entradas para a atividade de compras, transformação para a atividade de produção e lado das saídas para a atividade de distribuição. Os lados das entradas e saídas relacionam-se aos fornecedores e clientes e a transformação com as atividades internas da empresa.

Para Busi e Bititci (2006), enquanto que o foco nas medidas tradicionais de desempenho era nos processos operacionais internos a empresa, os princípios atuais procuram considerar as compras, a qualidade das mercadorias e o monitoramento dos fornecedores, porém um conceito mais amplo que busca avaliar redes mais abrangentes e empresas colaborativas ainda não está totalmente desenvolvido. Isso explica a crescente preocupação das pesquisas acadêmicas em criar um método de desempenho de redes empresarias. Mas, segundo os autores, as empresas estão ainda incapazes ou relutantes em medir e gerenciar o desempenho colaborativamente com seus parceiros.

Para Simatupang e Sridharan (2002), um sistema de mensuração de desempenho da cadeia de suprimentos deve focar num melhoramento contínuo para todos os membros da cadeia, bem como para os consumidores finais e outros stakeholders.

Segundo Searcy (2002), se as empresas da cadeia de suprimentos possuírem metas focadas no consumidor final, as empresas, por começarem a entender melhor seus clientes poderão apresentar melhores ganhos. Para eles, apesar do custo ser um dos principais objetivos da cadeia de suprimentos, o aumento da preocupação com os clientes gera um melhor direcionamento as práticas do Gerenciamento da Cadeia de suprimentos. Assim, as empresas 
devem enxergar além da redução de custo e entender o gerenciamento da cadeia como uma oportunidade de crescimento.

Para Hadaya e Cassivi (2007), o estudo da flexibilidade é elemento de grande importância para empresas que querem sobreviver em um ambiente dinâmico (de alta incerteza), sendo ela uma medida de desempenho chave em uma cadeia de suprimentos. Vickery et al. (1999) definem que a flexibilidade de uma empresa em um contexto de cadeia de suprimentos envolve cinco dimensões-chave: (1) flexibilidade de volume - representa a habilidade da empresa de ajustar a capacidade de produção; (2) flexibilidade de lançamento - representa a habilidade da empresa em introduzir rapidamente novos produtos ou variações de produtos; (3) flexibilidade de acesso - relativo a habilidade da empresa em atender toda a ampla rede de distribuição; (4) flexibilidade de produto - relativo a habilidade da empresa em produzir e customizar produtos com várias características e opções; e (5) responsividade ao mercado representa a habilidade da empresa em responder às necessidades e desejos de seus mercadosalvo.

Nos estudos de Shepherd e Gunter (2006), apesar de iniciativas surgirem no desenvolvimento de novos sistemas de medidas de desempenho, não há um consenso sobre o modo mais apropriado de categorizá-las. Alguns exemplos de como as métricas têm sido agrupadas são:

- Se são qualitativas ou quantitativas;

- O que medem - custo ou não; qualidade, custo, entrega e flexibilidade; custo, qualidade utilização de recursos, flexibilidade, visibilidade, confiança e inovação; recursos, produções e flexibilidade; eficiência de colaboração, eficiência de coordenação e configuração; entrada, saídas e medidas compostas;

- Se o foco estratégico, operacional e tático e

- Com quais processos da cadeia de suprimento elas relacionam.

Lambert e Pohlen (2001) sugerem um modelo para desenvolvimento de métricas para a cadeia de suprimentos. A estrutura começa com uma empresa focal e se move um elo (par de empresas fornecedor/cliente) por vez, de modo a alinhar o desempenho do início ao fim da cadeia com o objetivo geral de maximizar valor aos investidores de todas as empresas. $\mathrm{O}$ modelo consiste em sete passos: 
- Mapear a cadeia de suprimentos do ponto de origem ao ponto de consumo, identificando os fluxos de materiais e serviços, de forma a detectar a existência de elos importantes;

- Utilizar os processos de gerenciamento relacionamento com clientes e com fornecedores para analisar cada elo e determinar onde se pode adicionar valor na cadeia de suprimentos;

- Desenvolver relatórios de receitas e prejuízos dos clientes e fornecedores para descobrir o efeito do relacionamento na lucratividade e no valor adicionado aos investidores para as duas empresas;

- Realinhar processos e atividades da cadeia de suprimentos para alcançar os objetivos de desempenhos;

- Estabelecer mensurações não financeiras que alinhem o comportamento individual com os objetivos e metas financeiras da cadeia de suprimentos;

- Comparar o valor adicionado aos investidores e valorização de mercado das empresas com os objetivos estabelecidos e revisar processos e avaliações de desempenho quando necessário e

- Repetir os passos em cada elo da cadeia de suprimentos.

Para Morgan (2004), um sistema de medida de desempenho para a cadeia de suprimentos deve abordar dois elementos principais: (1) as medidas de desempenho devem estar relacionadas com a estratégia da empresa, ser partes de um sistema integrado de controle, ter validade interna e possibilitar um gerenciamento pró-ativo e (2) o sistema de medida deve ser dinâmico (monitorar em tempo real medidas internas e externas), intra-conectado (tanto externa como internamente), focado (de acordo com as estratégias) e praticável (medidas possíveis de serem alcançadas).

Segundo Hugos (2003), o desempenho da cadeia de suprimentos deve ocorrer de acordo com quatro dimensões:

- Serviço ao Consumidor - mensura a habilidade da cadeia em satisfazer as expectativas de seus consumidores. Algumas métricas são: tempo de resposta ao cliente, taxa de atendimento total do pedido (pedido completo), taxa de entregas no prazo, número de pedidos pendentes e taxa de retorno; 
- Eficiência Interna - refere-se à habilidade da empresa ou da cadeia em operar de maneira a gerar um nível apropriado de lucratividade. Algumas possíveis métricas: valor do estoque, giro do estoque, retorno sobre vendas e tempo total do fluxo de caixa;

- Flexibilidade da Demanda - mensura a habilidade de responder à incerteza nos níveis de demanda do produto. Possíveis métricas: tempo de ciclo da atividade; flexibilidade perante aumento de pedidos e flexibilidade externa e

- Desenvolvimento de produto - abrange a habilidade de uma empresa e da cadeia em continuar evoluindo conforme as necessidades do mercado. Algumas métricas são: quantidade de novos produtos introduzidos no mercado, porcentagem de vendas dos produtos introduzidos e tempo para desenvolver e entregar um novo produto.

Beamon (1998), após um levantamento sobre o que existia na literatura sobre análise de desempenho na cadeia de suprimentos, concluiu que as medidas baseavam-se basicamente em custos ou na responsividade ao cliente. O quadro 12 demonstra as medidas propostas.

Quadro 12 - Medidas de desempenho segundo BEAMON, 1998

\begin{tabular}{|c|c|c|}
\hline $\begin{array}{c}\text { Medidas } \\
\text { Qualitativas }\end{array}$ & & $\begin{array}{l}\text { - Satisfação do cliente } \\
\text { - Flexibilidade } \\
\text { - Integração de informação e fluxo de materiais } \\
\text { - Gerenciamento efetivo de risco } \\
\text { - Desempenho do fornecedor. }\end{array}$ \\
\hline \multirow{2}{*}{$\begin{array}{c}\text { Medidas } \\
\text { Quantitativas }\end{array}$} & Medidas baseadas em custo & $\begin{array}{l}\text { - Minimização de custo } \\
\text { - Maximização de vendas } \\
\text { - Maximização de lucro } \\
\text { - Minimização de investimento em estoque } \\
\text { - Maximização de retorno sobre o investimento }\end{array}$ \\
\hline & $\begin{array}{l}\text { Medidas baseadas na } \\
\text { responsividade ao cliente }\end{array}$ & $\begin{array}{l}\text { - Maximização da taxa de satisfação } \\
\text { - Minimização de atraso de produto } \\
\text { - Minimização de tempo de resposta do consumidor } \\
\text { - Minimização de lead-time } \\
\text { - Minimização de retrabalho }\end{array}$ \\
\hline
\end{tabular}

FONTE: BEAMON, 1998

No ano seguinte, a mesma autora evoluiu suas pesquisas sobre a análise de desempenho da cadeia e fez algumas críticas. Assim, Beamon (1999) avalia algumas limitações das medidas de desempenho existentes:

- Uso de medidas isoladas de desempenho da cadeia de suprimentos - o uso de uma medida isolada de desempenho é atraente devido a sua simplicidade, porém deve-se 
assegurar que se uma medida isolada for utilizada, ela tem que descrever adequadamente o desempenho da cadeia;

- Uso do custo como uma medida isolada de desempenho da cadeia de suprimentos apesar do custo ser uma importante medida de recursos, não se pode confiar no custo como a única medida de desempenho, pois podem ocorrer distorções ou avaliações incorretas de custos de estoques, como a omissão da obsolescência e do retrabalho (após mudanças de engenharia) e

- Inconsistências entre objetivos estratégicos e medidas de desempenho da cadeia de suprimentos - as medidas de desempenho de uma empresa estão diretamente relacionadas com a estratégia de produção escolhida pela empresa. Porém em uma cadeia de suprimentos pode ocorrer de cada membro possuir estratégias diferentes e assim utilizarem indicadores diferentes de desempenho.

Assim a autora afirma que o uso de medidas individuais de desempenho não é aconselhado, pois importantes características da cadeia de suprimentos e suas relações são ignoradas e, nesse contexto, sugere um modelo de análise de desempenho da cadeia de suprimentos baseado em três tipos de medida de desempenho:

- Medidas de recursos (R) - as medidas de recursos incluem níveis de estoques, necessidades de funcionários, utilização dos equipamentos, consumo de energia e custos;

- Medidas de saídas (S) - as medidas de saídas incluem: responsividade ao consumidor, qualidade e a quantidade produzida do produto final. Muitas medidas de desempenho de saídas são facilmente representadas numericamente, como o número de itens produzidos, o tempo necessário para produzir um item particular ou conjunto de itens e o número de entregas no prazo (pedidos). Porém, existem muitas outras que são muito mais difíceis de serem expressas numericamente, como a satisfação do consumidor e a qualidade do produto e

- Medidas de flexibilidade $(\mathrm{F})$ - pode mensurar a habilidade de um sistema em acompanhar flutuações de volume e planejamento dos fornecedores, produtores e consumidores.

O quadro 13 ilustra os tipos de medidas, seus objetivos e seus propósitos, bem como uma lista de alguns possíveis indicadores para cada uma delas. 
Quadro 13 - Medidas de desempenho segundo BEAMON, 1999

\begin{tabular}{|c|c|c|c|}
\hline Tipo & Objetivo & Propósito & Possíveis indicadores \\
\hline Recursos & $\begin{array}{l}\text { Alto nível de } \\
\text { eficiência }\end{array}$ & $\begin{array}{c}\text { O } \\
\text { gerenciamento } \\
\text { eficiente dos } \\
\text { recursos é } \\
\text { crítico para a } \\
\text { rentabilidade }\end{array}$ & $\begin{array}{l}\text { - Custo total - Custo total dos recursos utilizados } \\
\text { - Custos de distribuição - Custo total de distribuição, } \\
\text { incluindo custos de transporte e manuseio } \\
\text { - Custo de produção - Custo total de produção, } \\
\text { incluindo custos de mão-de-obra, manutenção e } \\
\text { retrabalho } \\
\text { - Estoques - Custos associados com a manutenção do } \\
\text { estoque (investimento em estoques; obsolescência e } \\
\text { avarias do estoque; produto em processo, produtos } \\
\text { acabados) } \\
\text { - Retorno do Investimento (ROI) - Mensura a } \\
\text { lucratividade de uma empresa, geralmente obtido pela } \\
\text { razão entre lucro líquido e os ativos totais }\end{array}$ \\
\hline Saídas & $\begin{array}{l}\text { Alto nível de } \\
\text { serviço ao } \\
\text { cliente }\end{array}$ & $\begin{array}{l}\text { Sem saídas } \\
\text { aceitáveis } \\
\text { (bons } \\
\text { produtos), os } \\
\text { clientes } \\
\text { mudarão de } \\
\text { cadeia de } \\
\text { suprimentos }\end{array}$ & $\begin{array}{l}\text { - Vendas - Receita total } \\
\text { - Lucro - Receita total menos despesas } \\
\text { - Taxa de atendimento - Proporção de pedidos atendidos } \\
\text { imediatamente (Realização do nível-alvo de } \\
\text { atendimento; nível médio de atendimento de um item) } \\
\text { - Entregas no prazo - Mensura o desempenho da entrega } \\
\text { de um item, pedido ou produto (atraso do produto; } \\
\text { atraso médio de pedido; antecipação média de pedidos; } \\
\text { porcentagem de pedidos entregues no prazo) } \\
\text { - Pedidos pendentes/falta de estoque - Mensura o } \\
\text { desempenho da disponibilidade de um item, pedido ou } \\
\text { produto (probabilidade de falta de estoque; número de } \\
\text { pedidos pendentes; número de faltas de estoques; nível } \\
\text { médio de pendências) } \\
\text { - Tempo de resposta do consumidor - Quantidade de } \\
\text { tempo entre um pedido e sua correspondente entrega } \\
\text { - Lead time de produção - Quantidade total de tempo } \\
\text { necessária para produzir um item ou lote particular } \\
\text { - Erros de despacho - Número de despachos incorretos } \\
\text { efetuados } \\
\text { - Reclamações do consumidor - Número registrado de } \\
\text { reclamações de consumidores. }\end{array}$ \\
\hline Flexibilidade & $\begin{array}{c}\text { Habilidade } \\
\text { para responder } \\
\text { às mudanças } \\
\text { do ambiente }\end{array}$ & $\begin{array}{l}\text { Em um } \\
\text { ambiente de } \\
\text { incertezas, a } \\
\text { cadeia de } \\
\text { suprimentos } \\
\text { tem que ser } \\
\text { capaz de } \\
\text { responder às } \\
\text { mudanças }\end{array}$ & $\begin{array}{l}\text { - Habilidade de adaptar-se e acomodar variações de } \\
\text { demanda, como sazonalidade } \\
\text { - Habilidade de adaptar-se e acomodar períodos de } \\
\text { baixo desempenho da produção (avarias de máquinas) } \\
\text { - Habilidade de adaptar-se e acomodar períodos de } \\
\text { baixo desempenho do fornecedor } \\
\text { - Habilidade de adaptar-se e acomodar períodos de } \\
\text { baixo desempenho de entrega } \\
\text { - Habilidade de adaptar-se e acomodar novos produtos, } \\
\text { novos mercados ou novos concorrentes }\end{array}$ \\
\hline
\end{tabular}

FONTE: BEAMON, 1999

Um estudo bastante detalhado foi realizado por Lambert e Burduroglu (2000) sobre avaliação de desempenho da logística, tanto para a empresa quanto para a cadeia como um todo. Segundo os autores, o desempenho deve ser analisado segundo o valor gerado pela logística aos stakeholders. Seis são as maneiras de medir esse valor: Satisfação dos clientes, Valor 
adicionado aos clientes (Customer value-added - CVA), Análise de Custo Total, Análise de rentabilidade, Modelo Estratégico de Rentabilidade (Strategic Profit Model - SPM) e Valor para os acionistas.

- Satisfação dos clientes - a satisfação dos clientes ocorre quando as empresas cumprem as suas obrigações com êxito em todos os componentes do mix de marketing: produto, preço, promoção (comunicação) e lugar (distribuição). A satisfação do cliente é uma medida crucial, uma vez que permite alinhar a gestão do pacote de serviços da empresa com as necessidades dos clientes. Níveis mais elevados de serviço aos clientes podem ter um impacto direto sobre os resultados financeiros por meio de maiores receitas. Para medir a satisfação dos clientes, geralmente utilizam-se levantamentos (survey) com aplicação de questionários. A medida de satisfação dos clientes não deve ser a única utilizada para avaliar o valor agregado pela logística, mas sim deve ser analisada em conjunto com custos e receitas;

- Valor adicionado ao cliente (Customer value-added - CVA) - o valor adicionado ao cliente mede o valor percebido pelo cliente em relação à empresa em comparação com o valor percebido pela empresa com relação aos seus concorrentes. O valor que o cliente espera receber por um produto ou serviço pode ser dado pela fórmula abaixo:

Valor esperado pelo cliente $=($ Benefícios percebidos $) /($ Sacrifícios percebidos $)$

Onde: Benefícios percebidos $=$ atributos do produto + atributos dos serviços Sacrifícios percebidos $=$ custo de transação + custo do ciclo de vida + riscos

Com isso, o CVA pode ser calculado como: $\mathrm{CVA}=$ (Valor percebido dos produtos/serviços da empresa) / (Valor percebido dos produtos/serviços dos concorrentes).

Assim, uma empresa pode aumentar o valor para o cliente ou aumentando a qualidade dos produtos e serviços ou reduzindo os custos de transação, do ciclo de vida ou de riscos.

- Análise de Custo Total - pode ser definida como sendo minimizar os custos totais da logística, incluindo transporte, armazenagem, estoques, processamento de pedidos, 
compras e sistemas de informação, bem como os custos produtivos, dado um determinado nível de serviço ao cliente. Como em muitos casos os custos logísticos representam boa parte dos custos empresariais, sua análise é sempre indicada. A redução dos custos logísticos representa uma criação de valor para a empresa, porém deve-se notar que o objetivo é a redução dos custos totais da cadeia e, conseqüentemente, a criação de valor por toda a cadeia de suprimentos.

- Análise de rentabilidade - este método não avalia apenas os custos, mas também as receitas. Entre as maneiras de analisar a rentabilidade, o método segmentando pela margem de contribuição parece ser uma medida de valor mais apropriada quando existem diferenças de receitas de acordo com o fornecedor;

- Modelo Estratégico de Rentabilidade (Strategic Profit Model - SPM) - uma limitação da Análise de Custo Total e Análise de Rentabilidade é que eles não medem os custos dos ativos que não sejam estoque e contas a receber. Assim, o SPM demonstra como o gerenciamento dos ativos e da margem irão influenciar o retorno sobre os ativos e o retorno sobre o patrimônio líquido, que é o retorno dos investimentos dos acionistas acrescidos de lucros retidos. A ilustração 31 mostra como as atividades logísticas afetam o retorno sobre o patrimônio líquido. Como exemplo da análise desse gráfico, um melhor gerenciamento da logística (por exemplo, medido pelo lead time, disponibilidade de estoque e taxa de preenchimento de pedido) pode resultar em maiores vendas, provenientes de maior valor adicionado, maiores volumes ou redução no tempo de introdução de novos produtos no mercado. Também menores custos de compras e de matéria prima podem resultar em menores custos dos bens vendidos. 
Impactos da Logística

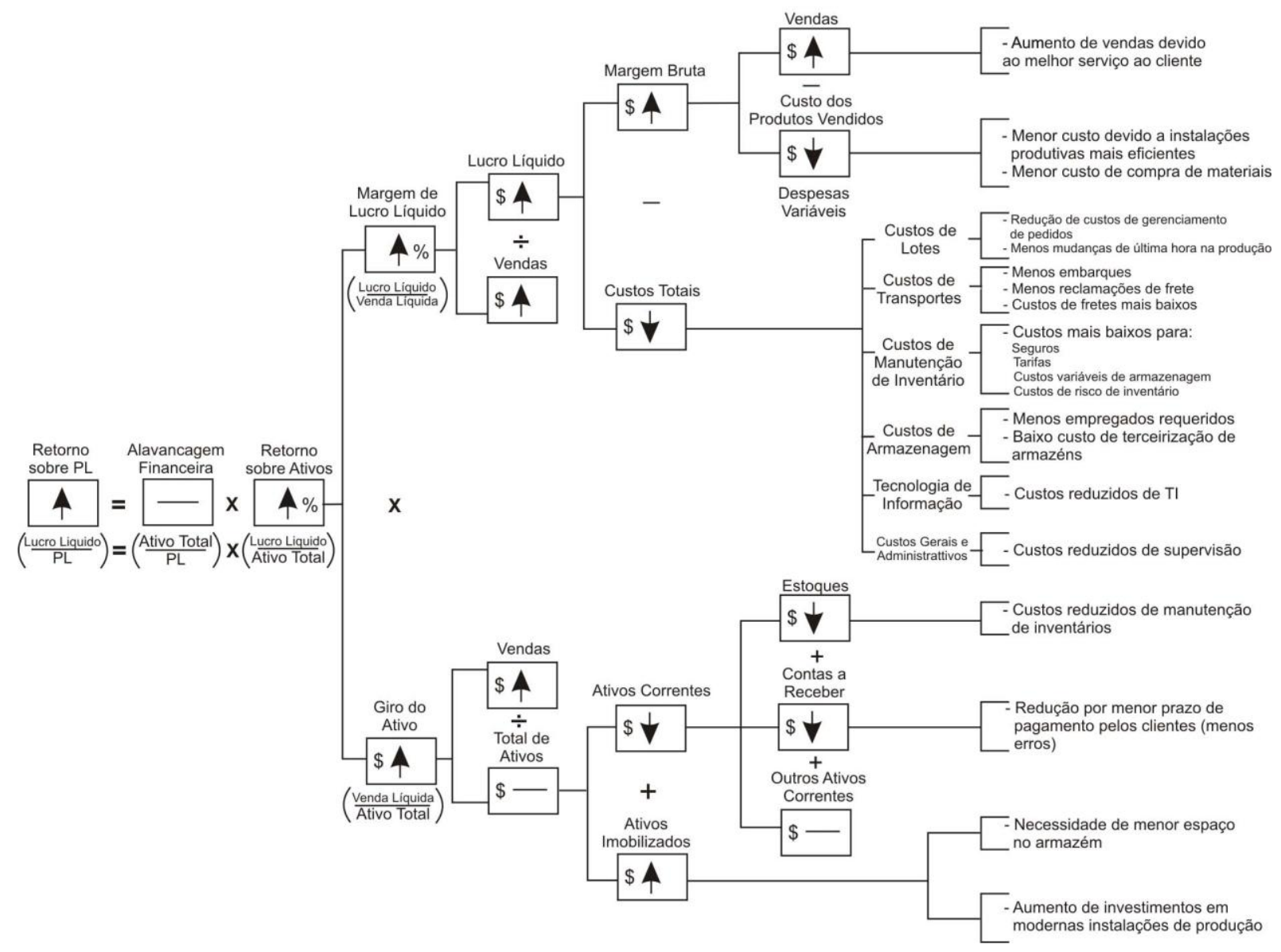

Ilustração 31 - Modelo Estratégico de Rentabilidade FONTE: LAMBERT; BURDUROGLU, 2000

- Valor para os acionistas - de acordo com a teoria do valor ao acionista, uma empresa cria valor quando atingir ou exceder o custo de capital, que reflete corretamente seu risco de investimento. A capacidade de criar riqueza para os acionistas é crucial para a sobrevivência das empresas, e os dois métodos mais aceitos que demonstram a ligação entre desempenho empresarial e criação de valor aos acionistas são a "Análise de Valor ao Acionista (Shareholder value analysis - SVA), criado pelo pesquisador Rappaport, e o "Valor Econômico Agregado (Economic value-added - EVA), criado por Joel Stern. A logística pode afetar o EVA em quatro áreas: receita, custos operacionais, capital de giro e ativos fixos (imobilizado). A ilustração 32 aborda como as atividades logísticas afetam o EVA. 


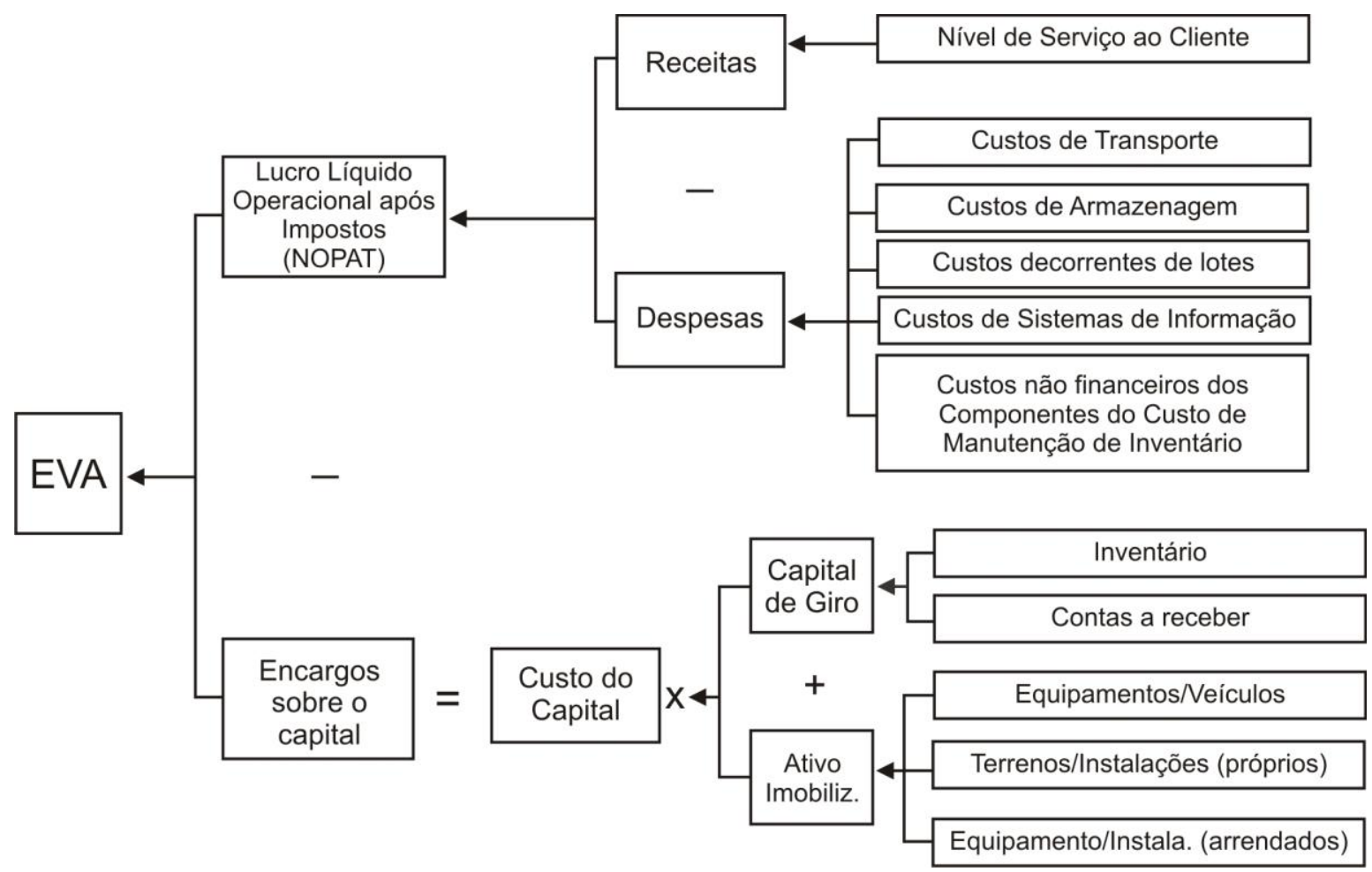

Ilustração 32 - Como as atividades logísticas afetam o EVA FONTE: LAMBERT; BURDUROGLU, 2000

Ainda segundo Lambert e Burduroglu (2000), os métodos acima descritos apresentam algumas vantagens e desvantagens descritas no quadro 14.

Quadro 14 - Vantagens e desvantagens de algumas medidas de desempenho

\begin{tabular}{|c|c|c|}
\hline Métrica & Vantagens & Desvantagens \\
\hline $\begin{array}{l}\text { Satisfação dos } \\
\text { clientes }\end{array}$ & $\begin{array}{l}\text { - Tem impacto direto através das } \\
\text { receitas totais e despesas } \\
\text { logísticas } \\
\text { - Melhora a participação de } \\
\text { mercado (market-share) } \\
\text { - Possibilita o alinhamento dos } \\
\text { serviços com as necessidades } \\
\text { dos clientes } \\
\text { - Medidas relativamente fáceis de } \\
\text { obter } \\
\text { - Cliente faz o trabalho, } \\
\text { preenchendo o questionário. }\end{array}$ & $\begin{array}{l}\text { - Confia no cliente a fim de determinar se o nível de } \\
\text { satisfação justifica pagar um preço maior ou compra } \\
\text { mais do fornecedor; } \\
\text { • Confia em gestores de fora da logística para } \\
\text { identificar o impacto sobre as receitas que } \\
\text { normalmente não acontece. }\end{array}$ \\
\hline $\begin{array}{c}\text { Valor } \\
\text { adicionado aos } \\
\text { clientes }\end{array}$ & $\begin{array}{l}\text { - Baseia-se na noção de que o } \\
\text { valor, mais que nos preços, } \\
\text { conduz a um maior número de } \\
\text { venda, a margens de lucro mais } \\
\text { elevadas e a maior valor para os } \\
\text { acionistas } \\
\text { - Medidas relativamente fáceis de } \\
\text { obter }\end{array}$ & $\begin{array}{l}\text { - Confia no cliente a fim de determinar se o valor } \\
\text { adicionado ao cliente justifica pagar um preço } \\
\text { maior ou compra mais do fornecedor } \\
\text { - Falha em medir o impacto financeiro em } \\
\text { proporcionar níveis mais altos de valor adicionado } \\
\text { aos clientes }\end{array}$ \\
\hline
\end{tabular}




\begin{tabular}{|c|c|c|}
\hline Métrica & Vantagens & Desvantagens \\
\hline & $\begin{array}{l}\text { - Cliente faz o trabalho, } \\
\text { preenchendo o questionário. }\end{array}$ & \\
\hline $\begin{array}{l}\text { Análise de } \\
\text { Custo Total }\end{array}$ & $\begin{array}{l}\text { - Preços e custos relacionados são } \\
\text { considerados } \\
\text { - Os gerentes podem aumentar } \\
\text { lucros através da redução do } \\
\text { custo total da logística }\end{array}$ & $\begin{array}{l}\text { - Não considera as implicações de receitas dos } \\
\text { serviços relacionados com a logística } \\
\text { - Consome mais tempo uma vez que tem de ser feito } \\
\text { baseado em um cliente individualmente } \\
\text { - Necessita de acesso a informações sobre custos } \\
\text { - Perpetua o mito de que a logística é simplesmente } \\
\text { um custo que deve ser reduzido }\end{array}$ \\
\hline $\begin{array}{l}\text { Análise de } \\
\text { rentabilidade }\end{array}$ & $\begin{array}{l}\text { - Receita e prejuízos são } \\
\text { considerados }\end{array}$ & $\begin{array}{l}\text { - Não mede o custo dos ativos empregados, com } \\
\text { exceção de estoque e contas a receber } \\
\text { - Precisa dos dados de receitas e de despesas do } \\
\text { fornecedor. O cliente pode não ter esses dados ou o } \\
\text { fornecedor não estar dispostos a compartilhar dados } \\
\text { - Necessita de sofisticado sistema de contabilidade. }\end{array}$ \\
\hline $\begin{array}{l}\text { Modelo } \\
\text { Estratégico de } \\
\text { Rentabilidade }\end{array}$ & $\begin{array}{l}\text { - Medidas do lucro líquido, ROA, } \\
\text { retorno sobre o patrimônio } \\
\text { líquido } \\
\text { - Auxilia os gestores na avaliação } \\
\text { de fluxos de caixa e decisões de } \\
\text { utilização de ativos. }\end{array}$ & $\begin{array}{l}\text { - Não considerar o tempo dos fluxos de caixa } \\
\text { - Sujeito a manipulação, no curto prazo. } \\
\text { - Além de receitas e despesas, ativos dedicados ao } \\
\text { relacionamento devem ser conhecidos. }\end{array}$ \\
\hline $\begin{array}{l}\text { Valor para os } \\
\text { acionistas }\end{array}$ & $\begin{array}{l}\text { - Reconhece o valor do dinheiro } \\
\text { no tempo e os riscos de um } \\
\text { investimento } \\
\text { - Foco no fluxo de caixa supera as } \\
\text { insuficiências das medidas } \\
\text { financeiras tradicionais. }\end{array}$ & $\begin{array}{l}\text { - Implementações demonstram preocupações } \\
\text { relacionadas com taxas de desconto, período de } \\
\text { programação, e fluxos de caixa projetados (faltando } \\
\text { articulação entre a estratégia de negócios e valor } \\
\text { acionista) } \\
\text { - Método com uso de muitos dados } \\
\text { - Consome muito tempo e é de difícil execução. }\end{array}$ \\
\hline
\end{tabular}

FONTE: LAMBERT; BURDUROGLU, 2000

Segundo Bowersox et al. (2007), a avaliação de desempenho de uma cadeia de suprimentos deve possuir duas avaliações: uma operacional e outra financeira. A avaliação operacional deve abordar medidas funcionais do desempenho logístico, medidas mais avançadas de atendimento ao cliente, medidas abrangentes da cadeia de suprimentos e, finalmente, Benchmarking. Por outro lado, a avaliação financeira deve abordar análises de custos e receitas e análise do lucro estratégico. O quadro 15 ilustra esse sistema de avaliação de desempenho proposto pelos autores. 
Quadro 15 - Medidas de desempenho segundo BOWERSOX, 2007

\begin{tabular}{|c|c|c|}
\hline \multirow[t]{4}{*}{$\begin{array}{l}\text { Avaliação } \\
\text { operacional }\end{array}$} & $\begin{array}{l}\text { Medidas } \\
\text { funcionais do } \\
\text { desempenho } \\
\text { logístico }\end{array}$ & $\begin{array}{l}\text { - Custo (custo total, custo unitário, custo como percentual de vendas, frete de } \\
\text { suprimento, frete de distribuição, administrativo, pedido do armazém, mão- } \\
\text { de-obra direta, comparação de real versus orçamentário, análise de } \\
\text { tendência de custo, lucratividade do produto direto, lucratividade do } \\
\text { segmento de clientes, manutenção de estoque, custo de produtos } \\
\text { devolvidos, custo das avarias, custo de falha no serviço, custo de pedidos } \\
\text { devolvidos) } \\
\text { - Serviço ao cliente (taxa de atendimento, faltas de estoque, erros de } \\
\text { embarque, entrega pontual, pedidos devolvidos, duração do ciclo, } \\
\text { consistência nas entregas, tempo de resposta a solicitações, acurácia das } \\
\text { respostas, pedidos completos, reclamações de clientes, reclamações da força } \\
\text { de vendas, confiabilidade total) } \\
\text { - Qualidade (frequiência de avarias, acurácia da entrada de pedidos, acurácia } \\
\text { de coleta/embarque, acurácia de documentos/faturas, disponibilidade de } \\
\text { informação, acurácia das informações, quantidade de pedidos de crédito, } \\
\text { quantidade de clientes que retornam) } \\
\text { - Produtividade (unidades embarcadas por funcionários, unidades por dólar } \\
\text { gasto com mão-de-obra, pedidos por representante de vendas, comparação } \\
\text { com padrão histórico, programas de metas, índice de produtividade, tempo } \\
\text { ocioso dos equipamentos, produtividade na entrada de pedidos, } \\
\text { produtividade da mão-de-obra do armazém, produtividade da mão-de-obra } \\
\text { de transportes) } \\
\text { - Gerenciamento de ativo (giros de estoque, níveis de estoque, em dias de } \\
\text { suprimento, estoque obsoleto, retorno sobre ativos líquidos, retorno sobre o } \\
\text { investimento, classificação do estoque - ABC, Economic value-added - } \\
\text { EVA }\end{array}$ \\
\hline & $\begin{array}{l}\text { Medidas mais } \\
\text { avançadas de } \\
\text { atendimento ao } \\
\text { cliente }\end{array}$ & $\begin{array}{l}\text { - Pedidos perfeitos - ausência de falhas em todas as etapas } \\
\text { - Desempenho absoluto - reduçãa dos tempos de medições } \\
\text { - Satisfação do cliente - coleta de dados diretamente com os clientes }\end{array}$ \\
\hline & $\begin{array}{l}\text { Medidas } \\
\text { abrangentes da } \\
\text { cadeia de } \\
\text { suprimentos }\end{array}$ & $\begin{array}{l}\text { - Conversão de caixa - duração do ciclo é o tempo necessário para se } \\
\text { converter um dólar gasto em estoque em um dólar recebido de receita de } \\
\text { vendas } \\
\text { - Dias de suprimento do estoque - estoque total de produtos acabados em } \\
\text { todas fábricas, armazéns, atacadistas, varejistas, etc. } \\
\text { - Tempo ocioso - relação entre a quantidade de dias que o estoque fica } \\
\text { parado na cadeia e a quantidade de dias que ele está sendo usado } \\
\text { - Percentual de estoques em prateleiras - produto disponível quanto e onde o } \\
\text { cliente quiser, na quantidade correta } \\
\text { - Custo total da cadeia de suprimentos - agregação de custos de todas as } \\
\text { empresas da cadeia } \\
\text { - Tempo de resposta da cadeia de suprimentos - tempo necessário para que } \\
\text { todas empresas reconhecerem uma mudança na demanda, fazerem } \\
\text { replanejamento e atenderem essa demanda }\end{array}$ \\
\hline & Benchmarking & $\begin{array}{l}\text { - Realizar Benchmarking irrestrito, comparando medidas e processos com } \\
\text { melhores práticas, independente de onde ela é encontrada }\end{array}$ \\
\hline \multirow[t]{2}{*}{$\begin{array}{l}\text { Avaliação } \\
\text { financeira }\end{array}$} & $\begin{array}{l}\text { Análises de } \\
\text { custos e receitas }\end{array}$ & $\begin{array}{l}\text { - Práticas contábeis - balanço patrimonial e demonstração de resultado } \\
\text { - Abordagem da Margem de Contribuição - identificar a lucratividade de } \\
\text { cada segmento através da determinaça dos custos fixos, variáveis, diretos e } \\
\text { indiretos } \\
\text { - Abordagem do Lucro Líquido - para esta abordagem deve-se atribuir a cada } \\
\text { segmento sua cota justa de custos fixos indiretos } \\
\text { - Custeio Baseado em Atividades (ABC) - os custos devem ser associados às } \\
\text { atividades realizadas e essas atividades devem ser relacionadas a produtos } \\
\text { ou segmentos de clientes específicos da empresa }\end{array}$ \\
\hline & $\begin{array}{l}\text { Análise do } \\
\text { lucro } \\
\text { estratégico }\end{array}$ & $\begin{array}{l}\text { - Retorno sobre investimentos (ROI) } \\
\text { - Retorno sobre o valor líquido (RONW) - lucratividade dos recursos que } \\
\text { os proprietários investiram na empresa } \\
\text { - Retorno sobre ativos (ROA) - lucratividade gerada através do } \\
\text { gerenciamento dos ativos operacionais da empresa. Uso do Modelo } \\
\text { Estratégico de Rentabilidade (Strategic Profit Model - SPM) }\end{array}$ \\
\hline
\end{tabular}


Na busca de criar um sistema de desempenho para a cadeia de suprimentos, Gunasekaran et al. (2001) sugeriram uma série de métricas de desempenho, classificados de acordo com o nível (estratégico, tático e operacional) e tipo (financeira e não financeiras). O quadro 16 ilustra essas métricas.

Quadro 16 - Medidas de desempenho segundo GUNASEKARAN et al., 2001

\begin{tabular}{|c|c|c|c|}
\hline Nível & Métricas de desempenho & Financeiro & Não Financeiro \\
\hline \multirow{15}{*}{ Estratégico } & Tempo total de ciclo da cadeia de suprimentos & & $\mathrm{X}$ \\
\hline & Tempo total do fluxo de caixa & $\mathrm{X}$ & $\mathrm{X}$ \\
\hline & Tempo de resposta ao cliente & $\mathrm{X}$ & $\mathrm{X}$ \\
\hline & Nível de valor percebido do produto pelo cliente & & $\mathrm{X}$ \\
\hline & Lucro líquido x Nível de produtividade & $\mathrm{X}$ & \\
\hline & Taxa de retorno sobre investimento & $\mathrm{X}$ & \\
\hline & Gama de produtos e serviços & & $\mathrm{X}$ \\
\hline & Variações sobre o orçamento (Previsto x Realizado) & $\mathrm{X}$ & \\
\hline & Lead time do Pedido & & $\mathrm{X}$ \\
\hline & $\begin{array}{l}\text { Flexibilidade dos sistemas de serviços para atender } \\
\text { necessidades particulares dos clientes }\end{array}$ & & $\mathrm{X}$ \\
\hline & Nível de relacionamento cliente-fornecedor & $\mathrm{X}$ & $\mathrm{X}$ \\
\hline & Lead time do fornecedor em relação à norma da indústria & & $\mathrm{X}$ \\
\hline & Nível das entregas sem defeitos do fornecedor & & $\mathrm{X}$ \\
\hline & Lead time da entrega & & $\mathrm{X}$ \\
\hline & Desempenho da entrega & $\mathrm{X}$ & $\mathrm{X}$ \\
\hline \multirow{14}{*}{ Tático } & Precisão das técnicas de previsão & & $\mathrm{X}$ \\
\hline & Tempo de ciclo de desenvolvimento de produto & & $\mathrm{X}$ \\
\hline & Métodos de entrada (colocação) de pedidos & & $\mathrm{X}$ \\
\hline & Efetividade dos métodos de entrega de faturas & & $\mathrm{X}$ \\
\hline & Tempo de ciclo de compra & & $\mathrm{X}$ \\
\hline & Tempo de ciclo de processos planejados & & $\mathrm{X}$ \\
\hline & Efetividade do plano mestre de produção (MPS) & & $\mathrm{X}$ \\
\hline & Ajuda do fornecedor em resolver problemas técnicos & & $\mathrm{X}$ \\
\hline & $\begin{array}{l}\text { Habilidade do fornecedor em resolver problemas de } \\
\text { qualidade }\end{array}$ & & $\mathrm{X}$ \\
\hline & Iniciativas de redução de custos do fornecedor & $\mathrm{X}$ & \\
\hline & Procedimentos de cadastro de fornecedor & & $\mathrm{X}$ \\
\hline & Confiabilidade na entrega & $\mathrm{X}$ & $\mathrm{X}$ \\
\hline & Reação a entregas urgentes & & $\mathrm{X}$ \\
\hline & Efetividade do programa de planejamento de distribuição & & $\mathrm{X}$ \\
\hline \multirow{11}{*}{ Operacional } & Custo por hora de operação & $\mathrm{X}$ & \\
\hline & Custo de obtenção de informações & $\mathrm{X}$ & $\mathrm{X}$ \\
\hline & Utilização da capacidade & & $\mathrm{X}$ \\
\hline & $\begin{array}{l}\text { Custos totais de estoque como: } \\
\text { - Matéria-prima } \\
\text { - Produtos em processo } \\
\text { - Refugos } \\
\text { - Produtos acabados em transito }\end{array}$ & $\mathrm{X}$ & \\
\hline & Taxa de rejeição do fornecedor & $\mathrm{X}$ & $\mathrm{X}$ \\
\hline & Qualidade da documentação de entrega & & $\mathrm{X}$ \\
\hline & Eficiência no tempo de ciclo de pedido de compra & & $\mathrm{X}$ \\
\hline & Freqüência de entrega & & $\mathrm{X}$ \\
\hline & Confiabilidade do motorista para desempenho & & $\mathrm{X}$ \\
\hline & Qualidade dos bens entregues & & $\mathrm{X}$ \\
\hline & Número de entregas sem defeitos & & $\mathrm{X}$ \\
\hline
\end{tabular}

FONTE: GUNASEKARAN et al., 2001 
Ainda segundo os autores, as mesmas métricas podem ser classificadas de acordo com os processos básicos da cadeia de suprimentos propostos pelo modelo SCOR: planejamento, recebimento, produção, entrega e retorno/satisfação dos clientes. A ilustração 33 mostra essa classificação.

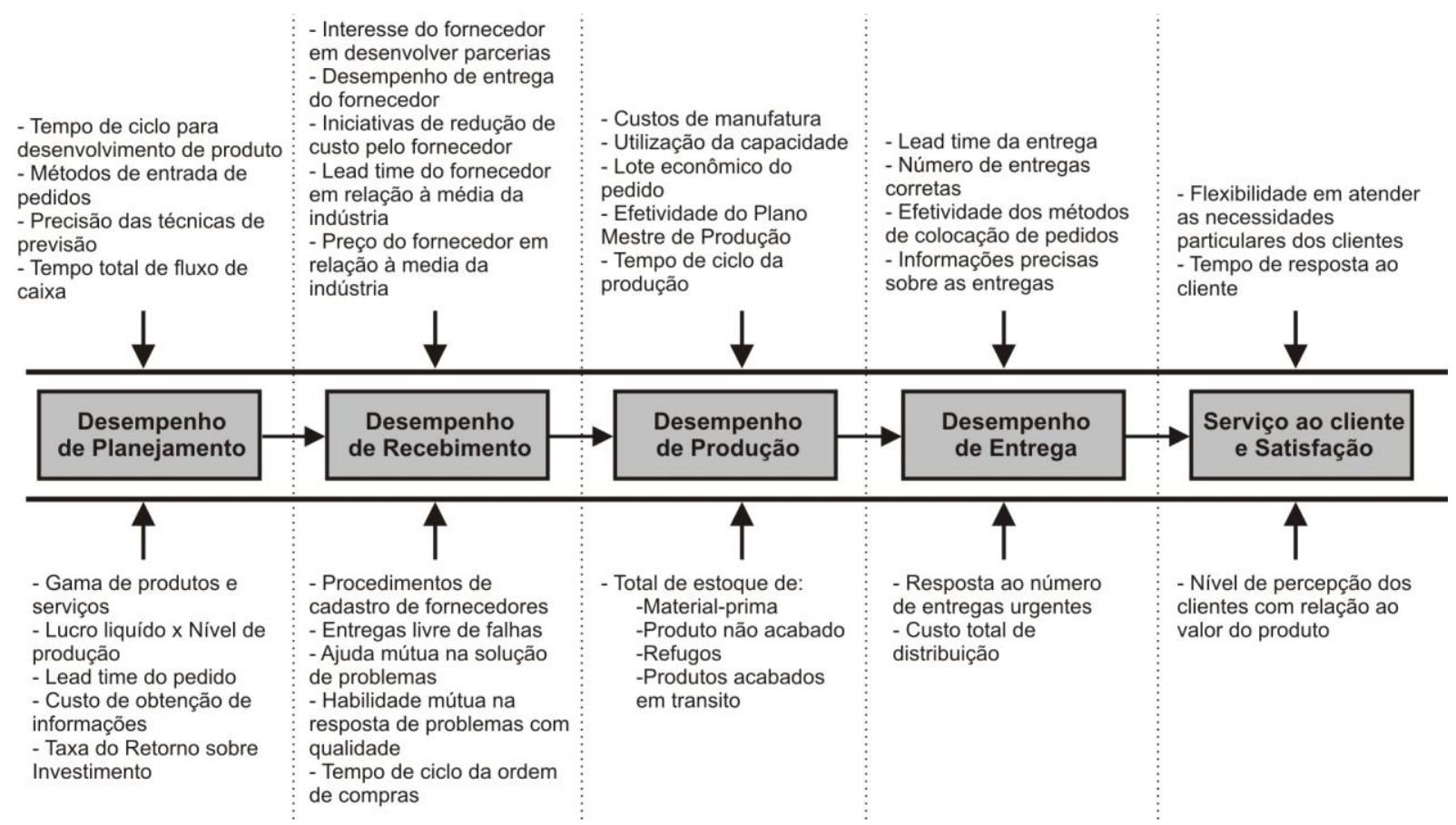

Ilustração 33 - Medidas e métricas conforme os cinco processos básicos do modelo SCOR FONTE: GUNASEKARAN et al., 2001

Assim, Gunasekaran et al. (2001) sugerem que quando usadas em conjunto em um estudo de avaliação de desempenho da cadeia, estas duas formas de classificação fornecem uma clara visão de quais métricas devem ser usadas, onde podem ser usadas, e quem serão os responsáveis. Para eles, essas duas classificações funcionam como um elo entre a necessidade por um modelo com o qual se pode avaliar a cadeia de suprimentos e a identificação das áreas que possam ser melhoradas.

De modo parecido, Gunasekaran et al. (2004) propuseram uma classificação dos indicadores de acordo com os quatro dos cinco processos do modelo SCOR (planejamento, compras, produção e entregas) e os níveis (estratégico, tático e operacional). O quadro 17 demonstra esses indicadores. 
Quadro 17 - Medidas de desempenho segundo o Modelo SCOR

\begin{tabular}{|c|c|c|c|}
\hline $\begin{array}{l}\text { Processos/Atividades } \\
\text { da Cadeia de } \\
\text { Suprimentos } \\
\end{array}$ & Estratégico & Tático & Operacional \\
\hline Planejamento & $\begin{array}{l}\text { Nível de valor } \\
\text { percebido dos clientes } \\
\text { em relação aos } \\
\text { produtos; variação } \\
\text { sobre o orçamento } \\
\text { (previsto x realizado); } \\
\text { tempo de pedido; custo } \\
\text { de processamento de } \\
\text { informação; lucro } \\
\text { líquido x nível de } \\
\text { produtividade; tempo } \\
\text { total de ciclo; tempo de } \\
\text { ciclo de } \\
\text { desenvolvimento de } \\
\text { produto }\end{array}$ & $\begin{array}{l}\text { Tempo de resposta ao } \\
\text { cliente; tempo de ciclo de } \\
\text { desenvolvimento de } \\
\text { produto; precisão nas } \\
\text { técnicas de previsão; tempo } \\
\text { de ciclo do planejamento do } \\
\text { processo; métodos de } \\
\text { entrada de pedidos; } \\
\text { produtividade dos recursos } \\
\text { humanos }\end{array}$ & $\begin{array}{l}\text { Métodos de entrada de } \\
\text { pedidos; produtividade } \\
\text { dos recursos humanos }\end{array}$ \\
\hline Compras & & $\begin{array}{l}\text { Desempenho na entrega do } \\
\text { fornecedor; tempo do } \\
\text { fornecedor x padrão do } \\
\text { setor; preço do fornecedor x } \\
\text { preço de mercado; } \\
\text { Eficiência do tempo de ciclo } \\
\text { do pedido de compra; } \\
\text { Eficiência do método de } \\
\text { fluxo de caixa; } \\
\text { procedimentos de cadastros } \\
\text { de fornecedores }\end{array}$ & $\begin{array}{l}\text { Eficiência do tempo de } \\
\text { ciclo do pedido de } \\
\text { compra; preço do } \\
\text { fornecedor x preço de } \\
\text { mercado }\end{array}$ \\
\hline $\begin{array}{l}\text { Produção e/ou } \\
\text { Montagem }\end{array}$ & $\begin{array}{l}\text { Extensão dos produtos e } \\
\text { serviços }\end{array}$ & $\begin{array}{l}\text { Porcentagem de falhas } \\
\text { (erros); custos por hora de } \\
\text { operação; utilização da } \\
\text { capacidade; utilização da } \\
\text { quantidade econômica de } \\
\text { pedido }\end{array}$ & $\begin{array}{l}\text { Porcentagem de falhas } \\
\text { (erros); custos por hora de } \\
\text { operação; índice de } \\
\text { produtividade dos } \\
\text { recursos humanos }\end{array}$ \\
\hline Entregas & $\begin{array}{l}\text { Flexibilidade da } \\
\text { empresa em detector as } \\
\text { necessidades do cliente; } \\
\text { Eficiência do programa } \\
\text { de planejamento da } \\
\text { distribuição }\end{array}$ & $\begin{array}{l}\text { Flexibilidade da empresa } \\
\text { em detector as necessidades } \\
\text { do cliente; Eficiência do } \\
\text { programa de planejamento } \\
\text { da distribuição; eficiência } \\
\text { dos métodos de fatura das } \\
\text { entregas; porcentagem de } \\
\text { produtos acabados em } \\
\text { trânsito; desempenho da } \\
\text { confiabilidade na entrega }\end{array}$ & $\begin{array}{l}\text { Qualidade dos produtos } \\
\text { entregues; entregas } \\
\text { realizadas no prazo; } \\
\text { eficiência dos métodos de } \\
\text { fatura das entregas; } \\
\text { número de faturas } \\
\text { corretas; porcentagem de } \\
\text { entregas urgentes; } \\
\text { Informações de qualidade } \\
\text { nos processos de entrega; } \\
\text { desempenho da } \\
\text { confiabilidade na entrega }\end{array}$ \\
\hline
\end{tabular}

FONTE: GUNASEKARAN et al., 2004

Para Shepherd e Gunter (2006), atualmente os pesquisadores têm se esforçado em criar sistemas de medida de desempenho sistêmicos e equilibrados. Para o autor, talvez a melhor maneira de se avaliar o desempenho na cadeia de suprimentos é definir métricas com base nos processos detalhados pelo modelo "Referência de Operações da Cadeia de Suprimentos" (Supply Chain Operations Reference - SCOR) criado em 1997 pelo Conselho de Cadeia de Suprimento (Supply Chain Council) e que tem sido descrito como uma abordagem sistemática 
para identificação, avaliação e monitoramento do desempenho da cadeia de suprimentos. $\mathrm{O}$ Modelo SCOR, detalhado no tópico 2.6 deste trabalho, propõem métricas de medida de desempenho para cada nível de detalhamento do modelo. Como exemplo, pode-se citar as métricas propostas para o nível 1, ilustradas no quadro 18. De maneira análoga, para os níveis 2 e 3, que são detalhamentos do nível 1, outras métricas são propostas.

Quadro 18 - Medidas de desempenho do nível 1 do Modelo SCOR

\begin{tabular}{|c|c|c|c|c|c|}
\hline \multirow{3}{*}{ Métricas Nível 1} & \multicolumn{5}{|c|}{ Atributos de desempenho } \\
\hline & \multicolumn{3}{|c|}{ Foco no cliente } & \multicolumn{2}{|c|}{ Foco Interno } \\
\hline & Confiança & Responsividade & Flexibilidade & Custo & Ativos \\
\hline $\begin{array}{l}\text { Preenchimento completo do } \\
\text { pedido }\end{array}$ & $\mathrm{X}$ & & & & \\
\hline $\begin{array}{l}\text { Tempo de ciclo do } \\
\text { preenchimento do pedido }\end{array}$ & & $\mathrm{X}$ & & & \\
\hline $\begin{array}{l}\text { Flexibilidade da cadeia de } \\
\text { suprimentos com os clientes }\end{array}$ & & & $\mathrm{X}$ & & \\
\hline $\begin{array}{l}\text { Adaptabilidade da cadeia de } \\
\text { suprimentos com os clientes }\end{array}$ & & & $\mathrm{X}$ & & \\
\hline $\begin{array}{l}\text { Adaptabilidade da cadeia de } \\
\text { suprimentos com os } \\
\text { fornecedores }\end{array}$ & & & $\mathrm{X}$ & & \\
\hline $\begin{array}{l}\text { Custos do gerenciamento da } \\
\text { cadeia de suprimentos }\end{array}$ & & & & $\mathrm{X}$ & \\
\hline $\begin{array}{l}\text { Custos das mercadorias } \\
\text { vendidas }\end{array}$ & & & & $\mathrm{X}$ & \\
\hline $\begin{array}{l}\text { Tempo de ciclo do fluxo de } \\
\text { caixa }\end{array}$ & & & & & $\mathrm{X}$ \\
\hline $\begin{array}{l}\text { Retorno sobre os ativos fixos } \\
\text { da cadeia de suprimentos }\end{array}$ & & & & & $\mathrm{X}$ \\
\hline $\begin{array}{l}\text { Retorno sobre o capital de } \\
\text { giro }\end{array}$ & & & & & $\mathrm{X}$ \\
\hline
\end{tabular}

FONTE: SHEPHERD; GÜNTER, 2006

Ainda no decorrer do trabalho, os autores realizaram vasta revisão bibliográfica em busca de métricas para a cadeia de suprimentos. Eles fizeram uma classificação dos indicadores de acordo com: os processos da cadeia de suprimentos propostos pelo modelo SCOR (planejamento, recebimento, produção, entrega e retorno/satisfação dos clientes), as estratégias (custo, qualidade, flexibilidade, tempo e inovação) e tipo (quantitativo e não quantitativo). A lista completa destes indicadores encontra-se no Anexo C.

Segundo Agan (2005), a literatura fornece diferentes dimensões de medida de desempenho: operacional (por exemplo, estoque, tempo de ciclo e produtividade), comportamental ou intangível (por exemplo, aprendizado e confiança), baseado no mercado (por exemplo, reputação e participação de mercado), baseado no cliente (por exemplo, satisfação do cliente), 
percepção (por exemplo, percepção de sucesso) e financeiro (por exemplo, ROI e lucratividade).

De forma semelhante, Morgan (2004) comenta que além das medidas tradicionais financeiras, as empresas da cadeia de suprimentos devem mensurar o desempenho segundo as perspectivas do desempenho operacional (por exemplo, tempo de set-up, estoques, utilização de máquinas), do mercado (por exemplo, participação de mercado, tempo de lançamento de novos produtos, número de produtos novos) e de qualidade (por exemplo, refugos, erros e retrabalho).

Conforme Bhagwat e Sharma (2007), no gerenciamento de cadeia de suprimentos, como em qualquer outra atividade empresarial, identificar as mensurações de desempenho necessárias é essencial e deve ser uma parte integrante de qualquer estratégia de empresa. Como geralmente as cadeias buscam fornecer uma grande gama de benefícios, sendo muitos deles intangíveis, métodos de avaliação que dependem de mensurações financeiras não são muito recomendáveis. Assim, uma abordagem equilibrada da avaliação pode apresentar melhores resultados.

Gunasekaran et al. (2001) relatam em seus trabalhos que elos discretos em uma cadeia de suprimentos não levam a uma melhora na produtividade total da cadeia se cada um perseguir seus objetivos individualmente (o que é a prática comum). Detectaram também que os sistemas de medidas de desempenho da cadeia de suprimentos devem ser mais profundamente estudados devido à falta de uma abordagem equilibrada e à falta de uma clara distinção de métricas nos níveis estratégico, tático e operacional. Eles argumentam que, apesar das empresas utilizarem o Balanced Scorecard, as medidas acabam sendo predominantemente financeiras ou operacionais.

Brewer e Speh (2000), também com o objetivo de criar um modelo de avaliação de desempenho para a cadeia, recomendam o uso de uma versão modificada do BSC como uma estrutura para a mensuração do desempenho da cadeia de suprimentos. Eles sugerem que mensurações de cadeia de suprimentos mais eficientes podem ser desenvolvidas ao relacionar os objetivos de cadeia de suprimentos com as quatro perspectivas (Financeira, clientes, processos e aprendizado/inovação) definidas na estrutura do BSC. A ilustração 34 aborda as relações entre o gerenciamento da cadeia de suprimentos e o BSC. 


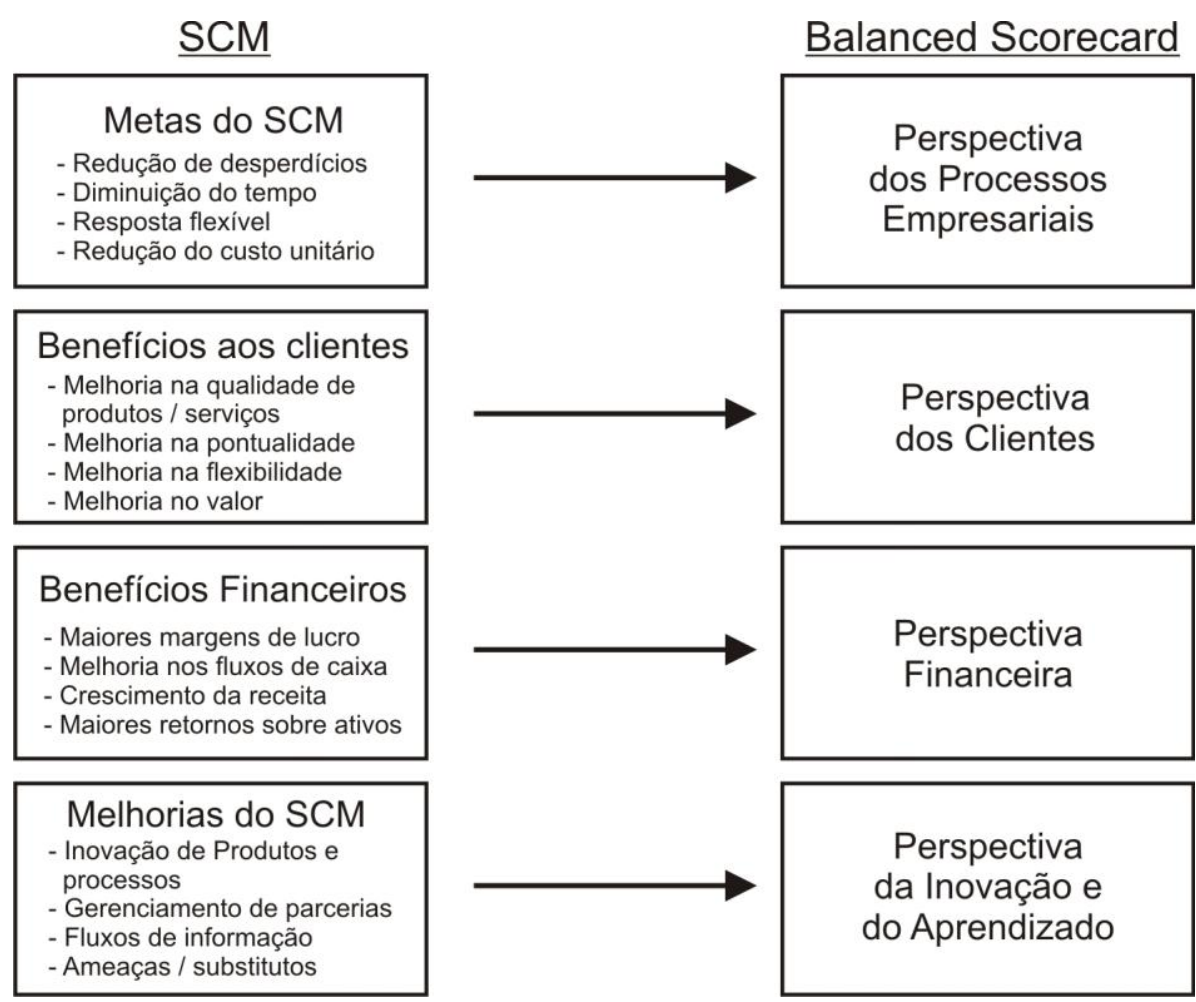

Ilustração 34 - Ligação entre o gerenciamento da cadeia de suprimentos e o Balanced Scorecard (BSC) FONTE: BREWER; SPEH, 2000

Park et al. (2005) afirmam que para adequar o BSC para a realidade do gerenciamento da cadeia de suprimentos algumas medidas devem ser tomadas:

- A perspectiva de processos internos deve ser ampliada para incluir os processos interempresariais para que ocorra a comunicação e a integração da cadeia;

- Os processos de previsão da demanda devem ser considerados tanto na perspectiva do cliente quanto na perspectiva de processos internos e

- As medidas devem incluir objetivos da cadeia como o relacionamento com fornecedores, planejamento colaborativo, etc.

Assim, os autores incluíram novas perspectivas ao BSC e criaram o Balanced Supply Chain Scorecard (BSCS). A ilustração 35 mostra esse modelo. 


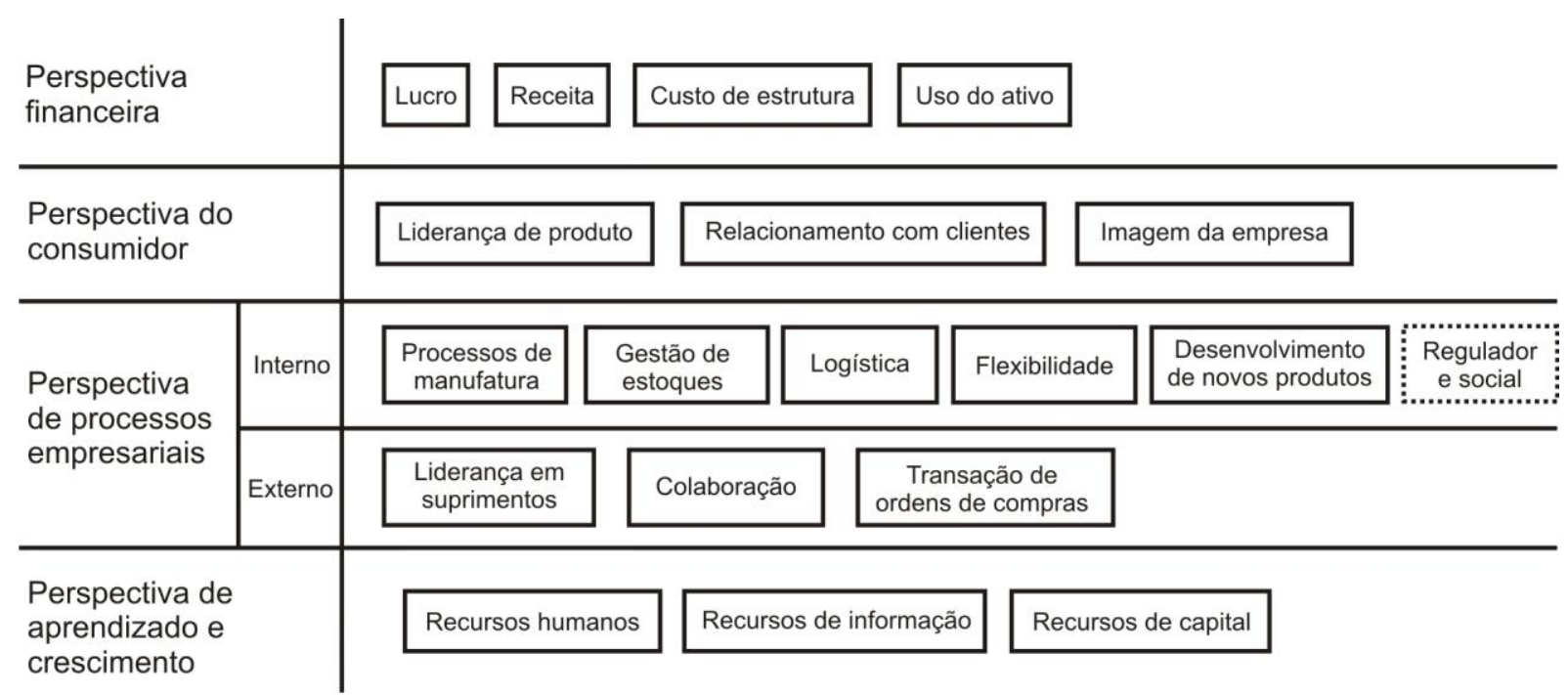

Ilustração 35 - O Balanced Supply Chain Scorecard (BSCS) FONTE: PARK et al., 2005

Os autores também determinaram os objetivos, as medidas e as contribuições do BSCS conforme descrito no quadro 19.

Quadro 19 - Objetivos e métricas do Balanced Supply Chain Scorecard (BSCS)

\begin{tabular}{|c|c|c|}
\hline Perspectiva & Objetivos & Métricas \\
\hline $\begin{array}{c}\text { Perspectiva } \\
\text { Financeira }\end{array}$ & $\begin{array}{l}\text { Aumento do lucro } \\
\text { Aumento das receitas } \\
\text { Melhora da estrutura dos custos } \\
\text { Melhora na utilização dos ativos }\end{array}$ & $\begin{array}{l}\text { Lucro total } \\
\text { Receitas totais } \\
\text { Crescimento de vendas } \\
\text { Custo total } \\
\text { Custo por unidade produzida } \\
\text { Custo de manutenção do estoque } \\
\text { Custo de entrega } \\
\text { Custo de set-up e alterações } \\
\text { Fluxo de caixa }\end{array}$ \\
\hline $\begin{array}{l}\text { Perspectiva } \\
\text { do Cliente }\end{array}$ & $\begin{array}{l}\text { Melhora da liderança em produtos } \\
\text { Melhora das relações com os } \\
\text { clientes } \\
\text { Imagem Corporativa }\end{array}$ & $\begin{array}{l}\text { Qualidade do produto } \\
\text { Preço do produto } \\
\text { Gama de produtos e serviços } \\
\text { Taxa de devoluções } \\
\text { Tempo de resposta aos clientes } \\
\text { Entregas no prazo } \\
\text { Estoque de produtos acabados } \\
\text { Falta de produtos acabados no estoque } \\
\text { Vendas a clientes atuais x vendas a novos } \\
\text { clientes } \\
\text { Preenchimento do pedido } \\
\text { Monitoramento dos pedidos } \\
\text { Percentagem de resolução do contato do cliente } \\
\text { Imagem } \\
\text { Reputação }\end{array}$ \\
\hline $\begin{array}{l}\text { Perspectiva } \\
\text { de Processos } \\
\text { Internos }\end{array}$ & $\begin{array}{l}\text { Melhora da eficiência dos } \\
\text { processos de manufatura } \\
\text { Melhora da gestão do estoque }\end{array}$ & $\begin{array}{l}\text { Lead time da manufatura } \\
\text { Nível de produção } \\
\text { Pericibilidade do estoque } \\
\text { Obsolescência do estoque } \\
\text { Acurácia do estoque } \\
\text { Estoque de materiais }\end{array}$ \\
\hline
\end{tabular}




\begin{tabular}{|c|c|c|}
\hline Perspectiva & Objetivos & Métricas \\
\hline & $\begin{array}{l}\text { Eficiência na Entrega } \\
\text { Aumento da flexibilidade } \\
\text { Melhora no desenvolvimento de } \\
\text { novos produtos }\end{array}$ & $\begin{array}{l}\text { Falta de materiais no estoque } \\
\text { Flexibilidade na entrega } \\
\text { Taxa de utilização do modal de transporte } \\
\text { Responsividade à entregas urgentes } \\
\text { Aderência do planejamento } \\
\text { Acurácia da previsão } \\
\text { Flexibilidade de volume } \\
\text { Flexibilidade de mix de produtos } \\
\text { Tempo de lançamento de novos produtos } \\
\text { Percentagem de venda de novos produtos }\end{array}$ \\
\hline $\begin{array}{l}\text { Perspectiva } \\
\text { de Processos } \\
\text { Externos }\end{array}$ & $\begin{array}{l}\text { Melhora da liderança em } \\
\text { suprimentos } \\
\text { Melhora da colaboração com } \\
\text { parceiros } \\
\text { Melhora da eficiência das } \\
\text { transações nas ordens de compra }\end{array}$ & $\begin{array}{l}\text { Qualidade dos produtos adquiridos } \\
\text { Custos do gerenciamento das compras } \\
\text { Preço dos produtos adquiridos } \\
\text { Tempo para propostas bem sucedidos } \\
\text { Percentagem de propostas bem sucedidas } \\
\text { Taxa de retorno de materiais } \\
\text { Entregas sem atrasos dos fornecedores } \\
\text { Compartilhamento das informações dos pedidos } \\
\text { Compartilhamento das informações do estoque } \\
\text { Compartilhamento das informações de previsão } \\
\text { Confiança nos parceiros } \\
\text { Percentagem de compras on-line } \\
\text { Processamento dos pedidos } \\
\text { Taxa de preenchimento dos pedidos de compra }\end{array}$ \\
\hline $\begin{array}{l}\text { Perspectiva } \\
\text { de } \\
\text { Aprendizado } \\
\text { e Inovação } \\
\end{array}$ & Aumento dos recursos intangíveis & $\begin{array}{l}\text { Recursos humanos } \\
\text { Recursos de informação } \\
\text { Recursos organizacionais }\end{array}$ \\
\hline
\end{tabular}

FONTE: PARK et al., 2005

Também Bhagwat e Sharma (2007), unindo o modelo de Balanced Scorecard de Kaplan e Norton (1992) com as métricas propostas por Gunasekaran et al. (2001) e propuseram um Balanced Scorecard aplicado ao Gerenciamento da Cadeia de Suprimentos. O Quadro 20 ilustra o modelo.

Quadro 20 - Balanced Scorecard aplicado ao gerenciamento da cadeia de suprimentos

\begin{tabular}{|c|l|}
\hline Perspectiva & \multicolumn{1}{|c|}{ Métricas de desempenho } \\
\hline \multirow{3}{*}{ Perspectiva } & $\begin{array}{l}\text { Lucro líquido x Nível de produtividade } \\
\text { Taxa de retorno sobre investimento } \\
\text { Variações sobre o orçamento (Previsto x Realizado) } \\
\text { Nível de parceria entre comprador e fornecedor } \\
\text { Desempenho da entrega } \\
\text { Iniciativas de redução de custos do fornecedor } \\
\text { Confiabilidade na entrega } \\
\text { Custo por hora de operação } \\
\text { Custo de obtenção de informação } \\
\text { Taxa de rejeição do fornecedor }\end{array}$ \\
\hline Perspectiva \\
do Cliente & $\begin{array}{l}\text { Tempo de resposta ao cliente de valor percebido do produto pelo cliente } \\
\text { Gama de produtos e serviços } \\
\text { Lead time do pedido } \\
\text { Flexibilidade dos sistemas de serviços para atender necessidades particulares dos clientes } \\
\text { Nível de parceria entre cliente e fornecedor }\end{array}$ \\
\hline
\end{tabular}




\begin{tabular}{|c|c|}
\hline Perspectiva & Métricas de desempenho \\
\hline & $\begin{array}{l}\text { Lead time da entrega } \\
\text { Desempenho da entrega } \\
\text { Efetividade dos métodos de entrega da fatura } \\
\text { Confiabilidade na entrega } \\
\text { Tempo de resposta a entregas urgentes } \\
\text { Efetividade do programa de planejamento de distribuição } \\
\text { Custo de obtenção de informações } \\
\text { Qualidade da documentação de entrega } \\
\text { Confiabilidade do motorista para desempenho } \\
\text { Qualidade dos bens entregados } \\
\text { Conquista de entregas sem defeitos }\end{array}$ \\
\hline $\begin{array}{l}\text { Perspectiva } \\
\text { de Processos } \\
\text { Internos }\end{array}$ & $\begin{array}{l}\text { Tempo total do ciclo da cadeia de suprimentos } \\
\text { Tempo total do fluxo de caixa } \\
\text { Flexibilidade dos sistemas de serviços para atender necessidades particulares dos clientes } \\
\text { Lead time do fornecedor em relação à norma da indústria } \\
\text { Nível das entregas sem defeitos do fornecedor } \\
\text { Precisão das técnicas de previsão } \\
\text { Tempo de ciclo de desenvolvimento de produto } \\
\text { Tempo do ciclo de compra } \\
\text { Tempo de ciclo de processos planejados } \\
\text { Efetividade do plano mestre de produção (MPS) } \\
\text { Taxa de utilização da capacidade } \\
\text { Custos totais de estoque como: } \\
\quad \text { - Matéria-prima } \\
\quad \text { - Produtos em processo } \\
\quad \text { - Refugos } \\
\quad \text { - Produtos acabados em transito } \\
\text { Taxa de rejeição do fornecedor } \\
\text { Eficiência do tempo do ciclo de compra } \\
\text { Freqüência de entrega }\end{array}$ \\
\hline $\begin{array}{c}\text { Perspectiva } \\
\text { de } \\
\text { Aprendizado } \\
\text { e Inovação }\end{array}$ & $\begin{array}{l}\text { Ajuda do fornecedor em solucionar problemas técnicos } \\
\text { Habilidade do fornecedor para resolver problemas de qualidade } \\
\text { Iniciativas de redução de custos do fornecedor } \\
\text { Procedimentos de cadastro de fornecedor } \\
\text { Taxa de utilização da capacidade } \\
\text { Métodos de entrada (colocação) de pedido } \\
\text { Precisão das técnicas de previsão } \\
\text { Tempo do ciclo de desenvolvimento de produto } \\
\text { Flexibilidade dos sistemas de serviços para atender necessidades particulares dos clientes } \\
\text { Nível de parceria entre cliente e fornecedor } \\
\text { Gama de produtos e serviços } \\
\text { Nível de valor percebido do produto pelo cliente }\end{array}$ \\
\hline
\end{tabular}

FONTE: BHAGWAT; SHARMA, 2007

\subsubsection{Dificuldades na mensuração do desempenho da cadeia de suprimentos}

Beamon (1999) relata que a dificuldades se encontram na padronização dos tipos de avaliação (qualitativa ou quantitativa) e correta definição das unidades a serem analisadas (uma única empresa ou várias, um único produto ou toda uma linha, e assim por diante).

Para Lambert e Pohlen (2001) as dificuldades em definir um conjunto balanceado de medidas de desempenho para uma cadeia de suprimentos ocorrem devido à complexidade de 
sobreposição entre as redes e também na dificuldade de compartilhamento de informações entre as empresas.

Segundo Gunasekaran et al. (2004) uma outra dificuldade encontrada entre as empresas é sobre a decisão de quantas métricas devem utilizar. Muitas vezes elas possuem um grande número de indicadores de desempenho que é cada vez aumentado ao adicionar novos indicadores baseados nas sugestões de colaboradores e consultores. As empresas deveriam compreender que a avaliação de desempenho pode ser mais eficiente se forem utilizados poucos, porém essenciais, indicadores.

Para Rafele (2004), uma questão muito difícil na mensuração de desempenho na cadeia de suprimentos é o desenvolvimento de um sistema de mensuração eficaz. A seleção do que mensurar e dos pontos relevantes pode ser complexo por devido à interdependência de todas as atividades na cadeia.

Park et al. (2005) relatam que as medidas atuais utilizadas para medir o desempenho na cadeia de suprimentos não consideram algumas características particulares de cada empresa da cadeia como o tipo de produto, estratégias corporativas, posição dela na cadeia e terceirizações.

Shepherd e Gunter (2006) definiram, com base em vários autores, algumas críticas aos sistemas atuais de medidas de desempenho da cadeia de suprimentos. Entre as críticas, podese ressaltar: falta de conexão com a estratégia; uso predominantemente de indicadores de custos; falta de uma abordagem equilibrada; medidas insuficientes sobre os consumidores e os concorrentes e perda de contexto da cadeia de suprimento prevalecendo a otimização local.

\subsubsection{Escolha das métricas}

Neely et al. (1995) identificaram pelo menos vinte e duas qualificações para considerar uma medida de desempenho como sendo "boa". Entre elas, pode-se citar: a clareza de relação entre a medida de desempenho e a estratégia empresarial; a facilidade em compreender; poder ser definida tanto para o fornecedor quanto para o cliente; pode gerar retornos precisos com relação às metas; clareza na definição e na apresentação; os dados devem ser apresentados em 
termos de tendências e não em termos absolutos, bem como serem apresentados em forma de informações e não em forma de opiniões abstratas; deve ser baseada em um acordo mútuo.

Segundo Miller (2001), de acordo com a literatura, os atributos de um bom sistema de mensuração do desempenho são: deve ser baseado na estratégia da empresa e ser um suporte para a mesma, deve representar bem os processos, deve ser orientado para a ação e permitir melhorias através do reforço da compreensão e aprendizagem, deve ser dinâmico e adaptável às mudanças.

Já Kaplan e Norton (1992) enfatizaram a necessidade de atingir um equilíbrio apropriado entre a mensuração com relação a: resultados de desempenho e direcionadores de desempenho, mensurações objetivas e subjetivas, perspectivas de curto e longo prazo.

Assim, seguindo o objetivo deste trabalho, serão abordados alguns estudos já realizados que visaram relacionar a integração da cadeia de suprimentos com o desempenho empresarial, ou seja, buscaram verificar quais os resultados trazidos com a integração da cadeia de suprimentos.

\subsection{Integração e desempenho}

Dos vários trabalhos pesquisados nesta revisão teórica, foram encontrados praticamente apenas estudos que estudavam somente a relação entre integração da cadeia de suprimentos e desempenho organizacional individual, ou seja, nenhum estudo mapeou uma cadeia e verificou a melhora entre os vários elos (somente na empresa focal, apesar de alguns estudos, para medir o nível e integração, considerou, além da empresa, os clientes e os fornecedores). A seguir serão comentados os principais trabalhos pesquisados.

Tan et al. (1998), confirmam que a integração entre as empresas da cadeia impactam em melhores desempenhos empresariais. O resultado do estudo por eles realizado apontou que maiores níveis de relacionamento das empresas com clientes e com fornecedores podem impactar positivamente os desempenhos financeiros e de mercado das empresas. 
Já Carr e Pearson (1999) realizaram um estudo verificando a relação entre a integração cliente-fornecedor e o desempenho financeiro da empresa. Neste trabalho, entre outras hipóteses, os autores confirmaram que a relação entre integração cliente-fornecedor e o desempenho financeiro da empresa foi positiva e estatisticamente significante.

Narasimhan e Das (2001) demonstram que quanto maior o alinhamento estratégico, maior o desempenho obtido pelas empresas na implementação de práticas de gestão da cadeia. Assim, o estudo dos autores sugere uma relação positiva entre a integração com fornecedores (participação do fornecedor no planejamento estratégico, acesso as informações estratégicas de seus clientes, desenvolvimento conjunto de produtos) e o desempenho de manufatura (qualidade, tempo, custo e flexibilidade) das empresas, porém os autores deixam evidente a necessidade da participação dos gerentes de suprimentos nas atividades de planejamento estratégico das empresas.

Entre os estudos de integração, um dos mais citados como referência na literatura pesquisada foi o de Frohlich e Westbrook (2001). Os autores realizaram um levantamento com trezentas e vinte e duas empresas do mundo todo, e ficou demonstrado que quanto mais alto o nível de integração com os fornecedores (coordenação de tecnologia de informação e fluxo de informação dos consumidores finais) e clientes (fluxo físico de produtos) na cadeia de suprimentos maior os benefícios potenciais (indicadores de mercado, de manufatura e "genéricos" ou "não-manufatura"). O maior grau (ou arco mais largo) da integração da cadeia de suprimentos foi fortemente associado com níveis mais altos de desempenho. Segundo os autores, esta descoberta ajuda a validar a metáfora de uma "corrente", já que elos fracos entre fornecedores e consumidores aparentam prejudicar o desempenho.

No ano seguinte, os mesmos autores, Frohlich e Westbrook (2002), realizaram outro trabalho, desta vez com quatrocentas e cinco empresas do Reino Unido, e também foi evidenciado que as empresas integradas com clientes (integração da previsão da demanda, dados do perfil do cliente, recebimento de pedidos on line e gerenciamento do relacionamento com o cliente) e fornecedores (planejamento de estoque, previsão da demanda e agendamento de pedidos integrados) possuem um maior nível de desempenho (velocidade de entrega, redução de custos de transação, aumento do giro de estoque e maior rentabilidade). 
De forma semelhante, Narasimhan e Kim (2002) apontam que a integração na cadeia (integração interna e externa, com clientes e fornecedores) impacta positivamente o desempenho das empresas (crescimentos das vendas, participação de mercado e rentabilidade).

O estudo de Rosenzweig et al. (2003) tentou verificar a relação entre a intensidade de integração na cadeia de suprimentos (integração interna, com cliente e com fornecedores) com quatro indicadores de desempenho empresarial: Retorno sobre Ativos (ROA), aumento das vendas, satisfação dos clientes e porcentagem de vendas proveniente de novos produtos. Eles concluíram que existe uma direta e positiva relação apenas entre intensidade de integração e duas medidas financeiras (Retorno sobre Ativos e vendas provenientes de novos produtos), não podendo tirar a mesma conclusão com o aumento de vendas ou satisfação dos clientes.

Vickery et al. (2003), criaram um modelo de integração da cadeia de suprimentos, com base nas evidências sugeridas pela literatura conforme mostra a ilustração 36.

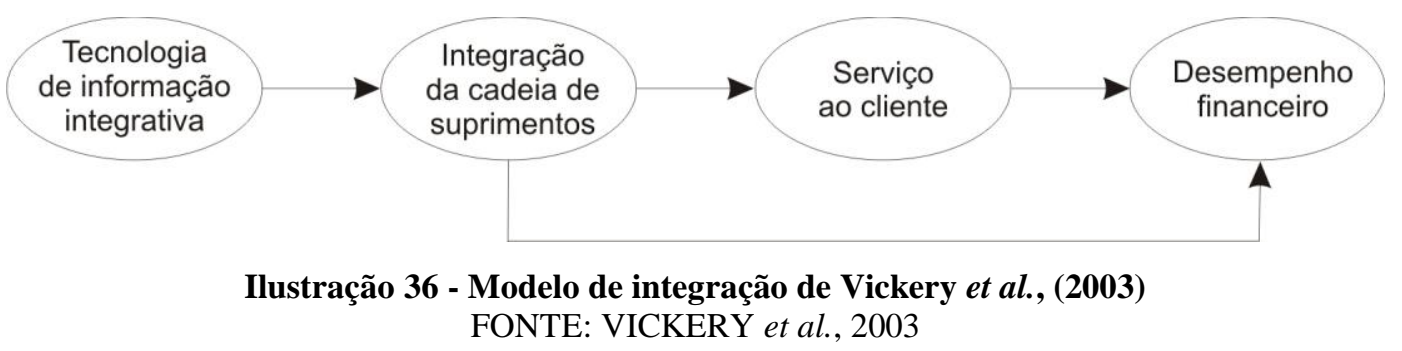

Assim, após suas pesquisas, os autores concluíram que existe uma relação positiva entre tecnologias integradas de informação e integração da cadeia de suprimentos, entre integração da cadeia de suprimentos e serviço ao cliente e entre serviço ao cliente e desempenho financeiro, porém a relação positiva entre integração da cadeia de suprimentos e desempenho financeiro não foi significante. Assim, neste trabalho, o que ficou mais evidente foi a forte relação entre integração da cadeia de suprimentos e satisfação dos clientes, e também a falta de relação entre integração da cadeia e desempenho financeiro.

Também Sahin e Robinson (2005) realizaram uma pesquisa entre empresa e fornecedor, porém em empresas de produção por encomenda. Eles mostraram que existe uma relação positiva entre integração (compartilhamento de informação e coordenação de fluxos físicos) com o desempenho financeiro das empresas. Outra evidência deste trabalho foi que a 
coordenação de fluxos físicos apresentou um maior impacto no desempenho das empresas do que o compartilhamento de informação.

Agan (2005) propõe um modelo de integração da cadeia de suprimentos conforme apresentado na ilustração 37. Para ele, a integração da cadeia de suprimentos melhora parcialmente o desempenho das empresas.

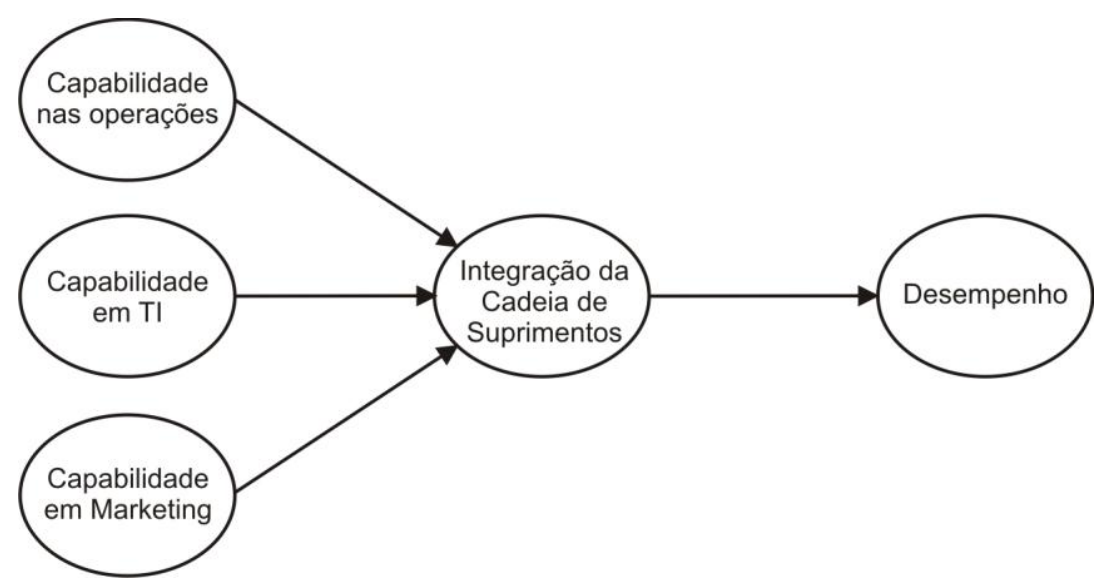

Ilustração 37 - Modelo de integração de Agan (2005)

FONTE: AGAN, 2005

Neste trabalho, o autor verificou que a integração da cadeia (gerenciamento da demanda, preenchimento do pedido, serviço ao cliente, compras, desenvolvimento de novos produtos, gerenciamento dos fluxos de manufatura, fluxo reverso) possui uma relação direta e positiva com os desempenhos operacional e com base no cliente (mercado), porém o mesmo não se pode concluir com relação ao desempenho financeiro.

Segundo Sezen (2008) sugere em seu trabalho, com bases em vários autores, que existe um relacionamento positivo entre os níveis de integração da cadeia de suprimentos e desempenho. Em seu estudo, o autor buscou estabelecer a relação entre integração das empresas (integração das atividades e planejamento, compartilhamento de informações com clientes, compartilhamento de informações com fornecedores e estrutura da cadeia) com seus desempenhos (desempenho de flexibilidade, desempenho de recursos e desempenho de mercado). Ficou demonstrado que a integração da cadeia possui uma relação direta e positiva com os desempenhos de recursos e de mercado, porém o mesmo não se pode verificar com o desempenho de flexibilidade. 
Também para Das et al. (2006), apesar de vários estudos terem relatado associações positivas entre níveis de integração e desempenho empresarial, dúvidas ainda restam como por exemplo, de como a integração afeta o desempenho, quais as práticas de integração são mais fundamentais e quais os reais retornos da integração. Os autores afirmam ainda que um maior integração com os fornecedores é a chave para um melhor desempenho da cadeia de suprimentos.

Segundo Badell et al. (2007), a sinergia entre finanças corporativas e gerenciamento de cadeia de suprimentos não foi muito bem explorado até agora. Assim, apesar das possíveis vantagens de uma integração funcional não terem sido avaliadas, existe um consenso positivo na literatura apoiando a ocorrência de tais vantagens.

Por outro lado, Fabbe-Costes e Jahre (2007) argumentam que a relação entre integração da cadeia de suprimentos e melhora de desempenho ainda é uma questão a se melhor explorada. No estudo elaborado pelos autores, foram examinados vários artigos sobre esse tema, e eles puderam mostrar que: (a) apesar do que muitos achavam, existem poucos artigos que tratam da relação entre integração da cadeia e desempenho de forma mais aprofundada; (b) apesar de quase todos os artigos mencionarem a relação positiva entre integração e desempenho, somente oito artigos argumentaram claramente e conseguiram provar tal evidencia; (c) outros artigo relataram que os possíveis benefícios discutidos na teoria não puderam comprovados em estudos práticos; (d) alguns autores argumentam que comprovar a relação entre integração e desempenho é difícil, pois o processo de integração não é uma tarefa tão simples; (e) outros autores afirmam que os benefícios da integração não são igualmente distribuídos entre todos os elos da cadeia; e finalmente, (f) alguns autores afirmam que os benefícios trazidos pela integração da cadeia são "mais teoria do que realidade".

Cousins e Menguc (2006) realizaram um estudo também em busca de verificar a relação entre integração da cadeia (planejamento, gerenciamento de pedidos, previsão e planejamento da produção) com o desempenho operacional da empresa (redução de custos, tempo de entrega de produtos, conformidade com as especificações, melhoria da qualidade, tempo de produção, melhoria nos processos). Como resultado, os autores mostraram que a relação entre integração e desempenho operacional mostrou não ser estatisticamente significante, contrariando a teoria estudada, porém os autores discorrem sobre as limitações de seus estudos como, por exemplo, o número pequeno da amostra. 
Também Swink et al. (2007) mostraram que a relação entre integração da empresa com clientes e fornecedores e o desempenho operacional (custo, qualidade, entrega, flexibilidade de processos e de produtos) e financeiro (aumento das vendas, participação de mercado e rentabilidade), não foi estatisticamente significante.

Assim, pode-se notar que os estudos acima citados buscaram verificam a relação entre integração da cadeia e desempenho individuais. Poucos estudos (e todos do tipo estudo de caso) foram realizados a fim de verificar a relação entre integração da cadeia e desempenho da cadeia. Entre eles pode-se citar os dois estudos seguintes.

De acordo com Zailani e Rajagopal (2005) várias pesquisas chegaram à conclusão de que o crescimento da produtividade é um indicador de sucesso da cadeia de suprimentos. Produtividade é uma medida do uso eficiente de recursos, geralmente expresso como a proporção de resultados (bens e serviços) e insumos (mão-de-obra, materiais, energia e outros recursos) usados para produzi-los. Os autores realizaram um estudo com quatorze empresas (seis asiáticas e oito americanas) e concluíram que em dez empresas o aumento da integração com os fornecedores (parcerias e/ou um envolvimento próximo entre eles) gerou uma melhoria no desempenho (crescimento da produtividade, da qualidade, da entrega e da flexibilidade) da cadeia.

Radhakrishnan (2005) buscou em seu trabalho, verificar a relação entre integração da cadeia de suprimentos (integração interna, integração externa com clientes e integração externa com fornecedores) e o desempenho operacional da cadeia (melhora da capabilidade da cadeia). Como resultado, o autor verificou que: (a) a integração da cadeia melhora as capabilidades da cadeia de suprimentos; (b) a integração da cadeia só é atingida quanto se tem a integração interna e externa simultaneamente; (c) a integração da cadeia só é atingida com o uso de Sistemas de Informação Inter-organizacional (Interorganizational Information Systems - IOIS ou IOS). Convêm notar que não foram mapeadas cadeias, mas apenas aplicados questionários com empresas focais.

Assim, foi elaborado um quadro resumindo como os autores mediram integração da cadeia e o desempenho das mesmas (ver Apêndice A). Em seguida, outro quadro foi elaborado mostrando as variáveis que mais apareceram nas pesquisas e também na teoria (ver Apêndice 
B). Este quadro será útil para a definição das variáveis independentes e dependentes deste trabalho, que irá ser abordado no próximo capítulo.

Assim, ao término da fundamentação teóricas alguns comentários tornam-se necessários:

- Cada autor define da sua maneira os conceitos de colaboração, coordenação e integração, não existindo um consenso, mas a maior parte do autores classifica integração como sendo uma relação mais complexa e duradoura entre as empresas;

- As medidas de desempenho utilizadas para avaliar os resultados empresariais isolados, bem como os resultados das cadeias na quase totalidade dos trabalhos pesquisados foram apenas medidas financeiras e operacionais. Poucos trabalhos se utilizaram de medidas de mercados e não foram encontrados trabalhados que se utilizaram de medidas balanceadas;

- Maior parte dos estudos mostra uma relação direta e positiva entre integração da cadeia de suprimentos e desempenho individual das empresas a elas pertencentes. Entre eles pode-se citar os estudos de: Carr e Pearson (1999), Frohlich e Westbrook (2001), Narasimhan e Das (2001), Rosenzweig et al. (2003), Vickery et al. (2003), Agan (2005) e Sezen (2008);

- Poucos estudos (e todos eles qualitativos), buscaram mostrar a relação entre integração da cadeia e desempenho global da cadeia;

- Nenhum estudo foi encontrado com o objetivo de verificar a relação entre desempenho individual e desempenho da cadeia. Isto é o que também afirmam Gunasekaran et al. (2001), Lambert e Pohlen (2001) e Fabbe-Costes e Jahre (2007), 


\section{MÉTODO}

Neste tópico, serão detalhados os procedimentos metodológicos, etapa essencial para a correta condução deste trabalho.

Para Richardson (2008), o conceito de ciência está ligado ao conceito de método científico. Para ele, o método é o caminho ou maneira para se chegar a um determinado fim ou objetivo, enquanto que metodologia são os procedimentos e regras utilizadas por um determinado método.

Também para Marconi e Lakatos (2005), todas as ciências se utilizam de métodos científicos e, segundo as autoras, a atividade científica tem como finalidade obter a verdade, comprovando hipóteses, observado a realidade e a teoria científica, a fim de explicar tal realidade.

Neste contexto, Gil (2008) define pesquisa como o procedimento racional e sistemático quem tem como objetivo proporcionar respostas aos problemas que são propostos.

Segundo Cooper e Schindler (2003), a pesquisa em administração pode ser definida como uma investigação sistemática que fornece informações para orientar as decisões empresariais.

Para Hair Jr. et al. (2005b), o processo de pesquisa em administração compreende em geral três fases: (1) formulação, envolvendo a definição da substância e do processo de pesquisa (teoria, questões de pesquisa, hipóteses e plano de estudo); (2) execução, onde o pesquisador reúne, codifica e armazena as informações de modo a permitir que sejam analisadas de forma rápida e precisa e (3) analítica, onde os dados são analisados, hipóteses são testadas e resultados são interpretados.

Vários autores destacam a várias maneiras de se classificar uma pesquisa e, nos próximos tópicos, será mostrado como este presente trabalho pode ser caracterizado. 


\subsection{Quanto à abordagem}

Com relação à abordagem utilizada, este trabalho pode ser classificado como Pesquisa Quantitativa, devido à mensuração e ao uso de expressão matemáticas de relações entre as variáveis, tanto na fase de coleta quanto na fase de análise.

Segundo Richardson (2008), o método quantitativo caracteriza-se pelo emprego da quantificação tanto nas modalidades de coleta de informações, quanto no tratamento delas por meio de técnicas estatísticas, desde as mais simples como percentual, média, desvio-padrão, às mais complexas, como coeficiente de correlação, análise de regressão, etc.

Para Malhotra (2006) a pesquisa quantitativa procura quantificar os dados, buscando evidências conclusivas e de alguma forma aplicando análises estatísticas. Contrastando com a pesquisa qualitativa, as descobertas da pesquisa quantitativa podem ser tratadas podem ser tratadas conclusivas e utilizadas para recomendar um curso final de ação.

\subsection{Quanto aos objetivos}

Quanto aos objetivos gerais, este trabalho pode ser classificado como Pesquisa Descritiva, devido ao fato de se buscar melhor compreender as variáveis do problema e estabelecer relações entre elas.

Para Gil (2008), uma pesquisa descritiva tem como objetivo primordial a descrição das características de determinada população ou fenômeno ou, então, o estabelecimento de relações entre variáveis.

Segundo Cooper e Schindler (2003), os estudos descritivos servem para: (1) descrições de fenômenos ou características associadas com a população-alvo; (2) estimativas das proporções de uma população que tenha essas características e (3) descoberta de associações entre as diferentes variáveis.

Para Hair Jr. et al. (2005b), diferente dos estudos exploratórios, os estudos descritivos com frequiência são confirmatórios, isto é, são usados para testar hipóteses. 


\subsection{Quanto aos procedimentos}

De acordo com os procedimentos, este estudo será realizado por meio de um levantamento (survey) transversal auto-administrado, pois serão recolhidas informações de muitos integrantes do universo pesquisado.

Segundo Gil (2008), os levantamentos caracterizam-se basicamente na solicitação de informações a um grupo significativo de pessoas acerca do problema estudado para, em seguida, mediante análise quantitativa, obterem-se as conclusões correspondentes aos dados coletados.

Para Malhotra (2006), levantamentos envolvem entrevistas com um grande número de pessoas e são aplicadas a elas uma série de perguntas, podendo ser conduzidos pessoalmente, por telefone, por um questionário enviado por correio ou eletronicamente pelo computador. $\mathrm{O}$ autor também define um levantamento transversal como aquele que envolve a coleta dos dados apenas uma vez.

Ainda segundo Hair Jr. et al. (2005b), os levantamentos recaem em duas amplas categorias: administração de questionários para que o próprio respondente responda (por correio ou por meio eletrônico) e entrevistas (pessoalmente, por telefone ou por computador). Cooper e Schindler (2003) definem o primeiro tipo de survey auto-administrado.

\subsection{Definição das variáveis}

$\mathrm{Na}$ definição das variáveis, foram utilizados os seguintes autores estudados no capítulo da Fundamentação Teórica: Tan et al. (1998), Carr e Pearson (1999), Frohlich e Westbrook (2001), Frohlich e Westbrook (2002), Narasimhan e Kim (2002), Rosenzweig et al. (2003), Vickery et al. (2003), Agan (2005), Radhakrishnan (2005), Zailani e Rajagopal (2005), Cousins e Menguc (2006), Das et al. (2006), Swink et al. (2007) e Sezen (2008).

Estes autores listaram em seus trabalhos as principais variáveis envolvendo os constructos de Integração da Cadeia de Suprimentos, Desempenho Individual e Desempenho da Cadeia. Assim, depois de estudados seus respectivos trabalhos, foram detectadas as variáveis mais relevantes (que estavam presentes em um número maior de estudos), as quais serão utilizadas neste estudo. Para facilitar a determinação dessas variáveis, foi elaborado o Apêndice A, 
contendo as variáveis separadas por autor, e posteriormente foi elaborado o Apêndice B, contendo as variáveis separadas por constructos.

As variáveis do constructo Integração da Cadeia de Suprimentos são consideradas como sendo variáveis independentes, tanto em relação às variáveis do constructo Desempenho Individual como em relação as variáveis do constructo Desempenho da Cadeia. Por outro lado, as variáveis do Desempenho da Cadeia são sempre dependentes (tanto em relação às variáveis da Integração da Cadeia de Suprimentos como em relação às do Desempenho Individual. Já as variáveis da Integração Individual assumem duas relações: são consideradas dependentes em relação às variáveis da Integração da Cadeia de Suprimentos e considerada independentes em relação as variáveis do Desempenho da Cadeia. Assim, as variáveis foram assim classificadas:

- Variáveis Independentes

$\checkmark$ Integração Interna

- Integração interna entre as funções

- Equipes multifuncionais

- Integração dos sistemas de informação entre as funções internas

Integração com Fornecedores

- Informações de previsão de demanda disponíveis aos fornecedores

- Monitoramento do status dos pedidos junto aos fornecedores

- Compartilhamento dos planos de produção com os fornecedores

- Compartilhamento de recursos com o fornecedor, tais como depósitos e instalações

- Gerenciamento conjunto de iniciativas de desenvolvimento de novos produtos

- Gerenciamento integrado da previsão da demanda

- Compartilhamento de informações importantes com os fornecedores

- Participação dos fornecedores na fase de design de produtos

- Integração direta entre os computadores da empresa com os dos principais fornecedores

- Conhecimento das capacidades de produção de nossos fornecedores

- Compartilhamento das informações de custos com os nossos principais fornecedores

- Compartilhamento de informações de custo por parte dos nossos fornecedores 
- Compartilhamento em tempo real das informações da programação de produção com os fornecedores

$\checkmark$ Integração com Clientes

- Fornecimento por parte dos clientes de suas informações de previsão da demanda

- Facilidade dos clientes em monitorar o status de seus pedidos realizados

- Planejamento conjunto de produção

- Compartilhamento de recursos, tais como depósitos e instalações

- Gerenciamento em conjunto de iniciativas de desenvolvimento de novos produtos

- Identificação em conjunto oportunidades de novos mercados.

- Gerenciamento integrado da previsão da demanda

- Gerenciamento do relacionamento com o cliente

- Acesso em tempo real dos clientes sobre a disponibilidade do produto

- Variáveis Independentes / Dependentes

$\checkmark$ Desempenho Individual-Perspectiva dos Processos Empresariais

- Tempo de entrega

- Confiabilidade na entrega

- Níveis de estoque

- Custos de manufatura

- Pedidos entregue no prazo

- Taxa de atendimento dos pedidos

- Lead-time da produção

- Lead-time da compras

- Flexibilidade de serviço ao cliente

- Flexibilidade para responder e atender variações de demanda, tais como a sazonalidade.

$\checkmark$ Desempenho Individual - Perspectiva dos Clientes

- Reclamações dos clientes

- Participação de mercado

- Retenção de clientes

- Tempo de resposta ao cliente

- Nível de serviço ao cliente 
Desempenho Individual - Perspectiva Financeira

- Vendas em unidades

- Receitas

- Lucro líquido

- Retorno sobre investimento

- Retorno sobre o ativo total

- Giro de estoque

- Custo dos produtos e serviços

Desempenho Individual - Perspectiva da Inovação e do Aprendizado

- Competitividade da empresa

- Melhoria contínua dos processos internos

- Variáveis Dependentes

Desempenho da Cadeia - Perspectiva dos Processos Empresariais

- Tempo de entrega

- Confiabilidade na entrega

- Pedidos entregue no prazo

- Taxa de atendimento dos pedidos

- Lead-time da produção

- Lead-time da compras

- Tempo total de ciclo do pedido

$\checkmark$ Desempenho da Cadeia-Perspectiva dos Clientes

- Satisfação dos clientes

- Reclamações dos clientes

- Retenção de clientes

- Tempo de resposta ao cliente

- Nível de serviço ao cliente

Desempenho da Cadeia - Perspectiva Financeira

- Custo total dos recursos utilizados

- Custos associados ao estoque parado

- Vendas em unidades

- Receitas

- Lucro líquido

- Retorno sobre investimento 
- Retorno sobre o ativo total

- Giro de estoque

$\checkmark$ Desempenho da Cadeia - Perspectiva da Inovação e do Aprendizado

- Competitividade global

- Melhoria contínua global dos processos

- Variável interveniente

- Setor de atividade

\subsection{Perguntas de pesquisa}

Entre as pesquisas estudadas, os autores buscaram estabelecer uma relação entre a integração da cadeia de suprimentos e os desempenhos organizacionais individuais das empresas.

Por outro lado, alguns autores afirmam que estudos envolvendo a relação entre desempenho individual e desempenho global de toda cadeia devem ser realizados a fim de verificar tal relação, entre eles pode-se destacar Lambert e Pohlen (2001), Gunasekaran et al. (2001) e Fabbe-Costes e Jahre (2007).

Assim, para auxiliar na definição das variáveis do trabalho e também na elaboração das hipóteses deste trabalho, surgem as seguintes perguntas:

- Qual a relação entre a integração da cadeia de suprimentos com os desempenhos organizacionais individuais e globais das cadeias em empresas brasileiras de grande porte?

- Quais os níveis de integração individuais atuais das empresas pesquisadas?

- Quais os desempenhos organizacionais individuais atuais das empresas pesquisadas?

- Qual a relação entre os níveis de integração individuais com os desempenhos organizacionais individuais atuais?

- Quais os desempenhos globais das cadeias mapeadas?

- Qual a relação entre os níveis de integração individuais com os desempenhos globais das cadeias mapeadas?

- Qual a relação entre os desempenhos individuais das empresas com os desempenhos globais das cadeias as quais elas pertencem? 
- Quais os níveis de integração, desempenhos organizacionais individuais e desempenhos globais da cadeia por setor de atividade?

\subsection{Hipóteses}

Segundo Richardson (2008), as hipóteses podem ser definidas como soluções tentativas, previamente selecionadas, do problema de pesquisa, permitindo orientar a análise dos dados no sentido de aceitar ou rejeitas as soluções tentativas.

De forma semelhante, Marconi e Lakatos (2005) definem hipótese como uma resposta suposta, provável e provisória para o problema formulado.

Segundo a teoria estudada, muitos autores afirmam que existe uma relação positiva entre integração da cadeia de suprimentos e desempenho organizacional individual (pelo menos alguns indicadores). Entre ele pode-se citar: Frohlich e Westbrook (2001), Narasimhan e Das (2001), Narasimhan e Kim (2002), Rosenzweig et al. (2003), Vickery et al. (2003), Radhakrishnan (2005), Sahin e Robinson (2005), Zailani e Rajagopal (2005), Sezen (2008),

Outros autores também afirmam que, apesar de ainda ser pouco investigado, existe um consenso da literatura sobre uma relação positiva entre integração da cadeia de suprimentos e desempenho global da cadeia. Entre ele pode-se citar: Das et al. (2006) e Badell et al. (2007).

Por outro lado, alguns autores como Lambert e Pohlen (2001) e Fabbe-Costes e Jahre (2007) afirmam que estudos devem ser realizados para verificar a relação entre desempenho organizacional individual e desempenho global da cadeia, e Gunasekaran et al. (2001) afirmam que a busca de cada empresa (elo da cadeia) em otimizar o seu desempenho, leva a uma não otimização da cadeia como um todo. Porém, não havendo uma busca para otimizar cada elo individualmente, mas sim apenas uma melhora de desempenho, qual seria a relação entre desempenho organizacional individual e desempenho global da cadeia?

Neste contexto, as hipóteses para este trabalho são:

Hipótese 1 (H1): Existe uma relação positiva entre integração da cadeia de suprimentos e desempenho organizacional individual. 
Hipótese 2 (H2): Existe uma relação positiva entre integração da cadeia de suprimentos e desempenho global da cadeia de suprimentos.

Hipótese 3 (H3): Existe uma relação positiva entre desempenho organizacional individual e desempenho global da cadeia de suprimentos.

Neste contexto, com base nas perguntas de pesquisa e nas hipóteses, foi elaborado o modelo a ser verificado neste trabalho. Foi verificada a existência ou não das relações entre integração da cadeia de suprimentos, desempenho organizacional individual e desempenho organizacional global da cadeia a qual as empresas respondentes pertencem. A ilustração 38 abaixo ilustra o modelo.

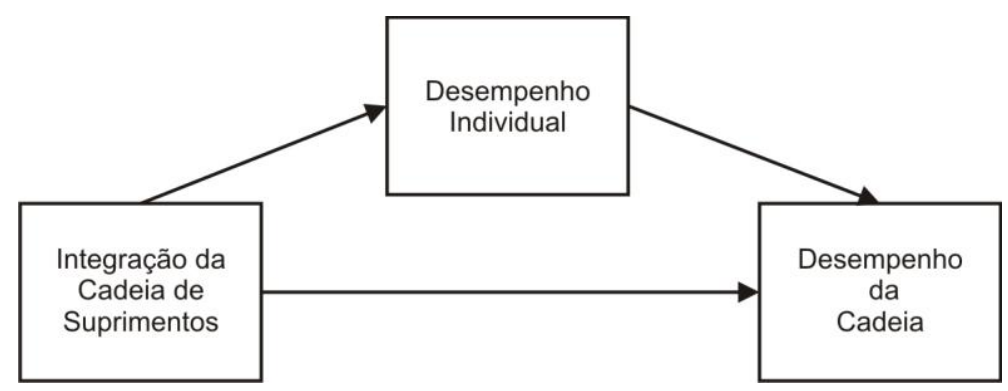

Ilustração 38 - Modelo básico da pesquisa

Detalhando mais o modelo, pode-se apresentar a ilustração 39, onde H1, H2 e H3 são as hipóteses a serem investigadas. 


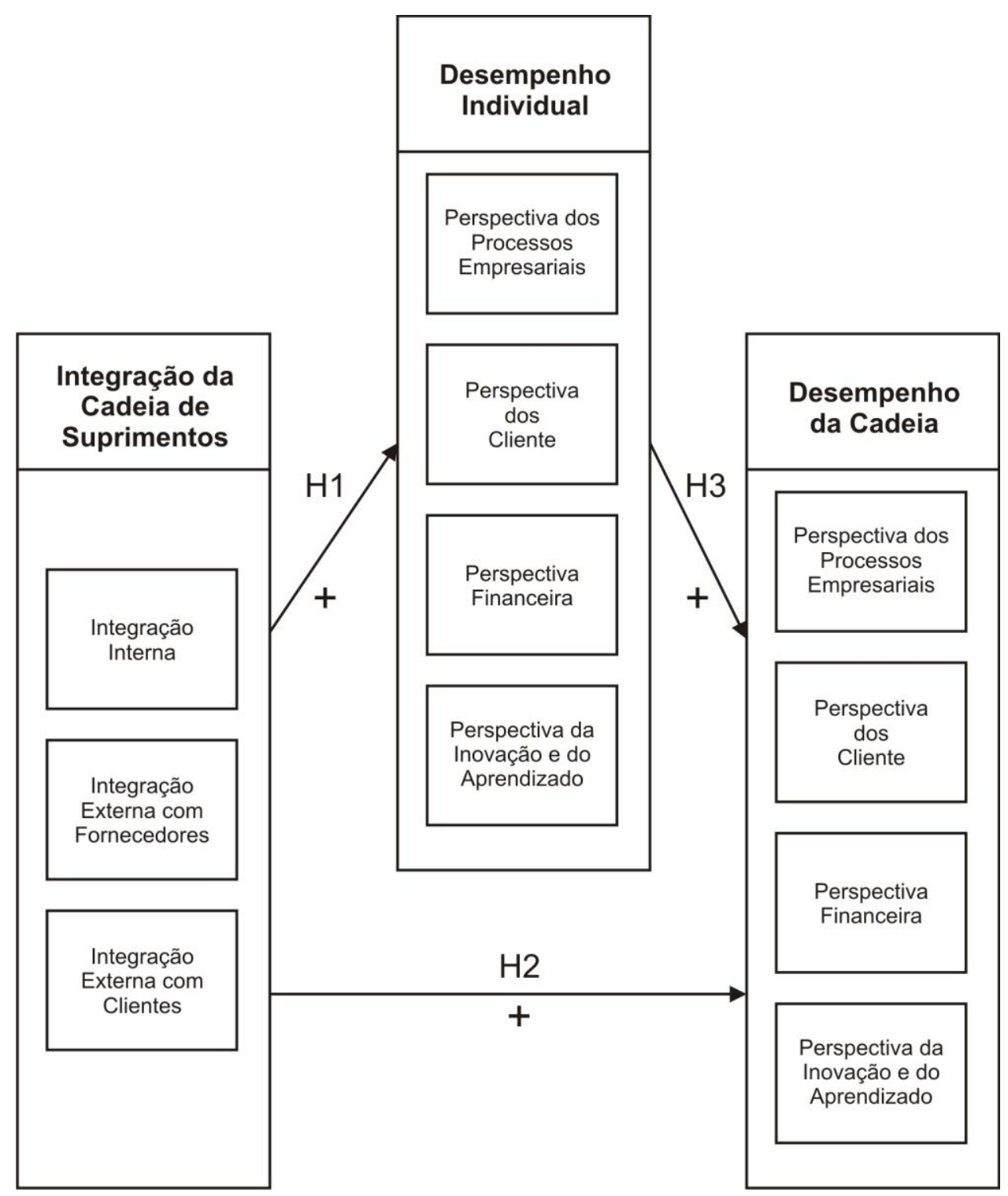

Ilustração 39 - Modelo detalhado da pesquisa

\subsection{Etapas do Levantamento (survey)}

Para este trabalho será utilizado o método de levantamento ou também chamado de survey. Segundo Malhotra (2006), o método de levantamento baseia-se no questionamento dos entrevistados, envolvendo entrevistas com um grande número de pessoas e aplicação a elas de uma série de perguntas.

De acordo com Martins e Theóphilo (2009), uma característica marcante do survey é que nele são estudados fenômenos que ocorrem naturalmente e a análise dos processos tal como ocorrem se opõe à maneira como são tratados os fenômenos no método do experimento, nos quais, muitas vezes, as condições do estudo afastam-se bastante das situações da vida real. 
Foi adotado o uso do survey transversal auto-administrado on-line, onde o questionário ficou disponível em um site. Segundo Cooper e Schindler (2003), este método está sendo bastante utilizado devido ao seu baixo custo, rapidez e facilidade.

Gil (2008) define as fases de um survey como sendo: (a) especificação dos objetivos, (b) operacionalização dos conceitos e variáveis, (c) elaboração do instrumento de coleta de dados, (d) pré-teste do instrumento, (e) seleção da amostra, (f) coleta e verificação dos dados, (g) análise e interpretação dos dados e (h) apresentação dos resultados.

Assim, como as etapas (a) e (b) já foram discutidas anteriormente, serão discutidas a seguir as etapas (c), (d) e (e). As últimas etapas serão abordadas nos próximos capítulos.

\subsubsection{Elaboração do instrumento de coleta}

Para Martins e Theóphilo (2009), as escalas sociais e de atitudes consistem em uma série graduadas de enunciados (itens) a respeito de uma situação, onde se solicita ao respondente que assinale o grau que melhor represente sua percepção a respeito do objeto de análise para cada item que compõe o instrumento.

Neste survey serão utilizados dois tipos de escalas. Para avaliar a integração da cadeia de suprimentos será utilizada a Escala Likert de sete pontos e para avaliar os desempenhos individuais e global será utilizada a Escala de Diferencial Semântico também de sete pontos, ambas consideradas escalas para medir atitudes segundo Mattar (2005).

Assim, optou-se por utilizar as escalas de atitude devido aos seguintes fatores: (a) dificuldade de se medir diretamente as variáveis deste estudo (como por exemplo, satisfação dos clientes, nível de estoque, entre outras), (b) flexibilidade e facilidade de construção e entendimento, segundo Malhotra (2006) e (c) possibilidade de serem tratadas como sendo escalas métricas, segundo Hair Jr. et al. (2005a), e assim serem mais bem analisadas estatisticamente.

Com base na tabela resumo das varáveis levantadas na revisão teórica (ver Apêndice B), começou o processo de construção do questionário. Inicialmente a tabela resumo foi enviada para dois profissionais da área de logística e suprimentos de duas grandes empresas e também 
para dois professores doutores na área. Buscou-se chegar a um consenso sobre quais as variáveis mais relevantes e, portanto quais deveriam fazer parte do questionário final. Foram então definidas a variáveis abordadas no tópico 3.4 "Definição das Variáveis". Esta etapa pode ser considerada, juntamente com a revisão teórica, a validação de conteúdo do questionário.

Convêm notar que como o questionário pretende analisar a cadeia das empresas, algumas questões iniciais foram necessárias para definir qual cadeia seria analisada. Primeiro foi solicitado para o respondente definir qual a principal linha de produtos e, com base nela, considerar os dois clientes e os dois principais fornecedores que estariam mais integrados com a empresa. Assim, o questionário final pode ser visto no Apêndice C.

\subsubsection{Validação do instrumento de coleta}

Apesar deste trabalho se basear em escalas já validadas, realizadas pelos autores estudados, para a elaboração do instrumento de coleta (questionário), é necessário avaliar a validade e confiabilidade deste instrumento elaborado.

Segundo Martins e Theóphilo (2009), a validade diz respeito à capacidade do instrumento em medir de fato o que se propõe a medir, enquanto a confiabilidade está relacionada com a constância dos resultados obtidos quando o mesmo indivíduo ou objeto é avaliado, medido ou quantificado mais do que uma vez. Assim, medidas confiáveis são replicáveis e consistentes, isto é, geram os mesmo resultados e medidas válidas são representações precisas da característica que se pretende medir.

De modo semelhante, Hair Jr. et al. (2005b) afirma que um instrumento é considerado confiável se sua aplicação repetida resulta em resultados coerentes. O autor define a existência de três tipos de confiabilidade: confiabilidade teste-reteste (uso repetido do mesmo instrumento com o mesmo grupo de respondentes e sob situação semelhante), confiabilidade de formas alternativas (criação de dois instrumentos com formas equivalentes de construtos e aplicação para o mesmo grupo de respondentes) e confiabilidade de coerência interna (usado para avaliar uma escala somada em que várias afirmações são somadas para formar um escore total para um constructo). 
Hair Jr. et al. (2005b) ainda afirma que a validade serve para verificar até que ponto um constructo mede o que deveria medir. Segundo os autores, para avaliar a validade, deve-se usar uma ou mais das seguintes abordagens: (a) validade de conteúdo - uma avaliação sistemática, porém subjetiva, da habilidade da escala para medir o que deve medir, envolvendo a consulta de uma pequena amostra de respondentes típicos e/ou especialistas para julgar a adequação dos itens escolhidos para representar o constructo, (b) validade de constructo - avalia o que o constructo ou escala está de fato medindo. Para isso, duas verificações devem ser feitas: validade convergente (até que ponto a variável de um constructo está positivamente relacionada com outras variáveis do mesmo constructo, ou seja, se as variáveis do mesmo constructo se relacionam entre si) e validade discriminante (até que ponto as variáveis de um constructo não se correlacionam com outros constructos) e (c) validade de critério - avalia se um constructo tem o desempenho esperado em relação a outras variáveis identificadas como critérios significativos. Para isso deve-se mostrar que os escores obtidos a partir da aplicação da escala que esta sendo validade conseguem prever escores obtidos em uma variável teoricamente dependente (variável de critério). Essas verificações são feitas por meio da validade concorrente (estabelecer alguma associação predeterminada entre os escores do constructo que este sendo avaliado e os escores de uma variável dependente indicado pela teoria e então verificar se são altamente correlacionados) e da validade preditiva (avalia a habilidade de um constructo medido prever uma outra variável de critério ou uma escala de itens múltiplos).

Para avaliar a validade e confiabilidade do questionário elaborado, foi utilizada uma adaptação do modelo de validação proposto por Singh e Smith (2006) que se basearam em diversos autores, entre eles: Flynn et al. (1990), Ahire et al. (1996), Malhotra e Grover (1998) e Hair Jr. et al. (2005a). Os testes estatísticos foram aplicados após a coleta de dados.

As etapas utilizadas foram:

Etapa 1 - Revisão da literatura - uma cuidadosa revisão da literatura foi feita de forma a garantir que os aspectos mais relevantes sejam abordados, garantindo assim que o instrumento tenha validação de conteúdo.

Etapa 2 - Identificação de constructos básicos - nesta etapa, as principais variáveis foram ser agrupadas em constructos (que são variáveis latentes, não podendo ser medidas diretamente). 
Etapa 3 - Escalas de mensuração - aqui foram definidas quais os tipos de escalas utilizadas no estudo. Para este trabalho, como já explicado anteriormente, foram utilizadas escalas Likert e de Diferencial Semântico.

Etapa 4 - Pré-teste - Pré-testes devem ser realizados a fim de verificar possíveis problemas ou possíveis melhoras no questionário. Assim, após a conclusão do questionário, foi realizado o pré-teste com seis respondentes.

Etapa 5 - Coleta de dados - Nesta etapa ocorre o contato com os respondentes e a efetiva resposta dos questionários.

Etapa 6 - Testes Estatísticos - Nesta etapa foram realizados os testes estatísticos pra avaliar a validade e confiabilidade. Assim, os testes realizados serão:

a) Teste de Multicolinearidade - Para Ahire et al. (1996), a Multicolinearidade ocorre quando dois ou mais itens medem a mesma coisa e, portanto, idênticas. Segundo Hair Jr. et al. (2005a), ítens altamente colineares podem distorcer os resultados substancialmente ou torná-los instáveis e não generalizáveis. Para este teste foi utilizada a ferramenta de Correlação de Pearson entre as variáveis de cada constructo.

b) Confirmação das variáveis do estudo - Como o questionário utilizado é composto por várias questões (variáveis), um teste para verificar se realmente todas as variáveis são relevantes seria bem aceito. Assim, foi utilizada a ferramenta de Análise Fatorial Exploratória, que segundo Hair Jr. et al. (2005a), tem como uns de seus objetivos o resumo dos dados.

c) Teste de Confiabilidade - $\mathrm{O}$ método mais comum para medir a confiabilidade de questionários auto-administrados consiste em estimar a consistência interna. $\mathrm{O}$ pressuposto da consistência interna é que as variáveis são todas medidas ligeiramente diferentes do mesmo conceito e assim, a inter-correlação entre elas devem ser altas, se realmente medirem o mesmo conceito. A medida comumente usada é o Alpha de Cronbach, que foi utilizada neste trabalho.

d) Teste de Atribuição de Itens - O próximo passo no processo de validação envolve avaliar se os itens foram "devidamente" atribuídos aos constructos. Para isso foi utilizada a análise das Cargas Fatoriais obtidas na Analise Fatorial Exploratória do item $b)$.

e) Teste de Validade Convergente de Constructo - Para verificar se as variáveis de um constructo se relacionam entre si, Ahire et al. (1996) sugere o uso da AVE (variância média extraída), obtido por meio da análise dos resultados da Modelagem das Equações Estruturais. 
f) Teste de Validade Discriminante de Constructo - Para verificar se as variáveis de um constructo estão estimando apenas este constructo, o autor sugere que seja medida pela comparação entre a raiz quadrada da variância média extraída (AVE), obtido por meio da análise dos resultados da Modelagem das Equações Estruturais, e as correlações entre as variáveis latentes para verificar a interdependências entre eles.

\subsubsection{Definição da amostra}

Segundo Malhotra (2006), a elaboração da amostragem começa com a especificação da população-alvo, sendo ela a coleção de elementos ou objetos que possuem a informação que o pesquisador está buscando.

Para este trabalho, a definição da população-alvo foi baseada na lista das mil maiores empresas nacionais, elaborada pela revista Valor Econômico no ano de 2009 (VALOR 1000, 2009). Tal escolha se deve ao julgamento do pesquisador de que a probabilidade das grandes empresas estarem integradas é maior do que a probabilidade das pequenas e médias empresas, pois estão sempre em busca de estarem atualizadas na utilização de melhores práticas gerenciais. A lista original contém mil empresas distribuídas em vinte e seis setores, porém foram descartados os setores que não se caracterizam pelo fluxo de matéria prima e/ou produtos pela cadeia. Também foram descartados o setor de Comércio Varejista (por ser o último elo da cadeia e, portanto possivelmente ser inviável medir a integração com clientes) e alguns setores fornecedores de matéria prima bruta, como por exemplo, Mineração (por serem elos iniciais da cadeia e, portanto possivelmente ser inviável medir a integração com fornecedores). Assim, a lista modificada é composta por quinhentas e quarenta e quatro empresas, distribuídas em treze setores. O quadro 21 abaixo ilustra os setores selecionados e o número de empresas em cada setor.

Quadro 21 - Setores da população-alvo

\begin{tabular}{|c|c|c|c|}
\hline $\begin{array}{c}\text { Alimentos } \\
(72 \text { empresas })\end{array}$ & $\begin{array}{c}\text { Bebidas e Fumo } \\
(21 \text { empresas })\end{array}$ & $\begin{array}{c}\text { Comércio Atacadista e } \\
\text { Exterior } \\
(54 \text { empresas })\end{array}$ & $\begin{array}{c}\text { Comunicação e Gráfica } \\
\text { (17 empresas) }\end{array}$ \\
\hline $\begin{array}{c}\text { Construção e } \\
\text { Engenharia } \\
\text { (55 empresas) }\end{array}$ & $\begin{array}{c}\text { Eletroeletrônica } \\
(34 \text { empresas) }\end{array}$ & $\begin{array}{c}\text { Farmacêutica e } \\
\text { Cosméticos } \\
(20 \text { empresas })\end{array}$ & $\begin{array}{c}\text { Material de Construção } \\
\text { e Decoração } \\
\text { (30 empresas) }\end{array}$ \\
\hline $\begin{array}{c}\text { Mecânica } \\
\text { (26 empresas) }\end{array}$ & $\begin{array}{c}\text { Metalurgia e } \\
\text { Siderurgia } \\
(65 \text { empresas) }\end{array}$ & $\begin{array}{c}\text { Química e Petroquímica } \\
(77 \text { empresas })\end{array}$ & $\begin{array}{c}\text { Têxtil, Couro e } \\
\text { Vestuário } \\
\text { (21 empresas) }\end{array}$ \\
\hline $\begin{array}{c}\text { Veículos e Peças } \\
\text { (51 empresas) }\end{array}$ & & & \\
\hline
\end{tabular}


Os próximos passos para a definição da amostra são: escolher a técnica de amostragem e definir o tamanho da amostra. Para este trabalho, optou-se por utilizar a Amostragem nãoprobabilística por julgamento ou intencional. Segundo Hair Jr. et al. (2005b), na amostragem não-probabilística, a seleção de elementos para a amostra não é necessariamente feito com o objetivo de ser estatisticamente representativa da população. Já a amostragem por julgamento ou intencional envolve a o julgamento do pesquisador na seleção da amostra por acreditar que eles representam a população-alvo, mas não necessariamente representativos.

Com relação ao tamanho da amostra, por ser uma amostragem não-probabilística, não foi utilizado nenhum cálculo para determinar o número necessário de respondentes. Das quinhentas e quarenta e quatro empresas contatadas, os gestores de cento e trinta e quatro delas responderam ao questionário, ou seja, $24,6 \%$ da população foi estudada.

\subsubsection{Coleta e Análise dos dados}

Inicialmente foi necessário entrar em contato com os gestores de logística e/ou suprimentos das empresas. A primeira tentativa foi ligar para as empresas e solicitar o contato desses gestores, porém não se obteve sucesso, pois na maior parte das vezes as pessoas com quem se conversava dizia não poder passar o contato. Também quando se conseguia o contato dos gestores, eles diziam não poder colaborar com a pesquisa.

Assim, como segunda tentativa, foi utilizado o site de relacionamento profissional Linkedin. Nesse site, existem grupos de discussão específicos de Logística e de Cadeia de Suprimentos. Após se inscrever nesses grupos, um email era enviado para a pessoa escolhida (gestor da empresa a qual pretendia pesquisar) explicando a pesquisa e pedindo a colaboração. Quando a pessoa respondia aceitando participar, então era passado a mesma o endereço da página do questionário (link) que estava disponível on line. Para conseguir o total de cento e trinta e cinco respondentes, foi necessário enviar exatamente mil setecentos e vinte e sete emails, o que representa uma taxa de retorno de $7,8 \%$.

Na fase de análise de dados, alguns testes estatísticos serão utilizados, porém eles serão mais bem detalhados no próximo capítulo do trabalho. Para verificar as hipóteses, optou-se por fazer a análise de dados de duas formas diferentes. 
A primeira forma de análise foi utilizando a Análise Fatorial e posteriormente a Regressão Linear. Inicialmente foi utilizada a Análise Fatorial Exploratória para cada um dos constructos (pois o número de variáveis é muito grande quando comparado ao tamanho da amostra) no intuito de reduzir o número de variáveis em alguns poucos fatores. Depois, utilizando os fatores gerados, foi calculada uma nota para cada um dos três principais constructos (Integração da Cadeia de Suprimentos, Desempenho Individual e Desempenho da Cadeia). Finalmente foi utilizada a Regressão Linear Simples e o Coeficiente de Correlação de Pearson para verificar a relação e correlação entre os pares de constructos. Para estas análises, utilizou-se o pacote estatístico SPSS (statistical package for social sciencies).

Segundo Hair Jr. et al. (2005a), a Análise Fatorial Exploratória analisa a estrutura das interrelações (correlações) entre um grande número de variáveis, definindo um conjunto de dimensões latentes comuns, chamadas de fatores, ou seja, o propósito geral da Análise Fatorial Exploratória é condensar (resumir) a informação contida em diversas variáveis originais em um conjunto menor de novas dimensões compostas (fatores) com uma perda mínima de informação.

Para Stevenson (1981), a análise da correlação e regressão compreende a análise de dados amostrais para saber se, e como, duas ou mais variáveis estão relacionadas uma com a outra numa população. Enquanto que a correlação mede a força, ou grau, de relacionamento entre duas variáveis, a análise de regressão tem como resultado uma equação que descreve o relacionamento em termos matemáticos. Para a análise da correlação, utilizou-se o coeficiente de correlação de Pearson, que pode assumir valores entre $-1,00$ e $+1,00$, sendo nesses casos a existência de uma associação perfeita entre variáveis (inversamente proporcional ou diretamente proporcional).

De posse dos fatores resultantes da Análise Fatorial Exploratória, foi utilizada a técnica de Modelagem de Equações Estruturais (Structural Equation Modeling - SEM) como uma segunda alternativa de análise e também como forma de validar o questionário proposto neste trabalho. 
Para Hair Jr. et al. (2005a), um dos objetivos das técnicas multivariadas é expandir a habilidade explanatória do pesquisador e a eficiência estatística, porém praticamente todas as técnicas existentes (regressão múltipla, análise fatorial, análise multivariada de variância, análise discriminante, entre outras) possuem a limitação de analisarem cada relação por vez. Porém, muitas vezes os pesquisadores se defrontam com um conjunto de questões interrelacionadas e nesse sentido a técnica de Modelagem de Equações Estruturais (SEM), uma extensão de diversas técnicas multivariadas, mostra-se bastante pertinente. Assim, a SEM examina uma série de relações de dependência simultaneamente, sendo útil quanto uma variável dependente se torna independente em subsequentes relações de dependência.

Neste trabalho, para realizar a SEM, optou-se por usar o software livre Smart PLS baseado na metodologia dos Mínimos Quadrados Parciais, ou abreviadamente, PLS (Partial Least Square) em vez de LISREL, que é baseado na metodologia de estruturas de covariâncias, ou abreviadamente, CSM (Covariance Structure Model). Segundo Chin (1997), a metodologia PLS possui alguns benefícios em relação à metodologia CSM, pois não requer suposições sobre a distribuição das variáveis e é adequado para explicar relações mais complexas.

De forma a complementar as análises, outros testes estatísticos foram realizados:

- Nas análises preliminares das variáveis, para detectar a presença de outliers (observações atípicas), Hair Jr. et al. (2005a) sugere o uso da distância de Mahalanobis $\left(\mathrm{D}^{2}\right)$ e com base nessas distâncias, realizou-se um teste t-student com nível de significância de $0,1 \%$ (teste conservador);

- Ainda nas análises preliminares, para verificar a normalidade dos dados, ou seja, verificar a distribuição das probabilidades das variáveis, Hair Jr. et al. (2005a) sugere o uso do teste de Kolmogorov-Smirnov;

- Para a verificação da consistência interna foi utilizado o coeficiente Alfa de Cronbach para cada fator resultante da Análise Fatorial Exploratória, verificando-se assim a confiabilidade;

- Na verificação da existência de diferença dos três constructos estudados (Integração da Cadeia de Suprimentos, Desempenho Individual e Desempenho da Cadeia) entre os treze setores estudados, foi utilizada a Análise de Variância (ANOVA) para verificar a diferença significativa entre as médias dos os setores; 
- Depois de verificado em qual dos três constructos havia diferença entre os setores, foi utilizado o teste Post Hoc LSD, a fim de verificar em quais setores existiam diferenças de média. 


\section{APRESENTAÇÃO E DISCUSSÃO DOS RESULTADOS}

Antes de iniciar a etapa de análise dos dados, serão apresentadas no quadro 22 as questões que foram utilizadas para as análises e suas respectivas codificações.

Quadro 22 - Codificação das variáveis do estudo

\begin{tabular}{|c|c|}
\hline Questão & Código \\
\hline Setor & Setor_cod \\
\hline Na minha empresa existe uma ampla integração interna entre as funções & $\mathrm{R} 4$ \\
\hline $\begin{array}{l}\text { A minha empresa usa equipes multifuncionais para apoiar os objetivos estratégicos da nossa } \\
\text { unidade }\end{array}$ & R5 \\
\hline Na minha empresa existe integração dos sistemas de informação entre as funções internas & R6 \\
\hline A minha empresa oferece aos fornecedores as informações de previsão de demanda & R7 \\
\hline A minha empresa pode facilmente monitorar o status de seus pedidos & R8 \\
\hline A minha empresa compartilha seus planos de produção com os fornecedores & R9 \\
\hline A minha empresa compartilha recursos com o fornecedor, tais como depósitos e instalações & R10 \\
\hline $\begin{array}{l}\text { O fornecedor e a minha empresa gerenciam em conjunto de iniciativas de desenvolvimento de } \\
\text { novos produtos }\end{array}$ & R11 \\
\hline A minha empresa possui gerenciamento integrado da previsão da demanda & R12 \\
\hline $\begin{array}{l}\text { A minha empresa compartilha uma grande quantidade de informações importantes com os nossos } \\
\text { fornecedores }\end{array}$ & R13 \\
\hline Nossos fornecedores participam da fase de design de nossos produtos & R14 \\
\hline $\begin{array}{l}\text { Existe uma integração direta entre os computadores da nossa empresa e os dos nossos principais } \\
\text { fornecedores }\end{array}$ & $\mathrm{R} 15$ \\
\hline A nossa empresa sabe das capacidades de produção de nossos fornecedores & R16 \\
\hline $\begin{array}{l}\text { A nossa empresa compartilha as nossas informações de custos com os nossos principais } \\
\text { fornecedores }\end{array}$ & $\mathrm{R} 17$ \\
\hline $\begin{array}{l}\text { A nossa empresa exige que o compartilhamento de informações de custo por parte dos nossos } \\
\text { fornecedores }\end{array}$ & $\mathrm{R} 18$ \\
\hline $\begin{array}{l}\text { A nossa empresa compartilha em tempo real a informação da programação de produção com os } \\
\text { fornecedores }\end{array}$ & R19 \\
\hline Os nossos clientes fornecem suas informações de previsão da demanda para a nossa empresa & R20 \\
\hline $\begin{array}{l}\text { Os nossos clientes podem facilmente monitorar o status de seus pedidos realizados na nossa } \\
\text { empresa }\end{array}$ & $\mathrm{R} 21$ \\
\hline Nossos clientes e a minha empresa coordenam conjuntamente o planejamento de produção & $\mathrm{R} 22$ \\
\hline A minha empresa compartilha recursos, tais como depósitos e instalações com os clientes & $\mathrm{R} 23$ \\
\hline $\begin{array}{l}\text { Nossos clientes e a minha empresa gerenciam em conjunto iniciativas de desenvolvimento de } \\
\text { novos produtos }\end{array}$ & $\mathrm{R} 24$ \\
\hline Nossos clientes e a minha empresa identificam em conjunto oportunidades de novos mercados. & $\mathrm{R} 25$ \\
\hline A nossa empresa realiza gerenciamento integrado da previsão da demanda & $\mathrm{R} 26$ \\
\hline A nossa empresa realiza gerenciamento do relacionamento com o cliente & $\mathrm{R} 27$ \\
\hline Os nossos clientes têm acesso em tempo real sobre a disponibilidade do produto da nossa empresa & $\mathrm{R} 28$ \\
\hline Tempo de entrega & R29 \\
\hline Confiabilidade na entrega & $\mathrm{R} 30$ \\
\hline Níveis de estoque & R31 \\
\hline Custos de manufatura & $\mathrm{R} 32$ \\
\hline Pedidos entregue no prazo & R33 \\
\hline Taxa de atendimento dos pedidos & R34 \\
\hline Lead-time da produção & $\mathrm{R} 35$ \\
\hline Lead-time da compras & R36 \\
\hline
\end{tabular}




\begin{tabular}{|l|c|}
\hline \multicolumn{1}{|c|}{ Questão } & Código \\
\hline Flexibilidade de serviço ao cliente & $\mathrm{R} 37$ \\
\hline Flexibilidade para responder e atender variações de demanda, tais como a sazonalidade. & $\mathrm{R} 38$ \\
\hline Reclamações dos clientes & $\mathrm{R} 39$ \\
\hline Participação de mercado & $\mathrm{R} 40$ \\
\hline Retenção de clientes & $\mathrm{R} 41$ \\
\hline Tempo de resposta ao cliente & $\mathrm{R} 42$ \\
\hline Nível de serviço ao cliente & $\mathrm{R} 43$ \\
\hline Vendas em unidades & $\mathrm{R} 44$ \\
\hline Receitas & $\mathrm{R} 45$ \\
\hline Lucro líquido & $\mathrm{R} 46$ \\
\hline Retorno sobre investimento & $\mathrm{R} 47$ \\
\hline Retorno sobre o ativo total & $\mathrm{R} 48$ \\
\hline Giro de estoque & $\mathrm{R} 49$ \\
\hline Custo dos produtos e serviços & $\mathrm{R} 50$ \\
\hline Competitividade da empresa & $\mathrm{R} 51$ \\
\hline Melhoria contínua dos processos internos & $\mathrm{R} 52$ \\
\hline Tempo de entrega & $\mathrm{R} 53$ \\
\hline Confiabilidade na entrega & $\mathrm{R} 54$ \\
\hline Pedidos entregue no prazo & $\mathrm{R} 55$ \\
\hline Taxa de atendimento dos pedidos & $\mathrm{R} 56$ \\
\hline Lead-time da produção & $\mathrm{R} 57$ \\
\hline Lead-time da compras & $\mathrm{R} 58$ \\
\hline Tempo total de ciclo do pedido & $\mathrm{R} 59$ \\
\hline Satisfação dos clientes & $\mathrm{R} 60$ \\
\hline Reclamações dos clientes & $\mathrm{R} 61$ \\
\hline Retenção de clientes & $\mathrm{R} 62$ \\
\hline Tempo de resposta ao cliente & $\mathrm{R} 63$ \\
\hline Nível de serviço ao cliente & $\mathrm{R} 64$ \\
\hline Custo total dos recursos utilizados & $\mathrm{R} 65$ \\
\hline Custos associados ao estoque parado & $\mathrm{R} 66$ \\
\hline Vendas em unidades & $\mathrm{R} 67$ \\
\hline Receitas & $\mathrm{R} 68$ \\
\hline Lucro líquido & $\mathrm{R} 69$ \\
\hline Retorno sobre investimento & $\mathrm{R} 70$ \\
\hline Retorno sobre o ativo total & $\mathrm{R} 71$ \\
\hline Giro de estoque & $\mathrm{R} 72$ \\
\hline Competitividade global & $\mathrm{R} 73$ \\
\hline Melhoria contínua global dos processos & $\mathrm{R} 74$ \\
\hline & \\
\hline
\end{tabular}

Também, conforme o modelo apresentado para este estudo são apresentadas as questões associadas aos constructos na ilustração 40. 


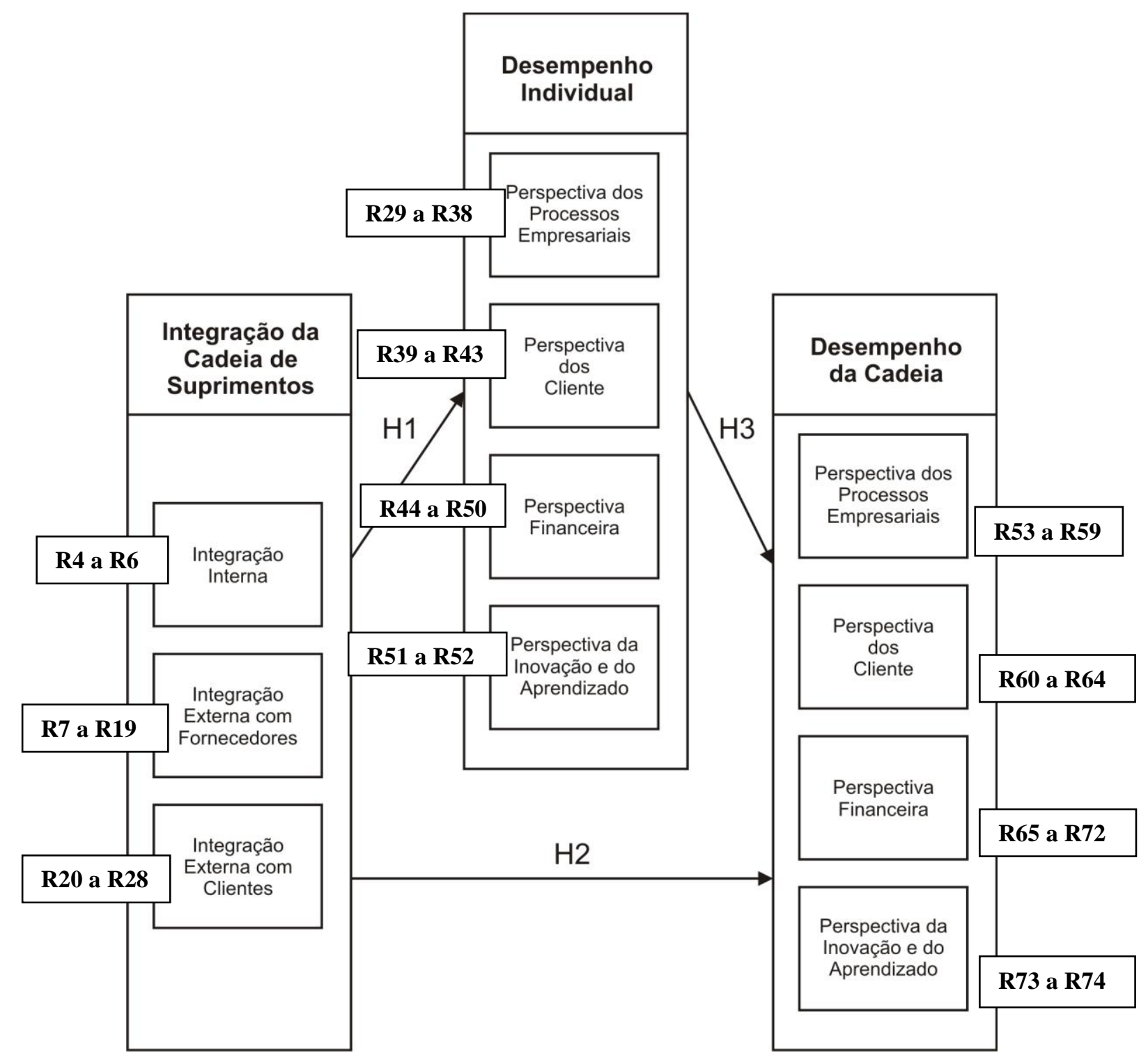

Ilustração 40 - Modelo detalhado da pesquisa e respectivas variáveis

O questionário ficou disponível on-line em uma página da internet, no endereço http://www.fearp.usp.br/papo/pesquisa, no período de novembro de 2010 a abril de 2011. No total foram 135 questionários preenchidos, de um total de 1727 emails enviados solicitando colaboração, representando então uma taxa de retorno de 7,8\%. Se for considerado que a população é de 544 empresas, o total de questionários respondidos representa $24,6 \%$ da população estudada.

As 135 empresas que compõem a amostra estão divididas em 13 setores distintos conforme a tabela 4. 
Tabela 4 - Setores estudados

\begin{tabular}{lrr}
\hline \multicolumn{1}{c}{ Setor } & Freqüência & Porcentagem \\
\hline Alimentos & 14 & 10,4 \\
Bebidas e Fumo & 2 & 1,5 \\
Comunicação e Gráfica & 1 & 0,7 \\
Construção e Engenharia & 3 & 2,2 \\
Eletroeletrônica & 24 & 17,8 \\
Farmacêutica e Cosméticos & 4 & 3,0 \\
Material de Construção e Decoração & 9 & 6,7 \\
Mecânica & 11 & 8,1 \\
Metalurgia e Siderurgia & 11 & 8,1 \\
Química e Petroquímica & 17 & 12,6 \\
Têxtil, Couro e Vestuário & 5 & 3,7 \\
Veículos e Peças & 33 & 24,4 \\
Sem identificação & 1 & 0,7 \\
\multicolumn{1}{c}{ Total } & 135 & 100,0 \\
\hline
\end{tabular}

\subsection{Análises preliminares}

\subsubsection{Casos Extremos (Outliers)}

Primeiramente verificou-se a presença de casos extremos, ou outliers, na base de dados. A presença de valores extremos na base de dados pode comprometer as análises e, portanto, devem ser retiradas caso existam. Esta análise foi realizada de forma multivariada, pela distância de Mahalanobis $\left(\mathrm{D}^{2}\right)$. Para isto foi realizada uma análise de regressão, onde como variáveis independentes foram utilizadas todas as variáveis do questionário e como variável dependente foi utilizada a primeira variável da integração da cadeia (R4) e assim, a distância de Mahalanobis foi salva na base de dados.

Com base nessas distâncias, realizou-se um teste t-student com nível de significância de $0,1 \%$ (teste conservador) e observou-se que não há casos extremos nos dados coletados, de forma que as análises subseqüentes foram realizadas com a amostra de 135 casos.

\subsubsection{Distribuição de probabilidade das variáveis}

Verificou-se a normalidade da distribuição das variáveis pelo teste de Kolmogorov-Smirnov para uma amostra. As hipóteses para esse teste são:

- H0: a variável possui distribuição normal;

- H1: a variável não possui distribuição normal. 
Para essa análise utilizou-se nível de significância 5\%, destacando-se que a variável está normalmente distribuída se a hipótese nula do teste K-S não for rejeitada. O quadro 23 a seguir apresenta os resultados do teste.

Quadro 23 - Distribuição de probabilidade das variáveis

\begin{tabular}{|l|l|l|}
\hline Variável & Valor P & Decisão (alfa=5\%) \\
\hline R4 & 0,000 & Rejeita-se H0 \\
\hline R5 & 0,000 & Rejeita-se H0 \\
\hline R6 & 0,000 & Rejeita-se H0 \\
\hline R7 & 0,000 & Rejeita-se H0 \\
\hline R8 & 0,000 & Rejeita-se H0 \\
\hline R9 & 0,001 & Rejeita-se H0 \\
\hline R10 & 0,005 & Rejeita-se H0 \\
\hline R11 & 0,001 & Rejeita-se H0 \\
\hline R12 & 0,001 & Rejeita-se H0 \\
\hline R13 & 0,014 & Rejeita-se H0 \\
\hline R14 & 0,026 & Rejeita-se H0 \\
\hline R15 & 0,000 & Rejeita-se H0 \\
\hline R16 & 0,000 & Rejeita-se H0 \\
\hline R17 & 0,001 & Rejeita-se H0 \\
\hline R18 & 0,011 & Rejeita-se H0 \\
\hline R19 & 0,002 & Rejeita-se H0 \\
\hline R20 & 0,002 & Rejeita-se H0 \\
\hline R21 & 0,001 & Rejeita-se H0 \\
\hline R22 & 0,001 & Rejeita-se H0 \\
\hline R23 & 0,004 & Rejeita-se H0 \\
\hline R24 & 0,010 & Rejeita-se H0 \\
\hline R25 & 0,008 & Rejeita-se H0 \\
\hline R26 & 0,001 & Rejeita-se H0 \\
\hline R27 & 0,000 & Rejeita-se H0 \\
\hline R28 & 0,050 & Rejeita-se H0 \\
\hline R29 & 0,000 & Rejeita-se H0 \\
\hline R30 & 0,000 & Rejeita-se H0 \\
\hline R31 & 0,000 & Rejeita-se H0 \\
\hline R32 & 0,000 & Rejeita-se H0 \\
\hline R33 & 0,000 & Rejeita-se H0 \\
\hline R34 & 0,000 & Rejeita-se H0 \\
\hline R35 & 0,000 & Rejeita-se H0 \\
\hline R36 & 0,000 & Rejeita-se H0 \\
\hline R37 & 0,000 & Rejeita-se H0 \\
\hline R38 & 0,000 & Rejeita-se H0 \\
\hline R39 & 0,005 & Rejeita-se H0 \\
\hline R40 & 0,001 & Rejeita-se H0 \\
\hline R41 & 0,000 & Rejeita-se H0 \\
\hline R42 & 0,000 & Rejeita-se H0 \\
\hline R43 & 0,000 & Rejeita-se H0 \\
\hline R44 & 0,000 & Rejeita-se H0 \\
\hline R45 & 0,000 & Rejeita-se H0 \\
\hline R46 & 0,001 & Rejeita-se H0 \\
\hline R47 & 0,002 & Rejeita-se H0 \\
\hline R48 & 0,005 & Rejeita-se H0 \\
\hline R49 & 0,000 & Rejeita-se H0 \\
\hline R50 & 0,000 & Rejeita-se H0 \\
\hline
\end{tabular}




\begin{tabular}{|l|l|l|}
\hline Variável & Valor P & Decisão (alfa=5\%) \\
\hline R51 & 0,000 & Rejeita-se H0 \\
\hline R52 & 0,000 & Rejeita-se H0 \\
\hline R53 & 0,000 & Rejeita-se H0 \\
\hline R54 & 0,002 & Rejeita-se H0 \\
\hline R55 & 0,001 & Rejeita-se H0 \\
\hline R56 & 0,000 & Rejeita-se H0 \\
\hline R57 & 0,001 & Rejeita-se H0 \\
\hline R58 & 0,000 & Rejeita-se H0 \\
\hline R59 & 0,000 & Rejeita-se H0 \\
\hline R60 & 0,000 & Rejeita-se H0 \\
\hline R61 & 0,008 & Rejeita-se H0 \\
\hline R62 & 0,000 & Rejeita-se H0 \\
\hline R63 & 0,001 & Rejeita-se H0 \\
\hline R64 & 0,000 & Rejeita-se H0 \\
\hline R65 & 0,000 & Rejeita-se H0 \\
\hline R66 & 0,000 & Rejeita-se H0 \\
\hline R67 & 0,003 & Rejeita-se H0 \\
\hline R68 & 0,000 & Rejeita-se H0 \\
\hline R69 & 0,000 & Rejeita-se H0 \\
\hline R70 & 0,000 & Rejeita-se H0 \\
\hline R71 & 0,000 & Rejeita-se H0 \\
\hline R72 & 0,001 & Rejeita-se H0 \\
\hline R73 & 0,000 & Rejeita-se H0 \\
\hline R74 & 0,000 & Rejeita-se H0 \\
\hline
\end{tabular}

Dessa forma, observa-se que há rejeição da hipótese nula para todas as variáveis métricas do estudo, o que indica que sua distribuição é não normal.

Porém, Hair Jr. et al. (2005a) afirma que a normalidade somente torna-se necessária se um teste estatístico for aplicado para a significância dos fatores, mas esses testes são raramente usados. Já segundo Corrar et al. (2007), se o método utilizado para a extração dos fatores for o da análise das componentes principais (que é o método utilizado neste trabalho), não há necessidade de haver normalidade. Assim, não será necessário fazer nenhum tipo de transformação dos dados.

\subsubsection{Teste de linearidade}

Para verificar a linearidade dos dados foi realizada uma análise de regressão, onde como variáveis independentes foram utilizadas todas as variáveis do questionário e como variável dependente foi utilizada a primeira variável da integração da cadeia (R4). O resultado mostra uma linearidade entre as variáveis independentes e dependente, pois o $\mathrm{R}^{2}$ de 0,83 é considerado um bom ajuste, indicando que as variáveis independentes explicam $83 \%$ da variância da variável dependente. 


\subsection{Análise Fatorial}

A análise fatorial é uma técnica para redução e sumarização dos dados, isto é, a ferramenta reduz as variáveis em uma quantidade menor de dimensões (ou fatores), que explicam as variáveis originais. Essa redução é baseada em correlações e exige que a amostra possua, pelo menos, tamanho cinco vezes maior do que a quantidade de variáveis.

Nesse sentido, tendo em vista que a base de dados possui 135 casos, aplicaram-se fatoriais exploratórias individuais para cada bloco de variáveis: integração da cadeia de suprimentos integração interna; integração da cadeia de suprimentos - integração externa com fornecedores; integração da cadeia de suprimentos - integração externa com clientes; desempenho individual - perspectiva dos processos empresariais; desempenho individual perspectiva dos clientes; desempenho individual - perspectiva financeira; desempenho individual - perspectiva da inovação e do aprendizado; desempenho da cadeia - perspectiva dos processos empresariais; desempenho da cadeia - perspectiva dos clientes; desempenho da cadeia - perspectiva financeira; desempenho da cadeia - perspectiva da inovação e do aprendizado.

A análise fatorial utilizada foi do tipo $\mathrm{R}$, onde as colunas da base de dados representam as variáveis e as linhas representam os casos.

Para cada bloco de variáveis realizou-se a análise dos componentes principais com rotação Varimax (rotação ortogonal que pressupõe independência entre os fatores) e critério de extração com auto-valor (eigenvalue) maior que 1.

Foram realizadas várias rodadas de análises fatoriais, pois foram necessárias retiradas de algumas variáveis.

Após a obtenção dos fatores, realizou-se a análise de confiabilidade da escala, por meio do cálculo do índice Alfa de Cronbach para cada fator. Este índice tem como objetivo avaliar a fidedignidade da dimensão, considerando a correlação entre as variáveis que a compõem. Valores acima de 0,6 para o Alfa de Cronbach indicam fatores com confiabilidade satisfatória. 
Diante do exposto, o quadro 24 a seguir apresenta os parâmetros de análise da qualidade dos modelos fatoriais obtidos segundo Hair Jr. et al. (2005a).

Quadro 24 - Parâmetros da Qualidade das Análises Fatoriais

\begin{tabular}{|l|l|l|}
\hline \multicolumn{1}{|c|}{ Indicador } & \multicolumn{1}{|c|}{ Definição } & \multicolumn{1}{|c|}{ Valor aceitável } \\
\hline KMO & $\begin{array}{l}\text { Verifica o quão apropriada é a } \\
\text { análise fatorial para o conjunto de } \\
\text { dados. }\end{array}$ & Deve ser maior que 0,5 \\
\hline Teste de Bartlett & $\begin{array}{l}\text { Teste estatístico que verifica a } \\
\text { significância geral das correlações } \\
\text { em uma matriz de correlações }\end{array}$ & $\begin{array}{l}\text { Deve rejeitar a hipótese nula (as } \\
\text { correlações entre os pares de } \\
\text { variáveis é igual a zero) }\end{array}$ \\
\hline MSA individuais & $\begin{array}{l}\text { Verifica o quão adequada é a } \\
\text { variável no conjunto de dados }\end{array}$ & Deve ser maior que 0,5 \\
\hline Comunalidades & $\begin{array}{l}\text { Variância compartilhada entre a } \\
\text { variável e as demais variáveis do } \\
\text { conjunto }\end{array}$ & Deve ser maior que 0,5 \\
\hline Carga fatorial & $\begin{array}{l}\text { Correlação entre a variável original } \\
\text { e os fatores extraídos pela análise }\end{array}$ & Deve ser maior que 0,5 \\
\hline $\begin{array}{l}\text { Eigenvalue } \\
\text { (autovalor) }\end{array}$ & $\begin{array}{l}\text { Também conhecido como raiz } \\
\text { latente, representa a quantidade de } \\
\text { variância atribuída a um fator }\end{array}$ & Deve ser maior que 1 \\
\hline Variância explicada & $\begin{array}{l}\text { Porcentagem da variância dos } \\
\text { dados originais que o modelo } \\
\text { consegue explicar }\end{array}$ & Deve ser maior que 50\% \\
\hline Alfa de Cronbach & \begin{tabular}{l} 
Coeficiente de confiabilidade \\
\hline
\end{tabular}
\end{tabular}

\subsubsection{Constructo Integração da Cadeia de Suprimentos}

Como o constructo Integração da Cadeia é composto por três blocos de variáveis (subconstructos), foram realizadas três análises fatoriais, uma para cada bloco e serão mostrados a seguir.

\subsubsection{Integração da cadeia de suprimentos - integração interna}

As variáveis utilizadas para rodar a análise fatorial para a Integração da cadeia de suprimentos - integração interna foram: R4, R5 e R6.

A tabela 5 apresenta o teste Kaiser-Meyer-Olkin (KMO) e o teste de esfericidade de Bartlett para o constructo Integração da cadeia de suprimentos - integração interna. 
Tabela 5 - KMO e teste de Bartlett para integração da cadeia - integração interna

\begin{tabular}{llr} 
Medida de adequação da amostra de Kaiser-Meyer-Olkin (KMO) & $\mathbf{6 7 5}$ \\
\hline Teste de esferificade de Bartlett & Qui-Quadrado aproximado & 133,857 \\
\cline { 2 - 3 } & Graus de liberdade & 3 \\
\cline { 2 - 3 } & Significância & $\mathbf{0 0 0}$ \\
\hline
\end{tabular}

A análise obteve índice de $\mathrm{KMO}=0,675$, considerado adequado e o teste de Bartlett rejeita a hipótese nula, ou seja, há boa aderência do modelo.

A tabela 6 mostra a Matriz Anti-Imagem para o constructo Integração da cadeia de suprimentos - integração interna, que representa o poder de explicação dos fatores em cada uma das variáveis analisadas.

Tabela 6 - Matriz Anti-Imagem - integração da cadeia - integração interna

\begin{tabular}{ccccc} 
& & $\mathrm{R} 4$ & $\mathrm{R} 5$ & $\mathrm{R} 6$ \\
\hline Correlação Anti-imagem & $\mathrm{R} 4$ & $\mathbf{, 6 4 7}^{\mathbf{a}}$ &,- 591 &,- 205 \\
& $\mathrm{R} 5$ &,- 591 & $\mathbf{, 6 3 4}^{\mathbf{a}}$ &,- 288 \\
& R6 &,- 205 &,- 288 & $\mathbf{, 8 0 2}^{\mathbf{a}}$ \\
\hline
\end{tabular}

a. Medida de Adequação da Amostra (MSA)

Os índices de adequação das variáveis individuais (MSA) são maiores que 0,5 , portanto as variáveis possuem correlação entre si.

A seguir, a tabela 7 apresenta as comunalidades para o constructo Integração da cadeia de suprimentos - integração interna.

Tabela 7 - Comunalidades - integração da cadeia - integração interna

\begin{tabular}{lrr} 
& Inicial & Extração \\
\hline R4 & 1,000 & $\mathbf{7 5 7}$ \\
R5 & 1,000 & $\mathbf{7 8 1}$ \\
R6 & 1,000 & $\mathbf{6 0 0}$ \\
\hline
\end{tabular}

As comunalidades possuem valores maiores que 0,5 , portanto as variáveis são adequadas ao modelo. 
A tabela 8 apresenta a variância total explicada para o constructo Integração da cadeia de suprimentos - integração interna.

Tabela 8 - Variância Total Explicada - integração da cadeia - integração interna

\begin{tabular}{crrr}
\hline \multirow{2}{*}{ Componentes } & \multicolumn{3}{c}{ Autovalores (Eigenvalues) } \\
\cline { 2 - 4 } & \multicolumn{1}{c}{ Total } & \% da variância & \% acumulada \\
\hline 1 & 2,138 & 71,255 & $\mathbf{7 1 , 2 5 5}$ \\
2 &, 558 & 18,589 & 89,844 \\
3 &, 305 & 10,156 & 100,000 \\
\hline
\end{tabular}

O fator extraído explica $71,255 \%$ da variância total, o que é considerado adequado.

A tabela 9 a seguir apresenta as cargas fatoriais (correlação da variável com o fator) de cada variável para o constructo Integração da cadeia de suprimentos - integração interna.

Tabela 9 - Matriz Componente - integração da cadeia - integração interna

\begin{tabular}{lcc}
\hline & Componente \\
& 1 & \\
\hline R5 & & $\mathbf{8 8 4}$ \\
R4 & $\mathbf{8 7 0}$ \\
R6 & $\mathbf{7 7 5}$ \\
\hline
\end{tabular}

As cargas fatoriais são maiores que 0,5 , o que significam que as variáveis são representativas deste fator.

Assim, nenhuma variável foi retirada e então o constructo Integração da cadeia de suprimentos - integração interna é composto pelas variáveis R4, R5 e R6.

\subsubsection{Integração da cadeia de suprimentos - integração externa com fornecedores}

As variáveis utilizadas foram: $R 7$ a 19

A tabela 10 apresenta o teste Kaiser-Meyer-Olkin (KMO) e o teste de esfericidade de Bartlett para o constructo Integração da cadeia de suprimentos - integração externa com fornecedores. 
Tabela 10 - KMO e teste de Bartlett para integração da cadeia - integração externa com fornecedores

\begin{tabular}{llr}
\hline Medida de adequação da amostra de Kaiser-Meyer-Olkin (KMO) & $\mathbf{, 8 6 8}$ \\
\hline Teste de esferificade de Bartlett & Qui-Quadrado aproximado & 700,486 \\
\cline { 2 - 3 } & Graus de liberdade & 78 \\
\cline { 2 - 3 } & Significância & $\mathbf{, 0 0 0}$ \\
\hline
\end{tabular}

Obteve-se o se índice de $\mathrm{KMO}=0,868$ e rejeição do teste de Bartlett, o que indica boa aderência do modelo.

A tabela 11 mostra a Matriz Anti-Imagem para o constructo Integração da cadeia de suprimentos - integração externa com fornecedores,

Tabela 11 - Matriz Anti-Imagem - integração da cadeia - integração externa com fornecedores

\begin{tabular}{|c|c|c|c|c|c|c|c|c|c|c|c|c|c|c|}
\hline & & R7 & $\mathrm{R} 8$ & R9 & $\mathrm{R} 10$ & $\mathrm{R} 11$ & $\mathrm{R} 12$ & $\mathrm{R} 13$ & $\mathrm{R} 14$ & $\mathrm{R} 15$ & R16 & $\mathrm{R} 17$ & $\mathrm{R} 18$ & R19 \\
\hline Correlação & $\mathrm{R} 7$ &, $849^{a}$ &,- 128 &,- 427 &,- 013 &,- 094 &,- 348 &,- 113 & ,078 & ,132 &,- 054 &,- 001 &,- 072 & 044 \\
\hline \multirow[t]{12}{*}{ Anti-imagem } & $\mathrm{R} 8$ &,- 128 &, $929^{a}$ &,- 101 & ,039 &,- 055 &,- 172 &,- 051 &,- 001 & ,033 &,- 110 & ,075 & ,045 &,- 068 \\
\hline & R9 &,- 427 &,- 101 &, $864^{\mathrm{a}}$ &,- 054 &,- 225 &, 003 &,- 192 &, 073 &,- 065 &, 050 &, 142 &,- 068 &,- 193 \\
\hline & $\mathrm{R} 10$ &,- 013 & 039 &,- 054 &, $864^{\mathrm{a}}$ &,- 125 & ,066 & ,070 & ,008 &,- 275 &,- 003 &,- 009 &,- 117 &,- 128 \\
\hline & $\mathrm{R} 11$ &,- 094 &,- 055 &,- 225 &,- 125 &, $868^{\mathrm{a}}$ &,- 079 &,- 142 &,- 390 &,- 003 &,- 003 &,- 040 & , 140 & ,093 \\
\hline & $\mathrm{R} 12$ &,- 348 &,- 172 & ,003 & ,066 &,- 079 &, $\mathbf{8 6 3}^{\mathrm{a}}$ &,- 081 & , 186 &,- 243 &,- 084 & ,056 &,- 142 &,- 040 \\
\hline & $\mathrm{R} 13$ &,- 113 &,- 051 &,- 192 &, 070 &,- 142 &,- 081 &, $937^{\mathrm{a}}$ &,- 095 &,- 091 &,- 185 &,- 140 &,- 080 &,- 117 \\
\hline & R14 & ,078 &,- 001 & ,073 & ,008 &,- 390 & 186 &,- 095 &, $789^{\mathrm{a}}$ &,- 268 &,- 120 &,- 073 &,- 294 & ,025 \\
\hline & R15 & ,132 & 033 &,- 065 &,- 275 &,- 003 &,- 243 &,- 091 &,- 268 &, $842^{\mathrm{a}}$ &,- 029 &,- 114 & ,138 &,- 138 \\
\hline & R16 &,- 054 &,- 110 &, 050 &,- 003 &,- 003 &,- 084 &,- 185 &,- 120 &,- 029 &, $929^{a}$ &,- 096 &, 046 &,- 180 \\
\hline & R17 &,- 001 & ,075 & , 142 &,- 009 &,- 040 & ,056 &,- 140 &,- 073 &,- 114 &,- 096 &, $825^{\mathrm{a}}$ &,- 421 &,- 171 \\
\hline & $\mathrm{R} 18$ &,- 072 & 045 &,- 068 &,- 117 &, 140 &,- 142 &,- 080 &,- 294 & ,138 & ,046 &,- 421 &, $\mathbf{8 0 2} 2^{\mathrm{a}}$ &,- 034 \\
\hline & R19 &, 044 &,- 068 &,- 193 &,- 128 & ,093 &,- 040 &,- 117 & ,025 &,- 138 &,- 180 &,- 171 &,- 034 &, $912^{\mathrm{a}}$ \\
\hline
\end{tabular}

a. Medida de Adequação da Amostra (MSA)

Os índices MAS invididuais são satisfatórios para todas as variáveis. 
Entretanto, verificou-se inadequação de algumas variáveis, com comunalidades abaixo de 0,5 , conforme ilustrada a tabela 12.

Tabela 12 - Comunalidades - integração da cadeia - integração externa com fornecedores

\begin{tabular}{lrr} 
& \multicolumn{1}{c}{ Inicial } & Extração \\
\hline R7 & 1,000 &, 730 \\
R8 & 1,000 &, 524 \\
R9 & 1,000 &, 693 \\
R10 & 1,000 & $\mathbf{, 3 1 1}$ \\
R11 & 1,000 & $\mathbf{, 4 7 9}$ \\
R12 & 1,000 &, 611 \\
R13 & 1,000 &, 652 \\
R14 & 1,000 &, 584 \\
R15 & 1,000 & $\mathbf{, 4 7 0}$ \\
R16 & 1,000 & $\mathbf{, 4 0 5}$ \\
R17 & 1,000 &, 596 \\
R18 & 1,000 & $\mathbf{4 9 4}$ \\
R19 & 1,000 & $\mathbf{, 4 5 4}$ \\
\hline
\end{tabular}

Dessa forma, realizou-se novamente a análise retirando-se a variável R10, por apresentar o menor valor $(0,311)$. Assim, foi realizada uma segunda rodada da análise fatorial. Nesta segunda análise sem a variável R10, ainda se mantiveram algumas variáveis com comunalidades inaceitáveis, conforme mostra a tabela 13.

Tabela 13 - Comunalidades - integração da cadeia - integração externa com fornecedores (segunda rodada)

\begin{tabular}{lrr}
\hline & \multicolumn{1}{c}{ Inicial } & \multicolumn{1}{c}{ Extração } \\
\hline R7 & 1,000 &, 727 \\
R8 & 1,000 &, 520 \\
R9 & 1,000 &, 696 \\
R11 & 1,000 & $\mathbf{, 4 7 6}$ \\
R12 & 1,000 &, 610 \\
R13 & 1,000 &, 664 \\
R14 & 1,000 &, 608 \\
R15 & 1,000 & $\mathbf{, 4 3 8}$ \\
R16 & 1,000 & $\mathbf{, 4 1 7}$ \\
R17 & 1,000 &, 642 \\
R18 & 1,000 &, 522 \\
R19 & 1,000 & $\mathbf{, 4 4 9}$ \\
\hline
\end{tabular}


Dessa maneira, procedeu-se à retirada da variável R16, por apresentar o menor valor $(0,417)$.

Uma terceira rodada da análise fatorial foi realizada. Obteve-se, com a retirada da variável R16, índice de KMO de 0,853 e rejeição do teste de Bartlett, conforme mostra a tabela 14, o que confirma a aderência do modelo.

Tabela 14 - KMO e teste de Bartlett para integração da cadeia - integração externa com fornecedores

\begin{tabular}{llr}
\hline Medida de adequação da amostra de Kaiser-Meyer-Olkin (KMO) & $\mathbf{, 8 5 3}$ \\
\hline Teste de esferificade de Bartlett & Qui-Quadrado aproximado & 611,346 \\
\cline { 2 - 3 } & Graus de liberdade & 55 \\
\cline { 2 - 3 } & Significância & $\mathbf{0 0 0}$ \\
\hline
\end{tabular}

As MAS individuais também mantiveram-se em níveis adequados conforme mostra a tabela 15 .

Tabela 15 - Matriz Anti-Imagem - integração da cadeia - integração externa com fornecedores (segunda rodada)

\begin{tabular}{|c|c|c|c|c|c|c|c|c|c|c|c|c|}
\hline & & R7 & $\mathrm{R} 8$ & R9 & $\mathrm{R} 11$ & $\mathrm{R} 12$ & $\mathrm{R} 13$ & $\mathrm{R} 14$ & $\mathrm{R} 15$ & $\mathrm{R} 17$ & $\mathrm{R} 18$ & R19 \\
\hline Correlação & R7 &, $837^{\mathrm{a}}$ &,- 134 &,- 427 &,- 097 &,- 354 &,- 125 & ,072 & ,132 &,- 007 &,- 071 & ,033 \\
\hline \multirow[t]{10}{*}{ Anti-imagem } & $\mathrm{R} 8$ &,- 134 &, $924^{\mathrm{a}}$ &,- 094 &,- 051 &,- 186 &,- 076 &,- 015 &, 042 & ,065 & ,055 &,- 086 \\
\hline & R9 &,- 427 &,- 094 &, $\mathbf{8 5 3}^{\mathrm{a}}$ &,- 234 & ,011 &,- 183 & ,080 &,- 082 &, 148 &,- 078 &,- 196 \\
\hline & $\mathrm{R} 11$ &,- 097 &,- 051 &,- 234 &, $860^{\mathrm{a}}$ &,- 072 &,- 138 &,- 395 &,- 039 &,- 042 & ,127 & ,079 \\
\hline & $\mathrm{R} 12$ &,- 354 &,- 186 &, 011 &,- 072 &, $855^{\mathrm{a}}$ &,- 104 &, 177 &,- 238 & ,049 &,- 132 &,- 048 \\
\hline & $\mathrm{R} 13$ &,- 125 &,- 076 &,- 183 &,- 138 &,- 104 &, $935^{\mathrm{a}}$ &,- 121 &,- 082 &,- 161 &,- 065 &,- 148 \\
\hline & $\mathrm{R} 14$ &, 072 &,- 015 & ,080 &,- 395 &, 177 &,- 121 &, $762^{a}$ &,- 282 &,- 085 &,- 292 & ,005 \\
\hline & $\mathrm{R} 15$ & 132 & ,042 &,- 082 &,- 039 &,- 238 &,- 082 &,- 282 &, $842^{a}$ &,- 125 & ,112 &,- 190 \\
\hline & $\mathrm{R} 17$ &,- 007 & ,065 &, 148 &,- 042 & ,049 &,- 161 &,- 085 &,- 125 &, $797^{\mathrm{a}}$ &,- 422 &,- 195 \\
\hline & $\mathrm{R} 18$ &,- 071 & ,055 &,- 078 & , 127 &,- 132 &,- 065 &,- 292 & ,112 &,- 422 &, $796^{\mathrm{a}}$ &,- 042 \\
\hline & $\mathrm{R} 19$ & ,033 &,- 086 &,- 196 & ,079 &,- 048 &,- 148 &, 005 &,- 190 &,- 195 &,- 042 &, $\mathbf{9 0 3}^{\mathrm{a}}$ \\
\hline
\end{tabular}

a. Medida de Adequação da Amostra (MSA)

Como mostra a tabela 16, as comunalidades das variáveis R11, 15 e 19, mantiveram-se abaixo de 0,5, porém ao se efetuar a exclusão da R19, não se observou melhora do modelo. Tendo em vista que os valores obtidos não estão tão abaixo do esperado, essas variáveis foram mantidas no modelo final. 
Tabela 16 - Comunalidades - integração da cadeia - integração externa com fornecedores (terceira rodada)

\begin{tabular}{lrr}
\multicolumn{3}{c}{ rodada) } \\
\hline & Inicial & Extração \\
\hline R7 & 1,000 &, 733 \\
R8 & 1,000 &, 518 \\
R9 & 1,000 &, 709 \\
R11 & 1,000 &, $\mathbf{4 9 0}$ \\
R12 & 1,000 &, 612 \\
R13 & 1,000 &, 660 \\
R14 & 1,000 &, 614 \\
R15 & 1,000 &, $\mathbf{4 4 3}$ \\
R17 & 1,000 &, 645 \\
R18 & 1,000 &, 542 \\
R19 & 1,000 & $\mathbf{4 4 0}$ \\
\hline
\end{tabular}

Já a tabela 17 mostra que foram extraídos dois fatores com autovalor maior que 1 e que explicam 58,226\% da variância total, o que é considerado adequado.

Tabela 17 - Variância Total Explicada - integração da cadeia - integração externa com fornecedores

\begin{tabular}{lrrr}
\hline \multirow{2}{*}{ Componentes } & \multicolumn{3}{c}{ Autovalores (Eigenvalues) } \\
\cline { 2 - 4 } 1 & Total & \% da variância & \% acumulada \\
\hline 2 & 3,416 & 31,057 & 31,057 \\
3 & 2,989 & 27,169 & $\mathbf{5 8 , 2 2 6}$ \\
4 &, 883 & 8,028 & 66,255 \\
5 &, 771 & 7,011 & 73,266 \\
6 &, 610 & 5,543 & 78,809 \\
7 &, 582 & 5,294 & 84,103 \\
8 &, 435 & 3,959 & 88,062 \\
9 &, 392 & 3,564 & 91,626 \\
10 &, 375 & 3,409 & 95,034 \\
11 &, 307 & 2,792 & 97,827 \\
\hline
\end{tabular}

Método de Extração: Análise das Componentes Principais

Apesar de o instrumento de medida prever apenas uma dimensão para essas variáveis, o modelo identifica dois fatores para a integração com fornecedores. 
A tabela 18 , mostra como as variáveis ficaram divididas entre os dois fatores.

Tabela 18 - Matriz de componentes rotacionada - integração da cadeia - integração externa com fornecedores

\begin{tabular}{lcc}
\multicolumn{3}{c}{ fornecedores } \\
\hline \multirow{2}{*}{ Variáveis } & \multicolumn{2}{c}{ Componentes } \\
& 1 & 2 \\
\hline R7 & $\mathbf{8 4 7}$ &, 127 \\
R9 & $\mathbf{, 8 1 2}$ &, 224 \\
R12 & $\mathbf{, 7 6 4}$ &, 170 \\
R8 & $\mathbf{, 7 1 9}$ &,- 003 \\
R13 &, $\mathbf{6 0 8}$ &, 539 \\
R11 &, $\mathbf{5 3 6}$ &, 450 \\
R17 &, 012 &, $\mathbf{8 0 3}$ \\
R14 &, 065 & $\mathbf{, 7 8 1}$ \\
R18 &, 159 & $\mathbf{, 7 1 9}$ \\
R15 &, 270 & $\mathbf{, 6 0 8}$ \\
R19 &, 424 & $\mathbf{, 5 1 0}$ \\
\hline
\end{tabular}

O fator 1 é composto pelas variáveis R7, R8, R9, R11, R12 e R13 e foi denominado de “Compartilhamento de Informações”. Já o fator 2 é composto pelas variáveis R14, R15, R17, 18 e R19 e foi denominado de "Participação dos Fornecedores no Negócio".

\subsubsection{Integração da cadeia de suprimentos - integração externa com clientes}

As variáveis utilizadas foram: $R 20$ a 28

A análise fatorial obteve coeficiente $\mathrm{KMO}=0,880$ e rejeição da hipótese nula, o que pode ser considerado satisfatório, conforme mostra a tabela 19.

Tabela 19 - KMO e teste de Bartlett para integração da cadeia - integração externa com clientes

\begin{tabular}{llr}
\hline Medida de adequação da amostra de Kaiser-Meyer-Olkin (KMO) & $\mathbf{8 8 0}$ \\
\hline Teste de esferificade de Bartlett & Qui-Quadrado aproximado & 557,066 \\
\cline { 2 - 3 } & Graus de liberdade & 36 \\
\cline { 2 - 3 } & Significância & $\mathbf{0 0 0}$ \\
\hline
\end{tabular}


Pela Matriz Anti-Imagem ilustrada na tabela 20, pode-se observar que as medidas MSA individuais são todas satisfatórias.

Tabela 20 - Matriz Anti-Imagem - integração da cadeia - integração externa com clientes

\begin{tabular}{llccccccccc}
\hline & & R20 & R21 & R22 & R23 & R24 & R25 & R26 & R27 & R28 \\
\hline Correlação & R20 & $\mathbf{, 8 8 8}^{\mathbf{a}}$ &,- 214 &,- 161 &,- 043 &,- 285 &,- 045 &,- 194 &,- 086 &, 189 \\
Anti-imagem & R21 &,- 214 & $\mathbf{, 8 7 5}^{\mathbf{a}}$ &,- 338 &, 007 &, 071 &, 048 &,- 174 &,- 077 &,- 299 \\
& R22 &,- 161 &,- 338 & $\mathbf{, 8 9 2}^{\mathbf{a}}$ &,- 184 &,- 143 &,- 204 &, 005 &, 086 &,- 128 \\
& R23 &,- 043 &, 007 &,- 184 &, $\mathbf{8 9 0}$ &,- 073 &,- 191 &, 078 &, 078 &,- 154 \\
& R24 &,- 285 &, 071 &,- 143 &,- 073 &, $\mathbf{8 9 1}$ &,- 210 &,- 215 &,- 161 &, 093 \\
& R25 &,- 045 &, 048 &,- 204 &,- 191 &,- 210 &, 902 &,- 210 &, 048 &,- 201 \\
& R26 &,- 194 &,- 174 &, 005 &, 078 &,- 215 &,- 210 &, $\mathbf{8 9 5}$ &,- 294 &, 010 \\
& R27 &,- 086 &,- 077 &, 086 &, 078 &,- 161 &, 048 &,- 294 &, $\mathbf{8 5 8}$ &,- 344 \\
& R28 &, 189 &,- 299 &,- 128 &,- 154 &, 093 &,- 201 &, 010 &,- 344 &, $\mathbf{8 1 8}$ \\
\hline
\end{tabular}

a. Medida de Adequação da Amostra (MSA)

Entretanto ocorreram problemas com as comunalidades de algumas variáveis, conforme mostra a tabela 21 .

Tabela 21 - Comunalidades - integração da cadeia - integração externa com clientes

\begin{tabular}{lrr} 
& \multicolumn{1}{c}{ Inicial } & \multicolumn{2}{c}{ Extração } \\
\hline R20 & 1,000 &, 554 \\
R21 & 1,000 &, 598 \\
R22 & 1,000 &, 623 \\
R23 & 1,000 &, $\mathbf{2 7 9}$ \\
R24 & 1,000 &, 567 \\
R25 & 1,000 &, 583 \\
R26 & 1,000 &, 618 \\
R27 & 1,000 &, $\mathbf{4 6 3}$ \\
R28 & 1,000 & $\mathbf{, 4 3 9}$ \\
\hline
\end{tabular}

Dessa maneira a variável R23 é excluída (por apresentar o menor valor) e as análises foram novamente realizadas. 
Assim, uma segunda rodada de análise fatorial foi realizada. Porém mesmo com a extração da R23, as variáveis R27 e R28 ainda persistiram com problemas de comunalidade, por isso, simulou-se a exclusão de R28. Porém, como não houve grande melhora nos resultados, as variáveis R27 e R28 foram mantidas no modelo final.

Esse modelo, conforme mostra a tabela 22 , obteve $\mathrm{KMO}=0,872$ e rejeição do teste de Bartlett, o que leva à boa aderência do modelo.

Tabela 22 - KMO e teste de Bartlett para integração da cadeia - integração externa com clientes

\begin{tabular}{llr} 
Medida de adequação da amostra de Kaiser-Meyer-Olkin (KMO) & $\mathbf{8 7 2}$ \\
\hline Teste de esferificade de Bartlett & Qui-Quadrado aproximado & 516,361 \\
\cline { 2 - 3 } & Graus de liberdade & 28 \\
\cline { 2 - 3 } & Significância & $\mathbf{0 0 0}$ \\
\hline
\end{tabular}

Os coeficientes MSA individuais são satisfatórios, conforme pode ser visto na tabela 23;

Tabela 23 - Matriz Anti-Imagem - integração da cadeia - integração externa com clientes (segunda rodada)

\begin{tabular}{lccccccccc}
\hline & & R20 & R21 & R22 & R24 & R25 & R26 & R27 & R28 \\
\hline Correlação & R20 &, $\mathbf{8 8 3}^{\mathbf{a}}$ &,- 214 &,- 172 &,- 289 &,- 054 &,- 192 &,- 083 &, 185 \\
Anti-imagem & 221 &,- 214 & $\mathbf{8 6 7}$ &,- 342 &, 072 &, 051 &,- 175 &,- 078 &,- 302 \\
& R22 &,- 172 &,- 342 &, $\mathbf{8 7 7}^{\mathbf{a}}$ &,- 160 &,- 248 &, 020 &, 103 &,- 161 \\
& R24 &,- 289 &, 072 &,- 160 &, $\mathbf{8 8 3}^{\mathbf{a}}$ &,- 229 &,- 211 &,- 156 &, 083 \\
& R25 &,- 054 &, 051 &,- 248 &,- 229 &, $\mathbf{8 9 0}^{\mathbf{a}}$ &,- 199 &, 064 &,- 238 \\
& R26 &,- 192 &,- 175 &, 020 &,- 211 &,- 199 & $\mathbf{8 9 5}$ &,- 302 &, 022 \\
& R27 &,- 083 &,- 078 &, 103 &,- 156 &, 064 &,- 302 &, $\mathbf{8 5 7}$ &,- 337 \\
& R28 &, 185 &,- 302 &,- 161 &, 083 &,- 238 &, 022 &,- 337 &, $\mathbf{8 0 6}$ \\
\hline
\end{tabular}

a. Medida de Adequação da Amostra (MSA) 
Como pode ser visto na tabela 24 , as comunalidades de R 27 e 28 ficam ligeiramente abaixo de 0,5 , porém as variáveis são mantidas no modelo.

Tabela 24 - Comunalidades - integração da cadeia - integração externa com clientes (segunda rodada)

\begin{tabular}{lrr} 
& \multicolumn{1}{c}{ Inicial } & \multicolumn{2}{c}{ Extração } \\
\hline R20 & 1,000 &, 566 \\
R21 & 1,000 &, 608 \\
R22 & 1,000 &, 607 \\
R24 & 1,000 &, 575 \\
R25 & 1,000 &, 568 \\
R26 & 1,000 &, 646 \\
R27 & 1,000 &, $\mathbf{4 9 1}$ \\
R28 & 1,000 &, $\mathbf{4 3 1}$ \\
\hline
\end{tabular}

Foi extraído um fator que explica $56,146 \%$ da variância total, o que pode ser considerado adequado. A tabela 25 ilustra esse resultado.

Tabela 25 - Variância Total Explicada - integração da cadeia - integração externa com clientes

\begin{tabular}{lrrr}
\multirow{2}{*}{ Componentes } & \multicolumn{3}{c}{ Autovalores (Eigenvalues) } \\
\cline { 2 - 4 } 1 & \multicolumn{1}{c}{ Total } & \% da variância & \% acumulada \\
\hline 2 & 4,492 & 56,146 & $\mathbf{5 6 , 1 4 6}$ \\
3 &, 897 & 11,213 & 67,359 \\
4 &, 720 & 9,000 & 76,359 \\
5 &, 571 & 7,138 & 83,497 \\
6 &, 387 & 4,834 & 88,330 \\
7 &, 337 & 4,216 & 92,546 \\
8 &, 317 & 3,969 & 96,515 \\
\hline
\end{tabular}

Método de Extração: Análise das Componentes Principais

A tabela 26 a seguir apresenta as cargas fatoriais das variáveis. 
Tabela 26 - Matriz de componentes rotacionada - integração da cadeia - integração externa com clientes

\begin{tabular}{|c|c|}
\hline Variáveis & $\begin{array}{c}\text { Componentes } \\
1 \\
\end{array}$ \\
\hline R26 & ,804 \\
\hline $\mathrm{R} 21$ & ,780 \\
\hline $\mathrm{R} 22$ & ,779 \\
\hline R24 & ,758 \\
\hline $\mathrm{R} 25$ & ,754 \\
\hline R20 & ,753 \\
\hline R27 & ,700 \\
\hline $\mathrm{R} 28$ & ,657 \\
\hline
\end{tabular}

Assim, a variável R23 foi excluída e o fator é composto pelas variáveis R21, R22, R24, R25, R26, R27 e R28.

\subsubsection{Constructo Desempenho Individual}

Como o constructo Desempenho Individual é composto por quatro blocos de variáveis (subconstructos), foram realizadas quatro análises fatoriais, uma para cada bloco e os resultados são mostrados a seguir.

\subsubsection{Desempenho individual - perspectiva dos processos empresariais}

As variáveis utilizadas foram: $R 29$ a 38

Obteve-se $\mathrm{KMO}=0,828$ e rejeição de $\mathrm{H} 0$ no teste de Bartlett, o que representa boa adequação do modelo, como ilustra a tabela 27.

Tabela 27 - KMO e teste de Bartlett para desempenho individual - perspectiva dos processos empresariais

\begin{tabular}{llr}
\hline Medida de adequação da amostra de Kaiser-Meyer-Olkin (KMO) & $\mathbf{, 8 2 8}$ \\
\hline Teste de esferificade de Bartlett & Qui-Quadrado aproximado & 619,459 \\
\cline { 2 - 3 } & Graus de liberdade & 45 \\
\cline { 2 - 3 } & Significância & $\mathbf{, 0 0 0}$ \\
\hline
\end{tabular}


Pela tabela 28, pode observar que as MSA individuais são satisfatórias.

Tabela 28 - Matriz Anti-Imagem - desempenho individual - perspectiva dos processos empresariais

\begin{tabular}{|c|c|c|c|c|c|c|c|c|c|c|c|}
\hline & & $\mathrm{R} 29$ & R30 & $\mathrm{R} 31$ & R32 & R33 & $\mathrm{R} 34$ & R35 & R36 & R37 & R38 \\
\hline Correlação & R29 &, $\mathbf{8 5 5} 5^{\mathrm{a}}$ &, 217 &,- 266 & ,114 & ,271 &,- 121 &,- 285 & ,028 &,- 009 & ,019 \\
\hline \multirow[t]{9}{*}{ Anti-imagem } & R30 & ,217 &, $902^{\mathrm{a}}$ & ,045 & 035 &,- 265 &,- 266 &,- 138 & 064 &,- 112 &,- 141 \\
\hline & R31 &,- 266 & 045 &, $817^{\mathrm{a}}$ &,- 229 & 033 & ,005 &, 054 &,- 159 &,- 068 &,- 053 \\
\hline & R32 & ,114 & 035 &,- 229 &, $\mathbf{8 1 8}^{\mathrm{a}}$ &,- 017 & 039 &,- 076 &,- 016 &, 156 & ,026 \\
\hline & R33 & ,271 &,- 265 & 033 &,- 017 &, $829^{a}$ &,- 580 &,- 089 & , 118 &,- 011 &,- 118 \\
\hline & R34 &,- 121 &,- 266 & ,005 & ,039 &,- 580 &, $\mathbf{8 0 3}^{\mathrm{a}}$ &, 275 &,- 184 &,- 032 & 030 \\
\hline & R35 &,- 285 &,- 138 & 054 &,- 076 &,- 089 & ,275 &, $762^{a}$ &,- 503 & ,089 & 021 \\
\hline & R36 & ,028 & 064 &,- 159 &,- 016 & , 118 &,- 184 &,- 503 &, $757^{\mathrm{a}}$ &, 105 &,- 017 \\
\hline & R37 &,- 009 &,- 112 &,- 068 & ,156 &,- 011 &,- 032 &, 089 & , 105 &, $842^{a}$ &,- 473 \\
\hline & R38 & 019, &,- 141 &,- 053 & ,026 &,- 118 & 030 & ,021 &,- 017 &,- 473 & ,848 \\
\hline
\end{tabular}

a. Medida de Adequação da Amostra (MSA)

A comunalidade de R32, como pode ser observado na tabela 29, ficou ligeiramente abaixo de 0,5, porém sua exclusão não acarreta em grande melhoria do modelo, portanto a variável será mantida.

Tabela 29 - Comunalidades - desempenho individual - perspectiva dos processos empresariais

\begin{tabular}{lrr} 
& \multicolumn{1}{c}{ Inicial } & Extração \\
\hline R29 & 1,000 &, 678 \\
R30 & 1,000 &, 777 \\
R31 & 1,000 &, 540 \\
R32 & 1,000 &, 448 \\
R33 & 1,000 &, 842 \\
R34 & 1,000 &, 757 \\
R35 & 1,000 &, 620 \\
R36 & 1,000 &, 666 \\
R37 & 1,000 &, 753 \\
R38 & 1,000 &, 717 \\
\hline
\end{tabular}


Foram extraídos 3 fatores com variância maior que 1 e que explicam 67,967\% da variância total, o que é considerado adequado. A tabela 30 mostra esse resultado.

Tabela 30 - Variância Total Explicada - desempenho individual - perspectiva dos processos empresariais

\begin{tabular}{lrrr}
\multirow{2}{*}{ Componentes } & \multicolumn{3}{c}{ Autovalores (Eigenvalues) } \\
\cline { 2 - 4 } 1 & \multicolumn{2}{c}{ Total \% da variância } & \% acumulada \\
\hline 2 & 3,092 & 30,921 & 30,921 \\
3 & 1,939 & 19,386 & 50,307 \\
4 & 1,766 & 17,661 & $\mathbf{6 7 , 9 6 7}$ \\
5 &, 939 & 9,392 & 77,359 \\
6 &, 653 & 6,532 & 83,891 \\
7 &, 459 & 4,591 & 88,482 \\
8 &, 390 & 3,896 & 92,378 \\
9 &, 353 & 3,529 & 95,908 \\
10 &, 254 & 2,543 & 98,451 \\
\hline
\end{tabular}

A tabela 31 a seguir apresenta a composição dos fatores.

Tabela 31 - Matriz de componentes rotacionada - desempenho individual - perspectiva dos processos empresariais

\begin{tabular}{lrrr}
\hline Variáveis & \multicolumn{3}{c}{ Componentes } \\
& 1 & 2 & 3 \\
\hline R33 & $\mathbf{, 8 6 6}$ &,- 212 &, 217 \\
R34 & $\mathbf{, 8 2 5}$ &,- 158 &, 227 \\
R30 & $\mathbf{, 8 2 4}$ &,- 157 &, 269 \\
R29 &,- 685 &, 457 &,- 004 \\
R36 &,- 099 & $\mathbf{, 7 6 0}$ &,- 280 \\
R35 &,- 270 & $\mathbf{, 6 7 8}$ &,- 294 \\
R31 &,- 299 & $\mathbf{, 6 5 5}$ &, 144 \\
R37 &, 353 &,- 116 & $\mathbf{, 7 8 4}$ \\
R38 &, 460 &, 007 & $\mathbf{, 7 1 1}$ \\
R32 &, 071 &, 392 & $\mathbf{- , 5 3 8}$ \\
\hline
\end{tabular}

Assim, o fator 1 é composto pelas variáveis R29, R30, R33 e R34 e foi denominado de "Entrega". O fator 2 é composto pelas variáveis R35, R36 e R31 e foi denominado de 
"Eficiência". E finalmente, o fator 3 é composto pelas variáveis R32, R37 e R38 e foi denominado de "Flexibilidade".

\subsubsection{Desempenho individual - perspectiva dos clientes}

As variáveis utilizadas foram: $R 39$ a 43

O modelo obteve KMO de 0,751 e rejeição de H0 no teste de Batlett, o que mostra aderência do modelo, conforme mostra a tabela 32 .

Tabela 32 - KMO e teste de Bartlett para desempenho individual - perspectiva dos clientes

\begin{tabular}{llr}
\hline Medida de adequação da amostra de Kaiser-Meyer-Olkin (KMO) & $\mathbf{, 7 5 1}$ \\
\hline Teste de esferificade de Bartlett & Qui-Quadrado aproximado & 205,039 \\
\cline { 2 - 3 } & Graus de liberdade & 10 \\
\cline { 2 - 3 } & Significância & $\mathbf{0 0 0}$ \\
\hline
\end{tabular}

Pela tabela 33, pode-se notar que variável R39 possui MSA abaixo de 0,5 o que indica que é inadequada ao modelo fatorial, portanto deve ser retirada.

Tabela 33 - Matriz Anti-Imagem - desempenho individual - perspectiva dos clientes

\begin{tabular}{|c|c|c|c|c|c|c|}
\hline & & R39 & $\mathrm{R} 40$ & R41 & $\mathrm{R} 42$ & R43 \\
\hline \multirow[t]{5}{*}{ Correlação Anti-imagem } & R39 &, $417^{\mathrm{a}}$ & , 146 &,- 121 &,- 148 &,- 056 \\
\hline & $\mathrm{R} 40$ & ,146 &, $812^{\mathrm{a}}$ &,- 338 & ,114 &,- 112 \\
\hline & $\mathrm{R} 41$ &,- 121 &,- 338 &, $782^{\mathrm{a}}$ &, 146 &,- 318 \\
\hline & $\mathrm{R} 42$ &,- 148 & ,114 & ,146 &, $740^{\mathrm{a}}$ & ,530 \\
\hline & $\mathrm{R} 43$ &,- 056 &,- 112 &,- 318 & ,530 &, $723^{\mathrm{a}}$ \\
\hline
\end{tabular}

a. Medida de Adequação da Amostra (MSA)

Assim como a MSA, a comunalidade de R39 fica abaixo de 0,5, conforme mostra a tabela 34, o que é inadequado, por isso deve ser retirada da base de dados. 
Tabela 34 - Comunalidades - desempenho individual - perspectiva dos clientes

\begin{tabular}{lrr} 
& Inicial & \multicolumn{1}{c}{ Extração } \\
\hline R39 & 1,000 &, $\mathbf{0 2 5}$ \\
R40 & 1,000 &, 540 \\
R41 & 1,000 &, 655 \\
R42 & 1,000 &, 687 \\
R43 & 1,000 &, 729 \\
\hline
\end{tabular}

O modelo final, conforme mostra a tabela 35, resulta em um KMO de 0,767 e rejeição de H0 no teste de Bartlett, o que indica aderência do modelo.

Tabela 35 - KMO e teste de Bartlett para desempenho individual - perspectiva dos clientes (segunda rodada)

\begin{tabular}{llr}
\hline Medida de adequação da amostra de Kaiser-Meyer-Olkin (KMO) & $\mathbf{, 7 6 7}$ \\
\hline Teste de esferificade de Bartlett & Qui-Quadrado aproximado & 198,428 \\
\cline { 2 - 3 } & Graus de liberdade & 6 \\
\cline { 2 - 3 } & Significância & $\mathbf{0 0 0}$ \\
\hline
\end{tabular}

Pela tabela 36, pode-se observar que as MSA individuais são adequadas

Tabela 36 - Matriz Anti-Imagem - desempenho individual - perspectiva dos clientes (segunda rodada)

\begin{tabular}{cccccc}
\hline & & $\mathrm{R} 40$ & $\mathrm{R} 41$ & $\mathrm{R} 42$ & \multicolumn{2}{c}{$\mathrm{R} 43$} \\
\hline Correlação Anti-imagem & $\mathrm{R} 40$ & $\mathbf{, 8 3 2}^{\mathbf{a}}$ &,- 327 &, 139 &,- 105 \\
& $\mathrm{R} 41$ &,- 327 & $\mathbf{, 7 9 6}^{\mathbf{a}}$ &, 131 &,- 328 \\
& $\mathrm{R} 42$ &, 139 &, 131 & $\mathbf{7 4 8}^{\mathbf{a}}$ &, 529 \\
& $\mathrm{R} 43$ &,- 105 &,- 328 &, 529 & $\mathbf{, 7 2 3}^{\mathbf{a}}$ \\
\hline
\end{tabular}

a. Medida de Adequação da Amostra (MSA)

As comunalidades ficam dentro do adequado, como ilustra a tabela 37.

Tabela 37 - Comunalidades - desempenho individual - perspectiva dos clientes (segunda rodada)

\begin{tabular}{lrr} 
& \multicolumn{1}{c}{ Inicial } & \multicolumn{1}{c}{ Extração } \\
\hline R40 & 1,000 &, 534 \\
R41 & 1,000 &, 668 \\
R42 & 1,000 &, 682 \\
R43 & 1,000 &, 737 \\
\hline
\end{tabular}


Assim, foi extraído um fator que explica $65,510 \%$ da variância total. A tabela 38 ilustra esse resultado.

Tabela 38 - Variância Total Explicada - desempenho individual - perspectiva dos clientes

\begin{tabular}{lrrr} 
& \multicolumn{3}{c}{ Autovalores (Eigenvalues) } \\
\cline { 2 - 4 } Componentes & \multicolumn{1}{c}{ Total } & \% da variância & \% acumulada \\
\hline 1 & 2,620 & 65,510 & $\mathbf{6 5 , 5 1 0}$ \\
2 &, 632 & 15,792 & 81,301 \\
3 &, 450 & 11,244 & 92,545 \\
4 &, 298 & 7,455 & 100,000 \\
\hline
\end{tabular}

A tabela 39 a seguir apresenta as cargas fatoriais das variáveis

Tabela 39 - Matriz de componentes rotacionada - desempenho individual - perspectiva dos clientes

\begin{tabular}{lr}
\hline Variáveis & \multicolumn{2}{c}{ Componentes } \\
& 1 \\
\hline R43 &, 858 \\
R42 &,- 826 \\
R41 &, 817 \\
R40 &, 731 \\
\hline
\end{tabular}

Assim, não foi retirada nenhuma variável e o fator é composto pela variáveis R40, R41, R42 e R43.

\subsubsection{Desempenho individual - perspectiva financeira}

As variáveis utilizadas foram: $R 44$ a 50

$\mathrm{O}$ modelo resultou em um KMO de 0,820 , o que pode ser considerado adequado e rejeita $\mathrm{H} 0$ no teste de Bartlett, o que mostra boa adequação do modelo. A tabela 40 mostra esse resultado. 
Tabela 40 - KMO e teste de Bartlett para desempenho individual - perspectiva financeira

\begin{tabular}{llr}
\hline Medida de adequação da amostra de Kaiser-Meyer-Olkin (KMO) & $\mathbf{, 8 2 0}$ \\
\hline Teste de esferificade de Bartlett & Qui-Quadrado aproximado & 643,100 \\
\cline { 2 - 3 } & Graus de liberdade & 21 \\
\cline { 2 - 3 } & Significância & $\mathbf{0 0 0}$ \\
\hline
\end{tabular}

Como pode ser visto pela tabela 41, as MSA individuais são adequadas.

Tabela 41 - Matriz Anti-Imagem - desempenho individual - perspectiva financeira

\begin{tabular}{|c|c|c|c|c|c|c|c|c|}
\hline & & R44 & R45 & R46 & $\mathrm{R} 47$ & R48 & R49 & R50 \\
\hline \multirow[t]{7}{*}{ Correlação Anti-imagem } & R44 &, $737^{\mathrm{a}}$ &,- 417 & ,000 &,- 156 & ,151 &,- 180 &,- 212 \\
\hline & $\mathrm{R} 45$ &,- 417 &, $826^{\mathrm{a}}$ &,- 401 & ,071 &,- 074 & ,097 &, 110 \\
\hline & R46 & ,000 &,- 401 &, $870^{\mathrm{a}}$ &,- 255 &,- 355 &,- 121 &,- 061 \\
\hline & R47 &,- 156 & 071 &,- 255 &, $814^{\mathrm{a}}$ &,- 663 &,- 141 & 070 \\
\hline & R48 & ,151 &,- 074 &,- 355 &,- 663 &, $\mathbf{8 0 1}^{\mathrm{a}}$ & ,020 & 034 \\
\hline & R49 &,- 180 & ,097 &,- 121 &,- 141 & 020 &, $873^{\mathrm{a}}$ & ,288 \\
\hline & R50 &,- 212 &, 110 &,- 061 & 070 & 034 & ,288 &, $735^{\mathrm{a}}$ \\
\hline
\end{tabular}

a. Medida de Adequação da Amostra (MSA)

As comunalidades são adequadas, como mostra a tabela 42 .

Tabela 42 - Comunalidades - desempenho individual - perspectiva financeira

\begin{tabular}{lrr} 
& \multicolumn{1}{r}{ Inicial } & Extração \\
\hline R44 & 1,000 &, 629 \\
R45 & 1,000 &, 708 \\
R46 & 1,000 &, 853 \\
R47 & 1,000 &, 843 \\
R48 & 1,000 &, 824 \\
R49 & 1,000 &, 519 \\
R50 & 1,000 &, 748 \\
\hline
\end{tabular}

Assim, conforme ilustra a tabela 43, foram extraídos dois fatores com autovalor maior que 1 , que explicam $73,202 \%$ da variância total. 
Tabela 43 - Variância Total Explicada - desempenho individual - perspectiva financeira

\begin{tabular}{lrrr}
\multirow{2}{*}{ Componentes } & \multicolumn{3}{c}{ Autovalores (Eigenvalues) } \\
\cline { 2 - 4 } & Total & \% da variância & \% acumulada \\
\hline 1 & 3,328 & 47,549 & 47,549 \\
2 & 1,796 & 25,652 & $\mathbf{7 3 , 2 0 2}$ \\
3 &, 739 & 10,563 & 83,764 \\
4 &, 582 & 8,317 & 92,081 \\
5 &, 334 & 4,770 & 96,851 \\
6 &, 136 & 1,945 & 98,796 \\
7 &, 084 & 1,204 & 100,000 \\
\hline
\end{tabular}

A tabela 44 abaixo apresenta a alocação das variáveis.

Tabela 44 - Matriz de componentes rotacionada - desempenho individual - perspectiva financeira

\begin{tabular}{lrr} 
Variáveis & \multicolumn{2}{c}{ Componentes } \\
& 1 & 2 \\
\hline R46 & $\mathbf{, 8 3 2}$ &, 401 \\
R45 & $\mathbf{8 3 1}$ &, 136 \\
R47 &, $\mathbf{7 8 0}$ &, 484 \\
R48 &, $\mathbf{7 6 6}$ &, 488 \\
R44 &, $\mathbf{7 6 0}$ &,- 225 \\
R50 &, 040 & $-\mathbf{- 8 6 4}$ \\
R49 &, 416 & $\mathbf{, 5 8 9}$ \\
\hline
\end{tabular}

Assim, o fator 1 é composto pelas variáveis R44, R45, R46, R47 e R48 e foi denominado de “Entradas" e o fator 2 é composto pelas variáveis R49 e R50 e foi denominado de "Saídas".

\subsubsection{Desempenho individual - perspectiva da inovação e do aprendizado}

As variáveis utilizadas foram: R51 e 52

O índice de KMO obtido foi de 0,5 (só há duas variáveis) é considerado adequado e há rejeição de $\mathrm{H} 0$ no teste de Bartlett. A tabela 45 mostra esse resultado 
Tabela 45 - KMO e teste de Bartlett para desempenho individual - perspectiva da inovação e do aprendizado

\begin{tabular}{llr}
\hline Medida de adequação da amostra de Kaiser-Meyer-Olkin (KMO) & $\mathbf{5 0 0}$ \\
\hline Teste de esferificade de Bartlett & Qui-Quadrado aproximado & 46,336 \\
\cline { 2 - 3 } & Graus de liberdade & 1 \\
\cline { 2 - 3 } & Significância & $\mathbf{, 0 0 0}$ \\
\hline
\end{tabular}

Conforme mostra a tabela 46, as MSA são adequadas.

Tabela 46 - Matriz Anti-Imagem - desempenho individual - perspectiva da inovação e do aprendizado

\begin{tabular}{lrrr}
\hline & & R51 & \multicolumn{1}{c}{ R52 } \\
\hline Correlação Anti-imagem & R51 & $\mathbf{, 5 0 0}^{\mathbf{a}}$ &,- 543 \\
& R52 &,- 543 & $\mathbf{, 5 0 0}^{\mathbf{a}}$ \\
\hline
\end{tabular}

a. Medida de Adequação da Amostra (MSA)

As comunalidades também são adequadas, como mostra a tabela 47.

Tabela 47 - Comunalidades - desempenho individual - perspectiva da inovação e do aprendizado

\begin{tabular}{lrr} 
& \multicolumn{1}{c}{ Inicial } & \multicolumn{1}{c}{ Extração } \\
\hline R51 & 1,000 &, 772 \\
R52 & 1,000 &, 772 \\
\hline
\end{tabular}

Assim, foi extraído um fator que explica $77,162 \%$ da variância total, como ilustra a tabela 48 .

Tabela 48 - Variância Total Explicada - desempenho individual - perspectiva financeira

\begin{tabular}{lrrr} 
& \multicolumn{3}{c}{ Autovalores (Eigenvalues) } \\
\cline { 2 - 4 } Componentes & Total & \% da variância & \% acumulada \\
\hline 1 & 1,543 & 77,162 & 77,162 \\
2 &, 457 & 22,838 & 100,000 \\
\hline
\end{tabular}

A tabela 49 mostra as cargas fatoriais. 
Tabela 49 - Matriz de componentes rotacionada - desempenho individual - perspectiva da inovação e do aprendizado

\begin{tabular}{lr}
\hline \multicolumn{1}{c}{ Variáveis } & Componentes \\
& 1 \\
\hline R51 &, 878 \\
R52 &, 878 \\
\hline
\end{tabular}

\subsubsection{Constructo Desempenho da Cadeia de Suprimentos}

Como o constructo Desempenho da Cadeia de Suprimentos é composto por quatro blocos de variáveis (sub-constructos), foram realizadas quatro análises fatoriais, uma para cada bloco e os resultados são mostrados a seguir.

\subsubsection{Desempenho da cadeia - perspectiva dos processos empresariais}

As variáveis utilizadas foram: $R 53$ a 59

O modelo obteve KMO de 0,840 e rejeição de $\mathrm{H} 0$ no teste de Bartlett, conforme mostra a tabela 50 .

Tabela 50 - KMO e teste de Bartlett para desempenho da cadeira - perspectiva dos processos empresariais

\begin{tabular}{llr}
\hline Medida de adequação da amostra de Kaiser-Meyer-Olkin (KMO) & $\mathbf{, 8 4 0}$ \\
\hline Teste de esferificade de Bartlett & Qui-Quadrado aproximado & 714,379 \\
\cline { 2 - 3 } & Graus de liberdade & 21 \\
\cline { 2 - 3 } & Significância & $\mathbf{0 0 0}$ \\
\hline
\end{tabular}

Como pode-se ver na tabela 51, as MSA individuais são satisfatórias. 
Tabela 51 - Matriz Anti-Imagem - desempenho da cadeia - perspectiva dos processos empresariais

\begin{tabular}{|c|c|c|c|c|c|c|c|c|}
\hline & & R53 & R54 & $\mathrm{R} 55$ & $\mathrm{R} 56$ & R57 & R58 & R59 \\
\hline Correlação & R53 &, $924^{a}$ & ,252 &, 156 &, 030 &,- 006 & ,047 &,- 258 \\
\hline \multirow[t]{6}{*}{ Anti-imagem } & R54 & ,252 &, $847^{\mathrm{a}}$ &,- 457 &,- 228 &,- 082 &,- 175 & , 194 \\
\hline & R55 & , 156 &,- 457 &, $822^{a}$ &,- 537 & ,081 & ,086 &,- 056 \\
\hline & R56 & ,030 &,- 228 &,- 537 &, $841^{\mathrm{a}}$ & 105 & , 159 &,- 200 \\
\hline & R57 &,- 006 &,- 082 & ,081 & , 105 &, $876^{\mathrm{a}}$ &,- 353 &,- 325 \\
\hline & $\mathrm{R} 58$ & ,047 &,- 175 & ,086 & , 159 &,- 353 &, $\mathbf{8 0 2}^{\mathrm{a}}$ &,- 499 \\
\hline & R59 &,- 258 & ,194 &,- 056 &,- 200 &,- 325 &,- 499 &, $782^{\mathrm{a}}$ \\
\hline
\end{tabular}

a. Medida de Adequação da Amostra (MSA)

As comunalidades também são adequadas, conforme ilustra a tabela 52.

Tabela 52 - Comunalidades - desempenho da cadeia - perspectiva dos processos empresariais

\begin{tabular}{lrr} 
& \multicolumn{1}{c}{ Inicial } & \multicolumn{1}{c}{ Extração } \\
\hline R53 & 1,000 &, 659 \\
R54 & 1,000 &, 861 \\
R55 & 1,000 &, 893 \\
R56 & 1,000 &, 826 \\
R57 & 1,000 &, 789 \\
R58 & 1,000 &, 831 \\
R59 & 1,000 &, 820 \\
\hline
\end{tabular}

Assim, como pode-se ver na tabela 53, são extraídos dois fatores que explicam $81,120 \%$ da variância total. 
Tabela 53 - Variância Total Explicada - desempenho da cadeia - perspectiva dos processos empresariais

\begin{tabular}{lrrr}
\hline & \multicolumn{3}{c}{ Autovalores (Eigenvalues) } \\
\cline { 2 - 4 } Componentes & Total & \% da variância & \% acumulada \\
\hline 1 & 3,142 & 44,886 & 44,886 \\
2 & 2,536 & 36,234 & $\mathbf{8 1 , 1 2 0}$ \\
3 &, 487 & 6,953 & 88,073 \\
4 &, 289 & 4,131 & 92,204 \\
5 &, 256 & 3,657 & 95,862 \\
6 &, 165 & 2,353 & 98,215 \\
7 &, 125 & 1,785 & 100,000 \\
\hline
\end{tabular}

A tabela 54 apresenta a composição dos fatores.

Tabela 54 - Matriz de componentes rotacionada - desempenho da cadeia - perspectiva dos processos empresariais

\begin{tabular}{lrr}
\hline Variáveis & \multicolumn{2}{c}{ Componentes } \\
& 1 & 2 \\
\hline R54 & $\mathbf{, 9 0 9}$ &,- 184 \\
R55 & $\mathbf{, 9 0 9}$ &,- 258 \\
R56 & $\mathbf{, 8 8 1}$ &,- 225 \\
R53 & $\mathbf{- , 7 3 0}$ &, 355 \\
R58 &,- 224 & $\mathbf{, 8 8 4}$ \\
R59 &,- 241 & $\mathbf{, 8 7 3}$ \\
R57 &,- 269 & $\mathbf{, 8 4 6}$ \\
\hline
\end{tabular}

Assim, o fator 1 é composto pela variáveis R53, R54, R55 e R56 e foi denominado de “Entrega". Já o fator 2 é composto pelas variáveis R57, R58 e R59 e foi denominado "Ciclo de Produção".

\subsubsection{Desempenho da cadeia - perspectiva dos clientes}

As variáveis utilizadas foram: $R 60$ a 64

O modelo obteve um KMO e 0,818 e há rejeição de H0, conforme ilustra a tabela 55 . 
Tabela 55 - KMO e teste de Bartlett para desempenho da cadeira - perspectiva dos clientes

Medida de adequação da amostra de Kaiser-Meyer-Olkin (KMO)

$\mathbf{8 1 8}$

Teste de esferificade de Bartlett

Qui-Quadrado aproximado

254,299

Graus de liberdade

Significância

, 000

Como mostra a tabala 56, as MSA são adequadas.

Tabela 56 - Matriz Anti-Imagem - desempenho da cadeia - perspectiva dos clientes

\begin{tabular}{lccrrrr}
\hline & & R60 & R61 & R62 & R63 & \multicolumn{2}{c}{ R64 } \\
\hline Correlação Anti-imagem & R60 & $\mathbf{, 8 0 7}^{\mathbf{a}}$ &,- 029 &,- 344 &, 292 &,- 309 \\
& R61 &,- 029 &, $\mathbf{8 0 5}^{\mathbf{a}}$ &, 000 &,- 038 &, 075 \\
& R62 &,- 344 &, 000 & $\mathbf{, 8 5 2}^{\mathbf{a}}$ &, 215 &,- 092 \\
& R63 &, 292 &,- 038 &, 215 &, $\mathbf{8 1 0}^{\mathbf{a}}$ &, 398 \\
& R64 &,- 309 &, 075 &,- 092 &, 398 & $\mathbf{, 8 1 4}^{\mathbf{a}}$ \\
\hline
\end{tabular}

a. Medida de Adequação da Amostra (MSA)

A comunalidade da variável R61 é baixa, portanto ela deve ser excluída, como mostra a tabela 57.

Tabela 57 - Comunalidades - desempenho da cadeia - perspectiva dos clientes

\begin{tabular}{lrr} 
& \multicolumn{1}{r}{ Inicial } & \multicolumn{1}{r}{ Extração } \\
\hline R60 & 1,000 &, 754 \\
R61 & 1,000 &, $\mathbf{0 2 5}$ \\
R62 & 1,000 &, 632 \\
R63 & 1,000 &, 749 \\
R64 & 1,000 &, 716 \\
\hline
\end{tabular}

Assim foi realizada uma segunda rodada da análise fatorial. O modelo final obteve um KMO de 0,818 e rejeição de $\mathrm{H} 0$ no teste de Bartlett, como mostra a tabela 58. 
Tabela 58 - KMO e teste de Bartlett para desempenho da cadeira - perspectiva dos clientes (segunda rodada)

Medida de adequação da amostra de Kaiser-Meyer-Olkin (KMO) , 818

Teste de esferificade de Bartlett

Qui-Quadrado aproximado 252,817

Graus de liberdade 6

Significância $\mathbf{0 0 0}$

Conforme ilustrado na tabela 59, as MSA são adequadas.

Tabela 59 - Matriz Anti-Imagem - desempenho da cadeia - perspectiva dos clientes (segunda rodada)

\begin{tabular}{lrrrrr}
\hline & & \multicolumn{1}{c}{ R60 } & \multicolumn{1}{c}{ R62 } & \multicolumn{1}{c}{ R63 } & \multicolumn{2}{c}{ R64 } \\
\hline Correlação Anti-imagem & R60 & $\mathbf{, 8 0 7}^{\mathbf{a}}$ &,- 344 &, 292 &,- 308 \\
& R62 &,- 344 & $\mathbf{8 5 1}^{\mathbf{a}}$ &, 216 &,- 092 \\
& R63 &, 292 &, 216 & $\mathbf{, 8 0 8}^{\mathbf{a}}$ &, 403 \\
& R64 &,- 308 &,- 092 &, 403 & $\mathbf{, 8 1 3}^{\mathbf{a}}$ \\
\hline
\end{tabular}

a. Medida de Adequação da Amostra (MSA)

Também pela tabela 60, pode-se observar que as comunalidades são adequadas.

Tabela 60 - Comunalidades - desempenho da cadeia - perspectiva dos clientes (segunda rodada)

\begin{tabular}{lrr} 
& \multicolumn{1}{c}{ Inicial } & \multicolumn{1}{c}{ Extração } \\
\hline R60 & 1,000 &, 759 \\
R62 & 1,000 &, 636 \\
R63 & 1,000 &, 750 \\
R64 & 1,000 &, 714 \\
\hline
\end{tabular}

Foi extraído um fator que explica $71,493 \%$ da variância total, como pode-se observar pela tabela 61 .

Tabela 61 - Variância Total Explicada - desempenho da cadeia - perspectiva dos clientes

\begin{tabular}{lrrr} 
& \multicolumn{3}{c}{ Autovalores (Eigenvalues) } \\
\cline { 2 - 4 } Componentes & \multicolumn{1}{c}{ Total } & \% da variância & \% acumulada \\
\hline 1 & 2,860 & 71,493 & $\mathbf{7 1 , 4 9 3}$ \\
2 &, 497 & 12,430 & 83,923 \\
3 &, 328 & 8,205 & 92,127 \\
4 &, 315 & 7,873 & 100,000 \\
\hline
\end{tabular}


A tabela 62 apresenta as cargas fatoriais.

Tabela 62 - Matriz de componentes rotacionada - desempenho da cadeia - perspectiva dos clientes Variáveis Componentes

\begin{tabular}{lr} 
& 1 \\
\hline R60 &, 871 \\
R63 &,- 866 \\
R64 &, 845 \\
R62 &, 798 \\
\hline
\end{tabular}

\subsubsection{Desempenho da cadeia - perspectiva financeira}

As variáveis utilizadas foram: $R 65$ a $R 72$.

O modelo obteve um KMO de 0,763 e rejeitou $\mathrm{H} 0$, o que indica boa adequação da fatorial. A tabela 63 mostra esse resultado.

Tabela 63 - KMO e teste de Bartlett para desempenho da cadeira - perspectiva financeira

\begin{tabular}{lrr}
\hline Medida de adequação da amostra de Kaiser-Meyer-Olkin (KMO) & $\mathbf{7 6 3}$ \\
\hline Teste de esferificade de Bartlett & Qui-Quadrado aproximado & 717,889 \\
\cline { 2 - 3 } & Graus de liberdade & 28 \\
\cline { 2 - 3 } & Significância & $\mathbf{0 0 0}$ \\
\hline
\end{tabular}

Pela tabela 64, pode-se observar que as MSA são adequadas.

Tabela 64 - Matriz Anti-Imagem - desempenho da cadeia - perspectiva financeira

\begin{tabular}{llcccccccc}
\hline & & R65 & R66 & R67 & R68 & R69 & R70 & R71 & R72 \\
\hline Correlação & R65 & $\mathbf{, 5 7 8}^{\mathbf{a}}$ &,- 589 &, 078 &,- 010 &,- 011 &,- 068 &, 115 &, 007 \\
Anti-imagem & R66 &,- 589 &, $\mathbf{5 0 4}^{\mathbf{a}}$ &,- 203 &, 083 &, 008 &, 070 &,- 114 &, 221 \\
& R67 &, 078 &,- 203 &, $\mathbf{6 4 9}^{\mathbf{a}}$ &,- 439 &, 018 &,- 287 &, 331 &,- 282 \\
& R68 &,- 010 &, 083 &,- 439 &, $\mathbf{8 3 4}^{\mathbf{a}}$ &,- 392 &,- 024 &,- 105 &, 168 \\
& R69 &,- 011 &, 008 &, 018 &,- 392 &, $\mathbf{8 8 8}^{\mathbf{a}}$ &,- 254 &,- 266 &, 057 \\
& R70 &,- 068 &, 070 &,- 287 &,- 024 &,- 254 &, $\mathbf{7 9 0}^{\mathbf{a}}$ &,- 709 &,- 031
\end{tabular}




\begin{tabular}{lllllllll} 
R71 &, 115 &,- 114 &, 331 &,- 105 &,- 266 &,- 709 &, $\mathbf{7 5 4}^{\mathbf{a}}$ &,- 208 \\
R72 &, 007 &, 221 &,- 282 &, 168 &, 057 &,- 031 &,- 208 &, $\mathbf{7 8 6}^{\mathbf{a}}$ \\
\hline
\end{tabular}

a. Medida de Adequação da Amostra (MSA)

Como mostra a tabela 65, as variáveis R72 e R67 apresentaram comunalidades excessivamente baixas, o que prejudica o modelo.

Tabela 65 - Comunalidades - desempenho da cadeia - perspectiva financeira

\begin{tabular}{lrr} 
& \multicolumn{1}{r}{ Inicial } & Extração \\
\hline R65 & 1,000 &, 747 \\
R66 & 1,000 &, 798 \\
R67 & 1,000 &, $\mathbf{4 1 3}$ \\
R68 & 1,000 &, 740 \\
R69 & 1,000 &, 834 \\
R70 & 1,000 &, 875 \\
R71 & 1,000 &, 819 \\
R72 & 1,000 &, $\mathbf{3 7 0}$ \\
\hline
\end{tabular}

Dessa maneira, a variável R72 foi retirada do modelo e uma segunda rodada da análise fatorial foi realizada.

Mesmo com a retirada de R72, a comunalidade de R67 permanece demasiadamente baixa, como pode-se ver pela tabela 66. Assim esta variável também é retirada e uma terceira rodada de análise fatorial foi realizada.

\begin{tabular}{|c|c|c|}
\hline & Inicial & Extração \\
\hline R65 & 1,000 & ,786 \\
\hline R66 & 1,000 & ,807 \\
\hline R67 & 1,000 & ,409 \\
\hline R68 & 1,000 & ,764 \\
\hline R69 & 1,000 & ,853 \\
\hline $\mathrm{R} 70$ & 1,000 & ,877 \\
\hline R71 & 1,000 & ,819 \\
\hline
\end{tabular}


Assim, o modelo final obteve um KMO de 0,777 e rejeição de H0 no teste de Bartlett, como mostra a tabela 67.

Tabela 67 - KMO e teste de Bartlett para desempenho da cadeira - perspectiva financeira

Medida de adequação da amostra de Kaiser-Meyer-Olkin (KMO)

, 777

Teste de esferificade de Bartlett Qui-Quadrado aproximado 603,313

Graus de liberdade 15

Significância , 000

Pela tabela 68, pode-se observar que as MAS são adequadas.

Tabela 68 - Matriz Anti-Imagem - desempenho da cadeia - perspectiva financeira (segunda rodada)

\begin{tabular}{llrrrrrr}
\hline & \multicolumn{2}{c}{ R65 } & \multicolumn{2}{c}{ R66 } & \multicolumn{2}{l}{ R68 } & \multicolumn{2}{c}{ R69 } & \multicolumn{2}{l}{ R70 } & \multicolumn{2}{c}{ R71 } \\
\hline Correlação Anti-imagem & R65 & $\mathbf{, 5 5 0}^{\mathbf{a}}$ &,- 602 &, 026 &,- 015 &,- 045 &, 100 \\
& R66 &,- 602 & $\mathbf{, 5 2 3}^{\mathbf{a}}$ &,- 016 &, 000 &, 034 &,- 029 \\
& R68 &, 026 &,- 016 &, $\mathbf{8 7 8}^{\mathbf{a}}$ &,- 433 &,- 169 &, 055 \\
& R69 &,- 015 &, 000 &,- 433 & $\mathbf{, 8 6 0}^{\mathbf{a}}$ &,- 255 &,- 282 \\
& R70 &,- 045 &, 034 &,- 169 &,- 255 & $\mathbf{, 7 7 9}^{\mathbf{a}}$ &,- 705 \\
& R71 &, 100 &,- 029 &, 055 &,- 282 &,- 705 &, $\mathbf{7 7 5}^{\mathbf{a}}$ \\
\hline
\end{tabular}

a. Medida de Adequação da Amostra (MSA)

As comunalidades também são adequadas, como mostra a tabela 69.

Tabela 69 - Comunalidades - desempenho da cadeia - perspectiva financeira (terceira rodada)

\begin{tabular}{lrr} 
& Inicial & Extração \\
\hline R65 & 1,000 &, 802 \\
R66 & 1,000 &, 808 \\
R68 & 1,000 &, 727 \\
R69 & 1,000 &, 884 \\
R70 & 1,000 &, 899 \\
R71 & 1,000 &, 876 \\
\hline
\end{tabular}

Assim, foram extraídos dois fatores que explicam $83,264 \%$ da variância total. A tabela 70 ilustra esse resultado. 
Tabela 70 - Variância Total Explicada - desempenho da cadeia - perspectiva financeira

\begin{tabular}{lrrr}
\hline & \multicolumn{3}{c}{ Autovalores (Eigenvalues) } \\
\cline { 2 - 4 } Componentes & \multicolumn{1}{c}{ Total \% da variância } & \% acumulada \\
\hline 1 & 3,378 & 56,300 & 56,300 \\
2 & 1,618 & 26,964 & $\mathbf{8 3 , 2 6 4}$ \\
3 &, 391 & 6,522 & 89,786 \\
4 &, 374 & 6,232 & 96,018 \\
5 &, 157 & 2,613 & 98,631 \\
6 &, 082 & 1,369 & 100,000 \\
\hline
\end{tabular}

A tabela 71 apresenta a composição dos fatores.

Tabela 71 - Matriz de componentes rotacionada - desempenho da cadeia - perspectiva financeira

\begin{tabular}{lrr}
\hline Variáveis & \multicolumn{3}{c}{ Componentes } \\
& 1 & 2 \\
\hline R70 & $\mathbf{9 4 5}$ &,- 073 \\
R69 & $\mathbf{9 3 9}$ &,- 055 \\
R71 & $\mathbf{9 3 1}$ &,- 096 \\
R68 & $\mathbf{, 8 5 2}$ &,- 040 \\
R66 &,- 026 & $\mathbf{, 8 9 8}$ \\
R65 &,- 102 & $\mathbf{, 8 9 0}$ \\
\hline
\end{tabular}

Assim, o fator 1 é composto pelas variáveis R68, R69, R70 e R71 e foi denominado "Indicadores Financeiros". Já o fator 2 é composto pelas variáveis R66 e R65 e foi denominado "Custos".

\subsubsection{Desempenho da cadeia - perspectiva da inovação e do aprendizado}

As variáveis utilizadas foram: $R 73$ e 74

Como mostra a tabela 72, foi obtido um KMO de 0,50 e a rejeição de H0 no teste de Bartlett indicam boa aderência do modelo. 
Tabela 72 - KMO e teste de Bartlett para desempenho da cadeira - perspectiva da inovação e do aprendizado

Medida de adequação da amostra de Kaiser-Meyer-Olkin (KMO) , 500

Teste de esferificade de Bartlett

Qui-Quadrado aproximado

Graus de liberdade

Significância

, 000

As MAS são adequadas (como mostra a tabela 73), assim como as comunalidades (tabela 74).

Tabela 73 - Matriz Anti-Imagem - desempenho da cadeia - perspectiva da inovação e do aprendizado

\begin{tabular}{rrrr}
\hline & & \multicolumn{1}{c}{ R73 } & \multicolumn{1}{c}{ R74 } \\
\hline Correlação Anti-imagem & R73 & $\mathbf{, 5 0 0}^{\mathbf{a}}$ &,- 576 \\
& R74 &,- 576 & $\mathbf{, 5 0 0}^{\mathbf{a}}$ \\
\hline
\end{tabular}

a. Medida de Adequação da Amostra (MSA)

Tabela 74 - Comunalidades - desempenho da cadeia - perspectiva da inovação e do aprendizado

\begin{tabular}{lrr} 
& \multicolumn{1}{r}{ Inicial } & \multicolumn{2}{c}{ Extração } \\
\hline R73 & 1,000 &, 788 \\
R74 & 1,000 &, 788 \\
\hline
\end{tabular}

Como pode-se observar pela tabela 75 , foi extraído um fator que explica $78,824 \%$ da variância total.

Tabela 75 - Variância Total Explicada - desempenho da cadeia - perspectiva da inovação e do aprendizado

\begin{tabular}{lrrr}
\hline & \multicolumn{4}{c}{ Autovalores (Eigenvalues) } \\
\cline { 2 - 4 } Componentes & \multicolumn{1}{c}{ Total } & \% da variância & \% acumulada \\
\hline 1 & 1,576 & 78,824 & 78,824 \\
2 &, 424 & 21,176 & 100,000 \\
\hline
\end{tabular}

A tabela 76 apresenta as cargas fatoriais. 
Tabela 76 - Matriz de componentes rotacionada - desempenho da cadeia - perspectiva da inovação e do aprendizado

\begin{tabular}{lr}
\hline \multicolumn{1}{c}{ Variáveis } & Componentes \\
& \multicolumn{1}{c}{1} \\
\hline R73 &, 888 \\
R74 &, 888 \\
\hline
\end{tabular}

\subsubsection{Análise da Confiabilidade dos Fatores}

Os fatores obtidos pelas análises fatoriais foram submetidos à avaliação de fidedignidade pelo coeficiente Alfa de Cronbach, conforme apresentam as tabelas a seguir.

\subsubsection{Análise da Confiabilidade dos Fatores - Integração da Cadeia de Suprimentos}

Na dimensão Integração Interna, o Alfa de Cronbach foi de 0,793 e a tabela 77 mostra que não há melhora na consistência interna com a retirada das variáveis.

Tabela 77 - Análise de Confiabilidade - integração da cadeia - integração interna

\begin{tabular}{lr} 
Variável & Alfa de Cronbach se o item for excluído \\
\hline R4 &, 682 \\
R5 &, 651 \\
R6 &, 818 \\
\hline
\end{tabular}

Já com relação a dimensão Compartilhamento de Informações (derivada da dimensão Integração Externa com Fornecedores), o Alfa de Cronbach foi de 0,856 e a tabela 78 mostra que não há melhora na consistência interna com a retirada das variáveis. 
Tabela 78 - Análise de Confiabilidade - integração da cadeia - Compartilhamento de Informações

\begin{tabular}{lr}
\hline Variável & Alfa de Cronbach se o item for excluído \\
\hline R7 &, 813 \\
R8 &, 852 \\
R9 &, 813 \\
R11 &, 848 \\
R12 &, 833 \\
R13 &, 829 \\
\hline
\end{tabular}

Com relação a dimensão Participação do Fornecedor no Negócio (derivada da dimensão Integração Externa com Fornecedores), o Alfa de Cronbach foi de 0,769 e a tabela 79 mostra que não há melhora na consistência interna com a retirada das variáveis.

Tabela 79 - Análise de Confiabilidade - integração da cadeia - Participação do Fornecedor no Negócio

\begin{tabular}{lr}
\hline Variável & Alfa de Cronbach se o item for excluído \\
\hline R14 &, 724 \\
R15 &, 738 \\
R17 &, 705 \\
R18 &, 721 \\
R19 &, 748 \\
\hline
\end{tabular}

E finalmente sobre a dimensão Integração Externa com Clientes , o Alfa de Cronbach foi de 0,887 e a tabela 80 mostra que não há melhora na consistência interna com a retirada das variáveis.

Tabela 80 - Análise de Confiabilidade - integração da cadeia - Integração Externa com Clientes

\begin{tabular}{lr}
\hline Variável & Alfa de Cronbach se o item for excluído \\
\hline R20 &, 873 \\
R21 &, 869 \\
R22 &, 869 \\
R24 &, 872 \\
R25 &, 872 \\
R26 &, 867 \\
R27 &, 877 \\
R28 &, 883 \\
\hline
\end{tabular}




\subsubsection{Análise da Confiabilidade dos Fatores - Desempenho Individual}

Com relação a dimensão Entrega (derivada da dimensão Perspectiva dos Processos Empresariais), o Alfa de Cronbach foi de 0,887 e a tabela 81 mostra que não há melhora na consistência interna com a retirada das variáveis.

\begin{tabular}{cr} 
Tabela 81 - Análise de Confiabilidade - Desempenho Individua \\
\cline { 2 - 2 } Variável & Alfa de Cronbach se o item for excluído \\
\hline R29 &, 904 \\
R30 &, 845 \\
R33 &, 816 \\
R34 &, 852 \\
\hline
\end{tabular}

Com relação a dimensão Eficiência dos Aspectos da Produção (derivada da dimensão Perspectiva dos Processos Empresariais), o Alfa de Cronbach foi de 0,633 e a tabela 82 mostra que não há melhora na consistência interna com a retirada das variáveis.

Tabela 82 - Análise de Confiabilidade - Desempenho Individual - Eficiência dos Aspectos da Produção

\begin{tabular}{lr}
\hline Variável & Alfa de Cronbach se o item for excluído \\
\hline R31 &, 749 \\
R35 &, 455 \\
R36 &, 395 \\
\hline
\end{tabular}

Com relação a dimensão Flexibilidade (derivada da dimensão Perspectiva dos Processos Empresariais), o Alfa de Cronbach foi de 0,644 e a tabela 83 mostra que não há melhora na consistência interna com a retirada das variáveis.

Tabela 83 - Análise de Confiabilidade - Desempenho Individual - Flexibilidade

\begin{tabular}{lr}
\hline Variável & Alfa de Cronbach se o item for excluído \\
\hline R32 &, 775 \\
R37 &, 326 \\
\hline
\end{tabular}




\begin{tabular}{lr}
\hline Variável & Alfa de Cronbach se o item for excluído \\
\hline R32 &, 775 \\
R37 &, 326 \\
R38 &, 423 \\
\hline
\end{tabular}

Com relação a dimensão Perspectiva dos Clientes, o Alfa de Cronbach foi de 0,816 e a tabela 84 mostra que não há melhora na consistência interna com a retirada das variáveis.

Tabela 84 - Análise de Confiabilidade - Desempenho Individual - Perspectiva dos Clientes

\begin{tabular}{lr}
\hline Variável & Alfa de Cronbach se o item for excluído \\
\hline R40 &, 819 \\
R41 &, 764 \\
R42 &, 758 \\
R43 &, 736 \\
\hline
\end{tabular}

Com relação a dimensão Perspectiva Financeira - Entradas (derivada da dimensão Perspectiva Financeira), o Alfa de Cronbach foi de 0,892 e a tabela 85 mostra que não há melhora na consistência interna com a retirada das variáveis.

Tabela 85 - Análise de Confiabilidade - Desempenho Individual - Perspectiva Financeira Entradas

\begin{tabular}{lr}
\hline Variável & Alfa de Cronbach se o item for excluído \\
\hline R44 &, 929 \\
R45 &, 868 \\
R46 &, 837 \\
R47 &, 846 \\
R48 &, 849 \\
\hline
\end{tabular}

Com relação a dimensão Perspectiva Financeira - Saídas (derivada da dimensão Perspectiva Financeira), o Alfa de Cronbach foi de 0,535.

Com relação a dimensão Perspectiva da Inovação e do Aprendizado, o Alfa de Cronbach foi de 0,702 . 


\subsubsection{Análise da Confiabilidade dos Fatores - Desempenho da Cadeia de Suprimentos}

Com relação a dimensão Entrega (derivada da dimensão Perspectiva dos Processos Empresariais), o Alfa de Cronbach foi de 0,918 e a tabela 86 mostra que não há melhora na consistência interna com a retirada das variáveis.

\begin{tabular}{lr} 
Tabela 86 - Análise de Confiabilidade - Desempenho da Cadeia \\
\cline { 2 - 2 } Variável & Alfa de Cronbach se o item for excluído \\
\hline R53 &, 932 \\
R54 &, 879 \\
R55 &, 866 \\
R56 &, 890 \\
\hline
\end{tabular}

Com relação a dimensão Ciclo de Produção (derivada da dimensão Perspectiva dos Processos Empresariais), o Alfa de Cronbach foi de 0,886 e a tabela 87 mostra que não há melhora na consistência interna com a retirada das variáveis.

Tabela 87 - Análise de Confiabilidade - Desempenho da Cadeia - Ciclo de Produção

\begin{tabular}{lr}
\hline Variável & Alfa de Cronbach se o item for excluído \\
\hline R57 &, 853 \\
R58 &, 821 \\
R59 &, 840 \\
\hline
\end{tabular}

Com relação a dimensão Perspectiva dos Clientes o Alfa de Cronbach foi de 0,866 e a tabela 88 mostra que não há melhora na consistência interna com a retirada das variáveis.

Tabela 88 - Análise de Confiabilidade - Desempenho da Cadeia - Perspectivas dos Clientes

\begin{tabular}{lr}
\hline Variável & Alfa de Cronbach se o item for excluído \\
\hline R60 &, 812 \\
R62 &, 855 \\
R63 &, 817 \\
\hline
\end{tabular}




\begin{tabular}{|c|c|}
\hline Variável & Alfa de Cronbach se o item for excluído \\
\hline R60 &, 812 \\
\hline R62 & 855 \\
\hline R63 & ,817 \\
\hline R64 & 830, \\
\hline
\end{tabular}

Com relação a dimensão Indicadores Financeiros (derivada da dimensão Perspectiva Financeira), o Alfa de Cronbach foi de 0,939 e a tabela 89 mostra que não há melhora na consistência interna com a retirada das variáveis.

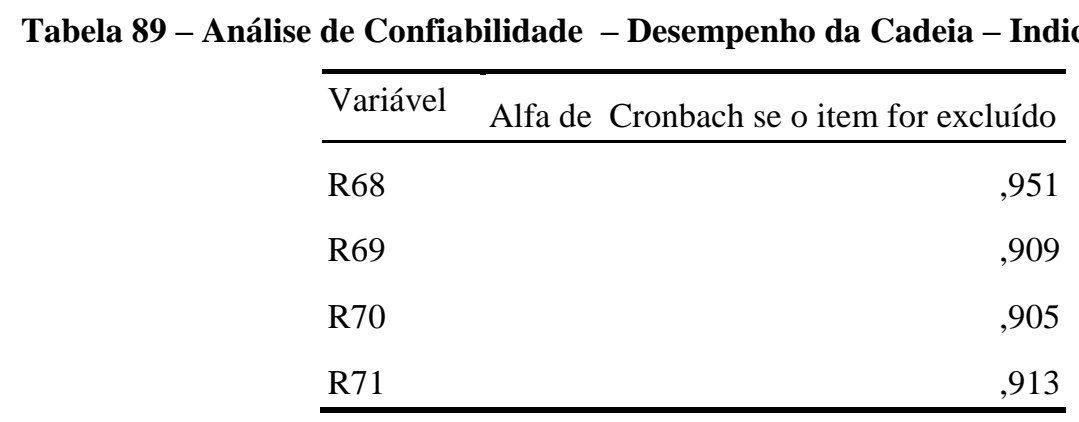

Com relação a dimensão Custos (derivada da dimensão Perspectiva Financeira), o Alfa de Cronbach foi de 0,755 .

Com relação a dimensão Perspectiva da Inovação e do Aprendizado, o Alfa de Cronbach foi de 0,725 .

\subsubsection{Resumo das Análises Fatoriais}

Para finalizar o tópico das Análises Fatorias, foi elaborado um resumo das análises fatoriais realizadas. 


\subsubsection{Resumo das Análises Fatoriais - Integração da Cadeia de Suprimentos}

Tendo em vista os parâmetros de análise definidos na seção anterior, os modelos finais obtiveram, em alguns casos, fatores diferentes dos inicialmente propostos no estudo. Isto ocorreu pela necessidade de exclusão de algumas variáveis e pela obtenção de mais de um fator onde inicialmente o modelo previa apenas um fator. Assim, a Integração da Cadeia de Suprimentos é explicada por quatro fatores: integração interna, compartilhamento de informações, participação dos fornecedores no negócio e integração externa com clientes.

A ilustração 41 a seguir ilustra o modelo final obtido. Em seguida, os resultados da análise fatorial são apresentados.

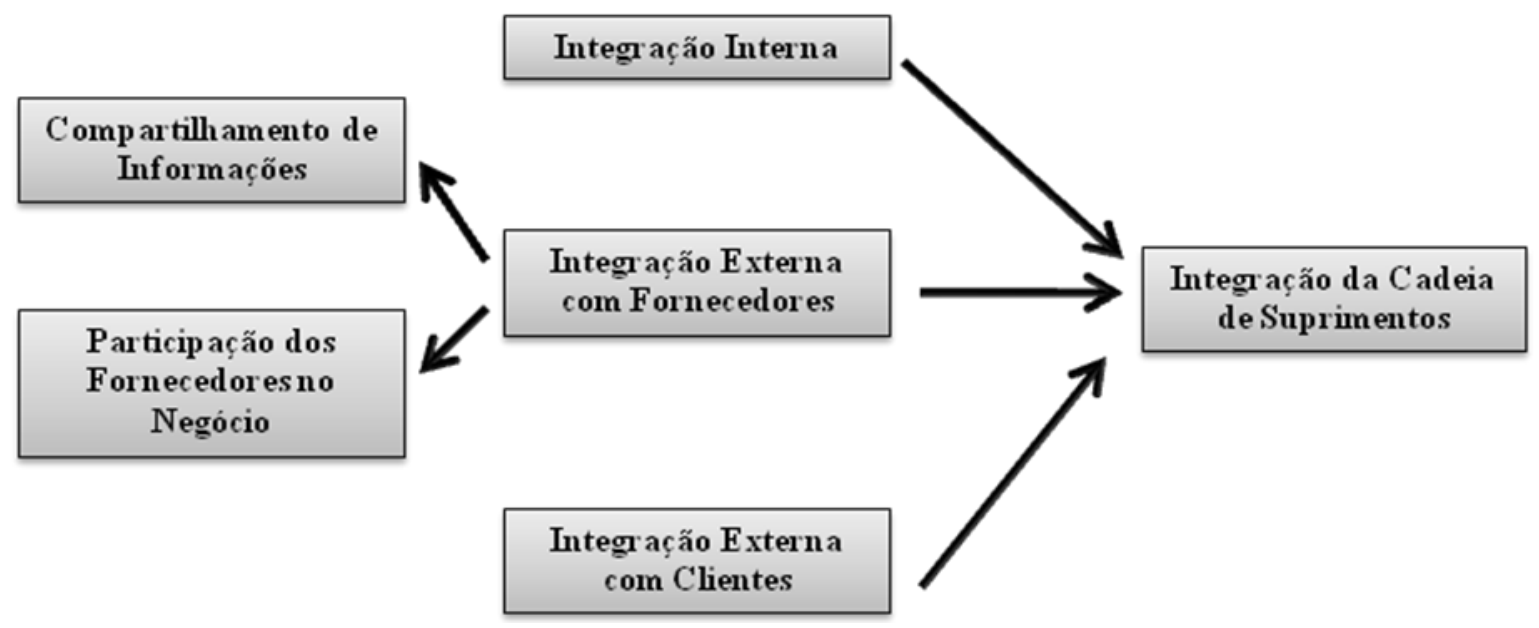

Ilustração 41 - Fatores obtidos pela Análise Fatorial para a Integração da Cadeia de Suprimentos

As análises fatoriais para o construto Integração da cadeia obtiveram os resultados ilustrados no quadro 25 a seguir.

Quadro 25 - Resumo das Análises Fatoriais - Integração da Cadeia de Suprimentos

\begin{tabular}{|c|c|c|c|c|c|c|c|}
\hline Construto & Variável & KMO & $\begin{array}{l}\text { Variância } \\
\text { Explicada }\end{array}$ & Comunalidade & $\begin{array}{c}\text { Carga } \\
\text { Fatorial }\end{array}$ & $\begin{array}{c}\text { Alfa de } \\
\text { Cronbach }\end{array}$ & $\begin{array}{l}\text { Variáveis } \\
\text { excluídas }\end{array}$ \\
\hline \multirow[t]{2}{*}{ Integração interna } & $\begin{array}{l}\text { Na minha } \\
\text { empresa existe } \\
\text { uma ampla } \\
\text { integração interna } \\
\text { entre as funções }\end{array}$ & \multirow[t]{2}{*}{0,675} & \multirow[t]{2}{*}{$71,3 \%$} & ,757 & ,884 & \multirow[t]{2}{*}{0,793} & \\
\hline & $\begin{array}{l}\text { A minha empresa } \\
\text { usa equipes } \\
\text { multifuncionais } \\
\text { para apoiar os } \\
\text { objetivos }\end{array}$ & & & ,781 & 870 & & \\
\hline
\end{tabular}




\begin{tabular}{|c|c|c|c|c|c|c|c|}
\hline \multirow[t]{3}{*}{ Construto } & Variável & KMO & $\begin{array}{l}\text { Variância } \\
\text { Explicada }\end{array}$ & Comunalidade & $\begin{array}{c}\text { Carga } \\
\text { Fatorial }\end{array}$ & $\begin{array}{c}\text { Alfa de } \\
\text { Cronbach }\end{array}$ & $\begin{array}{l}\text { Variáveis } \\
\text { excluídas }\end{array}$ \\
\hline & $\begin{array}{l}\text { estratégicos da } \\
\text { nossa unidade }\end{array}$ & & & & & & \\
\hline & $\begin{array}{l}\text { Na minha } \\
\text { empresa existe } \\
\text { integração dos } \\
\text { sistemas de } \\
\text { informação entre } \\
\text { as funções } \\
\text { internas }\end{array}$ & & & ,600 & ,775 & & \\
\hline \multirow[t]{6}{*}{$\begin{array}{l}\text { Integração externa } \\
\text { com fornecedores } \\
- \\
\text { Compartilhamento } \\
\text { de informações } \\
\text { estratégicas }\end{array}$} & $\begin{array}{l}\text { A minha empresa } \\
\text { oferece aos } \\
\text { fornecedores as } \\
\text { informações de } \\
\text { previsão de } \\
\text { demanda }\end{array}$ & \multirow[t]{8}{*}{0,853} & \multirow[t]{8}{*}{$58,2 \%$} & ,733 & ,847 & \multirow[t]{6}{*}{0,856} & \multirow[t]{8}{*}{$\mathrm{R} 10,16$} \\
\hline & $\begin{array}{l}\text { A minha empresa } \\
\text { pode rapidamente } \\
\text { monitorar o status } \\
\text { de seus pedidos }\end{array}$ & & & ,518 & ,719 & & \\
\hline & $\begin{array}{l}\text { Minha empresa } \\
\text { compartilha seus } \\
\text { planos de } \\
\text { produção com os } \\
\text { fornecedores }\end{array}$ & & & ,709 & ,812 & & \\
\hline & $\begin{array}{l}\text { O fornecedor e } \\
\text { minha empresa } \\
\text { gerenciam um } \\
\text { conjunto de } \\
\text { iniciativas de } \\
\text { desenvolvimento } \\
\text { de novos } \\
\text { produtos }\end{array}$ & & & ,490 & ,536 & & \\
\hline & $\begin{array}{l}\text { A minha empresa } \\
\text { possui } \\
\text { gerenciamento } \\
\text { integrado da } \\
\text { previsão da } \\
\text { demanda } \\
\end{array}$ & & & ,612 & ,764 & & \\
\hline & $\begin{array}{l}\text { A minha empresa } \\
\text { compartilha uma } \\
\text { grande } \\
\text { quantidade de } \\
\text { informações } \\
\text { importantes com } \\
\text { os nossos } \\
\text { fornecedores }\end{array}$ & & & ,660 & ,608 & & \\
\hline \multirow[t]{2}{*}{$\begin{array}{l}\text { Integração externa } \\
\text { com fornecedores } \\
\text { - Participação do } \\
\text { fornecedor no } \\
\text { negócio }\end{array}$} & $\begin{array}{l}\text { Nossos } \\
\text { fornecedores } \\
\text { participam da } \\
\text { fase de design de } \\
\text { nossos produtos }\end{array}$ & & & ,614 & ,781 & \multirow[t]{2}{*}{0,769} & \\
\hline & $\begin{array}{l}\text { Existe uma } \\
\text { integração direta } \\
\text { entre os } \\
\text { computadores da } \\
\text { nossa empresa e } \\
\text { os dos nossos } \\
\text { principais }\end{array}$ & & & ,443 & ,608 & & \\
\hline
\end{tabular}




\begin{tabular}{|c|c|c|c|c|c|c|c|}
\hline Construto & Variável & KMO & $\begin{array}{l}\text { Variância } \\
\text { Explicada }\end{array}$ & Comunalidade & \multirow[t]{2}{*}{$\begin{array}{c}\text { Carga } \\
\text { Fatorial } \\
\end{array}$} & $\begin{array}{c}\text { Alfa de } \\
\text { Cronbach }\end{array}$ & $\begin{array}{l}\text { Variáveis } \\
\text { excluídas }\end{array}$ \\
\hline & fornecedores & & & & & & \\
\hline & $\begin{array}{l}\text { A nossa empresa } \\
\text { compartilha as } \\
\text { nossas } \\
\text { informações de } \\
\text { custos com os } \\
\text { nossos principais } \\
\text { fornecedores }\end{array}$ & & & ,645 & ,803 & & \\
\hline & $\begin{array}{l}\text { A nossa empresa } \\
\text { exige que o } \\
\text { compartilhamento } \\
\text { de } \\
\text { informações de } \\
\text { custo por parte } \\
\text { dos nossos } \\
\text { fornecedores }\end{array}$ & & & ,542 &, 719 & & \\
\hline & $\begin{array}{l}\text { A nossa empresa } \\
\text { compartilha em } \\
\text { tempo real a } \\
\text { informação da } \\
\text { programação de } \\
\text { produção com os } \\
\text { fornecedores }\end{array}$ & & & ,440 & ,510 & & \\
\hline \multirow[t]{5}{*}{$\begin{array}{l}\text { Integração externa } \\
\text { com clientes }\end{array}$} & $\begin{array}{l}\text { Os nossos } \\
\text { clientes fornecem } \\
\text { suas informações } \\
\text { de previsão da } \\
\text { demanda para a } \\
\text { nossa empresa } \\
\end{array}$ & \multirow[t]{5}{*}{0,872} & \multirow[t]{5}{*}{$56,15 \%$} & ,566 &, 753 & \multirow[t]{5}{*}{0,887} & \multirow[t]{5}{*}{ R23 } \\
\hline & $\begin{array}{l}\text { Os nossos } \\
\text { clientes podem } \\
\text { facilmente } \\
\text { monitorar o status } \\
\text { de } \\
\text { seus pedidos } \\
\text { realizados na } \\
\text { nossa empresa }\end{array}$ & & & ,608 &, 780 & & \\
\hline & $\begin{array}{l}\text { Nossos clientes e } \\
\text { a minha empresa } \\
\text { coordenam } \\
\text { conjuntamente o } \\
\text { planejamento de } \\
\text { produção }\end{array}$ & & & ,607 &, 779 & & \\
\hline & $\begin{array}{l}\text { Nossos clientes e } \\
\text { a minha empresa } \\
\text { gerenciam em } \\
\text { conjunto } \\
\text { iniciativas de } \\
\text { desenvolvimento } \\
\text { de novos } \\
\text { produtos }\end{array}$ & & & ,575 & ,758 & & \\
\hline & $\begin{array}{l}\text { Nossos clientes e } \\
\text { a minha empresa } \\
\text { identificam em } \\
\text { conjunto } \\
\text { oportunidades de } \\
\text { novos mercados }\end{array}$ & & & ,568 & ,754 & & \\
\hline
\end{tabular}




\begin{tabular}{|c|c|c|c|c|c|c|c|}
\hline Construto & Variável & KMO & $\begin{array}{l}\text { Variância } \\
\text { Explicada }\end{array}$ & Comunalidade & $\begin{array}{c}\text { Carga } \\
\text { Fatorial }\end{array}$ & $\begin{array}{c}\text { Alfa de } \\
\text { Cronbach }\end{array}$ & $\begin{array}{l}\text { Variáveis } \\
\text { excluídas }\end{array}$ \\
\hline & $\begin{array}{l}\text { A nossa empresa } \\
\text { realiza } \\
\text { gerenciamento } \\
\text { integrado da } \\
\text { previsão da } \\
\text { demanda } \\
\end{array}$ & & & ,646 & ,804 & & \\
\hline & $\begin{array}{l}\text { A nossa empresa } \\
\text { realiza } \\
\text { gerenciamento do } \\
\text { relacionamento } \\
\text { com o cliente }\end{array}$ & & & ,491 &, 700 & & \\
\hline & $\begin{array}{l}\text { Os nossos } \\
\text { clientes têm } \\
\text { acesso em tempo } \\
\text { real sobre a } \\
\text { disponibilidade } \\
\text { do produto da } \\
\text { nossa empresa }\end{array}$ & & & ,431 & ,657 & & \\
\hline
\end{tabular}

Observa-se que algumas variáveis do construto "integração da cadeia de suprimentos" possui comunalidade ligeiramente inferior a 0,5 (valor mínimo aconselhável), porém, ao retirá-las do modelo, não se observou melhora significativa, o que levou à decisão de mantê-las no modelo final.

\subsubsection{Resumo das Análises Fatoriais - Desempenho Individual}

O constructo "desempenho individual" previa inicialmente quatro fatores, porém a análise fatorial, encontrou três dimensões para perspectiva dos processos empresariais (com eigenvalue maior que um) e duas dimensões para a perspectiva financeira (também com eigenvalue maior que um), conforme apresenta a ilustração 42 a seguir. 


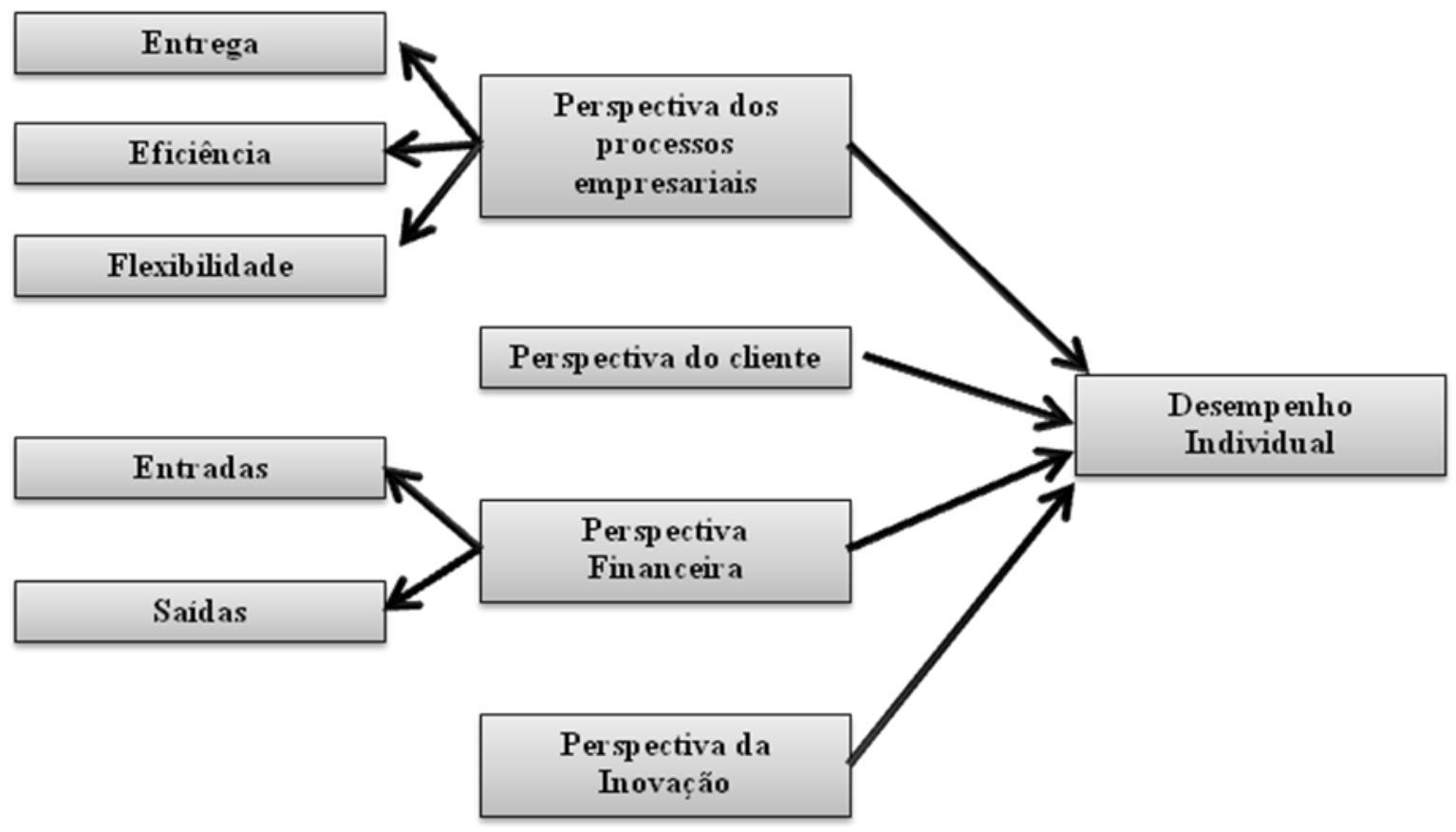

Ilustração 42 - Fatores obtidos pela Análise Fatorial para o Desempenho Individual

Os resultados obtidos pela análise fatorial para os construtos do desempenho individual da organização são mostrados no quadro 26.

Quadro 26 - Resumo das Análises Fatoriais - Desempenho Individual

\begin{tabular}{|c|c|c|c|c|c|c|c|}
\hline Construto & Variável & KMO & $\begin{array}{l}\text { Variância } \\
\text { Explicada }\end{array}$ & Comunalidade & $\begin{array}{c}\text { Carga } \\
\text { Fatorial }\end{array}$ & $\begin{array}{l}\text { Alfa de } \\
\text { Cronbach }\end{array}$ & $\begin{array}{l}\text { Variáveis } \\
\text { excluídas }\end{array}$ \\
\hline \multirow{4}{*}{$\begin{array}{l}\text { Perspectiva dos } \\
\text { processos } \\
\text { empresariais - } \\
\text { entrega }\end{array}$} & Tempo de entrega & \multirow[t]{10}{*}{0,828} & \multirow[t]{10}{*}{$68 \%$} & 0,678 & $-0,685$ & \multirow[t]{4}{*}{0,887} & \multirow[t]{10}{*}{$\longrightarrow$} \\
\hline & $\begin{array}{l}\text { Confiabilidade na } \\
\text { entrega }\end{array}$ & & & 0,777 & 0,824 & & \\
\hline & $\begin{array}{l}\text { Pedidos entregue } \\
\text { no prazo }\end{array}$ & & & 0,842 & 0,866 & & \\
\hline & $\begin{array}{l}\text { Taxa de } \\
\text { atendimento dos } \\
\text { pedidos }\end{array}$ & & & 0,757 & 0,825 & & \\
\hline \multirow{3}{*}{$\begin{array}{l}\text { Perspectiva dos } \\
\text { processos } \\
\text { empresariais - } \\
\text { eficiência }\end{array}$} & Níveis de estoque & & & 0,540 & 0,655 & \multirow[t]{3}{*}{0,633} & \\
\hline & $\begin{array}{l}\text { Lead-time da } \\
\text { produção }\end{array}$ & & & 0,620 & 0,678 & & \\
\hline & $\begin{array}{l}\text { Lead-time da } \\
\text { compras }\end{array}$ & & & 0,666 & 0,760 & & \\
\hline \multirow{3}{*}{$\begin{array}{l}\text { Perspectiva dos } \\
\text { processos } \\
\text { empresariais - } \\
\text { flexibilidade }\end{array}$} & $\begin{array}{l}\text { Custos de } \\
\text { manufatura }\end{array}$ & & & 0,448 & $-0,538$ & \multirow[t]{3}{*}{0,644} & \\
\hline & $\begin{array}{l}\text { Flexibilidade de } \\
\text { serviço ao cliente }\end{array}$ & & & 0,753 & 0,784 & & \\
\hline & $\begin{array}{l}\text { Flexibilidade para } \\
\text { responder e } \\
\text { atender variações } \\
\text { de } \\
\text { demanda, tais } \\
\text { como a } \\
\text { sazonalidade }\end{array}$ & & & 0,717 & 0,711 & & \\
\hline
\end{tabular}




\begin{tabular}{|c|c|c|c|c|c|c|c|}
\hline Construto & Variável & $\mathrm{KMO}$ & $\begin{array}{l}\text { Variância } \\
\text { Explicada }\end{array}$ & Comunalidade & $\begin{array}{c}\text { Carga } \\
\text { Fatorial }\end{array}$ & $\begin{array}{c}\text { Alfa de } \\
\text { Cronbach }\end{array}$ & $\begin{array}{l}\text { Variáveis } \\
\text { excluídas }\end{array}$ \\
\hline \multirow[t]{4}{*}{$\begin{array}{l}\text { Perspectiva do } \\
\text { cliente }\end{array}$} & $\begin{array}{l}\text { Participação de } \\
\text { mercado }\end{array}$ & \multirow[t]{4}{*}{0,767} & \multirow[t]{4}{*}{$65,5 \%$} & 0,534 & 0,731 & \multirow[t]{4}{*}{0,816} & \multirow[t]{4}{*}{39} \\
\hline & $\begin{array}{l}\text { Retenção de } \\
\text { clientes }\end{array}$ & & & 0,668 & 0,817 & & \\
\hline & $\begin{array}{l}\text { Tempo de } \\
\text { resposta ao } \\
\text { cliente }\end{array}$ & & & 0,682 & $-0,826$ & & \\
\hline & $\begin{array}{l}\text { Nível de serviço } \\
\text { ao cliente }\end{array}$ & & & 0,737 & 0,858 & & \\
\hline \multirow{5}{*}{$\begin{array}{l}\text { Perspectiva } \\
\text { financeira - } \\
\text { entradas }\end{array}$} & $\begin{array}{l}\text { Vendas em } \\
\text { unidades }\end{array}$ & \multirow[t]{7}{*}{0,820} & \multirow[t]{7}{*}{$73,2 \%$} & 0,629 & 0,760 & \multirow[t]{5}{*}{0,892} & \multirow[t]{7}{*}{ 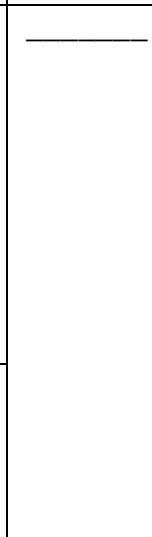 } \\
\hline & Receitas & & & 0,708 & 0,831 & & \\
\hline & Lucro líquido & & & 0,853 & 0,832 & & \\
\hline & $\begin{array}{l}\text { Retorno sobre } \\
\text { investimento }\end{array}$ & & & 0,843 & 0,780 & & \\
\hline & $\begin{array}{l}\text { Retorno sobre o } \\
\text { ativo total }\end{array}$ & & & 0,824 & 0,766 & & \\
\hline \multirow{2}{*}{$\begin{array}{l}\text { Perspectiva } \\
\text { financeira - saídas }\end{array}$} & Giro de estoque & & & 0,519 & 0,586 & \multirow[t]{2}{*}{0,535} & \\
\hline & $\begin{array}{l}\text { Custo dos } \\
\text { produtos e } \\
\text { serviços }\end{array}$ & & & 0,748 & 0,864 & & \\
\hline \multirow[t]{2}{*}{$\begin{array}{l}\text { Perspectiva da } \\
\text { inovação }\end{array}$} & $\begin{array}{l}\text { Competitividade } \\
\text { da empresa }\end{array}$ & \multirow[t]{2}{*}{0,5} & \multirow[t]{2}{*}{$77 \%$} & 0,772 & 0,878 & \multirow[t]{2}{*}{0,702} & \multirow[t]{2}{*}{ 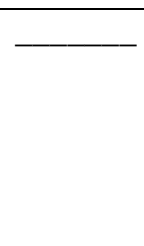 } \\
\hline & $\begin{array}{l}\text { Melhoria } \\
\text { contínua dos } \\
\text { processos } \\
\text { internos }\end{array}$ & & & 0,772 & 0,878 & & \\
\hline
\end{tabular}

Analogamente ao construto "integração da cadeia", o construto "desempenho individual" obteve uma variável com comunalidade inferior a 0,5 , porém ao excluí-la do modelo não se observou melhora, por isso optou-se por mantê-la no modelo final.

Adicionalmente, o fator "perspectiva financeira saída" obteve índice de confiabilidade inferior a 0,6, o que indica baixa confiabilidade do fator. Entretanto, por sua relevância, este será mantido no modelo para a realização da modelagem que equações estruturais.

\subsubsection{Resumo das Análises Fatoriais - Desempenho da Cadeia de Suprimentos}

O modelo teórico inicial previa apenas uma dimensão para as perspectivas dos processos empresariais e para a perspectiva financeira da cadeia. Entretanto, a análise fatorial encontrou mais de um fator com eigenvalue maior que um para ambas as dimensões, conforme apresenta a ilustração 43 a seguir. 


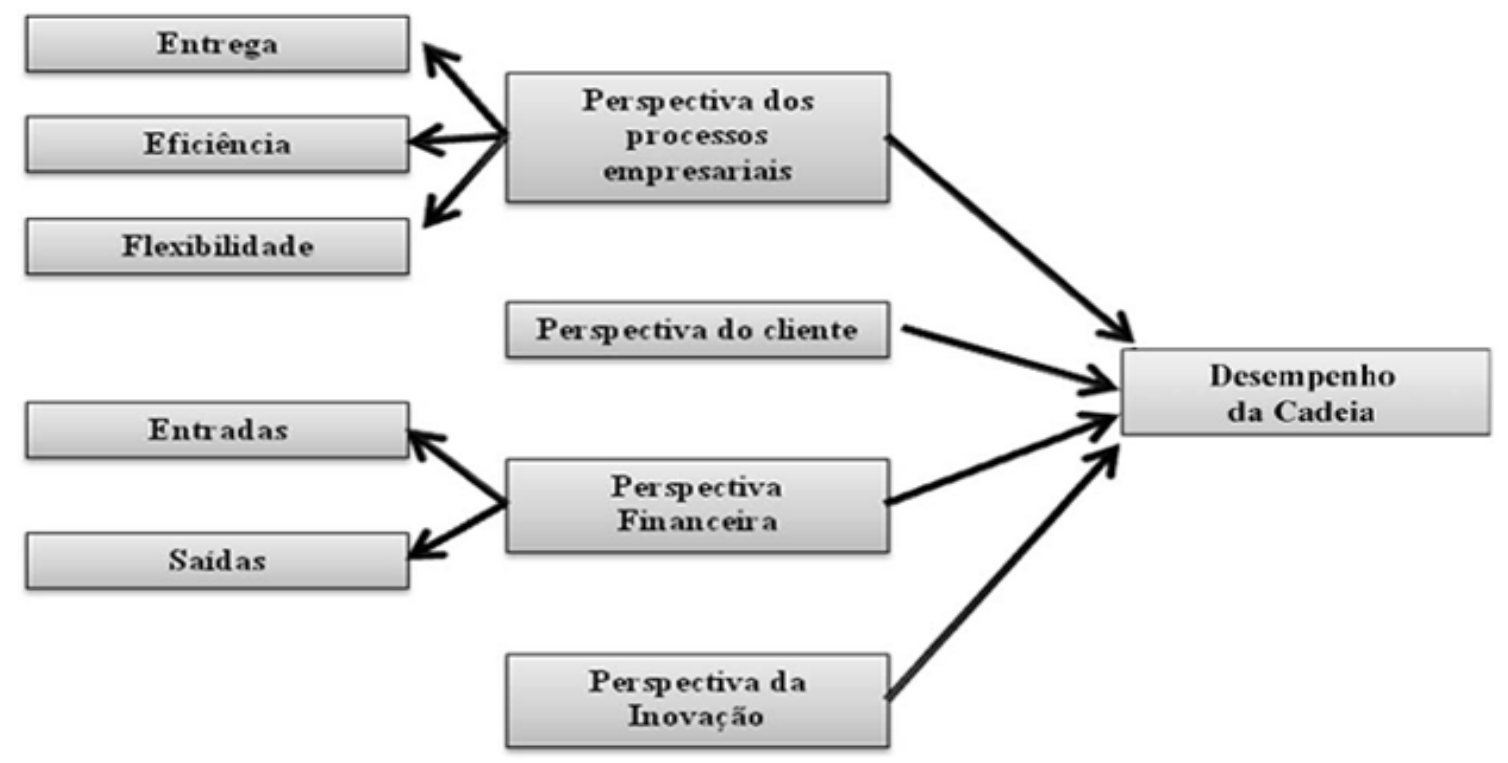

Ilustração 43 - Fatores obtidos pela Análise Fatorial para o Desempenho da Cadeia de Suprimentos

Os indicadores de aderência do modelo fatorial são apresentados no quadro 27 a seguir. Observa-se boa aderência em todos os fatores obtidos e fidedignidade adequada dos fatores.

Quadro 27 - Resumo das Análises Fatoriais - Integração da Cadeia de Suprimentos

\begin{tabular}{|c|c|c|c|c|c|c|c|}
\hline Construto & Variável & $\mathrm{KMO}$ & $\begin{array}{l}\text { Variância } \\
\text { Explicada }\end{array}$ & Comunalidade & $\begin{array}{c}\text { Carga } \\
\text { Fatorial }\end{array}$ & $\begin{array}{c}\text { Alfa de } \\
\text { Cronbach }\end{array}$ & $\begin{array}{l}\text { Variáveis } \\
\text { excluídas }\end{array}$ \\
\hline \multirow{4}{*}{$\begin{array}{l}\text { Perspectiva dos } \\
\text { processos } \\
\text { empresariais - } \\
\text { entrega }\end{array}$} & Tempo de entrega & \multirow[t]{7}{*}{0,840} & \multirow[t]{7}{*}{$81 \%$} & 0,659 & 0,909 & \multirow[t]{4}{*}{0,918} & \multirow[t]{7}{*}{$\longrightarrow$} \\
\hline & $\begin{array}{l}\text { Confiabilidade na } \\
\text { entrega }\end{array}$ & & & 0,861 & 0,909 & & \\
\hline & $\begin{array}{l}\text { Pedidos entregue } \\
\text { no prazo }\end{array}$ & & & 0,893 & 0,881 & & \\
\hline & $\begin{array}{l}\text { Taxa de } \\
\text { atendimento dos } \\
\text { pedidos }\end{array}$ & & & 0,826 & $-0,730$ & & \\
\hline \multirow{3}{*}{$\begin{array}{l}\text { Perspectiva dos } \\
\text { processos } \\
\text { empresariais - } \\
\text { ciclo de produção }\end{array}$} & $\begin{array}{l}\text { Lead-time da } \\
\text { produção }\end{array}$ & & & 0,789 & 0,884 & \multirow[t]{3}{*}{0,886} & \\
\hline & $\begin{array}{l}\text { Lead-time da } \\
\text { compras }\end{array}$ & & & 0,831 & 0,873 & & \\
\hline & $\begin{array}{l}\text { Tempo total de } \\
\text { ciclo do pedido }\end{array}$ & & & 0,820 & 0,846 & & \\
\hline \multirow[t]{4}{*}{$\begin{array}{l}\text { Perspectiva do } \\
\text { cliente }\end{array}$} & $\begin{array}{l}\text { Satisfação dos } \\
\text { clientes }\end{array}$ & \multirow[t]{4}{*}{0,818} & \multirow[t]{4}{*}{$71,5 \%$} & 0,759 & 0,871 & \multirow[t]{4}{*}{0,866} & \multirow[t]{4}{*}{61} \\
\hline & $\begin{array}{l}\text { Retenção de } \\
\text { clientes }\end{array}$ & & & 0,636 & 0,798 & & \\
\hline & $\begin{array}{l}\text { Tempo de } \\
\text { resposta ao } \\
\text { cliente }\end{array}$ & & & 0,750 & $-0,866$ & & \\
\hline & $\begin{array}{l}\text { Nível de serviço } \\
\text { ao cliente }\end{array}$ & & & 0,715 & 0,845 & & \\
\hline Perspectiva & Receitas & 0,777 & $83,3 \%$ & 0,727 & 0,852 & 0,939 & 67,72 \\
\hline
\end{tabular}




\begin{tabular}{|c|c|c|c|c|c|c|c|}
\hline Construto & Variável & KMO & $\begin{array}{l}\text { Variância } \\
\text { Explicada }\end{array}$ & Comunalidade & $\begin{array}{c}\text { Carga } \\
\text { Fatorial }\end{array}$ & $\begin{array}{c}\text { Alfa de } \\
\text { Cronbach }\end{array}$ & $\begin{array}{l}\text { Variáveis } \\
\text { excluídas }\end{array}$ \\
\hline \multirow{3}{*}{$\begin{array}{l}\text { financeira - } \\
\text { índices } \\
\text { financeiros }\end{array}$} & Lucro líquido & & & 0,884 & 0,939 & & \\
\hline & $\begin{array}{l}\text { Retorno sobre } \\
\text { investimento }\end{array}$ & & & 0,899 & 0,945 & & \\
\hline & $\begin{array}{l}\text { Retorno sobre o } \\
\text { ativo total }\end{array}$ & & & 0,876 & 0,931 & & \\
\hline \multirow[t]{2}{*}{$\begin{array}{l}\text { Perspectiva } \\
\text { financeira - custos }\end{array}$} & $\begin{array}{l}\text { Custo total dos } \\
\text { recursos } \\
\text { utilizados }\end{array}$ & & & 0,802 & 0,890 & \multirow[t]{2}{*}{0,755} & \\
\hline & $\begin{array}{l}\text { Custos associados } \\
\text { ao estoque parado }\end{array}$ & & & 0,808 & 0,898 & & \\
\hline \multirow[t]{2}{*}{$\begin{array}{l}\text { Perspectiva da } \\
\text { inovação }\end{array}$} & $\begin{array}{l}\text { Competitividade } \\
\text { global }\end{array}$ & \multirow[t]{2}{*}{0,50} & \multirow[t]{2}{*}{$78,8 \%$} & 0,788 & 0,888 & \multirow[t]{2}{*}{0,725} & \multirow[t]{2}{*}{ 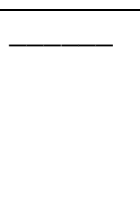 } \\
\hline & $\begin{array}{l}\text { Melhoria } \\
\text { contínua global } \\
\text { dos processos }\end{array}$ & & & 0,788 & 0,888 & & \\
\hline
\end{tabular}

\subsection{Análise de Regressão}

Aplicou-se a técnica análise de regressão para se verificar a existência de relação entre os construtos integração da cadeia de suprimentos, desempenho individual da organização e desempenho da cadeia. Destaca-se que a ferramenta tem como objetivo verificar a existência de relação entre os construtos e não a criação de um modelo de previsão.Avaliou-se entretanto, a normalidade dos resíduos, o que indica aderência do modelo.

Para a realização das análises de regressão, foram criadas três novas variáveis, cada uma representando um constructo, sendo elas: "integração da cadeia", "desempenho individual" e “desempenho da cadeia”. Assim, cada umas dessas variáveis foram obtidas pela média ponderada entre os fatores que os compõem, possuindo todos o mesmo peso (por exemplo, a "integração da cadeia" é dada pela ponderação entre "integração interna", "compartilhamento de informações", "participação dos fornecedores no negócio" e "integração externa com clientes").

Por sua vez, cada um dos fatores de cada um dos constructos foi calculado pela média aritmética entre as variáveis que o compõem (por exemplo, a "integração interna” é dada pela média das variáveis que a determinam, sendo elas: R4, R5 e R6). 
Convêm notar que embora as variáveis individualmente não apresentem distribuição normal, quando agrupadas, as novas variáveis geradas apresentam distribuição normal. A normalidade foi verificada pelo teste de Kolmogorov-Smirnov (K-S) cujas hipóteses afirmam:

- H0: a distribuição é normal

- H1: a distribuição não é normal

Assim, pela tabela 90, pode-se observar que há aceitação da hipótese nula no três caso, o que indica que a distribuição é normal.

Tabela 90 - Teste Kolmogorov-Smirnov (K-S) para os constructos - Análise de Regressão

\begin{tabular}{lccc}
\hline & $\begin{array}{c}\text { Integração da } \\
\text { cadeia }\end{array}$ & $\begin{array}{c}\text { Desempenho } \\
\text { Individual }\end{array}$ & $\begin{array}{c}\text { Desempenho da } \\
\text { Cadeia }\end{array}$ \\
\hline Kolmogorov-Smirnov Z &, 914 &, 929 &, 614 \\
Significância (bi-caudal) & $\mathbf{, 3 7 4}$ & $\mathbf{, 3 5 4}$ & $\mathbf{, 8 4 6}$ \\
\hline
\end{tabular}

\subsubsection{Variável dependente: Desempenho Individual - Variável independente: Integração da Cadeia}

A tabela 91 mostra os coeficientes de correlação $(\mathrm{R})$, de determinação $\left(\mathrm{R}^{2}\right)$, de determinação ajustado ( $\mathrm{R}^{2}$ ajustado) e o erro padrão da estimativa.

$\mathrm{O}$ valor positivo encontrado para $\mathrm{R}$ indica uma associação crescente em Desempenho Individual e Integração da Cadeia. Quanto maior a Integração maior será o Desempenho Individual. $\mathrm{O} \mathrm{R}^{2}$ de 0,191 indica que aproximadamente $20 \%$ da variância do Desempenho Individual poderia ser explicada pela Integração da Cadeia.

Tabela 91 - Resumo do modelo de regressão - Desempenho Individual x Integração da Cadeia

\begin{tabular}{cccc}
\hline $\mathrm{R}$ & $\mathrm{R}^{2}$ & $\mathrm{R}^{2}$ Ajustado & Erro padrão da estimativa \\
\hline, $437^{\mathrm{a}}$ &, 191 &, 185 &, 50402 \\
\hline
\end{tabular}

Já a tabela 92 mostra a Análise de Variância ou ANOVA do modelo criado. O valor calculado para a estatística $F$ foi igual a 31,166, com um nível de significância igual a 0,000. Este 
resultado indica que pelo menos um dos coeficientes do modelo é significativamente diferente de zero.

Tabela 92 - Análise de Variância - Desempenho Individual x Integração da Cadeia

\begin{tabular}{lccccc}
\hline & $\begin{array}{c}\text { Soma dos } \\
\text { quadrados }\end{array}$ & $\begin{array}{c}\text { Graus de } \\
\text { liberdade }\end{array}$ & $\begin{array}{c}\text { Média dos } \\
\text { quadrados }\end{array}$ & F & Sig. \\
\hline Regressão & 7,917 & 1 & 7,917 & 31,166 &, 000 \\
Resíduos & 33,533 & 132 &, 254 & & \\
Total & 41,450 & 133 & & & \\
\hline
\end{tabular}

Finalmente, a tabela 93 mostra os coeficientes do modelo de regressão. Ela apresenta, na coluna dos coeficientes não padronizados, os valores dos coeficientes (B) e dos erros padrões.

Tabela 93 - Coeficientes do modelo de regressão - Desempenho Individual x Integração da Cadeia

\begin{tabular}{lccccc}
\hline \multicolumn{1}{c}{$\begin{array}{c}\text { Coeficientes não } \\
\text { padronizados }\end{array}$} & \multicolumn{2}{c}{$\begin{array}{c}\text { Coeficientes } \\
\text { padronizados }\end{array}$} \\
\hline Variável & $\mathrm{B}$ & Erro Padrão & Beta & $\mathrm{t}$ & Sig. \\
\hline Constante & 3,747 &, 187 & & 20,019 &, 000 \\
Integração da Cadeia &, 233 &, 042 &, 437 & 5,583 &, 000 \\
\hline
\end{tabular}

No caso, o coeficiente da constante foi igual a 3,747 e o coeficiente da Integração da Cadeia foi de 0,233 . Assim, o modelo linear poderia ser apresentado como:

$$
\mathrm{Y}=3,747+0,233 \mathrm{X}
$$

Onde Y representa o Desempenho Individual e X representa a Integração da Cadeia. A interpretação do modelo indica que existe uma parte do Desempenho Individual não associada a Integração e outra parte que é função da Integração.

Assim, pode-se dizer que, existe uma relação entre Integração da Cadeia e Desempenho Individual, porém ela é relativamente fraca, já que o coeficiente de determinação $\left(\mathrm{R}^{2}\right)$ é relativamente baixo 


\subsubsection{Variável dependente: Desempenho da Cadeia - Variável independente: Integração da Cadeia}

Conforme mostra a tabela 94, o valor positivo encontrado para $\mathrm{R}$ indica uma associação crescente em Desempenho da Cadeia e Integração da Cadeia. Quanto maior a Integração maior será o Desempenho da Cadeia. $\mathrm{O} \mathrm{R}^{2}$ de 0,228 indica que aproximadamente $23 \%$ da variância do Desempenho da Cadeia poderia ser explicada pela Integração da Cadeia.

Tabela 94 - Resumo do modelo de regressão - Desempenho da Cadeia x Integração da Cadeia

\begin{tabular}{cccc}
\hline $\mathrm{R}$ & $\mathrm{R}^{2}$ & $\mathrm{R}^{2}$ Ajustado & Erro padrão da estimativa \\
\hline, $478^{\mathrm{a}}$ &, 228 &, 222 &, 46381 \\
\hline
\end{tabular}

Já a tabela 95 mostra a Análise de Variância ou ANOVA do modelo criado. O valor calculado para a estatística $\mathrm{F}$ foi igual a 39,044, com um nível de significância igual a 0,000. Este resultado indica que pelo menos um dos coeficientes do modelo é significativamente diferente de zero.

Tabela 95 - Análise de Variância - Desempenho da Cadeia x Integração da Cadeia

\begin{tabular}{lccccc}
\hline & $\begin{array}{c}\text { Soma dos } \\
\text { quadrados }\end{array}$ & $\begin{array}{c}\text { Graus de } \\
\text { liberdade }\end{array}$ & $\begin{array}{c}\text { Média dos } \\
\text { quadrados }\end{array}$ & F & Sig. \\
\hline Regressão & 8,399 & 1 & 8,399 & 39,044 &, 000 \\
Resíduos & 28,396 & 132 &, 215 & \\
Total & 36,796 & 133 & & \\
\hline
\end{tabular}

Finalmente, a tabela 96 mostra os coeficientes do modelo de regressão. Ela apresenta, na coluna dos coeficientes não padronizados, os valores dos coeficientes (B) e dos erros padrões.

Tabela 96 - Coeficientes do modelo de regressão - Desempenho da Cadeia x Integração da Cadeia

\begin{tabular}{lccccc}
\hline \multicolumn{7}{c}{$\begin{array}{l}\text { Coeficientes não } \\
\text { padronizados }\end{array}$} & \multicolumn{2}{c}{$\begin{array}{c}\text { Coeficientes } \\
\text { padronizados }\end{array}$} \\
\hline \multicolumn{1}{c}{ Variável } & $\mathrm{B}$ & Erro Padrão & Beta & $\mathrm{t}$ & Sig. \\
\hline Constante & 3,522 &, 172 & & 20,453 &, 000 \\
Integração da Cadeia &, 240 &, 038 &, 478 & 6,249 &, 000 \\
\hline
\end{tabular}


No caso, o coeficiente da constante foi igual a 3,522 e o coeficiente da Integração da Cadeia foi de 0,240. Assim, o modelo linear poderia ser apresentado como:

$$
\mathrm{Y}=3,522+0,240 \mathrm{X}
$$

Onde Y representa o Desempenho da Cadeia e X representa a Integração da Cadeia. A interpretação do modelo indica que existe uma parte do Desempenho da Cadeia não associada a Integração e outra parte que é função da Integração.

Assim, pode-se dizer que, existe uma relação entre Integração da Cadeia e Desempenho da Cadeia, porém ela é relativamente fraca, já que o coeficiente de determinação $\left(\mathrm{R}^{2}\right)$ é relativamente baixo

\subsubsection{Variável dependente: Desempenho da Cadeia - Variável independente: Desempenho Individual}

$\mathrm{O}$ valor positivo encontrado para $\mathrm{R}$ indica uma associação crescente em Desempenho da Cadeia e Desempenho Individual, como mostra a tabela 97. Quanto maior o Desempenho Individual maior será o Desempenho da Cadeia. $\mathrm{O} \mathrm{R}^{2}$ de 0,549 indica que aproximadamente 55\% da variância do Desempenho da Cadeia poderia ser explicada pelo Desempenho Individual.

Tabela 97 - Resumo do modelo de regressão - Desempenho da Cadeia x Desempenho Individual

\begin{tabular}{cccc}
\hline $\mathrm{R}$ & $\mathrm{R}^{2}$ & $\mathrm{R}^{2}$ Ajustado & Erro padrão da estimativa \\
\hline, $741^{\mathrm{a}}$ &, 549 &, 546 &, 35459 \\
\hline
\end{tabular}

Já a tabela 98 mostra a Análise de Variância ou ANOVA do modelo criado. O valor calculado para a estatística $\mathrm{F}$ foi igual a 160,647, com um nível de significância igual a 0,000. Este resultado indica que pelo menos um dos coeficientes do modelo é significativamente diferente de zero. 
Tabela 98 - Análise de Variância - Desempenho da Cadeia x Desempenho Individual

\begin{tabular}{lccccc}
\hline & $\begin{array}{c}\text { Soma dos } \\
\text { quadrados }\end{array}$ & $\begin{array}{c}\text { Graus de } \\
\text { liberdade }\end{array}$ & $\begin{array}{c}\text { Média dos } \\
\text { quadrados }\end{array}$ & F & Sig. \\
\hline Regressão & 20,199 & 1 & 20,199 & 160,647 &, 000 \\
Resíduos & 16,597 & 132 &, 126 & \\
Total & 36,796 & 133 & & \\
\hline
\end{tabular}

Finalmente, a tabela 99 mostra os coeficientes do modelo de regressão. Ela apresenta, na coluna dos coeficientes não padronizados, os valores dos coeficientes (B) e dos erros padrões.

Tabela 99 - Coeficientes do modelo de regressão - Desempenho da Cadeia x Desempenho Individual

\begin{tabular}{lccccc}
\hline & \multicolumn{2}{c}{$\begin{array}{c}\text { Coeficientes não } \\
\text { padronizados }\end{array}$} & \multicolumn{2}{c}{$\begin{array}{c}\text { Coeficientes } \\
\text { padronizados }\end{array}$} \\
& $\mathrm{B}$ & Erro Padrão & Beta & $\mathrm{t}$ & Sig. \\
\hline \multicolumn{1}{c}{ Variável } & 1,244 &, 264 & & 4,711 &, 000 \\
Constante &, 698 &, 055 &, 741 & 12,675 &, 000 \\
\hline
\end{tabular}

No caso, o coeficiente da constante foi igual a 1,244 e o coeficiente do Desempenho Individual foi de 0,698. Assim, o modelo linear poderia ser apresentado como:

$$
\mathrm{Y}=1,244+0,698 \mathrm{X}
$$

Onde Y representa o Desempenho da Cadeia e X representa o Desempenho Individual. A interpretação do modelo indica que existe uma parte do Desempenho da Cadeia não associada ao Desempenho Individual e outra parte que é função do Desempenho Individual..

Assim, pode-se dizer que, existe uma relação forte entre Integração da Cadeia e Desempenho Individual, já que o coeficiente de determinação $\left(\mathrm{R}^{2}\right)$ é relativamente alto. 


\subsubsection{Normalidade dos resíduos}

Foram realizados os testes para verificar a normalidade dos resíduos. A tabela 100 mostra esses resultados. A normalidade foi verificada pelo teste de Kolmogorov-Smirnov (K-S) cujas hipóteses são:

- H0: a distribuição é normal;

- H1: a distribuição não é normal.

Tabela 100 - Normalidade dos Resíduos

\begin{tabular}{|c|c|c|c|}
\hline & $\begin{array}{c}\text { Desempenho da } \\
\text { cadeia } \\
\mathrm{x} \\
\text { Desempenho } \\
\text { individual } \\
\end{array}$ & $\begin{array}{c}\text { Desempenho da } \\
\text { cadeia } \\
\mathrm{x} \\
\text { Integração da Cadeia }\end{array}$ & $\begin{array}{c}\text { Desempenho Individual } \\
\text { x } \\
\text { Integração da Cadeia }\end{array}$ \\
\hline Kolmogorov-Smirnov Z & 1,027 & ,658 & 619 \\
\hline Significância. (bi-caudal) & ,242 & ,780 & ,838 \\
\hline
\end{tabular}

Assim, pode-se observar que nos três casos aceita-se a hipótese nula, o que significa que as distribuições são normais.

\subsubsection{Resumo das Análises de Regressão}

Para finalizar o tópico sobre as análises de regressão, foi elaborado um resumo das regressões realizadas. A tabela 101 a seguir apresenta os resultados dessas regressões.

Tabela 101 - Resumo das Análises de Regressão

\begin{tabular}{|c|c|c|c|c|c|}
\hline $\begin{array}{c}\text { Variável } \\
\text { Dependente }\end{array}$ & $\begin{array}{c}\text { Variável } \\
\text { independente }\end{array}$ & $\mathbf{R}^{2}$ & $\begin{array}{c}\text { Beta } \\
\text { padronizado }\end{array}$ & $\begin{array}{c}\text { p-valor do } \\
\text { teste } t\end{array}$ & $\begin{array}{l}\text { Normalidade } \\
\text { dos resíduos }\end{array}$ \\
\hline $\begin{array}{l}\text { Desempenho da } \\
\text { cadeia }\end{array}$ & $\begin{array}{l}\text { Desempenho } \\
\text { individual }\end{array}$ & $54,9 \%$ & 0,741 & 0,000 & Normal \\
\hline $\begin{array}{l}\text { Desempenho da } \\
\text { cadeia }\end{array}$ & $\begin{array}{l}\text { Integração da } \\
\text { cadeia }\end{array}$ & $22,8 \%$ & 0,478 & 0,000 & Normal \\
\hline $\begin{array}{l}\text { Desempenho } \\
\text { individual }\end{array}$ & $\begin{array}{l}\text { Integração da } \\
\text { cadeia }\end{array}$ & $19,1 \%$ & 0,437 & 0,000 & Normal \\
\hline
\end{tabular}




\subsubsection{Correlação}

Diante das análises expostas, se observa uma inter-relação entre os construtos do estudo, porém observa-se relação mais forte entre os desempenhos $(r=0,741)$, conforme apresenta a tabela 102 de correlações de Pearson a seguir.

Tabela 102 - Correlações de Pearson para os constructos

\begin{tabular}{|c|c|c|c|c|}
\hline & & $\begin{array}{c}\text { Integração da } \\
\text { cadeia }\end{array}$ & $\begin{array}{c}\text { Desempenho } \\
\text { Individual }\end{array}$ & $\begin{array}{c}\text { Desempenho da } \\
\text { Cadeia }\end{array}$ \\
\hline \multirow[t]{2}{*}{ Integração da cadeia } & Correlação de Pearson & 1 &, $437^{* *}$ &, $\mathbf{4 7 8} 8^{* *}$ \\
\hline & Sig. (bi-caudal) & &, 000 &, 000 \\
\hline \multirow[t]{2}{*}{ Desempenho Individual } & Correlação de Pearson &, $\mathbf{4 3 7} 7^{* *}$ & 1 &, $741^{* *}$ \\
\hline & Sig. (bi-caudal) &, 000 & &, 000 \\
\hline \multirow[t]{2}{*}{ Desempenho da Cadeia } & Correlação de Pearson &, $\mathbf{4 7 8} 8^{* *}$ &, $741^{* *}$ & 1 \\
\hline & Sig. (bi-caudal) & 000 &, 000 & \\
\hline
\end{tabular}

Após a realização das análises fatoriais e das análises de regressão, pode-se retomar as hipóteses do trabalho e discuti-las. As três hipóteses sugeridas são:

Hipótese 1 (H1): Existe uma relação positiva entre integração da cadeia de suprimentos e desempenho organizacional individual.

Hipótese 2 (H2): Existe uma relação positiva entre integração da cadeia de suprimentos e desempenho global da cadeia de suprimentos.

Hipótese 3 (H3): Existe uma relação positiva entre desempenho organizacional individual e desempenho global da cadeia de suprimentos.

Assim, a H1 foi confirmada, como mostrou a análise de regressão e o coeficiente de correlação de Pearson. Este resultado confirma os estudos dos seguintes autores: Tan et al. 
(1998), Carr e Pearson (1999), Frohlich e Westbrook (2001), Narasimhan e Das (2001), Frohlich e Westbrook (2002), Narasimhan e Kim (2002), Rosenzweig et al. (2003), Vickery et al. (2003), Agan (2005), Radhakrishnan (2005), Sahin e Robinson (2005), Zailani e Rajagopal (2005) e Sezen (2008). Por outro lado, este resultado foi contrário aos resultados dos autores Cousins e Menguc (2006) e Swink et al. (2007) que não confirmaram uma relação entre integração e desempenho individual.

Porém convêm notar algumas diferenças entre este presente estudo e os estudos acima citados:

- Enquanto que os autores citados utilizaram indicadores operacionais e/ou financeiros e/ou de mercado, o presente estudo utilizou uma abordagem balanceada adaptada ao gerenciamento da cadeia de suprimentos (proposta pelos autores Brewer e Speh (2000), Park et al. (2005) e Bhagwat e Sharma (2007)). Para a definição das variáveis balanceadas, foram utilizados os estudos dos seguintes autores: Tan et al. (1998), Carr e Pearson (1999), Frohlich e Westbrook (2001), Frohlich e Westbrook (2002), Narasimhan e Kim (2002), Rosenzweig et al. (2003), Vickery et al. (2003), Agan (2005), Cousins e Menguc (2006), Das et al. (2006), Swink et al. (2007) e Sezen (2008);

- No presente trabalho, após a realização das análises fatoriais, as variáveis iniciais do questionário (e conseqüentemente seus sub-constructos) deram origem a três novas variáveis, cada uma representando um constructo, sendo elas: "integração da cadeia", "desempenho individual” e "desempenho da cadeia". Assim, as análises de regressão foram realizadas com pares de constructos (regressão bivariada), e os sub-constructos (como por exemplo, perspectiva financeira e perspectiva de processos) não foram analisados isoladamente, como realizado nos estudos dos autores citados.

A hipótese $\mathrm{H} 2$ também foi confirmada, como mostrou a análise de regressão e o coeficiente de correlação de Pearson. Este resultado confirma os estudos dos autores Radhakrishnan (2005) e Zailani e Rajagopal (2005), porém os estudos destes autores foram qualitativos do tipo estudo de caso.

Finalmente a hipótese $\mathrm{H} 3$ também foi confirmada como demonstrou a análise de regressão e o coeficiente de correlação de Pearson. Este resultado vem de encontro com as afirmações dos autores Lambert e Pohlen (2001) e Fabbe-Costes e Jahre (2007), que afirmam que estudos 
verificando a relação entre desempenho individual e desempenho da cadeia deveriam ser realizados.

\subsection{Teste de Significância - Análises dos Setores}

A seguir, foi verificado se os constructos "integração da cadeia", "desempenho individual" e “desempenho da cadeia" são significativamente diferentes entre os setores pesquisados.

Para análise dos setores, utilizou-se as três novas variáveis criadas na análise de regressão ("integração da cadeia", "desempenho individual" e "desempenho da cadeia"), onde cada umas dessas variáveis foram obtidas pela média ponderada entre os fatores que os compõem, possuindo todos o mesmo peso e, por sua vez, cada um dos fatores de cada um dos constructos foi calculado pela média aritmética entre as variáveis que o compõem.

Também, como comentado na análise de regressão, embora as variáveis individualmente não apresentem distribuição normal, quando agrupadas, as novas variáveis geradas apresentam distribuição normal, o que torna viável a aplicação de testes paramétricos para diferença de médias. Esses testes são mais poderosos e recomendados em casos cuja distribuição normal pode ser observada.

A normalidade foi verificada pelo teste de Kolmogorov-Smirnov (K-S), como mostra a tabela 103, cujas hipóteses afirmam:

- H0: a distribuição é normal;

- H1: a distribuição não é normal.

Tabela 103 - Teste Kolmogorov-Smirnov (K-S) para os constructos - Análise dos setores

\begin{tabular}{lccc}
\hline & $\begin{array}{c}\text { Integração da } \\
\text { cadeia }\end{array}$ & $\begin{array}{c}\text { Desempenho } \\
\text { Individual }\end{array}$ & $\begin{array}{c}\text { Desempenho da } \\
\text { Cadeia }\end{array}$ \\
\hline Kolmogorov-Smirnov Z &, 914 &, 929 &, 614 \\
Significância (bi-caudal) & $\mathbf{3 7 4}$ & $\mathbf{, 3 5 4}$ & $\mathbf{, 8 4 6}$ \\
\hline
\end{tabular}

Assim, como pode-se ver na tabela 103, nos três casos aceita-se a hipótese nula, significando que as distribuições são normais. 
Dessa forma, aplicou-se a análise de variância, ANOVA, para verificar diferença significativa de média entre os setores de atuação das organizações em cada um dos construtos do modelo. A tabela 104 a seguir apresenta as freqüências de organizações em cada setor. Observa-se maior frequiência de respondentes no setor de Veículos e Peças $(24,4 \%)$, seguido do setor de Eletroeletrônica $(17,8 \%)$ e do setor Químico e Petroquímico (12,6\%). Como o setor de Comunicação e Gráfica possui apenas um caso, para que a aplicação da ANOVA seja viável, essa empresa foi excluída da base.

Tabela 104 - Setores de Atividade

\begin{tabular}{|c|c|c|c|c|c|}
\hline & & Freqüiência & Porcentagem & $\begin{array}{c}\text { Porcentagem } \\
\text { Válida } \\
\end{array}$ & $\begin{array}{c}\text { Porcentagem } \\
\text { Acumulada } \\
\end{array}$ \\
\hline \multirow[t]{13}{*}{ Válidos } & Química e Petroquímica & 17 & 12,6 & 12,7 & 12,7 \\
\hline & Metalurgia e Siderurgia & 11 & 8,1 & 8,2 & 20,9 \\
\hline & Têxtil, couro e vestuário & 5 & 3,7 & 3,7 & 24,6 \\
\hline & Mecânica & 11 & 8,1 & 8,2 & 32,8 \\
\hline & Eletroeletrônica & 24 & 17,8 & 17,9 & 50,7 \\
\hline & Construção e engenharia & 3 & 2,2 & 2,2 & 53,0 \\
\hline & Farmaceutica e cosméticos & 4 & 3,0 & 3,0 & 56,0 \\
\hline & Veículos e peças & 33 & 24,4 & 24,6 & 80,6 \\
\hline & $\begin{array}{l}\text { Material de construção e } \\
\text { decoração }\end{array}$ & 9 & 6,7 & 6,7 & 87,3 \\
\hline & Alimentos & 14 & 10,4 & 10,4 & 97,8 \\
\hline & Comunicação e gráfica & 1 &, 7 &, 7 & $\mathbf{9 8 , 5}$ \\
\hline & Bebidas e fumo & 2 & 1,5 & 1,5 & 100,0 \\
\hline & Total & 134 & 99,3 & 100,0 & \\
\hline Faltantes & & 1 &, 7 & & \\
\hline Total & & 135 & 100,0 & & \\
\hline
\end{tabular}

Inicialmente são apresentadas a estatísticas descritivas dos setores para os construtos do modelo. Observa-se médias entre 4 e 5,5 para todos os setores nos três construtos e homogeneidade das variáveis, ou seja, os escores atribuídos pelas empresas do setor são similares, o que leva a Coeficientes de Variação ${ }^{1}$ de baixa e média dispersão, segundo Martins e Theóphilo (2009). A tabela 105 mostra esses resultados.

\footnotetext{
${ }^{1}$ Coeficiente de variação: $\mathrm{cv}=\left(\right.$ desvio-padrão amostral/média amostral) ${ }^{\star} 100$
} 
Tabela 105 - Estatística Descritiva - Setores de Atividade

\begin{tabular}{|c|c|c|c|c|}
\hline \multicolumn{2}{|c|}{ Setor } & \multirow{2}{*}{$\begin{array}{c}\begin{array}{c}\text { Integração } \\
\text { da Cadeia }\end{array} \\
4,1559\end{array}$} & \multirow{2}{*}{$\begin{array}{c}\begin{array}{c}\text { Desempenho } \\
\text { Individual }\end{array} \\
4,6480\end{array}$} & \multirow{2}{*}{$\begin{array}{c}\begin{array}{c}\text { Desempenho } \\
\text { da Cadeia }\end{array} \\
4,5925\end{array}$} \\
\hline \multirow{3}{*}{$\begin{array}{l}\text { Química e } \\
\text { Petroquímica }\end{array}$} & Média & & & \\
\hline & Desvio-padrão & 1,16780 & ,69337 &, 53555 \\
\hline & Coeficiente de variação & $28 \%$ & $15 \%$ & $12 \%$ \\
\hline \multirow{3}{*}{$\begin{array}{l}\text { Metalurgia e } \\
\text { Siderurgia }\end{array}$} & Média & 4,8785 & 4,8664 & 4,6723 \\
\hline & Desvio-padrão & ,71731 & ,22396 & ,36566 \\
\hline & Coeficiente de variação & $15 \%$ & $5 \%$ & $8 \%$ \\
\hline \multirow{3}{*}{$\begin{array}{l}\text { Têxtil, couro e } \\
\text { vestuário }\end{array}$} & Média & 3,7000 & 4,5408 & 4,2146 \\
\hline & Desvio-padrão & 1,18457 & ,38786 & ,51442 \\
\hline & Coeficiente de variação & $32 \%$ & $9 \%$ & $12 \%$ \\
\hline \multirow{3}{*}{ Mecânica } & Média & 4,2131 & 4,8514 & 4,5568 \\
\hline & Desvio-padrão & ,90979 &, 57763 & ,46562 \\
\hline & Coeficiente de variação & $22 \%$ & $12 \%$ & $10 \%$ \\
\hline \multirow{3}{*}{ Eletroeletrônica } & Média & 4,3318 & 4,7011 & 4,5009 \\
\hline & Desvio-padrão & ,73222 & ,55349 & ,59743 \\
\hline & Coeficiente de variação & $17 \%$ & $12 \%$ & $13 \%$ \\
\hline \multirow{3}{*}{$\begin{array}{l}\text { Construção e } \\
\text { engenharia }\end{array}$} & Média & 3,9463 & 4,5611 & 4,4306 \\
\hline & Desvio-padrão & 1,48750 & ,32160 & ,47236 \\
\hline & Coeficiente de variação & $38 \%$ & $7 \%$ & $11 \%$ \\
\hline \multirow{3}{*}{$\begin{array}{l}\text { Farmacêutica e } \\
\text { cosméticos }\end{array}$} & Média & 3,8417 & 4,6375 & 4,5495 \\
\hline & Desvio-padrão & 1,50540 & ,59558 & ,35144 \\
\hline & Coeficiente de variação & $39 \%$ & $13 \%$ & $8 \%$ \\
\hline \multirow{3}{*}{ Veículos e peças } & Média & 4,9136 & 4,8399 & 4,5960 \\
\hline & Desvio-padrão & 1,04348 &, 56531 & ,48100 \\
\hline & Coeficiente de variação & $21 \%$ & $12 \%$ & $10 \%$ \\
\hline \multirow{3}{*}{$\begin{array}{l}\text { Material de } \\
\text { construção e } \\
\text { decoração }\end{array}$} & Média & 4,4580 & 5,0287 & 5,0150 \\
\hline & Desvio-padrão & 1,10249 &, 57647 &, 52849 \\
\hline & Coeficiente de variação & $25 \%$ & $11 \%$ & $11 \%$ \\
\hline \multirow{3}{*}{ Alimentos } & Média & 3,5728 & 4,5739 & 4,2902 \\
\hline & Desvio-padrão & ,89195 & ,62169 &, 57302 \\
\hline & Coeficiente de variação & $25 \%$ & $14 \%$ & $13 \%$ \\
\hline \multirow{3}{*}{ Bebidas e fuma } & Média & 4,3819 & 5,3958 & 5,2135 \\
\hline & Desvio-padrão & ,02946 & 08053 & 00737 \\
\hline & Coeficiente de variação & $1 \%$ & $1 \%$ & $0 \%$ \\
\hline \multirow{3}{*}{ Total } & Média & 4,3713 & 4,7630 & 4,5674 \\
\hline & Desvio-padrão & 1,05122 & ,56037 &, 52761 \\
\hline & Coeficiente de variação & $24 \%$ & $12 \%$ & $12 \%$ \\
\hline
\end{tabular}


A análise de variância será aplicada com objetivo de identificar a ocorrência de diferença de escore entre os setores nos construtos estudados. Para aplicação da análise de variância inicialmente é necessário avaliar o pressuposto de homogeneidade de variâncias entre os grupos. Este teste possui as seguintes hipóteses:

- H0: as variâncias entre os grupos são iguais;

- H1: as variâncias entre os grupos não são iguais.

Considerando-se nível de significância de 5\%, observa-se pela tabela 106 que as variâncias são homogêneas (a hipótese nula não pode ser rejeitada), o que torna viável a aplicação do teste.

Tabela 106 - Teste de Homogeneidade das Variâncias

\begin{tabular}{lcccc}
\hline & Estatística Levene & g.1.1 & g.1.2 & Sig. \\
\hline Desempenho da Cadeia &, 987 & 10 & 122 & $\mathbf{, 4 5 8}$ \\
Desempenho Individual & 1,795 & 10 & 122 & $\mathbf{, 0 6 8}$ \\
Integração da Cadeia & 1,015 & 10 & 122 & $\mathbf{4 3 5}$ \\
\hline
\end{tabular}

Assim, foi realizada a análise de variância, que tem como objetivo verificar se há pelo menos um par de grupos com médias significativamente diferentes. As hipóteses são:

- H0: os grupos possuem médias iguais;

- H1: há pelo menos um par de grupos com médias significativamente diferentes.

Assim, pela tabela 107 observa-se que há diferença de médias apenas para o constructo “integração da cadeia de suprimentos" (há rejeição da hipótese nula ao nível de 5\% de significância). 
Tabela 107 - Análise de Variâncias - Setores

\begin{tabular}{|c|c|c|c|c|c|c|}
\hline & & $\begin{array}{l}\text { Soma dos } \\
\text { Quadrados }\end{array}$ & g.1. & $\begin{array}{l}\text { Média dos } \\
\text { Quadrados }\end{array}$ & $\mathrm{F}$ & Sig. \\
\hline \multirow[t]{3}{*}{ Desempenho da Cadeia } & Entre os grupos & 4,661 & 10 & ,466 & 1,772 & ,073 \\
\hline & Dentro dos grupos & 32,085 & 122 & ,263 & & \\
\hline & Total & 36,746 & 132 & & & \\
\hline \multirow[t]{3}{*}{ Desempenho Individual } & Entre os grupos & 3,085 & 10 & ,308 & ,981 & ,464 \\
\hline & Dentro dos grupos & 38,365 & 122 & ,314 & & \\
\hline & Total & 41,450 & 132 & & & \\
\hline \multirow[t]{3}{*}{ Integração da Cadeia } & Entre os grupos & 26,546 & 10 & 2,655 & 2,714 & ,005 \\
\hline & Dentro dos grupos & 119,321 & 122 & ,978 & & \\
\hline & Total & 145,867 & 132 & & & \\
\hline
\end{tabular}

Com isso, utilizando o constructo "integração da cadeia de suprimentos", foi realizado o teste Post Hoc LSD ao nível de significância de 5\% a fim de verificar quais grupos possuem diferença de média. As hipóteses para esse teste, para cada par de setor analisado, são:

- H0: a média do setor 1 é igual a média do setor 2;

- H1: a média do setor 1 é diferente da média do setor 2.

Tabela 108 mostra os resultados.

Tabela 108 - Teste Post Hoc - Setores (variável dependente - Integração da Cadeia)

\begin{tabular}{|c|c|c|c|c|}
\hline Setor & Setor & $\begin{array}{l}\text { Diferença } \\
\text { Média }\end{array}$ & $\begin{array}{c}\text { Erro } \\
\text { Padrão }\end{array}$ & Sig. \\
\hline \multirow[t]{10}{*}{ Química e Petroquímica } & Metalurgia e Siderurgia &,- 72265 & ,38268 & ,061 \\
\hline & Têxtil, couro e vestuário & ,45588 &, 50313 & ,367 \\
\hline & Mecânica &,- 05725 & ,38268 &, 881 \\
\hline & Eletroeletrônica &,- 17595 & ,31350 &, 576 \\
\hline & Construção e engenharia & ,20959 & ,61931 &, 736 \\
\hline & Farmacêutica e cosméticos & ,31422 &, 54958 & ,569 \\
\hline & Veículos e peças &,$- 75767^{*}$ & ,29524 &, 011 \\
\hline & Material de construção e decoração &,- 30214 & ,40768 & ,460 \\
\hline & Alimentos &, 58306 & ,35692 & , 105 \\
\hline & Bebidas e fumo &,- 22606 & ,73929 &, 760 \\
\hline Metalurgia e Siderurgia & Química e Petroquímica & ,72265 & ,38268 & ,061 \\
\hline
\end{tabular}




\begin{tabular}{|c|c|c|c|c|}
\hline \multirow[t]{10}{*}{ Setor } & Setor & $\begin{array}{l}\text { Diferença } \\
\text { Média }\end{array}$ & $\begin{array}{c}\text { Erro } \\
\text { Padrão }\end{array}$ & Sig. \\
\hline & Têxtil, couro e vestuário & $1,17854^{*}$ &, 53341 &, 029 \\
\hline & Mecânica &, 66540 & ,42169 &, 117 \\
\hline & Eletroeletrônica &, 54671 & ,36009 &, 132 \\
\hline & Construção e engenharia & ,93224 &, 64415 &, 150 \\
\hline & Farmacêutica e cosméticos & 1,03687 & ,57743 & 075 \\
\hline & Veículos e peças &,- 03502 & ,34431 & 919 \\
\hline & Material de construção e decoração & ,42051 &, 44450 & ,346 \\
\hline & Alimentos & $1,30572^{*}$ & ,39846 & ,001 \\
\hline & Bebidas e fumo & ,49659 & ,76022 &, 515 \\
\hline \multirow[t]{10}{*}{ Têxtil, couro e vestuário } & Química e Petroquímica &,- 45588 &, 50313 & ,367 \\
\hline & Metalurgia e Siderurgia & $-1,17854^{*}$ &, 53341 & ,029 \\
\hline & Mecânica &,- 51313 &, 53341 & ,338 \\
\hline & Eletroeletrônica &,- 63183 & ,48617 & ,196 \\
\hline & Construção e engenharia &,- 24630 & ,72223 & ,734 \\
\hline & Farmacêutica e cosméticos &,- 14167 & ,66341 &, 831 \\
\hline & Veículos e peças & $-1,21355^{*}$ & ,47460 & ,012 \\
\hline & Material de construção e decoração &,- 75802 &, 55162 &, 172 \\
\hline & Alimentos &, 12718 &, 51524 &, 805 \\
\hline & Bebidas e fumo &,- 68194 &, 82742 & 411 \\
\hline \multirow[t]{10}{*}{ Mecânica } & Química e Petroquímica &, 05725 & ,38268 & ,881 \\
\hline & Metalurgia e Siderurgia &,- 66540 & ,42169 &, 117 \\
\hline & Têxtil, couro e vestuário &, 51313 &, 53341 & ,338 \\
\hline & Eletroeletrônica &,- 11870 & ,36009 &, 742 \\
\hline & Construção e engenharia & ,26684 & ,64415 & 679 \\
\hline & Farmacêutica e cosméticos & ,37146 &, 57743 &, 521 \\
\hline & Veículos e peças &,$- 70042^{*}$ &, 34431 & ,044 \\
\hline & Material de construção e decoração &,- 24489 & ,44450 &, 583 \\
\hline & Alimentos & ,64031 & ,39846 &, 111 \\
\hline & Bebidas e fumo &,- 16881 & ,76022 &, 825 \\
\hline \multirow[t]{9}{*}{ Eletroeletrônica } & Química e Petroquímica &, 17595 & ,31350 & 576 \\
\hline & Metalurgia e Siderurgia &,- 54671 & ,36009 &, 132 \\
\hline & Têxtil, couro e vestuário & ,63183 & ,48617 &, 196 \\
\hline & Mecânica &, 11870 & ,36009 & ,742 \\
\hline & Construção e engenharia & ,38553 & ,60561 &, 526 \\
\hline & Farmacêutica e cosméticos & ,49016 &, 53410 & ,361 \\
\hline & Veículos e peças &,$- 58172^{*}$ & ,26531 &, 030 \\
\hline & Material de construção e decoração &,- 12620 & ,38655 & ,745 \\
\hline & Alimentos &, $75901^{*}$ & ,33258 &, 024 \\
\hline
\end{tabular}




\begin{tabular}{|c|c|c|c|c|}
\hline \multirow[t]{2}{*}{ Setor } & \multirow[b]{2}{*}{ Bebidas e fumo } & \multirow{2}{*}{$\begin{array}{c}\begin{array}{c}\text { Diferença } \\
\text { Média }\end{array} \\
-, 05012\end{array}$} & \multirow{2}{*}{$\begin{array}{c}\text { Erro } \\
\text { Padrão }\end{array}$} & \multirow{2}{*}{$\begin{array}{l}\text { Sig. } \\
, 945\end{array}$} \\
\hline & & & & \\
\hline \multirow[t]{10}{*}{ Construção e engenharia } & Química e Petroquímica &,- 20959 & ,61931 & ,736 \\
\hline & Metalurgia e Siderurgia &,- 93224 &, 64415 &, 150 \\
\hline & Têxtil, couro e vestuário & ,24630 &, 72223 & ,734 \\
\hline & Mecânica &,- 26684 &, 64415 & ,679 \\
\hline & Eletroeletrônica &,- 38553 &, 60561 &, 526 \\
\hline & Farmacêutica e cosméticos &, 10463 &, 75533 &, 890 \\
\hline & Veículos e peças &,- 96726 & ,59637 &, 107 \\
\hline & Material de construção e decoração &,- 51173 & ,65931 & ,439 \\
\hline & Alimentos &, 37348 & ,62919 &, 554 \\
\hline & Bebidas e fumo &,- 43565 & ,90279 &, 630 \\
\hline \multirow{10}{*}{$\begin{array}{l}\text { Farmacêutica e } \\
\text { cosméticos }\end{array}$} & Química e Petroquímica &,- 31422 &, 54958 & ,569 \\
\hline & Metalurgia e Siderurgia & $-1,03687$ &, 57743 & ,075 \\
\hline & Têxtil, couro e vestuário &, 14167 &, 66341 & ,831 \\
\hline & Mecânica &,- 37146 &, 57743 &, 521 \\
\hline & Eletroeletrônica &,- 49016 &, 53410 &, 361 \\
\hline & Construção e engenharia &,- 10463 &, 75533 &, 890 \\
\hline & Veículos e peças & $-1,07189^{*}$ & ,52359 & ,043 \\
\hline & Material de construção e decoração &,- 61636 &, 59429 & ,302 \\
\hline & Alimentos & ,26885 & ,56069 & ,632 \\
\hline & Bebidas e fumo &,- 54028 &, 85646 &, 529 \\
\hline \multirow[t]{10}{*}{ Veículos e peças } & Química e Petroquímica &, $75767^{*}$ & ,29524 & ,011 \\
\hline & Metalurgia e Siderurgia & ,03502 &, 34431 & ,919 \\
\hline & Têxtil, couro e vestuário & $1,21355^{*}$ & ,47460 & ,012 \\
\hline & Mecânica &, $70042^{*}$ & ,34431 & ,044 \\
\hline & Eletroeletrônica &, $58172^{*}$ & ,26531 &, 030 \\
\hline & Construção e engenharia & ,96726 & ,59637 & ,107 \\
\hline & Farmacêutica e cosméticos & $1,07189^{*}$ & ,52359 & ,043 \\
\hline & Material de construção e decoração & ,45553 & ,37190 & ,223 \\
\hline & Alimentos & $1,34073^{*}$ & ,31543 &, 000 \\
\hline & Bebidas e fumo &, 53161 &, 72018 & ,462 \\
\hline \multirow{7}{*}{$\begin{array}{l}\text { Material de construção e } \\
\text { decoração }\end{array}$} & Química e Petroquímica &, 30214 & ,40768 & 460 \\
\hline & Metalurgia e Siderurgia &,- 42051 &, 44450 & ,346 \\
\hline & Têxtil, couro e vestuário & ,75802 &, 55162 &, 172 \\
\hline & Mecânica & ,24489 &, 44450 &, 583 \\
\hline & Eletroeletrônica &, 12620 & ,38655 &, 745 \\
\hline & Construção e engenharia &, 51173 & ,65931 & ,439 \\
\hline & Farmacêutica e cosméticos & ,61636 & ,59429 & ,302 \\
\hline
\end{tabular}




\begin{tabular}{|c|c|c|c|c|}
\hline \multirow[t]{4}{*}{ Setor } & Setor & $\begin{array}{l}\text { Diferença } \\
\text { Média }\end{array}$ & $\begin{array}{c}\text { Erro } \\
\text { Padrão }\end{array}$ & Sig. \\
\hline & Veículos e peças &,- 45553 & ,37190 & ,223 \\
\hline & Alimentos &, $88521^{*}$ & ,42253 & ,038 \\
\hline & Bebidas e fumo & ,07608 &, 77311 & ,922 \\
\hline \multirow[t]{10}{*}{ Alimentos } & Química e Petroquímica &,- 58306 &, 35692 &, 105 \\
\hline & Metalurgia e Siderurgia & $-1,30572^{*}$ & ,39846 & ,001 \\
\hline & Têxtil, couro e vestuário &,- 12718 &, 51524 &, 805 \\
\hline & Mecânica &,- 64031 & ,39846 &, 111 \\
\hline & Eletroeletrônica &,$- 75901^{*}$ & ,33258 &, 024 \\
\hline & Construção e engenharia &,- 37348 & ,62919 &, 554 \\
\hline & Farmacêutica e cosméticos &,- 26885 & ,56069 & ,632 \\
\hline & Veículos e peças & $-1,34073^{*}$ & ,31543 &, 000 \\
\hline & Material de construção e decoração &,$- 88521^{*}$ & ,42253 & ,038 \\
\hline & Bebidas e fumo &,- 80913 &, 74758 & ,281 \\
\hline \multirow[t]{10}{*}{ Bebidas e fumo } & Química e Petroquímica & ,22606 &, 73929 &, 760 \\
\hline & Metalurgia e Siderurgia &,- 49659 &, 76022 &, 515 \\
\hline & Têxtil, couro e vestuário & ,68194 &, 82742 & ,411 \\
\hline & Mecânica &, 16881 &, 76022 &, 825 \\
\hline & Eletroeletrônica & ,05012 & ,72785 & ,945 \\
\hline & Construção e engenharia & ,43565 & ,90279 & ,630 \\
\hline & Farmacêutica e cosméticos &, 54028 &, 85646 &, 529 \\
\hline & Veículos e peças &,- 53161 &, 72018 & ,462 \\
\hline & Material de construção e decoração &,- 07608 &, 77311 & ,922 \\
\hline & Alimentos & ,80913 &, 74758 & ,281 \\
\hline
\end{tabular}

Observaram-se os seguintes pares de setores diferentes:

- "Veículos e peças" possui uma maior integração que "Química e petroquímica"

- "Veículos e peças" possui uma maior integração que "Têxtil, couro e vestuário"

- "Veículos e peças" possui uma maior integração que "Mecânica"

- "Veículos e peças" possui uma maior integração que "Eletroeletrônico"

- "Veículos e peças" possui uma maior integração que "Farmacêutico e cosméticos"

- "Veículos e peças" possui uma maior integração que "Alimentos"

- "Metalurgia e siderurgia" possui uma maior integração que "Têxtil, couro e vestuário"

- "Metalurgia e siderurgia" possui uma maior integração que Alimentos"

- "Eletroeletrônica" possui uma maior integração que "Alimentos"

- "Material de construção e decoração" possui uma maior integração que "Alimentos" 


\subsection{Modelagem de Equações Estruturais}

Aplicou-se a modelagem de equações estruturais para verificar a existência de relação entre os construtos: integração da cadeia, desempenho individual e desempenho da cadeia. Utilizou-se a modelagem PLS (software Smart PLS), pois esta é mais flexível em relação ao tamanho da amostra e à normalidade das variáveis.

A aderência do modelo foi avaliada de acordo com as seguintes medidas:

- Confiabilidade interna: verifica se os indicadores individuais (variáveis) mensuram um mesmo construto. Para tanto utilizou-se o coeficiente Alfa de Cronbach, que deve ser superior a 0,6 e a Confiabilidade composta, que também deve ser maior que 0,6.

- Confiabilidade convergente: representa a correlação entre medidas de um mesmo construto. Foi avaliada pela AVE (variância média extraída) e deve ser superior a 0,5.

- Validade discriminante: verifica o grau em que dois construtos são diferentes entre si, ou seja, mensuram conceitos distintos. É medida pela comparação entre a raiz quadrada da AVE e as correlações entre as variáveis latentes ou pela avaliação das cargas crossloadings, que devem ser altas em apenas um construto.

O estudo apresenta variáveis de primeira, segunda e terceira ordem, conforme apresenta o quadro 28 a seguir.

Quadro 28 - Modelagem de Equações Estruturais - Variáveis e respectivos níveis

\begin{tabular}{|l|l|l|}
\hline $1^{\text {a}}$. Ordem & - Integração externa com fornecedores - compartilhamento de informações \\
- Integração externa com fornecedores - participação no negócio \\
- Desempenho individual dos processos empresariais - entrega \\
- Desempenho individual dos processos empresariais - eficiência \\
- Desempenho individual dos processos empresariais - flexibilidade \\
- Desempenho individual perspectiva financeira entradas; \\
- Desempenho individual perspectiva financeira - saídas \\
- Desempenho da cadeia processos empresariais - entrega \\
- Desempenho da cadeia processos empresariais - ciclo de produção \\
- Desempenho da cadeia perspectiva financeira - indicadores financeiros \\
- Desempenho da cadeia perspectiva financeira - custos \\
- Integração interna \\
- Integração externa com clientes \\
- Desempenho individual - perspectiva do cliente \\
- Desempenho individual - perspectiva da inovação \\
• Desempenho da cadeia - perspectiva do cliente \\
\end{tabular}




\begin{tabular}{|l|l|}
\hline $2^{\text {a }}$ Ordem & - Integração externa com fornecedores \\
& - Desempenho individual - perspectiva dos processos empresariais \\
& - Desempenho individual - perspectiva financeira \\
& - Desempenho da cadeia - perspectiva dos processos empresariais \\
\hline $3^{\text {a. } \text { Ordem }}$ & $\begin{array}{l}\text { - Integração da cadeia de suprimentos } \\
\end{array}$ \\
& - Desempenho individual \\
\hline
\end{tabular}

O modelo apresentado na ilustração 44 a seguir mostra nas esferas os valores dos Coeficientes de Determinação $\left(\mathrm{R}^{2}\right)$ e nas setas, os valores de Beta, que indicam quais variáveis possuem maior influência no modelo de regressão.

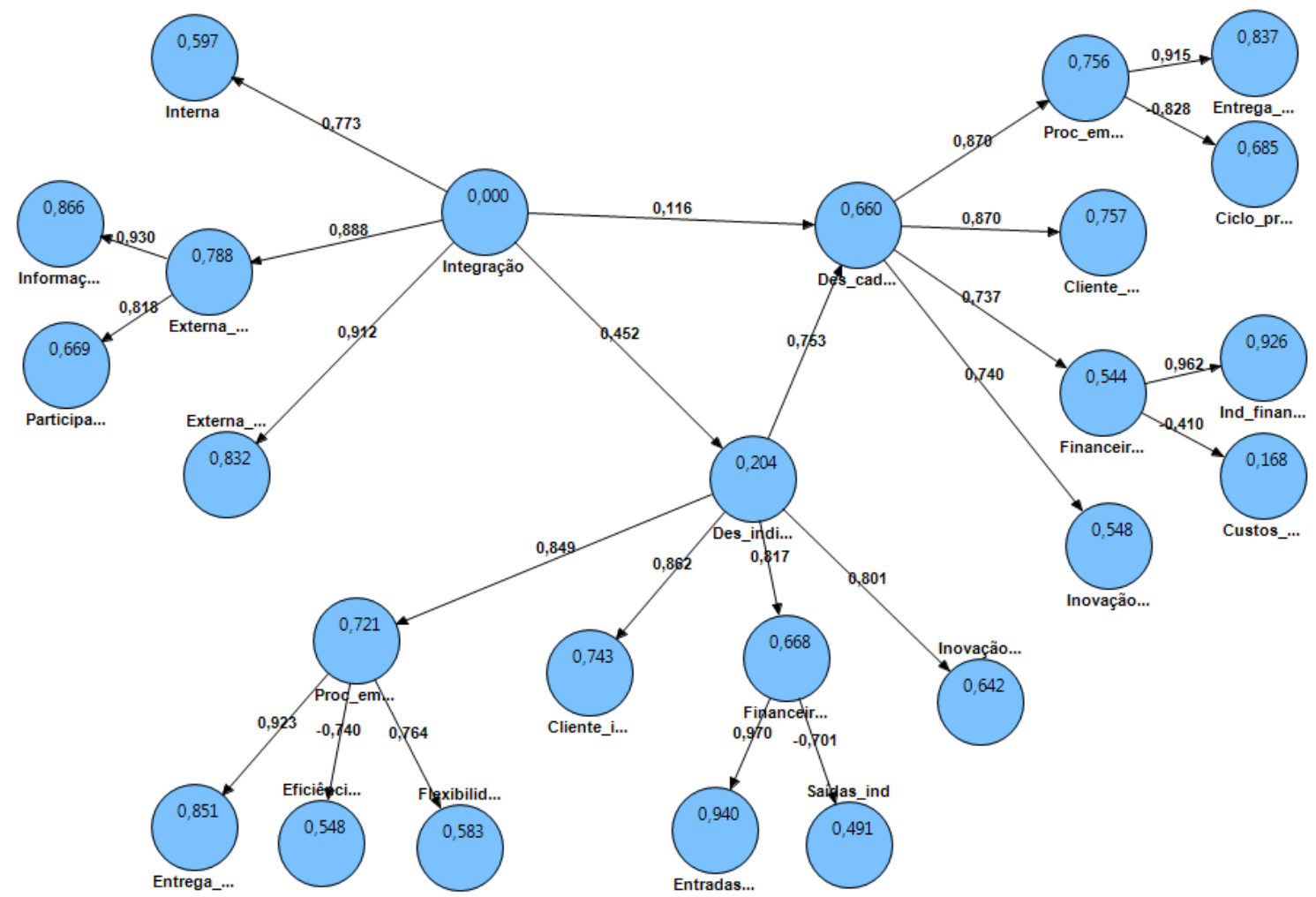

Ilustração 44 - Coeficientes de Determinação e Betas para o Modelo Inicial

Pode-se observar que para o construto integração observam-se escores Beta próximos, porém há maior influência da integração externa com clientes $(B=0,912)$, seguida pela integração com fornecedores $(B=0,888)$, e por fim pela integração interna $(B=0,773)$. 
Já para o construto desempenho individual os escores Beta também possuem valores próximos, sendo a maior influência advinda da perspectiva do cliente $(B=0,862)$.

Para o construto desempenho da cadeia, os valores de Beta também são próximos, sendo as maiores influências da perspectiva dos processos empresariais $(B=0,870)$ e da perspectiva dos clientes $(\mathrm{B}=0,870)$.

A fim de se verificar a significância das relações, realizou-se o Bootstrapping que verifica se cada relação é estatisticamente significante (estatística t). Ao nível de significância de 5\%, são consideradas significantes as relações cujo valor da estatística t tiver escore superior a 1,96. A ilustração 45 mostra os resultados.

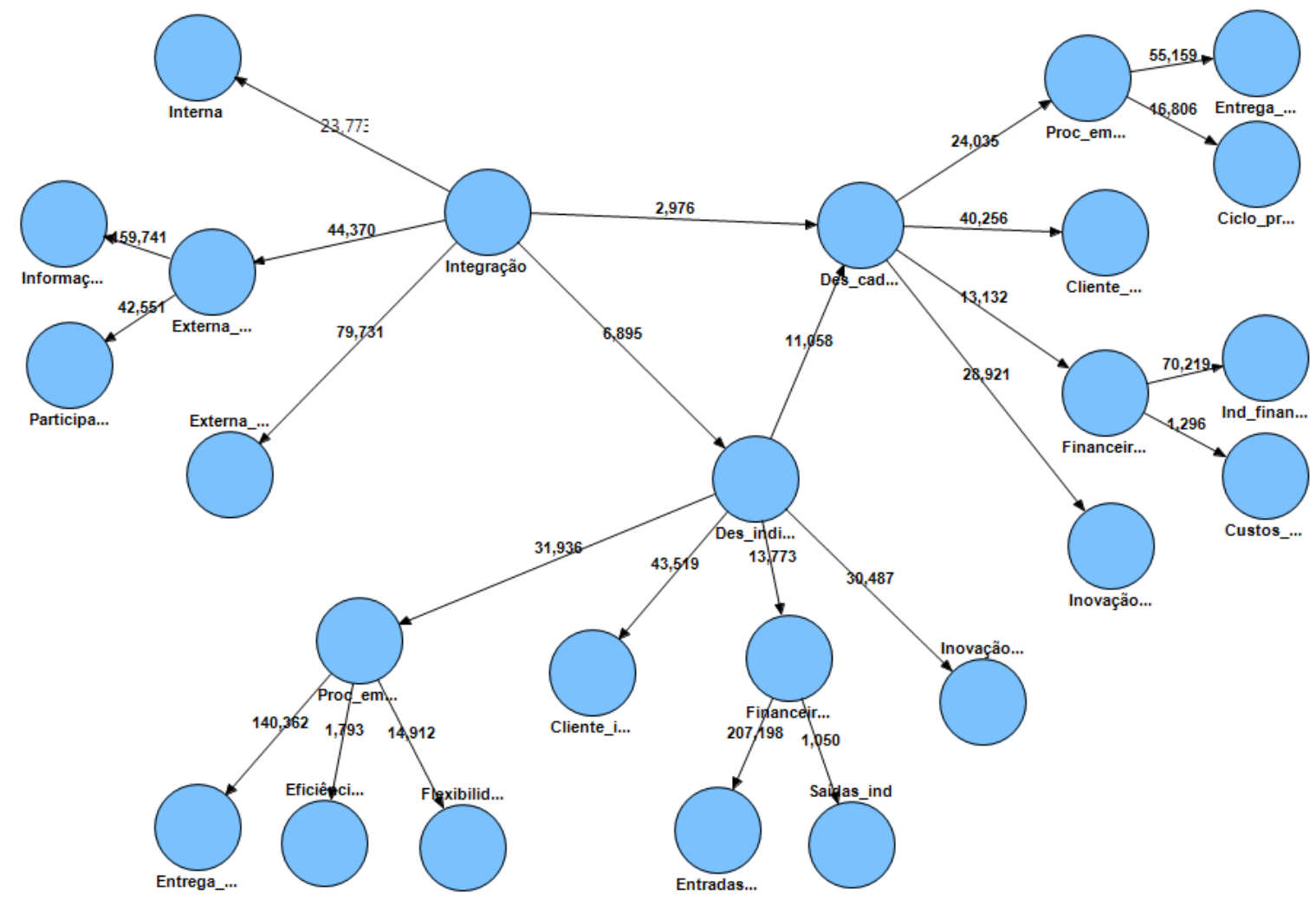

\section{Ilustração 45 - Estatística t para o Modelo Inicial}

Pode-se notar algumas relações não significantes:

- Desempenho individual - processos empresariais - eficiência $(t=1,793)$

- Desempenho individual - perspectiva financeira - saídas $(\mathrm{t}=1,050)$

- Desempenho da cadeia - perspectiva financeira - custos $(t=1,296)$ 
Assim, foram retiradas as relações não significantes e o modelo foi reaplicado, obtendo-se as resultados apresentados a seguir. O modelo representado pela ilustração 46 abaixo apresenta os valores de Beta e de $\mathrm{R}^{2}$.

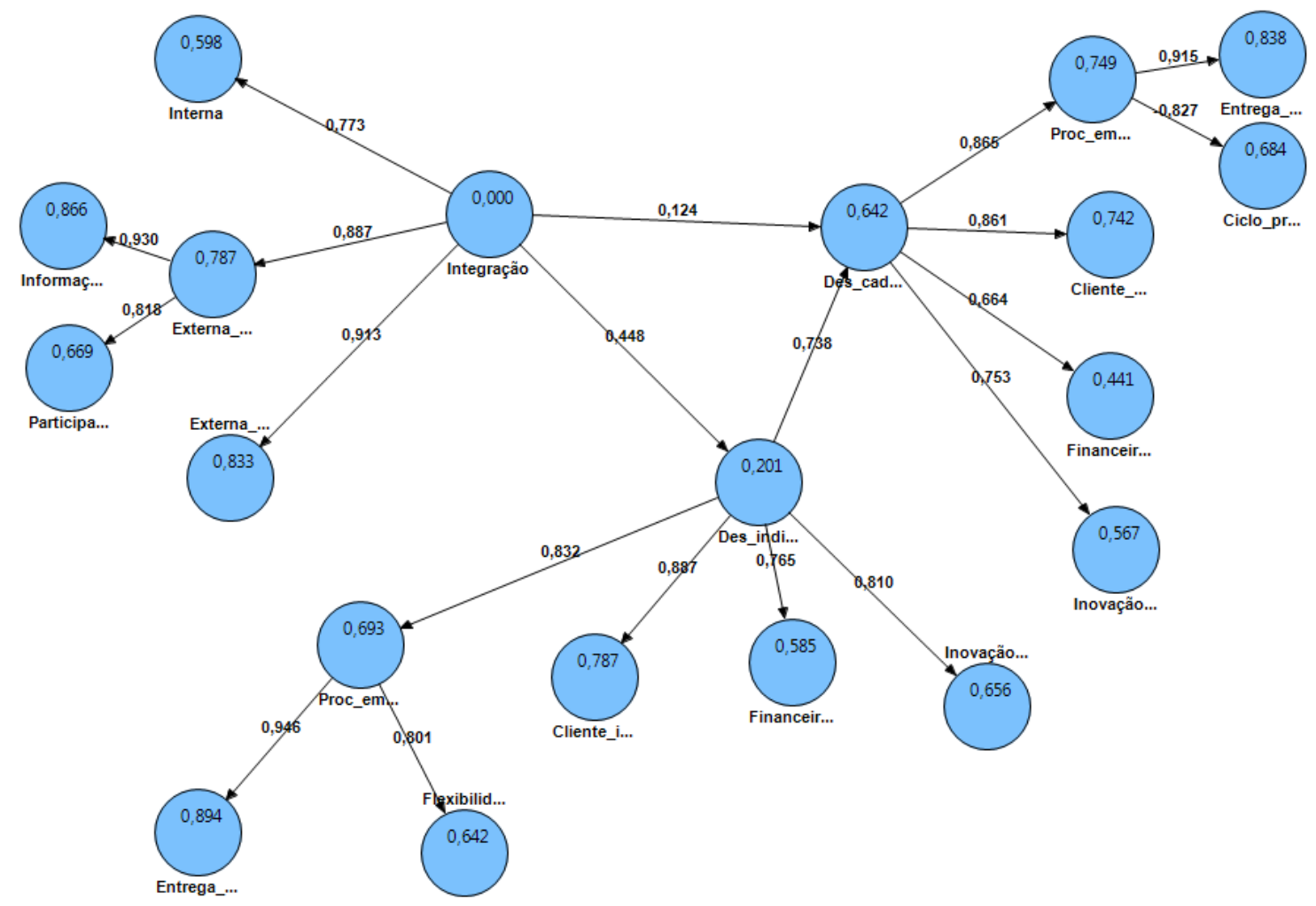

Ilustração 46 - Coeficientes de Determinação e Betas para o Modelo Final

Após a exclusão das relações não significantes, o modelo final apresenta todas as relações significantes, ao nível de 5\%, como pode-se observar na ilustração 47. 


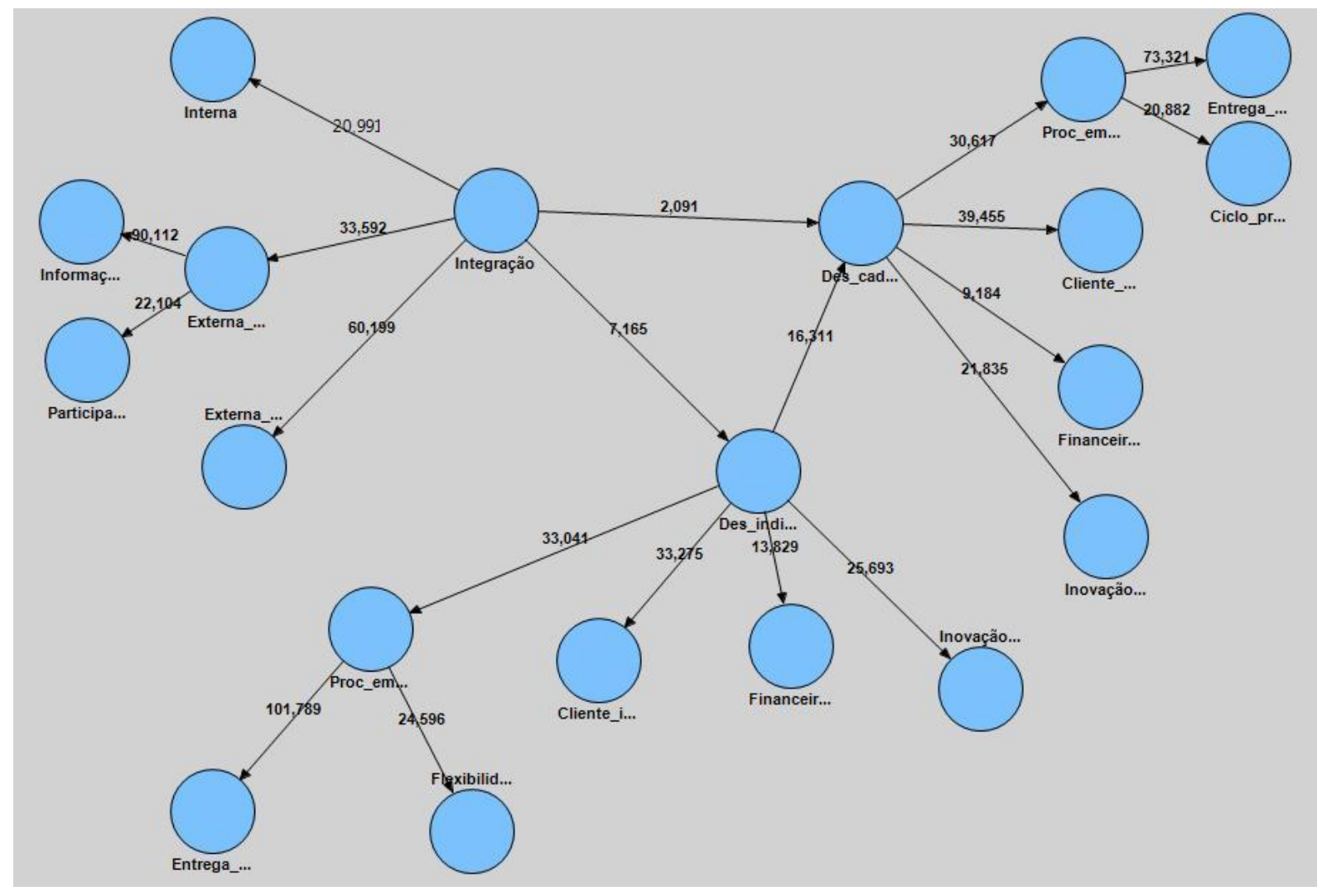

Ilustração 47 - Estatística t para o Modelo Final

O quadro 29 apresenta as medidas de adequação do modelo. Apesar de os indicadores em destaque apresentarem valores ligeiramente abaixo do recomendado, o modelo foi mantido devido à significância das relações verificadas. De forma geral o modelo apresenta bom ajuste em termos de variância explicada, confiabilidade e validade discriminante.

Quadro 29 - Modelagem de Equações Estruturais - Medidas de adequação do modelo

\begin{tabular}{|c|r|r|r|r|r|}
\hline & \multicolumn{1}{|c|}{ AVE } & \multicolumn{1}{c}{$\begin{array}{c}\text { Confiabilidade } \\
\text { Composta }\end{array}$} & \multicolumn{1}{c|}{$\mathbf{R}^{\mathbf{2}}$} & $\begin{array}{c}\text { Alfa de } \\
\text { Cronbach }\end{array}$ & Comunalidades \\
\hline Ciclo_produc_cad & 0,8143 & 0,9294 & 0,6838 & 0,886 & 0,8143 \\
\hline Cliente_cad & 0,7146 & 0,9091 & 0,7419 & 0,8665 & 0,7146 \\
\hline Cliente_ind & 0,6561 & 0,8838 & 0,7871 & 0,8242 & 0,6561 \\
\hline Des_cadeia & 0,6245 & 0,8680 & 0,6417 & 0,8079 & $\mathbf{0 , 4 5 6 9}$ \\
\hline Des_individual & 0,6532 & 0,9036 & 0,2008 & 0,9189 & $\mathbf{0 , 4 3 3 3}$ \\
\hline Entrega_cad & 0,803 & 0,9421 & 0,838 & 0,9171 & 0,803 \\
\hline Entrega_ind & 0,7552 & 0,9247 & 0,8942 & 0,8904 & 0,7552 \\
\hline Externa_clientes & 0,5612 & 0,9106 & 0,8327 & 0,8876 & 0,5612 \\
\hline Externa_forn & 0,7672 & 0,8678 & 0,7872 & 0,8659 & $\mathbf{0 , 4 3 3 6}$ \\
\hline Financeira_ind & 0,713 & 0,9243 & 0,5854 & 0,8937 & 0,713 \\
\hline Financeiro_cad & 0,8477 & 0,9569 & 0,4406 & 0,9395 & 0,8477 \\
\hline Flexibilidade_ind & 0,5906 & 0,8012 & 0,6421 & 0,636 & 0,5906 \\
\hline Informações & 0,5874 & 0,8944 & 0,8656 & 0,8575 & 0,5874 \\
\hline
\end{tabular}




\begin{tabular}{|c|r|r|r|r|r|}
\hline & AVE & $\begin{array}{c}\text { Confiabilidade } \\
\text { Composta }\end{array}$ & \multicolumn{1}{|c|}{$\mathbf{R}^{\mathbf{2}}$} & $\begin{array}{c}\text { Alfa de } \\
\text { Cronbach }\end{array}$ & Comunalidades \\
\hline Inovação_cad & 0,7864 & 0,8804 & 0,5667 & 0,7301 & 0,7864 \\
\hline Inovação_ind & 0,7753 & 0,8734 & 0,6562 & 0,7104 & 0,7753 \\
\hline Integração & $\mathbf{0 , 4 8 6 8}$ & 0,7940 & 0 & 0,9256 & $\mathbf{0 , 4 0 0 5}$ \\
\hline Interna & 0,7109 & 0,8801 & 0,5978 & 0,7955 & 0,7109 \\
\hline Participação & 0,5224 & 0,8454 & 0,6688 & 0,7719 & 0,5224 \\
\hline Proc_empresariais_cad & 0,7609 & 0,8639 & 0,7487 & $\mathbf{0 , 3 3 7}$ & 0,6228 \\
\hline Proc_empresariais_ind & 0,7681 & 0,8681 & 0,6929 & 0,8475 & 0,5477 \\
\hline
\end{tabular}

Em relação à validade discriminante tampouco se observou muitos problemas, o que indica bom ajuste do modelo final. O Apêndice D apresenta os resultados.

Assim, esta análise por meio da Modelagem de Equações Estruturais também chegou aos mesmos resultados que a análise feita pela analise de regressão, onde as três hipóteses do trabalho foram confirmadas.

Dentro do apresentado, é possível avaliar as hipóteses do estudo:

- Hipótese 1 (H1): Existe uma relação positiva entre integração da cadeia de suprimentos e desempenho organizacional individual. Confirmada

- Hipótese 2 (H2): Existe uma relação positiva entre integração da cadeia de suprimentos e desempenho global da cadeia de suprimentos. Confirmada

- Hipótese 3 (H3): Existe uma relação positiva entre desempenho organizacional individual e desempenho global da cadeia de suprimentos. Confirmada 


\section{CONCLUSÕES}

Assim, são apresentadas as conclusões desta tese, bem como suas limitações e sugestões para trabalhos futuros.

\subsection{Conclusões da tese}

Durante a etapa da revisão da literatura em busca de uma melhor compreensão dos tópicos abordados neste trabalho, notou-se que o tema Integração da Cadeia de Suprimentos ainda merece atenção e estudos mais aprofundados.

Alguns autores destacam a necessidade de se conhecer os reais benefícios trazidos pela integração da cadeia de suprimentos, pois apesar de muitos estudos demonstrarem possíveis benefícios gerados com tal prática, vários outros estudos não puderam comprovar tais resultados, trazendo como questionamento se os benefícios da integração da cadeia seriam "mais teoria do que realidade".

Outra questão importante diz respeito aos desempenhos empresariais individuais e desempenhos globais das cadeias. Alguns autores relatam em seus trabalhos que a prática comum de cada empresa pertencente a uma cadeia na busca da sua própria otimização de resultados não leva a uma melhora nos resultado da cadeia como um todo, ou seja, a otimização das partes não traz a otimização do todo.

Assim, o presente trabalho teve como objetivo geral verificar a existência (ou não), de relação entre a integração de empresas constituintes de uma cadeia de suprimentos (também denominado de integração da cadeia) com os respectivos desempenhos organizacionais individuais (de uma empresa isoladamente) e global da cadeia (da cadeia como um todo) em empresas brasileiras de grande porte.

Para atingir a esse objetivo, alguns objetivos específicos foram criados:

a) Verificar os níveis de integração individuais atuais das empresas;

b) Verificar os desempenhos organizacionais individuais atuais das empresas; 
c) Verificar desempenhos globais das cadeias as quais elas pertencem;

d) Verificar a relação entre os níveis de integração individuais com os desempenhos organizacionais individuais;

e) Verificar a relação entre os níveis de integração individuais com os desempenhos globais das cadeias as quais elas pertencem;

f) Verificar a relação entre os desempenhos individuais das empresas com os desempenhos globais das cadeias as quais elas pertencem;

g) Verificar os níveis de integração, desempenhos organizacionais individuais e desempenhos globais da cadeia por setor de atividade.

Neste contexto, para se verificar os objetivos a), b) e c), utilizou-se as três novas variáveis criadas na análise de regressão ("integração da cadeia", "desempenho individual” e “desempenho da cadeia"), onde cada umas dessas variáveis foram obtidas pela média ponderada entre os fatores que os compõem, possuindo todos o mesmo peso e, por sua vez, cada um dos fatores de cada um dos constructos foi calculado pela média aritmética entre as variáveis que o compõem. Assim, cada empresa obteve uma "nota", variando de 1 a 7 , para cada um dos constructos.

O objetivo g), complementando os objetivos acima citados, apresenta uma média de cada um dos três constructos por setor de atividades. A tabela 105 do tópico 4.4 ilustra esse resultado. Observou-se a existência de diferença de médias entre os setores apenas para o constructo "integração da cadeia de suprimentos". Assim, os setores apresentaram médias estatisticamente semelhantes nos constructos "desempenho individual" e "desempenho da cadeia de suprimentos".

O objetivo d) deu origem a Hipótese 1 (H1): Existe uma relação positiva entre integração da cadeia de suprimentos e desempenho organizacional individual. Esta hipótese foi confirmada por dois métodos distintos: Análise de Regressão e Modelagem de Equações Estruturais. O tópico 4.3 e 4.5 abordam os resultados dessas análises respectivamente.

Já o objetivo e) deu origem a Hipótese 2 (H2): Existe uma relação positiva entre integração da cadeia de suprimentos e desempenho global da cadeia de suprimentos. Esta hipótese também foi confirmada, tanto pela Análise de Regressão, quanto pela Modelagem de Equações Estruturais. 
Finalmente o objetivo f) deu origem a Hipótese $3(\mathrm{H} 3)$ : Existe uma relação positiva entre desempenho organizacional individual e desempenho global da cadeia de suprimentos. Esta hipótese também foi confirmada pelos dois métodos utilizados.

\subsection{Limitações}

Pelo fato de ter sido utilizada uma amostragem não-probabilística por julgamento, os resultados aqui obtidos não podem ser generalizados para toda população, sendo então apenas válidos para a amostragem estudada.

Outra questão foi o baixo número de respondentes. Alguns autores, como por exemplo Hair Jr. (2005a) sugerem um número mínimo de 200 respondentes para uma ideal análise por meio de Modelagem de Equações Estruturais pelo método Lisrel.

Como o questionário foi auto-administrado (disponível on line), o pesquisador não teve contato direto com os respondentes para tirar possíveis dúvidas ou até mesmo confirmar seus cargos nas empresas estudadas.

Também outra limitação deste estudo se dá ao fato de que este trabalho, assim como os demais estudados na revisão teórica, analisa empresas focais isoladamente (não foram mapeadas as cadeias as quais elas pertencem) e portanto, os indicadores relativos a cadeia como um todo são elaborados com base nas opiniões dos executivos dessas empresas focais.

\subsection{Sugestões para trabalhos futuros}

Assim, ao término deste trabalho, algumas sugestões e possibilidades para trabalhos futuros podem ser apresentados:

- Para avaliar a relação entre integração da cadeia e desempenho da cadeia, cadeias de suprimento, com no mínimo três empresas poderiam ser mapeadas e assim verificados 
os desempenhos individuais reais de cada empresa participante, bem como o desempenho total da cadeia;

- Para poder generalizar os resultados do resultado para toda população, um trabalho que utilize uma amostragem probabilística é uma boa sugestão para um trabalho futuro;

- Uma pesquisa futura com um número maior de respondentes também seria bem vinda;

- Cada um dos setores estudados neste trabalham poderiam ser estudados em profundidade e, ao invés de fazer uma comparação entre os setores, uma análise mais profunda de um setor específico poderia ser realizada;

- Comparar países diferentes seria uma outra sugestão interessante para uma continuação deste trabalho. 


\section{REFERÊNCIAS BIBLIOGRÁFICAS}

AGAN, Y. A resource-based approach to supply chain integration. ProQuest Dissertations and Theses, v.0454, n.1194, p.127 p. 2005.

AHIRE, S. L., et al. Development and validation of TQM implementation constructs.

Decision Sciences, v.27, n.1, Winter, p.23. 1996.

ALLNOCH, A. Efficient supply chain practices mean big savings to leading manufacturers. IIE Solutions, v.29, n.7, Jul, p.8-9. 1997.

AMARATUNGA, D.; BALDRY, D. Moving from performance measurement to performance management. Facilities, v.20, n.5/6, p.217-223. 2002.

ANDRASKI, J. C. Foundations for Successful Continuous Replenishment Programs. The International Journal of Logistics Management., v.5, n.1, p.1-8. 1994.

ANGERHOFER, B. J.; ANGELIDES, M. C. A model and a performance measurement system for collaborative supply chains. Decision Support Systems, v.42, n.1, Oct, p.283. 2006.

ASSAF NETO, A. Finanças corporativas e valor. São Paulo: Atlas. 2008

BADELL, M., et al. Empowering financial tradeoff with joint financial and supply chain planning models. Mathematical and Computer Modelling. , v.46, n.1-2, p.12-27. 2007.

BALLOU, R. H. The evolution and future of logistics and supply chain management. European Business Review, v.19, n.4, p.332-348. 2007.

BARRATT, M. Understanding the meaning of collaboration in the supply chain. Supply Chain Management, v.9, n.1, p.30-42. 2004.

BARRATT, M.; OLIVEIRA, A. Exploring the experiences of collaborative planning initiatives. International Journal of Physical Distribution \& Logistics Management, v.31, n.4, p.266-289. 2001.

BAYRAKTAR, E., et al. The role of forecasting on bullwhip effect for E-SCM applications. International Journal of Production Economics, v.113, n.1, May, p.193. 2008.

BEAMON, B. M. Supply chain design and analysis: Models and methods. International Journal o Production Economics., v.55, n.3, p.281-294. 1998.

Measuring supply chain performance. International Journal of Operations \& Production Management, v.19, n.3, p.275-292. 1999.

BHAGWAT, R.; SHARMA, M. K. Performance measurement of supply chain management: A balanced scorecard approach. Computers \& Industrial Engineering, v.53, n.1, Aug, p.43. 2007. 
BOWERSOX, D. J., et al. Gestão da Cadeia de Suprimentos e Logística. Rio de Janeiro: Elsevier. 2007

BREWER, P. C.; SPEH, T. W. Using the balanced scorecard to measure supply chain performance. Journal of Business Logistics, v.21, n.1, p.75-93. 2000.

BUSI, M.; BITITCI, U. S. Collaborative performance management: present gaps and future research. International Journal of Productivity and Performance Management, v.55, n.1/2, p.7-25. 2006.

CAGLIANO, R., et al. The linkage between supply chain integration and manufacturing improvement programmes. International Journal of Operations \& Production Management, v.26, n.3/4, p.282-299. 2006.

CARR, A. S.; PEARSON, J. N. Strategically managed buyer-supplier reIationships and performance outcomes. Journal of Operations Management, v.17, n.5, Aug, p.497-519. 1999.

CASSIVI, L. Collaboration planning in a supply chain. Supply Chain Management, v.11, n.3, p.249-258. 2006.

CHAN, F. T. S.; QI, H. J. An innovative performance measurement method for supply chain management. Supply Chain Management, v.8, n.3/4, p.209-223. 2003.

CHANTRASA, R. Decision-making approaches for information sharing in a supply chain. ProQuest Dissertations and Theses, v.0546, n.0050, p.264 p. 2005.

CHEN, I. J.; PAULRAJ, A. Towards a theory of supply chain management: the constucts and measurements. Journal of Operations Management, v.22, n.2, Apr, p.119-150. 2004.

CHIN, W. W. Overview of the PLS Method. University of Houston. 1997. Disponível em: http://disc-nt.cba.uh.edu/chin/PLSINTRO.HTM. Acessado em: julho 2011.

CHOPRA, S.; MEINDL, P. Gerenciamento da Cadeia de Suprimentos. Estratégia, Planejamento e Operação. São Paulo: Prentice Hall. 2003. 465 p.

COOKE, J. A. VMI: Very mixed impact? Logistics Management and Distribution Report, v.37, n.12, Dec, p.51-53. 1998.

COOPER, D. R.; SCHINDLER, P. S. Métodos de Pesquisa em Administração. 7 ed. Porto Alegre: Bookman. 2003

COOPER, M. C.; ELLRAM, L. M. Characteristics of supply chain management and the implications for purchasing c:md logistics strategy. International Journal of Logistics Management, v.4, n.2, p.13-24. 1993.

COOPER, M. C., et al. Supply chain management: more than a new name for logistics. The International Journal of Logistics Management. , v.8, n.1, p.1-14. 1997. 
CORRAR, L. J., et al. Análise Multivariada para Cursos de Administração, Ciências Contábeis e Economia. São Paulo: Atlas. 2007.

COUSINS, P. D.; MENGUC, B. The implications of socialization and integration in supply chain management. Journal of Operations Management, v.24, n.5, Sep, p.604. 2006.

CROOM, S., et al. Supply chain management: an analytical framework for critical literature review. European Journal of Purchasing \& Supply Management, v.6, n.1, p.67-83. 2000.

CROXTON, K. L., et al. The demand management process. International Journal of Logistics Management, v.13, n.2, p.51-66. 2002.

DAS, A., et al. Supplier integration--Finding an optimal configuration. Journal of Operations Management, v.24, n.5, Sep, p.563. 2006.

DEVARAJ, S., et al. Impact of eBusiness technologies on operational performance: The role of production information integration in the supply chain. Journal of Operations Management, v.25, n.6, Nov, p.1199. 2007.

DHAHRI, I.; CHABCHOUB, H. Nonlinear goal programming models quantifying the bullwhip effect in supply chain based on ARIMA parameters. European Journal of Operational Research, v.177, n.3, Mar 16, p.1800. 2007.

ELLINGER, A. E. Improving marketing/logistics cross-functional collaborations in the supply chain. Industrial Marketing Management, v.29, n.1, Jan, p.85-96. 2000.

ELLRAM, L. M. A managerial guideline for the development and implementation of Purchasing Partnerships. International Journal of Purchasing and Materials Management, v.31, n.2, Spring, p.9. 1995.

FABBE-COSTES, N.; JAHRE, M. Supply chain integration improves performance: the Emperor's new suit? International Journal of Physical Distribution \& Logistics Management, v.37, n.10, p.835-855. 2007.

FAWCETT, S. E.; MAGNAN, G. M. The rhetoric and reality of supply chain integration. International Journal of Physical Distribution \& Logistics Management, v.32, n.5, p.339. 2002 .

FAWCETT, S. E., et al. Benefits, barriers, and bridges to effective supply chain management. Supply Chain Management, v.13, n.1, p.35-48. 2008.

Information sharing and supply chain performance: the role of connectivity and willingness. Supply Chain Management, v.12, n.5, p.358. 2007.

FLYNN, B. B., et al. Empirical Research Methods in Operations Management. Journal of Operations Management, v.9, n.2, Apr, p.250. 1990.

FORME, F.-A. G. L., et al. A framework to analyse collaborative performance. Computers in Industry, v.58, n.7, Sep, p.687. 2007. 
FROHLICH, M. T.; WESTBROOK, R. Arcs of integration: An international study of supply chain strategies. Journal of Operations Management, v.19, n.2, Feb, p.185-200. 2001.

Demand chain management in manufacturing and services: Web-based integration, drivers and performance. Journal of Operations Management, v.20, n.6, Nov, p.729-745. 2002.

FUENTE, M. V. D. L., et al. Integrating Forward and Reverse Supply Chains: Application to a metal-mechanic company. International Journal of Production Economics, v.111, n.2, Feb, p.782. 2008.

GEARY, S., et al. On bullwhip in supply chains - historical review, present practice and expected future impact. International Journal of Production Economics, v.101, n.1, May, p.2-18. 2006.

GIL, A. C. Como elaborar projetos de pesquisa. 4 ed. São Paulo: Atlas. 2008

GITMAN, L. J. Princípios de administração financeira. São Paulo: Harbra. 1997

GUNASEKARAN, A., et al. Responsive supply chain: A competitive strategy in a networked economy*. Omega, v.36, n.4, Aug, p.549. 2008.

A framework for supply chain performance measurement. International Journal of Production Economics, v.87, n.3, Feb 18, p.333-347. 2004.

Performance measures and metrics in a supply chain environment. International Journal of Operations \& Production Management, v.21, n.1/2, p.71-87. 2001.

HADAYA, P.; CASSIVI, L. The role of joint collaboration planning actions in a demanddriven supply chain. Industrial Management + Data Systems, v.107, n.7, p.954-978. 2007.

HAIR JR., J. F., et al. Análise Multivariada de Dados. 5 ed. Porto Alegre: Bookman. 2005a Fundamentos de Métodos de Pesquisa em Administração. Porto Alegre:

Bookman. 2005b

HARLAND, C. M., et al. Barriers to supply chain information integration: SMEs adrift of eLands. Journal of Operations Management, v.25, n.6, Nov, p.1234. 2007.

HICKS, D. A. The state of supply chain strategy. IIE Solutions, v.31, n.8, Aug, p.24-29. 1999.

HOLMBERG, S. A systems perspective on supply chain measurements. International Journal of Physical Distribution \& Logistics Management, v.30, n.10, p.847-868. 2000.

HOLWEG, M., et al. Supply Chain Collaboration: Making Sense of the Strategy Continuum. European Management Journal, v.23, n.2, Apr, p.170-181. 2005.

HUGOS, M. Essentials of supply chain management. New Jersey: John Wiley \& Sons, Inc. 2003 
INNIS, D. E.; LA LONDE, B. J. Customer service: The key to customer satisfaction, customer loyalty, and market share. Journal of Business Logistics, v.15, n.1, p.1. 1994.

JAMMERNEGG, W.; REINER, G. Performance improvement of supply chain processes by coordinated inventory and capacity management. International Journal of Production Economics, v.108, n.1/2, Jul, p.183. 2007.

KALAKOTA, R.; ROBINSON, M. E-business: Estratégias para alcançar o sucesso. Porto Alegre: Bookman. 2002

KAPLAN, R. S.; NORTON, D. P. The Balanced Scorecard - Measures That Drive Performance. Harvard Business Review, v.70, n.1, Jan/Feb, p.71. 1992.

KELLE, P.; AKBULUT, A. The role of ERP tools in supply chain information sharing, cooperation, and cost optimization. International Journal of Production Economics, v.93,94, Jan 8, p.41-52. 2005.

KENNERLEY, M.; NEELY, A. Measuring performance in a changing business environment. International Journal of Operations \& Production Management, v.23, n.2, p.213-229. 2003.

KETCHEN, D. J., JR., et al. Best value supply chains: A key competitive weapon for the 21 st century. Business Horizons, v.51, n.3, May/Jun, p.236. 2008.

KIM, D. Process chain: A new paradigm of collaborative commerce and synchronized supply chain. Business Horizons, v.49, n.5, Sep/Oct, p.359. 2006.

KIM, S. W. The effect of supply chain integration on the alignment between corporate competitive capability and supply chain operational capability. International Journal of Operations \& Production Management, v.26, n.10, p.1084-1107. 2006.

KUMAR, K. Technology for supporting supply chain management. Association for Computing Machinery. Communications of the ACM, v.44, n.6, Jun, p.58-61. 2001.

KUMAR, S., et al. Serve your supply chain, not operations - a case study. Industrial Management + Data Systems, v.101, n.8/9, p.414-425. 2001.

KUTUCUOGLU, K. Y., et al. A framework for managing maintenance using performance measurement systems. International Journal of Operations \& Production Management, v.21, n.1/2, p.173-195. 2001.

LAMBERT, D. M.; BURDUROGLU, R. Measuring and selling the value of logistics. International Journal of Logistics Management, v.11, n.1, p.1-17. 2000.

LAMBERT, D. M.; COOPER, M. C. Issues in supply chain management. Industrial Marketing Management, v.29, n.1, Jan, p.65-83. 2000.

LAMBERT, D. M., et al. Supply chain management: Implementation issues and research opportunities. International Journal of Logistics Management, v.9, n.2, p.1. 1998. 
LAMBERT, D. M.; POHLEN, T. L. Supply chain metrics. International Journal of Logistics Management, v.12, n.1, p.1-19. 2001.

LAU, R. S. M., et al. Effects of inventory policy on supply chain performance: A simulation study of critical decision parameters. Computers \& Industrial Engineering., Article in press. 2008.

LAUDON, K. C.; LAUDON, J. P. Management Information Systems: Managing the Digital Firm. 9 ed. New Jersey: Prentice-Hall. 2006

LEE, H. L. Creating Value Through Supply Chain Integration. Supply Chain Management Review, n.September/October. 2000.

LEE, H. L., et al. The Bullwhip Effect in Supply Chains. Sloan Management Review, v.38, n.3, Spring, p.93-102. 1997.

LEE, H. L.; WHANG, S. E-business and supply chain integration. Stanford Global Supply Chain Management Forum, November. 2001.

LEVARY, R. R. Better supply chains through information technology. Industrial Management, v.42, n.3, May/Jun, p.24-30. 2000.

LOCKAMY, A., III; MCCORMACK, K. The development of a supply chain management process maturity model using the concepts of business process orientation. Supply Chain Management, v.9, n.3/4, p.272-278. 2004.

MALHOTRA, M. K.; GROVER, V. An assessment of survey research in POM: From constructs to theory. Journal of Operations Management, v.16, n.4, Jul, p.407-425. 1998.

MALHOTRA, N. K. Pesquisa de Marketing: Uma orientação aplicada. 4 ed. Porto Alegre: Bookman. 2004

Pesquisa de Marketing. 4 ed. Porto Alegre: Bookman. 2006. 720 p.

MALONI, M. J.; BENTON, W. C. Supply chain partnerships: Opportunities for operations researh. European Journal of Operational Research, v.101, n.3, Sep 16, p.419-429. 1997.

MARCONI, M. D. A.; LAKATOS, E. M. Fundamentos de Metodologia Científica. 6 ed. São Paulo: Atlas. 2005. 317 p.

MARTINS, G. D. A.; THEÓPHILO, C. R. Metodologia da Investigação Científica para Ciêncis Sociais e Aplicada. 2 ed. São Paulo: Atlas. 2009

MASON-JONES, R.; TOWILL, D. R. Total cycle time compression and the agile supply chain. International Journal of Production Economics, v.62, n.1,2, May 20, p.61-73. 1999.

MATIAS, A. B. Finanças corporativas de longo prazo, volume 2: criação de valor sim sustentabilidade financeira. São Paulo: Atlas. 2007 
MATTAR, F. N. Pesquisa de Marketing: metodologia e planejamento. v.1, 6 ed. São Paulo: Atlas. 2005

MCLAREN, T., et al. Supply chain collaboration alternatives: Understanding the expected costs and benefits. Internet Research, v.12, n.4, p.348-364. 2002.

MENTZER, J. T., et al. Defining supply chain management. Journal of Business Logistics, v.22, n.2, p.1-26. 2001.

Collaboration: The Enablers, Impediments, and Benefits. Supply Chain Management Review, n.September/October. 2000.

The nature of interfirm partnering in supply chain management. Journal of Retailing, v.76, n.4, Winter, p.549-568. 2000.

MILLER, C. A. The nature and design of supply chain performance measurement systems: An empirical study. ProQuest Dissertations and Theses, v.0454, n.0176, p.223 p. 2001.

MONCZKA, R. M., et al. Success factors in strategic supplier alliances: The buying company perspective. Decision Sciences, v.29, n.3, Summer, p.553-577. 1998.

MORGAN, C. Structure, speed and salience: performance measurement in the supply chain. Business Process Management Journal, v.10, n.5, p.522-536. 2004.

MUCKSTADT, J. A., et al. Guidelines for Collaborative Supply Chain System Design and Operation. Information Systems Frontiers, v.3, n.4, Dec, p.427. 2001.

NABAVI, M. Integrating information resources in supply chains: A simulation analysis of delivery performance and resource utilization. ProQuest Dissertations and Theses, v.0454, n.0138, p.276 p. 2006.

NARASIMHAN, R.; DAS, A. The impact of purchasing integration and practices on manufacturing performance. Journal of Operations Management, v.19, n.5, Oct, p.593-609. 2001.

NARASIMHAN, R.; KIM, S. W. Effect of supply chain integration on the relationship between diversification and performance: Evidence from Japanese and Korean firms. Journal of Operations Management, v.20, n.3, Jun, p.303-323. 2002.

NEELY, A., et al. Performance measurement system design. International Journal of Operations \& Production Management, v.15, n.4, p.80. 1995.

O'BRIEN, J. A. Sistemas de Informação e as Decisões Gerenciais na Era da Internet. São Paulo: Saraiva. 2004

PARK, J. H., et al. A framework for designing the balanced supply chain scorecard. European Journal of Information Systems, v.14, n.4, Dec, p.335-346. 2005. 
PATTERSON, K. A., et al. Adopting new technologies for supply chain management. Transportation Research. Part E, Logistics \& Transportation Review, v.39E, n.2, Mar, p.95. 2003.

PAULRAJ, A., et al. Levels of strategic purchasing: Impact on supply integration and performance. . Journal of Purchasing \& Supply Management v.12, n.3, p.107-122. 2006.

PORTER, M. E. Competitive Advantage: Creating and Sustaining Superior Performance. New York: Free Press. 1985

PORTER, M. E.; STERN, S. Innovation: Location Matters. MIT Sloan Management Review, v.42, n.4, Summer, p.28-36. 2001.

POWER, D. Supply chain management integration and implementation: a literature review. Supply Chain Management, v.10, n.3/4, p.252-263. 2005.

RADHAKRISHNAN, A. Impact of usage of inter-organizational information systems on supply chain capabilities. ProQuest Dissertations and Theses, v.0454, n.0050, p.280 p. 2005.

RAFELE, C. Logistic service measurement: a reference framework. Journal of Manufacturing Technology Management, v.15, n.3, p.280-290. 2004.

REBEHY, P. C. P. W. Estratégias financeiras em redes de empresas: uma aplicação dos conceitos de economia industrial. Faculdade de Economia, Administração e Contabilidade, Universidade de São Paulo, São Paulo, 2007. 238 p.

RICHARDSON, R. J. Pesquisa Social: Métodos e Técnicas. 3 ed. São Paulo: Atlas. 2008

ROSENZWEIG, E. D., et al. The influence of an integration strategy on competitive capabilities and business performance: An exploratory study of consumer products manufacturers. Journal of Operations Management, v.21, n.4, Jul, p.437. 2003.

RUSS, M.; CAMP, S. M. Strategic alliances and technology transfer: An extended paradigm. International Journal of Technology Management, v.14, n.5, p.513-527. 1997.

SAEED, K. A. Information technology antecedents to supply chain integration and firm performance. ProQuest Dissertations and Theses, v.0454, n.0202, p.187 p. 2004.

SAHIN, F.; ROBINSON, E. P. Flow coordination and information sharing in supply chains: Review, implications, and directions for future research. Decision Sciences, v.33, n.4, Fall, p.505-536. 2002.

SAHIN, F.; ROBINSON, E. P., JR. Information sharing and coordination in make-to-order supply chains. Journal of Operations Management, v.23, n.6, Sep, p.579-598. 2005.

SARANA, M.; MASON, R. J. The alignment of collaboration and the importance of integrated performance measurement. Intelligent Production Machines and Systems. 2006. 
SEARCY, D. L. Facilitators and impediments in moving firms toward supply chain management: A qualitative field study. ProQuest Dissertations and Theses, v.0272, n.0226, p.160 p. 2002.

SEIDMANN, A.; SUNDARARAJAN, A. Building and Sustaining Interorganizational Sharing Relationships: The Competitive Impact of Interfacing Supply Chain Operations With Marketing Strategy. Proceedings of the eighteenth international conference on Information Systems. Atlanta, Georgia, USA, 1997.

SEZEN, B. L. Relative effects of design, integration and information sharing on supply chain performance. Supply Chain Management, v.13, n.3, p.233-240. 2008.

SHEPHERD, C.; GUNTER, H. Measuring supply chain performance: current research and future directions. International Journal of Productivity and Performance Management, v.55, n.3/4, p.242-258. 2006.

SIMATUPANG, T. M.; SRIDHARAN, R. The collaborative supply chain. International Journal of Logistics Management, v.13, n.1, p.15-30. 2002. 369. 2005.

Supply chain discontent. Business Process Management Journal, v.11, n.4, p.349-

SIMATUPANG, T. M., et al. The knowledge of coordination for supply chain integration. Business Process Management Journal, v.8, n.3, p.289. 2002.

SIMCHI-LEVI, D., et al. Cadeia de Suprimentos - Projeto e gestão - Conceitos, estratégias e estudo de casos. Porto Alegre: Bookman. 2003

SINGH, P. J.; SMITH, A. An empirically validated quality management measurement instrument. Benchmarking, v.13, n.4, p.493-522. 2006.

SKJOETT-LARSEN, T. Supply chain management: A new challenge for researchers and managers in logistics. International Journal of Logistics Management, v.10, n.2, p.41-53. 1999.

SOOSAY, C. A., et al. Supply chain collaboration: capabilities for continuous innovation. Supply Chain Management, v.13, n.2, p.160-169. 2008.

STADLER, H.; KILGER, C. Supply chain management and advanced planning: concepts, models, software and case studies. New York: Springer. 2005

STAINER, A. Logistics - a productivity and performance perspective. Supply Chain Management, v.2, n.2, p.53. 1997.

STANK, T. P., et al. Supply chain collaboration and logistical service performance. Journal of Business Logistics, v.22, n.1, p.29-48. 2001.

STEDMAN, C. Few takers for benchmarks from Supply Chain Council. Computerworld, v.34, n.17, Apr 24, p.46. 2000. 
STEVENSON, W.J. Estatística aplicada à administração. São Paulo: Harbra. 1981.

SUDRAJAT, I. Supply chain integration practices in the U.S. electronics industry. ProQuest Dissertations and Theses, v.0546, n.0180, p.n/a. 2007.

SUPPLY CHAIN COUNCIL. Supply Chain Operations Reference - SCOR Model Overview 8.0. 2006.

SWAMINATHAN, J. M., et al. Modeling supply chain dynamics: A multiagent approach. Decision Sciences, v.29, n.3, Summer, p.607-632. 1998.

SWINK, M., et al. Managing beyond the factory walls: Effects of four types of strategic integration on manufacturing plant performance. Journal of Operations Management, v.25, n.1, Jan, p.148. 2007.

TAN, K. C., et al. Supply chain management: Supplier performance and firm performance. International Journal of Purchasing and Materials Management, v.34, n.3, Summer, p.29. 1998.

THEMISTOCLEOUS, M., et al. Evaluating the integration of supply chain information systems: A case study. European Journal of Operational Research, v.159, n.2, Dec 1, p.393-405. 2004.

THONEMANN, U. W. Improving supply-chain performance by sharing advance demand information. European Journal of Operational Research, v.142, n.1, Oct 1, p.81-107. 2002.

TRKMAN, P., et al. Process approach to supply chain integration. Supply Chain Management, v.12, n.2, p.116. 2007.

VALOR 1000. Anuário Valor Econômico. São Paulo. Agosto. 2009.

VENKATACHALAM, A. R. A Holistic Perspective on Enterprise Integration. Journal of Information Technology Case and Application Research, v.8, n.1, p.1-6. 2006.

VICKERY, S., et al. Supply chain flexibility: An empirical study. Journal of Supply Chain Management, v.35, n.3, Summer, p.16-24. 1999.

VICKERY, S. K., et al. The effects of an integrative supply chain strategy on customer service and financial performance: an analysis of direct versus indirect relationships. Journal of Operations Management, v.21, n.5, Dec, p.523-539. 2003.

WAGGONER, D. B., et al. The forces that shape organisational performance measurement systems: An interdisciplinary review. International Journal of Production Economics, v.60-61, Apr 20, p.53-60. 1999.

WALTER, A., et al. Value creation in buyer-seller relationships: Theoretical considerations and empirical results from a supplier's perspective. Industrial Marketing Management, v.30, n.4, May, p.365-377. 2001. 
WALTERS, D. The implications of shareholder value planning and management for logistics decision making. International Journal of Physical Distribution \& Logistics Management, v.29, n.4, p.240-258. 1999.

WELKER, G. A., et al. The influence of business conditions on supply chain informationsharing mechanisms: A study among supply chain links of SMEs. International Journal of Production Economics, v.113, n.2, Jun, p.706. 2008.

YAO, Y., et al. Supply chain integration in vendor-managed inventory. Decision Support Systems, v.43, n.2, Mar, p.663. 2007.

YUSUF, Y. Y., et al. Agile supply chain capabilities: Determinants of competitive objectives. European Journal of Operational Research, v.159, n.2, Dec 1, p.379-392. 2004.

ZAILANI, S.; RAJAGOPAL, P. Supply chain integration and performance: US versus East Asian companies. Supply Chain Management, v.10, n.5, p.379-393. 2005.

ZHOU, H.; BENTON, W. C., JR. Supply chain practice and information sharing. Journal of Operations Management, v.25, n.6, Nov, p.1348. 2007. 


\section{APÊNDICES}

APÊNDICE A - Variáveis consideradas em pesquisas de integração e desempenho (por autor)

\begin{tabular}{|c|c|c|}
\hline Autor & Variáveis independentes & Variáveis dependentes \\
\hline Zailani e Rajagopal (2005) & $\begin{array}{l}\text { Compartilhamento de informação } \\
\text { - troca de informação com fornecedores } \\
\text { - nível de interação com clientes por meio de redes de informação } \\
\text { Integração interna } \\
\text { - ampla integração interna entre as funçães } \\
\text { Integração externa com fornecedores } \\
\text { - integração da empresa com os fornecedores } \\
\text { - nível de parceria estratégica com os fornecedores } \\
\text { Integração externa com clientes } \\
\text { - integração da empresa com os clientes } \\
\text { - acompanhamento do feedback dos clientes }\end{array}$ & $\begin{array}{l}\text { Crescimento da produtividade } \\
\text { Qualidade } \\
\text { - capacidade de atender as normas de } \\
\text { qualidade } \\
\text { - capacidade de fornecer produtos no tempo } \\
\text { determinado } \\
\text { - histórico de desempenho. } \\
\text { Entrega } \\
\text { - rapidez na entrega } \\
\text { - confiabilidade na entrega } \\
\text { - lead-time da produção } \\
\text { Flexibilidade } \\
\text { - flexibilidade de serviço ao cliente } \\
\text { - flexibilidade do pedido } \\
\text { - flexibilidade de localização } \\
\text { - flexibilidade de tempo de entrega } \\
\text { Relacionamento com o cliente }\end{array}$ \\
\hline Sezen (2008) & $\begin{array}{l}\text { Integração da cadeia de suprimentos. } \\
\text { - empresas da nossa cadeia estabelecem contatos mais freqüente com as outras. } \\
\text { - empresas da nossa cadeia criam uma comunicação e sistemas de informação } \\
\text { compatíveis. } \\
\text { - nossa empresa amplia sua cadeia de suprimentos para além dos seus clientes e } \\
\text { fornecedores. } \\
\text { - nossa empresa participa nos esforços de marketing de seus clientes. } \\
\text { - nossa empresa participa nas decisões de terceirização de seus fornecedores. } \\
\text { Compartilhamento de informações com os fornecedores. } \\
\text { - nossa empresa oferece aos fornecedores as informações de previsão de demanda. } \\
\text { - nossa empresa e seus fornecedores compartilham suas informações de planejamento de } \\
\text { capacidade. } \\
\text { - nossa empresa pode facilmente monitorar o status de seus pedidos. } \\
\text { - nossa empresa pode encontrar facilmente informações sobre os produtos e os preços dos } \\
\text { fornecedores. }\end{array}$ & $\begin{array}{l}\text { Desempenho de flexibilidade } \\
\text { - capacidade para responder e atender } \\
\text { variações de demanda, tais como a } \\
\text { sazonalidade. } \\
\text { - capacidade de responder e adequar } \\
\text { períodos de baixo desempenho de produção } \\
\text { (quebra de máquinas). } \\
\text { - capacidade de responder e adequar } \\
\text { períodos de baixo desempenho dos } \\
\text { fornecedores. } \\
\text { - capacidade de responder e adequar } \\
\text { períodos de baixo desempenho de entrega. } \\
\text { - capacidade para responder e adequar a } \\
\text { novos produtos, a novos mercados ou a } \\
\text { novos concorrentes. }\end{array}$ \\
\hline
\end{tabular}




\begin{tabular}{|c|c|c|}
\hline Autor & Variáveis independentes & Variáveis dependentes \\
\hline & $\begin{array}{l}\text { - nossa empresa compartilha seus planos de produção com os fornecedores. } \\
\text { Compartilhamento de informações com os clientes. } \\
\text { - nossos clientes fornecem suas informações de previsão da demanda. } \\
\text { - nossos clientes compartilham seus planos de produção com a gente. } \\
\text { - nossos clientes podem facilmente monitorar o status de seus pedidos. } \\
\text { - nossa empresa compartilha com seus clientes as informações de planejamento de } \\
\text { capacidade. } \\
\text { Estrutura da cadeia de suprimentos. } \\
\text { - a proximidade com os fornecedores é um aspecto importante para a nossa empresa. } \\
\text { - os nossos critérios de seleção de fornecedores estão bem definidos. } \\
\text { - o número de fornecedores e suas capacidades são suficientes para lidar com quaisquer } \\
\text { possíveis necessidades de nossos clientes. } \\
\text { - os canais de distribuição em nossa cadeia podem atender suficientemente nossos } \\
\text { mercados atuais e potenciais. } \\
\text { - as atividades de logística em nossa cadeia são coordenadas para minimizar os problemas } \\
\text { na distribuição e nos serviços prestados. }\end{array}$ & $\begin{array}{l}\text { Desempenho de recursos } \\
\text { - custo total dos recursos utilizados. } \\
\text { - custo total da distribuição, incluindo } \\
\text { custos de transporte e manuseio. } \\
\text { - custo total de produção, incluindo a mão- } \\
\text { de-obra, manutenção e retrabalho. } \\
\text { - custos associados ao estoque parado. } \\
\text { - retorno sobre investimentos. } \\
\text { Desempenho de mercado } \\
\text { - vendas. } \\
\text { - taxa de atendimento dos pedidos. } \\
\text { - entregas no prazo. } \\
\text { - tempo de resposta ao cliente. } \\
\text { - erros de envio. } \\
\text { - lead time da produção. } \\
\text { - reclamações dos clientes. }\end{array}$ \\
\hline Radhakrishnan (2005) & $\begin{array}{l}\text { Integração externa com clientes } \\
\text { - o cliente e minha unidade coordenam conjuntamente iniciativas de design para o } \\
\text { produtos existentes. } \\
\text { - o cliente participa do processo de desenvolvimento da minha unidade. } \\
\text { - o cliente e minha unidade coordenam conjuntamente o planejamento de produção. } \\
\text { - o cliente e minha unidade coordenam conjuntamente a previsão de demanda. } \\
\text { - o cliente e minha unidade coordenam conjuntamente iniciativas "estoque gerenciado } \\
\text { pelo fornecedor" (Vendor Managed Inventory - VMI). } \\
\text { - a minha unidade compartilha recursos, tais como contêineres e equipamentos logísticos } \\
\text { com o cliente. } \\
\text { - a minha unidade compartilha recursos, tais como depósitos e instalações com o cliente. } \\
\text { - a minha unidade compartilhada serviços terceirizados de logística com o Cliente. } \\
\text { - o cliente e minha unidade respondem em conjunto a problemas imprevistos na } \\
\text { modificação de produtos e processos de engenharia. } \\
\text { - o cliente e minha unidade gerenciam em conjunto de iniciativas de desenvolvimento de } \\
\text { novos produtos. } \\
\text { - o cliente e minha unidade identificam em conjunto oportunidades de novos mercados. } \\
\text { Integração externa com fornecedores } \\
\text { - o fornecedor e minha unidade promoveram em conjunto iniciativas de design para os } \\
\text { produtos existentes. } \\
\text { - minha unidade participou do processo de desenvolvimento das capacidades do }\end{array}$ & $\begin{array}{l}\text { Melhoria das capabilidades da cadeia } \\
\text { (fornecedores e clientes) } \\
\text { - fabricar produtos com menor custo de } \\
\text { produção. } \\
\text { - menores despesas gerais de administração. } \\
\text { - oferecer produtos de menor preço. } \\
\text { - menor tempo de ciclo do pedido. } \\
\text { - proporcionar entregas no prazo de maneira } \\
\text { confiável } \\
\text { - mudar rapidamente mix de produtos. } \\
\text { - mudar rapidamente os volumes de } \\
\text { produção. } \\
\text { - oferecer maior mix de produtos. } \\
\text { - lidar com encomendas customizadas. } \\
\text { - oferecer produtos confiáveis que atendam } \\
\text { as necessidades dos clientes. } \\
\text { - oferecer produtos duráveis que atendam às } \\
\text { necessidades dos clientes. } \\
\text { - oferecer produtos de alto desempenho que } \\
\text { atendem as necessidades dos clientes. } \\
\text { - oferecer produtos em conformidade com a }\end{array}$ \\
\hline
\end{tabular}




\begin{tabular}{|c|c|c|}
\hline Autor & Variáveis independentes & Variáveis dependentes \\
\hline & $\begin{array}{l}\text { fornecedor. } \\
\text { - o fornecedor e minha unidade coordenam conjuntamente o processo de atendimento ao } \\
\text { pedido do cliente. } \\
\text { - o fornecedor e minha unidade coordenam conjuntamente iniciativas de "estoque } \\
\text { gerenciado pelo fornecedor" (Vendor Managed Inventory - VMI). } \\
\text { - a minha unidade compartilha recursos com o fornecedor, tais como containeres e } \\
\text { equipamentos logísticos. } \\
\text { - a minha unidade compartilha recursos com o fornecedor, tais como depósitos e } \\
\text { instalações. } \\
\text { - a minha unidade compartilhada serviços terceirizados de logística com fornecedores. } \\
\text { - o fornecedor e minha unidade respondem em conjunto a todos os problemas imprevistos } \\
\text { na produção e processos de distribuição. } \\
\text { - o fornecedor e minha unidade respondem em conjunto a problemas imprevistos na } \\
\text { modificação de produtos e processos de engenharia. } \\
\text { - o fornecedor e minha unidade gerenciam em conjunto de iniciativas de desenvolvimento } \\
\text { de novos produtos. } \\
\text { - o fornecedor e minha unidade identificam em conjunto oportunidades de novos } \\
\text { mercados. } \\
\text { Integração interna } \\
\text { - minha unidade de negócios usa equipes multifuncionais para apoiar os objetivos } \\
\text { estratégicos da nossa unidade. } \\
\text { - minha unidade de negócios realiza periodicamente diversas reuniões interdepartamentais } \\
\text { para apoiar os objetivos estratégicos da nossa unidade. } \\
\text { - minha unidade de negócios recompensa esforços multifuncionais para alcançar os } \\
\text { objetivos estratégicos da nossa unidade. }\end{array}$ & especificação do projeto. \\
\hline Frohlich e Westbrook (2001) & $\begin{array}{l}\text { Em relação aos clientes } \\
\text { - acesso aos sistemas de planejamento } \\
\text { - compartilhamento dos planos de produção } \\
\text { - integração de redes e acessos EDI } \\
\text { - conhecimento dos níveis e mix de estoque } \\
\text { - customização das embalagens } \\
\text { - freqüência de entrega } \\
\text { - uso comum de equipamentos logísticos } \\
\text { - uso comum de serviços logísticos terceirizados } \\
\text { Em relação aos fornecedores } \\
\text { - acesso aos sistemas de planejamento } \\
\text { - compartilhamento dos planos de produção } \\
\end{array}$ & $\begin{array}{l}\text { Mercado } \\
\text { - participação de mercado } \\
\text { - rentabilidade } \\
\text { - retorno sobre investimento } \\
\text { Produtividade } \\
\text { - custo unitário de produção médio } \\
\text { - custo total de materiais e despesas gerais } \\
\text { - lead time de produção } \\
\text { - tempo de transição de equipamentos } \\
\text { - lead time de compras } \\
\text { - tempo de entrega } \\
\text { - giro do estoque (vendas/estoque) } \\
\end{array}$ \\
\hline
\end{tabular}




\begin{tabular}{|c|c|c|}
\hline Autor & Variáveis independentes & Variáveis dependentes \\
\hline & $\begin{array}{l}\text { - integração de redes e acessos EDI } \\
\text { - conhecimento dos níveis e mix de estoque } \\
\text { - customização das embalagens } \\
\text { - frequiência de entrega } \\
\text { - uso comum de equipamentos logísticos } \\
\text { - uso comum de serviços logísticos terceirizados }\end{array}$ & $\begin{array}{l}\text { - produtividade dos trabalhadores } \\
\text { Não produtividade } \\
\text { - serviço ao cliente } \\
\text { - satisfação do cliente } \\
\text { - conformidade de qualidade } \\
\text { - variedade de produtos } \\
\text { - rapidez no desenvolvimento de produtos } \\
\text { - número de novos produtos desenvolvidos } \\
\text { - entregas no tempo } \\
\text { - qualidade dos fornecedores } \\
\end{array}$ \\
\hline Frohlich e Westbrook (2002) & $\begin{array}{l}\text { Integração com fornecedores } \\
\text { - planejamento integrado de estoque } \\
\text { - gerenciamento integrado da cadeia de suprimentos } \\
\text { - gerenciamento integrado da previsão da demanda } \\
\text { - gerenciamento integrado da programação e monitoramento de pedidos } \\
\text { Integração com os clientes } \\
\text { - marketing direcionado / perfil do cliente } \\
\text { - recebimento on line de pedidos } \\
\text { - gerenciamento integrado da previsão da demanda } \\
\text { - gerenciamento do relacionamento com o cliente }\end{array}$ & $\begin{array}{l}\text { Melhora no tempo de entrega } \\
\text { Redução dos custos de transação } \\
\text { Maior rentabilidade } \\
\text { Aumento do giro de estoque }\end{array}$ \\
\hline Tan et al. (1998) & $\begin{array}{l}\text { Utilização de práticas específicas de compras } \\
\text { - equipes de gestores para definir os níveis de custo, qualidade e tempo para avaliar o } \\
\text { desempenho do fornecedor } \\
\text { - gerentes locais das fabricas possuem autonomia para executar ordens de compras e } \\
\text { fluxos de suprimentos diários } \\
\text { - materiais de baixo custo ou baixo volume são gerenciados pelas pessoas das fábricas } \\
\text { locais com base em suas necessidades locais } \\
\text { - nossa empresa possui um programa de certificação da qualidade para os produtos dos } \\
\text { nossos fornecedores } \\
\text { - nossa empresa possui um programa de certificação da qualidade para os processos de } \\
\text { manufatura dos nossos fornecedores } \\
\text { - nossa empresa utiliza do suporte técnico e testes de capabilidade de nossos fornecedores } \\
\text { - nosso pessoal de produção visita regularmente as instalações dos nossos fornecedores } \\
\text { - nossos fornecedores recebem as alterações das nossas especificações após } \\
\text { desenvolvermos novos produtos } \\
\text { - nós compartilhamos uma grande quantidade de informações importantes com os nossos } \\
\text { fornecedores }\end{array}$ & $\begin{array}{l}\text { Participação de mercado } \\
\text { Retorno sobre o ativo total } \\
\text { Crescimento médio anual da participação de } \\
\text { mercado } \\
\text { Crescimento médio anual de vendas } \\
\text { Crescimento médio anual do retorno sobre o } \\
\text { ativo total } \\
\text { Custos médios de produção } \\
\text { Nível de serviço total ao cliente } \\
\text { Qualidade total do produto } \\
\text { Posição competitiva global }\end{array}$ \\
\hline
\end{tabular}




\begin{tabular}{|c|c|c|}
\hline Autor & Variáveis independentes & Variáveis dependentes \\
\hline & $\begin{array}{l}\text { - nós realizamos negociações anuais com nossos fornecedores para estabelecer os preços } \\
\text { das matérias primas } \\
\text { Utilização de práticas especificas de relacionamento com clientes } \\
\text { - determinação das expectativas futuras dos clientes } \\
\text { - determinação dos fatores-chave para construir e manter relacionamentos com os clientes } \\
\text { - melhora da capacidade do cliente em procurar ajuda } \\
\text { - avaliação de queixas formais e informais } \\
\text { - acompanhamento junto aos clientes dos feedbacks de qualidade e serviços } \\
\text { - interação com os clientes para definir confiabilidade, receptividade e outros padrões } \\
\text { - medição e avaliação dos fatores de satisfação do cliente }\end{array}$ & \\
\hline Narasimhan e Kim (2002) & $\begin{array}{l}\text { Integração com fornecedores } \\
\text { - intercâmbio de informações com os fornecedores através de tecnologia da informação } \\
\text { - nível de parceria estratégica com os fornecedores } \\
\text { - nível de participação dos fornecedores na fase de design } \\
\text { - nível de participação dos fornecedores no processo de aquisição e produção } \\
\text { - estabelecimento de um sistema rápido de pedidos } \\
\text { - compras estáveis através da cadeia } \\
\text { Integração com cliente } \\
\text { - acompanhamento junto aos clientes para obtenção de feedback } \\
\text { - nível de informatização para o recebimento dos pedidos dos clientes } \\
\text { - nível de ligação com os clientes através da rede de informação } \\
\text { - nível de compartilhamento de informações sobre o mercado } \\
\text { - agilidade do processo de realização dos pedidos } \\
\text { - frequiência de contatos periódicos com os clientes } \\
\text { - nível de comunicação com os clientes } \\
\text { Integração interna entre a cadeia } \\
\text { - integração de dados entre funções internas através de redes de informação } \\
\text { - integração dos sistemas de informação entre as funções internas } \\
\text { - acesso em tempo real do nível de estoque } \\
\text { - acesso em tempo real dos dados operacionais relativos à logística } \\
\text { - integração de dados no processo produtivo } \\
\text { - gerenciamento integrativo de estoque } \\
\text { - construção de um sistema de interação entre produção e vendas } \\
\text { - utilização de reuniões interdepartamentais periódicas entre as funções internas }\end{array}$ & $\begin{array}{l}\text { Crescimento das vendas } \\
\text { Crescimento da participação de mercado } \\
\text { Rentabilidade } \\
\text { - retorno sobre o investimento } \\
\text { - retorno sobre o ativo } \\
\text { - aumento das receitas } \\
\text { - lucro líquido } \\
\text { - liquidez financeira }\end{array}$ \\
\hline Carr e Pearson (1999) & $\begin{array}{l}\text { Estratégias de compras } \\
\text { - a função de compra tem um plano formal por escrito de longo prazo }\end{array}$ & $\begin{array}{l}\text { Desempenho financeiro } \\
\text { - Retorno sobre o investimento }\end{array}$ \\
\hline
\end{tabular}




\begin{tabular}{|c|c|c|}
\hline Autor & Variáveis independentes & Variáveis dependentes \\
\hline & $\begin{array}{l}\text { - o plano de compras de longo prazo é revisado e ajustado conforme as mudanças nos } \\
\text { planos estratégicos da empresa } \\
\text { - o plano de compras de longo prazo inclui os vários tipos de relações a serem } \\
\text { estabelecidas com os fornecedores } \\
\text { Sistemas de avaliação de fornecedores } \\
\text { - temos um programa de certificação formal do fornecedor } \\
\text { - nossa empresa tem um sistema formal para acompanhar o desempenho dos nossos } \\
\text { fornecedores } \\
\text { - nossa empresa tem um programa formal para avaliar e reconhecer os fornecedores } \\
\text { Relacionamento empresa-fornecedor } \\
\text { - nós possuímos acordos especiais com fornecedores que tenham um melhor desempenho } \\
\text { - somos leais aos nosso principais fornecedores } \\
\text { - nós temos frequientemente encontros pessoais para planejamentos de comunicação com } \\
\text { os principais fornecedores. } \\
\text { - existe um alto nível de comunicação da empresa com seus principais fornecedores para } \\
\text { questões mais importantes } \\
\text { - existe uma integração direta entre os computadores da nossa empresa e os dos nossos } \\
\text { principais fornecedores } \\
\text { - nosso departamento de compras pode influenciar a responsividade dos nossos } \\
\text { fornecedores de primeira camada nas suas exigências de compras }\end{array}$ & $\begin{array}{l}\text { - Lucro como um percentual das vendas } \\
\text { - lucro líquido da empresa antes de } \\
\text { impostos } \\
\text { - valor presente da empresa }\end{array}$ \\
\hline Agan (2005) & $\begin{array}{l}\text { A informação do pedido dos nossos clientes é visível aos nossos fornecedores } \\
\text { O embarque de pedidos com vários itens é consolidado antes da entrega } \\
\text { Os clientes podem selecionar o canal para receber seus pedidos. } \\
\text { Nossos clientes têm acesso em tempo real sobre a disponibilidade do produto } \\
\text { Nossos clientes estão envolvidos no desenvolvimento de novos produtos } \\
\text { Nossos clientes têm acesso a informações do pedido pela internet } \\
\text { Nossos clientes podem modificar os pedidos s on-line (por exemplo, mudar a quantidade } \\
\text { ou adicionar itens) } \\
\text { Nosso estoque é visível aos nossos fornecedores } \\
\text { Nós sabemos das capacidades de produção de nossos fornecedores } \\
\text { Nós integramos os processos de compras com os fornecedores } \\
\text { Nossos fornecedores estão envolvidos no desenvolvimento de novos produtos } \\
\text { Os nossos parceiros na cadeia de suprimentos têm visibilidade dos nossos processos de } \\
\text { devolução } \\
\text { Nós controlamos o processo de devolução com os nossos parceiros da cadeia } \\
\text { Realizamos os processos de planejamento e previsão com os nossos parceiros da cadeia }\end{array}$ & $\begin{array}{l}\text { Custo dos produtos e serviços } \\
\text { Qualidade dos produtos e serviços } \\
\text { Tempo de ciclo da entrega dos pedidos } \\
\text { Níveis de estoque } \\
\text { Rapidez no desenvolvimento de novos } \\
\text { produtos e serviços } \\
\text { Confiança entre os parceiros da cadeia } \\
\text { Aquisição de novos clientes } \\
\text { Satisfação dos clientes } \\
\text { Retenção de clientes } \\
\text { Crescimento da participação de mercado } \\
\text { nos últimos } 3 \text { anos } \\
\text { Crescimento das vendas nos últimos } 3 \text { anos } \\
\text { Crescimento do lucro nos últimos } 3 \text { anos } \\
\text { Retorno sobre o investimento ao longo dos } \\
\text { últimos } 3 \text { anos }\end{array}$ \\
\hline Rosenzweig et al. (2003) & Intimamente integrado com a própria empresa & Retorno sobre Ativos (ROA) \\
\hline
\end{tabular}




\begin{tabular}{|c|c|c|}
\hline Autor & Variáveis independentes & Variáveis dependentes \\
\hline & $\begin{array}{l}\text { Intimamente integrado com os fornecedores de matéria prima } \\
\text { Intimamente integrado com distribuidores e varejistas } \\
\text { Intimamente integrado com os clientes }\end{array}$ & $\begin{array}{l}\text { Aumento das vendas } \\
\text { Satisfação dos clientes } \\
\text { Porcentagem de vendas proveniente de } \\
\text { novos produtos }\end{array}$ \\
\hline Vickery et al. (2003) & $\begin{array}{l}\text { Tecnologias de informação integrativas } \\
\text { - intercâmbio eletrônico de dados (EDI) integrados } \\
\text { - sistemas de informação integrados } \\
\text { - sistemas informatizados de produção } \\
\text { Integração da cadeia de suprimentos } \\
\text { - parceria com fornecedores } \\
\text { - relacionamento estreito com os clientes } \\
\text { - equipes multifuncionais }\end{array}$ & $\begin{array}{l}\text { Serviço ao cliente } \\
\text { - atendimento ao cliente antes da venda } \\
\text { - suporte ao produto } \\
\text { - resposta ao cliente } \\
\text { - rapidez na entrega } \\
\text { - confiabilidade na entrega } \\
\text { Desempenho financeiro } \\
\text { - retorno sobre o ativo antes dos impostos } \\
\text { - retorno sobre investimento } \\
\text { - retorno sobre vendas }\end{array}$ \\
\hline Das et al. (2006) & $\begin{array}{l}\text { Práticas de integração externa } \\
\text { - solução conjunta de problemas com o fornecedor } \\
\text { - grau de confiança mútua com o fornecedor } \\
\text { - comprometimento da alta gerencia com o desenvolvimento do relacionamento com o } \\
\text { fornecedor } \\
\text { - investimentos conjuntos com o fornecedor } \\
\text { - assistência tecnológica para o fornecedor } \\
\text { - assistência financeira ao fornecedor } \\
\text { - treinamento em qualidade ao fornecedor } \\
\text { - comunicação direta entre programadores da produção do comprador e fábricas dos } \\
\text { compradores } \\
\text { - informações de custo compartilhadas pelo fornecedor } \\
\text { - informações de custo compartilhadas para o fornecedor } \\
\text { - uso de sistemas padronizados entre cliente e fornecedor } \\
\text { - procedimentos formais de avaliação de fornecedores } \\
\text { - Uso de custos totais } \\
\text { - Preocupação para que o fornecedor ganhe um lucro justo } \\
\text { - Fornecedores se preocupam para que o comprador ganhe um lucro justo } \\
\text { - Concessão de prêmios de desempenho e recompensas ao fornecedor } \\
\text { Práticas de integração interna } \\
\text { - estabelecimento de metas conjuntas com a manufatura } \\
\text { - o setor de compras atende regularmente aos interesses estratégicos da empresa } \\
\text { - o setor de compras recomenda mudanças nos produtos finais e insumos com base em }\end{array}$ & $\begin{array}{l}\text { Desempenho de manufatura } \\
\text { - redução de custos de manufatura } \\
\text { - aumento da qualidade } \\
\text { - redução do tempo de ciclo da manufatura } \\
\text { - tempo para introdução de novos produtos } \\
\text { - entregas } \\
\text { Desempenho financeiro } \\
\text { - lucro líquido } \\
\text { - aumento nas vendas } \\
\text { - retorno sobre o ativo } \\
\text { - participação de mercado }\end{array}$ \\
\hline
\end{tabular}




\begin{tabular}{|c|c|c|}
\hline Autor & Variáveis independentes & Variáveis dependentes \\
\hline & $\begin{array}{l}\text { análise do mercado fornecedor } \\
\text { - o setor de compras participa de equipes multifuncionais } \\
\text { - o setor de compras gasta tempo principalmente com desenvolvimento de fornecedores e } \\
\text { de certificação } \\
\text { - o setor de compras participa na criação de novos produtos } \\
\text { - o setor de compras participa no desenho de processos } \\
\text { - o setor de compras é medido por contribuições estratégicas para a empresa (novos } \\
\text { produtos ou tecnologias versus medidas de custos eficiência) }\end{array}$ & \\
\hline Cousins e Menguc (2006) & $\begin{array}{l}\text { Programação } \\
\text { Gerenciamento do pedido } \\
\text { Previsão } \\
\text { Planejamento da produção }\end{array}$ & $\begin{array}{l}\text { Desempenho operacional } \\
\text { - redução do custo total } \\
\text { - tempo de resposta ao mercado } \\
\text { - lead time } \\
\text { - conformidade com as especificações } \\
\text { - melhoria da qualidade } \\
\text { - programação das entregas } \\
\text { - melhoria dos processos } \\
\text { Desempenho de informação } \\
\text { - eficácia das comunicações } \\
\text { - qualidade e atualidade das informações } \\
\text { compartilhadas } \\
\text { - feedback do fornecedor }\end{array}$ \\
\hline Swink et al. (2007) & $\begin{array}{l}\text { Integração estratégica com o cliente } \\
\text { - mantemos um contacto próximo com os nossos clientes } \\
\text { - os resultados das pesquisas de satisfação dos clientes são compartilhados com todos os } \\
\text { funcionários } \\
\text { - estamos ativamente criando oportunidades para interação entre clientes e funcionários } \\
\text { - temos um programa formal para a "satisfação do cliente" } \\
\text { Integração estratégica com o fornecedor } \\
\text { - compartilhamos as nossas informações de custos com os nossos principais fornecedores } \\
\text { - exigimos o compartilhamento de informações de custo por parte dos nossos fornecedores } \\
\text { - exigimos que os principais fornecedores contribuam para a melhoria da qualidade e do } \\
\text { custo - compartilhamos em tempo real a informação da programação de produção com os } \\
\text { fornecedores } \\
\text { - enfatizamos o envolvimento dos novos fornecedores no desenvolvimento dos produtos } \\
\text { - usamos "junta administrativa" de clientes e fornecedores } \\
\text { Integração tecnológica de processos } \\
\text { - criamos novas maneiras de coordenar as questões de desenvolvimento e produção }\end{array}$ & $\begin{array}{l}\text { Desempenho de mercado } \\
\text { - taxa de crescimento de vendas em } \\
\text { unidades } \\
\text { - participação de mercado das principais } \\
\text { linhas de produtos } \\
\text { - rentabilidade } \\
\text { Satisfação do consumidor }\end{array}$ \\
\hline
\end{tabular}




\begin{tabular}{|c|c|c|}
\hline Autor & Variáveis independentes & Variáveis dependentes \\
\hline & $\begin{array}{l}\text { - usamos métodos "Projeto para Manufatura e Montagem" (DFMA) } \\
\text { - o envolvimento da manufatura é necessário para novos produtos } \\
\text { - nós usamos a rotação de trabalho entre desenvolvimento e engenharia de produção } \\
\text { - nossos desenvolvedores de produtos fazem uso de diretrizes de fabricação } \\
\text { - desenvolvedores de produtos e equipe de produção têm o estatuto de igualdade em } \\
\text { projetos de desenvolvimento de novos produtos } \\
\text { Integração da estratégia corporativa } \\
\text { - as estratégias de produção estão bem alinhadas com a estratégia corporativa } \\
\text { - temos claramente definidos os objetivos estratégicos e metas da produção } \\
\text { - nossas estratégias alavancam nossas capacidades existentes } \\
\text { - a estratégia corporativa em nossas unidades orientam decisões as de produção } \\
\text { - as estratégias de produção e as metas são comunicadas a todos os empregados } \\
\text { - as estratégias de manufatura são freqüentemente analisadas e revistas }\end{array}$ & \\
\hline
\end{tabular}


APÊNDICE B - Quadro resumo das variáveis consideradas em pesquisas de integração e desempenho

\begin{tabular}{|c|c|}
\hline Variáveis independentes & Variáveis dependentes \\
\hline $\begin{array}{l}\text { INTEGRAÇÃO DA CADEIA DE SUPRIMENTOS } \\
\text { Integração interna } \\
\text { - ampla integração interna entre as funções } \\
\text { - minha unidade de negócios usa equipes multifuncionais para apoiar os objetivos } \\
\text { estratégicos da nossa unidade. } \\
\text { - integração dos sistemas de informação entre as funções internas } \\
\text { - acesso em tempo real dos dados operacionais relativos à logística } \\
\text { - utilização de reuniões interdepartamentais periódicas entre as funções internas } \\
\text { Integração externa com fornecedores } \\
\text { - nossa empresa oferece aos fornecedores as informações de previsão de demanda. } \\
\text { - nossa empresa pode facilmente monitorar o status de seus pedidos. } \\
\text { - nossa empresa compartilha seus planos de produção com os fornecedores. } \\
\text { - a minha unidade compartilha recursos com o fornecedor, tais como depósitos e } \\
\text { instalações. } \\
\text { - o fornecedor e minha unidade gerenciam em conjunto de iniciativas de desenvolvimento } \\
\text { de novos produtos. } \\
\text { - gerenciamento integrado da previsão da demanda } \\
\text { - nós compartilhamos uma grande quantidade de informações importantes com os nossos } \\
\text { fornecedores } \\
\text { - nível de participação dos fornecedores na fase de design } \\
\text { - compras estáveis através da cadeia } \\
\text { - existe uma integração direta entre os computadores da nossa empresa e os dos nossos } \\
\text { principais fornecedores } \\
\text { - nós sabemos das capacidades de produção de nossos fornecedores } \\
\text { - assistência tecnológica para o fornecedor } \\
\text { - Preocupação para que o fornecedor ganhe um lucro justo } \\
\text { - Fornecedores se preocupam para que o comprador ganhe um lucro justo } \\
\text { - compartilhamos as nossas informações de custos com os nossos principais fornecedores } \\
\text { - exigimos o compartilhamento de informações de custo por parte dos nossos fornecedores } \\
\text { - compartilhamos em tempo real a informação da programação de produção com os } \\
\text { fornecedores } \\
\text { Integração externa com clientes } \\
\text { - nossos clientes fornecem suas informações de previsão da demanda. } \\
\text { - nossos clientes podem facilmente monitorar o status de seus pedidos. } \\
\text { - o cliente e minha unidade coordenam conjuntamente o planejamento de produção. } \\
\text { - a minha unidade compartilha recursos, tais como depósitos e instalações com o cliente. } \\
\text { - o cliente e minha unidade gerenciam em conjunto de iniciativas de desenvolvimento de }\end{array}$ & $\begin{array}{l}\text { DESEMPENHO INDIVIDUAL } \\
\text { Perspectiva dos processos empresariais } \\
\text { - melhora no tempo de entrega } \\
\text { - confiabilidade na entrega } \\
\text { - redução dos níveis de estoque } \\
\text { - redução de custos de manufatura } \\
\text { - pedidos entregue no prazo } \\
\text { - taxa de atendimento dos pedidos } \\
\text { - lead-time da produção } \\
\text { - lead-time da compras } \\
\text { - flexibilidade de serviço ao cliente } \\
\text { - flexibilidade para responder e atender variações de demanda, tais como a } \\
\text { sazonalidade. } \\
\text { - custo unitário de produção médio } \\
\text { - rapidez no desenvolvimento de novos produtos e serviços } \\
\text { Perspectiva dos clientes } \\
\text { - diminuição das reclamações dos clientes } \\
\text { - aumento na participação de mercado } \\
\text { - retenção de clientes } \\
\text { - tempo de resposta ao cliente } \\
\text { - aumento do nível de serviço ao cliente } \\
\text { - número de novos produtos desenvolvidos } \\
\text { Perspectiva financeira } \\
\text { - aumento nas vendas em unidades } \\
\text { - aumento das receitas } \\
\text { - lucro líquido } \\
\text { - liquidez financeira } \\
\text { - aumento da rentabilidade } \\
\text { - retorno sobre investimento } \\
\text { - retorno sobre o ativo total } \\
\text { - aumento do giro de estoque } \\
\text { - custo dos produtos e serviços } \\
\text { Perspectiva da inovação e do aprendizado } \\
\text { - aumento da competitividade } \\
\text { - melhoria nos processos }\end{array}$ \\
\hline
\end{tabular}




\begin{tabular}{|c|c|}
\hline Variáveis independentes & Variáveis dependentes \\
\hline & $\begin{array}{l}\text { Perspectiva dos clientes } \\
\text { - aumento da satisfação dos clientes } \\
\text { - diminuição das reclamações dos clientes } \\
\text { - retenção de clientes } \\
\text { - tempo de resposta ao cliente } \\
\text { - aumento do nível de serviço ao cliente } \\
\text { - número de novos produtos desenvolvidos }\end{array}$ \\
\hline & $\begin{array}{l}\text { Perspectiva da inovação e do aprendizado } \\
\text { - aumento da competitividade global } \\
\text { - melhoria global nos processos }\end{array}$ \\
\hline
\end{tabular}


APÊNDICE C - Questionário final

SIJEAUSP

\section{UNIVERSIDADE DE SÃO PAULO \\ FACULDADE DE ECONOMIA, ADMINISTRAÇÃOO E CONTABILIDADE DEPARTAMENTO DE ADMINISTRAÇÃOO \\ PROGRAMA DE PÓS-GRADUAÇÃO EM ADMINISTRAÇÃO}

\section{APRESENTAÇÃO}

Prezados Senhores,

Estamos realizando uma pesquisa sobre integração da cadeia de suprimentos com empresas de médio e grande porte. Esta pesquisa é parte da tese de doutorado do Sr. Fernando Scandiuzzi, aluno do Programa de Pós-Graduação em Administração da Faculdade de Economia, Administração e Contabilidade - FEA, da Universidade de São Paulo - USP, e tem como objetivo verificar a relação entre integração das empresas de uma cadeia de suprimentos e seus respectivos desempenhos empresariais.

Todos os dados serão considerados confidenciais e não serão identificados e nem analisados de forma individual, mas sim em conjunto com os dados das demais empresas respondentes. As questões não envolvem dados quantitativos como lucro, volume de vendas, etc., mas sim constituídas por Escalas (ativides de natureza comercial. Os resultados obtidos pela pesquisa ficarão a disposição das empresas colaboradoras, resguardadas as suas identificações.

Sua participação é de extrema importância e gostariamos muito de poder contar com sua colaboração. O questionário é de rápido preenchimento e pode ser acessado pelo link que se encontra na parte inferior da página, denominado "Responder Questionário".

Caso julguem necessário, nossos contatos são:

Telefone: ou

Email: mmattos@usp.br ou fscandi@usp.br

Ficamos no aguardo e desde já agradecemos pela atenção.

Prof. Dr. Marcio Mattos Borges de Oliveira

Orientador

\section{INSTRUÇÕES}

Praticamente todos os campos devem ser preenchidos, salvo as seguintes exceções:

- A questão 3 não é obrigatória, porém é de grande importância. Caso possua as informações, favor respondê-la;

- Caso a sua empresa seja apenas varejista, isto é, todos seus clientes forem pessoas físicas (consumidor final), as questões 2.3 e 2.4 , e as questões 20 a 28 não devem ser respondidas.

Se houver algum problema e/ou dificuldade com alguma questão, atribua um valor qualquer e descreva no último campo da pesquisa, denominado "OBSERVAÇÓES", o número da questão e o problema e/ou dificuldade encontrada.

Caso tenha outras dificuldades no preenchimento do questionário, favor entrar em contato pelos os email acima. 
UNIVERSIDADE DE SÃO PAULO

FACULDADE DE ECONOMIA, ADMINISTRACÃO E CONTABILIDADE

DEPARTAMENTO DE ADMINISTRAÇÃO

PROGRAMA DE PÓS-GRADUAÇÃOO EM ADMINISTRAÇÃO

\section{QUESTIONÁRIO}

\section{DADOS CADASTRAIS}
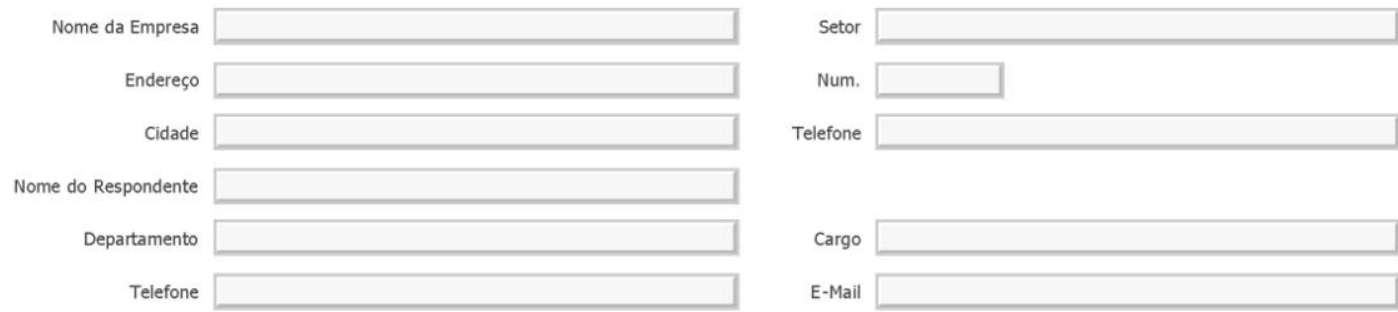

1. Cite a principal linha de produtos da empresa

2. Com base a principal linha de produtos citada na questão anterior, cite dois clientes e dois fornecedores que você considera estar mais integrado. Se a sua ế.

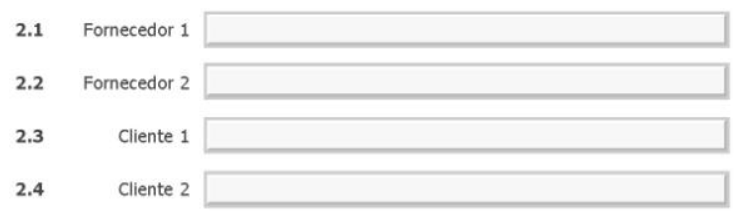

3. Se possivel, para cada uma das empresas citadas acima, explique como se dá a integração e qual a data aproximada em que esta integração começou.

Empresa

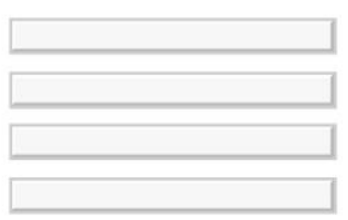

Como é feita a integração?

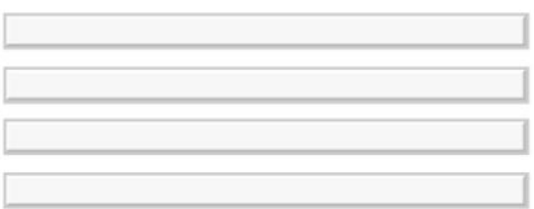

Data aproximada de início da integração

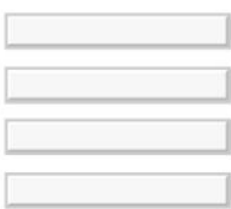

\section{Integração da Cadeia de Suprimentos}

Nesta parte do questionário, procuramos saber qual o nivel de integração da sua empresa com os dois clientes e fornecedores que foram citados na Questão 2. Se a sua empresa é somente varejo, ou seja, se seus clientes são somente pessoas físicas (consumidores finais), não responda as questốes de 20 a 28.

Por favor, indique o seu nivel de concordância com relação a cada item abaixo: 


\begin{tabular}{|c|c|c|c|c|c|c|c|}
\hline $\begin{array}{l}\text { 5. A minha empresa usa equipes multifuncionais para apoiar os } \\
\text { objetivos estratégicos da nossa unidade }\end{array}$ & $\odot 1$ & $\mathrm{O}_{2}$ & $\mathrm{O}_{3}$ & $\mathrm{O}_{4}$ & $\mathrm{O}_{5}$ & $\mathrm{O}_{6}$ & 07 \\
\hline $\begin{array}{l}\text { 6. Na minha empresa existe integração dos sistemas de } \\
\text { informação entre as funç̄es internas }\end{array}$ & $\odot_{1}$ & $\mathrm{O}_{2}$ & $\mathrm{O}_{3}$ & $\mathrm{O}_{4}$ & $\mathrm{O}_{5}$ & $\mathrm{O}_{6}$ & $0>$ \\
\hline $\begin{array}{l}\text { 7. A minha empresa oferece aos fornecedores as informaçöes de } \\
\text { previsāo de demanda }\end{array}$ & $\odot_{1}$ & $\mathrm{O}_{2}$ & $\mathrm{O}_{3}$ & $\mathrm{O}_{4}$ & $\mathrm{O}_{5}$ & $\mathrm{O}_{6}$ & $\mathrm{O}_{7}$ \\
\hline $\begin{array}{l}\text { 8. A minha empresa pode facilmente monitorar o status de seus } \\
\text { pedidos }\end{array}$ & $\odot_{1}$ & $\mathrm{O}_{2}$ & $\mathrm{O}_{3}$ & $\mathrm{O}_{4}$ & $\mathrm{O}_{5}$ & $\mathrm{O}_{6}$ & 07 \\
\hline $\begin{array}{l}\text { 9. A minha empresa compartilha seus planos de produção com os } \\
\text { fornecedores }\end{array}$ & $\odot_{1}$ & $\mathrm{O}_{2}$ & $\mathrm{O}_{3}$ & $\mathrm{O}_{4}$ & $\mathrm{O}_{5}$ & $\mathrm{O}_{6}$ & $0>$ \\
\hline $\begin{array}{l}\text { 10. A minha empresa compartiha recursos com o fornecedor, } \\
\text { tais como depósitos e instalaçōes }\end{array}$ & $\odot_{1}$ & $\mathrm{O}_{2}$ & $\mathrm{O}_{3}$ & $\mathrm{O}_{4}$ & $\mathrm{O}_{5}$ & $\mathrm{O}_{6}$ & 07 \\
\hline $\begin{array}{l}\text { 11. O fornecedor e a minha empresa gerenciam em conjunto de } \\
\text { iniciativas de desenvolvimento de novos produtos }\end{array}$ & $\odot_{1}$ & $\mathrm{O}_{2}$ & $\mathrm{O}_{3}$ & $\mathrm{O}_{4}$ & $\mathrm{O}_{5}$ & $\mathrm{O}_{6}$ & 07 \\
\hline $\begin{array}{l}\text { 12. A minha empresa possui gerenciamento integrado da } \\
\text { previsão da demanda }\end{array}$ & $\odot_{1}$ & $\mathrm{O}_{2}$ & $\mathrm{O}_{3}$ & $\mathrm{O}_{4}$ & $\mathrm{O}_{5}$ & $\mathrm{O}_{6}$ & 07 \\
\hline $\begin{array}{l}\text { 13. A minha empresa compartilha uma grande quantidade de } \\
\text { informaçoses importantes com os nossos fornecedores }\end{array}$ & $\odot_{1}$ & $\mathrm{O}_{2}$ & $\mathrm{O}_{3}$ & $\mathrm{O}_{4}$ & $\mathrm{O}_{5}$ & $\mathrm{O}_{6}$ & 07 \\
\hline $\begin{array}{l}\text { 14. Nossos fornecedores participam da fase de design de nossos } \\
\text { produtos }\end{array}$ & $\odot_{1}$ & $\mathrm{O}_{2}$ & $\mathrm{O}_{3}$ & $\mathrm{O}_{4}$ & $\mathrm{O}_{5}$ & $\mathrm{O}_{6}$ & $O_{7}$ \\
\hline $\begin{array}{l}\text { 15. Existe uma integração direta entre os computadores da nossa } \\
\text { empresa e os dos nossos principais fornecedores }\end{array}$ & $\odot_{1}$ & $\mathrm{O}_{2}$ & $\mathrm{O}_{3}$ & $\mathrm{O}_{4}$ & $\mathrm{O}_{5}$ & $\mathrm{O}_{6}$ & $\mathrm{O}>$ \\
\hline $\begin{array}{l}\text { 16. A nossa empresa sabe das capacidades de produção de } \\
\text { nossos fornecedores }\end{array}$ & $\odot_{1}$ & $\mathrm{O}_{2}$ & $\mathrm{O}_{3}$ & $\mathrm{O}_{4}$ & $\mathrm{O}_{5}$ & $\mathrm{O}_{6}$ & $\mathrm{O}_{7}$ \\
\hline $\begin{array}{l}\text { 17. A nossa empresa compartillha as nossas informaşōes de } \\
\text { custos com os nossos principais fornecedores }\end{array}$ & $\odot_{1}$ & $\mathrm{O}_{2}$ & $\mathrm{O}_{3}$ & $\mathrm{O}_{4}$ & $\mathrm{O}_{5}$ & $\mathrm{O}_{6}$ & 07 \\
\hline $\begin{array}{l}\text { 18. A nossa empresa exige que o compartilhamento de } \\
\text { informaçoes de custo por parte dos nossos fornecedores }\end{array}$ & $\odot_{1}$ & $\mathrm{O}_{2}$ & $\mathrm{O}_{3}$ & $\mathrm{O}_{4}$ & $\mathrm{O}_{5}$ & $\mathrm{O}_{6}$ & 07 \\
\hline $\begin{array}{l}\text { 19. A nossa empresa compartilha em tempo real a informação da } \\
\text { programação de produção com os fornecedores }\end{array}$ & $\odot_{1}$ & $\mathrm{O}_{2}$ & $\mathrm{O}_{3}$ & $\mathrm{O}_{4}$ & $\mathrm{O}_{5}$ & $\mathrm{O}_{6}$ & 07 \\
\hline $\begin{array}{l}\text { 20. Os nossos clientes fornecem suas informaşöes de previsão da } \\
\text { demanda para a nossa empresa }\end{array}$ & $\odot_{1}$ & $\mathrm{O}_{2}$ & $\mathrm{O}_{3}$ & $\mathrm{O}_{4}$ & $\mathrm{O}_{5}$ & $\mathrm{O}_{6}$ & 07 \\
\hline $\begin{array}{l}\text { 21. Os nossos clientes podem facilmente monitorar o status de } \\
\text { seus pedidos realizados na nossa empresa }\end{array}$ & $\odot_{1}$ & $\mathrm{O}_{2}$ & $\mathrm{O}_{3}$ & $\mathrm{O}_{4}$ & $\mathrm{O}_{5}$ & $\mathrm{O}_{6}$ & 07 \\
\hline $\begin{array}{l}\text { 22. Nossos clientes e a minha empresa coordenam } \\
\text { conjuntamente o planejamento de produção }\end{array}$ & $\odot_{1}$ & $\mathrm{O}_{2}$ & $\mathrm{O}_{3}$ & $\mathrm{O}_{4}$ & $\mathrm{O}_{5}$ & $\mathrm{O}_{6}$ & $\mathrm{O}>$ \\
\hline $\begin{array}{l}\text { 23. A minha empresa compartilha recursos, tais como depósitos } \\
\text { e instalaçôes com os clientes }\end{array}$ & $\odot_{1}$ & $\mathrm{O}_{2}$ & $\mathrm{O}_{3}$ & $\mathrm{O}_{4}$ & $\mathrm{O}_{5}$ & $\mathrm{O}_{6}$ & $\mathrm{O}>$ \\
\hline $\begin{array}{l}\text { 24. Nossos clientes e a minha empresa gerenciam em conjunto } \\
\text { iniciativas de desenvolvimento de novos produtos }\end{array}$ & $\odot_{1}$ & $\mathrm{O}_{2}$ & $\mathrm{O}_{3}$ & $\mathrm{O}_{4}$ & $\mathrm{O}_{5}$ & $\mathrm{O}_{6}$ & 07 \\
\hline $\begin{array}{l}\text { 25. Nossos clientes e a minha empresa identificam em conjunto } \\
\text { oportunidades de novos mercados }\end{array}$ & $\odot_{1}$ & $\mathrm{O}_{2}$ & $\mathrm{O}_{3}$ & $\mathrm{O}_{4}$ & $\mathrm{O}_{5}$ & $\mathrm{O}_{6}$ & 07 \\
\hline $\begin{array}{l}\text { 26. A nossa empresa realiza gerenciamento integrado da } \\
\text { previsão da demanda }\end{array}$ & $\odot_{1}$ & $\mathrm{O}_{2}$ & $\mathrm{O}_{3}$ & $\mathrm{O}_{4}$ & $\mathrm{O}_{5}$ & $\mathrm{O}_{6}$ & O 7 \\
\hline $\begin{array}{l}\text { 27. A nossa empresa realiza gerenciamento do relacionamento } \\
\text { com o cliente }\end{array}$ & $\odot_{1}$ & $\mathrm{O}_{2}$ & $\mathrm{O}_{3}$ & $\mathrm{O}_{4}$ & $\mathrm{O}_{5}$ & $\mathrm{O}_{6}$ & 07 \\
\hline
\end{tabular}


28. Os nossos clientes têm acesso em tempo real sobre a disponibilidade do produto da nossa empresa

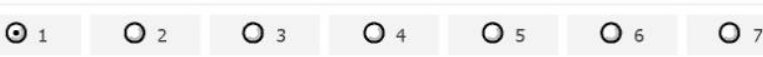

\section{Desempenho Individual}

De acordo com a principal linha de produtos citada na Questão 2, por favor, classifique o desempenho individual da sua empresa em comparação com a média do setor com relação aos seguintes itens:

\begin{tabular}{|c|c|c|c|c|c|c|c|}
\hline \multirow[b]{2}{*}{ 29. Tempo de entrega } & \multicolumn{5}{|c|}{$\begin{array}{l}\text { Muito abaixo da } \\
\text { média do setor }\end{array}$} & \multicolumn{2}{|c|}{$\begin{array}{l}\text { Muito acima da } \\
\text { média do seto }\end{array}$} \\
\hline & $\odot_{1}$ & $\mathrm{O}_{2}$ & $\mathrm{O}_{3}$ & $\mathrm{O}_{4}$ & $\mathrm{O}_{5}$ & $O_{6}$ & 07 \\
\hline 30. Confiabilidade na entrega & $\odot 1$ & $\mathrm{O}_{2}$ & $\mathrm{O}_{3}$ & $\mathrm{O}_{4}$ & $\mathrm{O}_{5}$ & O 6 & O 7 \\
\hline 31. Niveis de estoque & $\odot_{1}$ & $\mathrm{O}_{2}$ & $\mathrm{O}_{3}$ & $\mathrm{O}_{4}$ & $\mathrm{O}_{5}$ & $\mathrm{O}_{6}$ & $\mathrm{O}_{7}$ \\
\hline 32. Custos de manufatura & $\odot_{1}$ & $\mathrm{O}_{2}$ & $\mathrm{O}_{3}$ & $\mathrm{O}_{4}$ & $\mathrm{O}_{5}$ & $\mathrm{O}_{6}$ & 07 \\
\hline 33. Pedidos entregue no prazo & $\odot_{1}$ & $\mathrm{O}_{2}$ & $\mathrm{O}_{3}$ & $\mathrm{O}_{4}$ & $\mathrm{O}_{5}$ & $\mathrm{O}_{6}$ & 07 \\
\hline 34. Taxa de atendimento dos pedidos & $\odot_{1}$ & $\mathrm{O}_{2}$ & $\mathrm{O}_{3}$ & $\mathrm{O}_{4}$ & $\mathrm{O}_{5}$ & $\mathrm{O}_{6}$ & $\mathrm{O}_{7}$ \\
\hline 35. Lead-time da produção & $\odot_{1}$ & $\mathrm{O}_{2}$ & $\mathrm{O}_{3}$ & $\mathrm{O}_{4}$ & $\mathrm{O}_{5}$ & O 6 & 07 \\
\hline 36. Lead-time da compras & $\odot_{1}$ & $\mathrm{O}_{2}$ & $\mathrm{O}_{3}$ & $\mathrm{O}_{4}$ & $\mathrm{O}_{5}$ & $\mathrm{O}_{6}$ & 07 \\
\hline 37. Flexibilidade de serviço ao cliente & $\odot_{1}$ & $\mathrm{O}_{2}$ & $\mathrm{O}_{3}$ & $\mathrm{O}_{4}$ & $\mathrm{O}_{5}$ & $\mathrm{O}_{6}$ & $\mathrm{O}_{7}$ \\
\hline $\begin{array}{l}\text { 38. Flexibilidade para responder e atender variaçöes de } \\
\text { demanda, tais como a sazonalidade }\end{array}$ & $\odot_{1}$ & $\mathrm{O}_{2}$ & $\mathrm{O}_{3}$ & $\mathrm{O}_{4}$ & $\mathrm{O}_{5}$ & $\mathrm{O}_{6}$ & $\mathrm{O} 7$ \\
\hline 39. Reclamaçöes dos clientes & $\odot_{1}$ & $\mathrm{O}_{2}$ & $\mathrm{O}_{3}$ & $\mathrm{O}_{4}$ & $\mathrm{O}_{5}$ & $\mathrm{O}_{6}$ & 07 \\
\hline 40. Participação de mercado & $\odot_{1}$ & $\mathrm{O}_{2}$ & $\mathrm{O}_{3}$ & $\mathrm{O}_{4}$ & $\mathrm{O}_{5}$ & $\mathrm{O}_{6}$ & 07 \\
\hline 41. Retenção de clientes & $\odot_{1}$ & $\mathrm{O}_{2}$ & $\mathrm{O}_{3}$ & $\mathrm{O}_{4}$ & $\mathrm{O}_{5}$ & $\mathrm{O}_{6}$ & $\mathrm{O}_{7}$ \\
\hline 42. Tempo de resposta ao cliente & $\odot_{1}$ & $\mathrm{O}_{2}$ & $\mathrm{O}_{3}$ & $\mathrm{O}_{4}$ & $\mathrm{O}_{5}$ & $\mathrm{O}_{6}$ & 07 \\
\hline 43. Nivel de serviço ao cliente & $\odot_{1}$ & $\mathrm{O}_{2}$ & $\mathrm{O}_{3}$ & $\mathrm{O}_{4}$ & $\mathrm{O}_{5}$ & $\mathrm{O}_{6}$ & $\mathrm{O}_{7}$ \\
\hline 44. Vendas em unidades & $\odot_{1}$ & $\mathrm{O}_{2}$ & $\mathrm{O}_{3}$ & $\mathrm{O}_{4}$ & $\mathrm{O}_{5}$ & $\mathrm{O}_{6}$ & $\mathrm{O}_{7}$ \\
\hline 45. Receitas & $\odot_{1}$ & $\mathrm{O}_{2}$ & $\mathrm{O}_{3}$ & $\mathrm{O}_{4}$ & $\mathrm{O}_{5}$ & $\mathrm{O}_{6}$ & 07 \\
\hline 46. Lucro líquido & $\odot_{1}$ & $\mathrm{O}_{2}$ & $\mathrm{O}_{3}$ & $\mathrm{O}_{4}$ & $\mathrm{O}_{5}$ & $\mathrm{O}_{6}$ & $\mathrm{O}_{7}$ \\
\hline 47. Retorno sobre investimento & $\odot_{1}$ & $\mathrm{O}_{2}$ & $\mathrm{O}_{3}$ & $\mathrm{O}_{4}$ & $\mathrm{O}_{5}$ & $\mathrm{O}_{6}$ & $\mathrm{O}_{7}$ \\
\hline 48. Retorno sobre o ativo total & $\odot_{1}$ & $\mathrm{O}_{2}$ & $\mathrm{O}_{3}$ & $\mathrm{O}_{4}$ & $\mathrm{O}_{5}$ & $\mathrm{O}_{6}$ & 07 \\
\hline 49. Giro de estoque & $\odot_{1}$ & $\mathrm{O}_{2}$ & $\mathrm{O}_{3}$ & $\mathrm{O}_{4}$ & $\mathrm{O}_{5}$ & $\mathrm{O}_{6}$ & $O_{7}$ \\
\hline 50. Custo dos produtos e serviços & $\odot_{1}$ & $\mathrm{O}_{2}$ & $\mathrm{O}_{3}$ & $\mathrm{O}_{4}$ & $\mathrm{O}_{5}$ & $\mathrm{O}_{6}$ & 07 \\
\hline
\end{tabular}




$\begin{array}{llllllll}\text { 51. Competitividade da empresa } & \odot_{1} & \mathrm{O}_{2} & \mathrm{O}_{3} & \mathrm{O}_{4} & \mathrm{O}_{5} & \mathrm{O}_{6} & \mathrm{O}_{7} \\ \text { 52. Melhoria continua dos processos internos } & \odot_{1} & \mathrm{O}_{2} & \mathrm{O}_{3} & \mathrm{O}_{4} & \mathrm{O}_{5} & \mathrm{O}_{6} & \mathrm{O}_{7}\end{array}$

\section{Desempenho da Cadeia de Suprimentos}

De acordo com a principal linha de produtos citada na Questão 2, por favor, classifique a SUA PERCEPÇÃO sobre o desempenho global da cadeia de suprimentos a qual sua empresa participa em comparação com as cadeias concorrentes, com relaçấo aos seguintes itens:

\begin{tabular}{|c|c|c|c|c|c|c|c|}
\hline \multirow[b]{2}{*}{ 53. Tempo de entrega } & \multicolumn{5}{|c|}{$\begin{array}{l}\text { Muito abaixo da média das } \\
\text { cadeias concorrentes }\end{array}$} & \multicolumn{2}{|c|}{$\begin{array}{l}\text { Muito acima da média das } \\
\text { cadeias concorrentes }\end{array}$} \\
\hline & $\odot_{1}$ & $\mathrm{O}_{2}$ & $\mathrm{O}_{3}$ & $\mathrm{O}_{4}$ & $\mathrm{O}_{5}$ & $\mathrm{O}_{6}$ & 07 \\
\hline 54. Confiabilidade na entrega & $\odot_{1}$ & $\mathrm{O}_{2}$ & $\mathrm{O}_{3}$ & $\mathrm{O}_{4}$ & $\mathrm{O}_{5}$ & $\mathrm{O}_{6}$ & 07 \\
\hline 55. Pedidos entregue no prazo & $\odot_{1}$ & $\mathrm{O}_{2}$ & $\mathrm{O}_{3}$ & $\mathrm{O}_{4}$ & $\mathrm{O}_{5}$ & $\mathrm{O}_{6}$ & 07 \\
\hline 56. Taxa de atendimento dos pedidos & $\odot_{1}$ & $\mathrm{O}_{2}$ & $\mathrm{O}_{3}$ & $\mathrm{O}_{4}$ & $\mathrm{O}_{5}$ & $\mathrm{O}_{6}$ & $\mathrm{O}_{7}$ \\
\hline 57. Lead-time da produção & $\odot_{1}$ & $\mathrm{O}_{2}$ & $\mathrm{O}_{3}$ & $\mathrm{O}_{4}$ & $\mathrm{O}_{5}$ & $\mathrm{O}_{6}$ & 07 \\
\hline 58. Lead-time da compras & $\odot_{1}$ & $\mathrm{O}_{2}$ & $\mathrm{O}_{3}$ & $\mathrm{O}_{4}$ & $\mathrm{O}_{5}$ & $\mathrm{O}_{6}$ & 07 \\
\hline 59. Tempo total de ciclo do pedido & $\odot_{1}$ & $\mathrm{O}_{2}$ & $\mathrm{O}_{3}$ & $\mathrm{O}_{4}$ & $\mathrm{O}_{5}$ & $\mathrm{O}_{6}$ & $\mathrm{O}_{7}$ \\
\hline 60. Satisfação dos clientes & $\odot_{1}$ & $\mathrm{O}_{2}$ & $\mathrm{O}_{3}$ & $\mathrm{O}_{4}$ & $\mathrm{O}_{5}$ & $\mathrm{O}_{6}$ & $\mathrm{O}_{7}$ \\
\hline 61. Reclamações dos clientes & $\odot_{1}$ & $\mathrm{O}_{2}$ & $\mathrm{O}_{3}$ & $\mathrm{O}_{4}$ & $\mathrm{O}_{5}$ & $\mathrm{O}_{6}$ & 07 \\
\hline 62. Retenção de clientes & $\odot_{1}$ & $\mathrm{O}_{2}$ & $\mathrm{O}_{3}$ & $\mathrm{O}_{4}$ & $\mathrm{O}_{5}$ & $\mathrm{O}_{6}$ & $\mathrm{O}_{7}$ \\
\hline 63. Tempo de resposta ao cliente & $\odot_{1}$ & $\mathrm{O}_{2}$ & $\mathrm{O}_{3}$ & $\mathrm{O}_{4}$ & $\mathrm{O}_{5}$ & $\mathrm{O}_{6}$ & 07 \\
\hline 64. Nivel de serviço ao cliente & $\odot_{1}$ & $\mathrm{O}_{2}$ & $\mathrm{O}_{3}$ & $\mathrm{O}_{4}$ & O 5 & O 6 & 07 \\
\hline 65. Custo total dos recursos utilizados & $\odot_{1}$ & $\mathrm{O}_{2}$ & $\mathrm{O}_{3}$ & $\mathrm{O}_{4}$ & $\mathrm{O}_{5}$ & $\mathrm{O}_{6}$ & $0>$ \\
\hline 66. Custos associados ao estoque parado & $\odot_{1}$ & $\mathrm{O}_{2}$ & $\mathrm{O}_{3}$ & $\mathrm{O}_{4}$ & $\mathrm{O}_{5}$ & $\mathrm{O}_{6}$ & 07 \\
\hline 67. Vendas em unidades & $\odot 1$ & $\mathrm{O}_{2}$ & $\mathrm{O}_{3}$ & $\mathrm{O}_{4}$ & $\mathrm{O} 5$ & $\mathrm{O}_{6}$ & $\mathrm{O}_{7}$ \\
\hline 68. Receitas & $\odot_{1}$ & $\mathrm{O}_{2}$ & $\mathrm{O}_{3}$ & $\mathrm{O}_{4}$ & $\mathrm{O}_{5}$ & $\mathrm{O}_{6}$ & $\mathrm{O}_{7}$ \\
\hline 69. Lucro liquido & $\odot_{1}$ & $\mathrm{O}_{2}$ & $\mathrm{O}_{3}$ & $\mathrm{O}_{4}$ & $\mathrm{O}_{5}$ & $\mathrm{O}_{6}$ & 07 \\
\hline 70. Retorno sobre investimento & $\odot_{1}$ & $\mathrm{O}_{2}$ & $\mathrm{O}_{3}$ & $\mathrm{O}_{4}$ & $\mathrm{O} 5$ & $\mathrm{O}_{6}$ & 07 \\
\hline 71. Retorno sobre o ativo total & $\odot_{1}$ & $\mathrm{O}_{2}$ & $\mathrm{O}_{3}$ & $\mathrm{O}_{4}$ & $\mathrm{O}_{5}$ & $\mathrm{O}_{6}$ & $\mathrm{O}_{7}$ \\
\hline 72. Giro de estoque & $\odot_{1}$ & $\mathrm{O}_{2}$ & $\mathrm{O}_{3}$ & $\mathrm{O}_{4}$ & $\mathrm{O}_{5}$ & $\mathrm{O}_{6}$ & 07 \\
\hline
\end{tabular}




$\begin{array}{lllllllll}\text { 73. Competitividade global } & \odot_{1} & \mathrm{O}_{2} & \mathrm{O}_{3} & \mathrm{O}_{4} & \mathrm{O}_{5} & \mathrm{O}_{6} & \mathrm{O}_{7} \\ \text { 74. Melhoria contínua global dos processos } & \odot_{1} & \mathrm{O}_{2} & \mathrm{O}_{3} & \mathrm{O}_{4} & \mathrm{O}_{5} & \mathrm{O}_{6} & \mathrm{O}_{7}\end{array}$

\section{OBSERVAÇÕES}

Por favor, se tiver algum comentário e/ou sugestão sobre esta pesquisa, utilize o campo abaixo para relatá-la. 


\section{APÊNDICE D - Validade Discriminante}

\begin{tabular}{|c|c|c|c|c|c|c|c|c|c|c|c|c|c|c|c|c|c|c|c|c|}
\hline & Ciclo & Cli_cad & Cli_ind & $\begin{array}{c}\text { Des_ca } \\
\text { d }\end{array}$ & $\begin{array}{c}\text { Des_in } \\
\text { d }\end{array}$ & $\begin{array}{c}\text { Ent_ca } \\
\text { d }\end{array}$ & $\begin{array}{c}\text { Ent_in } \\
\text { d }\end{array}$ & Ext_cli & $\begin{array}{c}\text { Ext_for } \\
\text { n }\end{array}$ & Fin_ind & $\begin{array}{c}\text { Fin_ca } \\
\text { d }\end{array}$ & $\begin{array}{c}\text { Flex_in } \\
\text { d }\end{array}$ & Infor & $\begin{array}{c}\text { Ino_ca } \\
\text { d }\end{array}$ & Ino_ind & Integ & Inter & Partic & $\begin{array}{c}\text { Pro_em_ } \\
\text { cad }\end{array}$ & $\begin{array}{c}\text { Pro_em_ } \\
\text { ind }\end{array}$ \\
\hline $\begin{array}{c}\text { Ciclo_pro_ca } \\
\text { d }\end{array}$ & 0,9024 & & & & & & & & & & & & & & & & & & & \\
\hline Cliente_cad & $-0,5418$ & 0,8453 & & & & & & & & & & & & & & & & & & \\
\hline Cliente_ind & $-0,3828$ & 0,6677 & 0,8100 & & & & & & & & & & & & & & & & & \\
\hline Des_cadeia & $-0,7065$ & 0,8613 & 0,6848 & 0,7903 & & & & & & & & & & & & & & & & \\
\hline $\begin{array}{c}\text { Des_individu } \\
\text { al }\end{array}$ & $-0,4458$ & 0,7236 & 0,8872 & 0,7934 & 0,8082 & & & & & & & & & & & & & & & \\
\hline Entrega_cad & $-0,5307$ & 0,6795 & 0,4736 & 0,7980 & 0,5602 & 0,8961 & & & & & & & & & & & & & & \\
\hline Entrega_ind & $-0,3922$ & 0,6551 & 0,6129 & 0,6379 & 0,7802 & 0,6467 & 0,8690 & & & & & & & & & & & & & \\
\hline $\begin{array}{c}\text { Externa_clie } \\
\text { ntes }\end{array}$ & $-0,3058$ & 0,4585 & 0,3508 & 0,4422 & 0,4404 & 0,3363 & 0,4362 & 0,7491 & & & & & & & & & & & & \\
\hline Externa_forn & $-0,1730$ & 0,3479 & 0,2012 & 0,3080 & 0,3042 & 0,2721 & 0,3761 & 0,6766 & 0,8759 & & & & & & & & & & & \\
\hline $\begin{array}{c}\text { Financeira_i } \\
\text { nd }\end{array}$ & $-0,2800$ & 0,3623 & 0,5960 & 0,5874 & 0,7651 & 0,2513 & 0,3524 & 0,2357 & 0,0937 & 0,8444 & & & & & & & & & & \\
\hline $\begin{array}{c}\text { Financeiro_c } \\
\text { ad }\end{array}$ & $-0,3032$ & 0,3767 & 0,4864 & 0,6638 & 0,6277 & 0,2698 & 0,2713 & 0,2327 & 0,0872 & 0,8212 & 0,9207 & & & & & & & & & \\
\hline $\begin{array}{c}\begin{array}{c}\text { Flexibilidade } \\
\text { ind }\end{array} \\
\end{array}$ & $-0,3944$ & 0,6105 & 0,5448 & 0,5439 & 0,6780 & 0,4085 & 0,5632 & 0,3802 & 0,2896 & 0,3151 & 0,2718 & 0,7685 & & & & & & & & \\
\hline Informações & $-0,2112$ & 0,3878 & 0,2235 & 0,3533 & 0,3216 & 0,3092 & 0,3866 & 0,6661 & 0,9304 & 0,1123 & 0,1199 & 0,2891 & 0,7664 & & & & & & & \\
\hline $\begin{array}{c}\text { Inovação_ca } \\
\text { d }\end{array}$ & $-0,4089$ & 0,5940 & 0,5672 & 0,7528 & 0,6112 & 0,4555 & 0,3669 & 0,3312 & 0,2893 & 0,5065 & 0,5513 & 0,3274 & 0,3076 & 0,8868 & & & & & & \\
\hline Inovação_ind & $-0,3434$ & 0,6459 & 0,6998 & 0,6745 & 0,8101 & 0,4485 & 0,5357 & 0,3718 & 0,3062 & 0,5634 & 0,4870 & 0,5066 & 0,3133 & 0,6394 & 0,8805 & & & & & \\
\hline Integração & $-0,2721$ & 0,4822 & 0,3400 & 0,4546 & 0,4481 & 0,3709 & 0,4747 & 0,9126 & 0,8872 & 0,2181 & 0,2059 & 0,3666 & 0,8806 & 0,3849 & 0,4133 & 0,6977 & & & & \\
\hline Interna & $-0,2074$ & 0,4795 & 0,3562 & 0,4618 & 0,4500 & 0,3880 & 0,4383 & 0,6232 & 0,5606 & 0,2737 & 0,2366 & 0,2659 & 0,6434 & 0,4270 & 0,4423 & 0,7732 & 0,8431 & & & \\
\hline Participação & $-0,0612$ & 0,1820 & 0,1011 & 0,1435 & 0,1830 & 0,1320 & 0,2456 & 0,4902 & 0,8178 & 0,0329 & 0,0071 & 0,2070 & 0,5501 & 0,1718 & 0,2016 & 0,6344 & 0,2599 & 0,7228 & & \\
\hline $\begin{array}{c}\text { Proc_empres } \\
\text { _cad }\end{array}$ & $-0,8269$ & 0,7085 & 0,4959 & 0,8653 & 0,5836 & 0,9154 & 0,6154 & 0,3686 & 0,2629 & 0,3001 & 0,3233 & 0,4584 & 0,3058 & 0,4970 & 0,4610 & 0,3756 & 0,3563 & 0,1166 & 0,8723 & \\
\hline $\begin{array}{c}\text { Proc_empres } \\
\text { _ind } \\
\end{array}$ & $-0,4394$ & 0,7152 & 0,6589 & 0,6765 & 0,8324 & 0,6292 & 0,9456 & 0,4669 & 0,3870 & 0,3800 & 0,3039 & 0,8013 & 0,3947 & 0,3953 & 0,5881 & 0,4893 & 0,4232 & 0,2596 & 0,6262 & 0,8764 \\
\hline
\end{tabular}




\section{ANEXOS}

ANEXO A - Sistema Dupont

\section{Sistema DuPont}

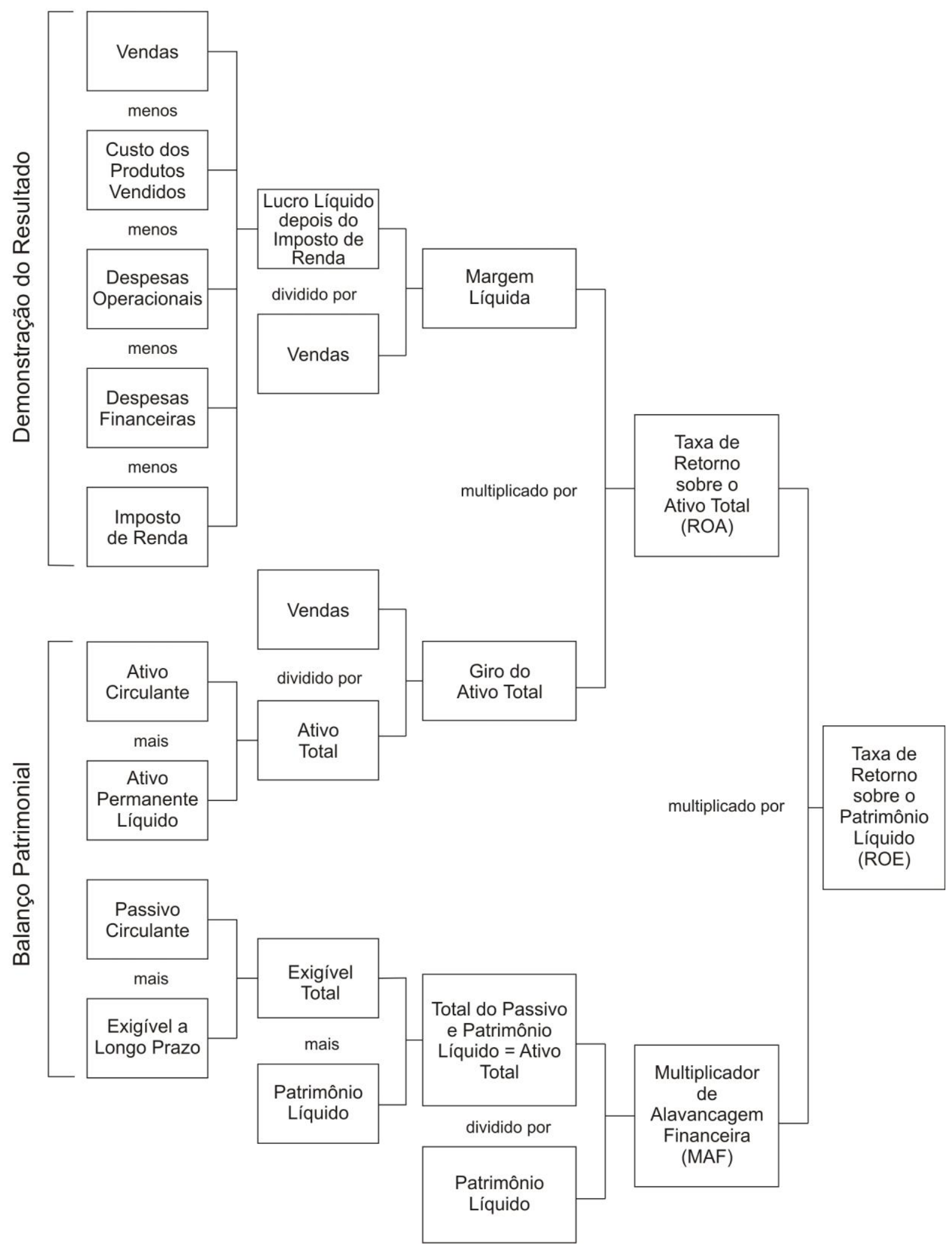

FONTE: Gitman (1997) 


\begin{tabular}{|c|c|}
\hline Índice & Fórmula \\
\hline \multicolumn{2}{|l|}{ Liquidez } \\
\hline Capital circulante & Ativo circulante - passivo circulante líquido \\
\hline \multirow[t]{2}{*}{ Liquidez corrente } & Ativo Circulante \\
\hline & Passivo Circulante \\
\hline \multirow[t]{2}{*}{ Liquidez seca } & (Ativo Circulante - Estoques) \\
\hline & Passivo Circulante \\
\hline \multicolumn{2}{|l|}{ Atividade } \\
\hline \multirow[t]{2}{*}{ Giro dos estoques } & Custo dos produtos vendidos \\
\hline & Estoques \\
\hline \multirow[t]{2}{*}{ Período médio de cobranças } & Duplicatas a receber \\
\hline & $\overline{\text { Vendas médias diárias }}$ \\
\hline \multirow[t]{2}{*}{ Período médio de pagamento } & Duplicatas a pagar \\
\hline & Compras médias diárias \\
\hline \multirow[t]{2}{*}{ Giro do ativo permanente } & Vendas \\
\hline & $\overline{\text { Ativo permanente líquido }}$ \\
\hline \multirow[t]{2}{*}{ Giro do ativo total } & Vendas \\
\hline & $\overline{\text { Ativo total }}$ \\
\hline \multicolumn{2}{|l|}{ Endividamento } \\
\hline \multirow[t]{2}{*}{ Endividamento geral } & Passivo Circulante + Exigível a longo prazo \\
\hline & Ativo total \\
\hline \multirow{2}{*}{$\begin{array}{l}\text { Exigível a longo prazo - patrimônio } \\
\text { líquido }\end{array}$} & Exigível a longo prazo \\
\hline & Patrimônio líquido \\
\hline \multirow{2}{*}{$\begin{array}{l}\text { Capacidade de honrar dividas: } \\
\text { cobertura de juros }\end{array}$} & Lucro antes dos juros e I.R. \\
\hline & Juros \\
\hline \multirow[t]{2}{*}{ Cobertura de pagamentos fixos } & Lucro antes dos juros e I.R.+ pagamentos de leasing \\
\hline & $\overline{\text { Juros }+ \text { pagamentos de leasing }+\{([\text { princ. }+ \text { div.pref. }) \times[1 /(1-\mathrm{T})]\}}$ \\
\hline \multicolumn{2}{|l|}{ Lucratividade } \\
\hline \multirow[t]{2}{*}{ Margem bruta } & Lucro bruto \\
\hline & Vendas \\
\hline \multirow[t]{2}{*}{ Margem operacional } & Lucro operacional \\
\hline & Vendas \\
\hline \multirow[t]{2}{*}{ Margem líquida } & Lucro líquido depois do I.R. \\
\hline & Vendas \\
\hline \multirow[t]{2}{*}{ Retorno sobre o ativo total (ROA) } & Lucro líquido depois do I.R. \\
\hline & Ativo total \\
\hline \multirow{2}{*}{$\begin{array}{l}\text { Retorno sobre o patrimônio líquido } \\
\text { (ROE) }\end{array}$} & Lucro líquido depois do I.R. \\
\hline & Patrimônio líquido \\
\hline \multirow[t]{2}{*}{ Lucro por ação (LPA) } & Lucro disponível aos acionistas ordinários \\
\hline & Número de ações ordinárias emitidas \\
\hline \multirow[t]{2}{*}{ Preço / Lucro (P/L) } & Preço de mercado da ação ordinária \\
\hline & Lucro por ação \\
\hline
\end{tabular}

FONTE: Gitman (1997) 
ANEXO C - Medidas de desempenho da cadeia de suprimentos

\begin{tabular}{|c|c|c|c|}
\hline Estágio na cadeia & Medida & \begin{tabular}{|c|} 
Custo $(\mathbf{C})$ \\
Qualidade (Q) \\
Flexibilidade (F) \\
Tempo (T) \\
Inovação $(\mathbf{I})$ \\
\end{tabular} & $\begin{array}{c}\text { Quantitativo } \\
\text { (QN) ou } \\
\text { Qualitativo } \\
\text { (QL) }\end{array}$ \\
\hline Planejamento & $\begin{array}{l}\text { Vendas } \\
\text { Lucro } \\
\text { Retorno sobre investimento (lucro liquido sobre } \\
\text { ativo total) } \\
\text { Taxa de Retorno sobre Investimento } \\
\text { lucro liquido x nível produtividade } \\
\text { Custo de obtenção de informações } \\
\text { Variação sobre o orçamento (Previsto x Realizado) } \\
\text { Custos totais da cadeia de suprimentos } \\
\text { Custos das mercadorias vendidas } \\
\text { giro do ativo } \\
\text { Valor agregado da produtividade } \\
\text { Custos indiretos } \\
\text { Custos intangíveis } \\
\text { Custos de incentivos e subsídios } \\
\text { Sensibilidade de custos de longo prazo } \\
\text { porcentagem de vendas de novos produtos } \\
\text { comparados com as vendas totais de um período } \\
\text { Capacidade de expansão } \\
\text { Custos de capital parado } \\
\text { Tempo de resposta total da cadeia de suprimentos } \\
\text { Tempo de ciclo total da cadeia de suprimentos } \\
\text { Tempo de pedido } \\
\text { Tempo para atendimento do pedido } \\
\text { Tempo de resposta ao cliente } \\
\text { Tempo do ciclo de desenvolvimento de produto } \\
\text { Tempo total do fluxo de caixa } \\
\text { Ciclo financeiro } \\
\text { Horizonte de relações empresariais } \\
\text { Redução percentual no tempo de produção de um } \\
\text { produto } \\
\text { Taxa de atendimento de pedidos } \\
\text { Métodos de entradas de pedidos } \\
\text { Precisão nas técnicas de previsão } \\
\text { Autonomia no planejamento } \\
\text { Efetividade percebida nas relações departamentais } \\
\text { Flexibilidade no pedido } \\
\text { Atendimento correto do pedido } \\
\text { Flidade no mix de produtos } \\
\text { Tlecnologias }\end{array}$ & $\begin{array}{l}C \\
C \\
C \\
C \\
C \\
C \\
C \\
C \\
C \\
C \\
C \\
C \\
C \\
C \\
C \\
C \\
C \\
C \\
C \\
C \\
C \\
C\end{array}$ & $\begin{array}{l}\text { QN } \\
\text { QN } \\
\text { QN } \\
\text { QN } \\
\text { QN } \\
\text { QN } \\
\text { QN } \\
\text { QN } \\
\text { QN } \\
\text { QN } \\
\text { QN } \\
\text { QN } \\
\text { QN } \\
\text { QN } \\
\text { QN } \\
\text { QN } \\
\text { QN } \\
\text { QN } \\
\text { QN } \\
\text { QN } \\
\text { QN } \\
\text { QN } \\
\text { QN } \\
\text { QN } \\
\text { QN } \\
\text { QN } \\
\text { QL } \\
\text { QN } \\
\text { QN } \\
\text { QN } \\
\text { QN } \\
\text { QN } \\
\text { QL }\end{array}$ \\
\hline Recebimento & $\begin{array}{l}\text { Iniciativas de redução de custos pelos fornecedores } \\
\text { Percentagem de entregas atrasadas ou erradas do } \\
\text { fornecedor } \\
\text { Tempo do fornecedor comparado com o padrão da } \\
\text { industria } \\
\text { Procedimentos de cadastro de fornecedores } \\
\text { Tempo de ciclo do pedido de compra }\end{array}$ & $\begin{array}{l}\mathrm{C} \\
\mathrm{C} \\
\mathrm{T} \\
\mathrm{T} \\
\mathrm{T}\end{array}$ & $\begin{array}{l}\text { QN } \\
\text { QN } \\
\text { QN } \\
\text { QN } \\
\text { QN }\end{array}$ \\
\hline
\end{tabular}




\begin{tabular}{|c|c|c|c|}
\hline Estágio na cadeia & Medida & $\begin{array}{c}\text { Custo (C) } \\
\text { Qualidade (Q) } \\
\text { Flexibilidade (F) } \\
\text { Tempo (T) } \\
\text { Inovação (I) }\end{array}$ & $\begin{array}{c}\text { Quantitativo } \\
\text { (QN) ou } \\
\text { Qualitativo } \\
\text { (QL) }\end{array}$ \\
\hline & $\begin{array}{l}\text { Eficiência no tempo de ciclo do pedido de compra } \\
\text { Nível de parceria com o fornecedor } \\
\text { Nível de entregas corretas do fornecedor } \\
\text { Taxa de rejeição do fornecedor } \\
\text { Confiança mutua } \\
\text { Satisfação com transferências de conhecimento } \\
\text { Satisfação no relacionamento com o fornecedor } \\
\text { Assistência do fornecedor na solução de problemas } \\
\text { técnicos } \\
\text { Extensão de cooperação e planejamento mutuo na } \\
\text { condução da melhoria da qualidade } \\
\text { Extensão de cooperação mutuo dos esforços na } \\
\text { resolução de problemas } \\
\text { Distribuição da capacidade de decisão entre } \\
\text { fornecedores e clientes } \\
\text { Qualidade e frequiência de trocas de informações } \\
\text { logísticas entre fornecedores e clientes } \\
\text { Qualidade na perspectivas de ganhos na rede de } \\
\text { suprimentos } \\
\text { Precisão de informação } \\
\text { Oportunidade de informação } \\
\text { Disponibilidade de informação } \\
\text { Habilidade do fornecedor em responder problemas } \\
\text { de qualidade }\end{array}$ & $\begin{array}{l}\mathrm{T} \\
\mathrm{Q} \\
\mathrm{Q} \\
\mathrm{Q} \\
\mathrm{Q} \\
\mathrm{Q} \\
\mathrm{Q} \\
\mathrm{Q} \\
\mathrm{Q} \\
\mathrm{Q} \\
\mathrm{Q} \\
\mathrm{Q} \\
\mathrm{Q} \\
\mathrm{Q} \\
\mathrm{Q} \\
\mathrm{Q} \\
\mathrm{Q}\end{array}$ & $\begin{array}{l}\text { QN } \\
\text { QL } \\
\text { QN } \\
\text { QN } \\
\text { QL } \\
\text { QL } \\
\text { QL } \\
\text { QL } \\
\text { QL } \\
\text { QL } \\
\text { QL } \\
\text { QL } \\
\text { QL } \\
\text { QL } \\
\text { QL } \\
\text { QL } \\
\text { QL }\end{array}$ \\
\hline Produção & $\begin{array}{l}\text { Custos totais dos recursos } \\
\text { Custos de produção (manufatura) } \\
\text { Investimento em estoque } \\
\text { Obsolescência do estoque } \\
\text { Trabalho em processo } \\
\text { Custo de hora trabalhada } \\
\text { Capacidade de utilização como nível de } \\
\text { recebimento de estoques; trabalho em processo; } \\
\text { índice de refugo; produtos acabados em trânsito } \\
\text { Custo de estoque } \\
\text { Taxa de giro do estoque } \\
\text { Taxa de fluxo (circulação) do estoque } \\
\text { Dias de suficiência de estoques } \\
\text { Quantidade econômica de pedido } \\
\text { Eficiência no programa mestre de produção } \\
\text { Número de itens produzidos } \\
\text { Custos de armazenagem } \\
\text { Capacidade de estocagem } \\
\text { Utilização do estoque } \\
\text { Probabilidade de falta de estoque } \\
\text { Número de backorders } \\
\text { Número de falta de estoques } \\
\text { Nível médio de backordes } \\
\text { Percentagem de excesso/falta de recursos em um } \\
\text { período } \\
\text { Custos de armazenagem por unidade de volume } \\
\text { Custos de distribuição }\end{array}$ & $\begin{array}{l}\mathrm{F} \\
\mathrm{C} \\
\mathrm{C} \\
\mathrm{C} \\
\mathrm{C} \\
\mathrm{C} \\
\mathrm{C} \\
\mathrm{C} \\
\mathrm{C} \\
\mathrm{C} \\
\mathrm{C} \\
\mathrm{C} \\
\mathrm{C} \\
\mathrm{C} \\
\mathrm{C} \\
\mathrm{C} \\
\mathrm{C} \\
\mathrm{C} \\
\mathrm{C} \\
\mathrm{C} \\
\mathrm{C} \\
\mathrm{C} \\
\mathrm{C} \\
\mathrm{C}\end{array}$ & $\begin{array}{l}\text { QN } \\
\text { QN } \\
\text { QN } \\
\text { QN } \\
\text { QN } \\
\text { QN } \\
\text { QN } \\
\text { QN } \\
\text { QN } \\
\text { QN } \\
\text { QN } \\
\text { QN } \\
\text { QN } \\
\text { QN } \\
\text { QN } \\
\text { QN } \\
\text { QN } \\
\text { QN } \\
\text { QN } \\
\text { QN } \\
\text { QN } \\
\text { QN } \\
\text { QN } \\
\text { QN }\end{array}$ \\
\hline
\end{tabular}




\begin{tabular}{|c|c|c|c|}
\hline Estágio na cadeia & Medida & $\begin{array}{c}\text { Custo }(\mathbf{C}) \\
\text { Qualidade }(\mathbf{Q}) \\
\text { Flexibilidade }(\mathbf{F}) \\
\text { Tempo }(\mathbf{T}) \\
\text { Inovação }(\mathbf{I})\end{array}$ & $\begin{array}{c}\text { Quantitativo } \\
\text { (QN) ou } \\
\text { Qualitativo } \\
\text { (QL) }\end{array}$ \\
\hline & $\begin{array}{l}\text { Tempo de ciclo dos processos planejados } \\
\text { Tempo de produção } \\
\text { Tempo necessário para produzir um item particular } \\
\text { ou uma seria de itens } \\
\text { Tempo necessário para produzir novo mix de } \\
\text { produtos } \\
\text { Precisão de estoque } \\
\text { Extensão do estoque } \\
\text { Percentagem de produtos produzidos erroneamente } \\
\text { - Falhas } \\
\text { Flexibilidade de produção } \\
\text { Flexibilidade de capacidade } \\
\text { Flexibilidade de volume } \\
\text { Número de tarefas que os operários podem realizar }\end{array}$ & $\begin{array}{l}\mathrm{T} \\
\mathrm{T} \\
\mathrm{T} \\
\mathrm{T} \\
\mathrm{Q} \\
\mathrm{F} \\
\mathrm{Q} \\
\mathrm{F} \\
\mathrm{F} \\
\mathrm{F} \\
\mathrm{F}\end{array}$ & $\begin{array}{l}\text { QN } \\
\text { QN } \\
\text { QN } \\
\text { QN } \\
\text { QN } \\
\text { QN } \\
\text { QN } \\
\text { QN } \\
\text { QN } \\
\text { QN } \\
\text { QN }\end{array}$ \\
\hline Entrega & $\begin{array}{l}\text { Custos totais logísticos } \\
\text { Custos de distribuição } \\
\text { Custos de entrega } \\
\text { Custos de transporte } \\
\text { Custos de transporte por unidade de volume } \\
\text { Custos pessoais por unidade de volume } \\
\text { movimentado } \\
\text { Produtividade no transporte } \\
\text { Erros de embarque } \\
\text { Eficiência na entrega } \\
\text { Percentagem de acerto na entrega } \\
\text { Tempo de entrega } \\
\text { Frequiência de entrega } \\
\text { Produtos atrasados } \\
\text { Media de pedidos atrasados } \\
\text { Media de pedidos adiantados } \\
\text { Percentagem de entregas pontuais (no tempo } \\
\text { correto) } \\
\text { Desempenho na entrega } \\
\text { Confiabilidade na entrega } \\
\text { Número de entregas pontuais (no tempo correto) } \\
\text { Eficiência do programa de planejamento da } \\
\text { distribuição } \\
\text { Eficiência dos métodos de fatura de entrega } \\
\text { Controles confiáveis de desempenho } \\
\text { Qualidade dos produtos entregues } \\
\text { Entregas corretas (sem erros) realizadas } \\
\text { Qualidade dos documentos de entrega } \\
\text { Flexibilidade na entrega } \\
\text { Agilidade nas entregas urgentes } \\
\text { Flexibilidade no transporte }\end{array}$ & $\begin{array}{l}C \\
C \\
C \\
C \\
C \\
C \\
C \\
C \\
C \\
C \\
C \\
C \\
C \\
T \\
T \\
T \\
T \\
T \\
T \\
T \\
T \\
Q \\
Q \\
Q \\
Q \\
Q\end{array}$ & $\begin{array}{l}\text { QN } \\
\text { QN } \\
\text { QN } \\
\text { QN } \\
\text { QN } \\
\text { QN } \\
\text { QN } \\
\text { QN } \\
\text { QN } \\
\text { QN } \\
\text { QN } \\
\text { QN } \\
\text { QN } \\
\text { QN } \\
\text { QN } \\
\text { QN } \\
\text { QN } \\
\text { QN } \\
\text { QN } \\
\text { QL } \\
\text { QN } \\
\text { QN } \\
\text { QL } \\
\text { QN } \\
\text { QL } \\
\text { QN } \\
\text { QN } \\
\text { QN }\end{array}$ \\
\hline $\begin{array}{l}\text { Retorno (satisfação } \\
\text { do cliente) }\end{array}$ & $\begin{array}{l}\text { Custos do processo de troca/devolução } \\
\text { Tempo de resposta as duvidas dos clientes } \\
\text { Satisfação (ou insatisfação) do cliente }\end{array}$ & $\begin{array}{l}\mathrm{C} \\
\mathrm{T} \\
\mathrm{Q}\end{array}$ & $\begin{array}{l}\text { QN } \\
\text { QN } \\
\text { QL }\end{array}$ \\
\hline
\end{tabular}




\begin{tabular}{|l|l|c|c|}
\hline \multirow{2}{*}{ Estágio na cadeia } & \multicolumn{1}{|c|}{ Medida } & $\begin{array}{c}\text { Custo (C) } \\
\text { Qualidade (Q) } \\
\text { Flexibilidade (F) } \\
\text { Tempo (T) } \\
\text { Inovação (I) }\end{array}$ & $\begin{array}{c}\text { Quantitativo } \\
\text { (QN) ou } \\
\text { Qualitativo } \\
\text { (QL) }\end{array}$ \\
\hline & $\begin{array}{l}\text { Nível de valor percebido dos produtos pelos } \\
\text { clientes } \\
\text { Reclamações dos clientes } \\
\text { Taxa de reclamação dos clientes } \\
\text { Qualidade do produto } \\
\text { Flexibilidade de sistemas de serviço para atender } \\
\text { as necessidades particulares dos clientes }\end{array}$ & Q & QL \\
QN & Q & QN \\
QL \\
QL
\end{tabular}

FONTE: Shepherd e Gunter (2006) 